\title{
SPENT FUEL SHIPPING CASK ACCIDENT EVALUATION
}

S. R. Fields

December 1975

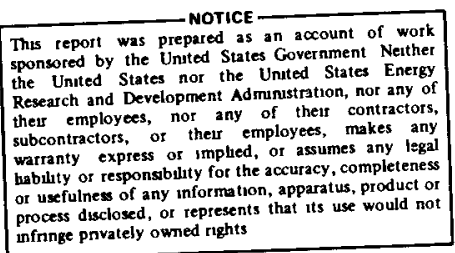

process disclosed, or represents
infringe pnvately owned nights

HANFORD ENGINEERING DEVELOPMENT LABORATORY

P.O. Box 1970 Richland, WA 99352

Operated by Westinghouse Hanford Company

A Subsidiary of Westinghouse Electric Corporation

Prepared for the U.S. Energy Research and Development

Administration under Contract No. EY-76-C-14-2170 


\section{DISCLAIMER}

This report was prepared as an account of work sponsored by an agency of the United States Government. Neither the United States Government nor any agency Thereof, nor any of their employees, makes any warranty, express or implied, or assumes any legal liability or responsibility for the accuracy, completeness, or usefulness of any information, apparatus, product, or process disclosed, or represents that its use would not infringe privately owned rights. Reference herein to any specific commercial product, process, or service by trade name, trademark, manufacturer, or otherwise does not necessarily constitute or imply its endorsement, recommendation, or favoring by the United States Government or any agency thereof. The views and opinions of authors expressed herein do not necessarily state or reflect those of the United States Government or any agency thereof. 


\section{DISCLAIMER}

Portions of this document may be illegible in electronic image products. Images are produced from the best available original document. 


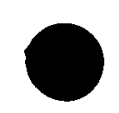

;

P

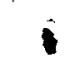

,

, 
HEDL-TME $75-138$

UC-71

\title{
SPENT FUEL SHIPPING CASK \\ ACCIDENT EVALUATION
}

\author{
S. R. Fields
}

\begin{abstract}
Mathematical models have been developed to simulate the dynamic behavior, following a hypothetical accident and fire, of typical casks designed for the rail shipment of spent fuel from nuclear reactors, and to determine the extent of radioactive releases under postulated conditions. The casks modeled were the IF-300, designed by the General Electric Company for the shipment of spent LWR fuel, and a cask designed by the Aerojet Manufacturing Company for the shipment of spent LMFBR fuel.
\end{abstract}




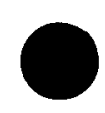

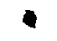

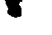

(1)

$\boldsymbol{\gamma}$

• 


\section{ACKNOWLEDGMENT}

I would like to acknowledge the assistance of R. E. Keyes in adapting the models to the AMCO cask.

S. R. Fields 


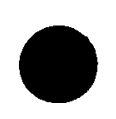

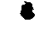

$d$
$d y$

1

I

$\bullet$ 
Page

SUMMARY

INTRODUCTION

RESULTS AND DISCUSSION

Cask Descriptions and Data

Fission Product Release Mechanisms 26

$\begin{array}{ll}\text { Results of the Simulations } & 27\end{array}$

A. Steady-State Temperatures in the Casks 29 Before the Accident

B. Analyses of Rate of Coolant Loss from the Casks

C. Analysis of Fission Product Release

D. Event Network

$\begin{array}{ll}\text { CONCLUSIONS AND RECOMMENDATIONS } & 79\end{array}$

$\begin{array}{ll}\text { APPENDIX } & 85\end{array}$

1. CASK SIMULATION MODELS FOR STEADY-STATE CONDITIONS 92 PRECEDING THE ACCIDENT

1.1 Coolant Circulation and Heat Transfer Paths in the Casks

1.2 Volumetric Heat Dissipation

102

1.3 Heat Conduction and Apparent Thermal 109 Conductivity

2. CASK SIMULATION MODELS FOR CALCULATION OF RATE OF COOLANT LOSS

2.1 Rate of Coolant Loss From the IF-300 
2.1.1 Coolant Loss From the Cask While in a

2.1.1.1 Energy Balance on the Breach

2.1.1.2 Rate of Coolant Loss From the

118 Breach and Mass Balance on the Cask

2.1.1.3 Energy Balances on the Cask and the Determination of Temperatures

2.1.1.3.1 Thermal Admittances, Heat

140

Transfer Coefficients, Therma 1

Capacities and Heat Generation

2.1.1.3.2 Energy Balance on the Fuel

150

2.1.1.3.3 Energy Balance on the Coolant

150

2.1.1.3.4 Energy Balances on the Cask Wall 150

2.1.1.3.5 Energy Balance on the Outer

2.1.1.3.6 Energy Balance on the Steam in the Water Jacket

151

2.1.1.3.7 Determination of Temperatures From the Energy Balances

152

2.1.2 Coolant Loss From the Cask While in a Breach Up Position

155

2.2 Rate of Coolant Loss From the AMC0 Cask 155

2.2.1 Coolant Loss From the Cask While in a 159 Breach Down Position

2.2.1.1 Energy Balance on the Breach

159

2.2.1.2 Rate of Coolant Loss From the

161 Breach and llass Balance on the Cask

2.2.2 Coolant Loss From the Cask While in a Breach Up Position

2.2.2.1 Energy Balances in the Cask Before Vaporization of the Coolant 
2.2.2.1.1 Energy Balance on the Fuel 179

2.2.2.1.2 Energy Balance on the Basket 180

2.2.2.1.3 Energy Balance on the Cask Wall 180

2.2.2.1.4 Energy Balance on the Coolant 181

2.2.2.1.5 Energy Balance at the Cask 181 Surface

2.2.2.2 Energy Balances in the Cask During 183 Vaporization of the Coolant

2.2.2.3 Transition From Subcooled to

183 Saturated Conditions in the Coolant Region

2.2.2.3.1 Logical Control Variables and

183 Branching Within the Model

2.2.2.3.2 Integration of the Energy

184 Balances on the Coolant

2.2.2.4 Determination of Temperatures From

187 Energy Balances on the Regions

2.2.2.5 Coolant Loss From the Cask

188

3. CASK SIMULATION MODELS FOR LOSS-OF-COOLANT TRANSIENT 189

3.1 Heat Transfer in the Fuel 197

$\begin{array}{lll}3.1 .1 & \text { Initial Conditions } & 197\end{array}$

3.1.2 Volumetric Heat Dissipation 197

3.1.3 Heat Conduction and Apparent Therma 1200

3.2 Fission Product Release Mechanisms 205

3.2.1 Fuel Pin Internal Pressures and Clad 213 Stresses

3.2.2.1 Volumetric Mass Dissipation 231 
3.2.2.2 Diffusion Network

Page

3.2.2.3 Coefficient for Diffusion of

233

Fission Gases in the Fuel

3.2.3 0xidation of the Fuel

237

3.2.3.1 Parabolic Rate Law

238

3.2.3.2 Oxidation Network

239

3.2.3.3 Oxygen-Uranium Ratios

241

3.2.3.4 Fuel 0xidation Reaction Rate 242

3.3 Cask Simulation Networks 247

3.4 Central Processor: Control of Thermal Radia- 2.52 tion, Melting and Fuel 0xidation

3.4.1 Thermal Radiation 252

3.4.2 Melting 254

3.4.3 Fuel 0xidation 260

3.5 Proposed Modifications to Loss-of-Coolant Models 263 to Simulate the Flow of Fission Gases and Residual Coolant Vapor from the Casks

3.5.1 Mass Balance on the Cask Containment 263

3.5.2 Energy Balance on the Breach: Determina- 272 tion of Flow Velocity

3.5.3 Proposed Modifications to the Loss-of- 278 Coolant Models

3.5.3.1 Fission Gas Leakage Network 279

3.5.3.2 Gas Mixture in Cask Containment 230 as a Coolant: Determination of Temperature and Pressure

3.5.3.3 Fission Gases in Cask Containment as a Deterrent to Fuel Pin Clad

Failure 
3.5.3.4 Choked Flow of Gas Mixture in the Breach: Determination of Sonic Velocity

3.5.3.5 Relationship of Gas Leakage to Volatile Solids Release Model

4. MODEL SIMULATING BEHAVIOR OF VOLATILE SOLIDS OR SOLID FISSION PRODUCTS RELEASED FROM DAMAGED SPEINT FUEL IN A CASK

4.1 Coagulation Equation - A Particle Balance Equation for Aerosols

4.1.1 Particle Size Distribution Function

4.1.2 Rate of Particle Removal from the Aeroso 1

4.1.2.1 Particle Removal by Settling

4.1.2.2 Particle Removal by Plateout

4.1.3 Rate of Aerosol Production $\quad 325$

4.1.4 Modification of the Particle Balance 327 Equation to Eliminate the Agglomeration Terms

4.1.5 Proposed Modification of the Model to Include Particle Removal by Leakage from the Cask

\subsubsection{Particle Removal by Leakage \\ 4.1.5.2 Modification of the Particle Balance Equations and the Model to Include the Leakage Term}

\subsection{Supplementary Equations and Procedures}

4.2.1 The Volume Fraction of the Disperse

Phase of the Aerosol Contained in the k-th Fuel Node

4.2.2 Calculation of the Volume, Mass and Activity of Average Particles in the Size Range $r_{i}$ to $r_{j}$ 
4.2.2.1 The Weighted Average Volume 348

4.2.2.2 Calculation of the Mass and Activity 350 of an Average Particle

4.2.2.3 Correction Factor Required for the Calculation of the Mass and Activity of an Average Particle

4.2.2.4 Calculation of the Number of Average Particles Available: Total, Free and Bound Up 


\section{List of Figures}

Figure

Page

1 General Electric IF-300 LWR Spent Fuel Shipping Cask

2 General Electric IF-300 LWR Spent Fuel Shipping Cask

3 Arrangement of PWR Spent Fuel Assemblies in the IF -300

$4 \quad$ LWR Fuel Assembly

5 AMCO LMFBR Spent Fuel Shipping Cask

6 FFTF Driver Fuel Assembiy

7 Steady-State Temperatures in the IF-300 Before the Accident

8 Steady-State Temperatures in the AMCO Cask

9 Cavity Pressure in the IF-300 as a Function of Time After the Accident

10 Temperatures in the IF-300 During Loss of Coolant (Breach Up Position, Breach Area $=0.25$ Sq. Inches)

11 Temperatures in the IF-300 During Loss of Coolant (Breach Area $=0.025 \mathrm{Sq}$. Inches, Breach Up Position)

12 Mass of Liquid Coolant Remaining in the IF-300 as a Function of Time After the Accident

13 Temperatures in the IF-300 During Loss of

Coolant (Breach Area $=0.25 \mathrm{Sq}$. Inches, Breach Down Position)

14 Temperatures in the IF-300 During Loss of Coolant (Breach Area $=0.025 \mathrm{Sa}$. Inches. Breach Down Position) 


\section{List of Figures}

(continued)

Figure

$\underline{\text { Page }}$

15 Behavior of the AMCO Spent Fuel Shipping Cask Following an Accident and 0.5 Hour Fire (Gradual Loss of Primary Coolant)

16 Behavior of the AMCO Spent Fuel Shipping Cask

Following an Accident and 0.5 Hour Fire (No Loss of Coolant)

17 Behavior of the AMCO Spent Fuel Shipping Cask

Following an Accident and 0.5 Hour Fire (No Loss of Coolant - Solar Shield Intact)

18 Total Radioactivity Released as Fission Gases from the Spent Fuel in the IF-300 (Breach Up Position, Breach Areas of 0.25 and $0.025 \mathrm{Sq}$. Inches)

19 Total Radioactivity Released as Fission Gases from the Spent Fuel in the IF-300 (Breach Down Position, Breach Areas of 0.25 and $0.025 \mathrm{Sq}$. Inches)

20 Temperatures in the IF-300 Following Loss of Coolant ( 0 to 1 Hour After Loss of Coolant)

Coolant ( 0 to 40 Hours After Loss of Coolant)

22 Temperatures in the IF-300 40 Hours After Loss of Coolant

23 Temperatures in the AMCO Cask Following Loss of Coolant as an Aerosol in the IF -300 (Breach Up Position, Breach Areas 0.025 and $0.25 \mathrm{Sq}$. Inches)

25 Total Radioactivity in Volatile Solids Suspended as an Aerosol in the IF-300 (Breach Down Position, Breach Areas 0.025 and $0.25 \mathrm{Sq}$. Inches)

26 Network of Events Following a Spent Fuel Shipping Cask Accident 


\section{List of Figures}

(continued)

Figure

$\underline{\text { Page }}$

A-1 Information Flow Among Simulation Models 88

1-1 Simulation Network of the Steady-State Model of 96 the IF-300

1-2 Idealized Representation of the AMCO Spent Fue 1

Shipping Cask and Simulation Network of the SteadyState Model

1-3 Representation of Steady-State Cooling by Natural

100 Convection in the IF-300 Before the Accident

2-1 Maximum Steam/Water Flow Rate and Local Stagnation Properties

2-2 Summary of Rules and Functions of MIMIC, A

Continuous System Simulation Program

2-3 MIMIC Listing of the Coolant Loss Rate Model of the IF-300 (Breach Down Version)

2-4 Idealized Representation of the IF-300 as an Electrical Analog

2-5 MIMIC Listing of the Coolant Loss Rate Model of the IF-300 (Breach Up Version)

2-6 MIMIC Listing of the Coolant Loss Rate Model of the AMCO Cask (Breach Down Version)

2-7 Idealized Representation of the AMCO Cask as an Electrical Analog

2-8 Calculation Control Flow Diagram of the Coolant Loss Rate Model of the AMCO Cask (Breach Up Version)

2-9 MIMIC Listing of the Coolant Loss Rate Model of the AMCO Cask (Breach Up Version)

3-1 Idealized Model of the IF-300 Spent Fuel Shipping Cask

3-2 Idealized Representation of Fuel Assemblies in the Containment Vessel of the IF-300 


\section{List of Figures}

(continued)

Figure

Page

3-3 Idealized Representation of a Fuel Assembly

194

in the AMCO Spent Fuel Shipping Cask

3-4 Hybrid-Type Computer Simulation of Spent Fuel

Shipping Cask

3-5 Representation of PWR Fuel Assembly as a

Collection of Concentric Cans

3-6 Pressures in the Fuel Pins in the IF-300

(Zircaloy-4, 10 Hour Creep Rupture)

214

3-7 Pressures in the Fuel Pins in the IF-300

215

(Zircaloy-4, 10 Hour Creep Rupture)

3-8 Pressures in the Fuel Pins in the IF-300

216

(Zircaloy-4, 10 Hour Creep Rupture)

3-9 Pressures in the Fuel Pins in the IF -300

(Zircaloy-4, 10 Hour Creep Rupture)

3-10 Pressures in the Fuel Pins in the AMCO

218

Cask for Breach Areas of 0.025 and 0.25

Sq. Inches (for Cask in Breach Down

Position)

3-11 Fuel Pin Clad Stresses in the IF-300

219

(Zircaloy-4, 10 Hour Creep Rupture)

3-12 Fuel Pin Clad Stresses in the IF-300

(Zircaloy-4, 10 Hour Creep Rupture)

3-13 Fuel Pin Clad Stresses in the IF-300

(Zircaloy-4, 10 Hour Creep Rupture)

3-14 Fuel Pin Clad Stresses in the IF-300

(Zircaloy-4, 10 Hour Creep Rupture)

3-15 Fuel Pin Clad Stresses in the AMCO Cask

for Breach Areas of 0.025 and $0.25 \mathrm{Sq}$.

Inches (for Cask in Breach Down Position)

3-16 Algorithm Controlling Simulation of Release Mechanisms 


\section{List of Figures \\ (continued)}

Figure

Page

3-17 Empirical Diffusion Coefficient for Xenon 236

3-18 Reaction Rate Constant for Oxidation of 247

3-19 Noda] Arrangement for Steady-State and 248 Loss-of-Coolant Models of the IF-300

3-20 Simulation Network of the Loss-of-Coolant Model of the IF -300

3-21 Idealized Representation of the AMCO Spent Fuel

Shipping Cask and Simulation Network of the Loss-of-Coolant Mode?

3-22 Geometric View Factors for a Typical FinCylinder Cavity

3-23 Algorithm for Controlling Latent Heat of Melting

3-24 Algorithm for Controlling the Switching of Admittances Simulating Melting

3-25 Algorithm Controlling the Simulation of the Release of "Bound Up" Fission Gases

3-26 Phase Diagram for Oxides of Uranium 262

3-27 Typical Portion of the Logic and Information 264 Control of the Processor

4-1 Calculation Control Flow Diagram of the Volatile Solids Release Model of the IF-300 Spent Fuel Shipping Cask

4-2 MIMIC Listing of the Volatile Solids Release Model for the IF-300

4-3 Cunningham Coefficient at Room Conditions

4-4 Diffusion Coefficient of Particles 323

4-5 Particle Balances on Size Groups and 332 Illustration of Particle Flow Between Groups 
•

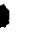

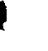




\section{List of Tables}

$\underline{\text { Table }}$

Page

1 Characteristics of Design Basis PWR 1 Fuel and

General Electric IF-300 Spent Fuel Shipping Cask

2 Characteristics of Design Basis PWR 1 Fuel

3 Descriptive Data on the AMCO LMFBR Spent Fuel

Shipping Cask

4 Data for FFTF Reactor Core

3-1 Comparison of Fission Product Inventories Calculated to be Present in the IF-300 Design Basis

PWR 1 Spent Fuel and in Spent Diablo Canyon Reference PWR Fuel

3-2 Calculated Amounts of Radioactivity in Fission Products Generated in Design Basis PWR 1 Fuel and Amounts That Have Migrated to the Fuel Pin Voids

3-3 Radioactivity of the Fission Products in the Spent Fuel in the IF-300 and Estimated Amounts Released

3-4 Total Amounts of Significant Gaseous Fission Product Elements Calculated to be Present in Spent FTR (FFTF) Fuel - 100 Days Decay Time

3-5 Calculated Radioactivity (Total) of Gaseous Fission Product Elements Present in Spent FFTF Reference Core Fuel (120 Days Decay Time)

3-6 Radioactivity in the Fission Gases in the AMCO Spent Fuel Shipping Cask (120 Days Decay Time)

3-7 Rate of $\mathrm{UO}_{2}$ Oxidation from Parabolic Rate Equation and Experimental Observations 
The objective of this study was to develop a series of models to analyze hypothetical spent fuel shipping cask accidents. Although rigorous standards have been developed by the Nuclear Regulatory Conmission (NRC) in connection with licensing spent fuel shipping casks, there is a continuing need to develop analytical tools to study extremely-low-probability incidents with potentially serious consequences. This study is intended to contribute to such a body of knowledge. ilo accident probabilities have been assigned in tnis study, but there is no doubt that licensed casks comply with all relevant IIRC standards.

The casks studied were the General Electric IF-300, designed for the shiplient of spent LWR fuel, (1) and a cask designed by tine Aerojet Manufacturing Company (AMCO) for shipment of spent LMFBR fuel. (2) A set of five models has been developed for the IF-300, and a similar set of models for tne AMCO cask. These models simulate cask behavior during normal operating conditions, and during conditions following an accident and fire. The accident evaluated was strictly a hypothetical one; tiere is no implication that such an accident has ever occurred or will occur.

It was assumed that damage to the casks in the accident included loss of any solar shield, loss of the water in the outer jacket or neutron shield, and a breach in the cask containment. It was further assumed that the fuel pins did not rupture at impact and, consequently, there was no prompt release of fission gases. This set of assumptions was arbitrarily selected as the initial condition of each cask for the analyses. The assumption of a breach in the cask containment is the most influential and, for the IF-300, it was assumed that this breach was due to damage to a pressure relief valve. This must not be interpreted as an implication that this valve is vulnerable to darnage or lialfunction. On the contrary, the relief valve is not only a well designed and proven component, but is also extremely well protected in the IF-300 design (see Figures 1 and 2 in the Results and Discussion section).

Altnough the AMCO cask design does not include a pressure relief valve, the salne breach flow areas were assumed for the analysis of its behavior 
following the accident. This allowed the calculation of the rate of primary coolant loss from the two different types of casks, and the subsequent hypothetical release of fission products, to be based on identical breach areas.

Two breach sizes or flow areas were assumed for each cask. The smallest flow area assumed was $0.025 \mathrm{in.}^{2}$, a reasonable area for a relief valve not fully reseated. The largest flow area assumed was 0.25 in. ${ }^{2}$, a reasonable area for a relief valve sheared off. Cask behavior was evaluated for each of these flow areas, once with the breach up and again with the breach down.

The sets of mollels developed in this study were used to predict the nature and timing of the release of fission products from the casks following the hypothetical accident, if the primary coolant containment were breached. The arbitrarily selected breach-causing mechanisms, along with other assumed damage to the casks, has been described in the preceding paragrapins. Results obtained from this preliminary analyis, in terms of some key events and their times of occurrence, are summarized in Table $i$ for the IF-300 and in Table ii for the AMCO cask.

When a fuel pin bursts, fission products are released; therefore the pin burst times presented in Tables $i$ and $i j$ also represent fission product release times. The results of Table $i$ show that all of the pins burst in the IF-300. This is equivalent to the release of 11,900 curies of fission gases, about $33 \%$ of the total in the spent fuel $(1)$, and about 113 curies of volatile solicis or solid fission products (cesiun conrounds). This amourit of volatile solids represents 211 of that fraction of the cesium that had migrated to the pin void spaces during reactor operation and that could conceivably be released. According to the AEC Staff, experimental data show it is unlikely that more than $3 \%$ of the total cesium in all of the fuel pins will migrate to the void space during reactor operation, and of this amount, less than $1 \%$ would be released under conditions postulated to occur in a severe transportation accident. Consequently, in the present study, the 113 curies represents all of the cesium that might be released, or about $0.01 \%$ of the total cesium in 011 of the fuel pins. Furthermore, it was assumed that the cesium was released as fine particles of the oxide $\mathrm{Cs}_{2} \mathrm{O}$ at the tirie the pins burst and the fission gases are released. 
Table $i$

Summary of Results: Events and Times Following a Hypothetical Accident Involving the IF-300 Spent Fuel Shipping Cask(a)

\begin{tabular}{|c|c|c|c|c|}
\hline \multirow[t]{2}{*}{ Event } & \multicolumn{2}{|c|}{$\begin{array}{c}\text { Breach Flow Area } \\
0.025 \mathrm{in}^{2}\end{array}$} & \multicolumn{2}{|c|}{$\begin{array}{c}\text { Breach Flow Area } \\
0.25 \mathrm{in}^{2}\end{array}$} \\
\hline & Breach Up & Breach Down & Breach Up & Breach Down \\
\hline $\begin{array}{l}\text { Cask Emptied of } \\
\text { Primary Coolant }\end{array}$ & 4 Hrs 37 Min & $1 \mathrm{Hr} 56 \mathrm{Min}$ & $1 \mathrm{Hr} 8 \mathrm{Min}$ & $16 \mathrm{Min}$ \\
\hline $\begin{array}{l}\text { First Pins } \\
\text { Burst }(c)(d)\end{array}$ & $6 \mathrm{Hrs} 37 \mathrm{Min}$ & $3 \mathrm{Hrs} 56 \mathrm{Min}$ & 4 Hrs 8 Min & $4 \mathrm{Hrs} 16 \mathrm{Min}$ \\
\hline $\begin{array}{l}\text { Last Pins } \\
\text { Burst }(c)(d)\end{array}$ & $11 \mathrm{Hrs} 37 \mathrm{Min}$ & $10 \mathrm{Hrs} 56 \mathrm{Min}$ & $12 \mathrm{Hrs} 8 \mathrm{Min}$ & $13 \mathrm{Hrs} 16 \mathrm{Min}$ \\
\hline
\end{tabular}

(a) Two different cooling times were used for the spent fuel carried in the IF-300. To be conservative with respect to the radioactivity of the fission product inventory, a cooling time of 90 days was used. The decay heat generation used was for fuel that had cooled 120 days.

(b) Except for a small amount of residual vapor.

(c) Fission product release times are the same as the pin burst times.

(d) A 10-hour creep-rupture strength vs. temperature relationship was used for the Zircaloy-4 pin clads ${ }^{(7)}$ (see Section 3.2.1 in the Appendix). This is only temporary until the model can be modified to calculate cladding failure based on a time-temperature dependent creep-rupture technique. (23) 
Table ii

Summary of Results: Events and Tinies Following a Hypothetical Accident Involving the AMCO Spent Fuel Shipping Cask (a)

\begin{tabular}{|l|c|c|c|c|}
\hline \multirow{2}{*}{ Event } & \multicolumn{2}{|c|}{$\begin{array}{c}\text { Breach Flow Area } \\
0.025 \text { in }^{2}\end{array}$} & \multicolumn{2}{|c|}{$\begin{array}{r}\text { Breach Flow Area } \\
0.25 \text { in }^{2}\end{array}$} \\
\cline { 2 - 5 } & Breach Up & Breach Down & Breach Up & Breach Down \\
\hline $\begin{array}{l}\text { Cask Emptied of } \\
\text { Primarly Coolant (b) }\end{array}$ & 20 Days & 7.0 Hours & 20 Days & 43 Min \\
\hline First Pins Burst (c)(d) & (e) & (e) & (e) & (e) \\
\hline
\end{tabular}

(a) Two different cooling times were used for the spent fuel carried in the AMCO cask. The heat source at steady-state conditions and during coolant loss was the decay heat from fuel trlat had cooled luu days. For the analyses of conditions following loss of the coolant, a decay heat was used corresponding to fuel tilat had cooled 120 days. The radioactivity of the fission product inventory was based on a cooling time of 120 days.

(b) Except for a small amount of residual vapor.

(c) Fission product release times are the same as the pin burst times.

(d) A 100-hour creep-rupture strength vs. temperature relationship was used for the Type 316 stainless steel pin clads ${ }^{(21)}$ (see Section 3.2.1 in the Appendix). This is only temporary until the model can be modified to calculate cladding failure based on a time-temperature dependent creep-rupture technique. (20)

(e) None of the pins were calculated to burst, at least not up to 52 hours after the coolant was lost. At this time, temperatures in the cask appear to be approaching a new steady-state distribution. 
In all the cases evaluated, the fuel temperature does not reach the vaporization temperature of the cesium $\left(1238^{\circ} \mathrm{F}\right)$ until about 15 hours after the last of the pins burst, or about 23 to 28 hours following loss of the coolant. It should be pointed out that this release of 113 curies of cesium is to the cask containment only. The amount that mignt we lost tinrough the breach has not been established but is expected to be small.

A model was developed to simulate the behavior of the aerosol formed by the fission gases and solids released from the pins. This model simulates coagulation, settling and plateout of particles in five size groups. A system of equations was developed to define the rate of flow of aerosol from the cask, but these equations were developed too late to include a leakage term in the present model. The results of the simulations show that, for all the cases evaluated, about 53\% of the cesium (about 60 curies) remains suspended in the cask containment 24 hours after loss of coolant or about 9 to 13 hours after the last of the pins burst. This represents a so-called "persistent tail" composed of the smallest particle sizes considered. The pressure in the cask after the coolant is lost is near atmospheric. As the pins burst and the fission products are released and heated, this pressure will increase. This will force some of the aerosol through the damaged relief valve. The amount of cesium lost from the cask in this manner will be determined when the leakage term is included in the aerosol model.

Simulation of the behavior of the AMCO cask following loss of its primary coolant gave results indicating that the fuel in this cask might not release any of its fission products, at least not by 52 hours after the coolant is lost. At this time, the temperatures in the cask appear to be approaching a new steady-state distribution. The temperature of the hottest fuel pins is about $1397^{\circ} \mathrm{F}$, but the corresponding pressure in the pins is 500 psia, compared to a pressure of about yyu psid required to burst the pin clads. 
The total amount of fission gases that are free or present in the fuel pin voids and available for release is about 1537 curies, or about $56 \%$ of the total in the spent fuel. The total amount of cesium that could be released is assumed to be about 657 curies, or $0.01 \%$ of the total in the cask's load of spent fuel.

A common way to present complex interacting parts of a system's behavior is in a fault tree-type event network. Such a network was constructed for both the IF-300 and AMCO casks, based on events and their times of occurrence obtained from the cask simulations. 
This report describes the development and use of simulation models of typical LWR and LMFBR spent fuel shipping casks to determine the quantity of fission products that mignt ve released froll tilese casks following a hypothetical accident and fire. It was assumed that these casks were damaged in the accident and were subsequently immersed in a petroleum fire with an effective temperature of $1475^{\circ} \mathrm{F}$. The casks modeled were the General Electric IF-300, designed for the shipment of spent LWR fuel, (1) and a cask designed by the Aerojet Manufacturing Company (AMCO) for the shipment of spent LMFBR fuel. (2)

A set of five simulation models has been developed for each of these casks. These models simulate cask behavior during normal operating conditions, and during conditions following an accident and fire. The sets of models include:

1. A model simulating the steady-state thermal behavior of a cask prior to an accident.

2. A model that determines the transient thermodynamic behavior of a cask and the gradual loss of primary coolant following impact and opening of a breach in the cask containment. This model applies to the case where the cask comes to rest with the breach down.

3. A model simulating the transient thermodynamic behavior of a cask and gradual loss of primary coolant following impact and opening of a breach in the cask containment. This model applies to the case where the cask comes to rest with the breach up.

4. A nodel simulating the transient thermal behavior of a cask following the eventual loss of primary coolant.

5. A model sinulating the transient behavior of volatile solids or solid fission products (cesium compounds) that may be released to the cask containment as an aerosol at the time the fuel pins burst and the fission gases are released. 
of these models, the second, third and fifth were developed for programming on the MIMIC simulation code. ${ }^{(3)}$ The first and fourth models were programmed on the TAP simulation code, $\left({ }^{4}\right)$ a network analyzer. For the IF-300, portions of the second and third models are represented by a chart devised by Moody ${ }^{(9)}$ relating the maximum steam and water flow rates to the local stagnation properties in a pressurized vesse1. For the AMCO cask, the second model is an energy balance relating the potential energy of the coolant column to the mass velocity of the coolant flowing from the breach and the time required to empty the cask. A detailed discussion of the development of these models is presented as an Appendix to this report. Results obtained using these simulation models are presented and discussed in the next section.

In addition to these models, equations were developed to define the rate of flow of fission gases and volatile solids or solid fission products from a cask. These equations are presented in the Appendix, in the sections describing the fourth and fifth models (Sections 3.5 and 4.1 .5 , respectively).

The models described above have been used to estimate the amount of radioactive fission products that might be released from a shipping cask following an extremely severe hypothetical accident. These calculated estimates are presented along with some other results of the simulations that include temperatures in the casks; the rate of primary coolant loss, the internal pressures in the fuel pins, etc.

If a probability could be assigned to the sequence of events that might eventually lead to the loss of primary coolant from a cask, it would be extremely low. It has been established that the probability of a rail accident is about $10^{-8}$ per vehicle mile. ${ }^{(32)}$ Further, the probability of a breach of the primary containment is very small because Nuclear Regulatory Commission (NRC) standards require that all licensed casks withstand severe drop and puncture conditions. (5) Combining these low probabilties results in an even lower probability that the cask containment would ever be breached. 
The General Electric Company made a study of a hypothetical accident as part of the design and safety analysis of its IF-300 Spent Fuel Shipping Cask. (1) For this analysis, General Electric assumed that the water in the neutron shield was lost at the time of the accident, and that the primary coolant in the cásk cavity was then gradually lost through a series of relief valve blowdowns as the temperatures in the cavity increased. This analysis, in which the pressure relief valve was assumed to be functioning properly, demonstrated that the radioactivity of the coolant released was within the limits specified in Section 71.36(a)(2) of the Code of Federa 1 Regulations (10CFR71). ${ }^{(5)}$

Analytical tools to predict cask behavior under simulated accident conditions should assist in the design of casks to withstand severe accidents. The development of the cask simulation models and the construction of an event diagram (Figure 26) displaying alternate paths leading to fission product release should be of value to cask designers.

The simulation of cask behavior helps to assure cask integrity and, consequently, the protection of the surroundings under accident conditions. Certain events may occur in a spent fuel shipping cask, following an accident and fire, that might lead to the release of fission products. If these events can be identified in advance through simulation, and steps taken to delay or prevent their occurrence, the safety and integrity of the cask design will be significantly increased.

The simulation models developed provide the means for answering two very important questions that should be asked when planning remedial procedures to be implemented in the event of an accident involving a spent fuel shipping cask. These questions are:

1. How much time would be available to evacuate personnel from the area after the accident if the same damage and arbitrarily selected breach-causing mechanism used in the simulation were assumed for the actual accident? 
2. How much time would be available for putting corrcctive measures into effect before radioactivity is released or before radiation shielding is reduced?

The results of this study provide some answers to these questions (see Results of the Simulations, parts $B$ and $C$, in the next section, and the section on Conclusions and Recommendations). 
RESULTS AND DISCUSSION

Cask Descriptions and Data

The LWR spent fuel shipping cask analyzed is the General Electric IF300 design presented in General Electric drawing 15905238 in Reference 1. Figures 1 and 2 are copies of portions of this drawing. Detailed data on this cask are presented in Table 1.

The IF-300 carries seven PWR fuel assemblies. These assemblies are surrounded by slotted stainless steel baskets. Several stainless steel-boron carbide rods are attached to the outer surfaces of the baskets for criticality control (see figure 3). The seven assemblies and their baskets are contained in an inner cavity or containment vessel, which is cooled by water and surrounded by four inches of depleted uranium shielding encased in stainless stee1. The outer surface of the uranium is cooled by water contained in a six-inch jacket. The type of fuel assembly that would be carried by this cask is shown in Figure $4 .^{\left({ }^{8}\right)}$ Detailed data on this fuel assembly are presented in Table $2 .(1,8)$

The LMFBR spent fuel shipping cask analyzed is one designed by the Aerojet Manufacturing Company (AMCO) for FFTF and LMFBR demonstration plant use. ${ }^{(2)}$ This cask is shown in Figure 5, and detailed data are presented in Table 3. ${ }^{(2,11)}$ Although this cask has been designed for shipment of FFTF and LMFBR demonstration plant spent fuel, it will be referred to throughout this report as an LMFBR spent fuel shipping cask.

The AMCO cask of Figure 5 carries nine fuel assemblies. Each of these nine hexagonal fuel assemblies is enclosed in a steel basket with slots for coolant flow. The nine assemblies and their baskets are contained in a stainless steel canister cooled by either Dowtherm-A or sodium. Dowtherm-A was selected as the coolant for this study. The fuel assemblies are arranged in a circular pattern, bounded on the inside by an expansion chamber shell with an outer diameter of 15.5 inches, and bounded on the outside by the inner wall of the canister. The canister has a one-inch thick wall, separated from the inner wall of the containment vessel by a 0.25 -inch helium filled gap. The containment vessel is surrounded by a $3.625-i n c h$ thick 

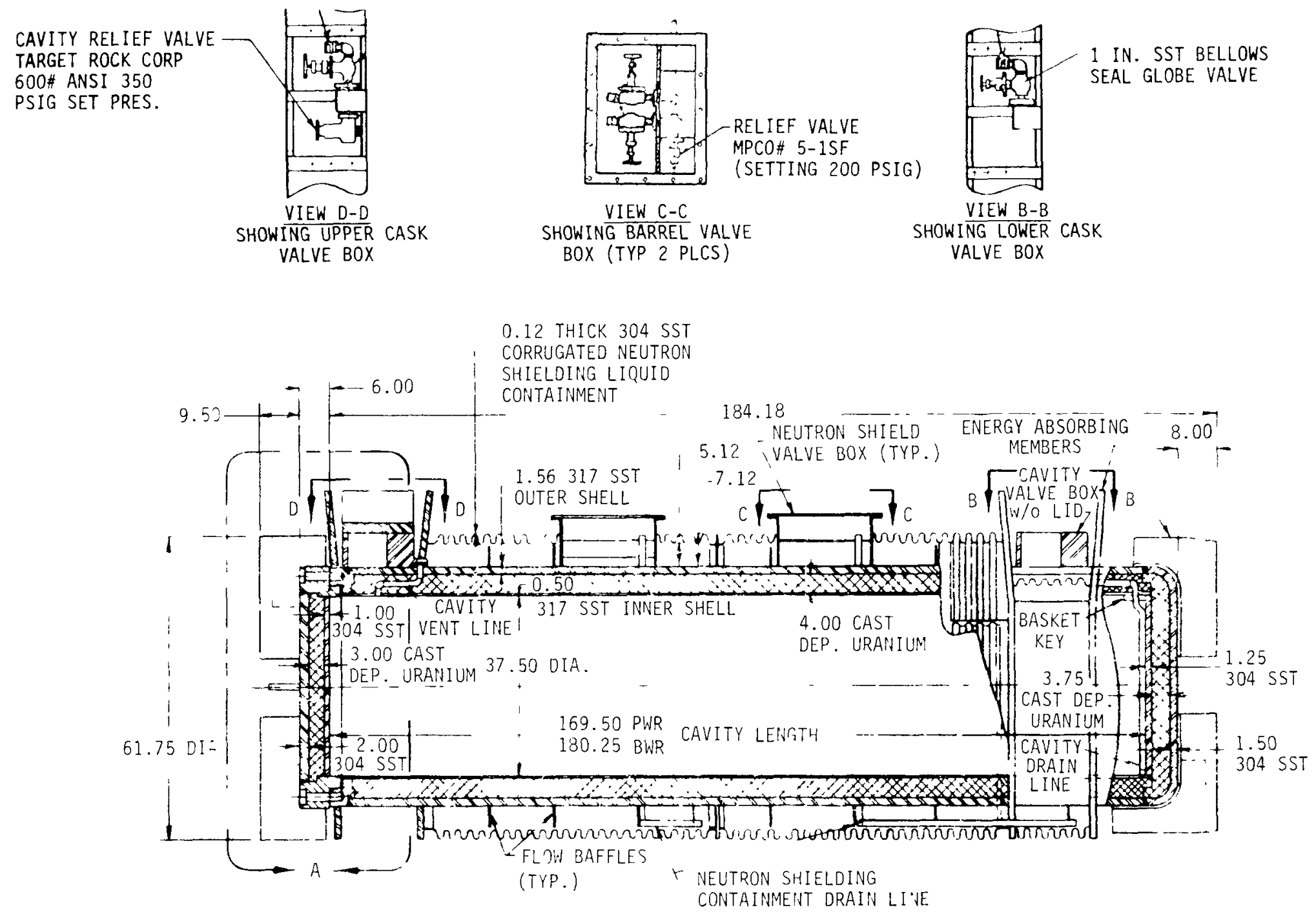

SECTIONAL VIEN OF CASK WITH PWR CASK HEAD

FIGURE 1. General Electric IF-300 LWR Spent Fuel Shipping Cask 

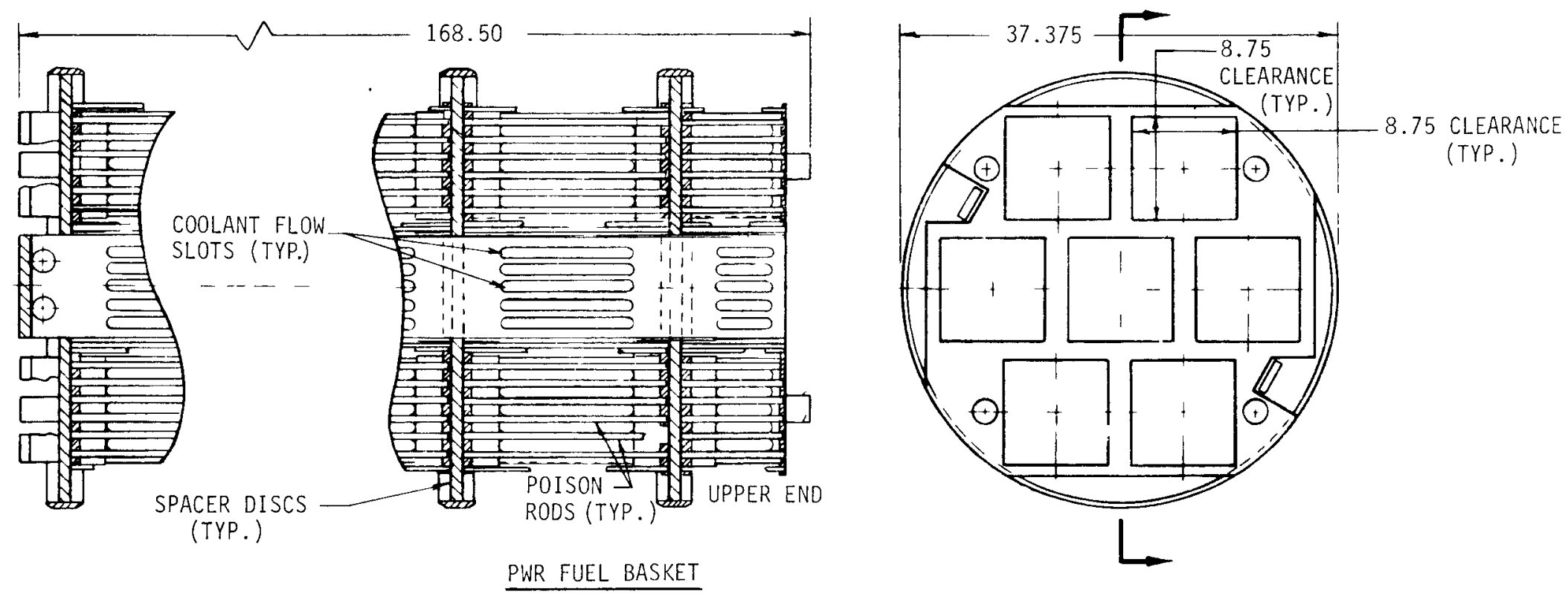

HEDL 7507-30.58

FIGURE 2. General Electric IF-300 LWR Spent Fuel Shipping Cask (Page 1 of 2) 


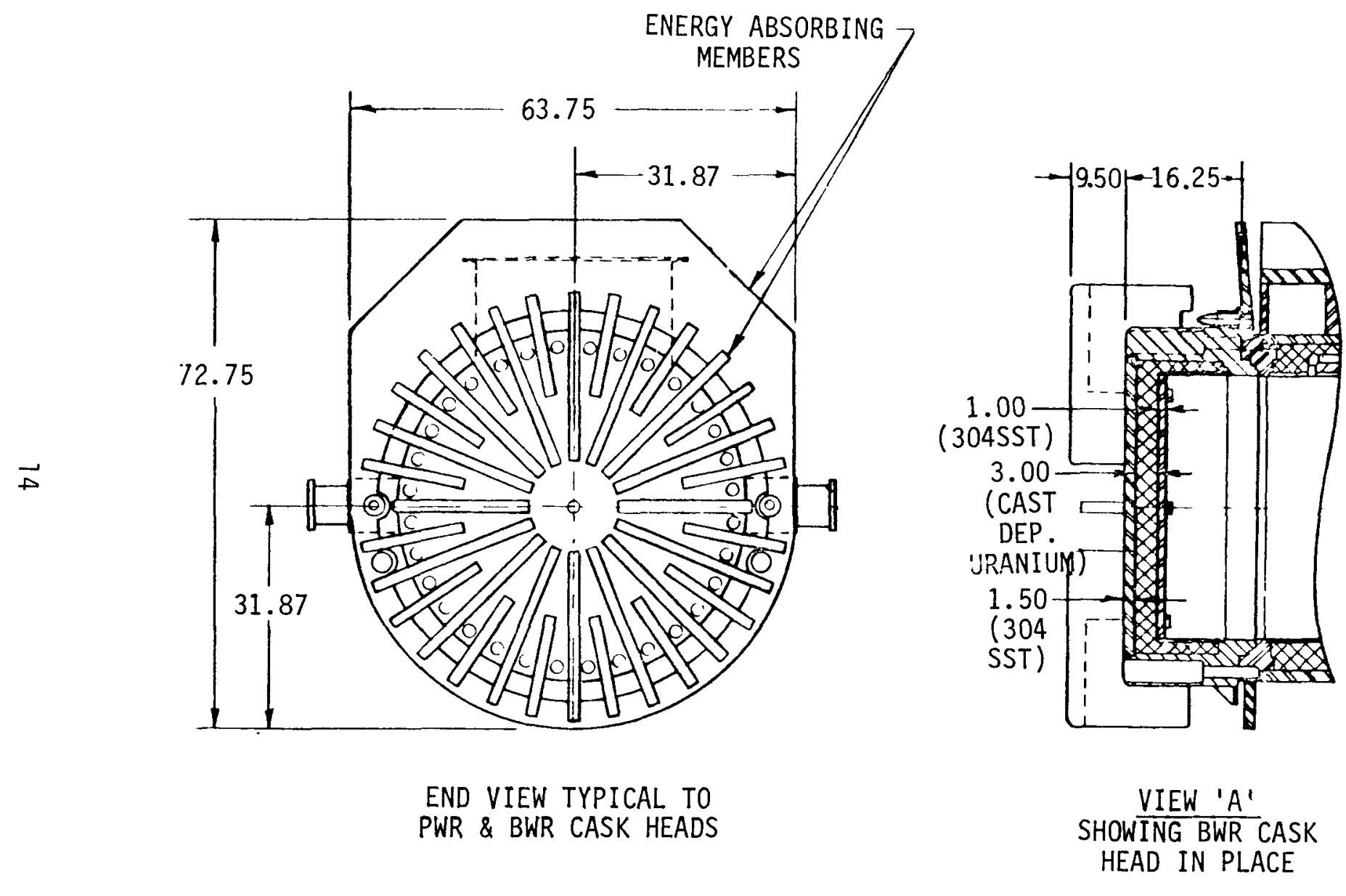

FIGURE 2. General Electric IF-300 LWR Spent Fuel Shipping Cask. (Page 2 of 2) 


\section{TABLE 1}

\section{Characteristics of Design Basis PWR 1 Fuel and General Electric IF-300 Spent Fuel Shipping Cask}

Fuel

Type PWR

Exposure, GWd/MTU (average) 35.0

Operating Power, kW/kgU 40.0

Assembly Heat Power, W/kgU 24.03

Assemblies per Cask Load

Uranium, kgU/Assembly 457

Maximum Decay Heat Rate-Cask, Btu/hr 262,000 *

Number of Fuel Rods/Assembly 205

Cask

Cavity Length, ft 14.104

Cavity Diameter, $\mathrm{ft}$ 3.1250

Inner Shell Thickness, ft 0.0417

Shielding Thickness, ft

0.3333

Outer She 11 Thickness, ft

0.1250

Cask Linear Surface Area, $\mathrm{ft}^{2} / \mathrm{ft}$

Cask Length, Excluding Fins, $\mathrm{ft}$

Cask Cavity Water, Ib 4800

Shielding Water, ib 4540

Cavity Relief Pressure, psig 350

Exterior Containing Relief Pressure, psig

Cooling System

Cooling Medium

Forced Air

Number of Fu11-Length Cooling Nozzles

Cooling Air Arrival Velocity, fps

47.0

System Classification

Surface Film Coefficient, Btu/hr-ft ${ }^{2}{ }^{\circ} \mathrm{F}$

Open

Minimum Air Flow, cfm

10,000

* This value was used in this study and by $\mathrm{GE}^{(1)}$ to be conservative. It is $25 \%$ higher than the heat rate sanctioned by the Nuclear Regulatory Commission. 
1. OUTER LINER

2. SHIELD

3. INNER LINER

4. WATER

5. CHANNEL

6. B 4 C POISON RODS

7. FUEL BUNDLE (PWR)

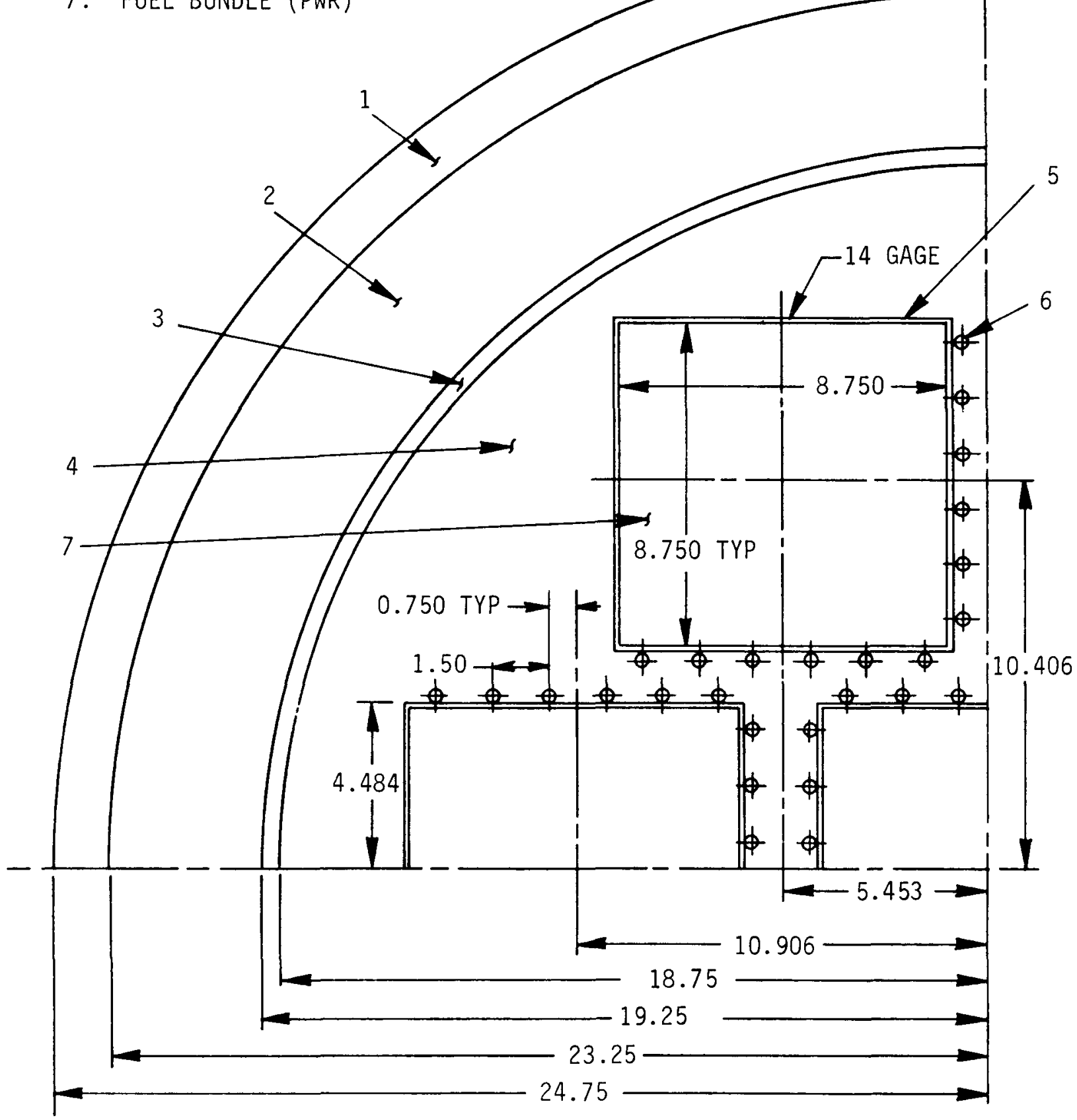

NOTE: 14 GAGE SHEET $=0.0747$ INCH THICK

HEDL $7507-30.18$

FIGURE 3. Arrangement of PWR Spent Fuel Assemblies in the IF-300 


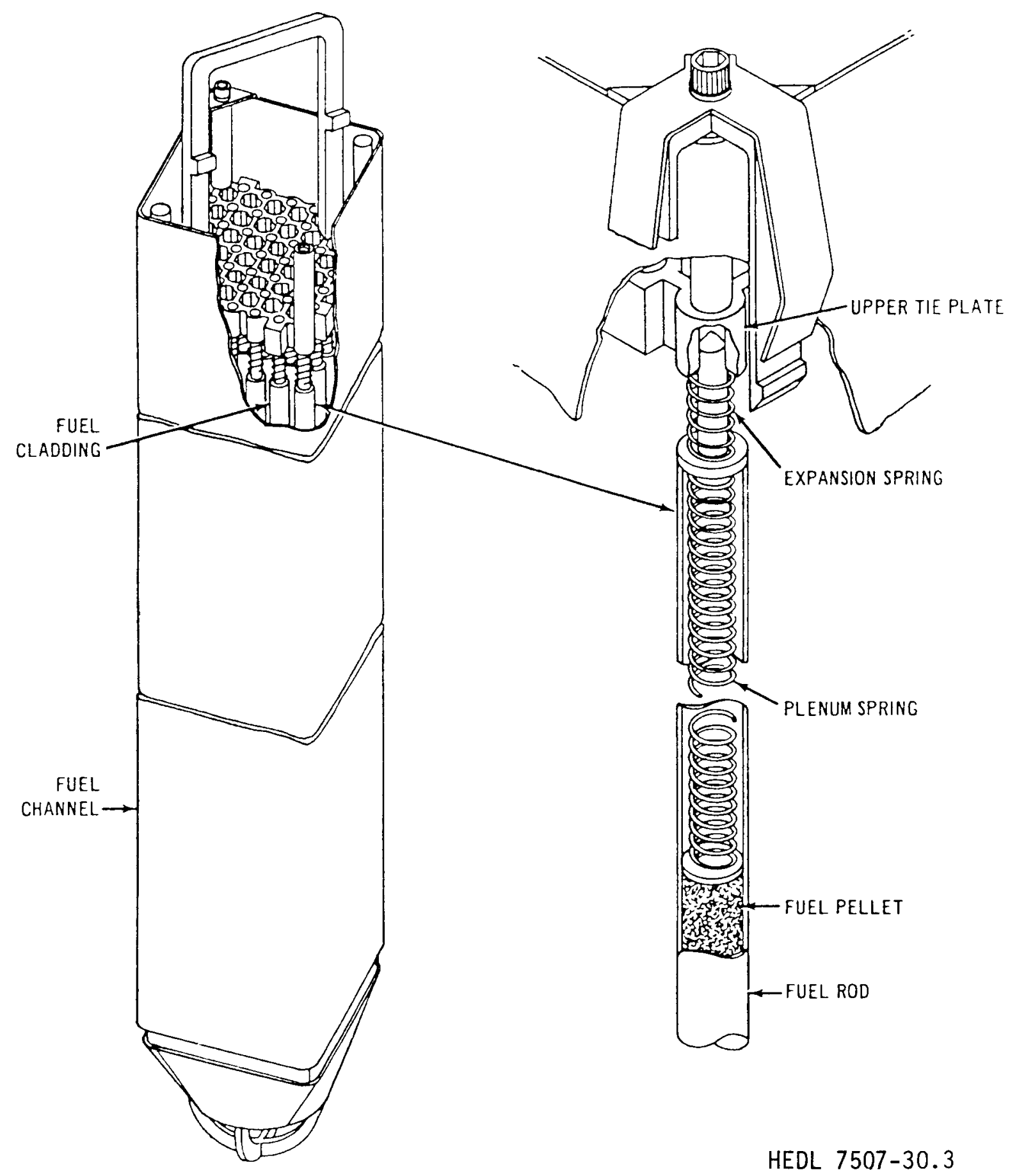

FIGURE 4. LWR Fuel Assembly 


\section{TABLE 2}

Characteristics of Design Basis PWR 1 Fuel

(Compiled from data obtained from References 1 and 8)

\section{Fuel Pin}

Fuel Pellet Diameter, in

Fuel Pellet length, in

Fuel Pellet Density, $\mathrm{gm} / \mathrm{cm}^{3}$

Cladding Thickness, in

Cladding Outside Diameter, in

Active Fuel Length, in

Length of Gas Plenum, in

Fuel Material

Cladding Material

Fuel Assembly

Fuel Pin Array

Pins per Assembly

Fuel Pin Pitch, in

Overal1 Dimensions, in

(Slotted envelope)

Weight of Uranium per Assembiy, $\mathrm{Kg}$

Assembly Cooling Time, days

Assembly Heat Generation, Watts/KgU $\sim 0.420$

0.6

10.19-10.3

0.020

0.460

144.

$\sim 4.0$

Sintered $\mathrm{UO}_{2}$ Zircal oy-4

$15 \times 15$

205

0.582

$8.75 \times 8.75$

457.

120

24.03 


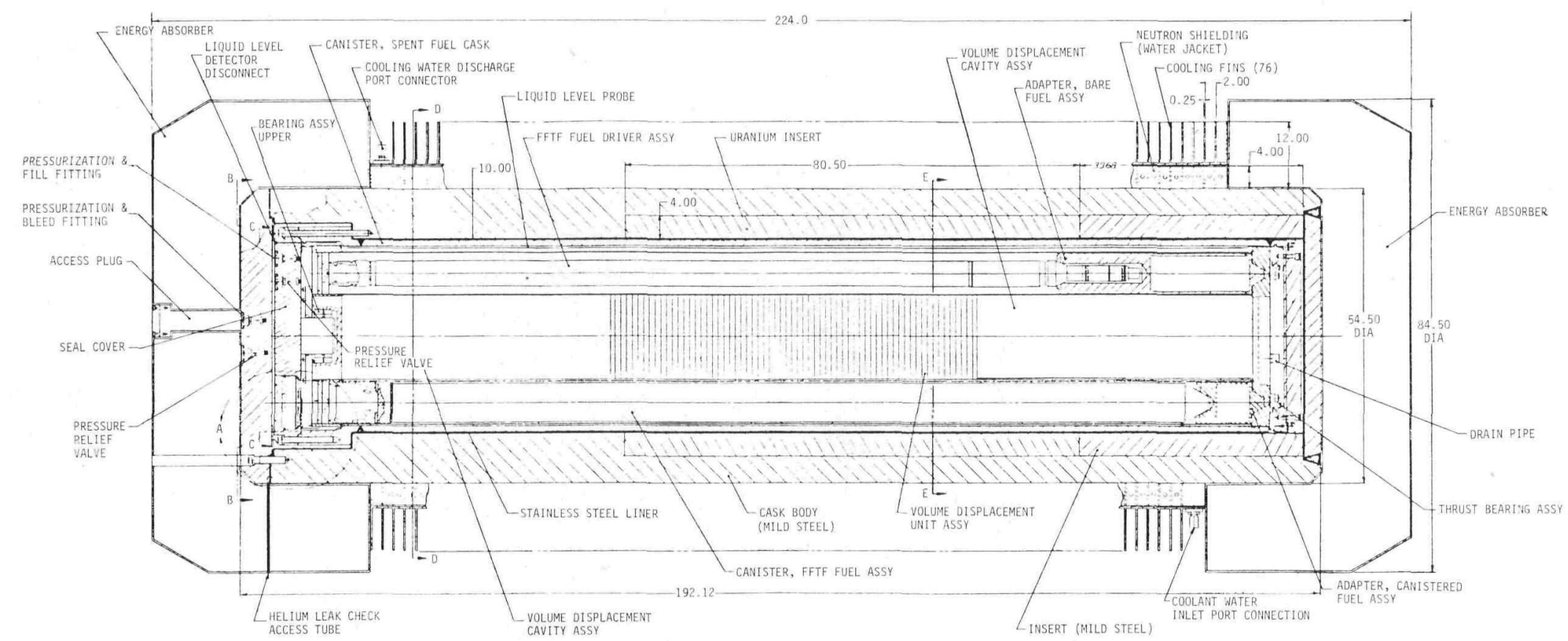

HEDL. $7507-30.59$

FIGURE 5. AMCO LMFBR Spent Fuel Shipping Cask (Reference 2) (Page 1 of 3) 


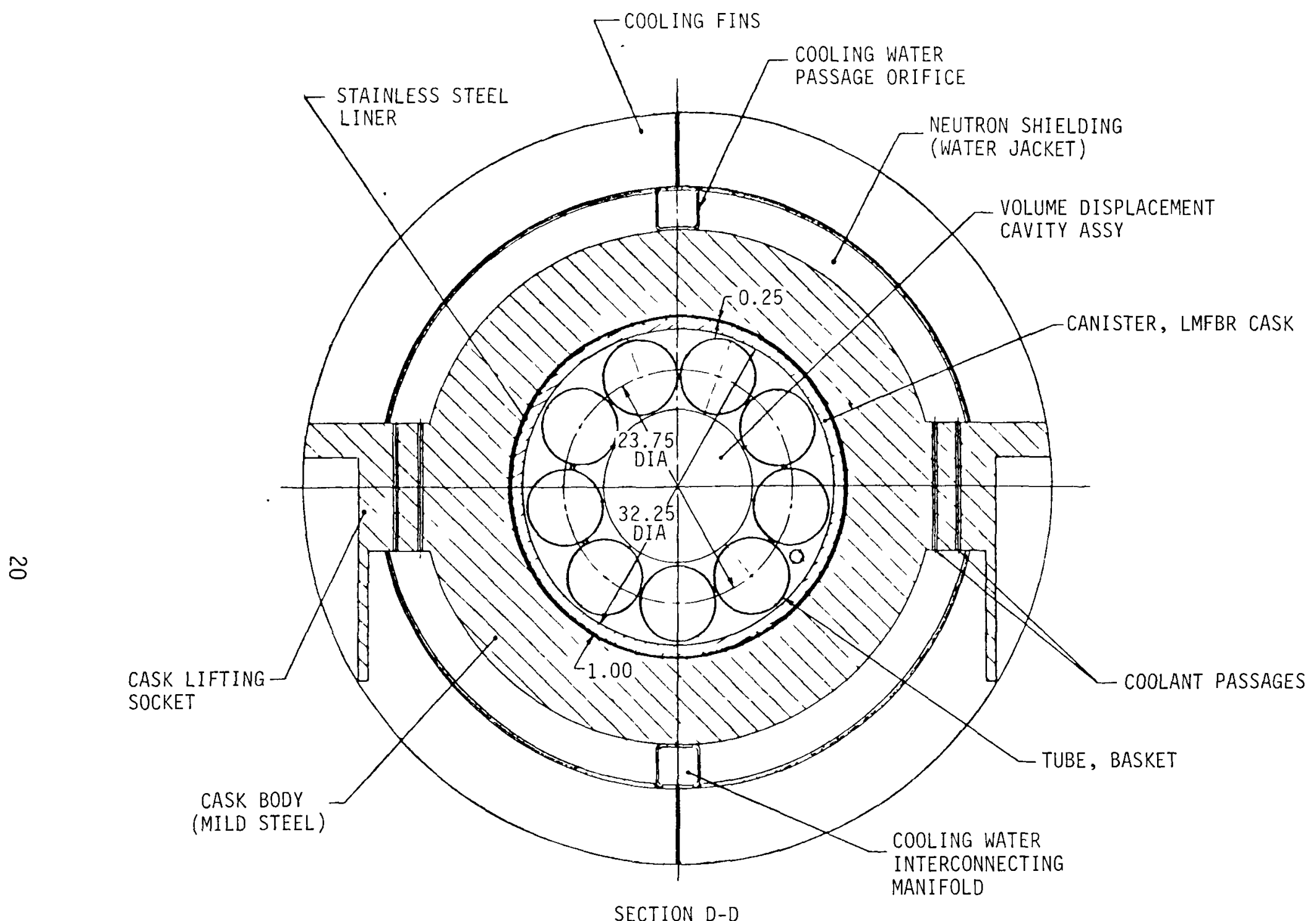

HEOL $7507-30.60$

FIGURE 5. AMCO LMFBR Spent Fuel Shipping Cask (Page 2 of 3) 


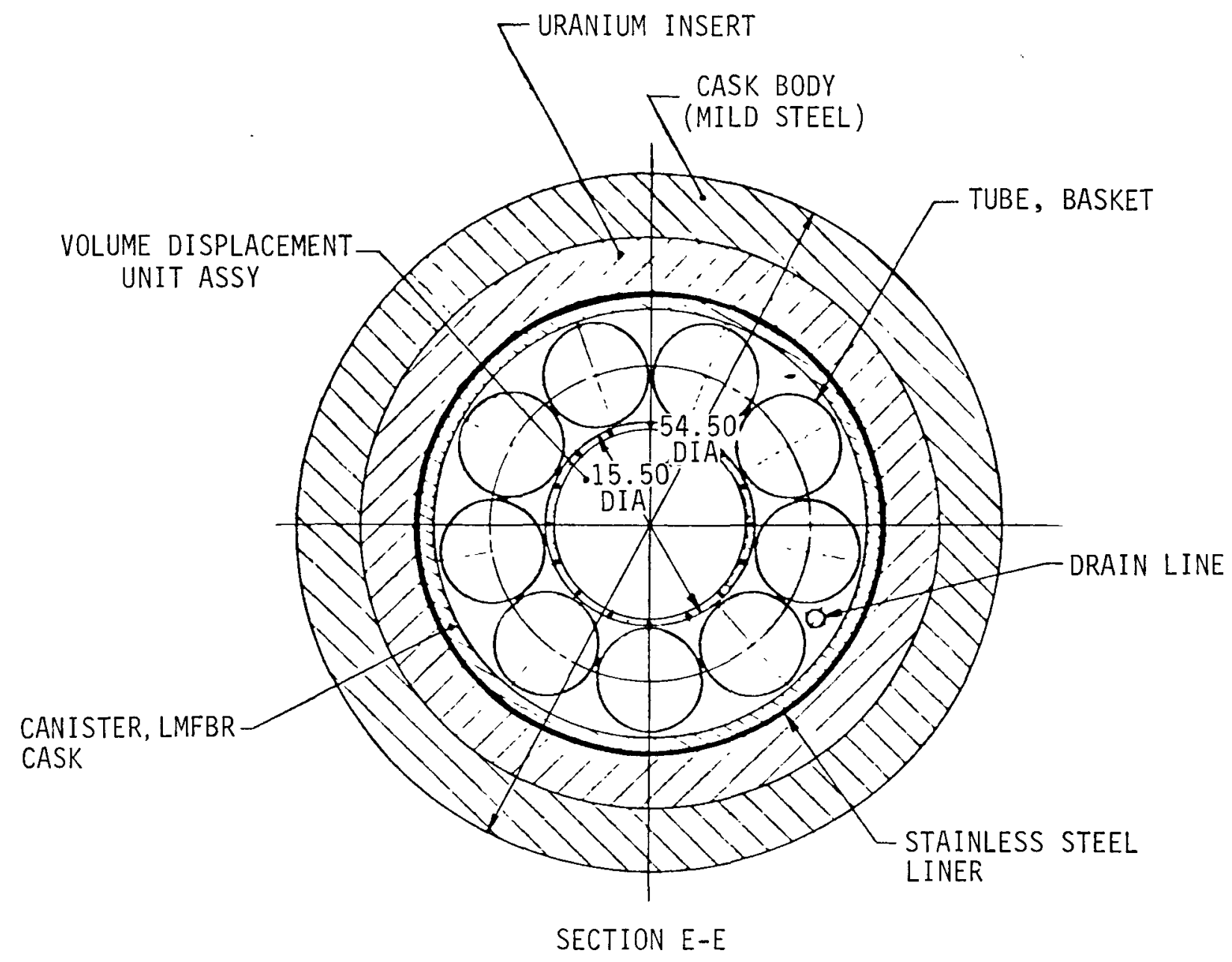

HEDL $7507-30.61$

FIGURE 5. AMCO LMFBR Spent Fuel Shipping Cask (Page 3 of 3 ) 
Descriptive Data on the AMCO LMFBR Spent Fuel Shipping Cask (References 2 and 11)

Typical Fuel Properties - FFTF Fuel

Elements per cask

Mass of fuel, $\mathrm{kg}(U+P u)$

Burnup, MWD/MT*

Peak

80,000

Operating

75,000

Average

50,000

Specific Power, MW/MT

159.1

Decay Time, days

100

Radioactivity, megacuries

Thermal power, Kw

19.8

Cask

Cavity diameter

32.25

Cavity length, ft

14

Inner shell thickness, in

1

Gamma shell thickness, in

$3.625 \mathrm{U}$

Outer shell thickness, in

6.0 Steel

Neutron shield thickness, in

4

Outer liner thickness, in

$\sim 0.25$

Fin height, in

8

Overall diameter, in

78.5

Overall length, ft

18.67

Internal coolant

Dowtherm-A

Shield Coolant

water

* MT $=$ Metric Ton 
uranium shield which, in turn, is surrounded by a 6-inch thick steel shell. The outer surface of the steel shell is cooled by water contained in a four-inch jacket partitioned by circumferential cooling fins extending through the jacket and protruding eight inches beyond the outer diameter of the jacket. The fuel assembly carried by this cask is shown in Figure 6 , and detailed data are presented in Table 4.

A simplified model of the IF-300 is shown in Figures 1-1, 1-3,3-1,3-2, 3-19 and 3-20 in the Appendix. The primary difference between this model and the actual cask is the representation of the fuel, cans and baskets as circular regions rather than the array of square fuel assemblies. A collection of fuel pins have a "lumped" characteristic. It was necessary to devise a method of "distributing" the "lumped" fuel to give homogeneous regions that could then be relumped to fit the nodal representation of a simulation network. The techniques for doing this are discussed in detail in the Appendix.

A simplified model of the AMCO cask is shown as a simulation network or electrical analog in Figures 1-2 and 3-21 in the Appendix. This model represents one-ninth of the cask cross-section, a pie-shaped slice containing one fuel assembly. As in the case of the LWR fuel assembly, the collection of LMFBR fuel pins in an assembly were distributed to give a homogeneous region and then relumped to fit the nodal representation of the simulation network.

These simplified models of the casks were used to simulate the steadystate conditions in the casks before the accident, and the thermal behavior of the casks following an accident, fire, and eventual loss of the primary coolant. Other models of the casks, even simpler and less detailed than those listed above, were used to simulate the thermal behavior of the casks during the fire following the accident, with gradual loss of primary coolant through a breach in the cask containment. These cask models are shown in Figures 2-4 ard 2-7 in the Appendix. 


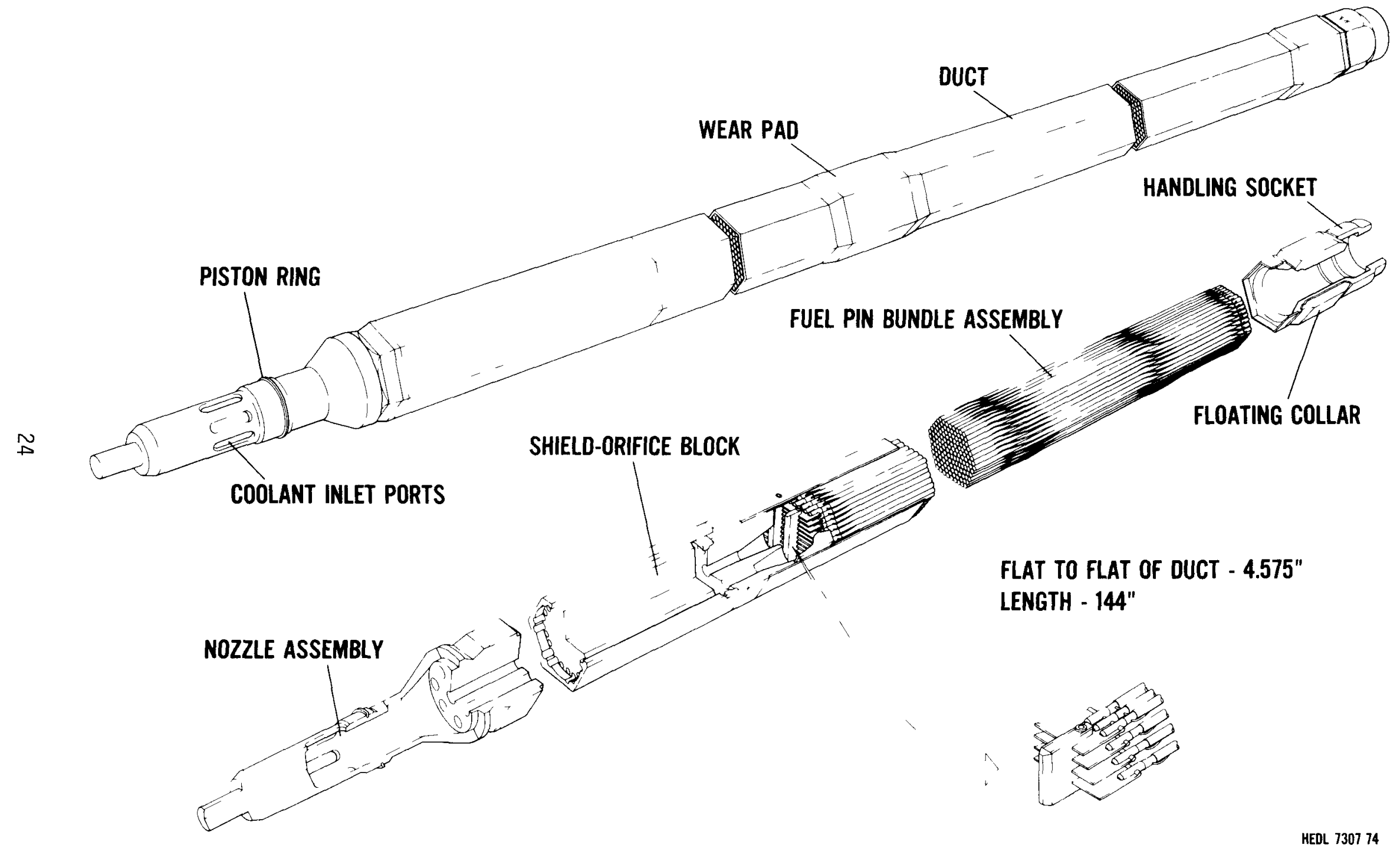

FIGURE 6. FFTF Driver Fuel Assembly 
FFTF Driver Fue] Pin, Cold

Fuel pellet diameter, in

0.196

Fuel pellet length, in

Fuel pellet density, $\mathrm{gms} / \mathrm{cm}^{3}$

0.25

Cladding thickness, in

10.

Cladding outside diameter, in

0.015

Active fuel length, in

0.23

Length of gas plenum, in

36.

Fuel material

Cladding material

42.

Number of fue 1 pins

$$
\begin{array}{r}
\mathrm{PuO}_{2}-\mathrm{UO}_{2} \\
\mathrm{SS}-316 \\
16,492
\end{array}
$$

\section{FFTF Fuel Assembly}

Number of fuel assemblies

76

Fuel pin array

Hexagona $1-6$ rows

Pins per assembly

217

Fuel pin pitch, in

0.286

Overall dimensions, in

Weight of $\mathrm{PuO}_{2}-\mathrm{UO}_{2}$ per fuel assembly, ibs

4.7 across flats

Fuel channel material

88.6

Wire wrap-wire diameter, in

SS-376

0.056 
Fission Product Release Mechanisms

Several fission product release mechanisms have been postulated or identified, and some have been evaluated. The bulk of the fission products released are fission gases and volatile solids or solid.fission products (cesium compounds). Before discussing release mechanisms it is necessary to define what is meant by "free" gases and "bound up" gases. Fission gases and volatile solids generated during reactor operation either migrate to the fuel pin voids (the spaces between the clad and the fuel, the spaces between the fuel pellets, and the plenum space or expansion chamber at the end of the fuel pin), or remain inside the fuel material. Those fission gases and vapors migrating to the pin voids are "free". The rellaining fission gases and vapors produced are bound up in the interstices of the fuel material, hence the term "bound up".

Some possible mechanisms for fission product release from the fuel to the cask containment are:

1. Clad rupture that releases the free fission gases and solid fission products from the fuel pin voids and exposes the fuel to the environment in the containment vessel.

2. Diffusion of bound up fission gases and volatile solids from the fuel, if the temperature is high enough. This is negligible for the times and temperatures encountered in the accident analysis.

3. Disintegration of the fuel upon oxidation that releases bound up fission gases and volatile solids. The exposed fuel oxidizes during the same time it is capable of losing bound up fission gases by diffusion. When oxidation progresses to the point where the fuel undergoes a phase change upon conversion to $\mathrm{U}_{3} \mathrm{O}_{8}$, a loose granular material, the bound up fission products are assumed to be released. Results obtained using the simulation models indicate that the cask interior is always at a higher pressure than the surroundings; 
therefore the chances of air entering the containment vessel are considered to be very low. The only time oxidation would be an important release mechanism would be in the unlikely event that massive damage would be suffered by the casks and the fuel would become directly exposed to the environment. 0xidation of the fuel by the water vapor remaining in the IF-300 after loss of coolant, to the extent required to release substantial amounts of fission products, is considered to be unlikely.

4. The radioactive crud entrained in the primary coolant will be lost from the cask in the event of coolant loss. When the fuel assemblies are placed in the shipping cask, there will be a certain amount of radioactive residue or "crud" adhering to the surfaces of the assemblies.

Fission products may be released from the cask containment by leakage from some breach in the cask containment. As stated earlier, the breach in the cask containment was arbitrarily assumed to be due to a damaged pressure relief valve. This was an arbitrary assumption for the purpose of this study and must not be interpreted as an implication that the pressure relief valve is vulnerable to damage or malfunction. On the contrary, the relief valve is not only a well designed and proven component, but is also extremely wel1 protected in the IF-300 design (see Figures $T$ and 2). The escape of nonvolatile fission products or of transuranium isotopes would require the assumption of extremely severe conditions, including extensive mechanical damage to the fuet.

Results of the Simulations

Some radioactivity in the form of crud, fuel particles, and some free fission gases from damaged fuel pins could be released immediately after impact as the primary coolant is lost. It was estimated that about 1.6 curies could be released as crud. The amount of radioactivity released at impact as fuel particles and free fission gases requires some knowledge 
of the extent of damage to the fuel pins, and of the mechanism of escape of the fuel particles from the damaged pins and their subsequent dispersion in the coolant. A reasonable estimate of the number of pins breached at impact nay be obtained from a mathematical model simulating the mechanical response of the fuel assemblies to the impact force, or from an equivalent experimental program. A model simulating this event in the accident sequence has not yet been developed for this study; however, similar studies in the past have led to the development of some preliminary models that simulate the elastic-plastic response of structures to an impulse such as that which might be experienced by the fuel assemblies at impact. ${ }^{34}$ ) Experience gained from this earlier work is directly applicable to the development of a mechanical response model for the fuel assemblies. The release of fuel particles and free fission gases will be delayed if the fuel pin clads do not fail at impact.

Although the extent of damage to the fuel pins at impact has not yet been determined, and the exact amount of fission products released cannot be reliably estimated, some indication of how these events may be factored into the present analysis is offered through the following scenario. If all or a fraction of the pins are ruptured at impact, fission products will be released. Fission gases would probably be released through any breach in the cladding, but particulate matter would only be released through those openings large enough to accommodate at least the smallest particles formed. Upon release, the fission gases would rise through the primary coolant to the top of the cask cavity, while the fine particles of solid material would be suspended and dispersed in the coolant and the larger particles would settle to the bottom of the cavity. If the cask is in a breach up position after impact, the fission gases will escape through the breach. Also, some fine solid particles may be entrained in the coolant vapor flowing through the breach. However, the larger particles, which have settled to the bottom of the cavity, would remain in the cask even after the cask has lost all coolant. If the cask is in a breach down position after impact, the fission gases will not be released until after the cask has been emptied of its liquid primary coolant. The fission gases will mix with the vapor phase primary 
coolant above the liquid. The fine solid particles suspended and dispersed in the liquid coolant would flow from the breach along with the coolant. The larger solid particles at the bottom of the cavity may be swept into the breach along with the coolant. If the breach is small enough, and the particles large enough, the particles may clog the breach and prevent further loss of coolant and fission products (especially if the cask is designed with an in-line filter). If the particles cannot completely clog the breach, the cask will eventually lose all its liquid coolant, and the vapor-fission gas mixture will flow through the breach. Some fission gases will remain in the cask, along with residual vapor, when the pressure inside the cask decreases to atmospheric pressure. Some elements of the analytical approaches presented in Sections 2, 3.5 and 4 in the Appendix may be used to help in any simulation of the events described in the above scenario. If it can be established that some fraction of the pins have been ruptured at impact, the behavior of the remaining undamaged pins would be simulated using the models developed for the study of this report.

A list of simulation models developed for this study has been presented and briefly discussed in the Introduction. This list includes a set of five simulation models for the IF-300 and a similar set of models for the AMCO cask. These models simulate cask behavior during normal operating conditions, and during conditions following an accident and fire. The development of each of these models is discussed in detail in the Appendix. Results obtained using these models will now be presented and discussed.

\section{A. Steady-State Temperatures in the Casks Before the Accident}

The steady-state temperatures in the casks before the accident were determined to establish initial conditions for the post-accident transient analyses to be discussed later. Details of the steady-state simulation models of the casks are discussed in Section 1 of the Appendix. These models simulate conditions in the casks while in transit, during an uneventful, normal trip. 
In both casks, decay heat generated by the spent fuel is transferred by natural convection to the primary coolant inside the fuel assembly cans, which in turn transfers the heat to the inner wall of the cans. The heat is then conducted through the can walls to the outer surface, where it is then transferred by natural convection to the primary coolant outside the fuel assemblies. The primary coolant outside the fuel assemblies then transfers the heat to the inner wall of the containment vessel, also by natural convection. The heat is then transferred by conduction through the steel liners and shielding of the cask wall, and by radiation and conduction across any small gaps. At the outer liner, some of this heat is transferred to the water in the outer jacket by natural convection. The AMCO cask design includes circumferential fins, which are attached to the outer liner and extend through the jacket to protrude eight inches beyond the outer shell of the jacket. These fins pick up some of the heat transferred to the water in the outer jacket, along with heat conducted through the fins from the outer liner. Heat is transferred from the fins and from the outer shell of the water jacket to the surroundings by natural convection and radiation. The IF-300 design does not have fins attached to the outer liner, which extend into and through the water jacket. Instead, the outer surface of the water jacket is corrugated, and air is forced over the outside of the corrugated surface to dissipate the heat transferred into the water jacket. Both casks are covered by a solar shield while in transit.

The coolant circulation patterns and heat transfer paths in the cavities in the casks, which contain the spent fuel, are discussed in Section 1.1 of the Appendix.

A collection of fuel pins, such as those in the fuel assemblies, have a "lumped" characteristic. A method was devised to "distribute" the "lumped" fuel to give homogeneous regions that could then be "re-lumped" to fit the nodal representation of the models. This was done by using the concepts of volumetric heat dissipation and an apparent thermal conductivity for materials with voids to represent the heat transfer in the fuel regions. The equations defining these concepts are presented in Sections 1.2 and 1.3 , respectively, in the Appendix. 
The steady-state temperatures in the IF-300, obtained for the coditions specified in Tables 1 and 2, are shown in Figure 7 . The maximum fuel temperature is $361^{\circ} \mathrm{F}$, the water in the cask cavity is about $333^{\circ} \mathrm{F}$, and the water inside the fuel cans is at about $360^{\circ} \mathrm{F}$. The calculated fuel temperature is about $44^{\circ} \mathrm{F}$ higher than that reported in Reference 1 , and the temperature of the water in the cask cavity is about $30^{\circ} \mathrm{F}$ higher. Temperatures obtained from Reference 1 are also shown in Figure 7. The General Electric study of Reference 1 was based on a two-dimensional model that considered heat flow from the ends of teh cask, as well as that which flows radially from the cask. The present study was based on a one-dimensional model where only heat flow from the cask in the radial direction was considered. This might account for the differences in the results.

Steady-state temperatures in the AMCO cask, obtained for the conditions specified in Tables 3 and 4 , are shown in Figure 8 . The maximum fuel temperature is $383^{\circ} \mathrm{F}$, and the Dowtherm-A in the cask cavity is at a temperature of about $343^{\circ} \mathrm{F}$. The fuel temperature is about $20^{\circ} \mathrm{F}$ higher, and the temperature of the coolant in the cask is only $2^{\circ} \mathrm{F}$ lower than the corresponding temperatures reported in Reference 2. The temperature of the coolant inside the fuel assembly cans was not reported in Reference 2. Temperatures obtained from Reference 2 are also shown in Figure 8.

\section{B. Analyses of Rate of Coolant Loss from the Casks}

Analyses were made for both the IF-300 and the AMCO casks in an effort to estimate realistic coolant loss rates. This was an important phase of the study because if it could be shown that the rate of coolant loss was low enough and the cask could be approached after the fire ends, before a substantial amount of coolant was lost, then steps could be taken to restore the cask to near pre-accident conditions. Results of these analyses show that, although the loss of the coolant is not instantaneous, the time required to empty the IF-300 is small enough, in all of the cases considered, to rule out any thought of restoring this cask to near pre-accident condi- 


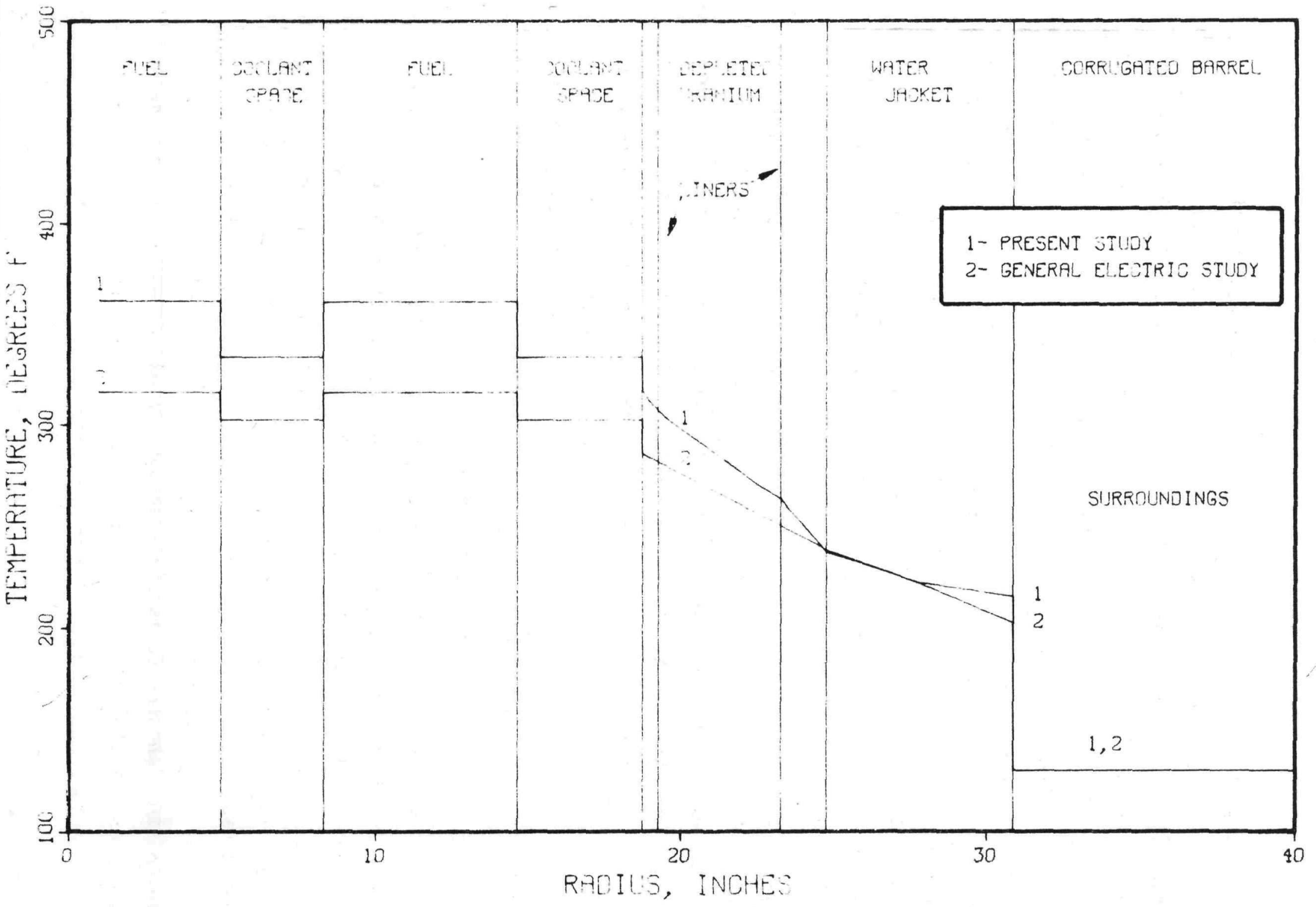

FIGURE 7. Steady-State Temperatures in the IF-300 Before the Accident 


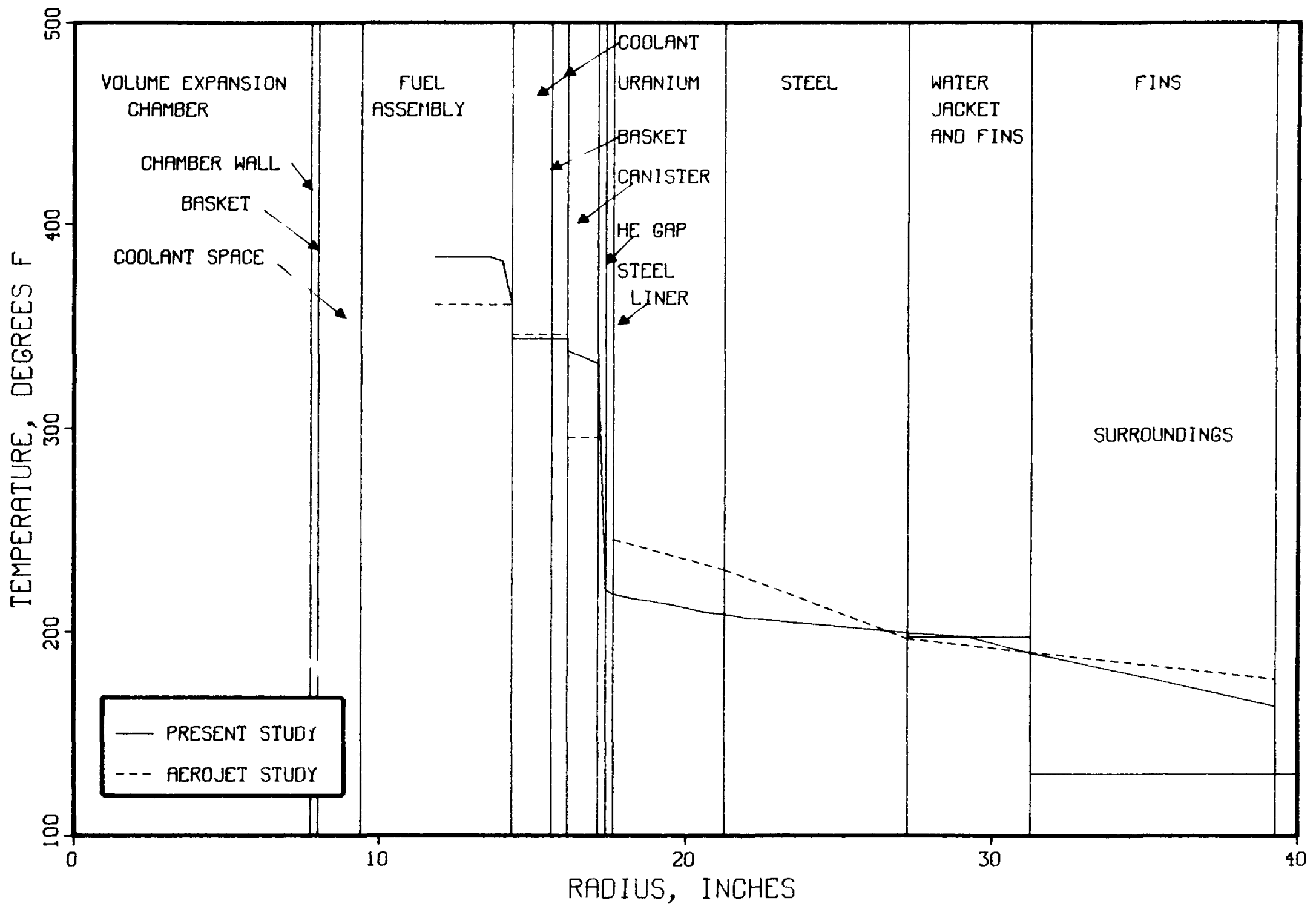

FIGURE 8. Steady-State Temperatures in the AMCO Cask Before the Accident 
tions. However, results show that there is ample time to restore the AMCO cask to near pre-accideni conditions in two of the four cases considered.

It was assumed that the primary coolant would be lost from the casks through a damaged or malfunctioning pressure relief valve. There are two possible ways in which the primary coolant may be lost from a breached cask. These depend upon the final orientation of the cask after the accident. At impact, if the tiedowns fail, the cask may become separated from the rail car and come to rest in one of four positions:

1. On end with the breach (damaged relief valve) up,

2. On end with the breach down,

3. On its side with the breach up, and

4. On its side with the breach down.

If the tiedowns do not fail at impact, the cask will remain in its original orientation on the rail car, i.e., on its side as in positions 3 and 4 above. The first mechanism for coolant loss depends on the cask being oriented in positions 2 and 4 . In these positions, the coolant may leak out under the driving force of its own liquid head and the static pressure in the cask. The second mechanism for coolant loss depends on the cask being oriented in positions 1 and 3 . In these positions, the coolant would not leak out, but would escape from the cask by vaporization as it absorbs the decay heat from the fuel.

A model was developed to simulate the transient thermodynamic behavior of the IF-300 and to determine the time required for it to lose its primary coolant. This model is based on energy and mass balances on the cask, and on an energy balance on the coolant flowing through the breach. The main driving force that causes the coolant to flow from the cask through the breach is the buildup of static pressure in the cask cavity. This pressure buildup is partiy due to that portion of the decay heat from the fuel stored in the liquid and vapor phases of the coolant during the transient, and partiy due to the choked flow in the breach. A detailed discussion of the development of a breach down version of this model is presented 
in Section 2.1.1 in the Appendix, and the breach up version of the model is discussed in Section 2.1.2.

Two breach sizes or flow areas were assumed. The smallest flow area assumed was $0.025 \mathrm{in}^{2}$, a reasonable area for a relief valve tnat is not fully reseated. The largest flow area assumed was $0.25 \mathrm{in}^{2}$, a reasonable area if the relief valve is sheared off. Additional damage assumed to be suffered by the cask in the accident included loss of the solar shield, and rupture of the outer water jacket with immediate loss of the water. It was also assumed that the cask was immersed in a fire at a temperature of $1475^{\circ} \mathrm{F}$ for 0.5 hour, as specified in the Code of Federal Regulations. (5)

If the IF-300 comes to rest with the breach up, only vapor will escape through the gap. If the cask comes to rest with the breach down, only liquid will escape from the gap. The initial temperatures of the fuel, fuel cans, coolant and baskets in the IF-300 at the time of the accident were determined using the steady-state pre-accident model, as were the temperatures of the cask wall and surface. This steady-state model is similar to the loss-of-coolant model to be discussed later, except that the primary coolant is not lost, the solar shield remains intact, and no water is lost from the neutron shield (outer water jacket). The iritial temperatures of the fuel, coolant inside the fuel cans, fuel cans and coolant outside the fuel cans at impact were $361^{\circ} \mathrm{F}, 360^{\circ} \mathrm{F}, 350^{\circ} \mathrm{F}$ and $333^{\circ} \mathrm{F}$, respectively. An average of the coolant temperatures, $347^{\circ} \mathrm{F}$, was used as the initial coolant temperature in the sirulation model that determines the rate of coolant luss. The water coulant is a saturated liquid at this temperature, with a corresponding saturation pressure of 130 psia. Since this saturation pressure is about 9 times atmospheric pressure, the cask was treated as a pressure vessel. The heat scurce in the cask in the steady-state analysis, and in subsequent transient analyses, was the decay heat from fuel that had cooled 1'20 days prior to shiphent.

A set of charts has been developed by Moody ${ }^{(9)}$ to provide a convenient method for evaluating the maximum rate of loss of steam or water from a pressurized vessel that suffers a sudden break in its containment. The maximum rate of loss of either the vapor or the liquid from the breach 
is governed by a thermodynamically defined critical or maximum mass flow rate based on isentropic flow of the fluid from the breath. A chart from Reference 9, presented as Figure 2-1 in the Appendix, relates the critical or maximum mass flow rate of steam and water to the stagnation enthalpy and pressure. This chart will be referred to as the "Moody chart" throughout this report. When the mass velocity is multiplied by the area of the breach produced at impact, the rate of coolant loss is obtained.

Results show that if the IF-300 comes to rest with the breach up, it would take about 68 minutes to empty the cask of its coolant if the breach flow area is $0.25 \mathrm{in}^{2}$, and about 4.62 hours if the flow area is $0.025 \mathrm{in}^{2}$. In the breach-up position, only the vapor produced by boiling of the coolant can escape. At the largest flow area, the pressure in the cask builds up to a maximum of 732 psia and then decreases to atmospheric pressure. The maximum mass velocity in the breach at the peak pressure (as obtained from the Moody chart) is $1471 \mathrm{lb}_{\mathrm{m}} / \mathrm{sec}-\mathrm{ft}^{2}$. At atmospheric pressure, 2.2 pounds of vapor remain in the cask. At the smallest flow area, the pressure in the cask reaches a maximum of about 1823 psia and then decreases to atmospheric pressure. The maximum mass velocity in the breach at this peak pressure is about $44681 \mathrm{~b}_{\mathrm{m}} / \mathrm{sec}-\mathrm{ft}^{2}$. For this case, at atmospheric pressure, 2.0 pounds of vapor are left in the cask. In both cases, the peak pressure occurs at the instant just before all of the liquid coolant disappears, leaving only the vapor phase. Pressures in the IF-300 as functions of time, for the breach up cases, are presented in Figure 9. The corresponding temperatures in the cask are presented in Figures 10 and 11 , and the masses of liquid coolant in Figure 12.

If the cask comes to rest in a breach down position, only saturated liquid would escape from the breach. Under these conditions, results indicate it would take about 16 minutes to empty the cask if the breach flow area is $0.25 \mathrm{in}^{2}$ and about 1.94 hours if the flow area is $0.025 \mathrm{in}^{2}$. At the largest flow area, the pressure reaches a maximum of about 177 psia before decreasing to atmospheric pressure. The mass velocity in the breach at the peak pressure is greater than $34121 \mathrm{~b}_{\mathrm{m}} / \mathrm{sec}-\mathrm{ft}^{2}$, the maximum obtained from the Moody chart for the saturated liquid, so the flow of the two-phase fluid 


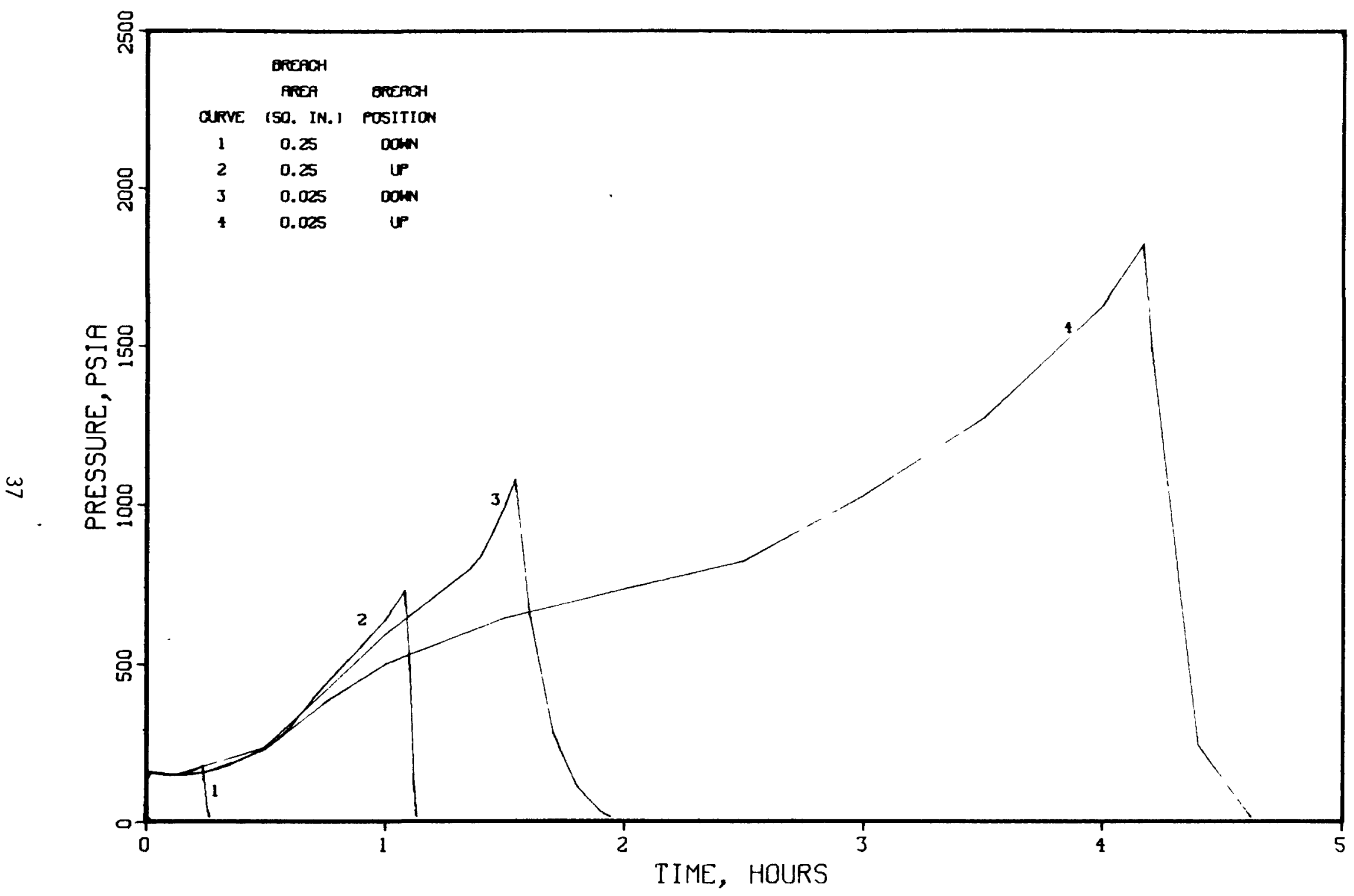

FIGURE 9. Cavity Pressure in the IF-300 as a Function of Time After the Accident 


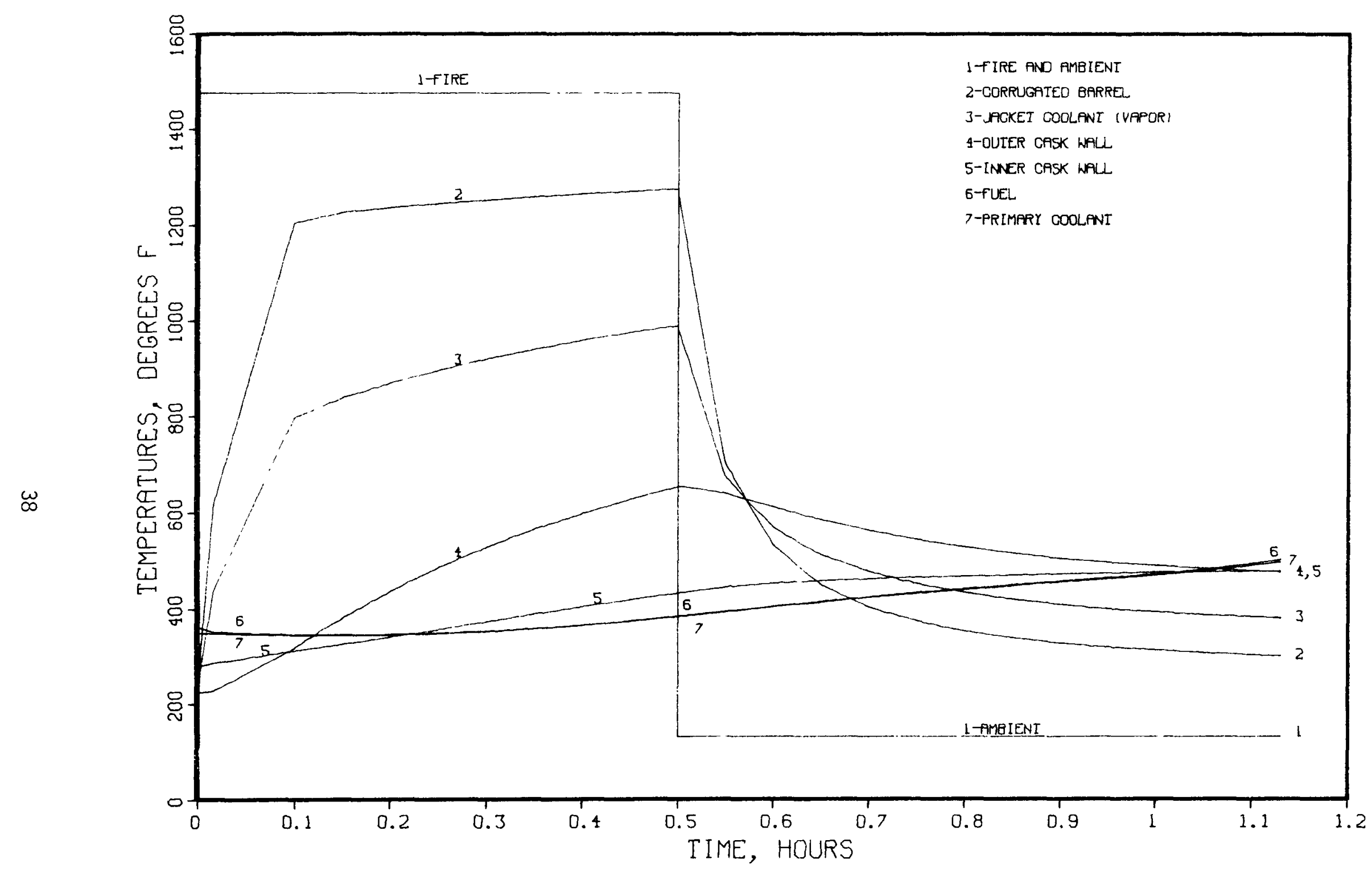

FIGURE 10. Temperatures in the IF-300 During Loss of Coolant (Breach Up Position, Breach Area $=0.25$ Sq. Inches) 


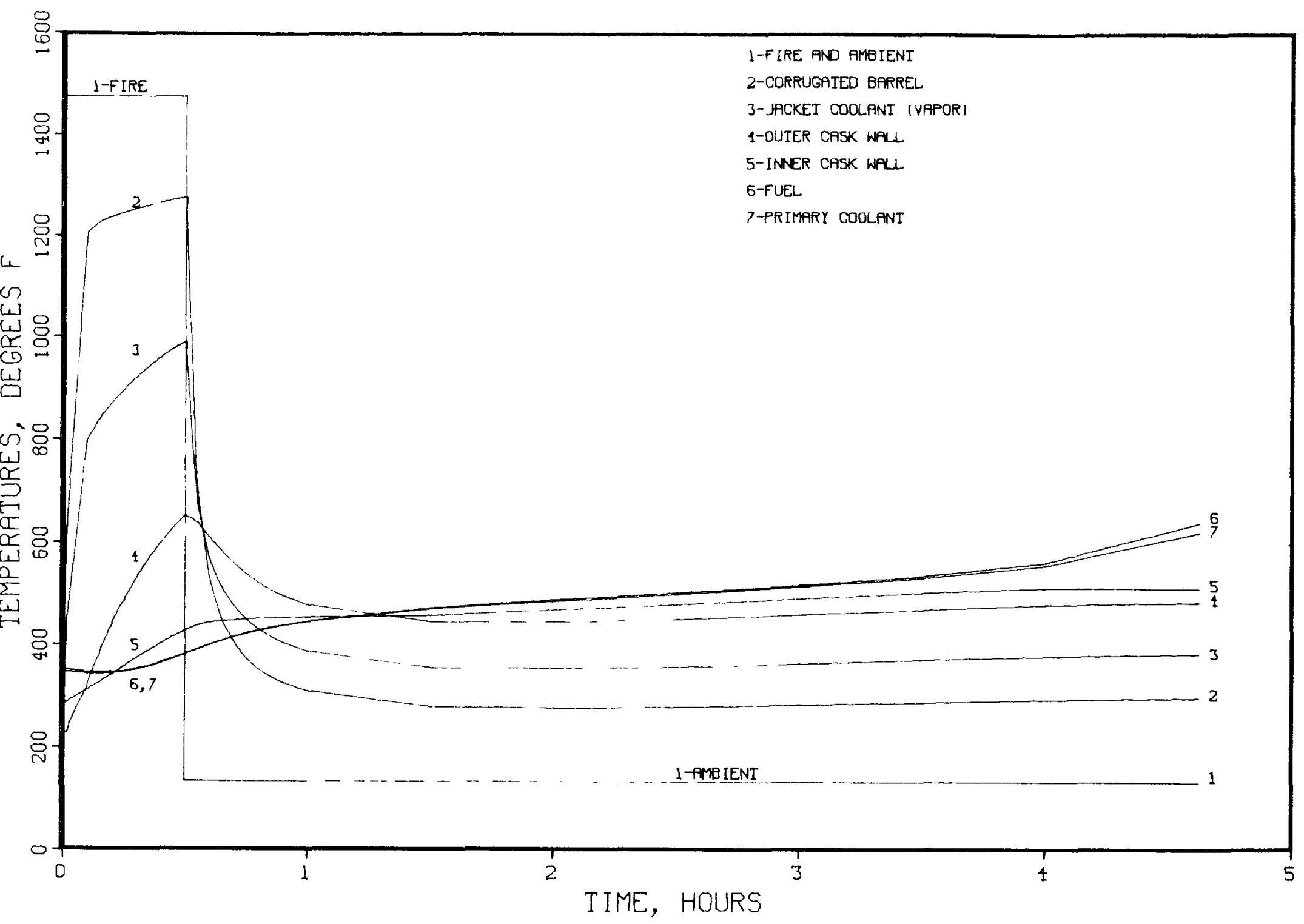

FIGURE 11. Temperatures in the IF-300 During Loss of Coolant (Breach Area=0.025 Sq. Inches, Breach Up Position) 


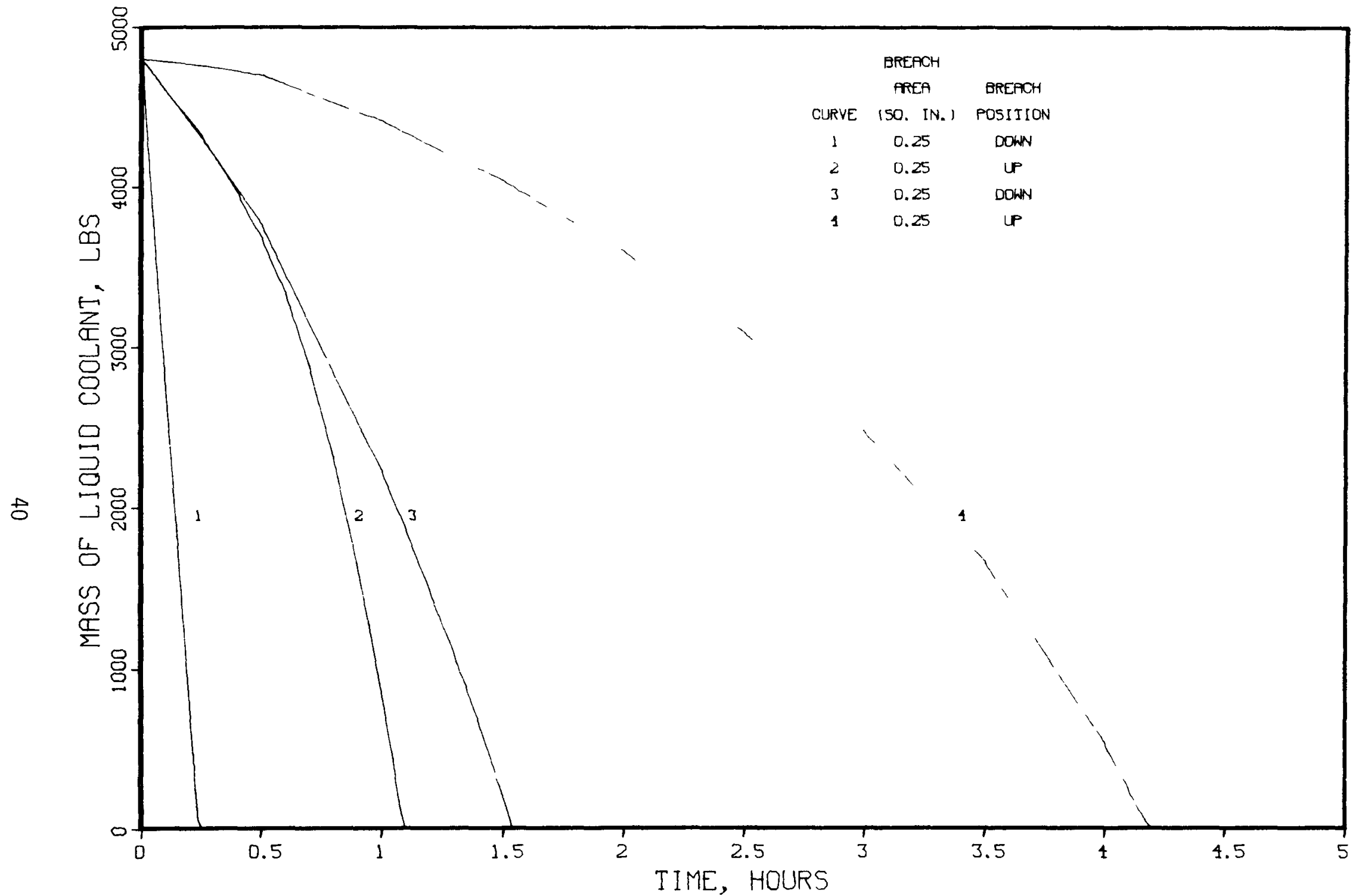

FIGURE 12. Mass of Liquid Coolant Remaining in the IF-300 As a Function of Time After the Accident 
from the breach is choked. At atmospheric pressure, 2.6 pounds of vapor remain in the cask. At the smallest flow area, the pressure peaks at about 1080 psia and then decreases to atmospheric. The maximum mass velocity at this peak pressure is greater than $74701 \mathrm{~b} / \mathrm{sec}-\mathrm{ft}^{2}$, the maximum obtained from the Moody chart. In this case, 2.1 pounds of vapor are left in the cask. As before, the peak pressure occurs just before all of the liquid coolant disappears, leaving only the vapor phase. Pressures as functions of time, for the breach down cases, are presented in Figure 9. The corresponding temperatures in the cask are presented in Figures 13 and 14 , and the masses of liquid coolant in Figure 12.

Initial temperatures in the AMCO cask were determined in the same manner as those for the IF-300. A steady-state pre-accident analysis indicated that the fuel, the coolant inside the fuel cans, fuel cans, and coolant outside the fuel cans were at temperatures of $383^{\circ} \mathrm{F}, 380^{\circ} \mathrm{F}, 364^{\circ} \mathrm{F}$ and $343^{\circ} \mathrm{F}$, respectively, at the time of impact. An average coolant temperature of $360^{\circ} \mathrm{F}$ was used as the initial coolant temperature in the model that determines the rate of coolant loss. The model used to determine the steady-state temperatures in the cask is similar to the loss-of-coolant model to be discussed later, except that the primary coolant is not lost, the solar shield remains intact, and no water is lost from the neutron shield (outer water jacket).

The heat source in the AMCO cask was the decay heat from fuel which had cooled 100 days prior to shipment. For the analysis of conditions in the cask after it had been emptied of its coolant, a decay heat corresponding to fuel that had cooled 120 days was used. The same damage was assumed for the AMCO cask as was assumed for the IF-300, i.e., the solar shield was lost, the outer water jacket was ruptured, and a breach was opened in the cask contairment. In addition, a 0.5 -hour fire at $1475^{\circ} \mathrm{F}$, as specified in the Code of Federal Regulations, ${ }^{(5)}$ was assumed.

The primary coolant in the AMCO cask is Dowtherm-A, which is a low vapor pressure coolant. Its saturation temperature at atmospheric pressure is $494.8^{\circ} \mathrm{F} .^{(9)}$ The average initial temperature of the Dowtherm-A coolant at the time of the accident is about $360^{\circ} \mathrm{F}$, as calculated using the steady- 


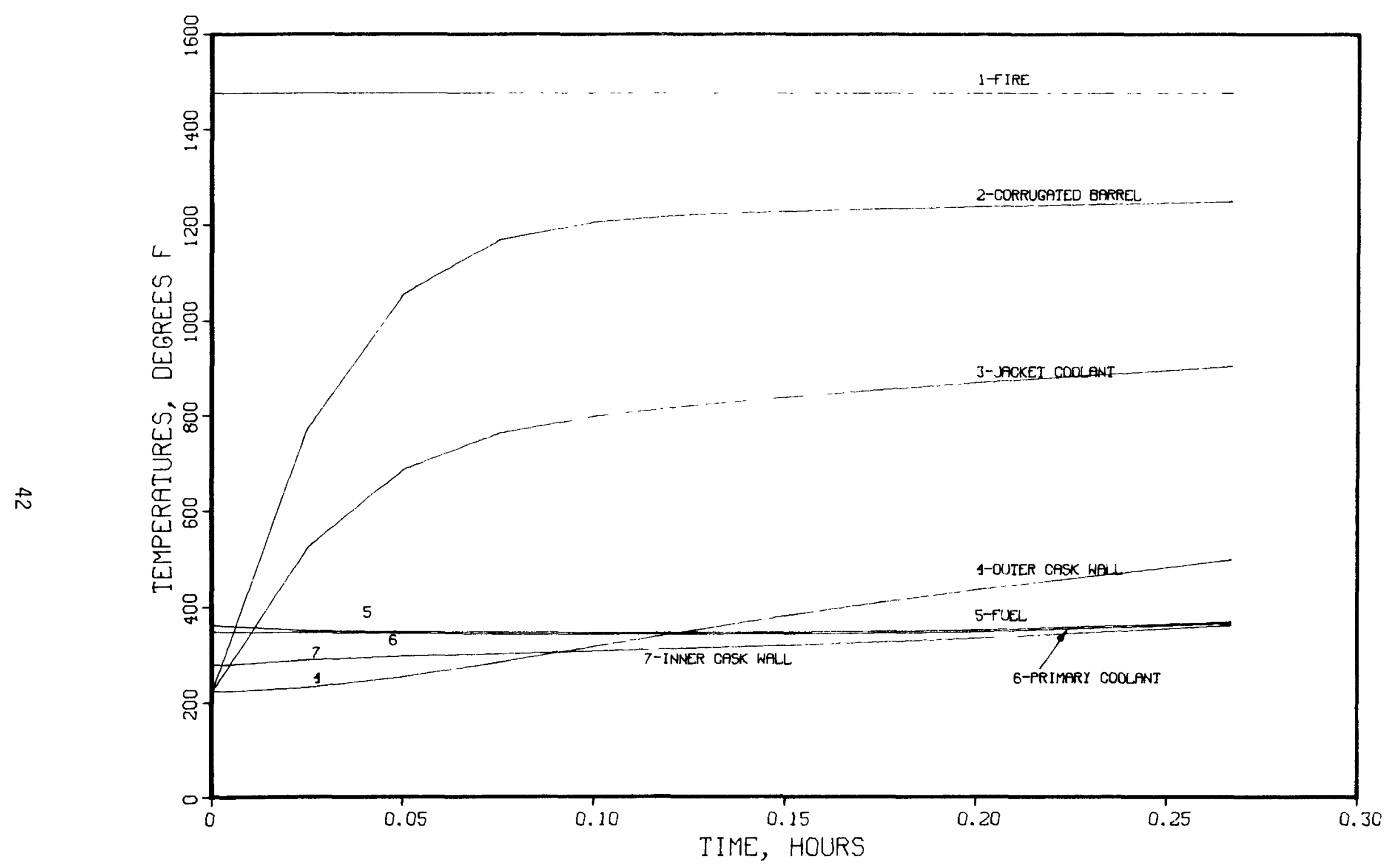

FIGURE 13. Temperatures in the IF-300 During Loss of Coolant (Breach Area=0.25 Sq. Inches, Breach Dowi? Position) 


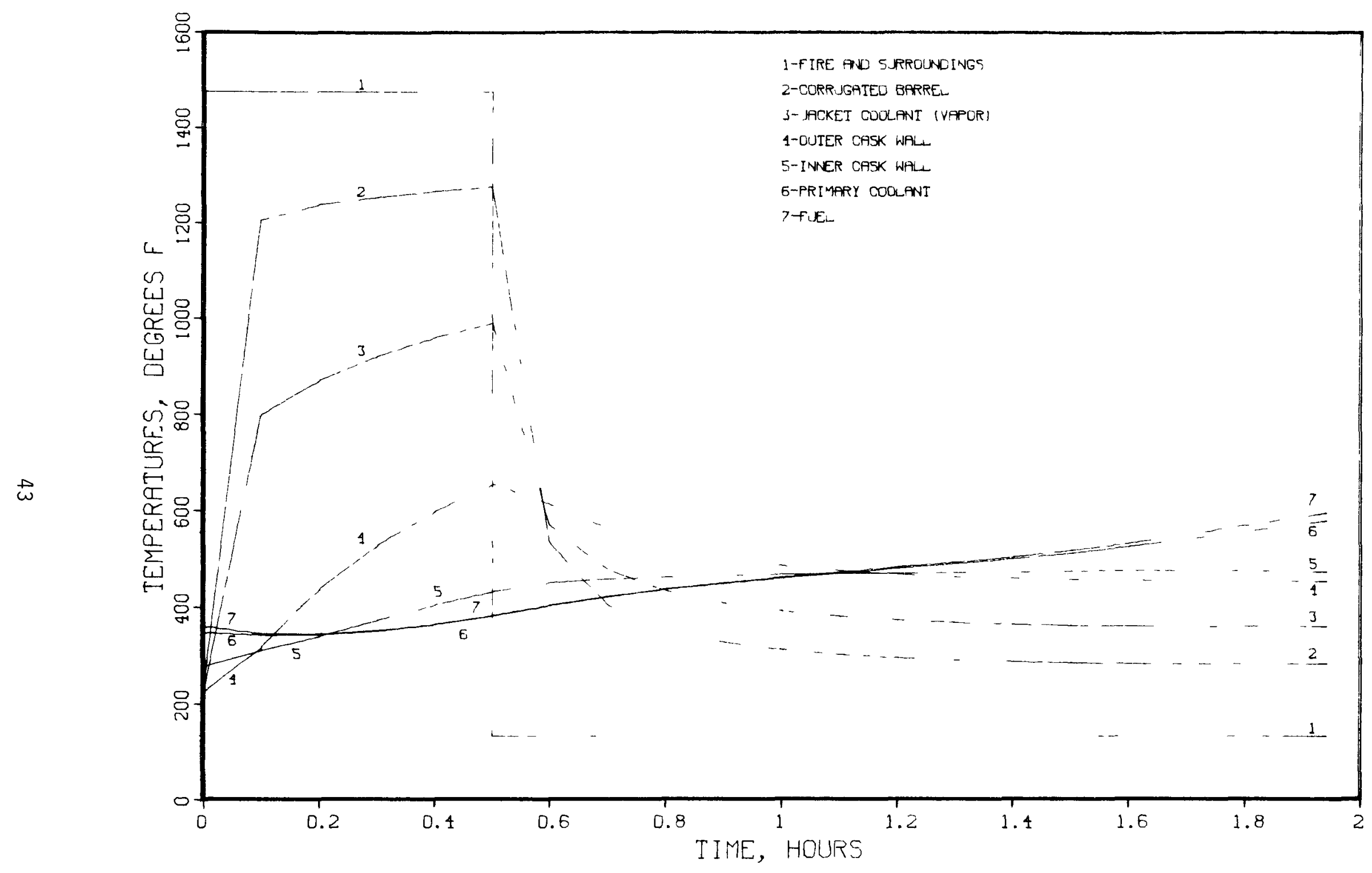

FIGURE 14. Temperatures in the IF-300 During Loss of Coolant (Breach Area=0.025 Sq. Inches, Breach Down Position) 
state pre-accident model. This means that the coolant is subcooled and not at saturation conditions as is the water in the IF-300. Since the pressure in the AMCO cask is about the same as atmospheric pressure at the time of impact, the rate of loss of the coolant from the breach was determined by methods different than those used for the IF-300.

A model was developed to simulate the transient thermal behavior of the AMCO cask and to determine the time required for it to lose its primary coolant, if it becomes separated from the rail car and comes to rest in a breach up position. This model is primarily a heat transfer model that simulates the thermal behavior of the cask after it has lost its solar shield and the water in its outer jacket or neutron shield. This model also applies to the case where no breach is opened in the cask containment at impact. A detailed discussion of the development of this model is presented in Section 2.2.2 in the Appendix. Results obtained from this model show that, for both the breach sizes considered, it would take about 20 days to empty the cask of its coolant if the cask breaks loose from the rail car and lands in the breach up position. This time is extrapolated from the results presented in Figure 15, since the actual computations were only carried out to about 13 days. It takes about 5.4 days for the Dowtherm-A to absorb the heat required to reach its saturation temperature of $494.8^{\circ} \mathrm{F}$. At this point, the coolant boils and leaves the cask as vapor. By 12.8 days, 1616 pounds or $42.6 \%$ of the total 3790 pounds of coolant has boiled away (see Figure 15). A straight line extrapolation of the curve of coolant mass remaining would give a conservative estimate of about 20 days for the cask to empty completely. The coolant leaves the cask as vapor with a maximum mass velocity of about $1301 \mathrm{~b} / \mathrm{sec}-\mathrm{ft}^{2}$ at a breach area of $0.025 \mathrm{in}^{2}$, the smallest breach size considered.

A different model was developed to estimate the rate of coolant loss from the AMCO cask and the time required to lose all of its primary coolant if it comes to rest in a breach down position. This model was based on an energy balance relating the isentropic flow of Dowtherm-A through the breach to the potential energy of the coolant column. The development of this model is discussed in detail in Section 2.2.1 in the Appendix. 


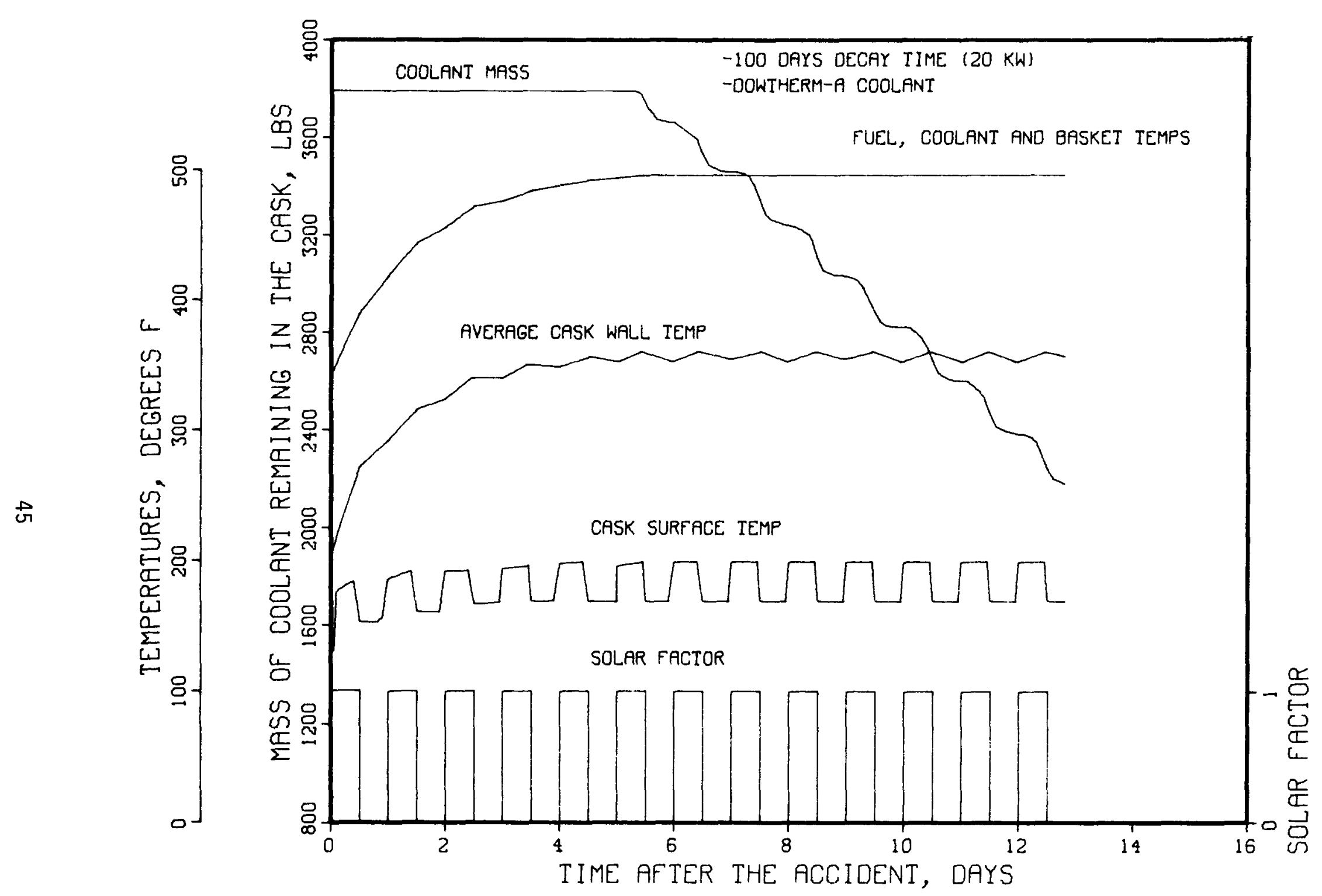

FIGURE 15. Behavior of the AMCO Spent Fuel Shipping Cask Following an Accident and 0.5 Hour Fire (Gradual Loss of Primary Coolant) 
Results from this model show that at impact, when the Dowtherm-A is at an average temperature of $360^{\circ} \mathrm{F}$, it would take about 43 minutes to empty the cask if the breach area were $0.25 \mathrm{in}^{2}$ and about 7.0 hours if the breach area were $0.025 \mathrm{in}^{2}$.

The results from these models indicate that there may be ample time to restore the AMCO cask to near pre-accident conditions if the cask comes to rest in the breach up position after the accident, regardless of the breach sizes considered. However, the results also show that, if the cask comes to rest in the breach down position and if the breach flow area is $0.25 \mathrm{in}^{2}$, there would not be enough time available to restore the cask to near preaccident conditions before the bulk of the coolant is lost. If the breach flow area is $0.025 \mathrm{in}^{2}$, enough time might be available to take some remedial action.

The model of the AMCO cask used to determine the rate of loss of coolant from the cask when it cones to rest in a breach up position was also used to sillulate the transient behavior of the cask for various other postaccivent cases. These post-accident cases were based on the common assumption that no breach was opened at impact. In one such case investigated, it was assumed that the only damage to the cask at impact was the loss of the solar shield and the loss of the water in the outer jacket. For these conditions, the cask reached a new steady-state condition in about 6.5 days (see Figure 16). The coolant temperature at this new steady-state condition oscillates between $501^{\circ} \mathrm{F}$ and $499^{\circ} \mathrm{F}$ due to the diurnal variation of solar heating. The saturation pressure at $500^{\circ} \mathrm{F}$ is $15.7 \mathrm{psia}, 1.0 \mathrm{psia}$ above atmospheric. The Dowtherm-A volume expands about $9.5 \%$ in going from an initial temperature of $343^{\circ} \mathrm{F}$ to the final temperature of about $500^{\circ} \mathrm{F}$; however, it was estimated that the cask could withstand a $16 \%$ coolant volume expansion.

Another case was studied in which it was assumed that the water in thr. outer jacket was lost, but that either the solar shield remained intact, or a solar shield was jury-rigged as soon as the fire died and the cask could be approached. Results for this case indicated that the cask approached a new steady-state condition in about 8 days when it began leveling off at a coolant temperature of $481^{\circ} \mathrm{F}$. In the next 4.5 days (for a total of 


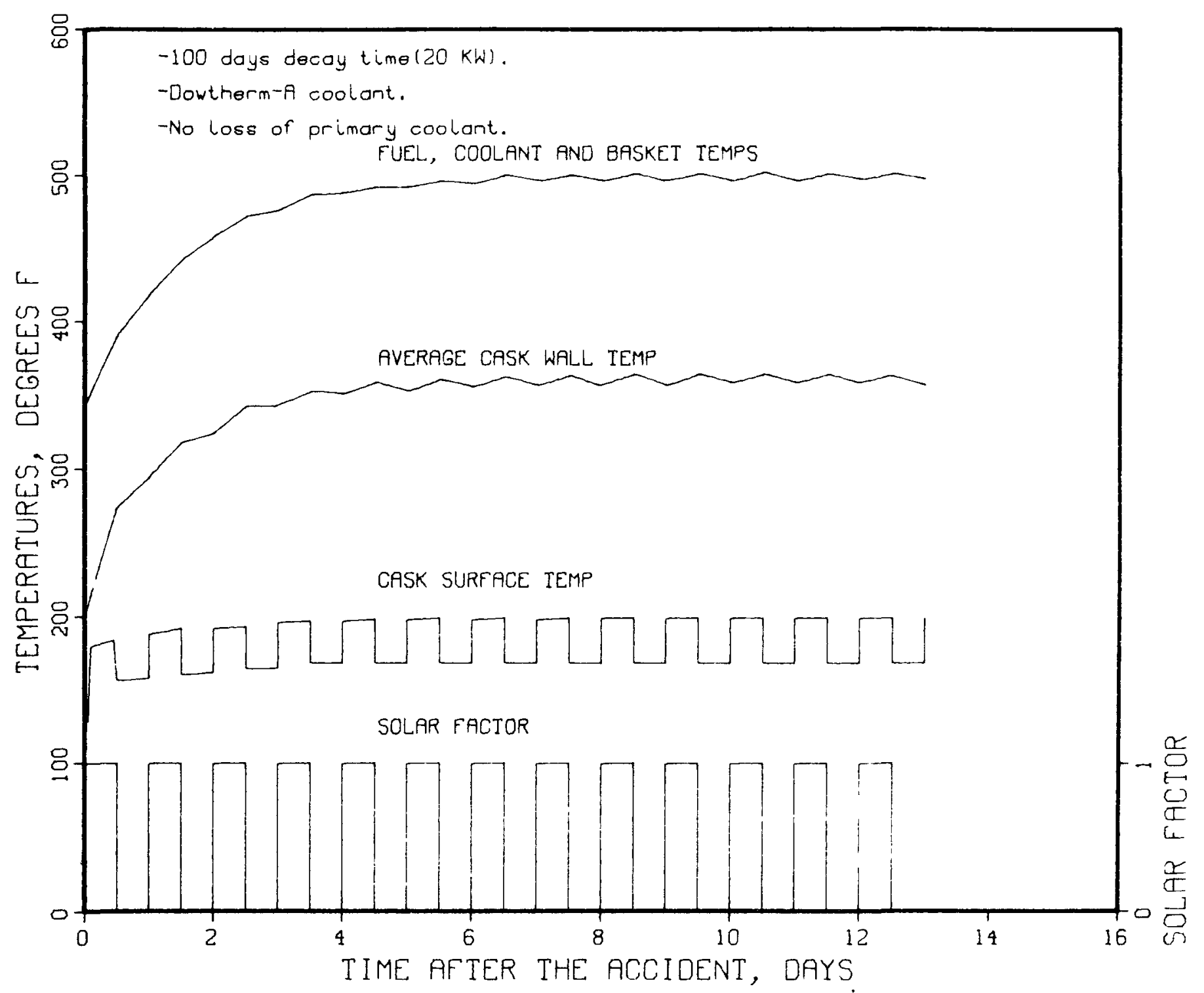

FIGURE 16. Behavior of the AMCO Spent Fuel Shipping Cask Following an Accident and 0.5 Hour Fire (No Loss of Coolant) 
12.5 days) the coolant temperature only rose another 0.6"I (see Figure 17). This temperature is well below the saturation temperature. For this case, the coolant volume expands by about $8.4 \%$. The length of the fire at the time of the accident does not appear to have a significant effect on the thermal behavior of the cask, at least for fires up to 2.0 hours duration. Calculations were made for no fire, a 0.5-hour fire, and a 2-hour fire, with no visible difference in the results.

The oscillatory nature of the coolant lass curve in Figure 15 (and the telıperature curves in Figures 15 and 16) is due to the diurnal variation of the solar heat input to the cask. During the 12 hours of daylight, solar neat is added at the rate of $19.5 \mathrm{BTU} / \mathrm{sec}$, which is enough to maintain the vapurization of the Dowtherm-A once it has reached its saturation temperature. During the 12 hours of night, with no solar heat input, the rate of coolant boiloff tends to level off at a level consistent with the improved conditions for heat loss from the cask. A further indication of the sensitivity of the behavior of the AMCO cask to solar heat input is apparent by comparing the results presented in Figures 16 and 17 . Figure 16 illustrates the behavior of the cask if the only damage suffered at impact was loss of the solar shield and of the water in the outer jacket, but with no loss of Dowtherm. Figure 17 reflects the behavior of the cask for the same conditions, except that the solar shield either remains intact or a substitute shield is jury-rigged as soon as the fire is out. Without a solar shield, the temperatures oscillate due to the diurnal variation of the solar heating. With the solar shield, the results do not have this oscillatory characteristic and the coolant temperature levels off at about 20 degrees less than that obtained without the solar shield, and about 13 degrees below the saturation temperature of $494.8^{\circ} \mathrm{F}$ at atmospheric pressure.

Solar heat input, as can be seen from these results, is an important factor. The total solar heat input during the day is $19.5 \mathrm{BTU} / \mathrm{sec}$, as compared to a total decay heat generation in the fuel for the AMCO cask of $19.0 \mathrm{BTU} / \mathrm{sec}$. The difference is that the solar heat is applied to the 


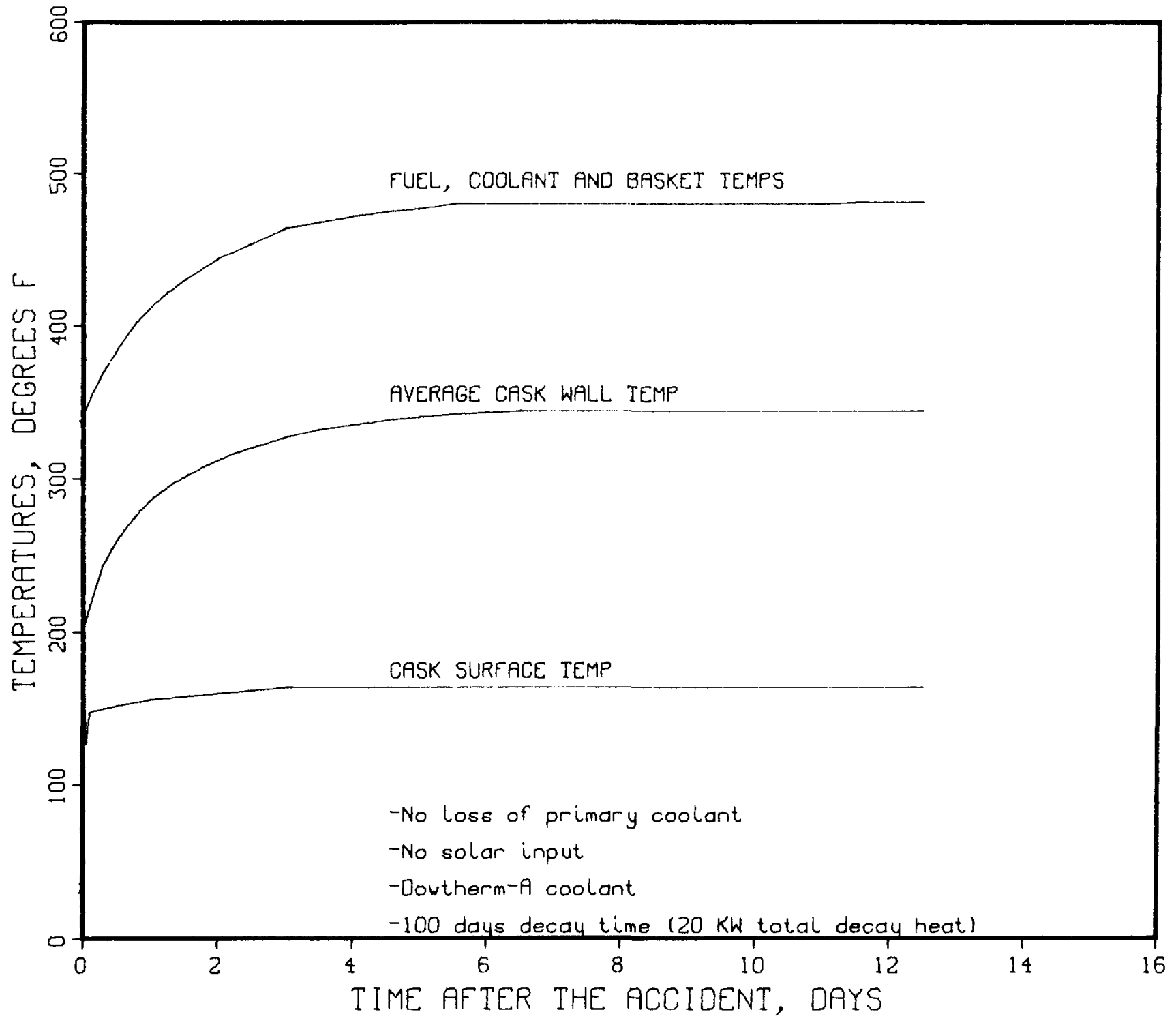

FIGURE 17. Behavior of the AMCO Spent Fuel Shipping Cask Following an Accident and 0.5 Hour Fire 
external surface of the cask where it only affects the external surface sink temperatures, while the decay heat is generated at the very heart of the cask internals and must flow to the surface. Some of this decay heat is absorbed by the internals (including the coolant) during the transient, which increases their temperatures. The question could be asked: If the solar heat input is so important and influential, why is the fire of so little consequence? The answer is that the fire, although at the high temperature of $1475^{\circ} \mathrm{F}$, is of a very short duration, 0.5 to 2.0 hours, compared to the 12.0 hours at a time that the solar heat is applied. The solar heat input to the cask varies from 0 BTU/sec at night to $19.5 \mathrm{BTU} / \mathrm{sec}$ during the day.

If either the IF-300 or AMCO cask comes to rest on its side after impact, or remains in this position on the rail car, the time to lose the primary coolant would probably fall somewhere near the times estimated for the positions already evaluated, depending on the final orientation of the breach.

\section{Analysis of Fission Product Release Following Loss of Coolant}

Simulation of the behavior of the IF-300 following emptying or loss of its primary coolant gave results that indicate that this cask might release about 11,900 curies of fission gases, about $33 \%$ of the total fission gases in the spent fuel (see Figures 18 and 19). According to Reference 1 (Tables IX-8 and IX-9), this is the total amount of free fission gases present in the fuel pin voids and available for release. This represents about $35 \%$ of the $k r-85$ and I-129, and about $3 \%$ of the $X e$ and I-131 in the cask's 3.2 MT of spent fuel.

While the primary coolant is being forced from the IF-300, and after the cask has lost its coolant (except for some residual steam), the fuel pin temperatures increase. Eventually, these increasing temperatures cause the pin clads to burst due to the expansion of free fission gases in the pin voids. The fission gases would then be released along with some particulate matter. At this time, until a time-temperature dependent 


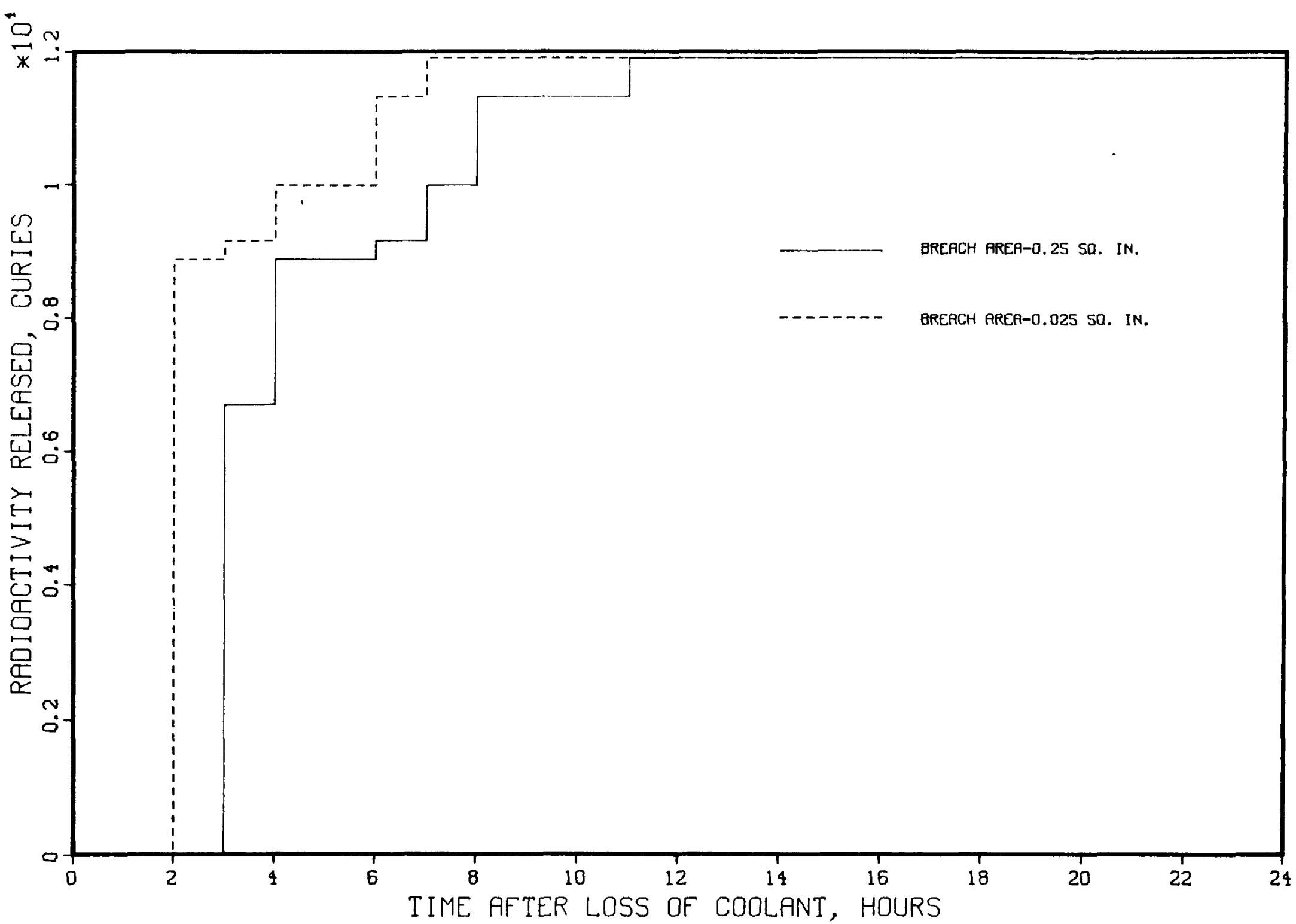

FIGURE 18. Total Radioactivity Released as Fission Gases from the Spent Fuel in the IF-300 (Breach Up Position, Breach Areas of 0.25 and $0.025 \mathrm{Sq}$. Inches) 


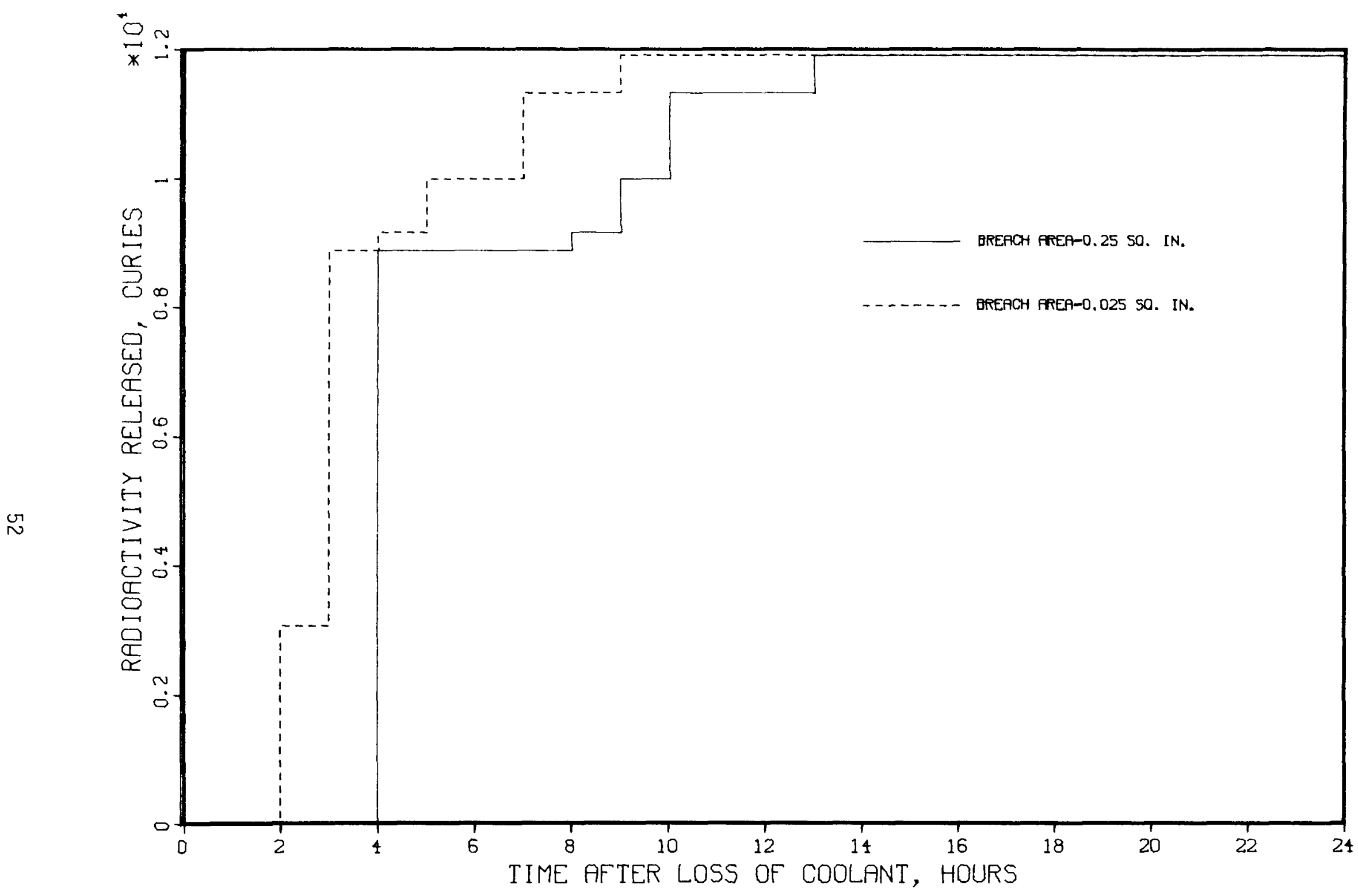

FIGURE 19. Total Radioactivity Released as Fission Gases from the Spent Fuel in the IF-300 (Breach Down Position, Breach Areas of 0.25 and $0.025 \mathrm{Sq}$. Inches) 
creep-rupture technique ${ }^{(19)}$ can be adapted to the models, the strength of the clads is assumed to follow a creep rupture strength vs. temperature relationship (see Section 3.2.1 in the Appendix).

Results of this simulation show that the temperature at which the fuel pin clads burst is about $921^{\circ} \mathrm{F}$, which corresponds to an internal pressure of about $1896 \mathrm{psia}$. For the breach flow area of $0.25 \mathrm{in}^{2}$, with the cask in the breach down position, the first pins burst 4.27 hours after impact (4.0 hours after loss of the primary coolant). For this case, the last of the pins burst at 13.27 hours after impact (13.0 hours after loss of coolant). For the same breach flow area, but with the cask in the breach up position, the first pins burst 4.13 hours after impact (3.0 hours following loss of coolant) and the last of the pins burst 8.0 hours later at 12.13 hours (11.0 hours after loss of coolant). At the smaller breach flow area of $0.025 \mathrm{in}^{2}$, with the cask in the breach down position, the first pins burst 3.94 hours after impact (2.0 hours after loss of coolant) and the last pins burst at 10.94 hours after impact $(9.0$ hours after loss of coolant). At this same flow area, but with the cask in the breach up position, the first pins burst 6.62 hours after impact $(2.0$ hours after loss of coolant).

Temperatures in the IF-300 following loss of primary coolant are presented in Figures 20,21 , and 22 for the case where the cask has a breach flow area of $0.25 \mathrm{in}^{2}$ and is in the breach down position. These temperatures are the only ones plotted and were chosen because, among the four cases considered, this was the only one in which the primary coolant was lost before the 0.5 -hour fire ended. Figure 20 shows how the temperatures in the cask vary within the first hour after loss of coolant. The temperatures as a function of time, up to 40 hours after loss of coolant, are presented in Figure 21. Figure 22 displays the temperature profile in the cask at the arbitrarily selected cut-off point of 40 hours.

The IF-300 spent fuel shipping cask shown in Figure 1 carries seven fuel assemblies of the type shown in Figure 2. An evaluation of the fission gas 


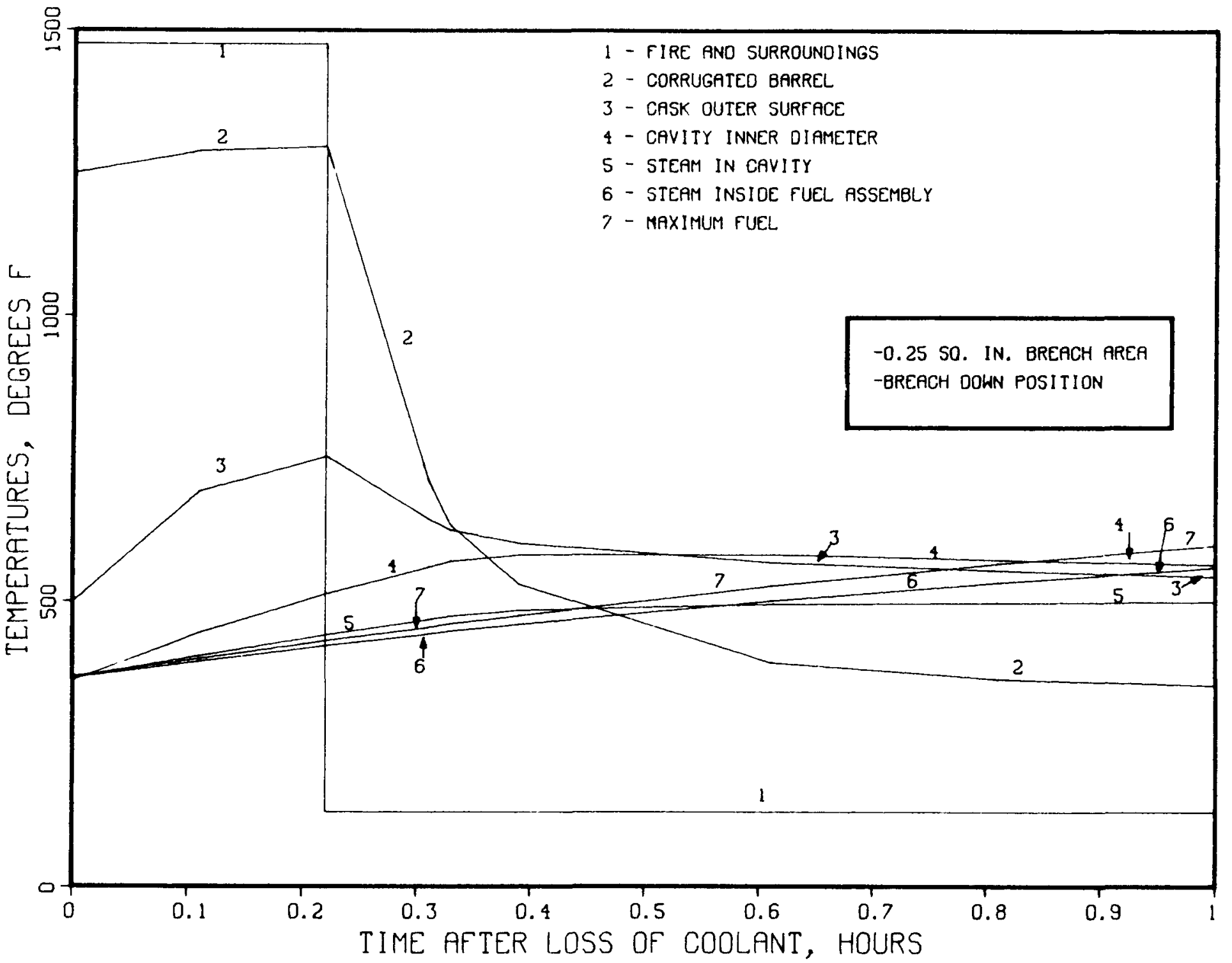

FIGURE 20. Temperatures in the IF-300 Following Loss of Coolant (0 to 1 Hour After Loss of Coolant) 


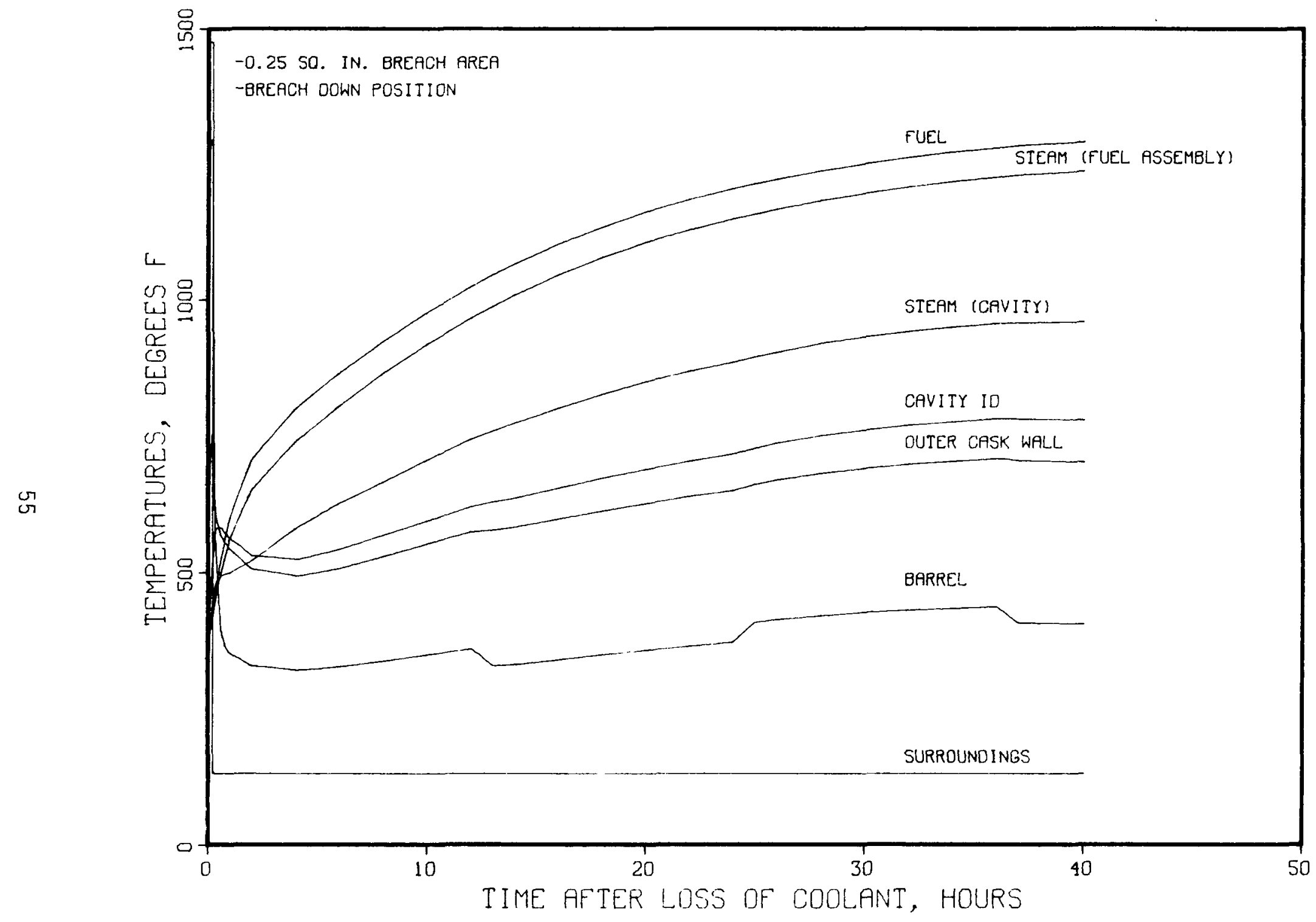

FIGURE 21. Temperatures in the IF-300 Following Loss of Coolant ( 0 to 40 Hours After Loss of Coolant) 


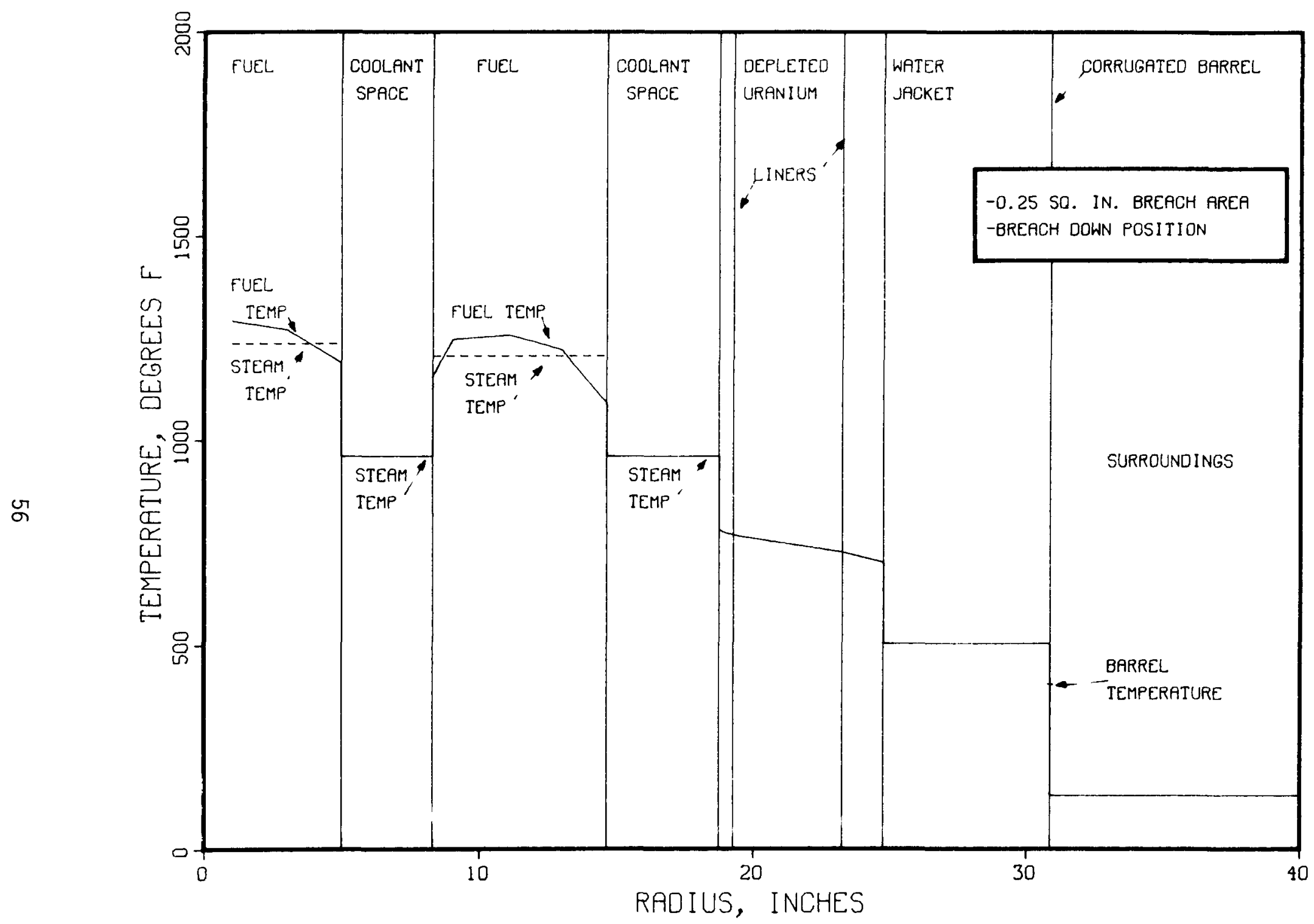

FIGURE 22. Temperatures in the IF-300 40 Hours After Loss of Coolant 
release from this cask was made assuming that these seven fuel assemblies were the Design Basis PWR 1 fuel assemblies described in Tables 1 and 2. The calculated fission gas inventory and activity for this spent fuel after 90 days cooling time were obtained from Reference 1 and are presented in the Appendix in Table 3-1. To be conservative, General Electric assumed a 90 day cooling period instead of the design basis 120 days. This same conservative cooling time was used in the present study.

In the early stages of this study, the most severe situation conceivable was simulated first to determine the sequence of events that might lead to fission product release. The most severe situation envisioned was the immediate loss of primary coolant at impact, along with loss of the solar shield, loss of the water in the outer jacket, and immersion in a fire at $1475^{\circ} \mathrm{F}$. Calculations were made for fires of 0.5 and 2.0 hours duration. In this initial phase of the study, a conceptual design of an LWR-type cask with a lead shield was simulated. The results of these early calculations showed that the length of the fire had little effect on the behavior of the cask internals during the fire, but there was an important effect on the fate of the lead shield. It was found that none of the lead melted during the 0.5 -hour fire, but that the outer 1.0 inch, representing about $14 \%$ of the total volume of the lead shield, melted away at about 1.33 hours into the 2.0-hour fire. For this type of cask design, the loss of this amount of lead would have two consequences: (1) it would reduce the amount of radiation shielding, and (2) it would result in higher temperatures of the cask internals because the resulting gap would present a barrier to the heat attempting to flow to the cask surface. These higher temperatures, in turn, would result in higher pressures in the pin voids and a more rapid release of fission gases.

Simulation of the behavior of the AMCO cask following emptying or loss of its primary coolant gave results indicating that the fuel in this cask might not release any of its fission products, at least not by 52 hours after the coolant is lost. At this time, the temperatures in the cask appear to be approaching a new steady-state distribution (see figure 23). The temperature of the hottest fuel pins is about $1397^{\circ} \mathrm{F}$, but the corresponding pressure in the pins is 500 psia, compared to a pressure of about 990 psia required 


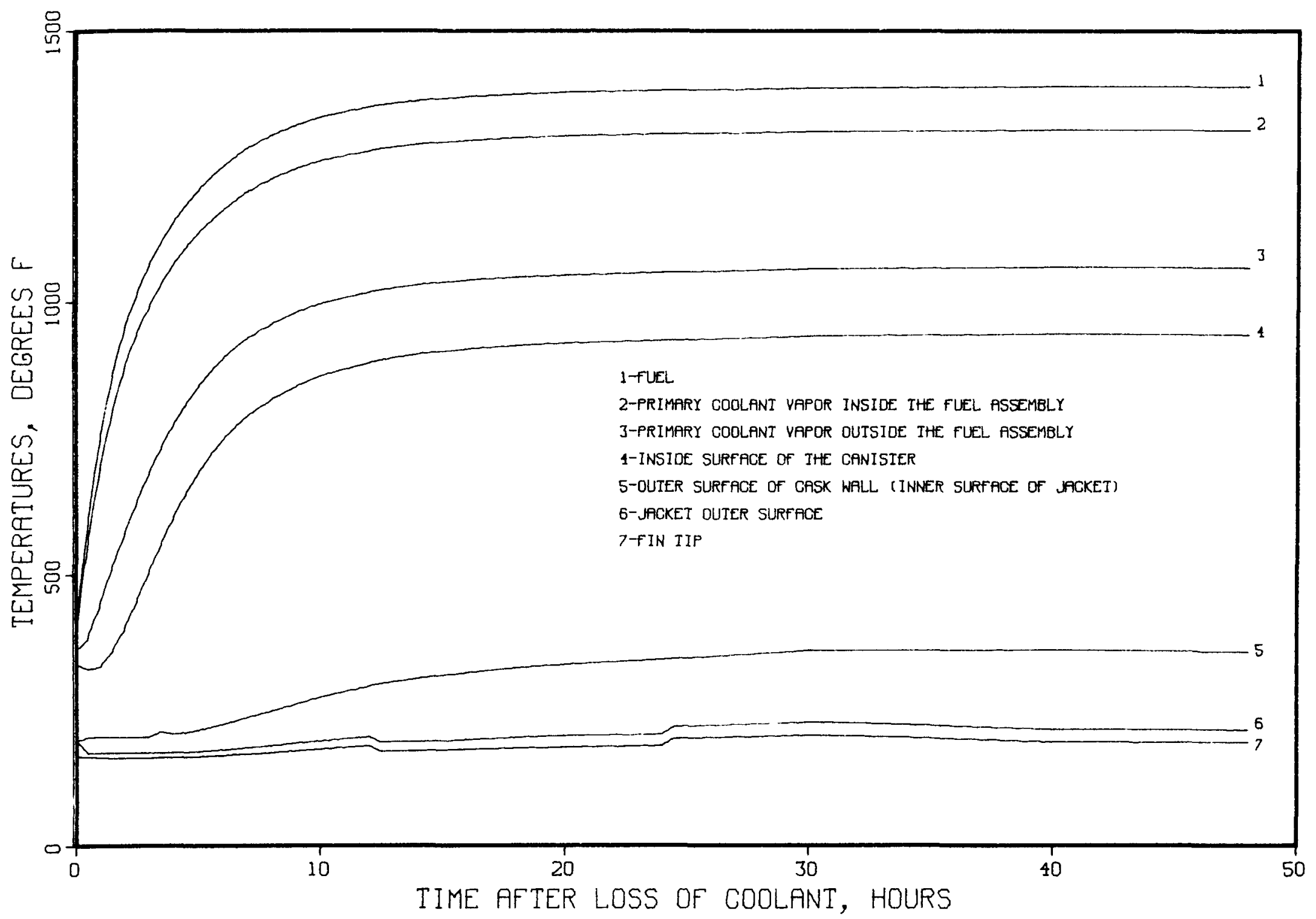

FIGURE 23. Temperatures in the AMCO Cask Following Loss of Coolant 
to burst the pin clads. There are two factors that might explain why the fuel pins in the IF-300 burst while those in the AMCO cask do not:

1. The internal pressure in the LMFBR fuel pins at $1397^{\circ} \mathrm{F}$ is 500 psia, while the internal pressure in the fuel pins in the IF300 would be about 5 times as much at about the same temperature. The fuel pin pressures for the IF-300 were calculated using the procedure outlined on pages 9-11 of Reference 1 and on pages 150-151 of Reference 7. The fuel pin pressures for the AMCO cask were calculated using a slightly different approach, but were based on an end-of-life pressure in the pins of 750 psia at $1100^{\circ} \mathrm{F}$, assuming $100 \%$ of the fission gases were released from the fuel. Details of the two approaches are presented in the Appendix in Section 3.2.1. The stresses in the clads of the fuel pins in the IF-300 model were determined from an equation relating the hoop stress to the pressure differential across the clad wall (see Section 3.2.1 of the Appendix). The stresses in the fuel pin clads in the AMCO cask were not calculated directly by the simulation model. Instead, experimental data on burst pressures as a function of temperature for Type 316 stainless stee $]$ clads were programmed into the model to monitor clad failure. The clad stresses were calculated later from pressures obtained from the model. The validity of this procedure was partially confirmed as described below. Since the hoop stress is proportional to the pressure differential across the clad wall, the ratio of a calculated stress to the allowable stress (100 hours creep rupture) at $1000^{\circ} \mathrm{F}$ was compared to the corresponding ratio of pressure differentials. The ratios were the same. The differential pressure corresponding to the allowable stress was the difference between the burst pressure at the same temperature, and the cask cavity pressure (see Section 3.2.1 of the Appendix). 
2. The decay heat rate used in the simulation model of the IF-300 was $76.8 \mathrm{kw}(262,000 \mathrm{~B} / \mathrm{hr})$, while that used in the simulation model of the AMCO cask was $19.8 \mathrm{kw}(67,577$ $\mathrm{B} / \mathrm{hr}$ ). The total heat load on the IF-300 was about 3.9 times that on the AMCO cask.

3. The outer surface of the AMCO cask is normally cooled by water contained in a 4-inch jacket partitioned by circumferential cooling fins, attached to the outer surface of the cask wa11, which extend through the jacket and protrude 8 inches beyond the outer surface of the jacket. The outer surface of the IF-300 is also normally cooled by water contained in a 6-inch jacket, except that there are no cooling fins extending through and beyond the outer surface of the jacket. The outer surface of the IF-300 jacket is a corrugated barrel, where the corrugations provide some of the advantages of a finned surface. When the outer jacket is ruptured in an accident and the jacket water is lost, the fins on the AMCO cask allow heat to be conducted from the cask surface, through the empty water jacket, to the outer surface of the cask where it is dissipated by natural convection and radiation to the surroundings. In contrast, the empty water jacket on the IF-300 represents a substantial barrier to heat flow since, in the absence of fins, heat must be transferred through the jacket to the outer corrugated barrel by natural convection and radiation. This results in higher temperatures in the cask.

The AMCO spent fuel shipping cask shown in Figure 3 carries nine fuel assemblies of the type shown in Figure 4. It was assumed that these nine fuel assemblies were average assemblies, i.e., each had been operating in the reactor at an average power of $5.2 \mathrm{MW}$. The calculated fission gas inventory and activity for this spent fuel after 120 days cooling time were derived from results presented in Reference 12 for fuel assemblies that had been operating at $7.0 \mathrm{MW}$ each. These data are presented in Tables 3-4 and 3-5 in the Appendix. 
A model was developed for both the IF-300 and the AMCO cask to simulate the transient behavior of volatile solids or solid fission products (cesium compounds) that may be released as an aerosol from the fuel pins to the cask containment at the time the pins burst and the fission gases are released. This model was based on the basic coagulation equation for aerosols having a distribution of particle sizes, modified to include terms for particle removal or loss to the system and a source term. (11) The coagulation equation was further modified by eliminating the agglomeration terms by using a "self-preserving" particle size distribution function. (12) A coagulation equation or particle balance equation was written for each of five particle size groups. Each of these particle balance equations was reduced to source, removal and storage terms by using the self-preserving particle size distribution function to determine the number of particles in each size group at any instant of time. Actually, this is mathematically factored into the particle balances through the settling, plateout and source terms (see Section 4 in the Appendix). A stirred settling rate equation and a plateout equation (based on a diffusional process) were obtained from the work of R. J. Davis. (12) The source term used is a pulsed input term representing the release of particles from the bursting fuel pins. The particles in the source term are distributed according to the self-preserving size distribution function. The storage term, when integrated over time, gives the number of particles suspended in the cask containment in five arbitrarily selected particle size groups. These five particle size groups encompass particle radii ranging from a minimum of 0.08 microns to a maximum of 0.7 microns. The smallest radius is apparently characteristic of the minimum or so-called primary particle size, based on observation of stainless steel-U0 $\mathrm{O}_{2}$ aerosols. ${ }^{(12)}$ The largest radius is apparently characteristic of the maximum particle size for chain agglomerates, as observed for steel oxide agglomerates. (12) Further work is planned to determine the correct particle size range either from first principles or from later experimental data that might be available. Details of the development of the aerosol model are presented in Section 4 in the Appendix. 
Of all the potentially volatile solids in PWR fuel, there is more cesium present than all the others combined. This cesium is not present as the metal, but probably exists as various chemical compounds including several oxides, the molybdenate, the iodide, the uranate and diuranate, and the zirconate. It was assumed that, when the pins burst, particles of these compounds would be released with the fission gases. Since the relative amounts of the compounds present are unknown, it was convenient to assume that they could all be considered to be the oxide $\mathrm{Cs}_{2} \mathrm{O}$.

Experimental data show that it is unlikely that more than $1 \%$ of the total cesium in all fuel pins will migrate to the pin void spaces during reactor operation, and of this amount less than $1 \%$ would be released under conditions postulated to occur in a severe transportation accident. The total cesium in the spent fuel in the IF-300 was calculated to be about 9300 grams, which is equivalent to about $1.13 \times 10^{6}$ curies. Therefore, only about $0.01 \%$ of this amount, or about 113 curies, would be released when the clads burst. General Electric's analysis of the release of fission products from the spent fuel in the IF-300 ${ }^{\left({ }^{1}\right)}$ was limited to the release of the fission gases I, $\mathrm{Kr}$, and Xe. Consequently, the fission product inventories presented in Reference 1 did not include cesium. The above estimates of the amounts of cesium present in the spent PWR fuel were derived from fission product inventories for spent Diablo Canyon reference fuel that had been cooled 90 days. ${ }^{(14)} \mathrm{A}$ small correction factor was applied to these data to account for differences in exposure.

The radioactivity in the solids suspended in the aerosol in the IF- 300 containment, as a function of time after the accident, is presented in Figures 24 and 25. The peak values coincide with the times the fuel pins burst in each of the seven fuel nodes (the pins in some of the nodes burst simultaneous7y). Figures 24 and 25 show that about $47 \%$ of the particles (equivalent to about 53 curies) settle or plate out within 24 hours after the accident. At 24 hours, the activity of the particles still in suspension is only about 60 curies. The particles still in suspension at this time 


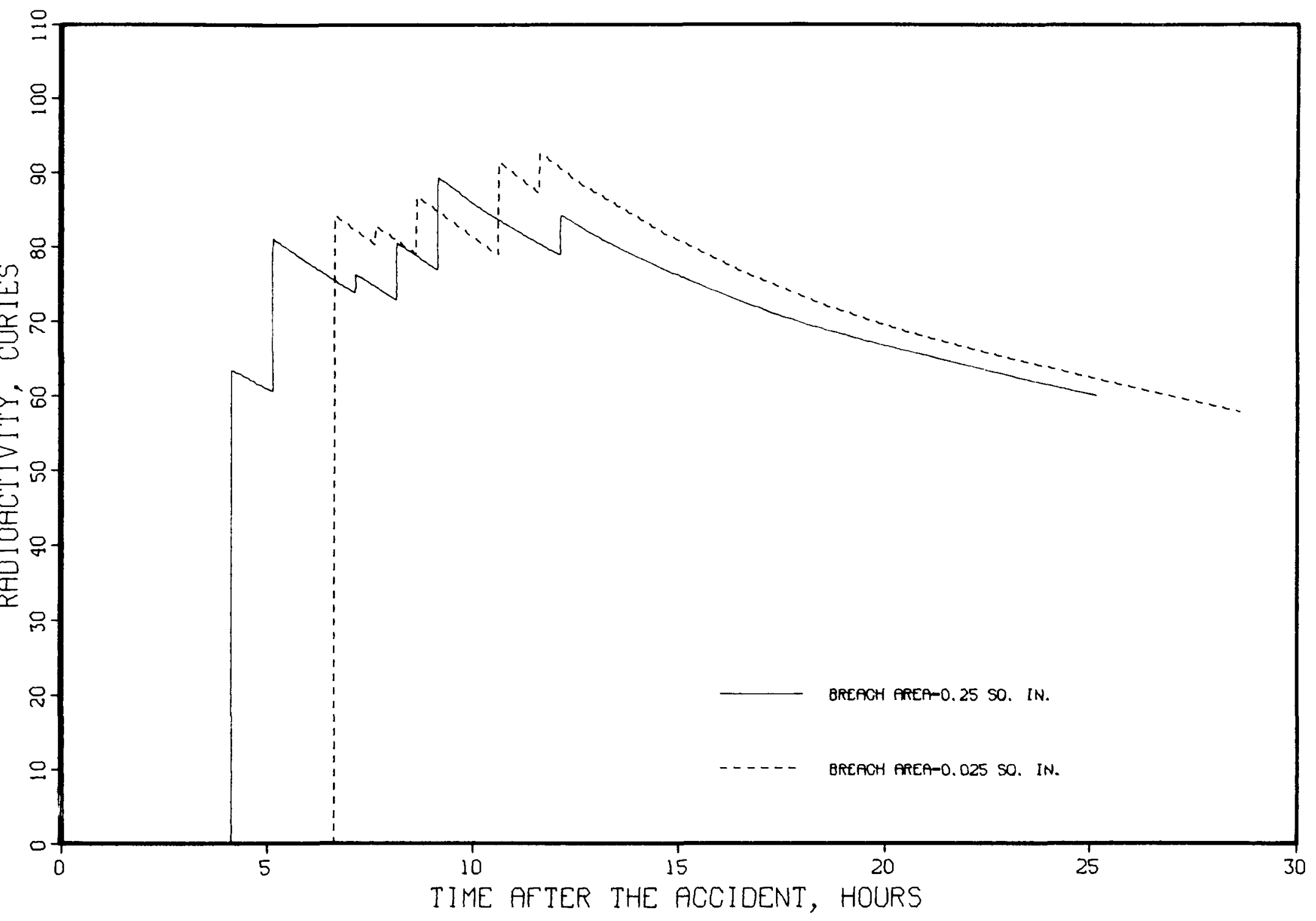

FIGURE 24. Total Radioactivity in Volatile Solids Suspended as an Aerosol in the IF-300 (Breach Up Position, Breach Areas 0.025 and $0.25 \mathrm{Sq}$. Inches) 


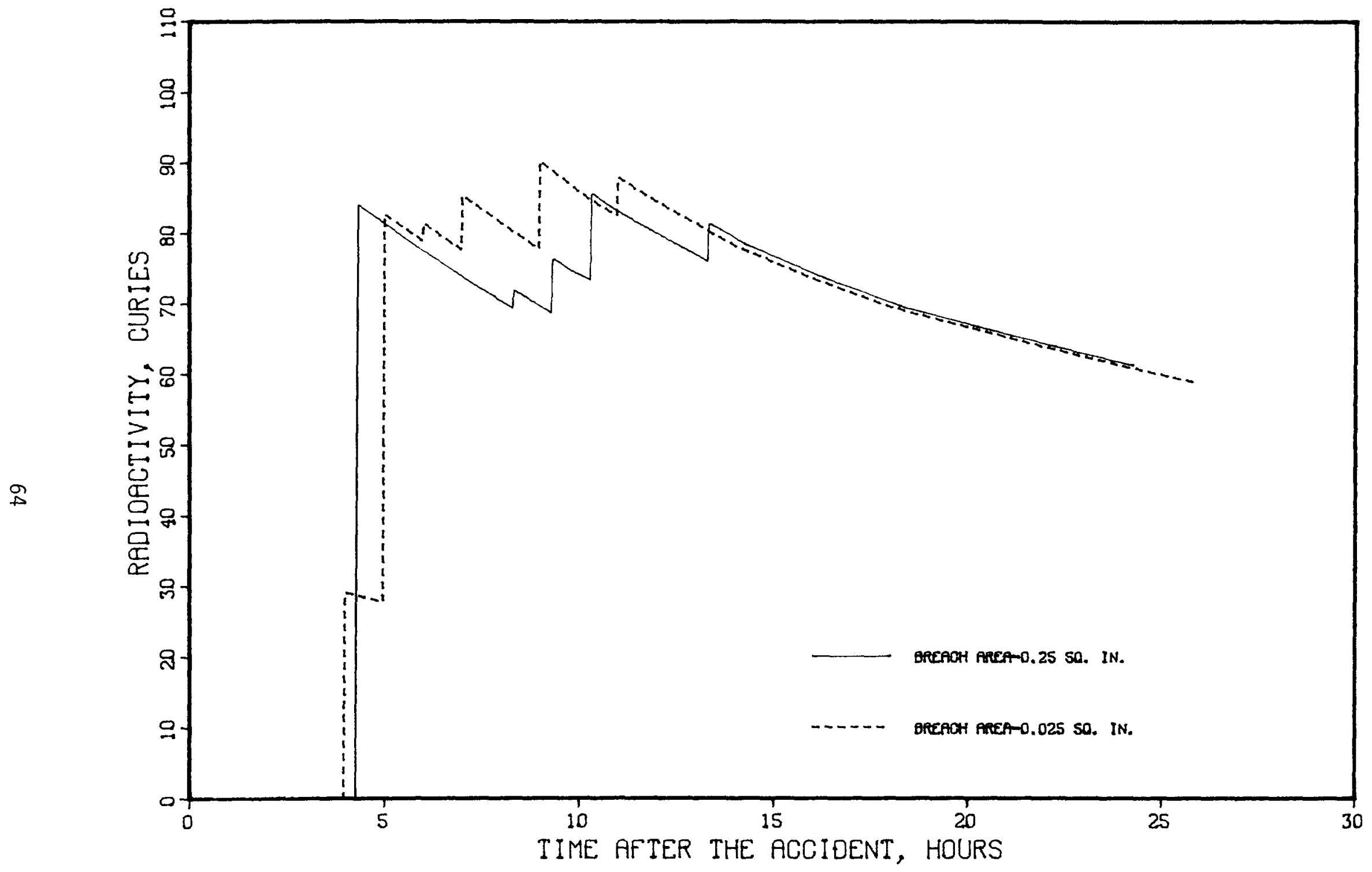

FIGURE 25. Total Radioactivity in Volatile Solids Suspended as an Aerosol in the IF-300 (Breach Down Position, Breach Areas 0.025 and 0.25 Sq. Inches) 
are the smallest particles, those in a size range from 0.08 to 0.2 micron (an average of 0.11 micron) and those in a size range from ().2 to 0.33 micron (an average of 0.25 micron).

At present, the model does not include a subterm of the removal term to account for leakage of aerosol from the cask containment through the damaged pressure relief valve. However, a system of equations has been developed to define the rate of flow of fission gases and particles from a cask. These equations were developed too late to be included in the present sets of models, but they may be included in the appropriate models during a later development phase. Most of the equations in this system will become part of the loss-of-coolant models and will form the basis for the leakage term in the volatile solids release models. The development of these equations is presented in Sections 3.5 and 4.1 .5 in the Appendix, along with suggested procedures for their inclusion in the models.

The leakage term is expected to be greater than both the settling and plateout terms. This will alter the results of the analysis, as typified by Figures 24 and 25, significantly. A large leakage term would increase the rate of removal of aerosol from the cask. This means that those portions of the plots in Figures 24 and 25 that represent decreasing radioactivity in the cask, due to removal of particles by settling and plateout, would now have steeper slopes because of the more rapid rate of removal from the cask containment due to leakage. The magnitude of the leakage term is not known at this time.

If the cask is designed with a filter between the cavity and the relief valve, some of the particles in the aerosol might be removed before the aerosol reaches the surroundings. This filter would have to be independent of the relief valve and located at a point where it would not be damaged, even if the relief valve is sheared off. The volatile solids release model, especially the leakage term, would be useful in evaluating possible filtering media or devices. 
The release of fission gases and solid fission products reported here represent only the free gases and solids present in the pin voids. Earlier in the study, another mechanism of release was considered that resulted in the release of the remaining "bound up" gases and solids. This mechanism was the oxidation of $\mathrm{UO}_{2}$ to $\mathrm{U}_{3} \mathrm{O}_{8}$, a fine granular material, from which these bound up gases and solids could more easily be released. As the study progressed, however, this mechanism appeared less and less likely. This was apparent from the results of the chain of simulations that seemed to indicate that the cask would be at a pressure higher than its surroundings. This would prevent influx of air to the fuel containment vessel.

There are at least two factors tending to make the pressure inside the cask higher than its surroundings. First, residual coolant vapor may be present in the cask for some time following the loss of primary coolant. The pressure of this residual vapor would increase as the vapor is heated, which should keep the pressure higher than atmospheric. Second, the fission gases are released from the fuel pins at a pressure high enough to burst the clads. For the IF-300, this pressure is about 1896 psia, which corresponds to a fuel pin temperature of about $921^{\circ} \mathrm{F}$. This would be the driving force that would propel the fission gases, along with the cesium compounds, from the pins as an aerosol. This release of fission gases would tend to prevent outside air from entering the cask. Without this air, oxidation of the exposed fuel would be quite unlikely. Although the pressure would drop considerably as the gases expand into the cask containment, it might increase again by some small amount as the gases are heated by the fuel assemblies.

Oxidation of the fuel by the water vapor in the IF-300 has not yet been evaluated, but it is not expected to be significant.

\section{Event Network}

The event network of Figure 26 was constructed after the events and their relative times of occurrence were obtained using the simulation models developed for the IF-300 and AMCO casks. The network originates with the initial event "impact", and terminates with the following nine events: 


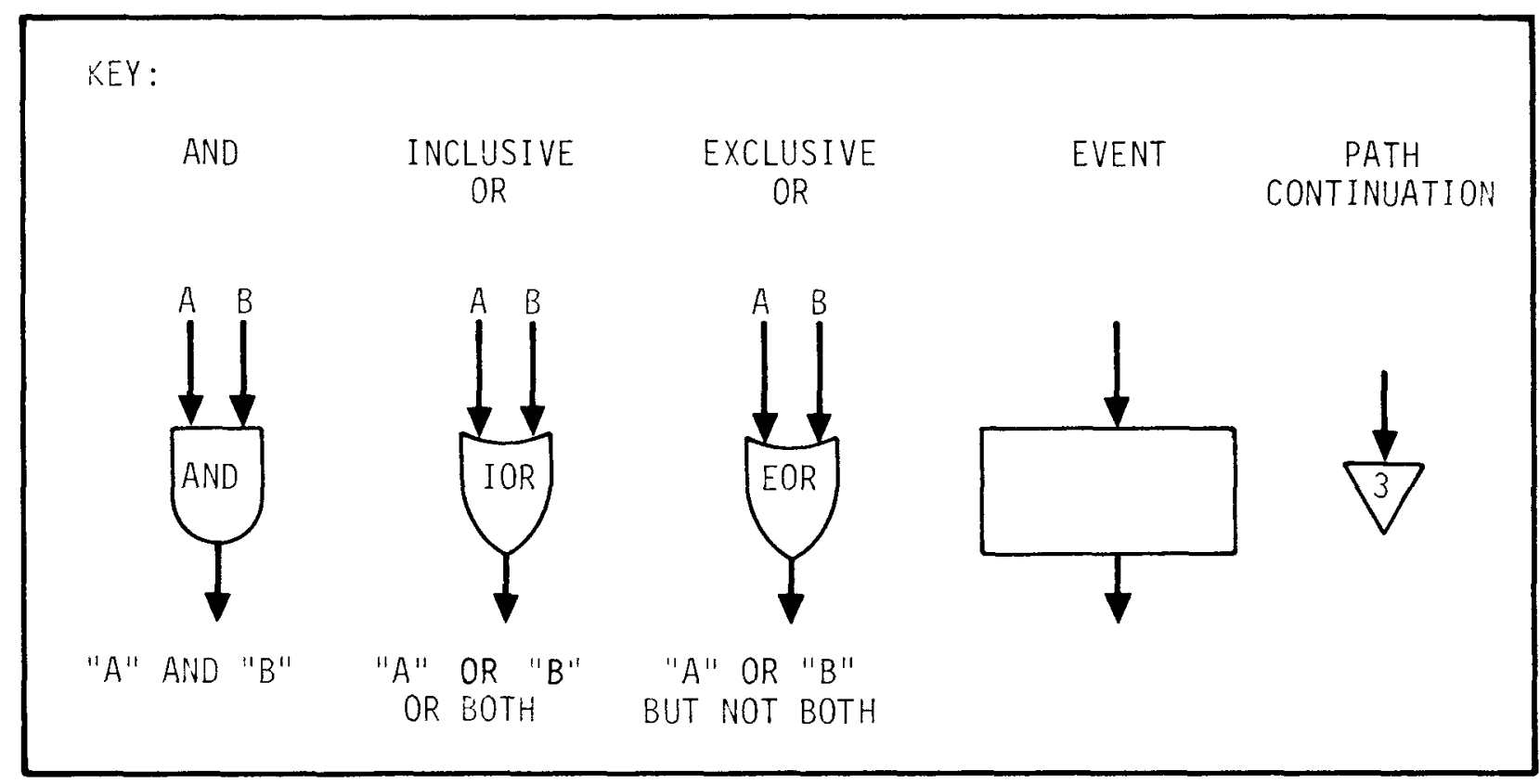

HEDL 7507-30.46

FIGURE 26. Network of Events Following a Spent Fuel Shipping Cask Accident (Page 1 of 10) 


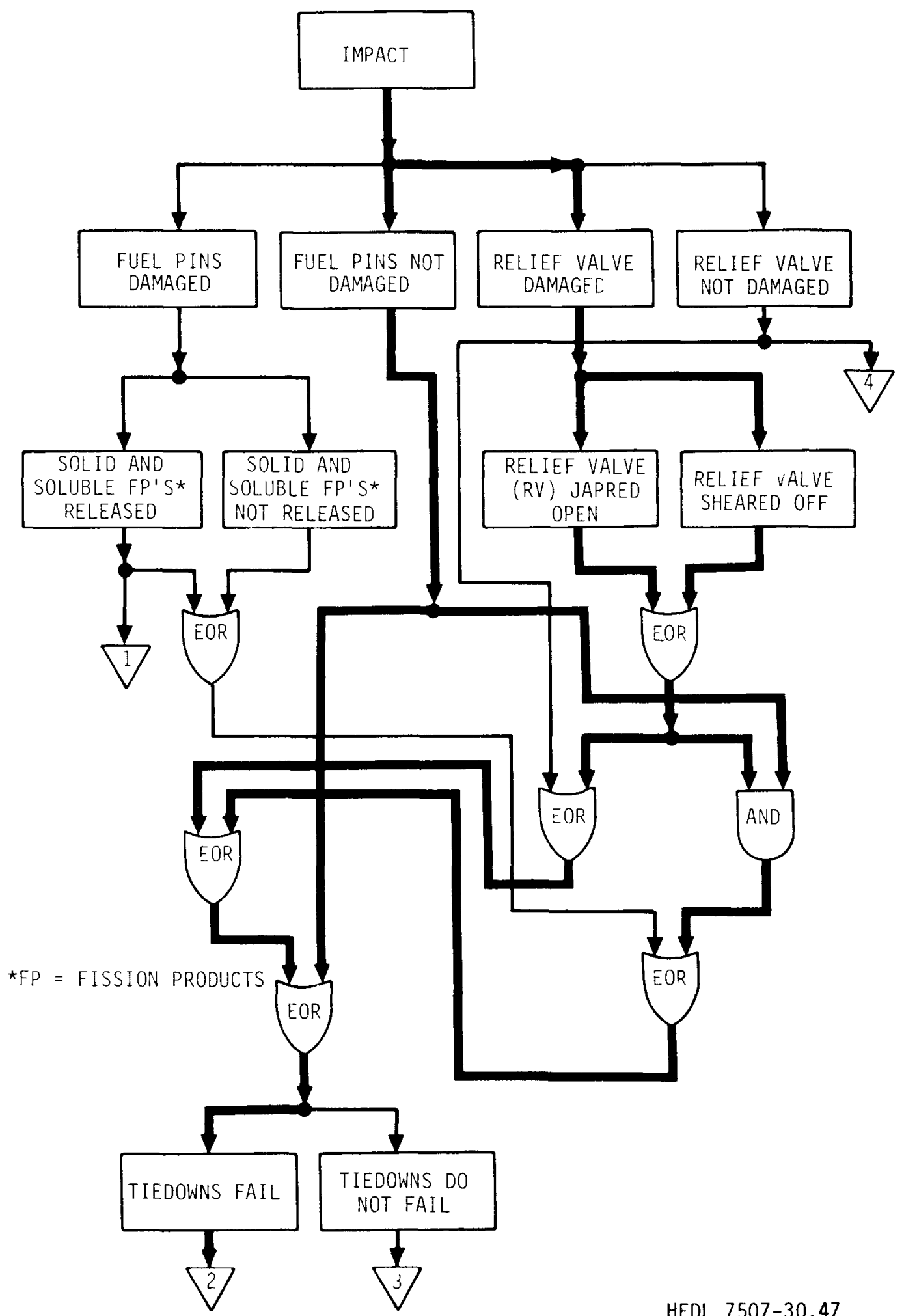

HEDL $7507-30.47$

FIGURE 26. Network of Events Following a Spent Fuel Shipping Cask Accident (Page 2 of 10) 


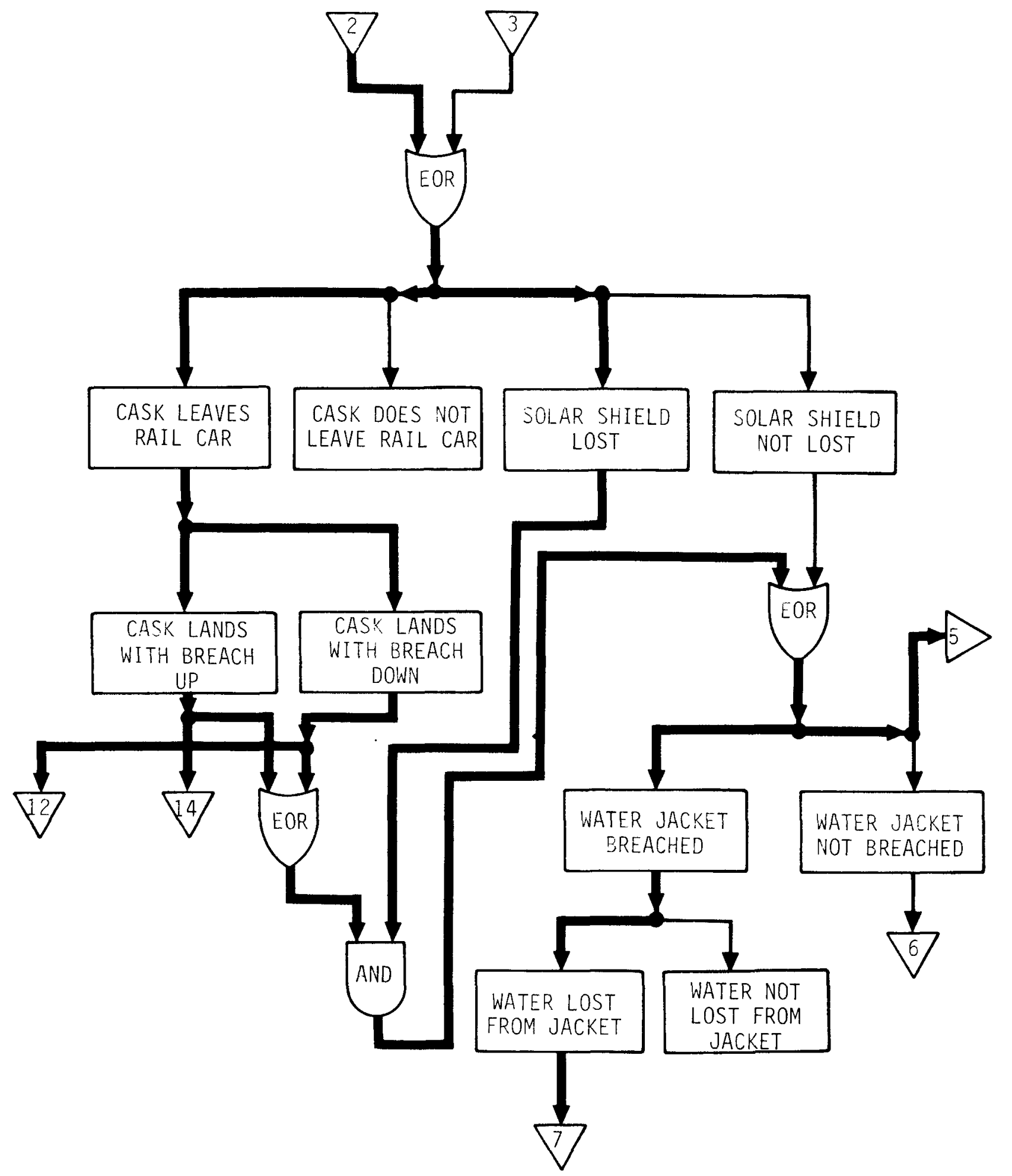

HEDL 7507-30.48

FIGURE 26. Network of Events Following a Spent Fuel Shipping Cask Accident (Page 3 of 10) 


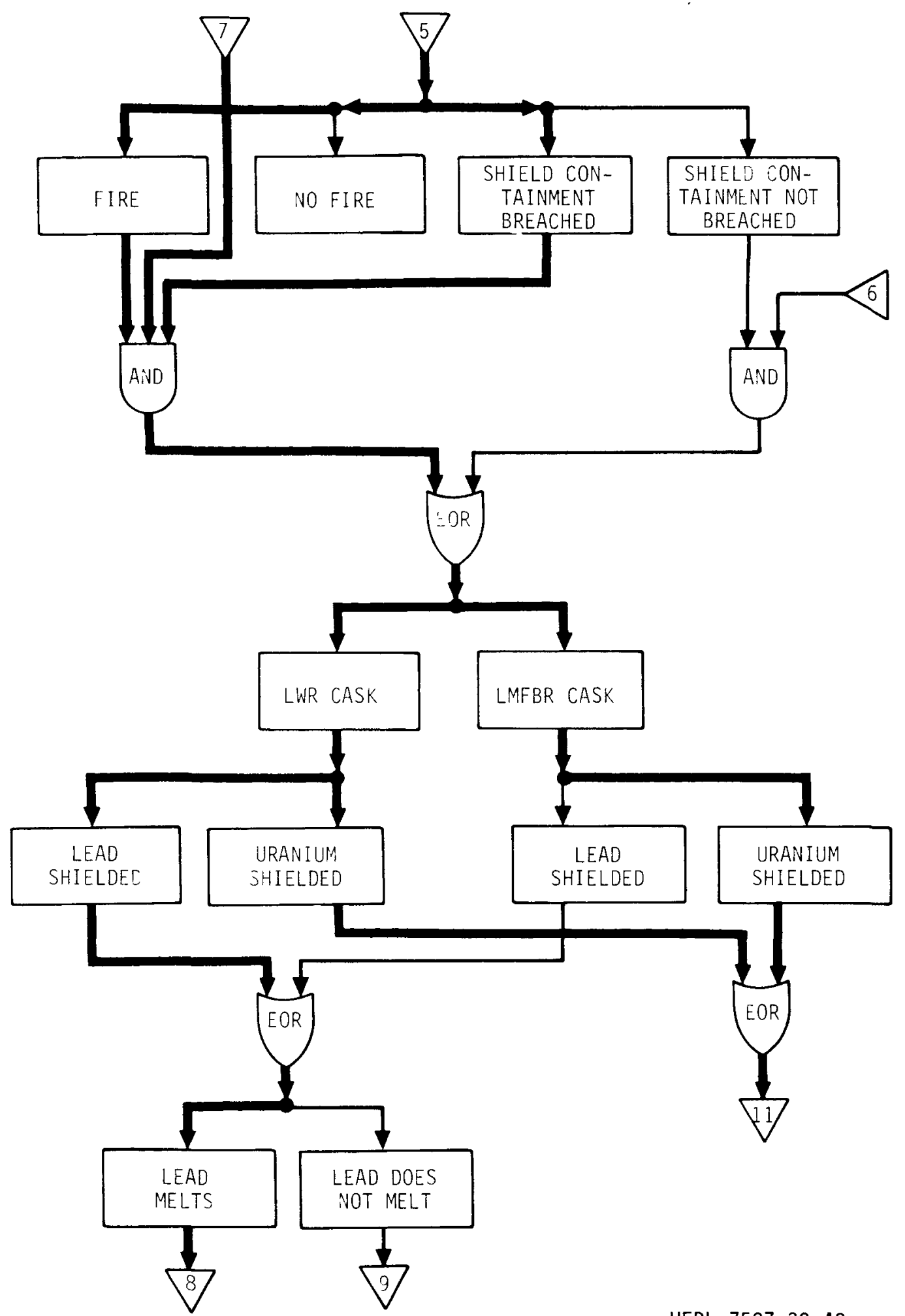

HEDL $7507-30.49$

FIGURE 26. Network of Events Following a Spent Fuel Shipping Cask Accident (Page 4 of 10) 


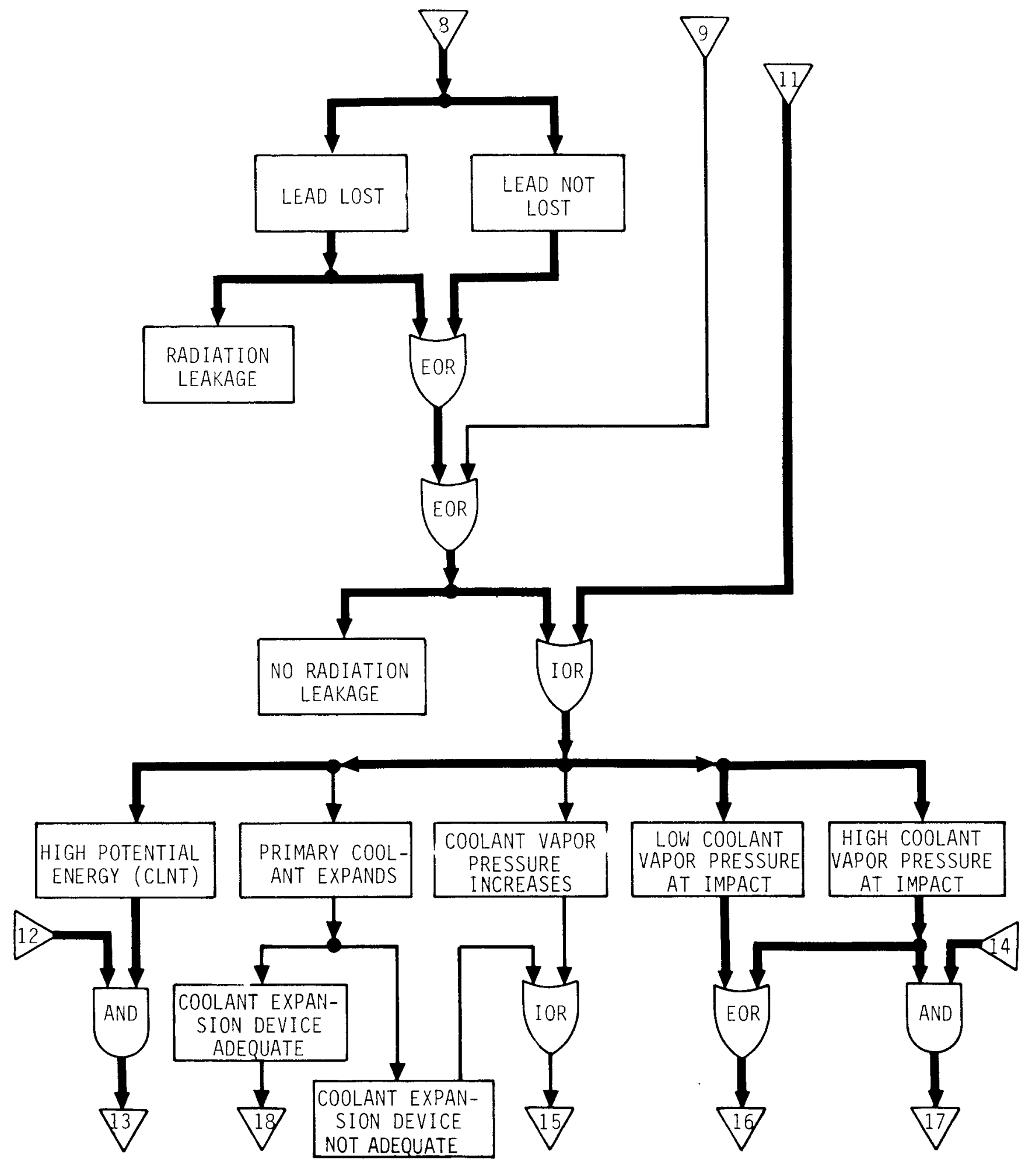

HEDL $7507-30.50$

FIGURE 26. Network of Events Following a Spent Fuel Shipping Cask Accident (Page 5 of 10) 


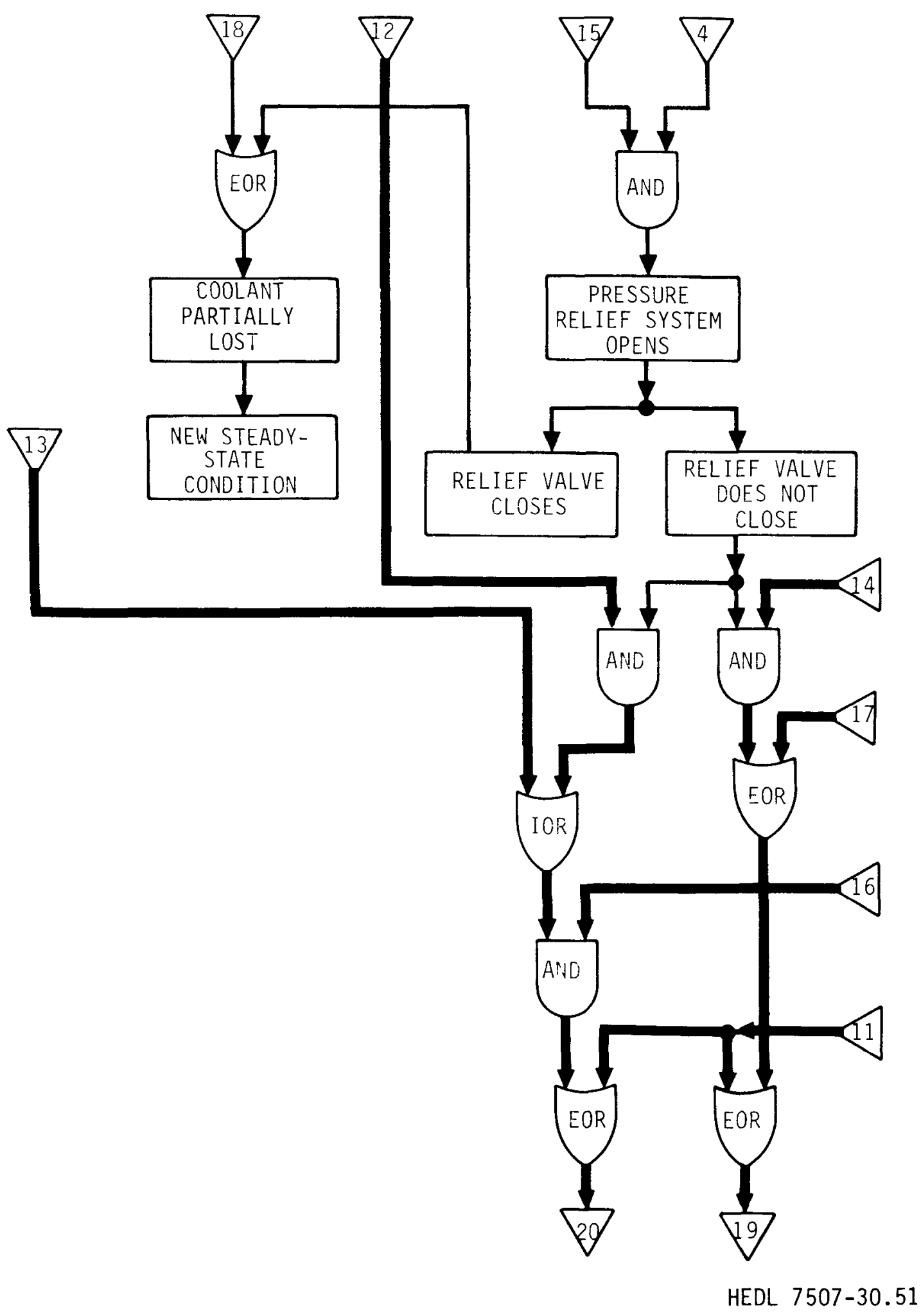

FIGURE 26. Network of Events Following a Spent Fuel Shipping Cask Accident (Page 6 of 10) 


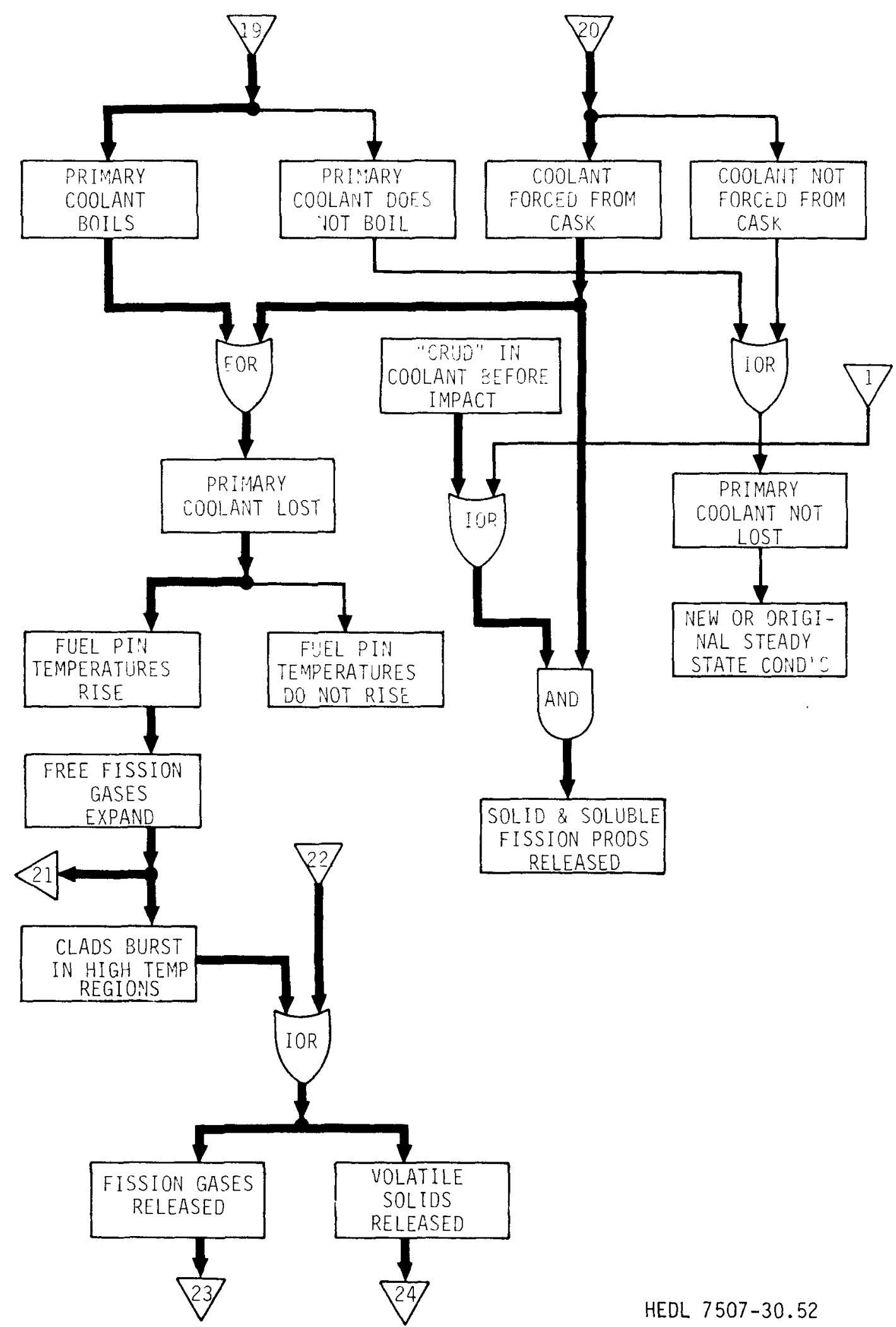

FIGURE 26. Network of Events Following a Spent Fuel Shipping Cask Accident (Page 7 of 10) 


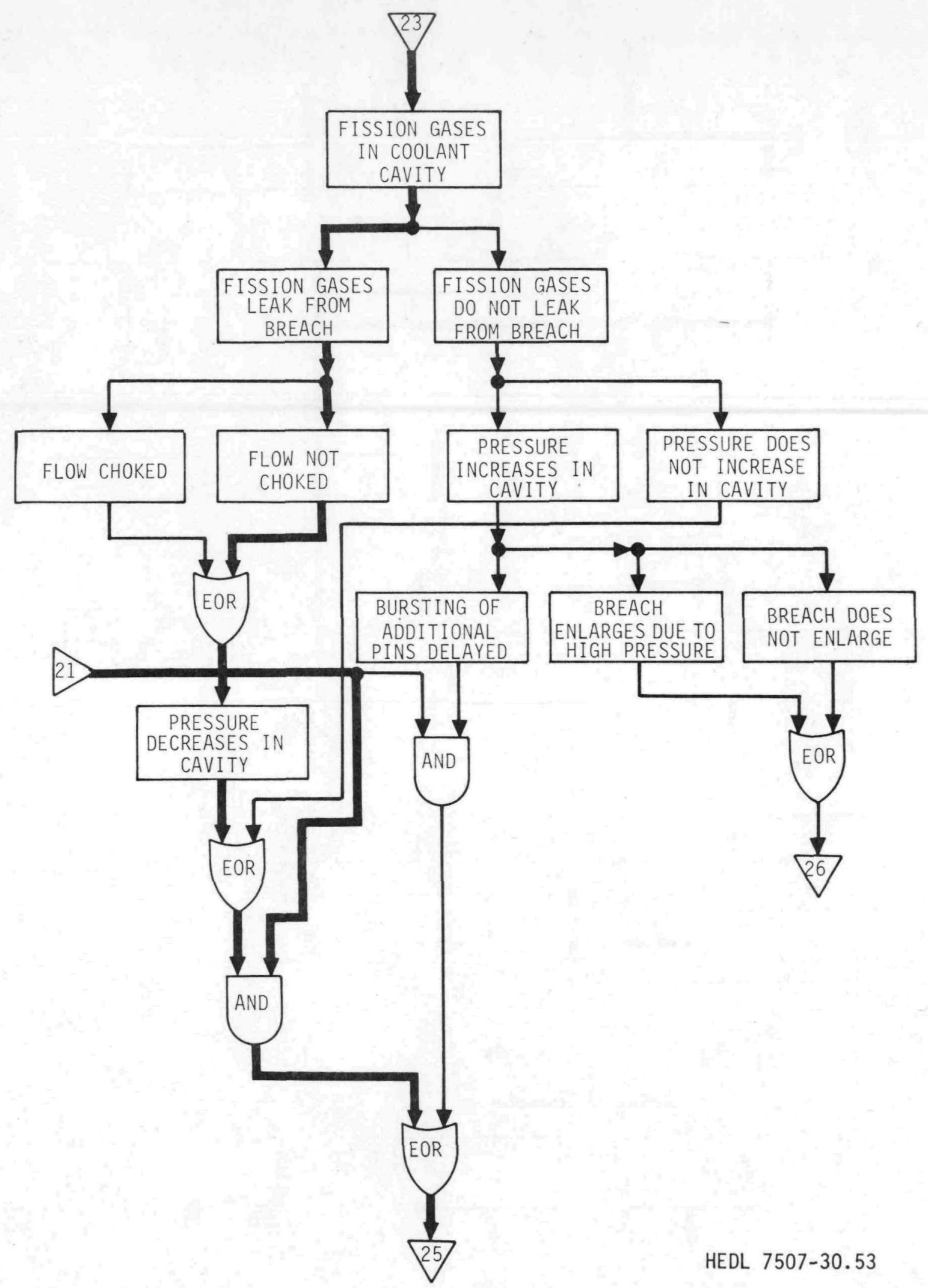

FIGURE 26. Network of Events Following a Spent Fuel Shipping Cask Accident (Page 8 of 10) 


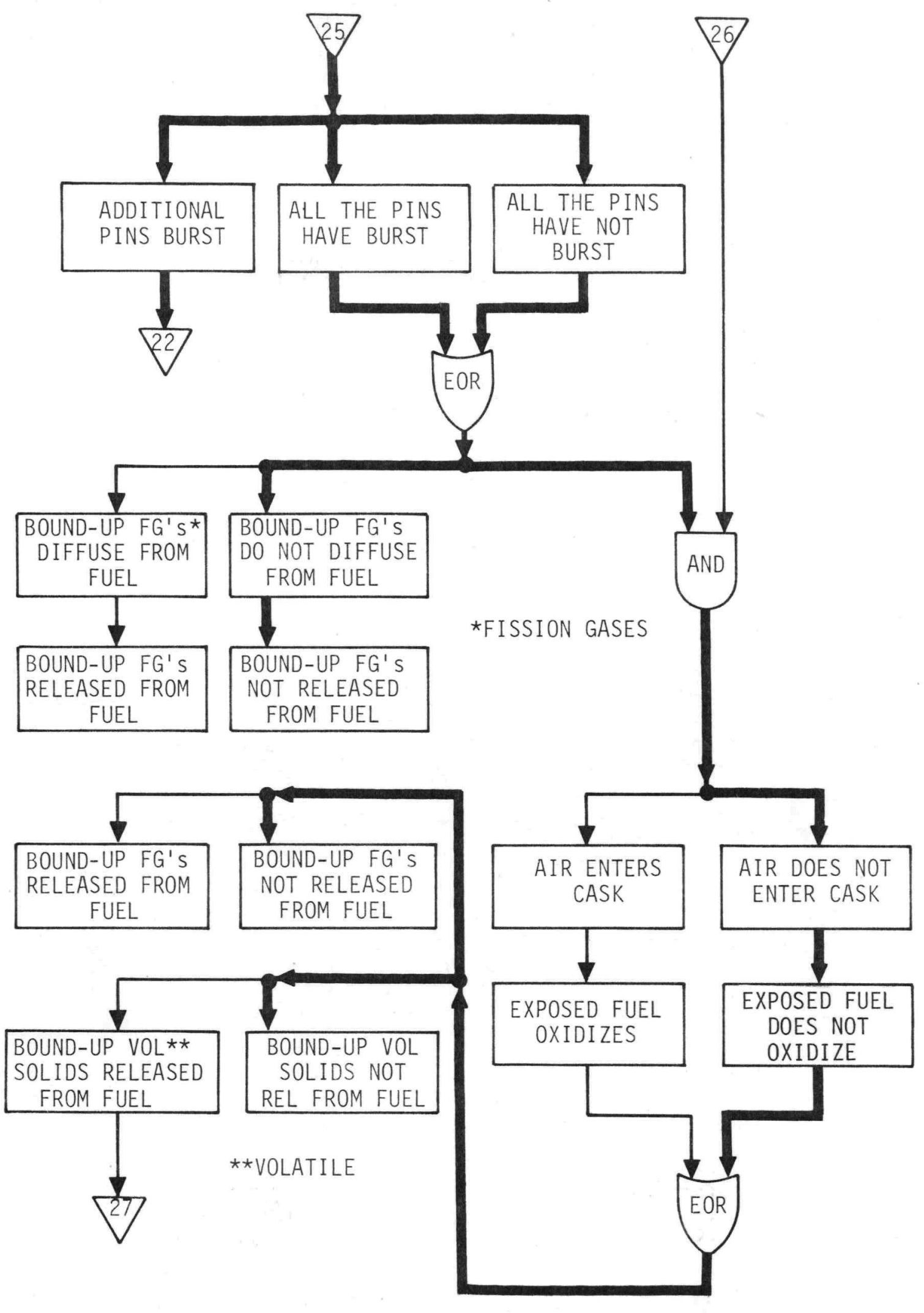

HEDL $7507-30.54$

FIGURE 26. Network of Events Following a Spent Fuel Shipping Cask Accident (Page 9 of 10) 


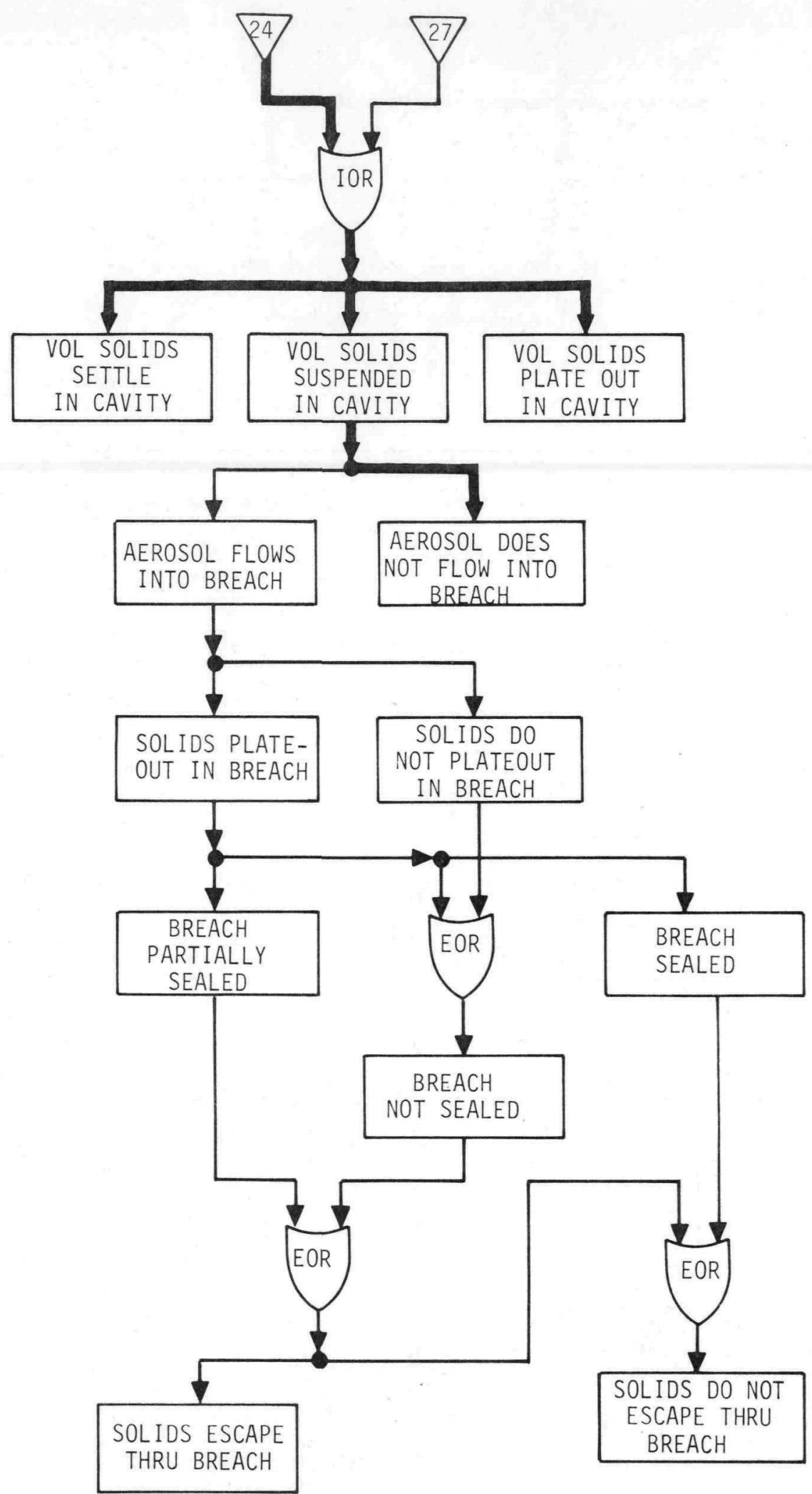

HEDL $7507-30.55$

FIGURE 26. Network of Events Following a Spent Fuel Shipping Cask Accident (Page 10 of 10) 
1. Radiation leakage

2. No radiation leakage

3. New steady-state condition reached

4. New or original steady-state condition reached

5. Solid and soluble fission products released from cask

6. Volatile solids escape from cask

7. Volatile solids do not escape from cask

8. Fission gases escape from cask

9. Fission gases do not escape from cask.

Two of the event blocks or nodes of the network represent conditions rather than events. These conditions are "LWR-type cask" and "LMFBR-type cask."

A choice of a path through the network is allowed by the branching paths emanating from some of the events, and by the logic gates "AND", "INCLUSIVE OR", and "EXCLUSIVE OR". This type of event network combines the decision or event tree construction with the logic gates of a fault tree. The logic gates focus or fold the expanding branches of the event tree.

The accented lines connecting some of the events in the network of Figure 26 represent paths revealed by use of the simulation models discussed in this report, in their present stage of development. It is apparent that several paths have not been investigated.

Eventually, probabilities and times will be determined for the paths connecting the events. These calculated probabilities and times will be obtained from parametric studies using the simulation models. Network algebra will be used to calculate the most probable path to the terminal events, and the probability of each of the terminal events, considering all the possible paths. Because of its size and complexity, the event network will be evaluated using the computer code GERT ${ }^{(30)}$ developed for this purpose.

The cask accident event network may be imbedded, as a subnetwork, in a larger, more comprehensive event network for the entire shipping study. 
Figure 26 identifies the events that may lead to a release of fission gases. Measures taken to prevent or delay these events could form a strategy of "defense in depth" for cask designers. The Cask Designer's Guide ${ }^{(7)}$ does not identify levels of safety for shipping casks per se, but does discuss the integrity of cask containment following impact, including the protection of closures from impact (valves, pressure relief lines, etc.), energy absorbers, and the integrity of the cask's seal. It may be useful to attempt to identify "levels of safety" for cask design that would serve a function similar to the three levels of safety identified for nuclear reactors. ${ }^{(6)}$ 
Figure 26 identifies the events that may lead to a release of fission gases. Measures taken to prevent or delay these events could form a strategy of "defense in depth" for cask designers. The Cask Designer's Guide ${ }^{(7)}$ does not identify levels of safety for shipping casks per se, but does discuss the integrity of cask containment following impact, including the protection of closures from impact (valves, pressure relief lines, etc.), energy absorbers, and the integrity of the cask's seal. It may be useful to attempt to identify "levels of safety" for cask design that would serve a function similar to the three levels of safety identified for nuclear reactors. ${ }^{(6)}$ 


\section{CONCLUSIONS AND RECOMMENDATIONS}

The IF-300 loses its primary coolant at a much faster rate than the AMCO cask following an accident in which a breach is opened in the cask containment. The breach is assumed to be due to a relief valve, which is either sheared off or stuck in a partially open position due to damage at impact.

Breach flow areas in these cases were assumed to be 0.25 in $^{2}$ and 0.025 in $^{2}$, respectively. Results of the simulations show that, for the largest breach fiow area and with the casks in a breach down position, it takes about 15 minutes to empty the IF-300 of its primary coolant and about 43 minutes to empty the AMCO cask. Since the accident conditions include a 30-minute fire, it is obvious that, in this case, the casks could not be approached to take measures to prevent the loss of the coolant. For the smallest breach flow area, with the casks in the same breach down position, the IF-300 ioses its coolant in about 1.5 hours while the AMCO cask loses its coolant in about 7.0 hours. It is not likely that loss of the coolant from the IF- 300 in this case could be prevented since, during the 30-minute fire, about $22 \%$ of the coolant is lost, and the rest would be lost before the cask cooled enough to be approached. In the case of the AMCO cask, however, enough time might be available to take some remedial steps to prevent the loss of a substantial portion of the coolant. For the largest breach flow area and with the casks in a breach up position, it takes about 66 minutes to empty the IF-300 and about 20 days to empty the AMCO cask. For ine smallest breach flow area and with the casks in a breach up position, it takes about 4.18 hours to empty the IF-300 and about 20 days to empty the AMCO cask. It is not likely that much could be done to prevent the loss of coolant from the IF-300, but it appears that ample time would be available to prevent the loss of coolant from the AMCO cask.

The differences in the coolant loss rates are due to the vapor pressures of the different coolants at the time of the accident. The average temperature of the water in the IF-300 during normal operating conditions was determined to be about $347^{\circ} \mathrm{F}$, while that of the Dowtherm-A in the AMCO cask was determined to be about $360^{\circ} \mathrm{F}$. The saturation pressure of water at $347^{\circ} \mathrm{F}$ is $130 \mathrm{psia}$. The saturation pressure of Dowtherm-A at $360^{\circ} \mathrm{F}$ is $2.0 \mathrm{psia}$, far below atmospheric pressure, which means that this coolant is subcooled. 
When a breach is opened in the IF-300, water will be driven through the opening mainly due to the high pressure in the cask. If the cask is in a breach down position, saturated liquid will be expelled and, if the cask is in a breach up position, saturated vapor will be expelled.

When a breach is opened in the AMCO cask, the Dowtherm-A will be driven through the opening due to forces other than the internal pressure in the cask. The internal pressure in the cask would probably be near atmospheric pressure, so this driving force would not be a factor. If this cask is in a breach down position, the Dowtherm-A would be driven through the opening due to the force exerted by the riquid column. If the cask is in a breach up position, the Dowtherm-A would leave the cask as a vapor. However, in this case, the Dowtherm- $A$ is subcooled and must wait until enough heat is absorbed to bring its temperature to $494.8^{\circ} \mathrm{F}$, its saturation temperature at atmospheric pressure. Also, at night, heat transfer from the Dowtherm-Acooled cask to the surroundings improves with the removal of the solar heat input. This reduces boil-off since less heat is available to the coolant.

It is apparent that casks using coolants with low vapor pressures would have substantially lower coolant loss rates. As a result, more time would be available to prevent the loss of the coolant and to take steps to restore the cask to near normal operating conditions.

As discussed earlier, results of the simulations would indicate that there would not be enough time to prevent the loss of coolant from the IF-300, but that enough time might be available to prevent the loss of coolant from the AMCO cask and to restore it to near normal operating conditions. A simple, but effective, procedure would be to bring the cask to a breach up position (if it is not already in this position), replace the solar shield, and reintroduce water into the outer jacket. Once these measures are taken, then attention could be focused on ways to close the breach.

The fuel pins that fail first in the IF-300 burst at about 4 hours following the accident when the cask is in the breach down position and the breach flow area is $0.025 \mathrm{in}^{2}$. It is the smallest time span of the 
four cases considered. All of the coolant is lost in about 2 hours, and the first fuel pins burst 2 hours later. If the cask cools sufficiently and other conditions permit, the following are suggested as possible steps that might prevent or delay overheating and bursting of the pins. Introduction of an inert gas to the cask cavity might provide enough cooling to prevent bursting of the pins. Air is to be avoided to prevent oxidation of the fuel if the cooling attempts fail. Also, water is to be avoided since it would probably flash to steam, which might force radioactive particles from the cask. If it were possible, the introduction of small-diameter steel shot, along with the inert gas, would provide an additional heat sink capability. Also, the shot, with the qas in the voids, would provide a good conduction path from the fuel to the cask wall. At the same time, water could be introduced into the water jacket at the outer surface. It is recommended that the effectiveness of these measures be evaluated in later studies.

An analysis of the behavior of the AMCO cask following loss of its primary coolant produced results that indicate the pins in this cask might not burst and, consequently, no fission products would be released. This might be due to any one of the following three factors, or a combination of all three. First, the internal pressures in the fuel pins are about half that required to burst the pins, even at 52 hours after the primary coolant is lost. Second, the decay heat rate of the spent fuel in this cask is about one-fourth that of the spent fuel in the IF-300. Finally, the AMCO cask, unlike the IF-300, has circumferential cooling fins attached to the outer surface of the cask wall, extending through the water jacket and protruding 8 inches beyond the outer diameter of the cask. When the water in the outer jacket is lost at the time of the accident, these fins continue to provide a path for heat flow. Without these fins, the heat would have to be transferred across the empty water jacket by natural convection and radiation and, as a result, the temperatures in the cask would be higher. It is recommended that, if a cask is designed with a water jacket as a neutron shield, cooling fins extending through the jacket should be included as part of the design. It is also recommended that, in subsequent phases of this study, the calculation of internal pressures in the fuel pins and 
the validity of the burst pressure data be reviewed to verify the results obtained.

As stated earlier, in the Results and Discussion section, some of the fuel pin clads may be damaged at impact. The extent of this damage could be estimated using mathematical models based on experience gained in setting up similar modeis in the past. It is recommended that these models be developed.

Results from the simulation of the behavior of the IF-300 following loss of its primary coolant indicated that all of the fuel pins in this cask would burst, releasing about 11,900 curies of fission gases (about $33 \%$ of the total in the spent fuel) and about 113 curies of fission product solids, assumed to be $\mathrm{Cs}_{2} \mathrm{O}$ (representing about $0.01 \%$ of the total cesium in the spent fuel). A model simulating the behavior of the aerosol formed by the fission gases and the $\mathrm{Cs}_{2} 0$ particles showed that, if the aerosol were confined to the cask cavity, about $47 \%$ of the particles (about 53 curies) would settle or plate out within 24 hours after the accident. The remaining $53 \%$ (about 60 curies) are suspended in the cask as an aerosol at this time. The particles suspended are those in two of the five size groups considered. These two size groups contain the smallest particles, those in the size range from 0.08 to 0.2 micron (an average of 0.11 micron) and those in the size range from 0.2 to 0.33 micron (an average of 0.25 micron). It is not known at this time how much of the aerosol would escape from the cask through the damaged relief valve. Equations have been developed to define the rate of flow of the aerosol from an opening in a cask's containment system; however, the equations were developed too late to be included in the sets of models discussed in this report. These equations will become part of the loss-of-coolant models and will form the basis for the leakage term in the volatile solids release models. It is recommended that these models be modified to include the equations describing the flow of fission products from the cask containment (see Sections 3.5 and 4.1 .5 of the Appendix). The modified models would be used to determine the amount of fission products lost from a cask through a given breach flow area.

If a cask is designed with a filter between the cavity and the pressure relief valve, some of the solids in the aerosol could be removed before the 
aerosol reaches the surroundings. The volatile solids release models, especially the leakage term, would be useful in evaluating pcssible filtering media or devices.

The amounts of fission gases and solid fission products reported here represent only the amounts present in the pin voids. In the early stages of this study, before the coolant loss rate models were developed, another mechanism of release was considered that resulted in the release of the remaining "bound up" gases and solids. This mechanism was the oxidation of the $\mathrm{UO}_{2}$ to $\mathrm{U}_{3} \mathrm{O}_{8}$, a fine granular material, from which these bound up gases and solids are more readily released. As the study progressed and the coolant loss rate models were developed, this mechanism appeared less and less likely. This was apparent from the results obtained from these models, which seemed to indicate that a cask would be at a pressure higher than its surroundings. This would prevent the influx of air, which is necessary for oxidation of the fuel, to the containment vessel.

In the very early stages of this study, the most severe situation envisioned was simulated first to give a preliminary "worst case" estimate of the extent of fission product release. The most severe situation envisioned was the immediate loss of primary coolant at impact, along with loss of the solar shield, loss of water in the outer jacket, and immersion in a fire at $1475^{\circ} \mathrm{F}$. Calculations were made for fires of 0.5 and 2.0 -hours duration. The cask modeled in this initial phase of the study was neither the IF-300 nor the AMCO cask. It was an early conceptual design of an LWR spent fuel shipping cask with lead shielding. The results of the calculations showed that the length of the fire had 1ittle effect on the thermal behavior of the cask internals, but there was an important effect on the fate of the lead shield. It was found that none of the lead melted during the 0.5 -hour fire, but that the outer 1.0 inch, representing about $14 \%$ of the lead shield, melted away at about 1.33 hours into the 2.0-hour fire. The loss of this much of the lead shield would have two consequences: 
(1) It would reduce the amount of radiation shielding, and

(2) It would result in higher temperatures of the cask internals because the resulting gap would present a barrier to the heat flowing to the cask surface. These higher temperatures would, in turn, result in higher pressures in the fuel pins and a more rapid release of fission products.

In summary, the results of the simulations for the accident conditions considered indicate that the IF-300 would lose its primary coolant at a much faster rate than the AMCO cask and that, after the coolant is lost, all of the pins in the IF-300 would burst, releasing all the fission gases (11,900 curies) and a smal1 percentage of cesium (113 curies) from the pin voids. In contrast, the fuel pins in the AMCO cask do not burst and no fission products are released from the voids. Several factors were cited to explain the difference in performance:

(1) The different coolant loss rates are due to the vapor pressures of the different coolants used. The IF-300 uses water which, at the time of the accident, has a vapor pressure about 9 times atmospheric. The AMCO cask uses Dowtherm-A, which is subcooled at the time of the accident.

(2) Long after loss of primary coolant (52 hours), the pressures in the fuel pins in the AMCO cask are only about half that required to burst the pins. In contrast, all the fuel pins in the IF-300 burst between 7 and 13 hours after loss of its coolant, depending upon breach size and cask orientation. (This could be the result of a number of other related factors, including pin design and the factors listed below).

(3) The decay heat rate of the spent fuel in the AMCO cask is about one-fourth that of the spent fuel in the IF- 300 .

(4) The AMCO cask, unlike the IF-300, has cooling fins attached to the outer surface of the cask wall extending through the water jacket. These fins provide a path for heat transfer even when the jacket water is rost. 
The objectives of this study have been to develop simulation models of typical casks for the rail shipment of spent fuel from nuclear reactors, to use these models to study the behavior of the casks following a postulated accident and fire, and to determine the extent of radioactive releases from the casks following the accident. The casks modeled were the IF-300, designed by General Electric for the shipment of spent LWR fuel ( ${ }^{1}$ ), and a cask designed by the Aerojet Manufacturing Company (AMCO) for the shipment of spent LMFBR fuel.

This study has progressed by definite steps or stages, with each successive stage being an improvement or refinement of the total modeling effort. These improvements or refinements were based on what had been learned from the preceding stages, and on new information gathered from other sources. An attempt will be made in these opening paragraphs of the Appendix to outline, in chronological order, some of the more important stages of this "bootstrapping" process.

At the outset, it should be made clear that the IF-300 was not modeled until the final stages of the study. The LWR spent fuel shipping cask modeled and studied through most of the study was a conceptual design that was never actually built. There are several important differences between the IF-300 and this conceptual design. First of all, lead was used for the gamma shield in the conceptual design instead of depleted uranium. Second, the neutron shield or outer water jacket of the conceptual design is partitioned by circumferential cooling fins attached to the outer surface of the cask wall, extending through the jacket and protruding several inches beyond the outer surface of the water jacket. Although this same type of fin structure was used in the AMCO cask, the IF-300 design does not include fins. Instead, the IF-300 uses a corrugated shell as the outer surface of the water jacket, where the corrugations offer some of the advantages of fins. However, if the outer jacket loses its water, it would become a substantial barrier to heat flow from the cask, since no fins extend through the jacket to the cask wal1. Third, the corrugated outer surface of the water jacket on the IF-300 is cooled by air forced over the surface by diesel-driven blowers. The conceptual design relies on air flowing over 
the fins by natural convection, along with radiant heat transfer, to cool the outer surface. Finally, the conceptual design uses thick, massive baskets to contain the fuel assemblies. These baskets are made of sandwiched layers of copper and boron carbide for cirticality control. Both copper and boron carbide have high thermal capacities that make these baskets potentially effective heat sinks. By contrast, the IF-300 uses thin slotted stainless steel baskets with $\mathrm{B}_{4} \mathrm{C}$-filled stainless steel tubes welded to the baskets for criticality control.

Some statements made in the Introduction to summarize the modeling effort will be repeated to provide some orientation before launching into the chronological account of the study and detailed discussions of the models.

A set of five simulation models has been developed for the IF-300, and a set of similar models for the AMCO cask. These models simulate cask behavior during normal operating conditions, and during conditions following an accident and fire. The sets of models include:

1. A model simulating the steady-state thermal behavior of a cask prior to an accident.

2. A model that determines the transient thermodynamic behavior of a cask and the gradual loss of primary coolant following impact and opening of a breach in the cask containment. This model applies to the case where the cask comes to rest with the breach down.

3. A model simulating the transient thermodynamic behavior of a cask and gradual loss of primary coolant following impact and opening of a breach in the cask containment. This mode 1 applies to the case where the cask comes to rest with the breach up. 
4. A model simulating the transient thermal behavior of a cask following the eventual loss of primary coolant.

5. A model simulating the transient behavior of the volatile solids or solid fission products (cesium compounds) that may be released to the cask containment as an aerosol at the time the fuel pins burst and the fission gases are released.

of these models, the second, third and fifth were developed for programming on MIMIC, a continuous system simulation program. (3) The first and fourth models were programmed on the TAP simulation code, a network analyzer. (4) For the IF-300, portions of the second and third models are represented by a chart devised by Moody (9) that relates the maximum steam and water flow rates to the local stagnation properties in a pressurized vesse1. For the AMCO cask, the second model is an energy balance that relates the potential energy of the coolant column to the mass velocity of the coolant flowing from the breach and the time required to empty the cask.

Figure A-I shows the information flow between models and the order in which they are used.

Radioactivity could be released from the casks as fission products if the primary coolant containment is breached. In this study, the fission products are the fission gases and volatile solids or solid fission products (cesium compounds) in the spent fuel. In addition to the sets of models listed above, equations were developed to define the rate of flow of these fission products from the casks. These equations were developed too late to be included in the sets of models. However, they will be included in the appropriate models during a later development phase. The derivation of these equations is discussed here, along with discussions of the development of the models.

At the time the study of spent fuel shipping cask accident behavior was begun, it was decided to start with the most pessimistic case to determine at the outset the most conservative estimate of fission product release and the times of release. The most pessimistic case visualized was one in which a cask loses its solar shield, outer jacket water, and primary coolant at 


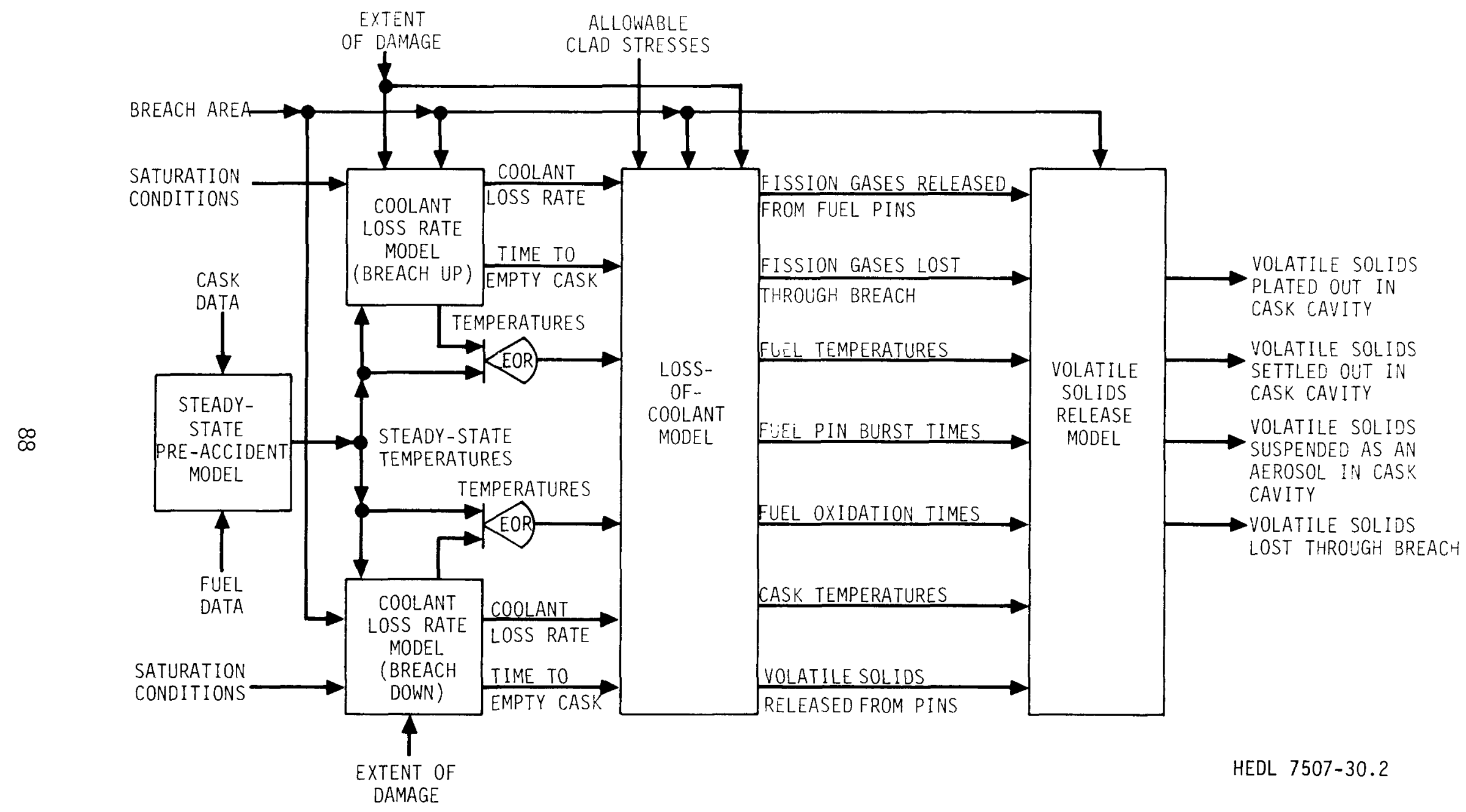

FIGURE A-1. Information Flow Among Simulation Models 
the instant an accident occurs, and it is subjected to a fire at $1475^{\circ} \mathrm{F}$ for at least 0.5 hour. Consequently, the first simulation models constructed were so-called "loss-of-coolant" models.

To provide initial conditions for the loss-of-coolant models, a steadystate pre-accident version of each of the models was constructed in which use was made of the concept of volumetric heat dissipation to represent heat transfer from the fuel regions to the coolant. In these steady-state models, of course, the solar shield remained intact and the outer jacket was water-filled.

As the study progressed, the emphasis shifted from simulation of the pessimistic to an effort to approach realism. The first step in this direction was prompted by the desire to relax what was thought to be the rather severe assumption that all of the primary coolant is lost instantaneously at the moment of impact. This led to the development of what will be referred to as the "no-loss-of-coolant" models. These models were eventually to become the "coolant loss rate" models but, at first, they were developed to study cask behavior following an accident and fire with no loss of primary coolant. It was assumed that the only damage sustained by the casks was loss of their solar shields and the water in the outer jackets, and that the pressure relief system was inoperable. The temperatures obtained from these models approached new, higher steady-state values. This presented no problem in the case of the AMCO cask since its primary coolant is Dowtherm-A, a coolant with a vapor pressure about equal to that of atmospheric pressure at its new steady-state temperature. However, since the primary coolant in the conceptual LWR cask design considered is water, its internal pressure reached an intolerable level.

Later, the no-loss-of-coolant models were modified to form the "coolant loss rate" models. These new models were disigned primarily to estimate the rate at which primary coolant would be lost from the casks following impact and opening of a breach in the cask containment. They also simulated the transient thermodynamic behavior of the casks following these events, during a fire, and while the coolant was being lost from the cask. 
It was difficult to conceive of an accident situation severe enough to cause a breaci in the primary coolant containment, since these casks are extremely well designed. Also, results from various experimental programs, including 30-foot drop tests, puncture tests, etc., in which cask models were used, indicated that the chances of a cask containment being breached in this manner would be extremely small, in fact, quite unlikely. It seemed reasonable to assume, however, that any access to the primary coolant that had been included as part of the cask design, such as pressure relief passages and valves, fill passages and valves, etc., might be vulnerable to damage or malfunction. Since the function of the pressure relief valve is to automatically respond to changes in conditions that may occur in the coolantfilled cask cavity, it seemed reasonable to assume that this would be the most vulnerable access to the coolant and the most likely candidate for a breach-causing failure. Although this valve is usually well protected, it was assumed that it could be jarred sufficiently at impact to be forced into a partially open position, or it could fail to reseat after performing its function during normal operating conditions. To arrive at an upper limit to the damage that might occur to this valve at impact, it was assumed that it. could be sheared off entirely, resulting in more than a full open position.

About the time the development of the coolant loss rate models was nearing completion, work had begun on a simulation model to determine the behavior of volatile solids released as an aerosol from the fuel in the casks following loss of primary coolant. At first, this model was incorporated into the loss-of-coolant models, but this proved to be cumbersome, so a separate model was developed.

Finally, the second step to approach realism or "real world" conditions was taken in the final stages of the study when the conceptual design of an LWR spent fuel shipping cask was replaced by the "real" IF-300. A11 of the LWR cask models were restructured to simulate the IF-300.

This account of the order in which the models were developed sets the stage for more detailed discussions of each of the models. The models are linked together and used in a sequence quite different from the order of 
their development (see Figure A-1). The discussions that follow are in the order of each model's use in the chain of Figure A-1, rather than in the order of their development. For this reason, in some of the sections, some references may be made to equations derived in subsequent sections. In some cases, the derivation of certain equations and concepts may be included in an earlier section where they may be presented in a more logical order, even though they were first derived for a model in a later section. 


\section{CASK SIMULATION MODELS FOR STEADY-STATE CONDITIONS}

PRECEDING THE ACCIDENT

The models discussed in this section are referred to as "Steady-State Pre-accident Simulation Models." These models were developed first to provide the initial conditions for the post-accident transient analyses. They simulate conditions in the casks while in transit, during an uneventful, normal trip. Later, modifications to these models produced the so-called "Loss-of-Coolant" models discussed in Section 3. Both the pre-accident and loss-of-coolant models are programmed on the TAP Simulation Code. (4)

Before the steady-state models are discussed, the IF-300 and AMCO casks will be described. The steady-state models will then be discussed and compared to the loss-of-coolant models. Following this, in Section 1.1, the coolant circulation patterns and heat transfer paths in the casks will be discussed, and, in Sections 1.2 and 1.3, equations will be derived that define some concepts used in the development of the models.

The IF-300 carries seven PWR fuel assemblies (see Figures 1 and 2). These assemblies are surrounded by slotted stainless steel baskets. Several $\mathrm{B}_{4} \mathrm{C}$-filled stainless steel tubes are attached to the outer surfaces of the baskets for criticality control (see Figure 3 ). The seven assemblies and their baskets are contained in an inner cavity filled with water. This fuel containment cavity is surrounded by 4 inches of depleted uranium encased in stainless steel. The outer surface of the uranium is cooled by water contained in a 6 -inch jacket. The type of fuel assembly carried by this cask is shown in Figure 4, and detailed data are presented in Table 2.

The AMCO cask simulated is shown in Figure 5. This cask carries nine fuel assemblies of hexagonal cross-section, each encased in a steel basket with slots for crosswise coolant flow. The nine assemblies and their baskets are contained in a stainless steel canister filled with either Dowtherm-A or sodium. The cask analyzed in this study was assumed to be filled with Dowtherm-A. The fuel assemblies are arranged in a circular pattern, bounded on the inside by a coolant expansion chamber of 15.5 inches diameter, and bounded on the outside by the inner wall of the containment vessel or canister. The canister has a 
one-inch thick wall that is separated from the inner wall of the containment vessel by a 0.25 -inch helium-filled gap. The containment vessel is surrounded by a 3.625-inch thick uranium shield which, in turn, is surrounded by a 6 -inch thick steel shel1. The outer surface of the steel shell is cooled by water contained in a 4-inch jacket partitioned by circumferential cooling fins, which extend through the jacket to protrude 8 inches beyond the outer diameter of the jacket. The fuel assembly carried by this cask is shown in Figure 6, and detailed data are presented in Table 4.

The coolant circulation pattern and heat transfer paths in the IF-300 are discussed in Section 1.1 and illustrated in Figures 1-1 and 1-3. A similar circulation pattern exists in the AMCO cask, but the heat transfer paths are somewhat different, as shown in Figure 1-2.

In both casks, the decay heat generated in a fuel assembly is transferred from the fuel pins to the primary coolant inside the fuel assembly can by natural convection. The coolant, in turn, transfers the heat to the inner wall of the fuel assembly can, also by natural convection. The heat is then conducted through the can wall and is transferred by natural convection to the primary coolant outside the fuel assembly cans, in the cask cavity. Most of the decay heat from the fuel pins is dissipated in this manner. A small amount is transferred radially through the fuel assembly by conduction, but this is negligible compared to that transferred by natural convection to the coolant and then to the can wall. In the IF-300, the heat in the cask cavity is transferred to the inner wall of the containment vessel by natural convection, and then by conduction through the steel shells and the uranium shielding, eventually arriving at the inner surface of the neutron shield or outer water jacket. In the AMCO cask, the heat in the cask cavity is transferred to the inner wall of the canister by natural convection, and then by conduction through the canister wall to the holium gap, by radiation and conduction across this gap to the cask wall, and then by conduction through the steel and uranium in the cask wall to the inner surface of the water-filled neutron shield. The AMCO cask (and the conceptual LWR cask) are designed with circumferential cooling fins attached to the outer surface of the cask wall that extend through the water jacket and protrude beyond the outer surface of the jacket. Part of the heat from 
the cask wall is conducted through these fins, through the jacket, and is dissipated to the surroundings by natural convection and radiation from the fins. The rest of the heat is transferred to the water in the outer jacket by natural convection which, in turn, transfers the heat to the outer surface of the jacket (and to the fins) by natural convection, where it is then conducted through the jacket wall and finally dissipated to the surroundings by natural convection and radiation. The IF-300 does not have fins such as those just described. However, the outer surface of its water jacket is corrugated, and the corrugations provide some advantages of a finned surface. In addition, the IF-300 is cooled at the outer corrugated surface by air forced over the corrugations by diesel-driven blowers.

The steady-state model of the conceptual cask was constructed first, but was sufficiently general to be easily adapted to the IF-300 and AMCO casks. The primary difference between the LWR casks and the AMCO cask is in the layout of the fuel assemblies and baskets in the containment vessel.

An idealized model of the IF-300 is shown in Figures 3-1 and 3-2. The primary difference between this model and the actual cask is the representation of the fuel, fuel cans and baskets as circular regions rather than the array of square fuel assemblies. This simplified model was divided into radial nodes as shown in Figure 3-19. The network of admittances connecting these nodes is shown in Figures $1-1$ and 3-20. An idealized representation of the IF- 300 was necessary because the array of square fuel assemblies was not symmetrical (see figures 2 and 3-2).

Unlike the IF-300, the arrangement of the fuel assemblies in the containment vessel of the AMCO cask is symmetrical. This allows the simulation network to be based on a symmetrical cut of the cask as shown in Figures 1-2 and 3-21. The hexagonal fuel assembly and its basket are represented as concentric cylinders divided into radial nodes as shown in Figures 3-3, 1-2 and 3-21. The baskets surrounding the fuel assemblies are designed with slotted holes for free passage of the coolant.

The steady-state models and the loss-of-coolant models are very similar. The primary difference between these models, of course, is that 
the loss-of-coolant models are not steady-state models, but were developed to simulate transient conditions in the cask following an accident, fire, loss of solar shield, loss of coolant in the neutron shield, and eventual loss of primary coolant. This means that the simulation networks (electrical analogs) of the loss-of-coolant models include a thermal capacitance at all nodes representing material mass. Also, since the primary coolant and the coolant in the outer jacket were lost, except for some residual vapor, the convection admittances in the fuel assemblies, cask cavity, and in the outer jacket are for the vapor rather than the liquid. The conduction admittances in the fuel assemblies are also affected by the replacement. of liquid by vapor. In addition, with the liquid coolant gone, admittances were added to the networks in the cavity and outer jacket to represent paths for heat transfer by radiation between surfaces. Loss of the solar shield required some additional changes at the outer surface of the cask.

Later, as the study progressed, circuits were added to the loss-ofcoolant models to simulate melting of the lead shield (of the conceptual LWR cask), release of fission gases from the fuel pins due to bursting of the clads, and diffusion and oxidation of the fuel.

The simulation network for the steady-state pre-accident model of the IF-300 is presented as Figure 1-1, and the corresponding network for the AMCO cask is presented as Figure 1-2. These figures should be compared with Figures 3-19 and 3-20 for the transient loss-of-coolant model of the IF-300, and Figure 3-21 for the corresponding model of the AMCO cask.

A collection of fuel pins such as in the fuel assemblies have a "lumped" characteristic. A method was devised to "distribute" the "lumped" fuel to give homogeneous regions that could then be "re-lumped" to fit the nodal representation of the models. This was done by using the concepts of volumetric heat dissipation and an apparent thermal conductivity for materials with voids to represent the heat transfer in the fuel regions. The equations that define these concepts are presented in Sections 1.2 and 1.3 , respective7y. Equations that define the apparent thermal conductivity of a homogenized fuel region following loss of the primary coolant are derived in Section 3.1 . 


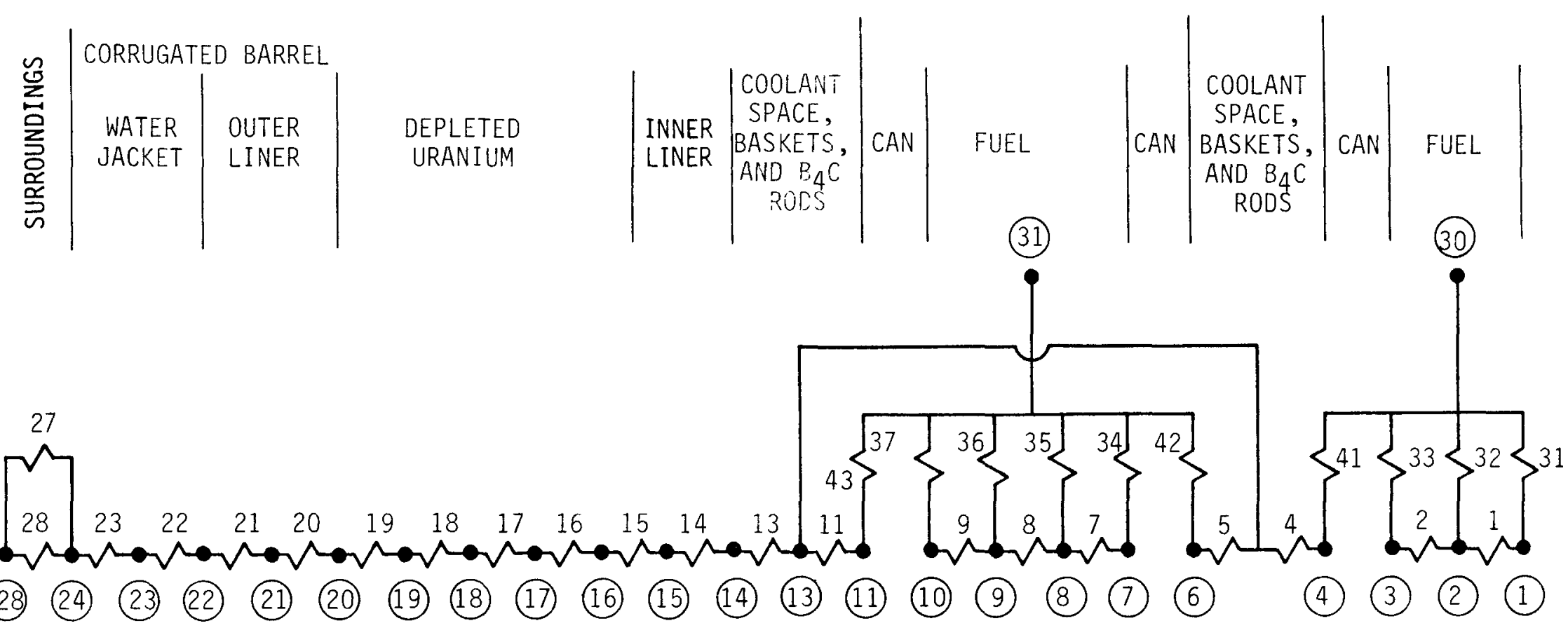

HEDL $7507-30.10$

FIGURE 1-1. Simulation Network of the Steady-State Model of the IF-300 


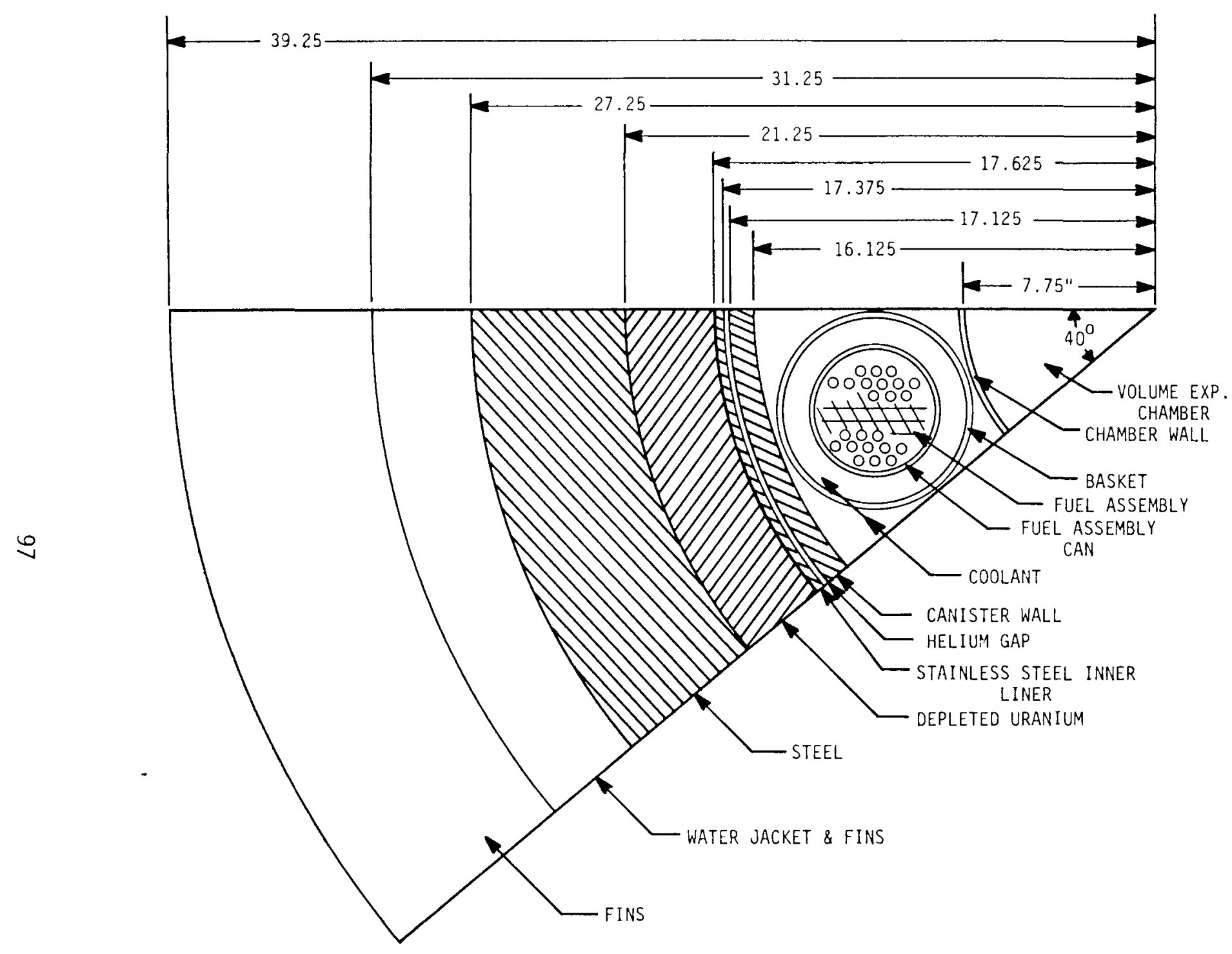

FIGURE 1-2. Idealized Representation of the AMCO Spent Fuel Shipping Cask and Simulation livetwork of the Steady-State Model (Page 1 of 2) 

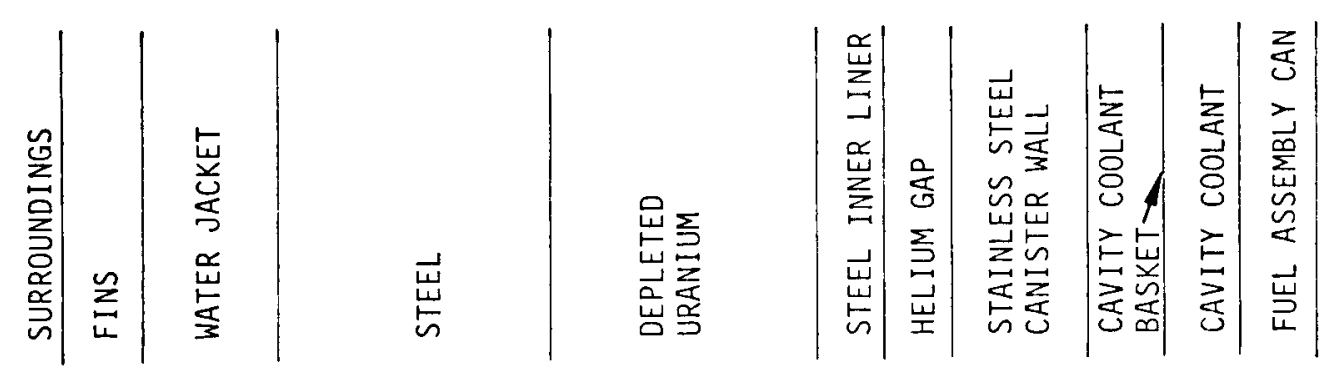

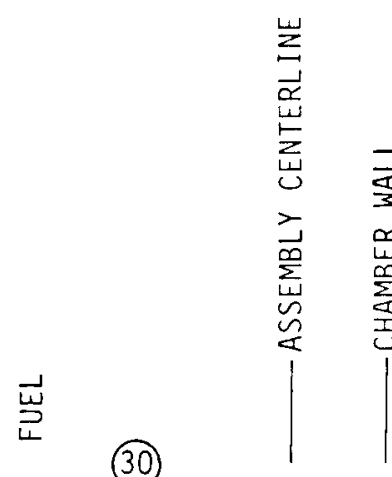

$\infty$

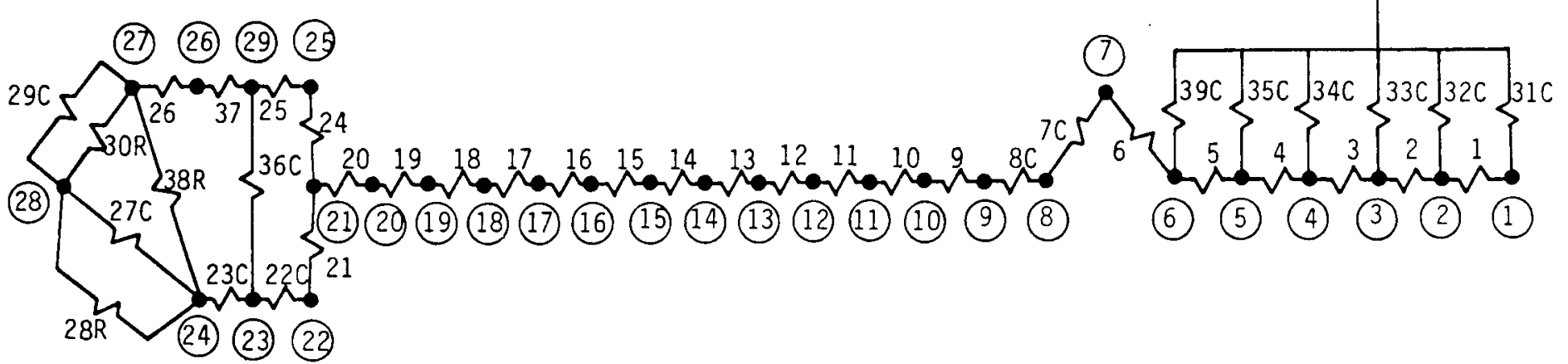

HEDL 7507-30.12

FIGURE 1-2. Idealized Representation of the AMCO Spent Fuel Shipping Cask and Simulation Network of the Steady-State Model (Page 2 of 2) 
Equations representing heat balances on the various nodes are not presented here or in Section 3 since both the steady-state pre-accident models and the loss-of-coolant models are quite detailed, with many admittances and nodes, especially the loss-of-coolant models. Heat balances that are of the same form as those that could have been presented here are presented in Section 2 for the "coolant loss rate" models of the casks.

Listings of the simulation models programmed on the TAP code are not presented in this report since the format used is unique, and those not familiar with the code would find the listings of little value.

\subsection{Coolant Circulation and Heat Transfer Paths in the Casks}

In both casks, the decay heat generated in a fuel assembly is transferred from the fuel pins to the primary coolant inside the fuel assembly can by natural convection. The coolant, in turn, transfers the heat to the inner wall of the fuel assembly can, also by natural convection. The heat is then conducted through the can wall and is transferred by natural convection to the primary coolant outside the fuel assembly cans, in the cask cavity. Most of the decay heat from the fuel pins is dissipated in this manner. A small amount is transferred radially through the fuel assembly by conduction, but this is negligible compared to that transferred by natural convection to the coolant and then to the can wall. The heat in the primary coolant in the cask cavity is transferred to the inner wall of the containment vessel by natural convection.

An illustration of the complex coolant circulation pattern and the heat flow paths in the IF-300 (and conceptual cask) is presented in Figure 1-3. This figure represents a two-stage simplification process starting with the actual IF-300 layout showing the coolant circulation pattern, and ending with a network simulating the heat transfer from the fuel to the inner surface of the containment vessel wall. Figure 1-3(a) shows the actual cask layout and the coolant circulation pattern. 


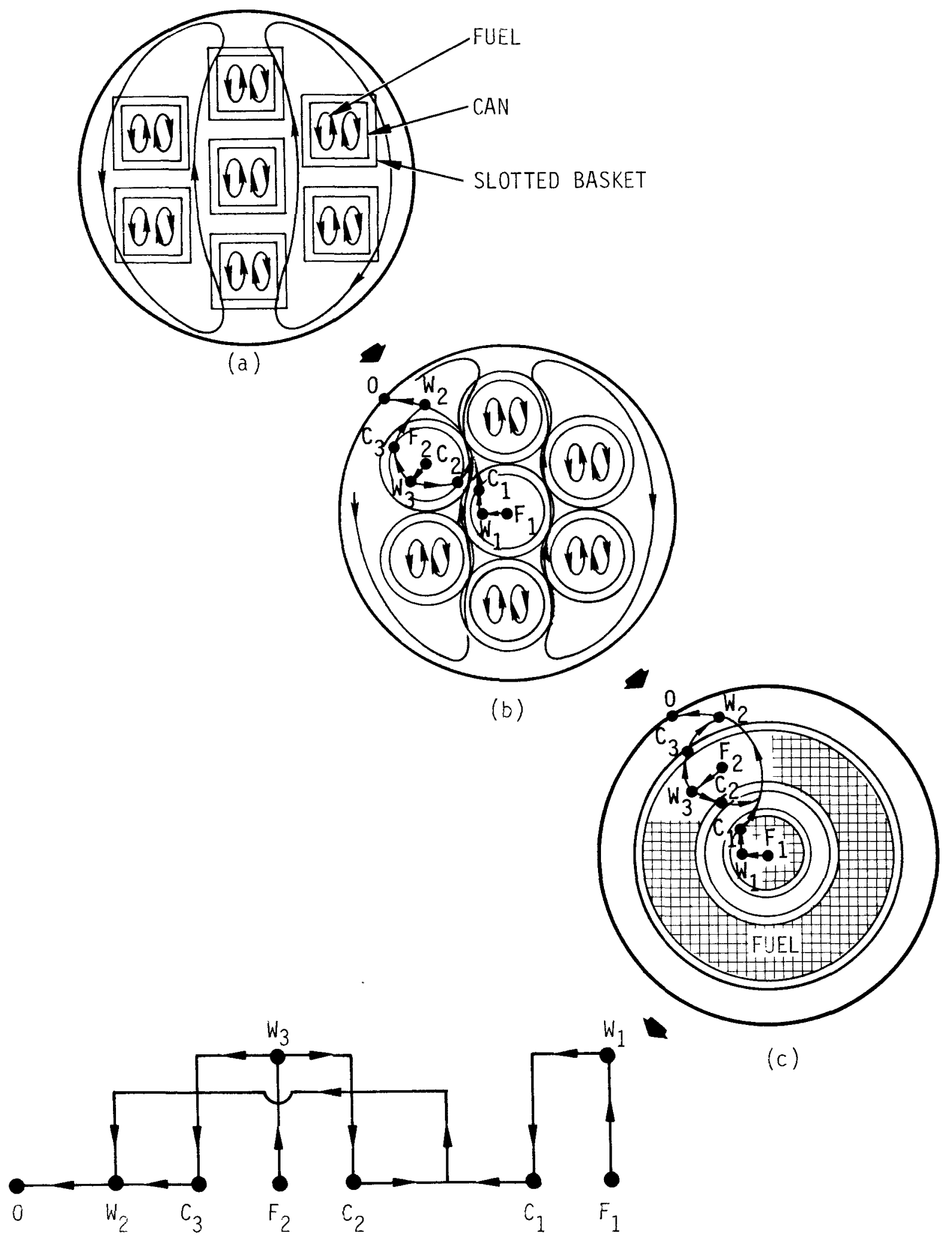

(d)

HEDL $7507-30.15$

FIGURE 1-3. Representation of Steady-State Cooling by Natural Convection in the IF-300 Before the Accident 
The first stage of the simplification, shown in Figure 1-3(b), is based on the assumption that the square fuel assemblies can be represented by cylindrical assemblies, contained in a cylindrical can, and the canned assembly enclosed in a cylindrical slotted basket. It was assumed that the baskets in the coolant-filled steady-state pre-accident model would be at the same temperature as the coolant in the cavity, and that the simulation of the heat transfer in the cask cavity would not be affected if the baskets were neglected. This will not be the case in the loss-of-coolant models to be discussed later, where the baskets will definitely play a part in the transfer of heat by radiation. It was also assumed that the temperature drop across a can wall would be quite small, and that the can wall could be represented by a single node.

The coolant circulation flow pattern is shown in Figure 1-3(b), along with one of six 60-degree symmetrical segments of the cask containing typical heat transfer paths.

The final step of the simplification is shown in Figure 1-3(c). In this step, the assumption is made that there is no heat flow across the radial boundaries of the 60 -degree segments, i.e., there is no heat flow angularly in the cask. This allows the fuel, cans, and coolant spaces to be represented as concentric rings. The heat transfer path shown is presented more clearly in Figure 1-3(d).

In Figure 1-3(d), four types of nodes are shown for the analog of the heat transfer paths: fuel nodes (F), can nodes (C), coolant nodes (W), and the node at the inner surface of the containment vessel wall (0). The arrows on the connectors between nodes point in the direction of heat flow. These heat transfer paths were described in the opening paragraph of this section.

The heat transfer paths in the AMCO cask are not as complex as those in the IF-300 since the basket arrangement is not as complex. In the AMCO cask, each fuel assembly and basket combination could be treated individually, rather than as concentric regions, since the cluster of nine fuel assemblies is symmetrical and no single assembly is located in the center of the cluster. 


\subsection{Volumetric Heat Dissipation}

Simulation of the heat transfer from the fuel pins to the coolant in each fuel assembly required the use of a unique technique. Due to the complexity posed by the "lumped" nature of the fuel pin bundles, the concept of volumetric heat dissipation was used as a simplification. ${ }^{(15)}$ This concept, along with that of an apparent thermal conductivity, was used to "distribute" the "lumped" fuel to convert the fuel assemblies into homogeneous regions which could then be "re-lumped" into nodes for the heat transfer network. This concept was also used in the development of the coolant loss rate models of Section 2 .

An energy balance on a differential volume element of this homogeneous or distributed fuel is illustrated in the following sketch:

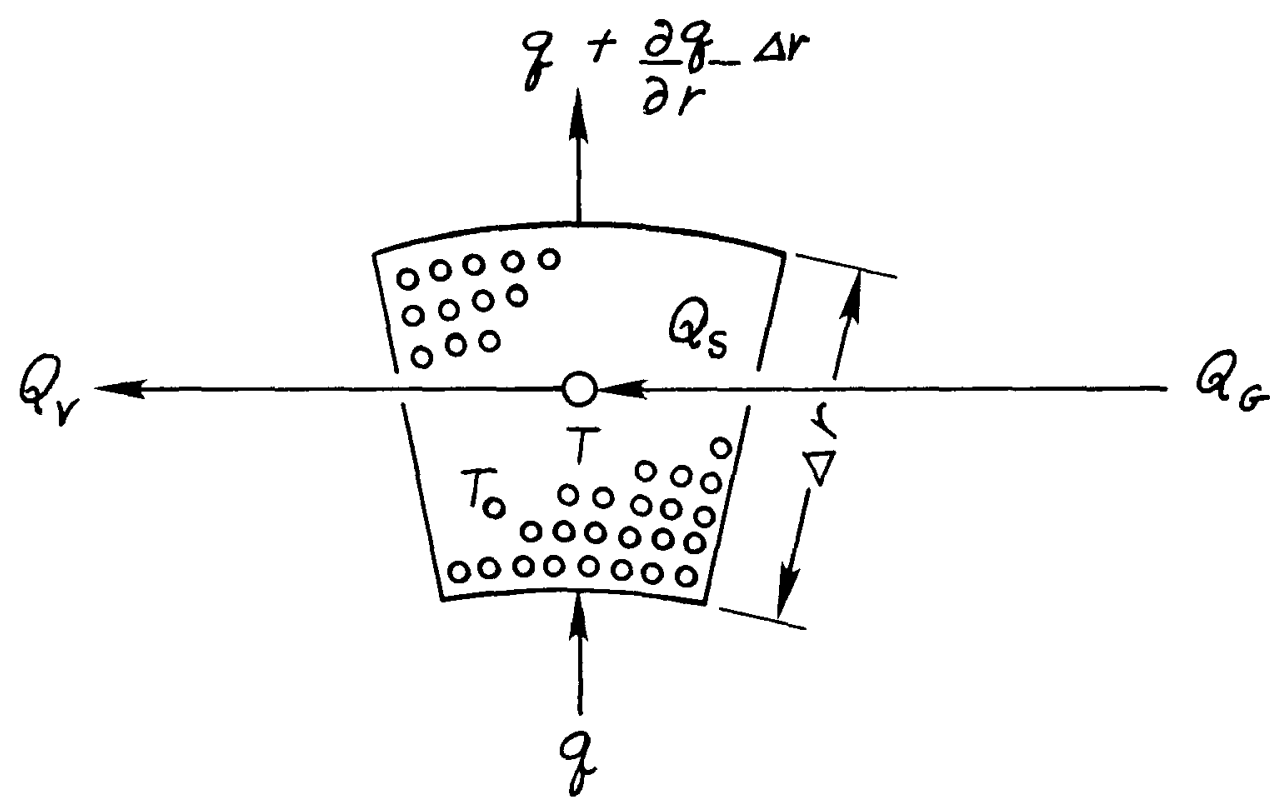

An energy balance is usually written as

$$
\text { Input-Output }=\text { Accumulation. }
$$

The energy balance on the volume element is

$$
q+Q_{G}-q-\frac{\partial q}{\partial r} \Delta r-Q_{v}=Q_{S}
$$


where

$$
\begin{aligned}
Q & =\text { heat conduction, } H / 0 \\
Q_{G} & =\text { heat generation, } H / 0 \\
Q_{V} & =\text { heat dissipation, } H / \theta \\
Q_{S} & =\text { energy accumulation or storage, } H / \theta .
\end{aligned}
$$

The basic equation for heat conduction in this porous material is

$$
q=-2 \pi r k_{a} \frac{\partial T}{\partial r} \Delta x
$$

where

$\mathrm{k}_{\mathrm{a}}=$ an apparent thermal conductivity, $\mathrm{H} / \theta \mathrm{LT}$

$T=$ the temperature, $T$

$r=$ the radius, $L$

$x=$ the length of the element, $L$.

Differentiating this equation with respect to the radius gives

$$
\begin{aligned}
\frac{\partial q}{\partial r} & =-2 \pi r k_{a} \frac{\partial^{2} T}{\partial r^{2}} \Delta x-2 \pi k_{a} \frac{\partial T}{\partial r} \Delta x \\
& =-2 \pi r k_{a}\left(\frac{\partial^{2} T}{\partial r^{2}}+\frac{1}{r} \frac{\partial T}{\partial r}\right) \Delta x \\
& =-2 \pi r k_{a} \nabla^{2} T \Delta x .
\end{aligned}
$$

Heat generation in the element may be expressed as:

$$
Q_{G}=2 \pi r q_{G} \Delta r \Delta x
$$

where

$\mathrm{q}_{G}=$ the volumetric heat generation in the porous material, $\mathrm{H} / \mathrm{\theta L}^{3}$. Heat dissipation in the volume element is defined by the equation,

$$
Q_{V}=2 \pi r H_{V}\left(T-T_{0}\right) \Delta r \Delta x
$$


where

$H_{v}=$ a volumetric heat dissipation coefficient, $H / \theta \mathrm{L}^{3} \mathrm{~T}$,

$T_{0}=$ the coolant temperature, $T$.

Finaliy, the energy accumulation or storage in the volume element is

$$
Q_{S}=2 \pi r \rho C \frac{\partial T}{\partial T} \Delta r \Delta x
$$

where

$$
\begin{aligned}
& 0=\text { the density of the porous material, } M / L^{3} \\
& C=\text { the heat capacity, H/MT } \\
& t=\text { time, } \theta .
\end{aligned}
$$

Substituting from Equations $(1-3),(1-4),(1-5)$ and (1-6) into Equation (1-2), and simplifying, the energy balance becomes

$$
q_{G}+k_{a} \nabla^{2} T-H_{V}\left(T-T_{0}\right)=\rho C \frac{\partial T}{\partial t} .
$$

This equation is similar to that for heat transfer in a fin with heat generation, except that an apparent thermal conductivity is used for the porous material, and a volumetric heat dissipation coefficient is used instead of a conventional convection coefficient.

A fuel pin and its surrounding coolant was considered to be a "unit ce 17" as shown in the following sketch:

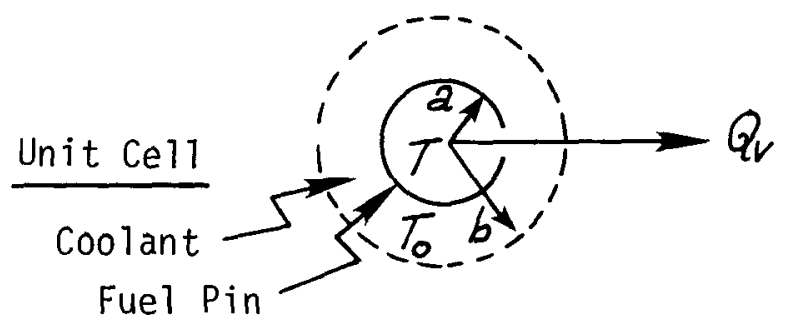


The surrounding coolant is represented by an equivalent cylinder rather than as the more complicated shape that would be traced by the common zero heat transfer boundary of adjacent pins.

The heat transfer from the pin to the coolant in the unit cell is

$$
Q_{v}=2 \pi a h\left(T-T_{0}\right) \Delta x
$$

where

$$
\begin{aligned}
Q_{v}= & \text { the heat transferred, } H / \theta \\
a= & \text { the fuel pin radius, } L \\
\Delta x= & \text { the length of the unit cell, L } \\
h= & \text { the heat transfer coefficient for natural convection from } \\
& \text { the pin to the coolant, } H / \theta L^{2} T \\
T= & \text { the average temperature of the fue } 1 \text { pin, } T \\
T_{0}= & \text { the coolant temperature, } T .
\end{aligned}
$$

The heat transfer from the pin can be written in equivalent volumetric terms as

$$
Q_{v}=\pi b^{2} H_{v}\left(T-T_{0}\right) \Delta x
$$

where

$b=$ the radius of the unit cell, L

$H_{v}=$ a volumetric neat dissipation coefficient, $\mathrm{H} / \theta^{3} \mathrm{~L}^{3}$.

Since the heat transferred is the same, Equations (1-8) and (1-9) are set equal and likè terms are cancelled. After some rearrangement,

$$
H_{v}=\frac{2 a h}{b^{2}} .
$$

The void fraction of the unit cell is defined as

$$
B=\frac{\pi b^{2} \Delta x-\pi a^{2} \Delta x}{\pi b^{2} \Delta x}=\frac{b^{2}-a^{2}}{b^{2}} .
$$


Rearranging Equation (1-11) and substituting in Equation (1-10), the volumetric heat transfer coefficient is defined as

$$
H_{v}=\frac{2(1-B) h}{a} \text {. }
$$

Equation (1-9) may be rewritten in terms of a heat dissipation admittance for use later in the heat transfer network,

$$
Q_{V}=Y_{H}\left(T-T_{0}\right)
$$

where

$$
\begin{aligned}
Y_{H} & =\text { the heat dissipation admittance, } H / \theta T, \\
& =H_{v} S_{\text {node }} \Delta x \\
S_{\text {node }} & =\text { the cross-sectional area of a node, } L^{2} .
\end{aligned}
$$

Substituting from Equation (1-12), Equation (1-14) may be written as

$$
Y_{H}=\frac{2(1-B) h S_{\text {node }} \Delta x}{a} \text {. }
$$

The heat transfer coefficient for natural convection was determined from McAdams' equation for liquids heated outside single horizontal tubes, (16)

$$
\frac{h D}{k}=0.525 \quad\left[\left(\frac{D_{\rho}^{3}{ }^{2} \beta g(\Delta t)}{\mu^{2}}\right)\left(\frac{C_{p} \mu}{k}\right)\right]^{0.25}
$$

where

$$
\begin{aligned}
D & =\text { pin diameter, } L \\
k & =\text { coolant thermal conductivity, } H / \theta L T \\
\rho & =\text { coolant density, } M / L^{3} \\
B & =\text { thermal coefficient of expansion of the coolant, } I / T \\
g & =\text { acceleration of gravity, } L / \theta^{2} \\
\Delta t & =\text { temperature difference, } T \\
\mu & =\text { absolute viscosity of the coolant, M/L } \theta \\
C_{p} & =\text { specific heat of the coolant, H/MT. }
\end{aligned}
$$


Stoever $(16)$ has evaluated Equation (1-16) for various liquids and gases, and has presented the results as a base heat transfer coefficient, which is a function of the temperature difference between the tube surface and the coolant. These results are plotted as straight lines on log-log plots and can be represented by the equation

$$
h_{0}=B(|\Delta t|)^{A}
$$

where

$$
\begin{aligned}
h_{0}= & \text { the base heat transfer coefficient, } H / \theta^{2}{ }^{2} T \\
A= & \text { a constant representing the slope of the straight line } \\
& \text { on a log-log plot of } h_{0} v s \Delta t, \\
B= & \text { a constant representing the } y \text {-intercept of the straight } \\
& \text { line on the log-log plot of } h_{0} v \Delta \Delta t .
\end{aligned}
$$

For liquids, the base coefficient of Equation (1-17) is multiplied by temperature and diameter correction factors to give the heat transfer coefficient for a specific film temperature and tube size,

$$
h=h_{0} F_{t} F_{d}
$$

where

$$
\begin{aligned}
& F_{t}=\text { the temperature correction factor } \\
& F_{d}=\text { the diameter correction factor. }
\end{aligned}
$$

These factors are also presented in Reference 16. The temperature correction factor is a function of the film temperature as defined by

$$
F_{t}=f\left(T_{f}\right)
$$

and

$$
T_{f} \cong 1 / 2\left(T_{s}+T_{c}\right)
$$


where

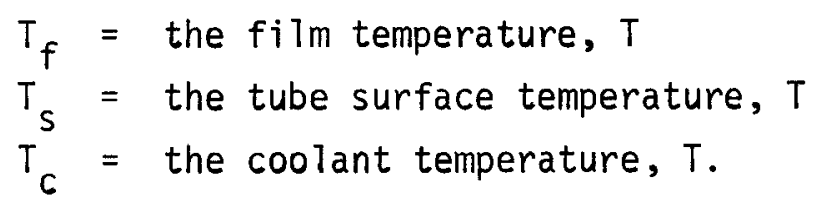

The diameter correction factor is a function of the tube diameter as defined by

$$
F_{d}=f(d)
$$

where

$\mathrm{d}=$ the tube diameter, $\mathrm{L}$.

Equivalent forms of Equations (1-17) through (1-21) are programmed into the model to provide the correct heat transfer coefficient during the iterative computation of the temperatures in the cask.

Unfortunately, one of the fluids not included on Stoever's charts was Dowtherm-A. The following procedure was used to place a line on the log-log plot to represent Dowtherm-A as a first approximation. Using a correlation from Reference 2 and Dowtherm properties at $350^{\circ} \mathrm{F}$, the heat transfer coefficient was obtained from

$$
h=57.4 \Delta t^{1 / 3} . \quad \text { (Reference 2) }
$$

Assuming a value of $\Delta t$, $h$ was determined. Using the proper diameter correction factor, and assuming that a temperature correction factor for water at $350^{\circ} \mathrm{F}$ would be a reasonable approximation, a value of the base coefficient was determined from Equation $(1-18)$. This value of $h_{0}$ was then marked on the $\log -\log$ plot at the $\Delta t$ selected, and a line passing through this point was drawn parallel to the other lines on the plot. This line was then used for Dowtherm-A. Also, a constant average temperature correction factor of 1.0 was used throughout the study. 


\subsection{Heat Conduction and Apparent Thermal Conductivity}

The fuel assemblies in the casks were considered to be porous bodies. The apparent thermal conductivity for a porous body may be determined from the llaxwe11 equation $(16)$

$$
k_{a}=k_{s}\left[\frac{\left.k_{p}\right) B}{1-\left(1-\alpha \frac{k_{s}}{1+(\alpha-1) B}\right.}\right]
$$

where

$$
\begin{aligned}
k_{a}= & \text { the apparent thermal conductivity of the fuel assembly, } \\
& H / \theta L T, \\
k_{S}= & \text { the thermal conductivity of the solid material or fuel, } \\
& H / \theta L T, \\
k_{p}= & \text { the thermal conductivity of the material in the pores, } \\
& H / \theta L T, \\
\alpha= & \frac{3 k_{s}}{2 k_{s}+k_{p} .}
\end{aligned}
$$

For a coolant-filled fuel assembly, $k_{p}$ would be the thermal conductivity of the coolant. 


\section{CASK SIMULATION MODELS FOR CALCULATION OF RATE OF COOLANT LOSS}

In the opening paragraphs of this Appendix it was pointed out that the "coolant loss rate" models evolved from so-called "no-loss-of-coolant" models. The "no-loss-of-coolant" label was applied very early in the study when the primary function of the models was to determine conditions in the casks after an accident and fire, if the primary coolant was not lost. The label was applied as a logical reference to a model whose primary function was the opposite of that of the "loss-of-coolant" models.

The no-loss-of-coolant models were originally developed to determine conditions in the casks following an accident in which the casks lost their solar shields, lost the water in their outer jackets, were subjected to a 0.5 -hour petroleum fire at $1475^{\circ} \mathrm{F}$, but did not lose any primary coolant. It was also assumed that the pressure relief systems were inoperable. The objective was to determine the new, higher steady-state temperatures that would be reached. The new steady-state condition in the AMCO cask presented no problem since its primary coolant is Dowtherm-A, a coolant with a vapor pressure about equal to atmospheric pressure at its new higher steady-state temperature. However, the LWR cask considered (the conceptual cask in this early stage of the study) used water as a coolant, consequently its internal pressure reached an intolerably high level.

In the early stages of the study, it was assumed that the casks lost their primary coolant instantaneously at impact and were subjected to a petroleum fire at $1475^{\circ} \mathrm{F}$. This led to the development of the "loss-ofcoolant" models. However, it was difficult to conceive of an accident situation severe enough to cause a breach in the primary coolant containment, since these casks are extremely well-designed. Also, results from various experimental programs, including 30-foot drop tests, puncture tests, etc., in which cask models were used, indicated that the chances of a cask containment being breached in this manner would be extremely small. It seemed reasonable to assume, however, that any access to the primary coolant which had been included as part of the cask design, such as pressure relief passages and valves, fill passages and valves, etc., would have the potential for allowing coolant to escape. Since the function of 
the pressure relief valve is to automatically respond to changes in the coolant-filled cask cavity, it seemed reasonable to assume that this access to the coolant would be the most likely candidate for a breach-causing failure. It was assumed that this valve could be jarred into a partially open position at impact, or it could fail to reseat after performing its function during normal operating conditions. Also, as an upper limit on postulated damage, it was assumed that the valve could be sheared off entirely. This assumption, however, does not mean that the valve's shearing off is considered at all likely. On the contrary, the pressure relief valve is a wel1-designed and proven component of the IF-300 cask, and is also we11protected in the IF-300 design. Breaches of this type would result in gradual rather than instantaneous loss of coolant. Consequently, the "noloss-of-coolant" models were modified to determine the rate at which the coolant would be lost from a breach.

There are two possible mechanisms for the loss of primary coolant from a cask. These two mechanisms depend upon the final orientation of the cask after the accident. At impact, if the tiedowns fail, the cask may become separated from the rail car and come to rest in one of four positions:

1. On end with the breach up (damaged pressure relief valve),

2. On end with the breach down,

3. On its side with the breach up, and

4. On its side with the breach down.

If the tiedowns do not fail at impact, the cask will remain in its original orientation on the rail car, i.e., on its side as in positions 3 and 4 above. The first mechanism for coolant loss depends on the cask being oriented in either positions 2 or 4 . In these positions, the coolant may leak out under the driving force of its own liquid head and the static pressure in the cask. The second mechanism for coolant loss depends on the cask being oriented in positions 1 and 3 . In these positions the height of the coolant column would not be a driving force, but the coolant would be driven from the cask by its static pressure anc by vaporization as it absorbs the decay heat from the fuel. 
At impact, when a breach might be opened in a cask, the temperatures in the cask would be the steady-state temperatures determined from the preaccident models. For the IF-300, the temperatures of the fuel, coolant inside the fuel cans, fuel cans, and coolant outside the fuel cans at this time were $361^{\circ} \mathrm{F}, 360^{\circ} \mathrm{F}, 350^{\circ} \mathrm{F}$ and $333^{\circ} \mathrm{F}$, respectively. An average of the water temperatures is $347^{\circ} \mathrm{F}$, with a corresponding vapor pressure of 130 psia. This pressure is aimost 9 times atmospheric pressure, therefore this cask was treated as a pressure vessel. In the AMCO cask, the temperatures of the fuel, coolant inside the fuel cans, fuel cans, and coolant outside the fuel cans at impact were $383^{\circ} \mathrm{F}, 380^{\circ} \mathrm{F}, 364^{\circ} \mathrm{F}$ and $343^{\circ} \mathrm{F}$, respectively. An average of the Dowtherm-A temperatures is about $360^{\circ} \mathrm{F}$, with a corresponding saturation pressure of about $2.0 \mathrm{psia}$. This means that the Dowtherm is subcooled since the saturation pressure is well below atmospheric pressure. It is not likely that the pressure in the cask would be less than that of the surroundings.

\subsection{Rate of Coolant Loss From the IF-300}

The coolant loss rate model developed for the IF-300 is based on energy and mass balances on the cask, and on an energy balance on the breach. The main driving force causing the coolant to flow from the cask through the breach is the buildup of static pressure in the cask cavity. This pressure buildup is partly due to that portion of the decay heat from the fuel stored in the liquid and vapor phases of the coolant during the transient, and partly due to the choked flow in the breach. The breach down version of this model is developed in Section 2.1.1, and the breach up version in Section 2.1.2.

\subsubsection{Coolant Loss From the Cask While in a Breach Down Position}

A MIMIC listing of the breach down version of the coolant loss rate model of the IF-300 is presented in Figure 2-3.

\subsubsection{Energy Balance on the Breach}

An energy balance on the breach, in terms of a unit mass of coolant flowing, yields the First Law of Thermodynamics for a steady flow process 


$$
\begin{gathered}
d E=J \delta Q-\delta W \\
J d e+d\left(\frac{U^{2}}{2 g_{c}}\right)+\frac{g}{g_{C}} d Z+d(p v)=J \delta Q-\delta W
\end{gathered}
$$

where

$d E=$ the change in the total energy of the fluid, $\frac{L-F}{M}$

$\delta Q=$ the increment of heat added to the fluid, $\frac{H}{M}$

$\delta W=$ the increment of work done by the fluid, $\frac{L-F}{M}$

de $=$ the change in the internal energy of the fluid, $\frac{H}{M}$

$U=$ the velocity of the fluid, $\frac{L}{\theta}$

$g_{c}=$ the gravitational constant, $\frac{M L}{F_{\theta}^{2}}$

$g=$ the local acceleration of gravity, $\frac{L}{\theta^{2}}$

$d z=$ the change in the height of the fluid, $L$

$d\left(\frac{U^{2}}{2 g_{C}}\right)=$ the change in the kinetic energy of the fluid, $\frac{L-F}{M}$

$d(p v)=$ the change in the flow work of the fluid, $\frac{L-F}{M}$

$p=$ the static pressure of the fluid, $\frac{F}{L^{2}}$

$v=$ the specific volume of the fluid, $\frac{L^{3}}{M}$

$J=$ the mechanical equivalent of heat, $\frac{L-F}{H}$.

By definition

$$
J d e=J d h-p d v .
$$

Using Equation (2-3), and assuming that

$$
\delta W=0,
$$

Equation (2-2) may be changed to 


$$
J d h-p d v+d\left(\frac{u^{2}}{2 g_{C}}\right)+\frac{g}{g_{C}} d z+p d v+v d p=J \delta Q-\delta W
$$

or $\quad J d h+d\left(\frac{u^{2}}{2 g_{c}}\right)+\frac{g}{g_{c}} d z+v d p=J \delta Q$.

An energy balance on the unit mass of fluid, using a frame of reference moving with the fluid, yields the first Law for a non-flow process,

$$
J \mathrm{de}=J \delta Q_{T}-\mathrm{pdv}
$$

where

$$
\begin{aligned}
p d v= & \text { the total compression effects } \\
J_{\delta Q_{T}=} & \text { the total thermal effects from all sources, including } \\
& \text { friction, etc. }
\end{aligned}
$$

The total thermal effects may be expressed as

$$
J \delta Q_{T}=J \delta Q+J \delta F
$$

where

$\delta \mathrm{F}=$ the heat added due to friction

$\delta Q=$ the heat added from all other sources other than friction.

Combining Equations $(2-6)$ and (2-7) gives

$$
J d e=J \delta Q+J \delta F-p d v .
$$

Substituting from Equation (2-3) and cancelling like terms, Equation (2-8) may be written as

$$
J d h=J \delta Q+J \delta F .
$$


Finally, substituting from Equation (2-9) into (2-5) gives the mechanical energy balance

$$
d\left(\frac{u^{2}}{2 g_{C}}\right)+\frac{g}{g_{C}} d z+v d p=-J \delta F .
$$

The maximum rate of loss and the minimum time required to empty the cask would occur if it is assumed that the flow of fluid from the breach is isentropic, i.e.,

$$
J \delta F=0
$$

Using the condition defined by Equation (2-11), the energy balance $(2-10)$ reduces to

$$
d\left(\frac{u^{2}}{2 g_{C}}\right)+\frac{g}{g_{C}} d z+v d p=0 .
$$

Since $g=g_{c}$ under normal conditions, Equation (2-12) may be rearranged to yield

$$
d\left(\frac{u^{2}}{2 g_{C}}\right)=-d z-v d p
$$

or, in terms of the density rather than the specific volume,

$$
d\left(\frac{u^{2}}{2 g_{c}}\right)=-d z-\frac{d p}{\rho_{w}}
$$

where $\rho_{W}=$ the density of the fluid, $\frac{M}{L^{3}}$.

Integrating from the inside of the cask to the breach exit, assuming that the density of the fluid flowing is the same as that inside the cask, gives 


$$
\begin{aligned}
\int_{u_{i}}^{U_{0}} d\left(\frac{u^{2}}{2 g_{c}}\right) & =-\int_{Z_{w}}^{0} d z-\frac{1}{\rho_{w}} \int_{p}^{P_{A T M}} d p \\
\frac{u_{0}^{2}-u_{i}^{2}}{2 g_{c}} & =z_{w}+\frac{P-P_{A T M}}{\rho_{w}} \\
& =z_{w}+z_{p}
\end{aligned}
$$

where

$$
\begin{aligned}
Z_{p}= & \frac{P-P_{A T M}}{\rho_{W}} \\
= & \text { the height or head of fluid of density } \rho_{W} \text { equivalent } \\
& \text { to the difference between the static pressure in the } \\
& \text { cask and that at the exit of the breach, } L \text { (the units } \\
& \text { of } Z_{p} \text { are actually } \frac{L-F}{M} \text {, but since } g=g_{C} \text {, the density } \\
& \text { is equivalent to a specific weight in units of } \frac{F}{L^{3}}, \text { i.e., } \\
& \left.\gamma=\rho \frac{g}{g_{C}}\right) \\
Z_{W}= & \text { the height of the coolant column, } L \\
P= & \text { the static pressure inside the cask, } \frac{M}{L^{3}} \\
P_{A T M}= & \text { the static pressure at the breach exit (atmospheric } \\
& \text { pressure), } \frac{F}{L^{2}} \\
\rho_{W}= & \text { the density of the liquid coolant in the cask, } \frac{M}{L^{3}} .
\end{aligned}
$$

The height of the liquid coolant column is

$$
z_{w}=\frac{M_{w}}{\rho_{w} A_{C A S K}}
$$


where

$$
\begin{aligned}
M_{W} & =\text { the mass of the liquid coolant in the cask, } M \\
A_{\text {CASK }} & =\text { the cross-sectional area of the free space in the cask, } L^{2} .
\end{aligned}
$$

The cross-sectional area of the free space in the cask is determined from initial conditions and the equation

$$
A_{\text {CASK }}=\frac{M_{w i}}{\rho_{w} Z_{i}}
$$

where

$$
\begin{aligned}
& M_{w i}=\text { the initial mass of the coolant in the cask, M } \\
& z_{i}=\text { the initial height of the coolant column, L. }
\end{aligned}
$$

Setting

$$
z=z_{w}+z_{p}
$$

and assuming that the fluid velocity inside the cask is

$$
U_{i} \cong 0,
$$

then Equation (2-16) may be expressed as

$$
u_{0}=\sqrt{2 g_{C} z}
$$

The mass velocity of the coolant leaving the cask is defined by

$$
G=\rho_{W} U_{0}
$$


A set of charts has been developed by Moody ${ }^{9}$ ) to provide a convenient method for evaluating the maximum rate of loss of steam or water from a pressurized vessel that suffers a break in its containment. The maximum rate of loss of either the vapor or the liquid from the breach is governed by a thermodynamically defined critical or maximum mass flow rate based on isentropic flow of the fluid from the breach. A chart is presented in Reference 9 , and as Figure 2-1, that relates the critical or maximum mass flow rate of steam and water to the stagnation enthalpy and pressure.

\subsubsection{Rate of Coolant Loss From the Breach and Mass Balance on the Cask}

When the cask is in a breach down position, saturated liquid would flow through the breach. The maximum mass velocity of this liquid would be obtained from the Moody chart as a function of the static or stagnation pressure in the cask

$$
G_{\text {MAXF }}=f(P)
$$

where

$G_{\text {MAXF }}=$ the maximum mass velocity of the saturated

If $G$ is greater than $G_{\text {MAXF }}$, the flow of liquid (two-phase) through the breach is choked and the maximum rate at which fluid can flow from the breach is $G_{\text {MAXF }}$. Therefore, it is convenient to define a mass velocity $G_{\text {OUT }}$, based on both $G$ and $G_{\text {MAXF. }}$.

$$
\begin{array}{ll}
G_{\text {OUT }}=G & \text { when } G \leq G_{\text {MAXF }} \\
G_{\text {OUT }}=G_{\text {MAXF }} & \text { when } G>G_{\text {MAXF }} .
\end{array}
$$




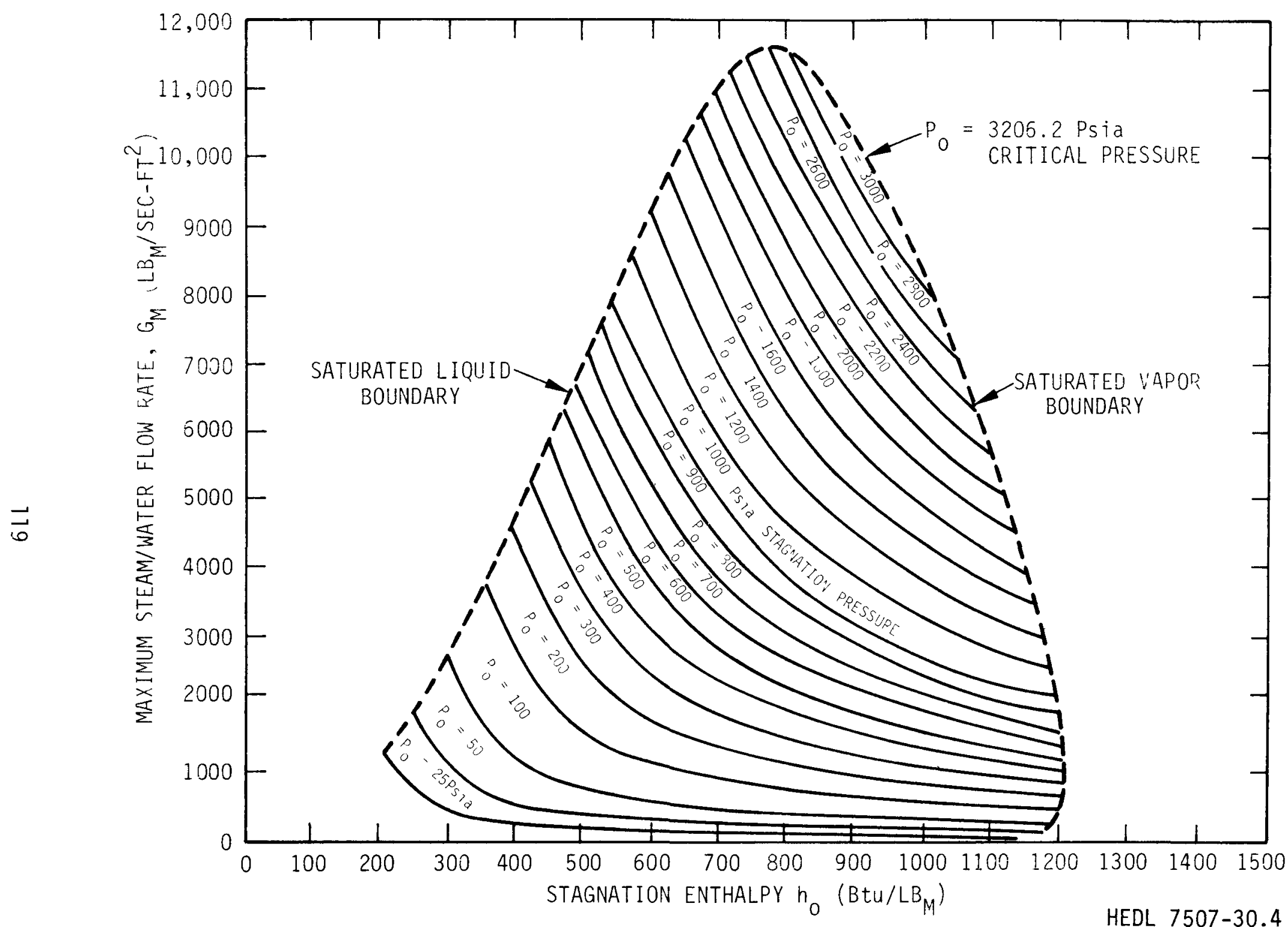

FIGURE 2-1. Maximum Steam/Water Flow Rate and Local Stagnation Properties (Reference 9) 
One of the functions available in the MIMIC simulation program is one which chooses the smallest of six values. This function, as applied to the situation defined by Equations $(2-27)$ and $(2-28)$, would be written as

$$
G_{\text {OUT }}=\operatorname{MIN}\left(G, G_{\text {MAXF }}\right)
$$

where

$\begin{aligned} G_{\text {OUT }}= & \text { the actual mass velocity of the fluid flowing from the breach, } \\ & M / \theta L^{2} .\end{aligned}$ The rate of change of the mass of coolant in the cask is

$$
\frac{d I_{x}}{d t}=-G_{\text {OUT }} A_{G A P}
$$

where

$$
A_{G A P}=\text { the flow area of the breach, } L^{2} .
$$

As coolant flows from the breach, a space filled with coolant vapor in equilibrium with the liquid is created above the liquid. The total mass of coolant remaining in the cask as a mixture of liquid and vapor is

where

$$
M_{x}=-\int_{0}^{t} G_{O U T} A_{G A P} d t+M_{W i}
$$

$$
\begin{aligned}
M_{x}= & \text { the total mass of coolant remaining in the cask as a mixture of } \\
& \text { liquid and vapor, } M \\
M_{W i}= & \text { the initial mass of coolant in the cask, } M .
\end{aligned}
$$

A mass balance on the cask may be written as

$$
M_{\text {wo }}=M_{w i}-M_{x}
$$


Where

$$
M_{1: C}=\text { the mass of coolant lost, } M \text {. }
$$

The volumes occupied by the liquid and vapor portions of the coolant remaining in the cask are unknown. However, since the sum of the volumes must be equal to the total free cask volume, $V_{\text {CASK }}$, the average density of the liquid-vapor mixture may be defined by

$$
\rho_{x}=\frac{M_{x}}{V_{\text {CASK }}}
$$

where

$$
V_{\text {CASK }}=Z_{i} A_{\text {CASK }}
$$

Assuming that the mixture consists of saturated vapor and saturated liquid, the densities of each may be obtained as functions of the saturation temperature of the mixture,

$$
\begin{aligned}
& \rho_{W}=f\left(T_{W}\right) \\
& \rho_{G}=f\left(T_{W}\right)
\end{aligned}
$$

where

$$
\begin{aligned}
& \rho_{G}=\text { the density of the vapor, } M / L^{3} \\
& T_{W}=\text { the saturation temperature of the mixture, } T \text {. }
\end{aligned}
$$

Using the concept of quality of a mixture of vapor and liquid, the specific volume of the mixture may be written as

$$
v_{x}=x v_{G}+(1-x) v_{W}
$$

or

$$
\frac{1}{\rho_{x}}=\frac{x}{\rho_{G}}+\frac{(1-x)}{\rho_{W}}
$$


Solving Equation (2-38) for the quality gives

$$
x=\frac{\left(\frac{1}{\rho_{X}}\right)-\left(\frac{1}{\rho_{W}}\right)}{\left(\frac{1}{\rho_{G}}\right)-\left(\frac{1}{\rho_{W}}\right)}
$$

where

$$
x=\text { the quality of the mixture, } \frac{M \text { (VAPOR })}{M(M I X T U R E)} \text {. }
$$

The masses of the liquid and vapor portions of the mixture may be obtained using the total mass of the mixture and the quality in the following equations,

$$
M_{V}=x M_{x}
$$

and

$$
M_{W}=(1-x) M_{x}
$$

where

$M_{V}=$ the mass of the vapor in the mixture, $M$.

When all of the liquid coolant is expelled from the cask, a substantial amount of vapor remains. At this point,

$$
x=1
$$

and

$$
M_{V}=M_{X}
$$

As shown in Section 2.1.1.1, Equation (2-16), the forces driving the coolant from the cask are the potential energy of the liquid column and the pressure in the cask. The pressure in the cask during most of the transient is due to the vapor portion of the mixture and is defined by the ideal gas law 


$$
\frac{P=M_{V} R\left(T_{W}+460\right)}{V \cdot 10 L_{V}}
$$

where

$$
\begin{aligned}
R & =\text { the gas constant, } L-F /(M O L E)(T) \\
V & =\text { the volume of the vapor, } L^{3} \\
M L_{V} & =\text { the molecular weight of the vapor, } M / M O L E .
\end{aligned}
$$

Initially, if the coolant expands at a faster rate than it is lost from the cask, a vapor portion is not formed immediately. In this short initial period, the pressure is obtained from the Steam Tables ${ }^{(27)}$ and expressed as the relation

$$
P=f\left(T_{W}\right)
$$

A11 integrations in the MIMIC simulation program are performed by a centralized integration routine. The particular algorithm employed is a fourth order variable step Runge-Kutta method. Because of this step-wise procedure, the values of some variables may slightly "overshoot" their actual physical limits when these limits are reached during the course of the simulation. If this is not prevented, the realism of the simulation might be jeopardized. This is true of the coolant mixture quality, $x$, and the height $Z_{w}$ of the column of liquid. The quality must be within the limits 0 and 1 , and the height can only vary from $z_{j}$ to 0 . During the course of the present simulation, these variables slightly overshot these limits and produced erroneous results. This was remedied by using a MIMIC "1imiter" function (see Figure 2-2). Using this limiter function, the quality may be represented by

$$
X=\text { LIM (QUALTY, 0., 1.) }
$$


where

$$
\text { QUALTY }=\frac{\left(\frac{1}{\rho_{X}}\right)-\left(\frac{1}{\rho_{W}}\right)}{\left(\frac{1}{\rho_{G}}\right)-\left(\frac{1}{\rho_{W}}\right)} \text {. }
$$

This application of the limiter function assures that

$$
\begin{aligned}
& X=0, \text { when QUALTY }<0 \\
& X=\text { QUALTY, when } 0 \leq \text { QUALTY } \leq 1 \\
& X=1, \text { when QUALTY }>1 .
\end{aligned}
$$

Similarly, the height of the liquid column may be represented by

$$
Z W A=\operatorname{LIM}(Z W B, 0 ., 14 .)
$$

where $\quad Z W A=Z_{W A}=$ an interim value of the height $Z_{W}$,

and

$$
Z W B=Z_{W B}=\frac{M_{W}}{\rho_{W} A_{C A S K}} .
$$

This application of the limiter assures that

$$
\begin{array}{llrl}
Z_{W A}=0 . & \text { when } & Z_{W B}<0 . \\
Z_{W A}=Z_{W B}=\frac{W_{W}}{\rho_{W} A_{\text {CASK }}} \text { when } & 0 . \leq Z_{W B} \leq 14 . \\
Z_{W A}=14 . & \text { when } & Z_{W B}>14 .
\end{array}
$$

The height $Z_{W}$ is actually the interim value $Z_{W A}$ and could be obtained from Equation (2-46). However, a MIMIC "implicit function" must be used to avoid a closed algebraic loop. This algebraic loop is formed because, as will be shown later, $Z_{W}$ is used to determine the quality $x$, which is then used to determine $M_{W}$, which in turn is used to determine $Z_{W \mid}$ from Equation (2-47). The implicit function evaluates Equation (2-46) using an iterative process. The action of the implicit function is to prevent the independent variable, time, from being incremented until the difference between the last 
calculated value of $Z_{W}$ and the previously calculated value is less than or equal to $5 \times 10^{-6}$ times the previously calculated value. The MIMIC implicit function statement for $Z_{W}$ is

$$
Z W=\operatorname{IMP}(Z W, Z W A) .
$$

An initial value of $Z_{W}$ is given on a data card corresponding to the parameter (PAR) card naming $Z_{W}$ (see the model listing of Figure 2-3). See Reference 3 for a detailed discussion of the implicit function.

The nature of the coolant loss rate models dictates that the flow of computations within the models must proceed along one of several alternate paths, with the choice of path depending upon the values attained by certain key variables. The MIMIC simulation program accommodates this branching process through the use of logical control variables generated by the combination of a function switch, or one or more logical functions, and the constants TRUE and FALSE. One of the uses of a logical variable is to provide control over the execution of individual MIMIC statements or operations. If a statement or operation is flagged by a logical variable name, then the statement will be evaluated when the control variable has a "true" value and not when the control variable has a "false" value. This means that the logical control variable can be used to select, under program control, which of several statements should be evaluated. This use of a logical control variable generated by a function switch or logical function serves the same function as the conditional transfer statements in FORTRAN, i.e., the IF and computed GO TO statements. Specific uses of logical control variables to achieve branching within the coolant loss rate models will be presented in the remainder of this sub-section for the breach down version, and in Section 2.1.2 for the breach up version. See Reference 3 for a detailed explanation of the use of logical control variables in MIMIC programming. A summary of the functions available in MIMIC, including the logical control variables, is presented in Figure 2-2.

It was assumed that, at the time a breach is opened in the cask containment, the cavity contains only liquid coolant, i.e., no vapor space 
LIST CF MIMIC FUACTIONS

MIYIC

YIYIC

MIMIC

MIYIC

YI IIC

4 I 4 IC

MIYIC

YIYIC

MIMIC

$4 I M I C$

MI IIC

YI IIC

YIYIC

MIMIC

MIYIC

YIYIC

MIYIC

MIYIC

MIYIC

MIYIC

MIYIC

MIYIC

MIYIC

MIYIC

MIUIC

YIYIC

YIM IC

YIY IC

MINIC

MIMIC

YIYIC

YIYIC

MIMIC

MIYIC

YIYIC

MIYIC

MIYIC

MIYIC

MIYIC

MIYIC

MIYIC

MI IIC

YIMIC

YIYIC

MIYIC

YIYIC

MIMIC

MIYIC

MIYIC

MIM IC

MIYIC

YIMIC

MIYIC

FIGURE 2-2. Summary of Rules and Functions of MIMIC, A Continuous System Simulation Program (Page 1 of 4 ) 


\begin{tabular}{|c|c|c|c|c|}
\hline FIJNCTICH & $C r O=$ & INFU1 (5) & DUTPUT/REMARKS & YIYIC \\
\hline & & & & YIY IC \\
\hline AYSCLUT: VALUE & $A \cap S$ & $A$ & $?=A B S(A)$ & $\begin{array}{l}\text { YIYIC } \\
\text { MIYIC }\end{array}$ \\
\hline APCOSINF & $\triangle C S$ & $\Delta$ & $P=A R C O S(A)$ & YIYIC \\
\hline$\triangle O T I T I C \cdot$ & $\begin{array}{l}\text { ADT } \\
\text { SUM }\end{array}$ & $A, B(, C, O, E, F)$ & $R=A+3(+C(+)(+C(+F)))$ & $\begin{array}{l}Y I M I C \\
Y I M I C \\
Y I M I C\end{array}$ \\
\hline$\therefore N]$ & $A N 3$ & $A, B(, C, O, E, F)$ & $\begin{array}{l}R=T R U E \text { IF A ANL B(ETC.)TRUE. } \\
R=F A L S F \text { OTHERWISE }\end{array}$ & $\begin{array}{l}\text { YIYIC } \\
\text { YIYIC } \\
\text { YIYIC } \\
\text { YIYIC }\end{array}$ \\
\hline ARCSINE & $A S N$ & $A$ & $R=A R C S I N(A)$ & $\begin{array}{l}4 I Y I C \\
Y I Y I C\end{array}$ \\
\hline ARCTANGENT & $A T N$ & $A, B$ & $\begin{aligned} P= & A R C T A N(A / 3) \text {. } 3 \text { IS ASSUMEJ } \\
& +1 . \text { IF NOT SPECIFIER. }\end{aligned}$ & $\begin{array}{l}Y I Y I C \\
M I Y I C \\
M I Y I C\end{array}$ \\
\hline $\begin{array}{l}\text { NAME FUNSTION } \\
\text { (CONSTANTI }\end{array}$ & CFN & $A$ & $\begin{array}{l}R=N A Y \text { OF } A R Z A Y . \\
A=N O . \text { OF PAIRS CF FOINTS. }\end{array}$ & $\begin{array}{l}\text { YIYIC } \\
\text { YIYIC } \\
\text { YIMIC }\end{array}$ \\
\hline LOGISAL COMFL EMEN!T & $\begin{array}{l}\text { COM } \\
\text { NCT }\end{array}$ & $A$ & $\begin{array}{l}\gtrless=T R U E \text { IF A FALSE. } \\
Q=F A L S E \text { IF A TRUE. }\end{array}$ & $\begin{array}{l}4 I Y I C \\
4 I M I C \\
Y I 4 I C\end{array}$ \\
\hline NAMF CCNCTANTS & CCN & $A, R, C, D, E, F$ & ENTERS CONSTANT AAMES & $\begin{array}{l}\text { MIYIC } \\
\text { YIYIC }\end{array}$ \\
\hline COSINE & $\cos$ & $\triangle(R A D S)$ & $P=\cos (A)$ & $\begin{array}{l}4 I Y I C \\
\text { YIMIC }\end{array}$ \\
\hline HYFEDAOLIC COSINF & $\mathrm{CSH}$ & $A$ & $\alpha=\cos H(A)$ & $\begin{array}{l}\text { MIYIC } \\
\text { MIYIC }\end{array}$ \\
\hline DEP I VATIVE & OER & $A, 3, C$ & $\begin{array}{l}R=C B / J A \\
R=C \text { AT } T=0 .\end{array}$ & $\begin{array}{l}\text { YIYIC } \\
M I M I C \\
M I M I C\end{array}$ \\
\hline I IVITE & OIV & $A, 9$ & $R=A / 3$ & $\begin{array}{l}\text { MIMIC } \\
\text { MIYIC }\end{array}$ \\
\hline TEAD SFACE & DSF & $A, B, C$ & 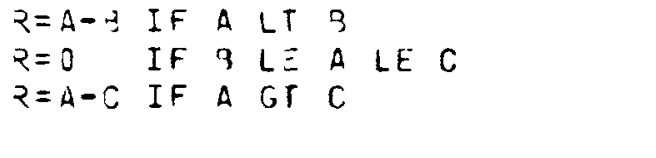 & $\begin{array}{l}M I Y I C \\
Y I Y I C \\
M I M I C \\
Y I Y I C\end{array}$ \\
\hline FNJ OF PPCSRAY & END & & & $\begin{array}{l}Y I Y I C \\
M I Y I C\end{array}$ \\
\hline$=X$ XLUSIVE OP & $\equiv O R$ & $A, 9$ & $\begin{array}{l}R=\text { TRUE IF A TRUE AND } 3 \text { FALSE } \\
\text { OF IF A FALSE AND } 3 \text { TRUE. } \\
R=\text { FALSE OTHERWISE }\end{array}$ & $\begin{array}{l}\text { YIMIC } \\
\text { YIMIC } \\
\text { YIYIC } \\
\text { YIMIC }\end{array}$ \\
\hline I TUALITY & EQL & $A$ & $Q=A$ & $\begin{array}{l}4 I Y I C \\
Y I Y I C\end{array}$ \\
\hline EXFONENTIATION & $E \times P$ & $A(, 9)$ & $\begin{array}{l}\mathrm{Q}=3 * * A . E=2.781 \ldots \text { IS ASSUMEO } \\
\text { FOP UNSPECIFIED } \mathrm{E} .\end{array}$ & $\begin{array}{l}4 I 4 I C \\
4 I Y I C \\
4 I 4 I C\end{array}$ \\
\hline GO TC NEXT CASE & FIN & $A, B$ & GO TO NEXT CASE IF A GE 3 & $\begin{array}{l}\text { YIYIC } \\
\text { YIMIC }\end{array}$ \\
\hline TRUNCATICN & $F I X$ & $A$ & $R=$ INTEGER PART OF $A$ & $\begin{array}{l}\text { MIMIC } \\
\text { MIMIC }\end{array}$ \\
\hline$F L I P-F L O F$ & FLF & $A, B, C$ & $\begin{array}{l}R=\text { TRUE IF (A TRUE) OR } \\
\text { (B FALSE AND R TRUE). } \\
R=F A L S E \text { OTHERWISE. } \\
\text { AT T=0. } Q=C .\end{array}$ & $\begin{array}{l}\text { MIYIC } \\
\text { YIYIC } \\
\text { YIMIC } \\
\text { YIMIC } \\
\text { YIYIC }\end{array}$ \\
\hline
\end{tabular}

FIGURE 2-2. Summary of Rules and Functions of MIMIC, A Continuous System Simulation Program (Page 2 of 4) 


\begin{tabular}{|c|c|c|c|c|}
\hline FUNCTICN: SWITC,H & FSW & $A, B, C, D$ & $\begin{array}{llllll}r=B & \text { IF } & A & L T & J \\
R=C & \text { IF } & A & E O & 0 . \\
R=0 & \text { IF } & A & G T & 0 .\end{array}$ & $\begin{array}{l}M I Y I C \\
\text { YIYIC } \\
M I M I C \\
\text { YIYIC }\end{array}$ \\
\hline $\begin{array}{l}\text { FIRST CODER } \\
\text { TRANSFER FUNCTION }\end{array}$ & F TR & $A, B$ & $\begin{aligned} R= & \text { INVERSE LAPLACE TRANSFORY } \\
& (1 /(B S+1)) A(S)\end{aligned}$ & $\begin{array}{l}\text { YIYIC } \\
\text { YIYIC } \\
\text { YIYIC }\end{array}$ \\
\hline FUNCTICN & FUN & 1,3 & $2=A(3)$ & YIYIC \\
\hline FUNCTICN & FUN & $A, P, C$ & $R=A(?, C)$ & $\begin{array}{l}\text { MIMIC } \\
\text { YIMIC }\end{array}$ \\
\hline$H E A \eta=P$ & $\begin{array}{l}\text { HCR } \\
\text { HEA }\end{array}$ & $A, 3, C, D, \vec{c}, F$ & PRINT HEADING NAMES & $\begin{array}{l}\text { YIYIC } \\
\text { YIYIC } \\
\text { MIYIC }\end{array}$ \\
\hline I MPLICIT FUNCTIOA & $I \backsim P$ & $A, B(A)$ & $P=A$ WHERE $A-B(A)=0$ & $\begin{array}{l}\text { YIMIC } \\
\text { MIMIC }\end{array}$ \\
\hline INTEGRATION & $I \wedge T$ & $A, B(, C, 9)$ & $\begin{array}{llll}\text { P }=3+\text { INT (A) } & & \\
\text { C FALSE } & \text { J FALSE } & \text { CPERATE } \\
C \text { FALSE } & \text { D TRUE } & \text { HOLO } \\
C \text { TRUE } & \text { J FALSE } & \text { RESET } \\
C \text { TPUF } & \text { D TRUE } & \text { CPERATE }\end{array}$ & $\begin{array}{l}M I M I C \\
Y I Y I C \\
Y I M I C \\
M I Y I C \\
M I Y I C \\
M I Y I C\end{array}$ \\
\hline INCLUSIJE OR & $I O R$ & $A, B(, C, D, E, F)$ & $\begin{array}{l}२=T R U E \text { IF A OR B(ETC.)TRUE. } \\
\text { Q FALSE OTHERWISE }\end{array}$ & $\begin{array}{l}Y I Y I C \\
M I Y I C \\
Y I Y I C\end{array}$ \\
\hline LIMITFR & $\operatorname{LIY}$ & $A, B, C$ & $\begin{array}{llllllll}\gtrless=? & \text { IF } & A & L T & 3 \\
२=A & \text { IF } & B & \text { LE } & A & \text { LE } & C \\
R=C & \text { IF } & A & G T & C & & \end{array}$ & $\begin{array}{l}M I Y I C \\
M I Y I C \\
Y I Y I C \\
Y I Y I C\end{array}$ \\
\hline LIYIT LVTE FEATORS & LIN & $A, 3, C, 0$ & $\begin{array}{l}\text { P= JERIVATIVE OF B, WHERE } \\
\text { IS THE LIMITED INTEGRATOR } \\
\text { OUTPUTIC LE } 3 \text { LE DI.A IS THE } \\
\text { JEFIUATIVE OF UNLIMITED } 3 \text {. }\end{array}$ & $\begin{array}{l}4 I 4 I C \\
M I M I C \\
4 I \backsim I C \\
4 I 4 I C \\
Y I Y I C\end{array}$ \\
\hline LOTARITHN & LOG & $\Delta(.3)$ & $\begin{array}{l}2=\text { LOG }(A), B A S E \text { Q (ASSUMED } \\
\text { AS ABOVE IF ACT SPECIFIEO) }\end{array}$ & $\begin{array}{l}\text { YI YIC } \\
\text { MIMIC } \\
M I Y I C\end{array}$ \\
\hline LOGICAL SWITCH & LSW & $A, B, C$ & $\begin{array}{l}R=Q \text { IF A TRUE. } \\
P=C \text { IF A FALSE. }\end{array}$ & $\begin{array}{l}\text { YIYIC } \\
\text { YIYIC } \\
\text { YIYIC }\end{array}$ \\
\hline NULTIFLY AND $\triangle .70$ & $* A D$ & $A, 3, C(, D, E, F)$ & $R=A * G+C \quad(* D(+E(* F)))$ & $\begin{array}{l}\text { YIMIC } \\
\text { YIYIC }\end{array}$ \\
\hline $4 \Delta \times I Y \cup 4$ & $\Delta x$ & $A, B(,[], F, F)$, & $2=A \times(A, B \quad(, C(, D(, E(, F))))$ & $\begin{array}{l}\text { YIYIC } \\
\text { MIMIC }\end{array}$ \\
\hline MINI YUM & $Y I N$ & $A, B(, C, D, E, F)$ & $R=Y I \wedge(A, 3(, C(, D(, E(, F))))$ & $\begin{array}{l}\text { MIYIC } \\
\text { MIYIC }\end{array}$ \\
\hline 407ULO & MOD & $A, B$ & $R=A \quad$ YOUULO $\quad 3=A-(A / B) * B$ & $\begin{array}{l}\text { MIYIC } \\
\text { MIYIC }\end{array}$ \\
\hline $\begin{array}{l}\text { MONOSTABLE } \\
\text { MULTIVIBRATOR }\end{array}$ & MMV & $A, B$ & $\begin{array}{l}\text { R SET TRUE WHEN A TRUE AND } \\
\text { STAYS TRUE FOR B SECONOS } \\
\text { AFTER A GOES FALSE. } \\
\text { R=A AT T=0. }\end{array}$ & $\begin{array}{l}M I \nsucc I C \\
Y I Y I C \\
Y I Y I C \\
M I M I C \\
4 I Y I C\end{array}$ \\
\hline YULLTIFLICATICN & YFY & $A, B(, C, O, E, F)$ & $R=A * 3 \quad(* C(* D(* E(* F)))$ & MIYIC \\
\hline$N=G A T I C N$ & $N \in G$ & A & $R=-A$ & $\begin{array}{l}\text { YIYIC } \\
\text { YIYIC }\end{array}$ \\
\hline FRIAT OUTFUT & $\begin{array}{l}\text { OUT } \\
\text { PRI }\end{array}$ & $A, 3, C, D, E, F$ & $\begin{array}{l}\text { PRINT A, } 3, C, J, E, F \text { EVERY } \\
\text { OT UNITS OF T. }\end{array}$ & $\begin{array}{l}\text { MIYIC } \\
\text { MIYIC }\end{array}$ \\
\hline
\end{tabular}

FIGURE 2-2. Summary of Rules and Functions of MIMIC, A Continuous System Simulation Program (Page 3 of 4 ) 


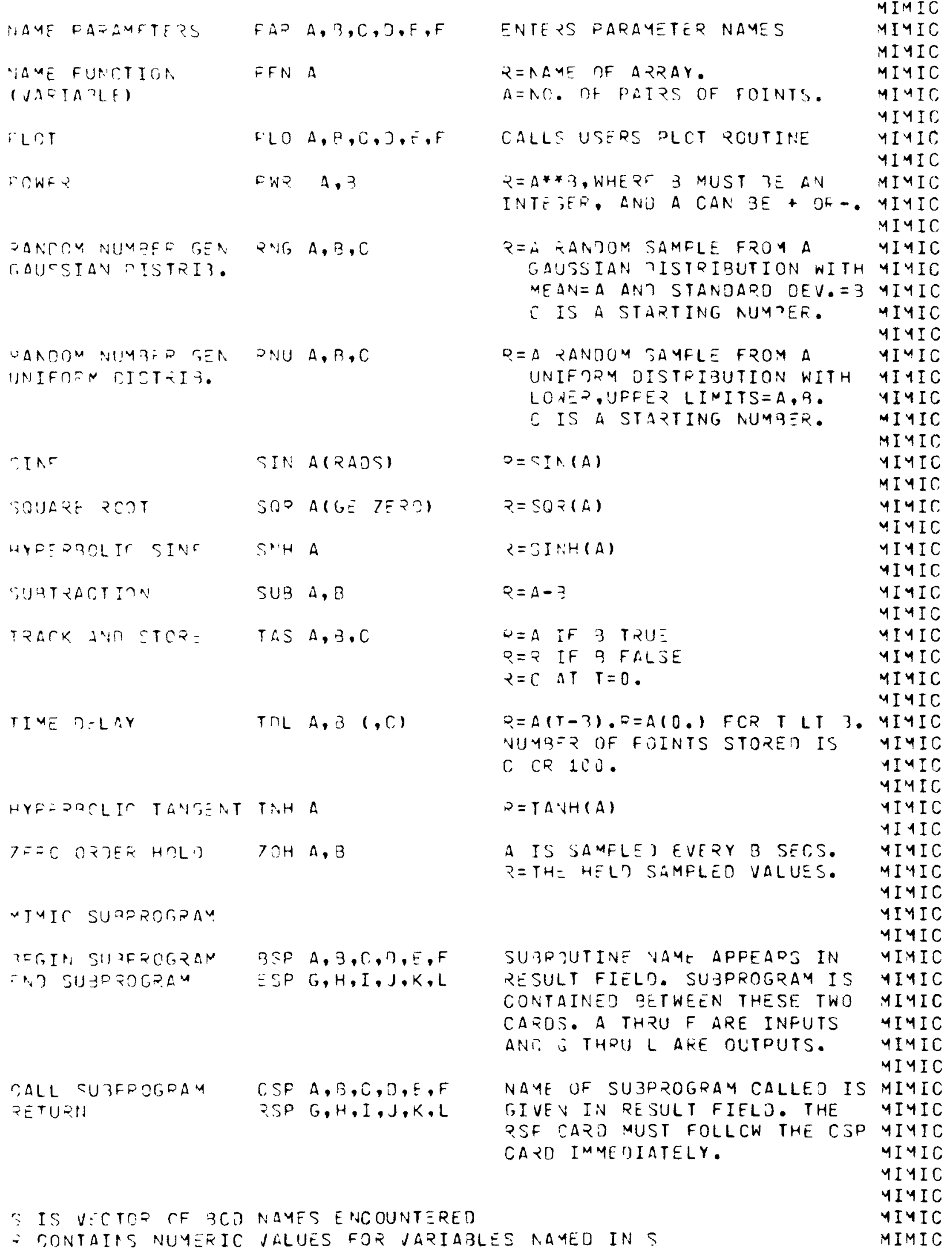

FIGURE 2-2. Summary of Rules and Functions of MIMIC, A Continuous System Simulation Program (Page 4 of 4 ) 
exists, and

$$
z_{w}=z_{i}
$$

where $z_{i}=$ the initial height of the liquid column.

This condition also prevails initially in the transient if the coolant expands at a sufficient rate to keep the cask full of liquid, even though some of the coolant is lost from the cask. When enough coolant is lost, a vapor space is formed above the liquid and

$$
0 \leq Z_{W}<Z_{i}
$$

When both liquid and vapor are present, the quality of the mixture is in the range

$$
0<x<1
$$

When only liquid is present,

$$
x=0 \text {, }
$$

and, when only vapor is present,

$$
x=1 \text {. }
$$

Since Equations (2-51), (2-52) and (2-53) define three conditions which cannot exist at the same time, the quality must be determined from different expressions.

The local control variables that select the proper computational flow paths for the conditions defined by Equations (2-49) and (2-50) are XOFF and $X O N$, respectively. XOFF is defined by the function switch expression

$$
X O F F=F S W(Z W-Z I, F A L S E, T R U E, T R U E)
$$

where $Z W=Z_{W}$

$$
Z I=Z_{i}
$$


and XON is defined by the logical complement of XOFF

$$
X O N=N O T(X O F F)
$$

When Equation (2-49) is true, XOFF is true and XON is false. If XOFF is true, any expression flagged by this logical control variable is evaluated. There are two equations in the model that define the quality $x$. One of these is Equation (2-52), which is flagged by XOFF to give

$$
\text { XOFF } \quad X=0
$$

where $x=x$.

The second expression is Equation $(2-44)$, which is flagged by XON to give

$$
\text { XON } \quad X=\text { LIM(QUALTY, } 0 ., 1 .)
$$

where QUALTY is defined by Equation (2-45). When Equation (2-50) is true, XOFF is false and XON is true, and Equation (2-57) is evaluated instead of Equation $(2-56)$.

The pressure in the cask is also determined by two different equations, depending upon whether or not vapor is present. If vapor is present, the pressure is defined by Equation (2-42). If the cask contains only 1iquid, the pressure is defined by Equation (2-43). To select the appropriate equation, it was convenient to establish the function switch expression

$$
\text { XPAND }=\text { FSW }(X, \text { TRUE, ,TRUE, , TALSE })
$$

and its logical complement

$$
\text { CNTRCT }=\text { NOT }(X P A N D)
$$

When the cask is filled with liquid, Equation $(2-56)$ applies and XPAND is true and CNTRCT is false. Therefore, Equation (2-43) is flagged by XPAND to give 


$$
\text { XPAND } \quad P=\text { FUN }(P S A T, T W)
$$

where the equation is written as a MIMIC function expression (see Figure 2-2 and Reference 3 ). If the cask is filled with a mixture of liquid and vapor, or with vapor only, Equation (2-57) applies to make XPAND false and CNTRCT true. In this case, Equation (2-42) is flagged by CNTRCT to give

$$
\text { CNTRCT } P=M V * R *(T W+460 .) /(M O L V * V * 744 .)
$$

where the equation is expressed in FORTRAN notation as programmed for MIMIC.

While liquid coolant is in the cask, the vapor volume is defined by

$$
V=\frac{M_{v}}{\rho_{G}},
$$

but when all of the liquid is expelled from the cask, the vapor volume is defined by

$$
V=V_{\text {CASK }} \cdot
$$

The following equations are valid only while liquid coolant is in the cask:

$$
\begin{aligned}
Z p & =\frac{P-P_{\text {ATM }}}{\rho_{W}} \\
G & =\rho_{W} \sqrt{2 g_{C} Z} \\
G_{\text {OUT }} & =\operatorname{MIN}\left(G, G_{M A X F}\right) \\
V & =\frac{M}{\rho_{G}} .
\end{aligned}
$$


Corresponding equations, which are valid only when all of the liquid coolant has been expelled from the cask, are written for the vapor in the cask and for vapor flowing through the breach:

$$
Z p=\frac{\left(P-P_{A T M}\right)}{\rho_{G}}
$$

$$
G=\rho_{G} \sqrt{2 g C^{Z}}
$$

$$
G_{\text {OUT }}=\operatorname{MIN}\left(G, G_{\text {MAXG }}\right)
$$

and

$$
V=V_{\text {CASK }} \text {, }
$$

where

$$
G_{M A X G}=f(P)
$$

is the maximum mass velocity of the saturated vapor flowing through the breach. Since these two sets of equations cannot be used at the same time, the computation flow must be divided into two branching paths at this point.

As discussed earlier, control of computation flow in a model programmed in the MIMIC simulation language is accomplished by the use of logical control variables. The model presented here was constructed to determine conditions in and the rate of coolant loss from the cask both before and after the liquid coolant has been expelled, i.e.,

$$
M_{W}>0
$$


and

$$
M_{w} \leq 0
$$

respectively. The logical control variables representing the conditions defined by Equations (2-68) and (2-69) are CLNT and EMPTY, respectively. CLNT is defined by the function switch expression

$$
\text { CLNT }=\text { FSW (MW, FALSE, FALSE, TRUE })
$$

and EMPTY by the logical complement of CLNT

$$
\text { EMPTY }=\text { NOT }(C L N T) \text {. }
$$

When Equation (2-68) is true, CLNT is true and EMPTY is false. Conversely, when Equation (2-69) is true, CLNT is false and EMPTY is true. These control variables are to be used only when the cask contains either a mixture of liquid and vapor, or vapor only. Therefore, they must, in turn, be flagged by the logical control variable CNTRCT defined by Equation (2-59):

$$
\begin{array}{ll}
\text { CNTRCT } & \text { CLNT }=\text { FSW (MW, FALSE, FALSE, TRUE) } \\
\text { CNTRCT } & \text { EIIPTY }=\text { NOT (CLNT) }
\end{array}
$$

The use of all the logical control variables presented in this section is illustrated in the MIMIC listing of the model in Figure 2-3. 


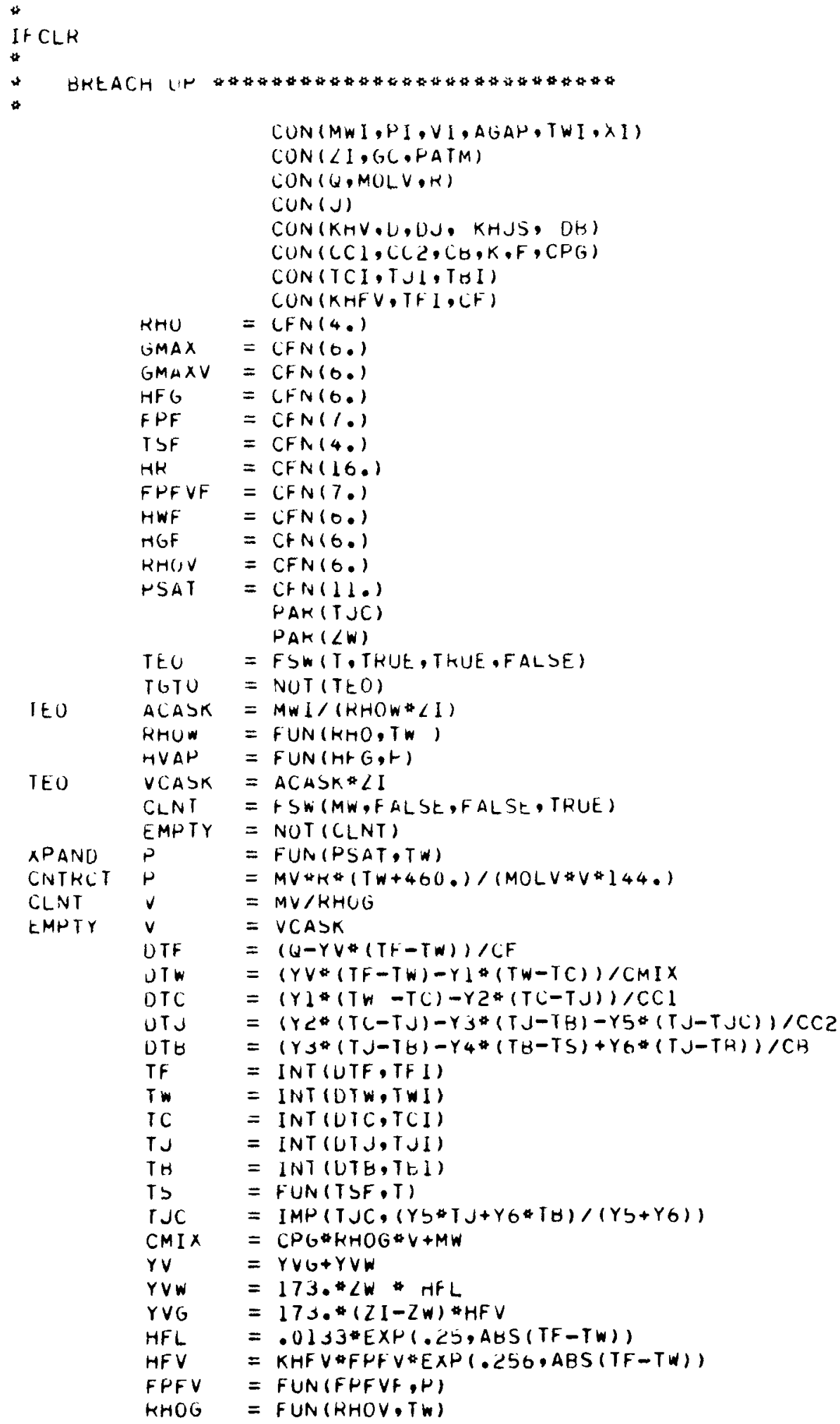

FIGURE 2-3. MIMIC Listing of the Coolant Loss Rate Model of the IF-300 (Breach Down Version) (Page 1 of 3 ) 


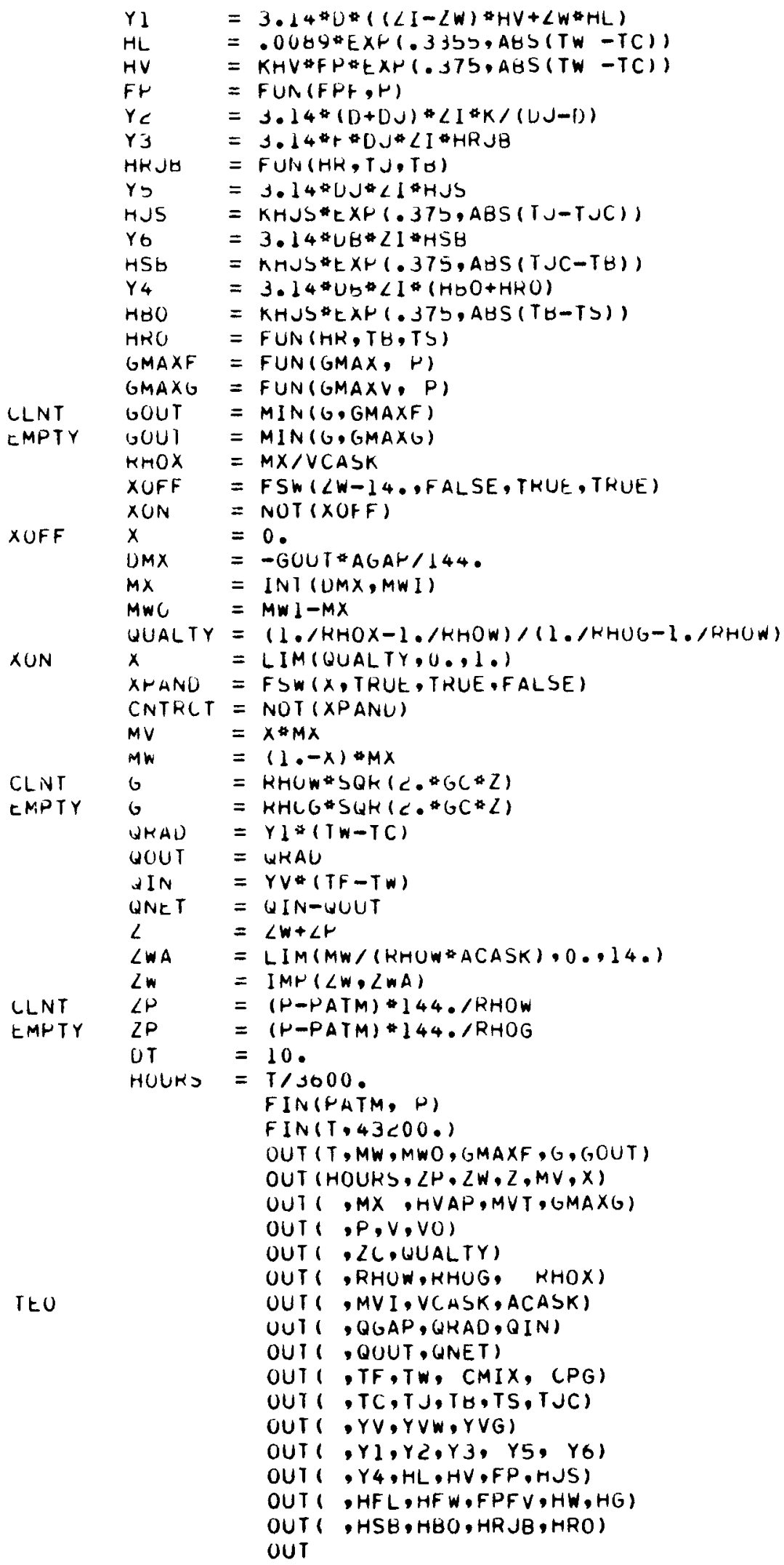

FIGURE 2-3. MIMIC Listing of the Coolant Loss Rate Model of the IF-300 (Breach Lown Version) (Page 2 of 3 ) 


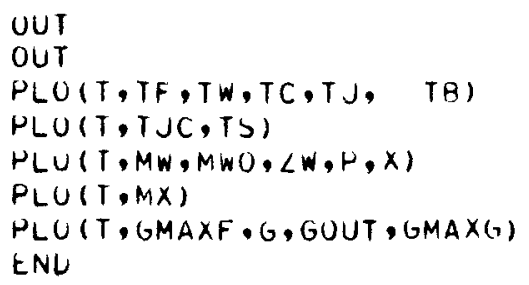

FIGURE 2-3. MIMIC Listing of the Coolant Loss Rate Model of the IF-300 (Breach Down Version) (Page 3 of 3 ) 


\subsubsection{Energy Balances on the Cask and the Determination of Temperatures}

The densities of the liquid and vapor phases of the coolant in the cask, and the pressure in the cask, are functions of the coolant temperature. The maximum mass velocities of the liquid and vapor flowing from the breach are, in turn, functions of the pressure. The coolant temperature was obtained as a function of time, along with some other temperatures in the cask, from a set of energy balances on various regions of the cask.

An idealized representation of the cask, shown as an electrical analog in Figure 2-4, was used to construct a heat transfer sub-model. This idealized mode 1 of the IF- 300 consists of four regions represented by seven nodes, for which energy balances were written to form the sub-model. The four regions are:

1. The fuel assemblies as one homogeneous region, represented by one node,

2. The coolant in the cask cavity, represented by one node,

3. The cask wall (steel and uranium), represented by two nodes, one at the inner surface and one at the outer surface, and

4. The outer water jacket, represented by two nodes, one for the vapor in the jacket and one representing the outer corrugated shell.

The seventh node represents the temperature of the surroundings (including the 0.5-hour fire).

Heat enters the cask as decay heat generated in the fuel and as heat input from the fire. Heat leaves the cask by natural convection and radiation from the cask surface to the surroundings, and in the coolant lost from the cask. Solar heat input was neglected since the time required to empty the cask was expected to be small enough that the effects of solar heating would be negligible.

Initial temperatures in the cask are obtained from the temberature distribution established by the steady-state pre-accident model. 


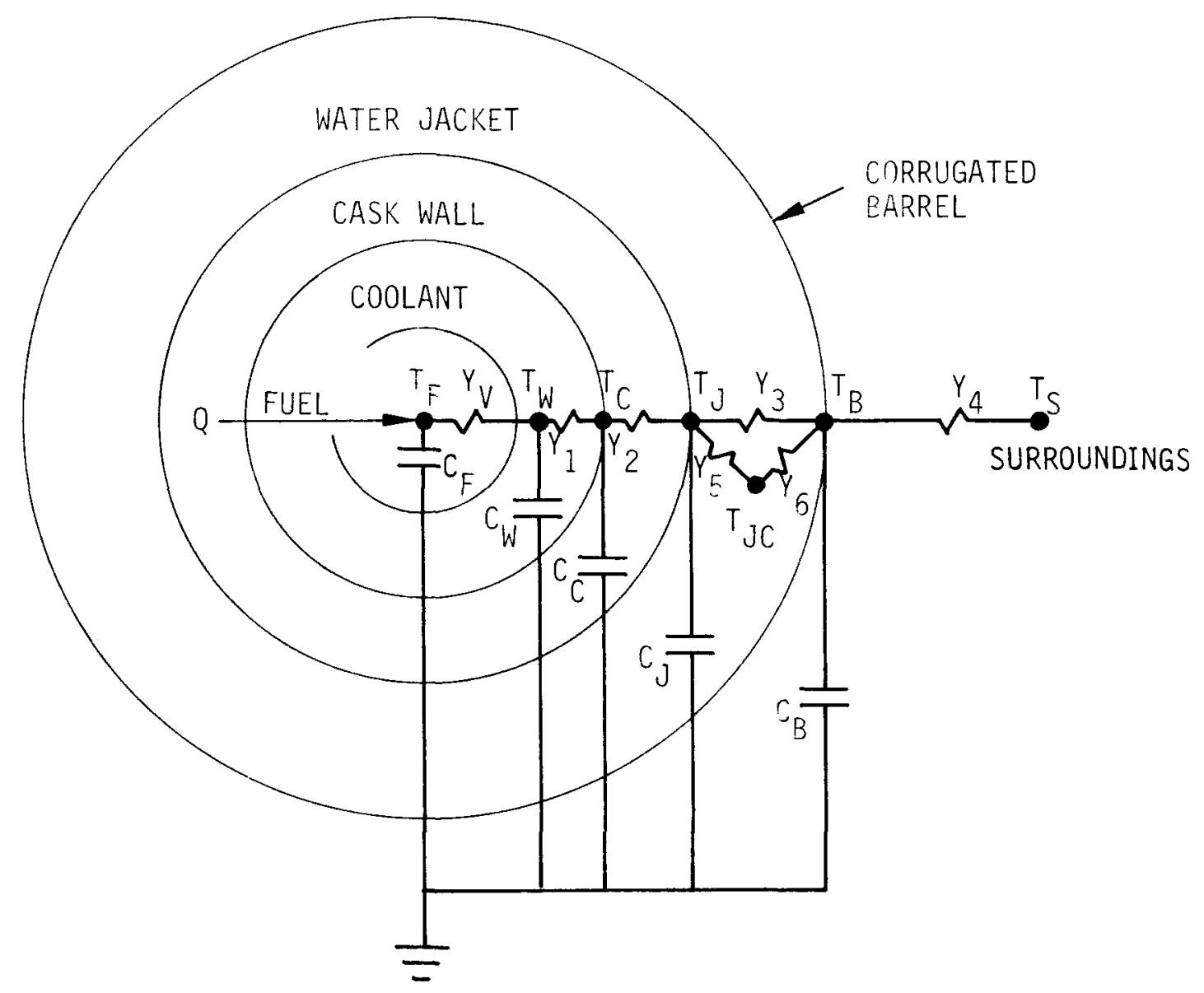

HEDL $7507-30.5$

FIGURE 2-4. Idealized Representation of the IF-300 as an Electrical Analog 
The temperature of the surroundings is a function of time. During the fire, it is the temperature of the fire and, when the fire burns out, it becomes the ambient temperature of the surroundings. This variation of the temperature is programmed into the model as a time-varying step function.

It is convenient to define and discuss in general, beforehand, some of the terms to be used in the energy balance equations.

\subsection{Thermal Admittances, Heat Transfer Coefficients, Thermal}

\section{Capacities and Heat Generation}

Since the purpose of the coolant loss rate model was to provide estimates of the time required for the cask to lose its coolant, no attempt was made to determine detailed temperature distributions in the cask. Consequent$1 y$, all but one of the thermal admittances in the heat balance equations are for heat transfer by convection, radiation, or combined convection and radfation. The only heat conduction admittance is for the cask wall.

A11 convection admittances, except the one representing heat transfer from the fuel to the coolant, are defined by the general equation

$$
Y_{h}=h A
$$

where

$$
\begin{aligned}
Y_{h}= & \text { the admittance for heat transfer by convection, } H / \theta T, \\
h= & \text { the coefficient for heat transfer by natural convection, } \\
& H / \theta L^{2} T, \\
A= & \text { the surface area for heat transfer, } L^{2} .
\end{aligned}
$$

Heat transfer by natural convection from the fuel to the coolant is represented by a volumetric heat dissipation admittance which has been defined by Equation (1-15) in Section 1.2, i.e.

$$
Y_{v}=\frac{2(1-B) h S_{\text {node }} \Delta x}{a}
$$


where

$$
\begin{aligned}
Y_{v}= & \text { the volumetric heat dissipation admittance, } H / \theta T, \\
B= & \text { the void fraction of the fuel region, } \\
h= & \text { the coefficient for heat transfer by natural convection from } \\
& \text { a fuel pin to the coolant, } H / \theta L^{2} T, \\
a= & \text { the fuel pin radius, } L, \\
S_{\text {node }=} & \text { the cross-sectional area of the fuel node (in this case, } S_{\text {node }} \\
& \text { is the area of the entire fuel region), } L^{2}, \\
\Delta x= & \text { the incremental length of the fuel region (in this case, } \\
& \Delta x \text { represents the lengths of the respective vapor-and- } \\
& \text { liquid-cooled portions of the fuel), L. }
\end{aligned}
$$

Heat conduction through the cask wall, from the cask cavity to the inside surface of the outer water jacket, was represented by the admittance

$$
Y_{2}=\frac{k A_{\text {WALL }}}{\Delta r}
$$

where

$$
\begin{aligned}
& Y_{2}=\text { the admittance for heat transfer by conduction, } H / \theta T \text {, } \\
& k=\text { the thermal conductivity of the cask wall, H/ } \mathrm{LLT} \text {, } \\
& \Delta r=\text { the thickness of the cask wall, L } \\
& A_{W A L L}=\text { the mean area of the cask wall, } L^{2} \text {. }
\end{aligned}
$$

The thickness of the cask wall is

$$
\Delta r=1 / 2\left(D_{j}-D\right)
$$

where

$$
\begin{aligned}
& D_{J}=\text { the diameter of the wall at the outer surface, } L, \\
& D=\text { the diameter of the cask cavity, } L \text {. }
\end{aligned}
$$


The mean area of the cask wall is defined by

$$
A_{W A L L}=\frac{\pi}{2}\left(D+D_{j}\right) Z_{i}
$$

where

$z_{i}=$ the length of the cask wall, L.

Admittances representing heat transfer by radiation are defined by the general equation

$$
Y_{r}=h_{r} A F
$$

where

$Y_{r}=$ the admittance for heat transfer by radiation, $H / \theta T$,

$h_{r}=$ the coefficient for heat transfer by radiation, $H /{ }^{2} L^{2} T$,

$A=$ the area of one of the surfaces, $L^{2}$,

$F=$ a combined emissivity and shape factor based on the surface corresponding to $A$.

The coefficient for heat transfer by natural convection from a fuel pin to the coolant was obtained from McAdam's equation ${ }^{(16)}$ for liquids and gases heated outside single horizontal tubes [see Equation (1-16) of Section 1.2]. As discussed earlier in Section 1.2, Stoever ${ }^{(16)}$ has evaluated this equation for several liquids and gases and has presented the results as a base heat transfer coefficient, $h_{0}$, which is a function of the temperature difference between the tube surface and the coolant [see Equation (1-17)].

The base coefficient for the liquid is multiplied by temperature and diameter correction factors to obtain the heat transfer coefficient for a specific film temperature and tube size [see Equation (1-18) of Section 1.2]. For gases, an additional pressure correction factor is required. In general, the heat transfer coefficient for the gas is obtained from the equation 


$$
h=h_{0} F_{t} F_{d} F_{p}
$$

where

$$
\begin{aligned}
& F_{t}=\text { the temperature correction factor } \\
& F_{d}=\text { the diameter correction factor } \\
& F_{p}=\text { the pressure correction factor. }
\end{aligned}
$$

The factors $F_{t}$ and $F_{d}$ are defined by Equations $(1-19),(1-20)$ and $(1-21)$ in Section 1.2. The pressure correction factor $F_{p}$ is a function of the pressure, $P$, in the cask,

$$
F_{p}=f(P)
$$

These factors are tabulated in Reference 16. Only the pressure correction factor was used in the present stage of model development. The other two factors will be used in later stages. The product of the temperature and diameter correction factors would be greater than 1.0 , so not using these factors is conservative since higher fuel temperatures are obtained.

The constants $A$ and $B$ in Equation (1-17) were determined from the $\log -\log$ plots of $h_{0}$ vs $\Delta t$ for water and steam in Reference 16 to give the following equations:

and

$$
\begin{gathered}
h_{F L}=0.0133\left(\left|T_{F}-T_{W}\right|\right)^{0.25} \\
h_{F V}=2.22 \times 10^{-4} F_{P F V}\left(\left|T_{F}-T_{W}\right|\right)^{0.256}
\end{gathered}
$$


where

$h_{F L}=$ the coefficient for heat transfer by natural convection from the fuel to the water in the cask, $B / \mathrm{sec}-f t^{2}-{ }^{\circ} \mathrm{F}$,

$h_{F V}=$ the coefficient for heat transfer by natural convection from the fuel to the steam in the cask, $B / s e c-f t^{2}-{ }^{\circ} \mathrm{F}$,

$T_{F}=$ the fuel temperature, ${ }^{\circ} \mathrm{F}$

$T_{W}=$ the temperature of the steam-water mixture, ${ }^{\circ} \mathrm{F}$,

$F_{P F V}=$ the pressure correction factor applied to the base heat transfer coefficient for steam.

$=f(P)$.

The volumetric heat dissipation admittance consists of a steam portion and a water portion

$$
Y_{V}=Y_{V W}+Y_{V G}
$$

where

$$
\begin{aligned}
Y_{V W}= & \text { the volumetric heat dissipation admittance for the water- } \\
& \text { cooled portion of the fuel, H/OT, } \\
Y_{V G=} & \text { the volumetric heat dissipation admittance for the steam- } \\
& \text { cooled portion of the fuel, } H / \theta T .
\end{aligned}
$$

Using Equation (2-75) and appropriate terms for $S_{\text {node }}$ and $\Delta x$, the following equations may be written:

$$
Y_{V W}=\frac{2(1-B) h_{F L} S_{F U E L} Z_{W}}{a}
$$

and

$$
Y_{V G}=\frac{2(1-B) h_{F V} S_{F U E L}\left(Z_{f}-Z_{W}\right)}{a}
$$


where

$S_{\text {FUEL }}=$ the cross-sectional area of the fuel, $L^{2}$.

After inserting the values of $a, B$ and $S_{F U E L}$, these equations are rewritten as

$$
Y_{V W}=173 z_{W} h_{F L}
$$

and

$$
Y_{V G}=173\left(z_{i}-z_{W}\right) h_{F V}
$$

where $Y_{V W}$ and $Y_{V G}$ are in units of $B / \mathrm{sec}-{ }^{\circ} \mathrm{F}$.

The coefficients for heat transfer by natural convection from the water in the cavity to the inner surface of the cavity, and the coefficients for heat transfer to the steam in the outer jacket, from the surfaces bounding the water jacket, yere obtained by the same procedures used to obtain $h_{F L}$ and $h_{F V}$. These coefficients were obtained from the Colburn-Hougen equation for liquids and gases heated on vertical plates ${ }^{(15)}$ [see Equation (3-3) of Section 3.1.2]. The large diameter surfaces in the cask were assumed to behave the same as vertical plates. Stoever ${ }^{(15)}$ has also evaluated the Colburn-Hougen equation for several liquids and gases and presented the results as a base heat transfer coefficient as a function of the temperature difference between the surface and the coolant. These results are also plotted on log-log plots and may be represented by Equation (1-17).

Using the same procedure described above, the following equations were obtained for the heat transfer coefficients at the inner surface of the cask cavity:

and

$$
\begin{array}{r}
h_{L}=0.0089\left(\left|T_{W}-T_{C}\right|\right)^{0.3355} \\
h_{V}=1.25 \times 10^{-4} F_{P}\left(\left|T_{W}-T_{C}\right|\right)^{0.375}
\end{array}
$$


where

$h_{L}=$ the coefficient for heat transfer by natural convection from the water in the cask to the inner surface of the cask cavity, $B /$ sec $-f t^{2}-{ }^{\circ} \mathrm{F}$,

$h_{V}=$ the coefficient for heat transfer by natural convection from the steam in the cask to the inner surface of the cask cavity, $B / \sec -f t^{2}-{ }^{\circ} \mathrm{F}$,

${ }^{T}{ }_{C}=$ the temperature of the inner surface of the cask cavity, ${ }^{\circ} \mathrm{F}$

$F_{p}=$ the pressure correction factor applied to the base coefficient for steam

$=f(P)$.

Like $Y_{V}$, the admittance for heat transfer by natural convection from the water-steam mixture to the inner surface of the cask cavity consists of a water portion and a steam portion

$$
\begin{gathered}
Y_{1}=Y_{1 V}+Y_{1 L} \\
Y_{1}=\pi D\left(Z_{i}-z_{W}\right) h_{V}+\pi D Z_{W} h_{L} \\
=\pi D\left[\left(z_{i}-z_{W}\right) h_{V}+z_{W} h_{L}\right] .
\end{gathered}
$$

The heat transfer coefficients and admittances for natural convection of steam in the outer jacket are:

$$
\begin{aligned}
& h_{J S}=1.25 \times 10^{-4}\left(\left|T_{J}-T_{J C}\right|\right)^{0.375} \\
& h_{S B}=1.25 \times 10^{-4}\left(\left|T_{J C}-T_{B}\right|\right)^{0.375}
\end{aligned}
$$




$$
\begin{aligned}
& Y_{5}=\pi D_{j} Z_{i} h_{J S} \\
& Y_{6}=\pi D_{B} z_{i} h_{S B}
\end{aligned}
$$

where

$$
\begin{aligned}
h_{J S}= & \text { the coefficient for heat transfer by natural convection from } \\
& \text { the outer surface of the cask wall to the steam in the } \\
& \text { jacket, } B / \mathrm{sec}-\mathrm{ft}^{2}-{ }^{\circ} \mathrm{F}, \\
h_{S B}= & \text { the coefficient for heat transfer by natural convection from } \\
& \text { the steam in the jacket to the inside surface of the } \\
& \text { corrugated barrel, B/sec }-\mathrm{ft}^{2}-{ }^{\circ} \mathrm{F}, \\
Y_{5}= & \text { the admittance corresponding to } h_{J S}, B / s e c-{ }^{\circ} \mathrm{F}, \\
Y_{6}= & \text { the admittance corresponding to } h_{S B}, B / s e c-{ }^{\circ} \mathrm{F}, \\
D_{J}= & \text { the diameter of the outer cask wall, ft, } \\
D_{B}= & \text { the diameter of the corrugated barrel, ft. }
\end{aligned}
$$

The coefficient for heat transfer by radiation between two surfaces is defined by

$$
h_{r}=\frac{\sigma\left(T_{1}^{4}-T_{2}^{4}\right)}{\left(t_{1}-t_{2}\right)}
$$

where

$$
\begin{aligned}
\sigma & =\text { the Stefan-Boltzmann constant, } B / h r-f t^{2}-{ }^{\circ} R^{4}, \\
T_{1} & \text { and } T_{2}=\text { the absolute temperatures of the two surfaces, }{ }^{\circ} R \\
t_{1} \text { and } t_{2} & =\text { the temperatures of the two surfaces, }{ }^{\circ} \mathrm{F} .
\end{aligned}
$$


Stoever $(16)$ has evaluated this equation for temperatures from 0 to $2400^{\circ} \mathrm{F}$ and presented the results in the form of a chart. This chart was programmed into the model as the bivariate function

$$
h_{r}=f\left(t_{1}, t_{2}\right)
$$

with $h_{r}$ in units of $\mathrm{B} / \mathrm{sec}-\mathrm{ft} \mathrm{t}^{2}{ }^{\circ} \mathrm{F}$ and the temperatures in ${ }^{\circ} \mathrm{F}$.

The admittance for heat transfer by radiation across the outer water jacket is derived from Equations (2-79) and (2-101), i.e.,

$$
Y_{3}={ }_{\pi} D_{j} Z_{i} F h_{r j b}
$$

where

$$
h_{r J B}=f\left(T_{J}, T_{B}\right)
$$

and

$$
F=F_{A} F_{\varepsilon}
$$

The shape factor, $F_{A}$, is assumed to be 1.0 , and the emissivity factor is assumed to be

$$
F_{\varepsilon}=\varepsilon_{j} \varepsilon_{B}
$$

where

$$
\begin{aligned}
\varepsilon_{J}= & \text { the emissivity of the outer surface of the cask wall } \\
& \cong 0.8 \\
\varepsilon_{B}= & \text { the emissivity of the corrugated barrel } \\
& \cong 0.8 .
\end{aligned}
$$

Finally, the admittance for heat transfer by combined radiation and natural convection from the outer surface of the corrugated barrel was written as

$$
Y_{4}=\pi D_{B} Z_{i}\left(h_{B O}+h_{r o}\right)
$$


where

$h_{B 0}=$ the coefficient for heat transfer by natural convection to air and steam at the outer barrel surface, B/sec $-\mathrm{ft}^{2}-^{\circ} \mathrm{F}$,

$h_{\text {ro }}=$ the coefficient for heat transfer by radiation form the outer surface of the barrel to the surroundings, $B / \sec -f t^{2}-{ }^{\circ} \mathrm{F}$.

The coefficient $h_{\text {Bo }}$ is defined by the equation

$$
h_{B O}=1.25 \times 10^{-4}\left(\left|T_{B}-T_{S}\right|\right)^{0.375}
$$

and $h_{\text {ro }}$ by the equation

$$
n_{\text {ro }}=f\left(T_{B}, T_{S}\right)
$$

where

$$
T_{S}=\text { the temperature of the surroundings, }{ }^{\circ} \mathrm{F} \text {. }
$$

Thermal capacities are defined by the general equation

$$
C=\rho C_{p} V
$$

where

$$
\begin{aligned}
& C_{P}=\text { the heat capacity of the region material, H/MT, } \\
& \rho=\text { the density of the material, } M / L^{3}, \\
& V=\text { the volume of tre region, } L^{3} .
\end{aligned}
$$

Since the fuel is porous, its volume must be expressed as

$$
V_{F}=(1-B) V_{F R}
$$


where

$V_{F R}=$ the overall volume of the fuel region of length $Z_{i}, L^{3}$.

The thermal capacity of the cask wall was computed as a volumeweighted average of the thermal capacities of steel and uranium.

The thermal capacity of the mixture of water and steam was assumed to be

$$
C_{M I X}=C_{P G} \rho G V+M_{W}
$$

where

$C_{P G}=$ the heat capacity of the steam, H/MT.

The heat generated in the fuel region is the maximum decay heat rate in the cask obtained from Table 1 , converted to $\mathrm{B} / \mathrm{sec}$.

\subsection{Energy Balance on the Fuel}

An energy balance on the fuel region of Figure 2-4 is

$$
C_{F} \frac{d T_{F}}{d t}=Q-Y_{V}\left(T_{F}-T_{W}\right)
$$

where

$C_{F}=$ the thermal capacity of the fuel region, $H / T$

$Q=$ the decay heat generated in the fuel, $\mathrm{H} / \theta$.

\subsection{Energy Balance on the Coolant}

The energy balance on the coolant may be written as

$$
C_{M I X} \frac{d T_{W}}{d t}=Y_{V}\left(T_{F}-T_{W}\right)-Y_{1}\left(T_{W}-T_{C}\right)
$$

\subsection{Energy Balances on the Cask Wall}

The energy balance on the inner half of the cask wall is 


$$
C_{C 7} \frac{d T_{C}}{d t}=Y_{1}\left(T_{W}-T_{C}\right)-Y_{2}\left(T_{C}-T_{J}\right)
$$

where

$$
\begin{aligned}
C_{C l}= & \text { the thermal capacity of the inner half of the cask } \\
& \text { wall, H/T. }
\end{aligned}
$$

The energy balance on the outer half of the cask wall is

$$
C_{C 2} \frac{d T_{J}}{d t}=Y_{2}\left(T_{C}-T_{J}\right)-Y_{3}\left(T_{J}-T_{B}\right)-Y_{5}\left(T_{J}-T_{J C}\right)
$$

where

$$
\begin{aligned}
C_{C 2}= & \text { the thermal capacity of the outer half of the cask } \\
& \text { wall, H/T. }
\end{aligned}
$$

2.1.1.3.5 Energy Balance on the Outer Surface of the Water Jacket

The energy balance on the corrugated barrel or outer surface of the water jacket may be written as

$$
C_{B} \frac{d T_{B}}{d t}=Y_{3}\left(T_{J}-T_{B}-Y_{4}\left(T_{B}-T_{S}\right)+Y_{6}\left(T_{J C}-T_{B}\right)\right.
$$

where

$C_{B}=$ the thermal capacity of the barrel, H/T.

\subsection{Energy Balance on the Steam in the Water Jacket}

The energy balance on the residual steam in the water jacket may be expressed as

$$
0=Y_{5}\left(T_{J}-T_{J C}\right)-Y_{6}\left(T_{J C}-T_{B}\right)
$$

or, in terms of the temperature of the steam,

$$
T_{J C}=\frac{Y_{5} T_{J}+Y_{6} T_{B}}{Y_{5}+Y_{6}} \text {. }
$$


It was assumed that heat storage in the residual vapor is negligible compared to that in the surrounding surfaces and that, for convenience, it could be neglected.

\subsection{Determination of Temperatures From the Energy Balances}

The temperatures of the various regions of the cask model are determined by integrating the energy balance equations, i.e.,

$$
\begin{aligned}
& T_{F}=T_{F i}+\int_{0}^{t} \frac{d T_{F}}{d t} d t \\
& T_{W}=T_{W i}+\int_{0}^{t} \frac{d T_{W}}{d t} d t \\
& T_{C}=T_{C i}+\int_{0}^{t} \frac{d T_{C}}{d t} d t \\
& T_{J}=T_{J i}+\int_{0}^{t} \frac{d T_{J}}{d t} d t \\
& T_{B}=T_{B i}+\int_{0}^{t} \frac{d T_{B}}{d t} d t
\end{aligned}
$$


where $T_{F i}, T_{W i}, T_{C i}, T_{J i}$ and $T_{B i}$ are the initial temperatures.

A11 the simulation models in Sections 2 and 4 include several equations which must be integrated with respect to time. Therefore, a brief discussion of the integrator statement used in MIMIC is appropriate at this time.

All integrations in the MIMIC simulation program are performed by a centralized integration routine. The particular algorithm employed is the fourth order variable step Runge-Kutta method.

The integrator statement is normally used with two inputs, an integrand $A$ and an initial condition $B$. The integrator statement is written as

$$
R=\operatorname{INT}(A, B)
$$

where $R$ is the result of the integration. This statement is the equivalent of

$$
R=B+\int_{0}^{t} A d t
$$

where $t$ is the time. There are three modes of operation for the integrators in MIMIC that can be controlled for each individual integrator. These modes of operation are RESET, OPERATE and HOLD. In RESET, the output of the integrator is set equal to the initial condition argument and no integration takes place. In OPERATE, the integrator is updated by the integration routine. In HOLD, the input to the integrator is removed. These modes are controlled by two additional arguments of the integration statement (see Figure 2-2),

$$
R=\operatorname{INT}(A, B, C, D) \text {. }
$$

The additional arguments $C$ and $D$ are either true or false, and the four possible combinations control the mode of each integrator, as shown in the following table. 


\begin{tabular}{|c|c|c|}
\hline D C & TRUE & FALSE \\
\hline TRUE & OPERATE & HOLD \\
\hline FALSE & RESET & OPERATE \\
\hline
\end{tabular}

If $C$ and $D$ are not specified, as in Equation (2-14), the integrator mode is automatically set at OPERATE. Mode-controlled integration is illustrated later in Section 2.2.2.3.2, where logical control variables are used to control the integrator mode.

The MIMIC integration statements equivalent to Equation (2-119) through (2-123) are

$$
\begin{aligned}
& \text { TF }=\text { INT (DTF, TFI) } \\
& \text { TW }=\text { INT (DTW, TWI) } \\
& \text { TC }=\text { INT (DTC,TCI) } \\
& \text { TJ }=\text { INT (DTJ,TJI) } \\
& \text { TB }=\text { INT (DTB,TBI). }
\end{aligned}
$$

where

$$
D T F=\frac{d T_{F}}{d t}, T F I=T_{F i} \text {, etc. }
$$

The temperature of the vapor in the water jacket is obtained from Equation (2-118). However, a MIMIC "implicit function" must be used to avoid a closed algebraic loop. This algebraic loop is formed because $T_{J C}$ is used to determine $T_{B}$ and $T_{J}$, which are then used in Equation $(2-118)$ to determine $T_{J C}$. The implicit function evaluates Equation (2-118) in an iterative manner. Equation (2-118), written in terms of the equivalent MIMIC implicit function statement, becomes

$$
T J C=\operatorname{IMP}\left(T J C,\left(Y 5^{\star} T J+Y 6^{\star} T B\right) /(Y 5+Y 6)\right)
$$


where an initial or starting value of $T_{J C}$ is entered as an input parameter. An implicit function was also required earlier, in Section 2.1.1.2, to overcome an algebraic loop involving the liquid column height, $Z_{w}$. See Reference 3 for a detailed discussion of the implicit function.

2.1.2 Coolant Loss From the Cask While in a Breach Up Position

When the cask is in a breach up position, only saturated vapor flows through the breach, and the potential energy of the liquid coolant is no longer part of the force driving coolant from the cask. Aside from a few changes required to simulate these new conditions, the coolant loss rate model for the cask in a breach up position is almost the same as the model developed in the previous section for the breach down position.

The changes required to convert the breach down version of the model into the breach up version are:

(1) Since only saturated vapor flows through the breach, Equation $(2-21)$ is changed to

$$
Z=z_{p}
$$

(2) The logical control variable CNTRCT is removed as the control on Equations (2-72) and (2-73), which define the logical control variables CLNT and EMPTY, respectively.

(3) XPAND replaces CLNT as the control variable on Equations (2-18), (2-25) and (2-29), and

(4) CNTRCT replaces EMPTY as the control on Equations (2-64), (2-65) and $(2-66)$.

A MIMIC listing of the breach up version of the coolant loss rate model is presented in Figure 2-5.

\subsection{Rate of Coolant Loss From the AMCO Cask}

Two separate and dissimilar coolant loss rate models were developed for the AMCO cask. The first model, the breach down model, is based on an energy balance relating the isentropic flow of Dowtherm-A through the breach to the potential energy of the coolant column. This model, developed in Section 2.2.1, is presented as a MIMIC listing in Figure 2-6. 


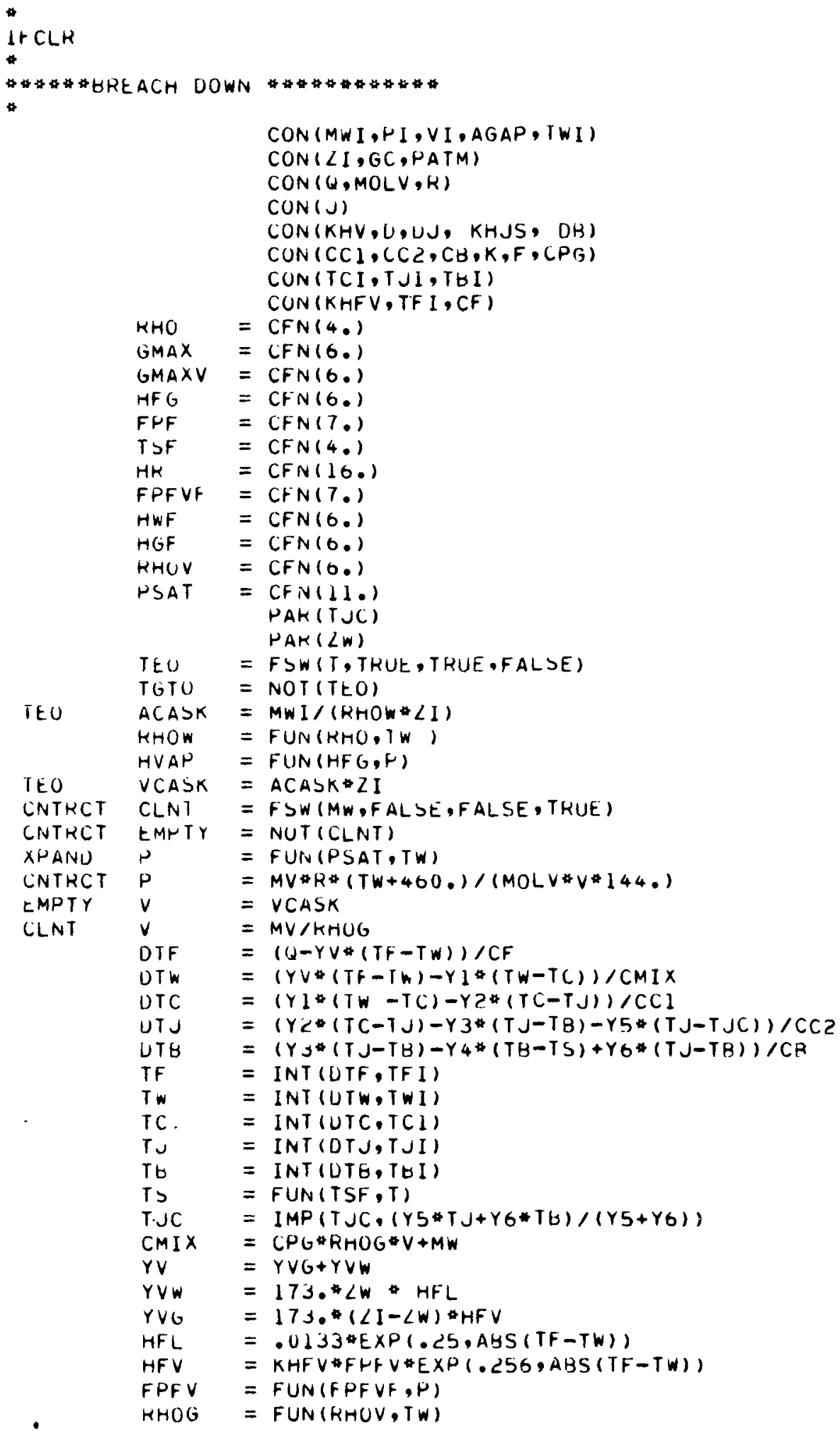

FIGURE 2-5. MIMIC Listing of the Coolant Loss Rate Model of the IF-300 (Breach Up Version) (Page 1 of 3 ) 


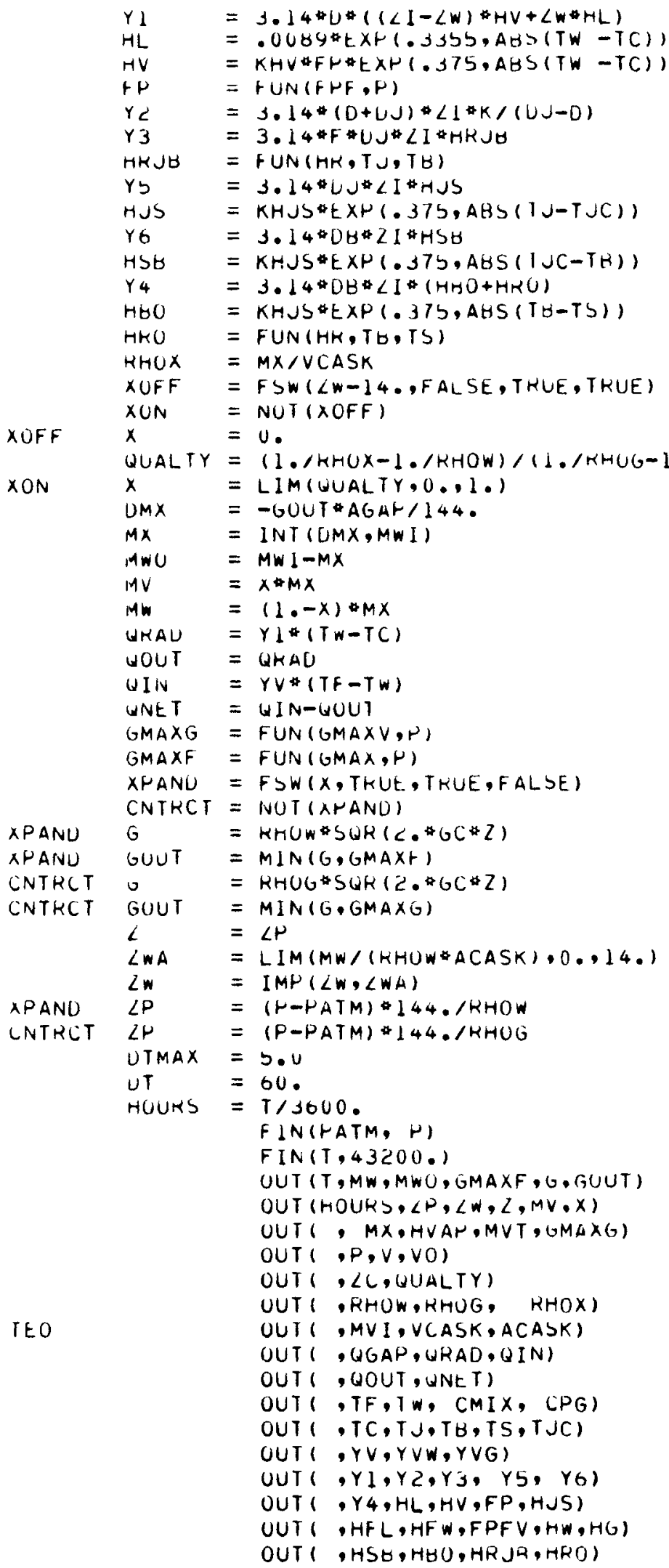

FIGURE 2-5. MIMIC Listing of the Coolant Loss Rate Model of the IF-300 (Breach Up Version) (Page 2 of 3 ) 
OUT

HLU (T,TF,TW,TC,T.J, TH)

PLU(T,TJC,TS)

PLO $(T, M W, M W O, L W, P, X)$

PLO (T,MX)

PLU(T, GMAXF, G, GOUT, UMAXG)

ENU

FIGURE 2-5. MIMIC Listing of the Coolant Loss Rate Model of the IF-300 (Breach Up Version) (Page 3 of 3 ) 
The second model, the breach up model, is primarily a transient heat transfer simulation of the cask in which energy balances are used to determine the time required to bring the Dowtherm-A to its saturation temperature, and the time required to lose the coolant due to vaporization. This model, developed in Section 2.2.2, is presented as a MIMIC 1isting in Figure 2-9. 2.2.1 Coolant Loss From the Cask While in a Breach Down Position

The average temperature of the Dowtherm-A in the cask, as determined by the steady-state pre-accident model, is about $360^{\circ} \mathrm{F}$. The saturation pressure at this temperature is about 2.0 psia, well below atmospheric pressure. This means that the Dowtherm is subcooled.

When the Dowtherm- $A$ is subcooled, and the cask lands with the breach down, the only force driving the coolant from the cask would be the potential energy of the coolant column. The static pressure in the cask would not be a factor, since it would not be greater than the atmospheric pressure.

A MIMIC listing of the breach down version of the coolant loss rate model of the AMCO cask is presented in Figure 2-6.

\subsubsection{Energy Balance on the Breach}

The energy balance on the breach would be the same as the energy balance developed earlier in Section 2.1.1.1 for the IF-300, except that the pressure energy or flow work term

$$
v d P=0
$$

The final equation in Section 2.1.1.1, which defines the mass velocity of the coolant leaving the cask, would be the same

$$
G=\rho_{w} \sqrt{2 g_{c} Z}
$$

but now

$$
Z=Z_{W}
$$


***MIMIL JUJKCE-LAIVUUAUE PRUURAM*** JERSIU. 1 J4/08/71 YOJ -EJEL 0002

\begin{tabular}{|c|c|c|}
\hline \multirow[t]{4}{*}{ A } & $\because *_{1}$ & sut di, \\
\hline & & CUN(MHI,GL,ZI, TW, HGAR) \\
\hline & rat & $=-F \cdot\left(B_{.}\right)$ \\
\hline & TEC & $=F \supset W(T, T \cap U E, T K U E, F A L S E)$ \\
\hline \multirow[t]{4}{*}{ TEu } & A & $=4 w[/(K+10 w+Z I)$ \\
\hline & $M \cdot$ & $=1 N I-P . W 0$ \\
\hline & Anv & $=\operatorname{INT}(G M A X * \dot{H} G A>14+0,0)$. \\
\hline & $L$ & $=M N /(K H U W * H \cup H J K)$ \\
\hline \multirow[t]{8}{*}{ TEU } & KHUW & $=F \operatorname{UN}(K H O, T W)$ \\
\hline & $\operatorname{4mx}$ & $=r H O w * s Q R\left(2 . * i c^{*} 2\right)$ \\
\hline & $\Delta T$ & $=130$. \\
\hline & HJUKj & $=T / 300 \mathrm{u}$ \\
\hline & & $P \operatorname{LiV}(N) W O, 37>0)$. \\
\hline & & $F+1(T, 32403)$. \\
\hline & & UUT $(T, A N, M N O)$ \\
\hline & & JUT (HUUKJ, L, JMAX) \\
\hline \multirow[t]{5}{*}{ TeO } & & JUT (, KHOW, HUASK) \\
\hline & & UuT \\
\hline & & JUT \\
\hline & & $P L U(T, M W, M W U)$ \\
\hline & & $\begin{array}{l}\operatorname{HLJ}_{\mathrm{L}}(T, Z, \text { Gi1AX) } \\
\text { ENU }\end{array}$ \\
\hline
\end{tabular}

FIGURE 2-6. MIMIC Listing of the Coolant Loss Rate Model of the AMCO Cask (Breach Down Version) 
instead of

$$
z=z_{w}+z_{p}
$$

since

$$
\begin{aligned}
Z_{p} & =\frac{P-P_{\text {ATM }}}{\rho_{W}} \\
& =0 .
\end{aligned}
$$

\subsubsection{Rate of Coolant Loss From the Breach and Mass Balance on the Cask}

When the cask is in a breach down position, only the subcooled Dowtherm-A would flow through the breach. The maximum mass velocity of the coolant flowing from the breach would be the same as the mass velocity defined by Equation (2-25), i.e.,

$$
G_{\text {MAX }}=G=\rho_{W} \sqrt{2 g_{C} Z}
$$

where

$$
z=z_{w}=\frac{M_{w}}{\rho_{w} A_{\text {CASK }}}
$$

and

$$
A_{\text {CASK }}=\frac{M_{W i}}{\rho_{w} Z_{j}} .
$$

The rate at which coolant is lost from the breach is

$$
\frac{d M}{d t}=G_{M A X} A_{G A P}
$$

where

$$
A_{G A P}=\text { the flow area of the breach, } L^{2} \text {. }
$$


The total mass of coolant lost at any time is

$$
M_{\text {wO }}=\int_{0}^{t} G_{M A X} A_{G A P} d t+M_{\text {wo }}
$$

where

$$
\begin{aligned}
M_{\text {wo }} & =\text { the mass of coolant lost, } M \\
\|_{\text {woi }} & =\text { the initial mass of coolant lost, } M \\
& =0 .
\end{aligned}
$$

Finally, a mass balance on the cask may be written as

$$
M_{w}=M_{w i}-M_{w o}
$$

where

$$
\begin{aligned}
& M_{W}=\text { the mass of coolant remaining in the cask, } M \\
& M_{W i}=\text { the mass of coolant initially in the cask, } M .
\end{aligned}
$$

\subsubsection{Coolant Loss From the Cask While in a Breach Up Position}

The coolant loss rate model developed in this section is primarily a transient heat transfer simulation of the AMCO cask. Energy balances are used to determine the time required to bring the Dowtherm-A to its saturation temperature, and the time required to lose the coolant by vaporization. An idealized model of the cask, in the form of an electrical analog, is shown in Figure 2-7. This idealized cask consists of five components or regions for which energy balances were written to form the model. These regions are:

1. the fuel assemblies, represented as one homogeneous region,

2. a basket region surrounding the fuel region,

3. the coolant, 


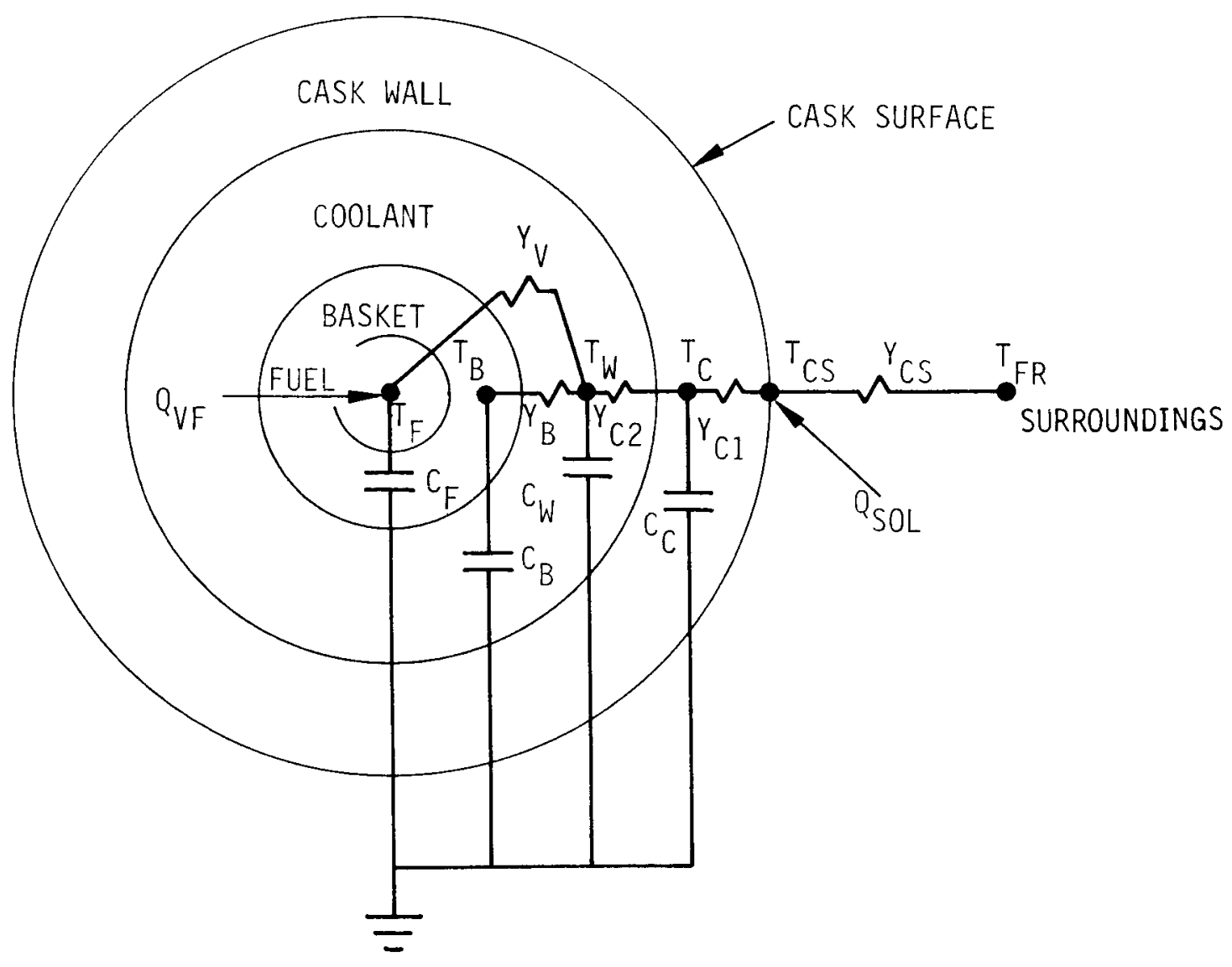

HEDL 7507-30.6

FIGURE 2-7. Idealized Representation of the AMCO Cask as an Electrical Analog 
4. the cask wall, represented as one region, including the outer cooling jacket, and

5. the outer surface of the cask wall.

Only coolant vapor would be lost from the cask when it is in a breach up position. At the time of the accident, it was assumed that the cask loses its solar shield and all of the water in its outer jacket or neutron shield. The loss of the water in the outer jacket creates a barrier in the path of the heat flowing from the cask, consequently the temperatures in the cask gradually increase. Also, loss of the solar shield allows an increase in the heat input to the cask at its outer surface. As the temperatures in the cask increase, the Dowtherm-A reaches its saturation temperature and vapor is formed.

Energy balances that describe the thermal behavior of the cask before the coolant reaches saturation conditions are presented in Section 2.2.2.1. Modifications to this system of equations, which are required to simulate the thermal behavior of the cask during vaporization, are presented in Section 2.2.2.2.

The equations that form the model are presented in an algorithm or calculation flow diagram in Figure 2-8. A 1 isting of the equations programmed for the MIMIC simulation code is presented as Figure 2-9.

Heat enters the cask in three forms:

1. as decay heat generated in the fuel,

2. as solar heat, and

3. as heat input from the fire.

Heat leaves the cask by natural convection and radiation from the cask surface to the surroundings, and in the coolant lost from the cask due to vaporization.

The initial temperatures in the cask are obtained from the temperature distribution established by the steady-state pre-accident model. 


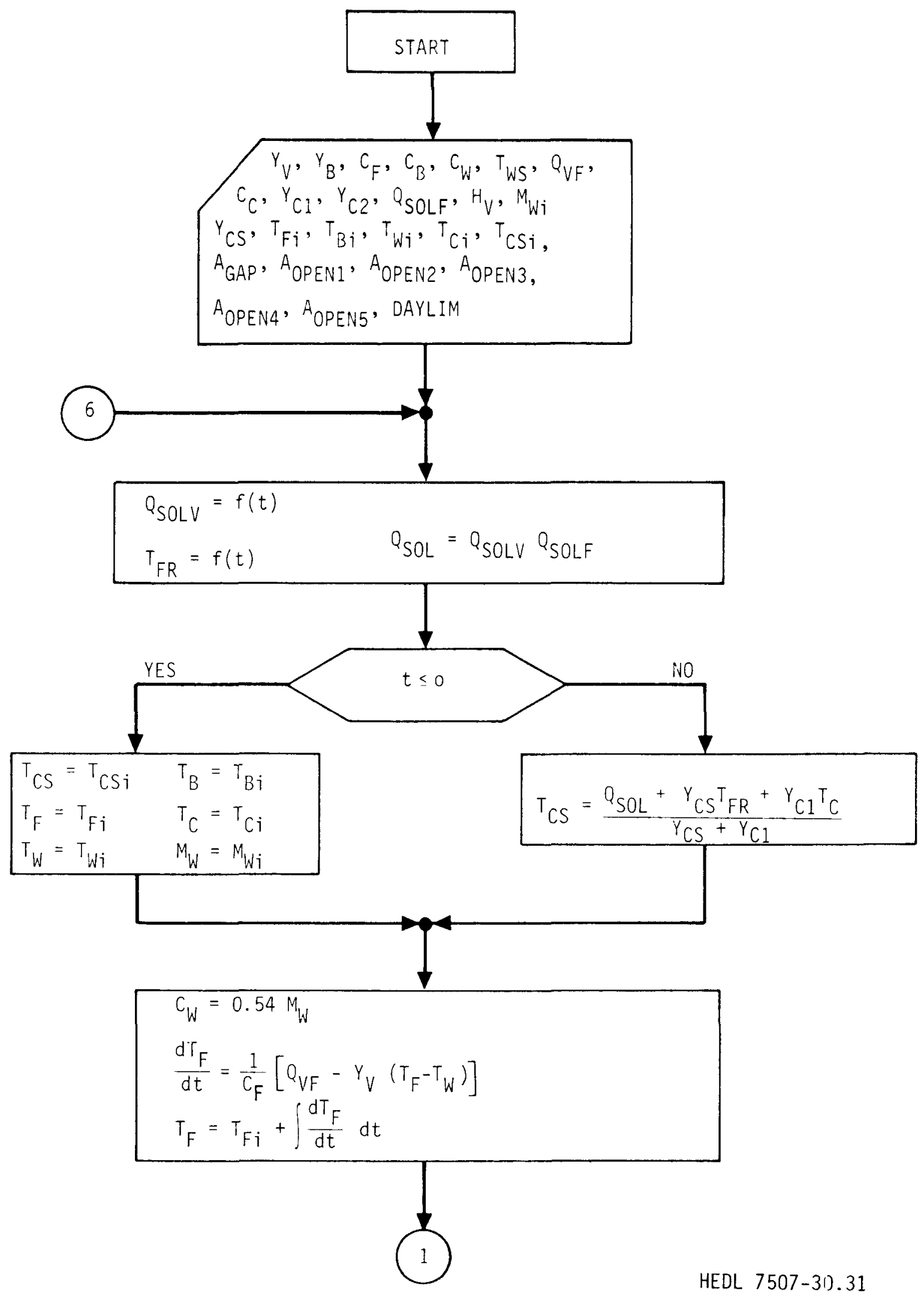

FIGURE 2-8. Calculation Control Flow Diagram of the Coolant Loss Rate Model of the AMCO Cask (Breach Up Version) (Page 1 of 5) 


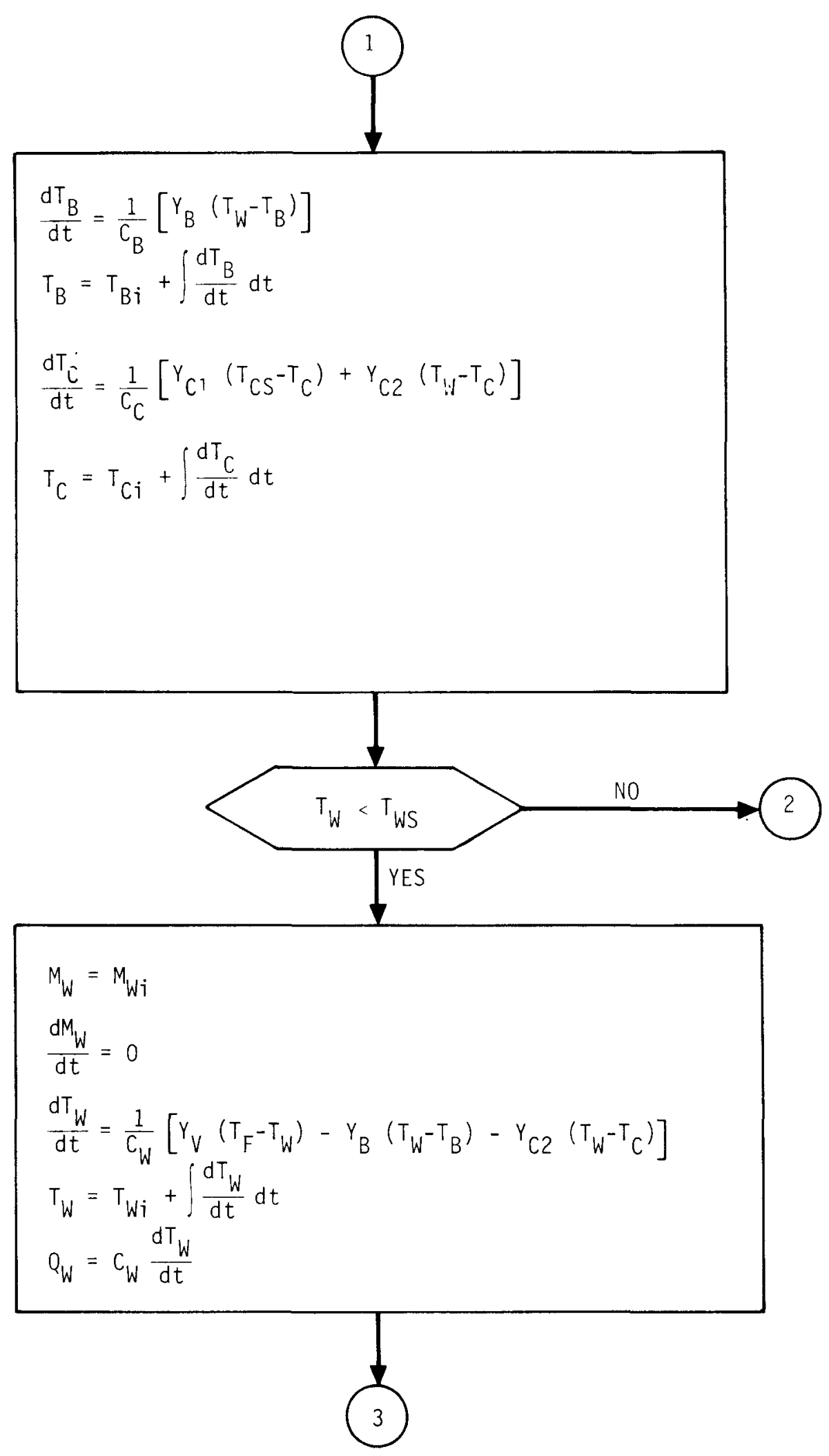

HEDL $7507-30.3 ?$

FIGURE 2-8. Calculation Control Flow Diagram of the Coolant Loss Rate Model of the AMCO Cask (Breach Up Version) (Page 2 of 5 ) 


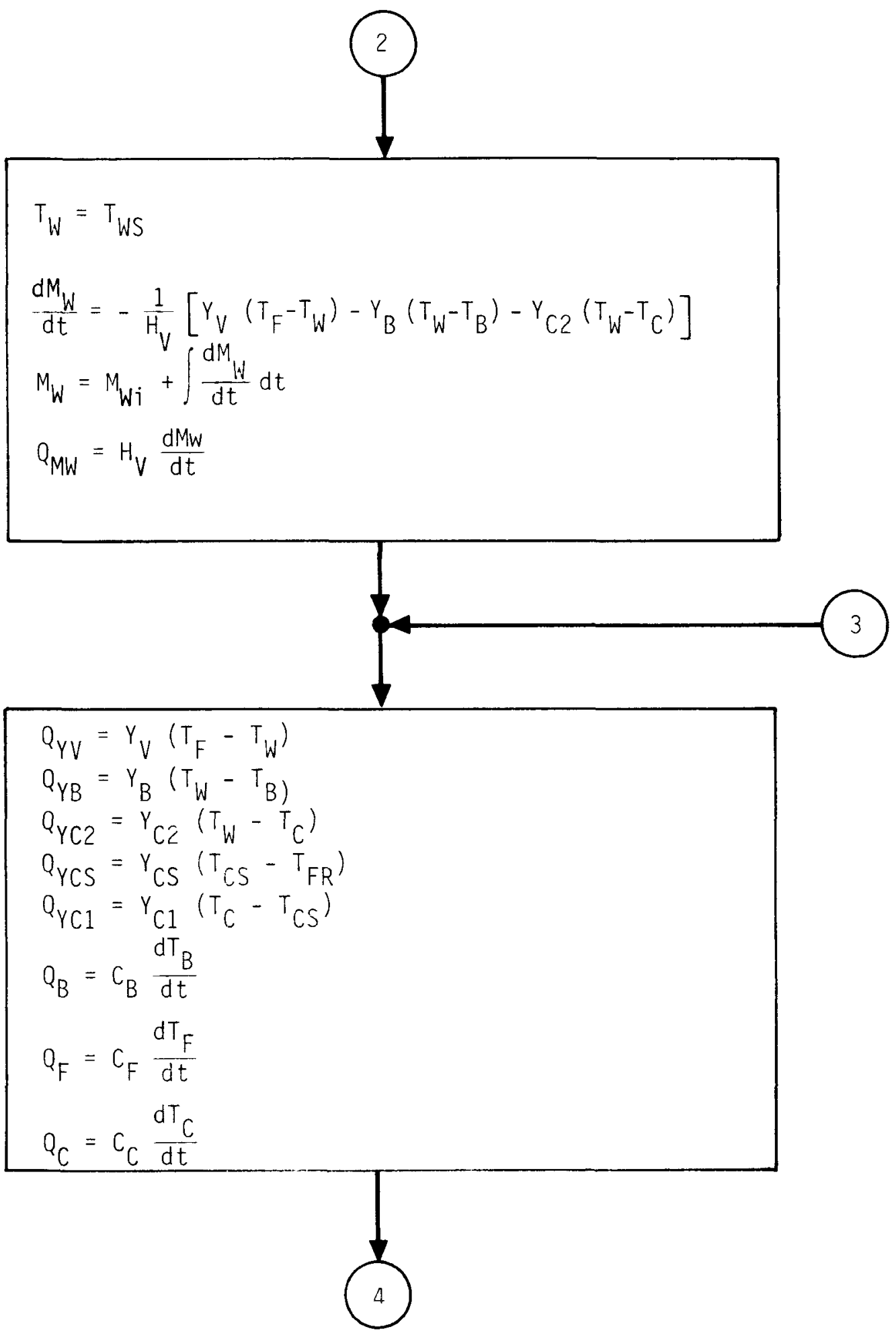

HEDL $7507-30.33$

FIGURE 2-8. Calculation Control Flow Diagram of the Coolant Loss Rate Model of the AMCO Cask (Breach Up Version) (Page 3 of 5) 


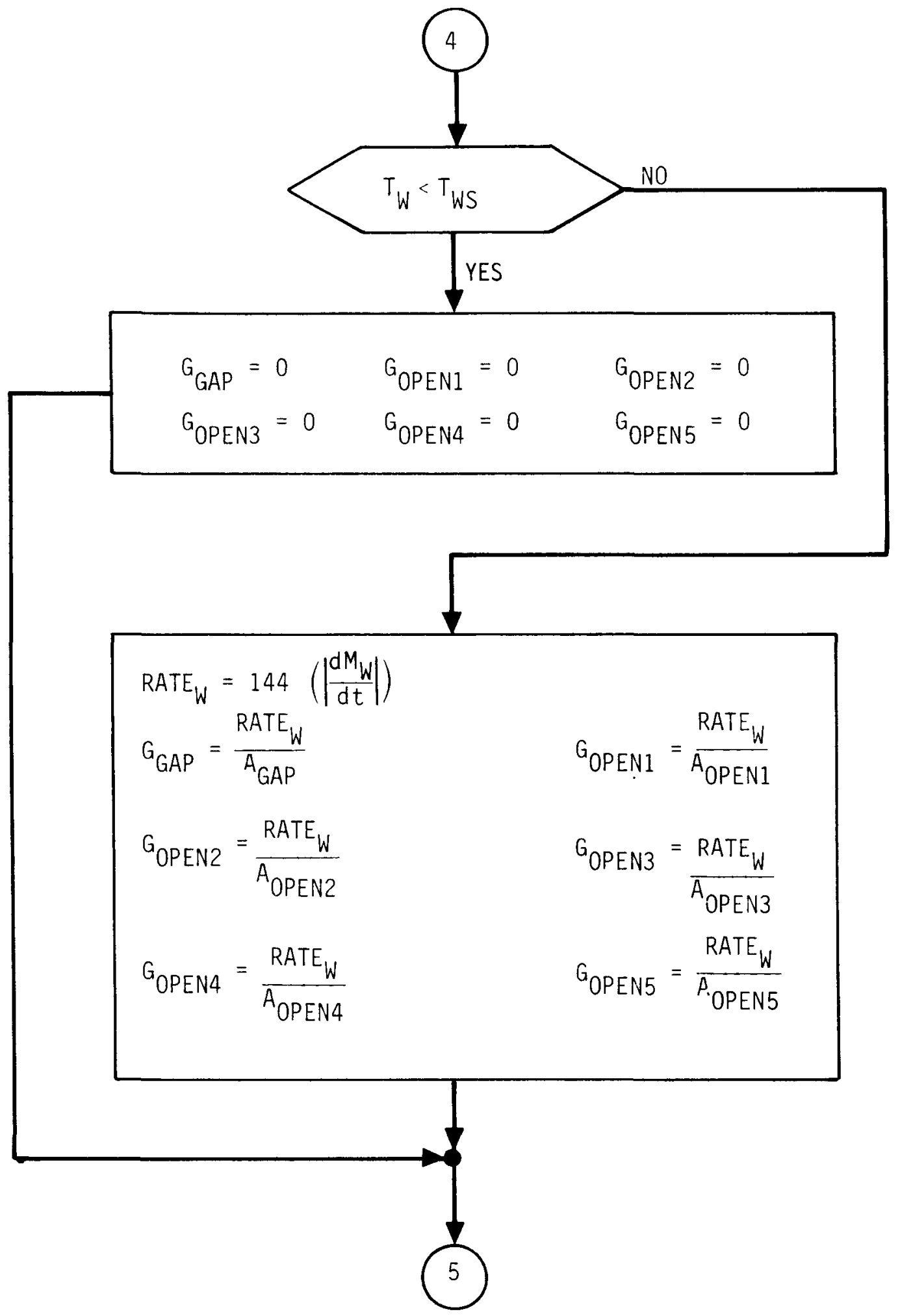

HEDL $7507-30.34$

FIGURE 2-8. Calculation Control Flow Diagram of the Coolant Loss Rate Model of the AMCO Cask (Breach Up Version) (Page 4 of 5 ) 


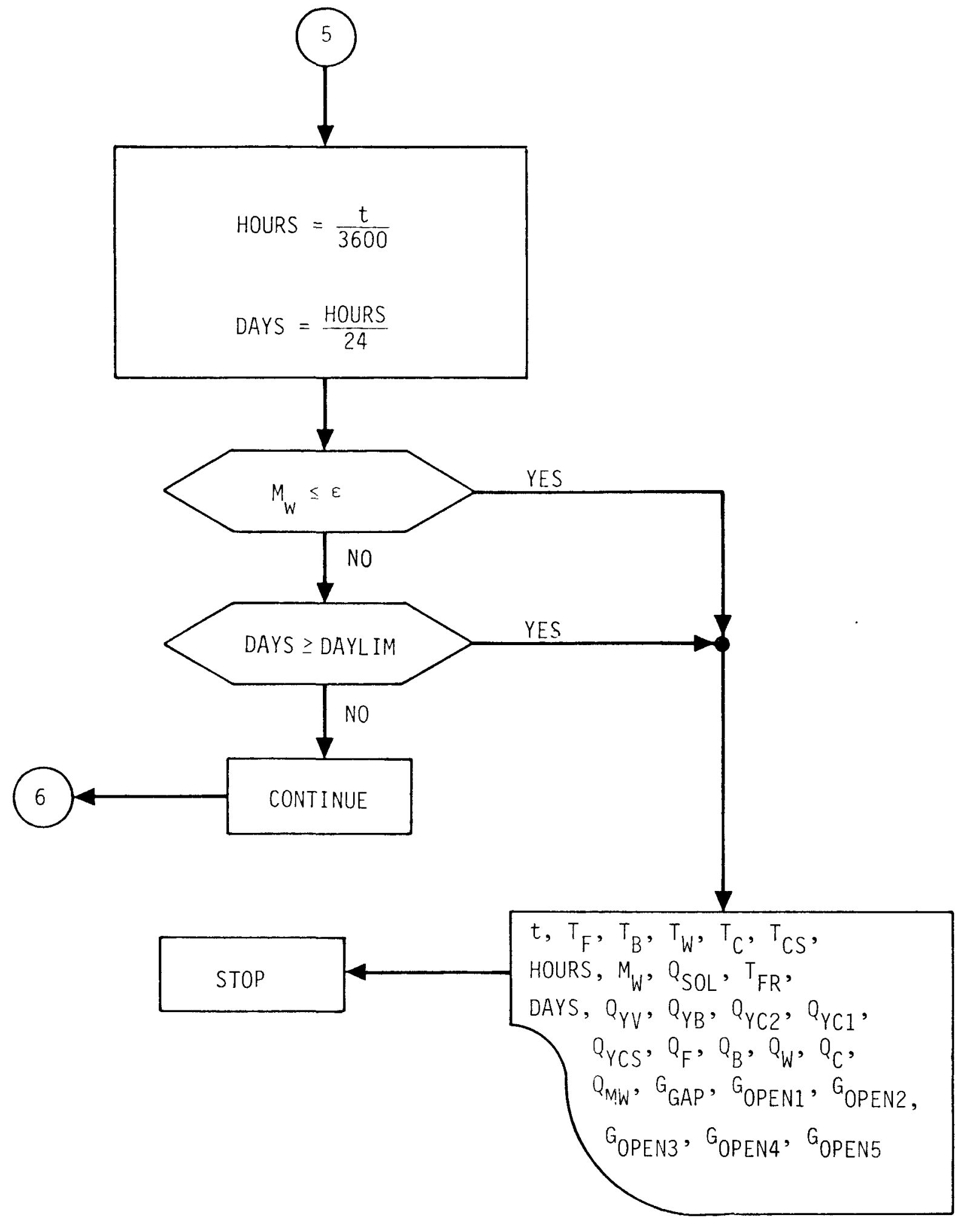

HEDL 7507-30.35

FIGURE 2-8. Calculation Control Flow Diagram of the Coolant Loss Rate Model of the AMCO Cask (Breach Up Version) (Page 5 of 5 ) 


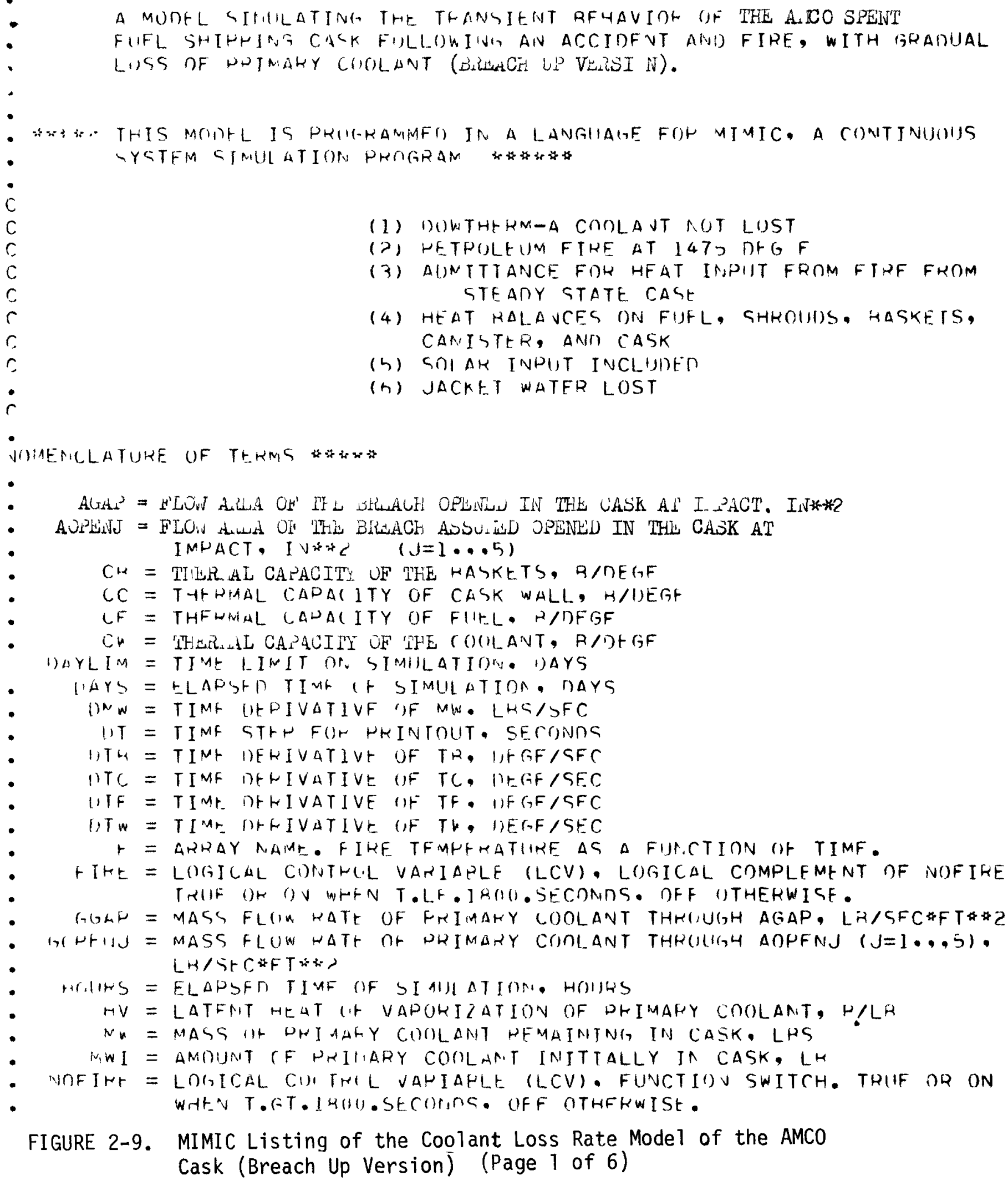

FIGURE 2-9. MIMIC Listing of the Coolant Loss Rate Model of the AMCO Cask (Breach Up Version) (Page 1 of 6 ) 


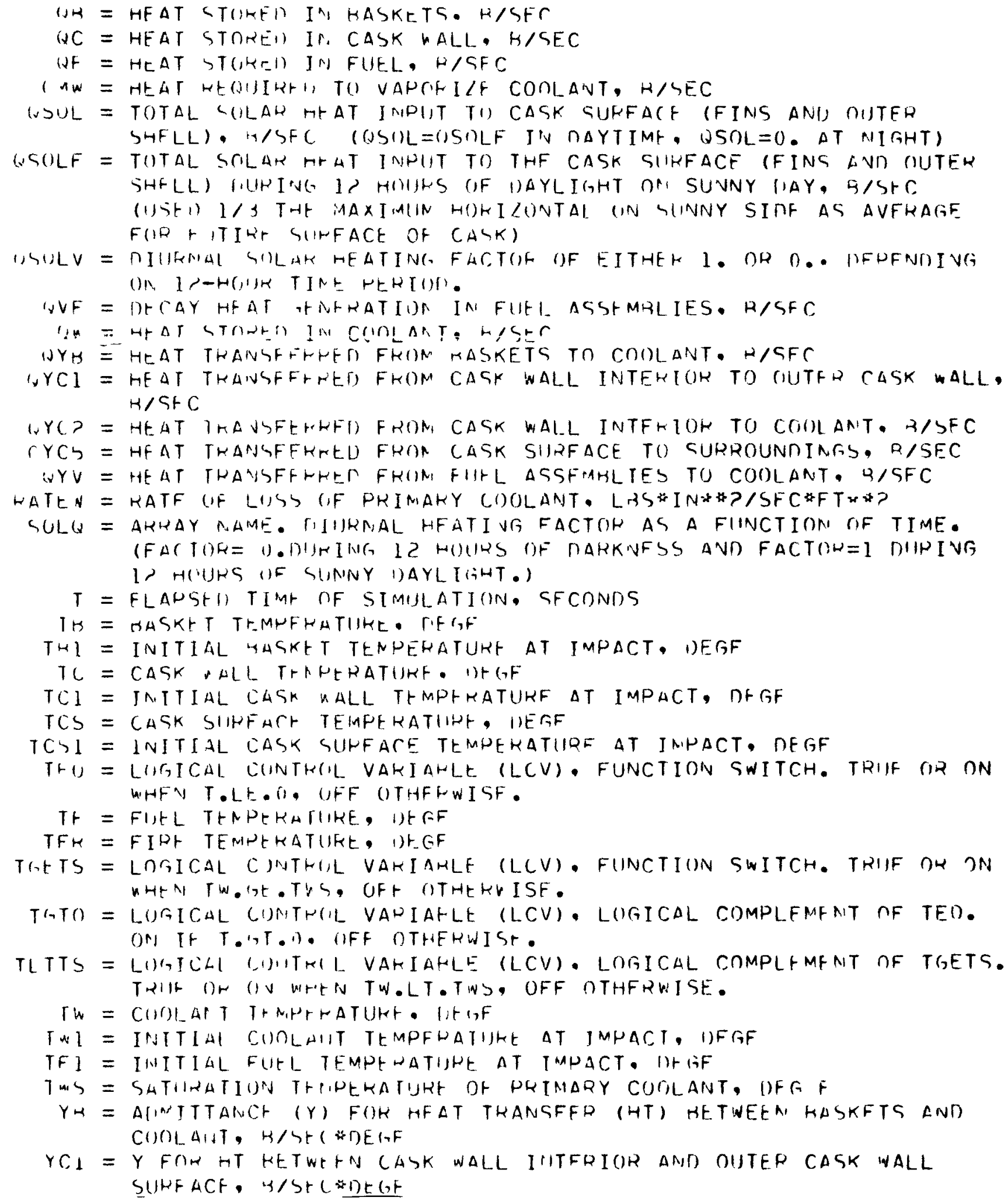

FIGURE 2-9. MIMIC Listing of the Coolant Loss Rate Model of the AMC0 Cask (Breach Up Version) (Page 2 of 6 ) 


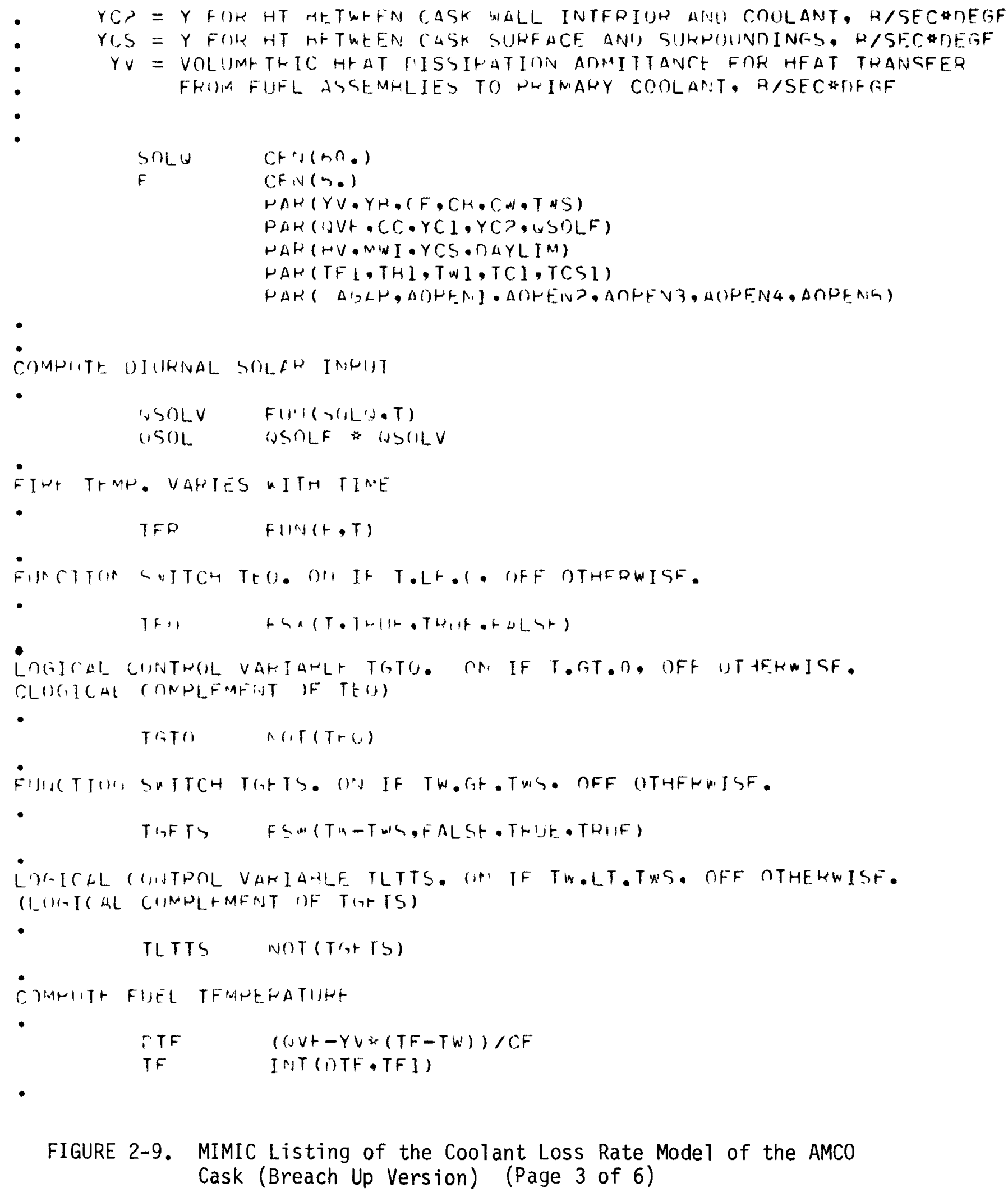


CONOITE SENGIRLE HFAT TI WOW-A DMO OOW-A TFMHFRATHKF

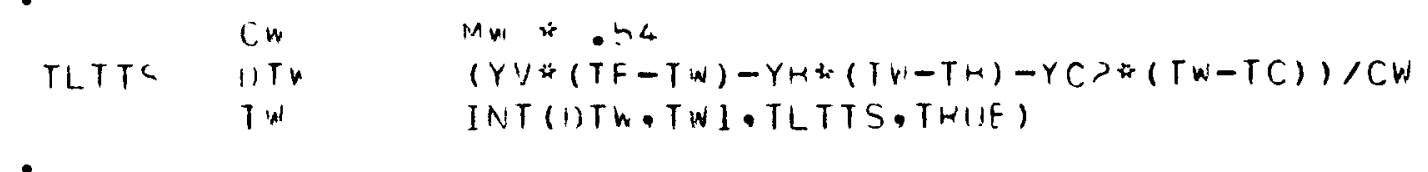

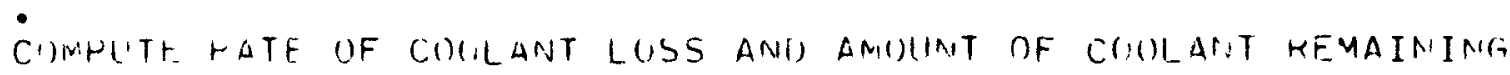

-

TLTTS UMW =

TitTS liMw $\quad-(Y V *(T H-T N)-Y M *(T W-T S)-Y C 2 *(T W-T C) / H V$

MW $\quad=I N T(O M N, M W I, T, F T S)$

COMPITT GASKET TEMAERATIJRE.

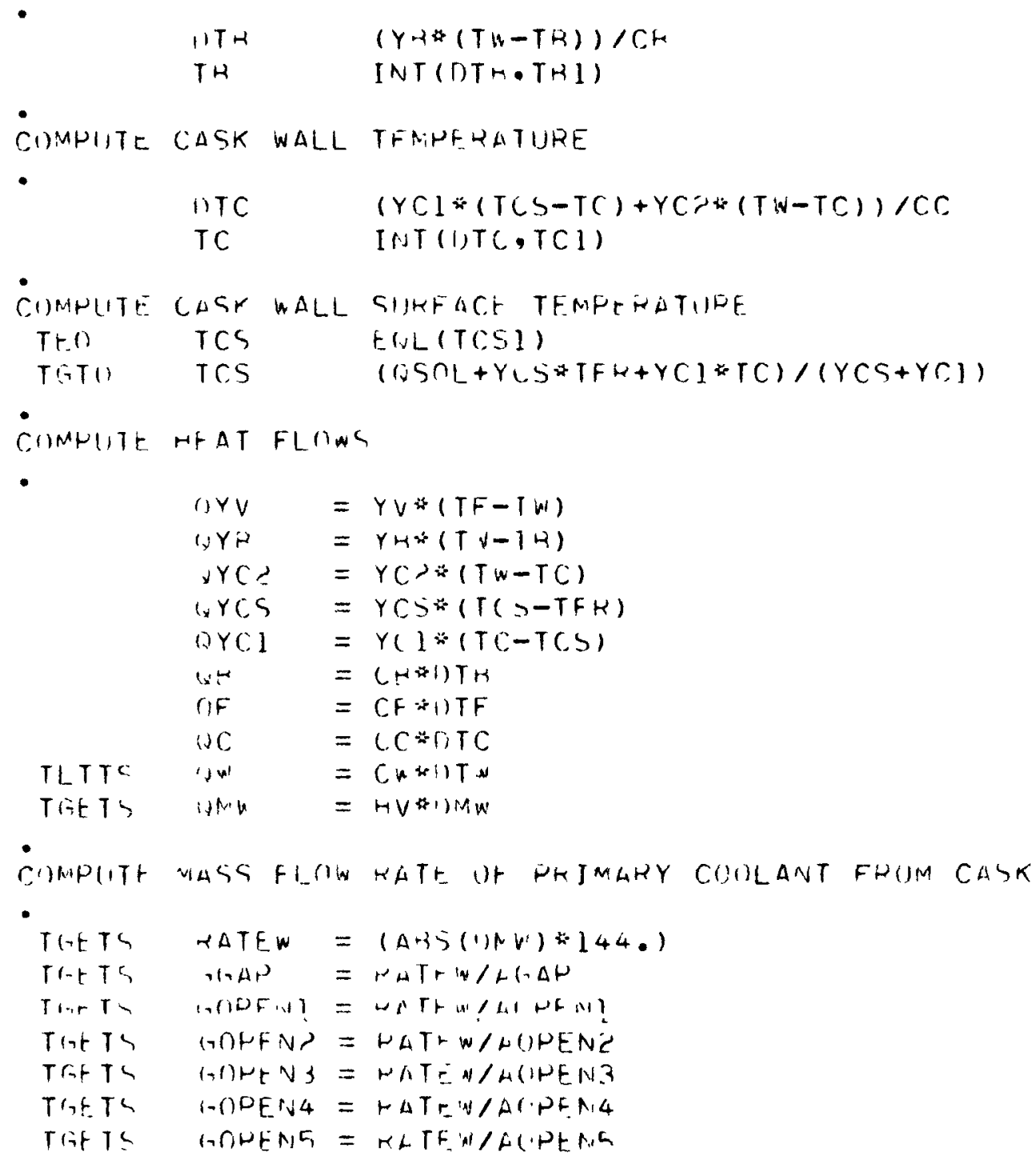

FIGURE 2-9. MIMIC Listing of the Coolant Loss Rate Model of the AMCO Cask (Breach Up Version) (Page 4 of 6) 


$$
\begin{aligned}
& \text { TLTIS , SEAN }=0 \text {. } \\
& \text { TLTTS GOAENL = } \\
& \text { TLTTY GOLFIV }=0 \text {. } \\
& \text { TLTTS IONFEN3 = } \\
& \text { TLTTL GONEN4 = } 0 \\
& \text { TLTTS MUENA = } 1 \text {. }
\end{aligned}
$$

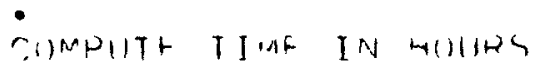

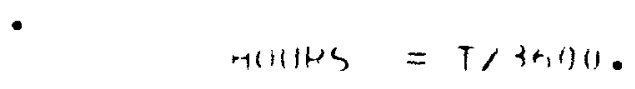

FIGURE 2-9. MIMIC Listing of the Coolant Loss Rate Model of the AMCO Cask (Breach Up Version) (Page 5 of 6 ) 


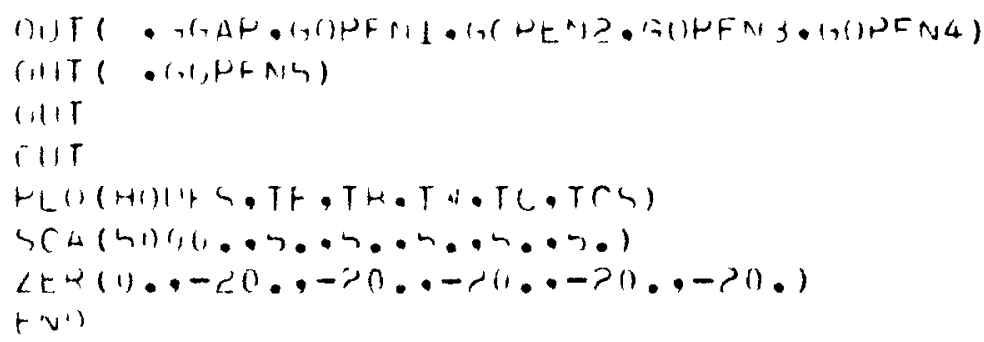

FIGURE 2-9. MIMIC Listing of the Coolant Loss Rate Model of the AMCO Cask (Breach Up Version) (Page 6 of 6) 
When the solar shield is lost, the cask is exposed to solar heating. A diurnal variation of the solar heat input was used in the model developed in this section and in the loss-of-coolant models discussed later in Section 3. It was assumed that the accident occurs at 6:00 a.m., and the solar heat falls on the cask at a constant rate until 6:00 p.m., when it drops to zero. This variation of solar heating was programmed into the models as a pulsed function of time, where this "on-off" characteristic was repeated as long as required. The solar heat reaching the cask was arbitrarily assumed to be one-third of that which would fall on a flat surface. This was an assumed correction factor to allow for the non-flat, $360^{\circ} \mathrm{F}$ cylindrical surface of a cask. It is impossible for the entire surface of a cask to face the sun.

The temperature of the surroundings is a function of time. During the fire, it is the temperature of the fire and, when the fire burns out, it becomes the ambient temperature of the surroundings. This variation of the temperature of the surroundings is programmed into the model as a timevarying step function.

\subsubsection{Energy Balances in the Cask Before Vaporization of the Coolant}

It is convenient to define and discuss in general, beforehand, some of the terms which will be used in the energy balance equations presented here and in Section 2.2.2.2.

Since the purpose of this model was to provide estimates of the time required for the cask to lose its coolant by vaporization, no attempt was made to determine detailed temperature distributions in the fuel, baskets and cask wall. Consequently, all of the thermal admittances in the heat balance equations are for heat transfer by combined conduction and convection or by combined conduction, convection and radiation. Each of the regions considered was represented as a single node.

A11 admittances, except the one representing heat transfer to the coolant from the fuel, are defined by the general equation 


$$
Y_{h}=U A
$$

where

$Y_{h}=$ the admittance for heat transfer by combined conduction and convection or by combined conduction, convection and radiation, $\mathrm{H} / \theta \mathrm{T}$,

$U=$ an overall coefficient for heat transfer, $H / \theta L T$,

$A=$ the area for heat transfer, $L^{2}$.

The heat transfer submodel of the coolant loss rate model of the IF-300, developed in Section 2.1.1.3, was developed after the model discussed here and, consequently, includes some significant improvements. Some of these are related to the calculation of the heat transfer admittances. First of all, individual admittances were used for conduction, convection and radiation paths rather than admittances based on combinations of paths. Second, equations for the heat transfer coefficients for convection and radiation were included in the IF-300 model and were evaluated as functions of the temperatures. For the AMCO cask, temperatures were estimated beforehand, the heat transfer coefficients determined from side calculations, and these were then used to determine the appropriate admittances. The admittances then remained constant throughout the transient. Any future work on the AMCO cask model should include revisions of the network and computational procedure to match those used for the IF-300 model.

Heat transfer by natural convection from the fuel to the coolant was represented by a volumetric heat dissipation admittance defined by Equation $(1-15)$ in Section 1.2., i.e.,

$$
Y_{v}=\frac{2(1-B) h S_{\text {node }} \Delta x}{a}
$$

where

$Y_{v}=$ the volumetric heat dissipation admittance, $H / \theta T$,

$B=$ the void fraction of the fuel region, 


$$
\begin{aligned}
h= & \text { the coefficient for heat transfer by natural convection } \\
& \text { from a fuel pin to the coolant, } H / \theta L^{2} T, \\
a= & \text { the fuel pin radius, } L, \\
S_{\text {node }=} & \text { the cross sectional area of a fuel node (in this case, } \\
& S_{\text {node }} \text { is the cross sectional area of the entire fuel } \\
& \text { region) } L^{2}, \\
\Delta x= & \text { the incremental length of the fuel region (in this } \\
& \text { case, } \Delta x \text { represents the lengths of the respective } \\
& \text { vapor-and-liquid-cooled portions of the fue } 1 \text { ), } L .
\end{aligned}
$$

The coefficient for heat transfer by natural convection from a fuel pin to the coolant was obtained using the following correlation(2)

$$
\frac{h D}{k}=0.53\left(\frac{D^{3}{ }^{2} g \beta \Delta T C_{P}}{\mu k}\right)^{1 / 3}
$$

where

$$
\begin{aligned}
h= & \text { the heat transfer coefficient, } H / L{ }^{2} \theta T, \\
D= & \text { the fuel pin diameter, } L \\
k= & \text { thermal conductivity of the coolant, } H / L \theta T, \\
\rho= & \text { coolant density, } M / L^{3} \\
g= & \text { gravitational constant, } M L / F \theta^{2}, \\
\beta= & \text { volume expansion coefficient of the coolant, } 1 / T \\
\Delta T= & \text { the temperature difference between the coolant and } \\
& \text { the fuel pin, } T, \\
C_{P}= & \text { the heat capacity of the coolant, H/MT, } \\
\mu= & \text { the viscosity of the coolant, } M / L \theta .
\end{aligned}
$$

This same correlation was used to obtain the coefficient for heat transfer from the coolant to the inside surface of the cask cavity, and between the basket and the coolant.

The admittance for heat transfer from the interior of the cask wall to the outer shell of the outer jacket, $Y_{C 1}$, (see Figure 2-7) includes a complex network of conduction, convection and radiation paths from the outer 
surface of the cask wall, through the fins and empty water jacket, to the outer surface of the cask (the outer she 11 of the water jacket, and the protruding portion of the fins). The network representing the empty water jacket of the AMCO cask is shown in Figure 3-21. The admittances in the network of Figure 3-21 were combined into one equivalent admittance, using network reduction methods. As stated earlier, the loss-of-coolant models were developed before the coolant loss rate models, so the conduction, convection and radiation admittances in the network had already been determined. The conduction and convection admittances had been predetermined, and the radiation admittances were determined by the TAP code during the course of the loss-of-coolant transient (see Section 3.4.1).

Thermal capacities are defined by the general equation

$$
C=P C_{p} V
$$

where

$$
\begin{aligned}
& L_{p}=\text { the heat capacity of the region material, H/MT, } \\
& \rho=\text { the density of the material, M/L } \\
& V=\text { the volume of the region, } L^{3} .
\end{aligned}
$$

Since the fuel region is porous, its volume must be expressed as

$$
V=(1-B) V_{F R}
$$

where

$$
\begin{aligned}
V_{F R} & =\text { the overall volume of the fuel region, } L^{3}, \\
B & =\text { the void fraction. }
\end{aligned}
$$

The heat generated in the fuel region is the total thermal power in kilowatts obtained from Table 3 , converted to $\mathrm{B} / \mathrm{sec}$.

\subsection{Energy Balance on the Fuel}

The energy balance on the fuel region of Figure 2-7 is 


$$
C_{F} \frac{d T_{F}}{d t}=Q_{V F}-Y_{V}\left(T_{F}-T_{W}\right)
$$

where

$C_{F}=$ the thermal capacity of the fuel region, $H / T$,

$T_{F}=$ the temperature of the fuel region, $T$,

$Q_{V F}=$ the decay heat generated in the fuel, $\mathrm{H} / \theta$,

$Y_{v}=$ the volumetric heat dissipation admittance for the transfer of heat by convection from the fuel region to the coolant, $\mathrm{H} / \theta \mathrm{T}$,

$T_{W}=$ the temperature of the coolant, $T$.

\subsection{Energy Balance on the Basket}

The energy balance on the basket region may be written as

$$
C_{B} \frac{d T_{B}}{d t}=Y_{B}\left(T_{W}-T_{B}\right)
$$

where

$C_{B}=$ the thermal capacity of the basket, $H / T$,

$T_{B}=$ the temperature of the basket region, $T$,

$Y_{B}=$ the admittance for the transfer of heat by convection from the basket region to the coolant, $H / \theta T$.

The heat transfer area used in the admittance $Y_{B}$ is the combined areas of the inner and outer surfaces of the basket.

\subsection{Energy Balance on the Cask Wall}

The energy balance on the cask wall is

$$
C_{C} \frac{d T_{C}}{d t}=Y_{C 1}\left(T_{C S}-T_{C}\right)+Y_{C 2}\left(T_{W}-T_{C}\right)
$$


where

$$
\begin{aligned}
C_{C}= & \text { the thermal capacity of the cask wall, } H / T, \\
T_{C}= & \text { the temperature of the cask wall, } T, \\
Y_{C 1}= & \text { the equivalent admittance for heat transfer by com- } \\
& \text { bined conduction, convection and radiation from the } \\
& \text { interior of the cask wall, through the empty water } \\
& \text { jacket, to the outer shell of the water jacket, } H / \theta T, \\
T_{C S}= & \text { the temperature of the outer surface of the cask (the } \\
& \text { outer shell of the water jacket and the protruding } \\
& \text { fins), } T, \\
& \text { the equivalent admittance for the combined transfer of } \\
& \text { heat by convection from the primary coolant to the } \\
& \text { inner surface of the cask wall, and by conduction from } \\
& \text { the surface to the cask wall interior, } H / \theta T .
\end{aligned}
$$

\subsection{Energy Balance on the Coolant}

The energy balance on the coolant before it reaches its saturation temperature, is

$$
C_{W} \frac{d T_{W}}{d t}=Y_{V}\left(T_{F}-T_{W}\right)-Y_{B}\left(T_{W}-T_{B}\right)-Y_{C 2}\left(T_{W}-T_{C}\right)
$$

where $C_{W}=$ the thermal capacity of the Dowtherm-A coolant, H/T.

Equation (2-149) is valid as long as the temperature of the Dowtherm-A is less than its saturation temperature. A different equation, presented in Section 2.2.2.2, is used when the coolant reaches saturation conditions. The procedure used to switch equations in the model at the proper time will also be described in Section 2.2.2.2.

\subsection{Energy Balance at the Cask Surface}

The electrical analog of the idealized model of the cask, Figure 2-7, does not include a thermal capacity for the node representing the cask surface. This means that, although heat is stored in the thin outer shell 
and the fins, it was considered to be small enough compared to the thermal capacity of the cask wall that, for convenience, it could be neglected. This is believed to be a conservative assumption since there would now be no $\mathrm{lag}$ in the response of the surface to the heat input from the fire and solar heating, and no delay in transmitting this heat to the cask wall.

The energy balance at the cask surface may be written as

$$
0=Q_{S O L}+Y_{C T}\left(T_{C}-T_{C S}\right)-Y_{C S}\left(T_{C S}-T_{F R}\right) .
$$

Rearrangement of Equation (2-150) gives the temperature of the cask surface as

$$
T_{C S}=\frac{Q_{S O L}+Y_{C I}{ }_{C}+Y_{C S} T_{F R}}{{ }_{C I}+Y_{C S}}
$$

where

$$
\begin{aligned}
Q_{S O L}= & \text { the solar heat input, } H / \theta, \\
{ }^{Y_{C S}=} & \text { the admittance for heat transfer by convection and radiation } \\
& \text { between the surroundings and the cask surface (water jacket } \\
& \text { outer she11 and fins), H/ } \theta \mathrm{T}, \\
T_{F R=} & \text { the temperature of the surroundings, either the fire or } \\
& \text { ambient conditions, } T .
\end{aligned}
$$

The temperature of the surroundings, $T_{F R}$, is a function of time. During the fire, it is the temperature of the fire and, when the fire burns out, it becomes the ambient temperature of the surroundings. This variation of the temperature of the surroundings is programmed into the model as a time-varying step function.

The solar heat input is also a function of time. During the 12 hours of daylight, solar heat is added to the cask at a rate of $19.5 \mathrm{~B} / \mathrm{sec}$.

During the 12 hours of darkness, there is no solar heat input. This diurnal variation of solar heating is programmed into the model as an oscillating function of time, as shown in Figures 15 and 16. 


\subsubsection{Energy Balances in the Cask During Vaporization of the Coolant}

When the Dowtherm-A coolant reaches saturation conditions, it boils, and the vapor formed flows through the breach opened in the cask containment at impact. For this case, all the energy balances presented in Section 2.2.2.1 remain the same, except for the energy balance on the coolant.

The erergy balance on the coolant, when it reaches saturation conditions, is

$$
-H_{v} \frac{d M_{W}}{d t}=Y_{v}\left(T_{F}-T_{W}\right)-Y_{B}\left(T_{W}-T_{B}\right)-Y_{C 2}\left(T_{W}-T_{C}\right)
$$

where

$$
\begin{aligned}
& H_{V}=\begin{array}{l}
\text { the latent heat of vaporization of the Dowtherm- } A \text { at the } \\
\text { saturation temperature } T_{W S}, H / M,
\end{array} \\
& \frac{d M_{W}}{d t}=\text { the rate of change of the mass of coolant in the cask, } M / \theta, \\
& T_{W}=\text { the saturation temperature, } T .
\end{aligned}
$$

At this point, the temperature is held at the saturation temperature, i.e.,

$$
T_{W}=T_{W S} \text {. }
$$

\subsubsection{Transition From Subcooled to Saturated Conditions in the Coolant Region}

The transition from the subcooled condition of the coolant, as represented by Equation (2-149), to the saturated condition represented by Equation (2-152) was accomplished by the use of logical control variables.

\subsection{Logical Control Variables and Branching Within the Model}

As discussed earlier in Section 2.1.1.2, control of computation flow within a model programmed in the MIMIC simulation language is accomplished by the use of logical control variables. 
The model presented here was constructed to simulate conditions in the cask both before and after the coolant reached its saturation temperature, i.e.,

$$
T_{W}<T_{W S},
$$

and

$$
T_{w} \geq T_{w S}
$$

respectively. The logical control variables representing the conditions defined by Equations (2-154) and (2-155) are TLTTS and TGETS, respectively. TGETS is defined by the function switch expression

$$
\text { TGETS = FSW(TW-TWS, FALSE, TRUE, TRUE), }
$$

and TLTTS by the logical complement of TGETS

$$
\text { TLTTS }=\text { NOT (TGETS), }
$$

where

$$
\begin{aligned}
T W & =t_{W}, \\
T W S & =t_{W S} .
\end{aligned}
$$

When Equation (2-155) is true, TGETS is true and TLTTS is false. Conversely, when Equation (2-154) is true, TGETS is false and TLTTS is true.

Logical control variables are also used to control the mode of operation of integration statements in the MIMIC simulation program. This was also discussed in detail earlier in Section 2.1.1.2. The particular application to the present model will be discussed in the following section.

\subsection{Integration of the Energy Balances on the Coolant}

There are two energy balances on the coolant, one for subcooled conditions (Equation 2-149) and one for saturated conditions (Equation 2-152). When the expression

$$
T_{W}<T_{W S}
$$

is true, Equation (2-149) is solved for the time derivative of the coolant temperature, $\mathrm{dT}_{\mathrm{w}} / \mathrm{dt}$. When the expression 


$$
T_{W} \geq T_{W S}
$$

is Erue, Equation (2-152) is solved for the rate of change of the mass of coolant in the cask, $\mathrm{dM}_{\mathrm{W}} / \mathrm{dt}$. Figure 2-9 shows how the logical control variables TLTTS and TGETS are used to flag Equations (2-149) and (2-152) for execution.

After Equations (2-149) and (2-152) have been solved for $\mathrm{dT}_{w} / \mathrm{dt}$ and $d M_{W} / d t$, respectively, these results are then integrated tc give $T_{W}$ and $\|_{: i} \cdot$ The temperature of the coolant is defined by the equation

$$
T_{w}=T_{w i}+\int_{0}^{t_{B}} \frac{d T_{w}}{d t} d t,
$$

and the mass of coolant remaining in the cask by

$$
w_{w}=M_{w i}+\int_{t_{B}}^{t} \frac{d M_{w}}{d t} d t,
$$

where

$$
\begin{aligned}
& t_{B}=\text { the time at which } T_{W} \geq T_{W S}, \theta, \\
& T_{W i}=\text { the initial temperature of the coolant, } T, \\
& M_{W i}=\text { the mass of coolant in the cask initially, M. } \\
& \text { The MIMIC integration statements equivalent to Equations } \\
& (2-158) \text { and (2-159) are }
\end{aligned}
$$$$
T W=\operatorname{INT}(D T W, T W I, T L T T S, T R U E)
$$ 
and

$$
M W=\operatorname{INT}(D M W, M W I, T G E T S, \text { TRUE }) \text {, }
$$

respectively,

where

$$
\begin{aligned}
& \text { DTW }=d T_{W} / d t, \\
& \text { TWI }=T_{W i} \\
& \text { DMW }=\mathrm{dM}_{W} / \mathrm{dt}, \\
& \text { MWI }=M_{W i} \cdot
\end{aligned}
$$

The logical control variables TLTTS and TGETS are included in the above integration statements to control the mode of operation of the respective integrators. [Mode-controlled integration is discussed in detail in Section 2.1.1.2, in connection with the general integration statement defined by Equation (2-126), and in Reference (3).]

When TLTTS is true $\left(T_{W}<T_{W S}\right)$, the integrator represented by Equation (2-160) is in the OPERATE mode. This means that the integrator is updated by the MIMIC integration routine and the result of the integration is equivalent to that defined by Equation (2-158). A1so, when TLTTS is true, TGETS is false and the integrator represented by Equation (2-161) is in the HOLD mode. This means that the input to the integrator $\left(\mathrm{dM}_{W} / \mathrm{dt}\right)$ is removed and $M_{W}$ is equal to $M_{W i}$.

When TGETS is true (when $T_{W} \geq T_{W S}$ ), TLTTS is false, and the integrator of Equation (2-160) is now in the HOLD mode. This means that the input to the integrator $\left(d T_{W} / d t\right)$ is removed and $T_{W}$ is held equal to the last value it had reached, i.e., $T_{\text {WS }}$. Also, when TGETS is true, the integrator represented by Equation (2-161) is now in the OPERATE mode, which means that the integrator is updated and the result of the integration is equivalent to that defined by Equation (2-159). 


\subsubsection{Determination of Temperatures From Energy Balances on the Regions}

The energy balances on all the other regions of the cask model are valid throughout the transient, reqardless of the state of the coolant. These energy balances have been presented as Equations (2-146), (2-147), $(2-148)$ and (2-150) of Section 2.2.2.1.

Equations (2-146), (2-147) and (2-148) yield the time derivatives of the temperatures of the fuel, basket and cask wall regions, respectively. The temperatures of these regions are obtained by the following integrations:

$$
\begin{aligned}
& T_{F}=T_{F i}+\int_{0}^{t} \frac{d T_{F}}{d t} d t, \\
& T_{B}=T_{B i}+\int_{0}^{t} \frac{d T_{B}}{d t} d t, \text { and } \\
& T_{C}=T_{C i}+\int_{0}^{t} \frac{d T_{C}}{d t} d t,
\end{aligned}
$$

where $T_{F i}$, $T_{B i}$ and $T_{C i}$ are the initial temperatures of the regions. The equivalent MIMIC integration statements are:

$$
\begin{aligned}
& T F=\operatorname{INT}(D T F, T F I), \\
& T B=\operatorname{INT}(D T B, T B I), \\
& T C=\operatorname{INT}(D T C, T C I),
\end{aligned}
$$

where

$$
\begin{aligned}
& D T F=d T_{F} / d t, \\
& T F I=T_{F i},
\end{aligned}
$$




$$
\begin{aligned}
\text { DTB } & =\mathrm{dT}_{\mathrm{B}} / \mathrm{dt}, \\
\text { TBI } & =\mathrm{T}_{\mathrm{Bi}}, \\
\text { DTC } & =\mathrm{dT}_{\mathrm{C}} / \mathrm{dt}, \\
\text { TCI } & =\mathrm{T}_{\mathrm{Ci}} .
\end{aligned}
$$

Note that the integration statements (2-165), (2-166) and (2-167) do not have the third and fourth arguments to control the mode of integration. When the third and fourth arguments of a MIMIC integration statement are missing, the program assumes they are true and the integrator is automaticaliy placed in the OPERATE mode.

The temperature of the cask surface (the outer shell of the water jacket and the fins) may be obtained directly from Equation (2-151.).

\subsubsection{Coolant Loss From the Cask}

The rate of loss of the coolant from the cask by vaporization is the time derivative - $d M_{W} / d t$. The time to empty the cask is, the time required for $M_{W}$, as determined from Equation $(2-161)$, to decrease from $M_{w i}$ to 0.

The mass velocity of the coolant vapor leaving the cask through the breach is

$$
G_{G A P}=\frac{C F\left|\frac{d M_{w}}{d t}\right|}{A_{G A P}}
$$

where

$$
\begin{aligned}
A_{G A P} & =\text { the area of the breach, } \mathrm{in}^{2}, \\
C F & =a \text { conversion factor }=144 \mathrm{in}^{2} / \mathrm{ft}^{2} .
\end{aligned}
$$




\section{CASK SIMULATION MODELS FOR LOSS-OF-COOLANT TRANSIENT}

Models were developed to simulate the behavior of the IF-300 and AMCO casks following an accident in which the solar shields were lost, along with the water in the outer jackets or neutron shields, and after the casks have lost their primary coolant (cask behavior prior to loss of the primary coolant was simulated using the so-called "coolant loss rate" models discussed in Section 2). The models discussed in this section are referred to as "loss-of-coolant" models.

These loss-of-coolant models are basically heat transfer models, but in addition to the equations describing the heat transfer in the casks they include equations that describe the consequences of loss of the primary coolant. The loss of primary coolant causes overheating of the fuel, which results in expansion of free fission gases in the fuel pins and eventual failure of some fuel pin clads. Failure of the fuel pin clads releases free fission gases and some solid fission products (cesium compounds) to the cask containment, from which they may escape if the containment is breached.

It was stated in the introduction to this Appendix that, at the time the study of spent fuel shipping cask behavior was begun, it was decided to start with the most pessimistic case to determine at the outset the most conservative estimate of fission product release. The most pessimistic case visualized was an accident in which a cask loses its solar shield, the water in its outer jacket, and its primary coolant at the instant the accident occurs. The cask was also assumed to be subjected to a fire at $1475^{\circ} \mathrm{F}$ for half an hour following the accident. Consequently, the first simulation models constructed were the loss-of-coolant models. At this time, to insure that nothing was overlooked, potential mechanisms governing the possible release of the remaining fission gases bound up in the fue 1 were included in the model. These potential mechanisms are:

1. oxidation of the $\mathrm{UO}_{2}$ to $\mathrm{U}_{3} \mathrm{O}_{8}$, a loose granular material, from which the bound up fission gases could escape, and 
2. diffusion of the bound up fission gases from the fuel

if the temperatures were high enough.

As the study progressed, however, it appeared that the probabilities of these mechanisms occurring may be quite smal1. The diffusional process requires extremely high temperatures to produce a significant release rate. Also, it seems probable that the cask will always be at a pressure higher than the surroundings, so the possibility of air entering the cask to cause oxidation of the fuel seems remote. The equations describing these mechanisms are derived and discussed in this section of the Appendix since they are still part of the present models.

A system of equations was developed that defines the rate of flow of fission yases from the casks through a breach in the containment. This system of equations was developed too late to be included in the present loss-of-coolant models, but the equations will be derived and discussed here, since they will be included in the models during later development phases。

The electrical analogs of the loss-of-coolant models are larger and more complex than those of the coolant loss rate models of Section 2 . Consequently, it was not practical to present heat balances for each node as was done for the coolant loss rate models. However, the heat balances are of the same form as those presented in Sections 2.1 and 2.2.

Al1 cask simulation models, except the loss-of-coolant models and the steady-state models, were developed for programming on the MIMIC simulation code. (3) The steady-state pre-accident models and the loss-of-coolant mode1s were programmed on the TAP simulation code. (4) The language and procedures for programming MIMIC closely resemble FORTRAN programming, therefore, MIMIC listings are presented for some of the models, along with a calculation flow diagram or algorithm. The language and procedures for programming a model on TAP, however, are vastly different and unique; consequently, listings of the loss-of-coolant models are not presented, since they would be of little help to one not familiar with the code. However, general algorithms of portions of the models are presented. 
A model simulating the transient behavior of the conceptual LWR cask design following an accident and loss of primary coolant was contructed first, but was sufficiently general to be easily adapted to the IF-300 and AMCO designs. Provision was made for melting of the shield in the model of the lead-shielded conceptual cask, but not in the models of the IF-300 or AMCO casks, because melting of the uranium or steel is not likely.

An idealized model of the IF-300 is shown in Figures $3-1$ and $3-2$. The primary difference between this model and the actual cask is the representation of the fuel, fuel cans, and baskets as circular regions rather than the array of square fuel assemblies (see Figure 3-2). This simplified model was divided into radial nodes as shown in Figure 3-19, and the network of admittances connecting these nodes is shown in Figure 3-20. An idealized representation of the IF-300 was necessary because the array of square fuel assemblies was not symmetrica? (see Figure 3-2).

Unlike the IF-300, the arrangement of the fuel assemblies in the containment vessel of the AMCO cask is symmetrical. This allowed the simulation network to be based on a symmetrical cut of the cask as shown in Figure 3-21. In this mode1, the fuel assembly, the fuel assembly can, and the basket are represented as concentric cylinders divided into radial nodes as shown in Figures $3-3$ and 3-21. The baskets surrounding the fuel assemblies are designed with slotted holes for free passage of the liquid coolant under normal conditions. When the primary coolant is lost, these slots allow heat to be transferred by radiation from the fuel can to the expansion chamber wall and to the canister wall. Heat is also transferred by radiation from the outside surface of this basket to the expansion chariber and canister walis.

The loss-of-coolant models were constructed as hybrid-type computer simulations as diagrammed in Figure 3-4. The models consist of three interacting simulation networks (heat transfer, oxidation, and fission 


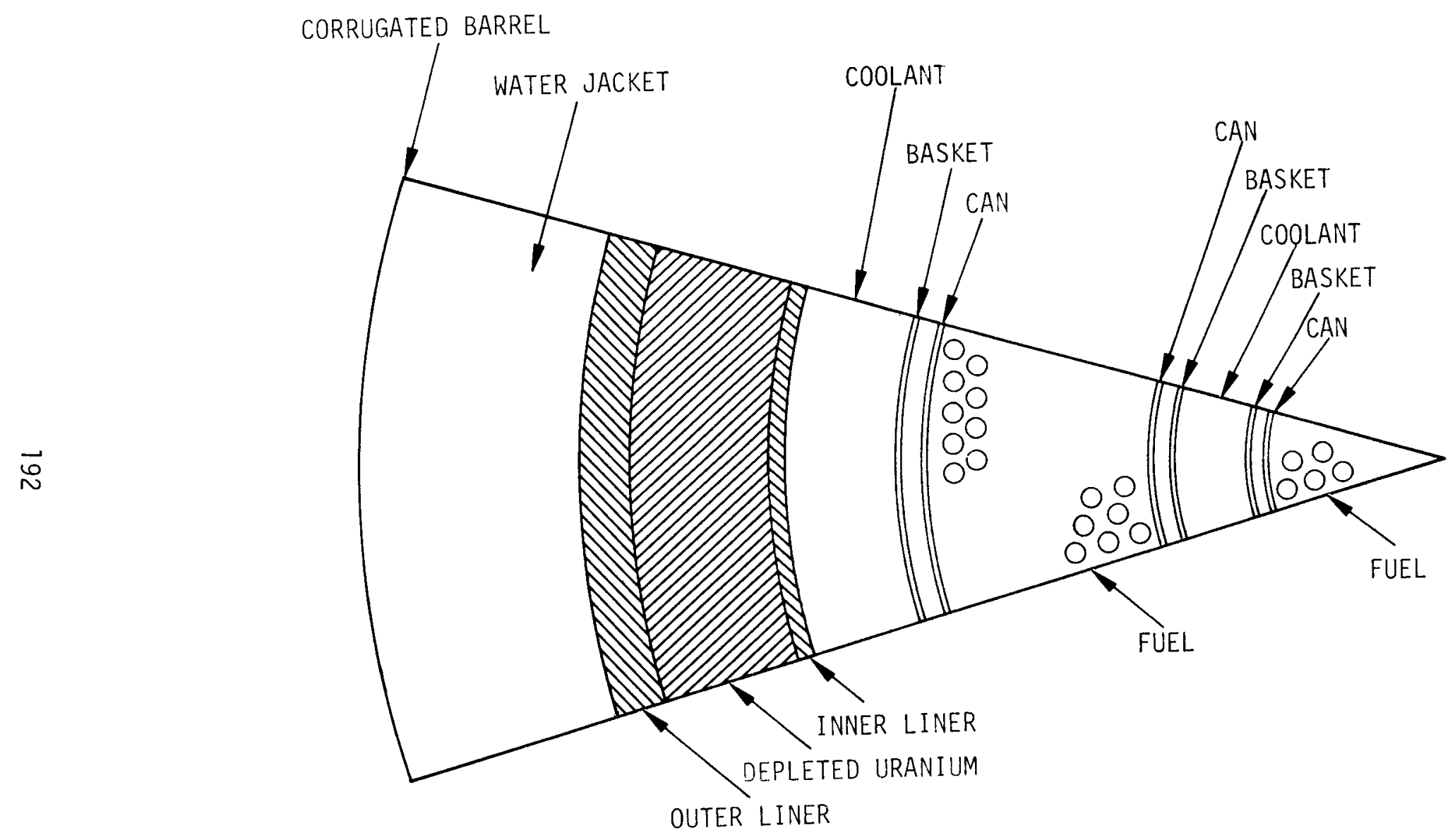

HEDL $7507-30.8$

FIGURE 3-1. Idealized Model of the IF-300 Spent Fuel Shipping Cask 

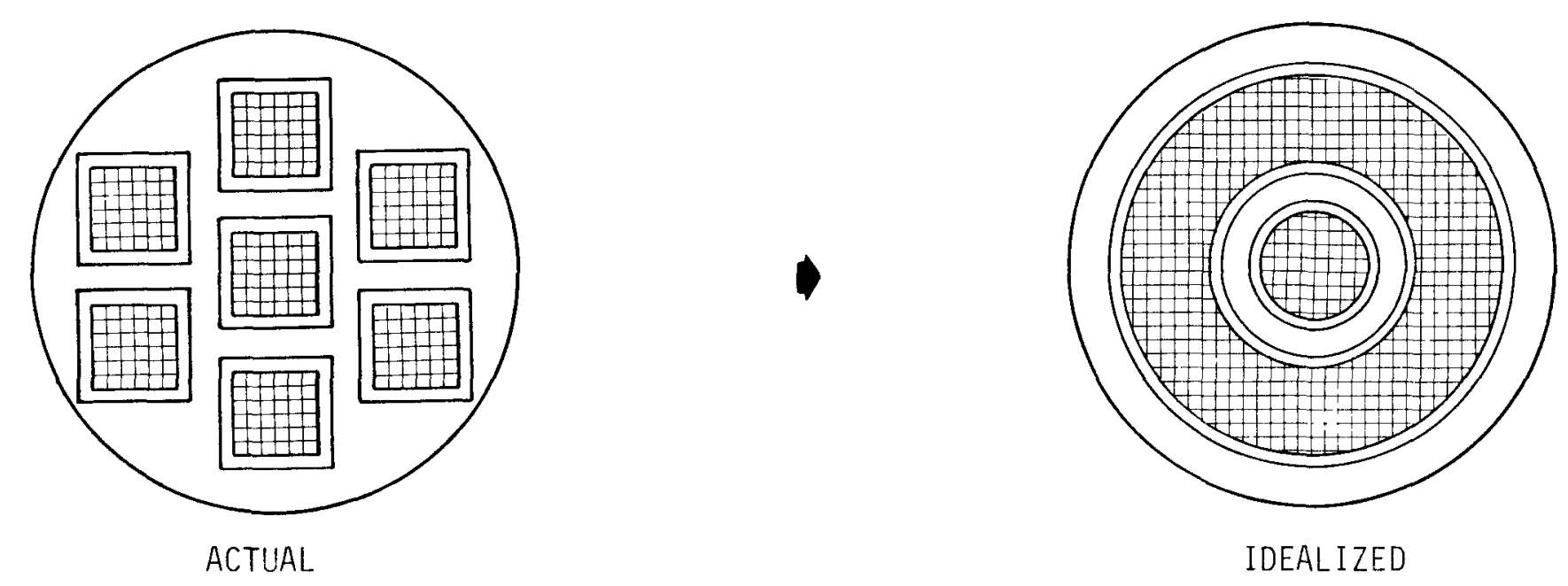

HEDL $7507-30.13$

FIGURE 3-2. Idealized Representation of Fuel Assemblies in the Containment Vessel of the IF-300 


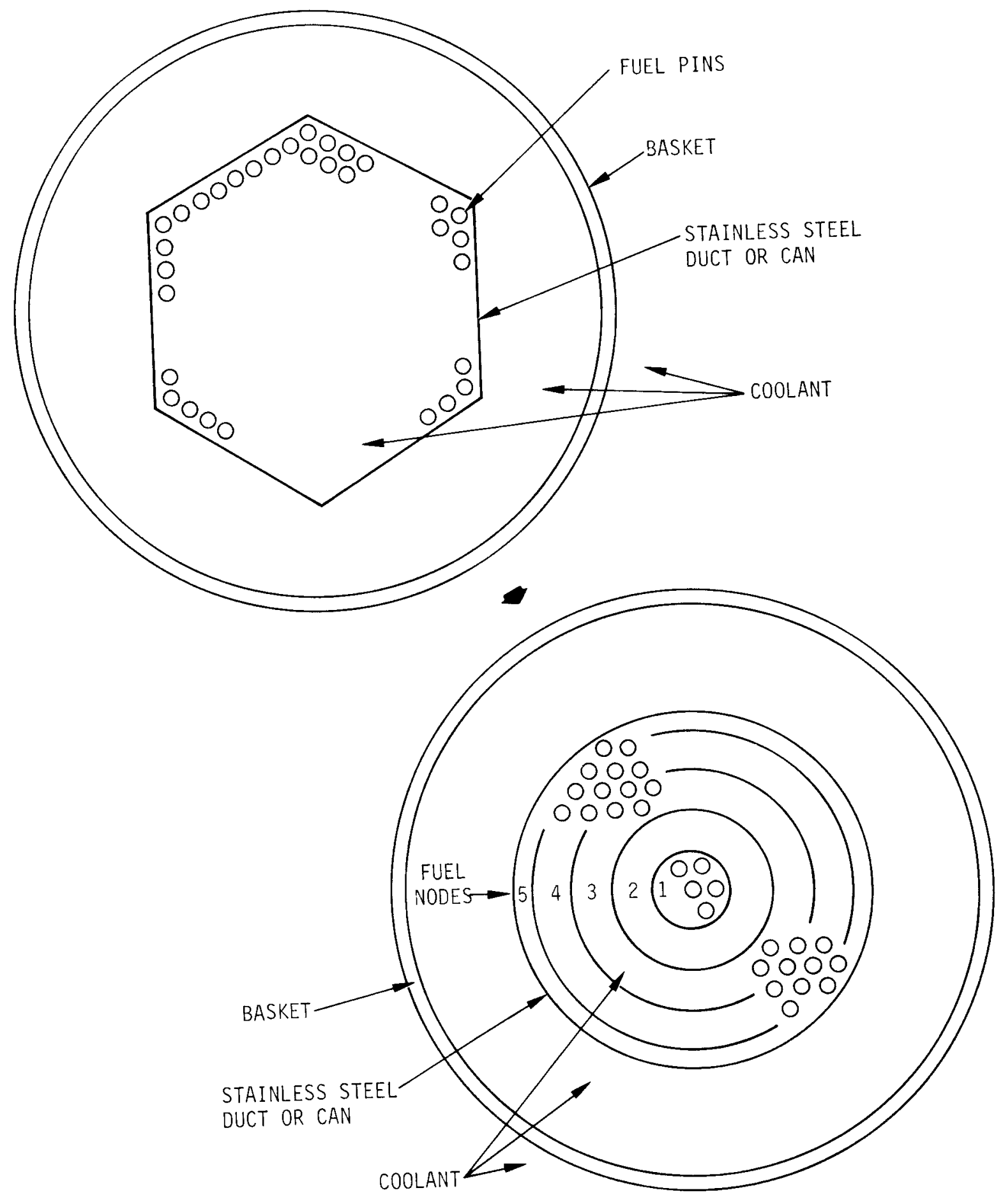

HEDL 7507-30.14

FIGURE 3-3. Idealized Representation of a Fuel Assembly in the AMCO Spent Fuel Shipping Cask 


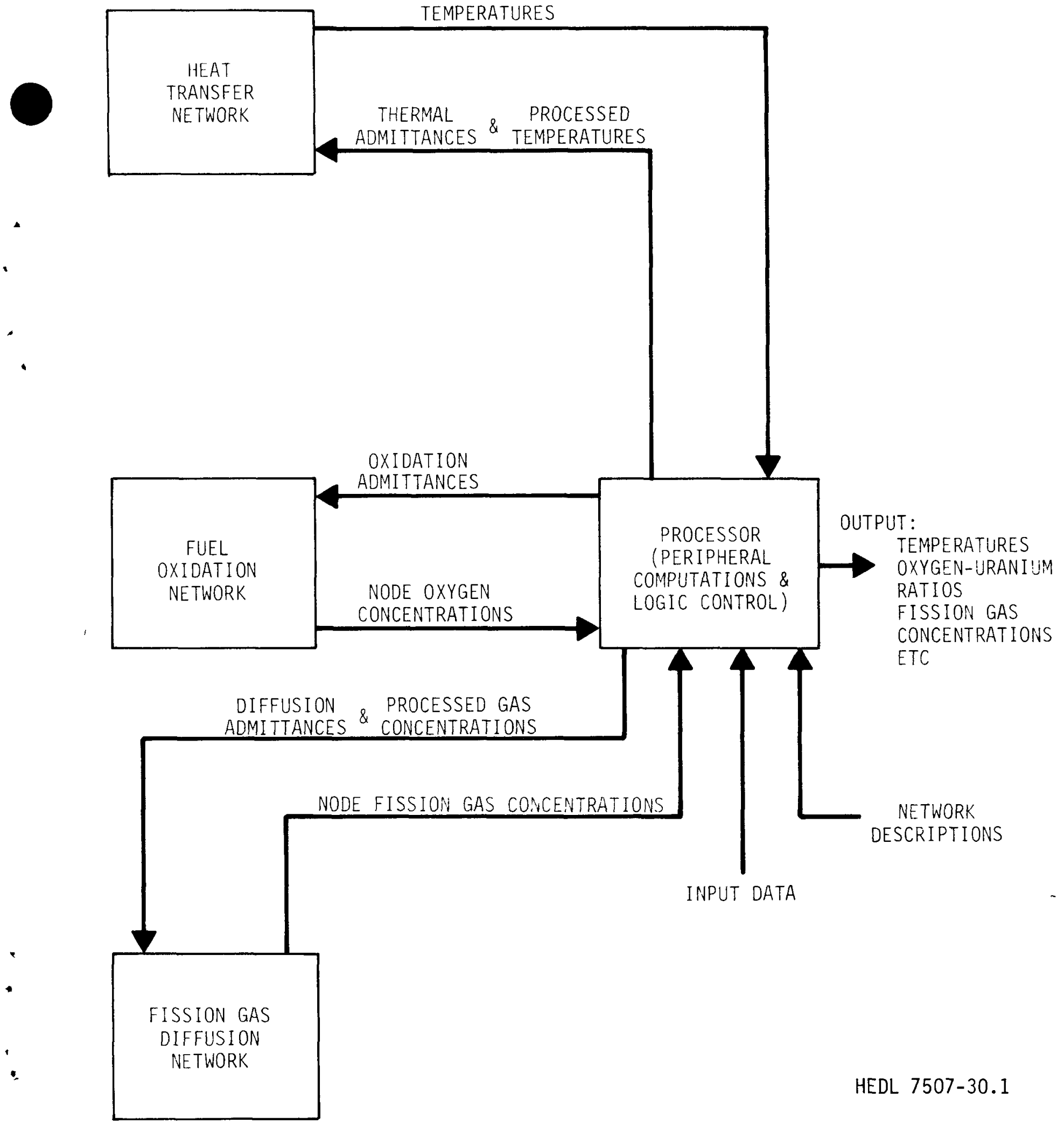

FIGURE 3-4. Hybrid-Type Computer Simulation of Spent Fuel Shipping Cask 
gas diffusion) and a processor for peripheral computations and logic control. The processor controls the network interactions, melting, ${ }^{*}$ thermal radiation, temperature and time varying inputs, various switching circuits and programming of events. This hybrid-type simulation is accomplished using the TAP (Thermal Analyzer Program) Code. (4)

As discussed earlier, in Section 2.2.2, when the solar shield is lost, the cask is exposed to solar heating. A diurnal variation of the solar heat input was used in both of the loss-of-coolant models discussed here, and in the coolant loss rate model presented in Section 2.2.2. It was assumed that the accident occurs at 6:00 a.m. and that the solar heat falls on the casks at a constant rate until 6:00 p.m. when it drops to zero. This variation of solar heating was programmed into the models as a pulsed function of time where this "on-off" characteristic was repeated as long as required. The solar heat reaching the casks was assumed to be one-third of that which would fall on a flat surface. This was an assumed correction factor to allow for the non-flat, $360^{\circ}$ cylindrical surface of a cask. It is impossible for the entire surface of a cask to face the sun.

The cask designs simulated do not have the baskets attached to the inner wall of the containment vessel. If it had been assumed that they had been attached to the containment vessel wall, this would have provided a good path for heat transfer when evaluating conditions following the loss of primary coolant. When bonded to the vessel wall, the baskets act as fins that pick up the heat from the fuel assemblies and transfer it by conduction to the vessel wall. ORNL has assumed this to be the case in some of their earlier studies. (18) When the baskets are not attached to the containment vessel wall, the result is higher fuel temperatures and a shorter time to clad failure and fission product release.

A collection of fuel pins such as in the fuel assemblies have a "Tumped" characteristic. It was necessary to devise a method to "distribute"

*This applies only to the lead-shielded conceptual cask. 
the "lumped" fuel to give homogeneous regions that could then be "relumped" to fit the nodal representation of the networks. This was done by using the concepts of volumetric heat dissipation and an apparent thermal conductivity for materials with voids for heat transfer in the fuel regions, and the concept of volumetric mass dissipation for diffusion of fission gases in the fuel. Representation of the oxidation of the fuel did not require such specialized treatment. The equations defining the heat transfer in the fuel regions, the diffusion of fission gases in the fuel regions, and the oxidation of the fuel, and their electrical analog representations, are presented and discussed in the following sections.

\subsection{Heat Transfer in the Fuel}

\subsubsection{Initial Conditions}

The initial conditions used for the transient loss-of-coolant models are the temperature distributions obtained from either the steady-state pre-accident models or the coolant loss rate models at the time the casks have lost all of their primary coolant. This is illustrated in Figure A-1, which shows the flow of information within the system of simulation models developed. The initial temperatures used in the loss-of-coolant model of the IF-300 are the temperatures obtained from its coolant loss rate models. The initial temperatures used in the loss-of-coolant model of the AMCO cask-are either the final temperatures obtained from its coolant loss rate model for the breach up position, or from its steadystate pre-accident model if the cask is in the breach down position.

\subsubsection{Volumetric Heat Dissipation}

Due to the complexity posed by the "Tumped" nature of the fuel pin bundles, the concept of volumetric heat dissipation, along with that of an apparent thermal conductivity, was used to simplify the simulation of the heat transfer in these bundles or assemblies. These concepts were used to "distribute" the "lumped" fuel to convert the fuel assemblies into 
homogeneous regions which could then be "re-lumped" into nodes for the heat transfer network. The concept of volumetric heat dissipation was also used in the development of the steady-state pre-accident models of Section 1 and the coolant loss rate models of Sections 2.1 and 2.2.

The concept of volumetric heat dissipation and the derivation of a volumetric heat dissipation coefficient have been developed in detail in Section 1.2. The volumetric heat dissipation coefficient is based on the coefficient for heat transfer by natural convection from the fuel pins to the coolant. The natural convection coefficient in Section 1.2 is defined by Equation (1-16), which is McAdam's equation for liquids heated outside single horizontal tubes. (16)

Results from the coolant loss rate models indicate that some residual coolant vapor will remain in the casks after the liquid coolant is gone. This is clearly evident in the case of the IF-300 where the results show that, when the pressure in the cask drops to atmospheric pressure, about 2.0 pounds of steam are left in the cask. This coolant vapor will circulate in the fuel assemblies and in the cask cavity by natural convection, transferring heat from the fuel pins to the inside surface of the cask cavity in the same way the liquid coolant did earlier.

The coefficient for heat transfer from the fuel pins to the coolant vapor is also defined by Equation (1-16), which Stoever (16) states is valid for gases heated by natural convection outside single horizontal tubes. Stoever has evaluated Equation (1-16) for various gases and has presented the results as a base heat transfer coefficient, $h_{0}$, which is a function of the temperature difference between the tube surface and the gas [see Equation $(1-17)]$.

The base coefficient is multiplied by temperature, pressure and tube diameter correction factors to give the heat transfer coefficient for any combination of film temperature, cavity pressure and tube size:

$$
h=h_{0} F_{t} F_{p} F_{d}
$$


where

$F_{t}=$ the temperature correction factor

$F_{p}=$ the pressure correction factor

$F_{d}=$ the tube diameter correction factor.

This was the same procedure followed in Section 2.1.1.3.1. The factors $F_{t}$ and $F_{d}$ are defined by Equations $(1-19),(1-20)$, and $(1-21)$ in Section 1.2, and the factor $F_{p}$ by Equation (2-81) in Section 2.1.1.3.1. Values of these factors are tabulated in Reference 16.

Equivalent forms of Equations (3-2), (1-19), (1-20), (1-21), and (2-81) are programmed into the model to provide the correct heat transfer coefficient during computation of the transient temperatures in the cask.

Dowtherm-A vapor was not among the gases included on Stoever's charts, therefore, it was assumed that this vapor could be represented by steam.

It should be mentioned here that, in both the steady-state preaccident models and the loss-of-coolant models, the coefficient for the transfer of heat by natural convection from the coolant in the cask cavity to the inner surface of the cask cavity was determined using a procedure similar to that outlined here and in Sections 1.2 and 2.1.1.3.1. However, a different heat transfer coefficient equation was used. It was assumed that heat transfer to the inner surface of the cask cavity, and in the outer water jacket, would be the same as that to vertical plates.

The Colburn and Hougen equation was used to determine the heat transfer for both liquids and gases heated by natural convection on vertical plates ${ }^{(16)}$

$$
h=0.128\left(\frac{k_{\rho}^{3}{ }^{2} c_{p} \beta g(\Delta t)}{\mu}\right)^{1 / 3} .
$$

See Equation (1-16) in Section 1.2 for the definitions of the terms used in the above equation. 


\subsubsection{Heat Conduction and Apparent Thermal Conductivity}

When the cask loses its coolant due to the accident, the Maxwell equation is no longer appropriate for determining the apparent thermal conductivity. For this case, a fuel assembly was represented by a fuel pin at the center of the assembly surrounded by a series of concentric "cans" made of fuel material, as shown in Figure 3-5. The cans are separated by spaces filled with residual steam. Heat is assumed to be transferred from the center pin to the nearest can, and from can to can, by radiation and conduction, and by conduction across the can walls. Heat transfer by radiation through the spaces between the fuel pins was not allowed. The apparent thermal conductivity for this configuration was determined using the Euken-Nusselt equation for a body composed of a system of alternate parallel solid plates and steam gaps, (16)

$$
k_{a}=\frac{L_{13}}{\frac{L_{12}}{k_{s}}+\frac{L_{23}}{k_{g, r}}}
$$

where

$$
\begin{aligned}
L_{12}= & \text { the thickness of the plate or can wall, L } \\
L_{23}= & \text { the thickness of the gap separating the cans, } L \\
L_{13}= & L_{12}+L_{23}, L \\
k_{g, r}= & \text { the thermal conductivity of the gap, including the } \\
& \text { effect of radiation, H/ } \mathrm{ALT} .
\end{aligned}
$$

The thermal conductivity, $\mathrm{k}_{\mathrm{g}, \mathrm{r}}$, is obtained by combining the heat transferred across the gap by conduction with that transferred by radiation. The heat transferred across the gap is

$$
q_{23}=q_{c}+q_{r}=\frac{k_{g, r} A}{L_{23}}\left(T_{2}-T_{3}\right),
$$




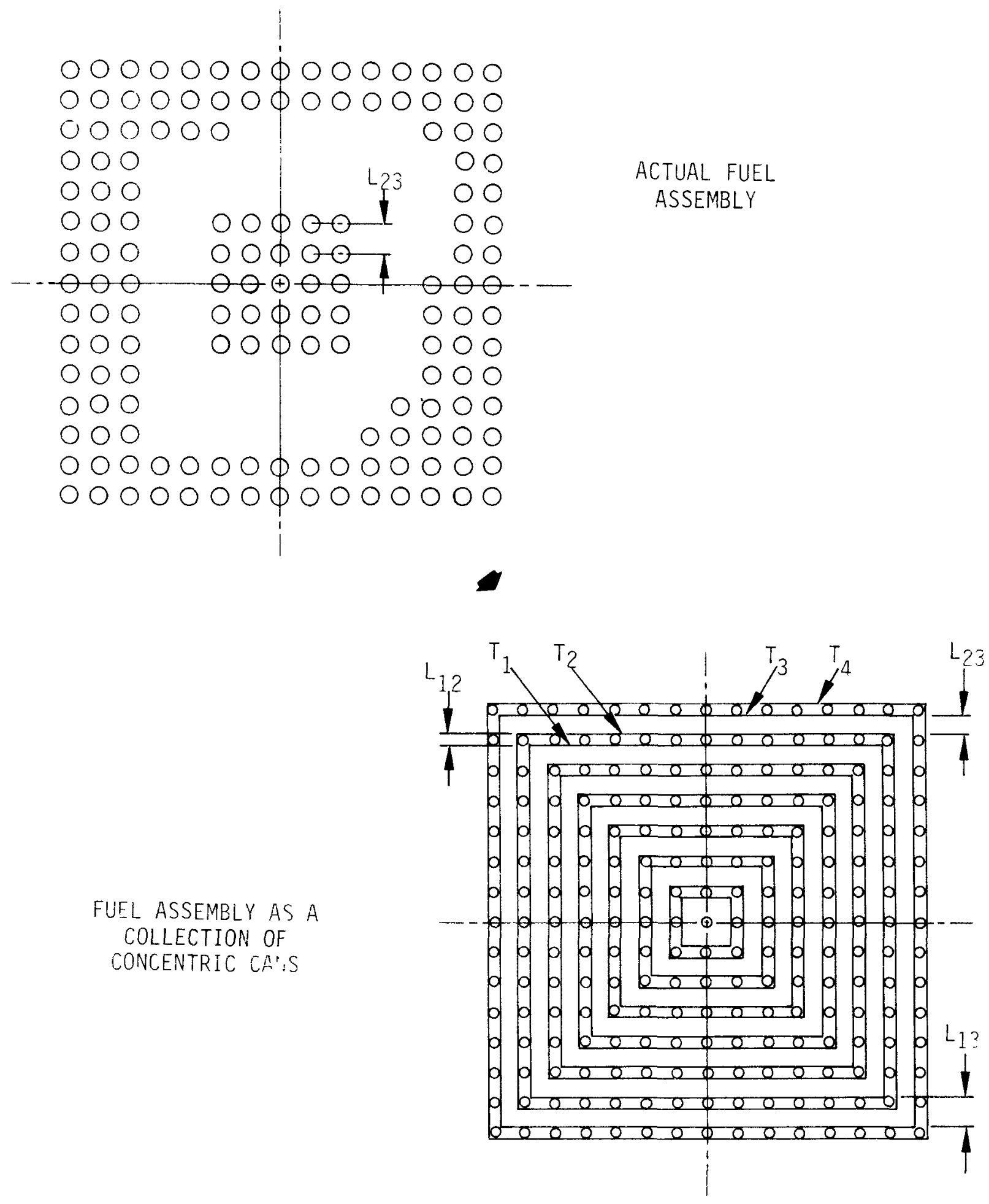

HEDL $7507-30.16$

FIGURE 3-5. Representation of PWR Fuel Assembly as a collection of Concentric Cans 
where the conduction component is

$$
q_{c}=k_{g} \frac{A}{L_{23}}\left(T_{2}-T_{3}\right)
$$

and the radiation component is

$$
\mathrm{q}_{r}=A F_{23} \sigma\left(\mathrm{T}_{2}^{4}-\mathrm{T}_{3}^{4}\right)
$$

where

$$
\begin{aligned}
F_{23}= & \text { the combined emissivity and shape factor for } \\
& \text { radiant energy transfer between surfaces } 2 \\
& \text { and } 3 \\
\sigma= & \text { the Stefan-Boltzmann constant, } H / \theta L T^{4} .
\end{aligned}
$$

If the radiation component is written in terms of an equivalent thermal conductivity for radiation, then Equation (3-7) becomes

$$
q_{r}=k_{r} \frac{A}{L_{23}}\left(T_{2}-T_{3}\right)
$$

where

$$
\begin{aligned}
k_{r}= & \text { the equivalent thermal conductivity for radiation, } \\
& H / \theta L T \text {. }
\end{aligned}
$$

Since Equations (3-7) and (3-8) are equivalent, they may be combined to give

$$
k_{r} \frac{A}{L_{23}}\left(T_{2}-T_{3}\right)=A E_{23} \sigma\left(T_{2}^{4}-T_{3}^{4}\right)
$$


or

$$
k_{r}=\frac{E_{23} \sigma\left(\mathrm{T}_{2}^{4}-\mathrm{T}_{3}^{4}\right) \mathrm{L}_{23}}{\mathrm{~T}_{2}-\mathrm{T}_{3}} \text {. }
$$

If $T_{2}$ is nearly equal to $T_{3}$, then differentials may be used in Equation (3-10) instead of the differences,

$$
k_{r}=F_{23} \sigma \frac{d T^{4}}{d T} L_{23}
$$

Now

$$
\frac{d}{d T}\left(T^{4}\right)=4 T^{3}
$$

therefore Equation $(3-11)$ becomes

$$
k_{r}=4 E_{23} \sigma T^{3} L_{23}
$$

Substititution of Equations (3-6) and (3-8) into (3-5) yields

$$
k_{g}, r \frac{A}{L_{23}}\left(T_{2}-T_{3}\right)=k_{g} \frac{A}{L_{23}}\left(T_{2}-T_{3}\right)+\frac{k_{r} A}{L_{23}}\left(T_{2}-T_{3}\right)
$$

or

$$
k_{g, r}=k_{g}+k_{r}
$$

Substituting from Equation (3-13) gives

$$
k_{g, r}=k_{g}+4 l_{23} u T^{3} L_{23} .
$$


The apparent thermal conductivity is then obtained by substituting the expression for $k_{g, r}$ in Equation (3-4),

$$
k_{a}=\frac{L_{13}}{\frac{L_{12}}{k_{s}}+\frac{L_{23}}{k_{g}+4 F_{23} \sigma T^{3} L_{23}}} \text {. }
$$

The neat transferred between fuel nodes in the heat transfer network is:

$$
q=\frac{k_{a} A}{L}\left(T_{m+1}-T_{m}\right)=Y_{K}\left(T_{m+1}-T_{m}\right)
$$

where

$$
\begin{aligned}
q & =\text { the heat transferred, } H / \theta, \\
A & =\text { the heat transfer area, } L^{2} \\
L & =\text { the path length, } L \\
T_{m} & =\text { temperature of node } m, T, \\
Y_{K} & =\text { the heat conduction admittance, } H / \theta T . \\
& =k_{a} A / L .
\end{aligned}
$$




\subsection{Fission Product Release Mechanisms}

Several possible mechanisms for the release of fission products from the spent fuel were postulated during the initial phases of model construction. other possible mechanisms were suggested later as more information became available and the results of cask behavior were revealed by analyses using the simulation models. Since most of the fission products that could be released from the fuel assemblies in the casks are fission gases and volatile solids or solid fission products (cesium compounds), the mechanisms governing their release were included early in the development of the loss-of-coolant models.

During reactor operation, fission gases are generated. Some of these gases migrate to the fuel pin voids, i.e., the space between the clad and the fuel, between fuel pellets, and in the plenum or expansion chamber at the end of a pin. These are referred to in this report as "free" gases.

An evaluation of the fission product release from the IF-300 was made assuming that the seven fuel assemblies in the cask were the Design Basis PWR 1 fuel assemblies of Table III- 1 in Reference 1. Characteristics of this fuel are presented in Tables 1 and 2 . The calculated fission product inventory and activity for this spent fuel after 90 days cooling time were derived from data presented in References 1 and 74 . The fission products considered and the number of grams and curies of each in the inventory are given in Table 3-1. According to Reference 1, only about 33\% of the fission gases in this inventory (35\% of the $\mathrm{Kr}-85$ and I-129, and $3 \%$ of the $\mathrm{Xe}$ and I-131) is expected to migrate to the fuel pin voids during reactor operation and be available for release if the clads burst. The calculated amounts of radioactivity in the fission products generated in the Design Basis PWR 1 fuel and the amounts that have migrated to the fuel pin voids are presented in Table 3-2. The radioactivity of the fission products in the spent fue 1 in the IF-300 and the estimated amounts released are presented in Table 3-3.

The AMCO cask carries nine fuel assemblies of the type shown in Figure 6 . It was assumed that these fuel assemblies were average assemblies, i.e., each had been operating in the reactor at an average power of $5.2 \mathrm{MW}$. The 
Comparison of Fission Product Inventories Calculated to Be Present in the IF-300 Design Basis PWR 1 Spent Fuel and in Spent Diablo Canyon Reference PWR Fuel.

(Compiled from References 1 and 14)

\begin{tabular}{|c|c|c|c|c|}
\hline \multicolumn{5}{|c|}{ Fission Product Inventories } \\
\hline \multicolumn{5}{|c|}{ Cooling Time $=90$ Days } \\
\hline \multirow[t]{2}{*}{ Isotope } & \multicolumn{2}{|c|}{$\begin{array}{l}\text { IF-300 Design Basis } \\
\text { PWR } 1 \text { Spent Fuel (1) }\end{array}$} & \multicolumn{2}{|c|}{$\begin{array}{l}\text { Spent Diablo Canyon } \\
\text { Reference PWR Fuel }\end{array}$} \\
\hline & $\begin{array}{l}\text { Total } \\
\text { Generated* } \\
\left(C_{i} / \text { MTU }\right)\end{array}$ & $\begin{array}{l}\text { Total } \\
\text { Generated* } \\
\text { (Grams/MTU) }\end{array}$ & $\begin{array}{l}\text { Total } \\
\text { Generated** } \\
\left(C_{i} / \text { MTU }\right)\end{array}$ & $\begin{array}{l}\text { Total } \\
\text { Generated** } \\
\text { (Grams/MTU) }\end{array}$ \\
\hline $\begin{array}{l}\mathrm{Kr} \\
\mathrm{Xe} \\
\mathrm{I} \\
\mathrm{Cs}\end{array}$ & $\begin{array}{r}10500 . \\
169 . \\
535 . \\
\sim 353000 . * \star \star\end{array}$ & $\begin{array}{c}377 . \\
5836 . \\
249 . \\
\sim 2910 . \star \star \star\end{array}$ & $\begin{array}{r}11300 . \\
117 \\
381 \\
333000\end{array}$ & $\begin{array}{r}374 . \\
5420 . \\
271 \\
2740\end{array}$ \\
\hline TOTALS & 364204 . & 9372. & 344798. & 8805. \\
\hline \multicolumn{2}{|c|}{ * $E=35 \frac{G W D}{\text { MTU }}$} & \multicolumn{3}{|c|}{$\star \star E=33 \frac{G W D}{M T U}$} \\
\hline \multicolumn{2}{|c|}{$P_{0}=40 \frac{\mathrm{KW}}{\mathrm{KgU}}$} & \multicolumn{3}{|c|}{$P_{0}=30 \frac{\mathrm{KW}}{\mathrm{KgU}}$} \\
\hline
\end{tabular}

*** The amounts shown here are reasonably close despite the differences in conditions. Tables IX-1 through IX-3 in Reference 1 indicate that changes in inventory due to specific power are small while the changes due to exposure are large, therefore, approximate concentrations for cesium were obtained by multiplying the values for the Diablo Canyon fuel by the ratio of the exposures. 
Calculated Amounts of Radioactivity in Fission Products Generated in Desian Basis PWR 1 Fuel and the Amounts That Have Migrated to the Fuel Pin Voids

(Compiled from data presented in References 1 and 14)

\begin{tabular}{|c|c|c|c|c|}
\hline \multicolumn{5}{|c|}{ Fission Product Inventory } \\
\hline \multicolumn{5}{|c|}{ Cooling Time $=90$ Days } \\
\hline Isotope & $\begin{array}{c}\text { Total Generated } \\
\text { in the Fue } 1 \\
\left(C_{i} / \text { MTU }\right)\end{array}$ & $\begin{array}{l}\text { Total in the } \\
\text { Fuel Pin Voids } \\
\left(C_{i} / \text { MTU }\right)\end{array}$ & $\begin{array}{c}\text { Total Generated } \\
\text { Present in } 7 \\
\text { Fuel Assemblies } \\
\text { (Curies) }\end{array}$ & $\begin{array}{c}\text { Total in the Pin } \\
\text { Voids in } 7 \text { Fue } 1 \\
\text { Assemblies } \\
\text { (Curies) }\end{array}$ \\
\hline $\begin{array}{c}\mathrm{Kr}-85 \\
X E-131 \mathrm{~m} \\
X E-133 \\
\mathrm{I}-129 \\
\mathrm{I}-131 \\
\mathrm{CS}\end{array}$ & $\begin{array}{c}10500 . \\
150 . \\
19 . \\
0.03 \\
535 . \\
353000 .\end{array}$ & $\begin{array}{c}3675 . \star \\
4.5^{\star \star} \\
0.6^{\star \star} \\
0.01^{\star \star} \\
16.1^{\star \star} \\
3530 . \star \star \star\end{array}$ & $\begin{array}{c}33339.60 \\
476.21 \\
60.2 \\
0.098 \\
1698.69 \\
1120838.24\end{array}$ & $\begin{array}{c}11668.86 \\
23.81 \\
3.01 \\
0.0049 \\
84.934 \\
11208.382\end{array}$ \\
\hline $\begin{array}{c}\text { Total } \\
\text { Fission } \\
\text { Gases }\end{array}$ & 11204.03 & 3696.21 & 35574.798 & $11780.618 * * * *$ \\
\hline $\begin{array}{l}\text { Total } \\
\text { Cesium }\end{array}$ & 353000 . & 3530. & 1120838.24 & $11208.382 * \star \star \star *$ \\
\hline $\begin{array}{l}\text { Total } \\
\text { Fission } \\
\text { Products }\end{array}$ & 364204.03 & 7226.21 & 1156413.04 & 22989.0 \\
\hline
\end{tabular}

* Based on $35 \%$ migration to pin voids.

** Based on $5 \%$ migration to pin voids.

$* * *$ Based on $1 \%$ migration to pin voids.

$\star \star \star \star$ These values are about $1 \%$ less than those used in the model due to slight conversion errors. 
Radioactivity of the Fission Products in the Spent Fuel in the IF-300 and Estimated Amounts Released.

\begin{tabular}{|c|c|c|c|c|c|c|}
\hline \multirow{3}{*}{$\begin{array}{c}\text { Fuel Node } \\
\text { in } \\
\text { Loss-of- } \\
\text { Coolant } \\
\text { Model }\end{array}$} & \multicolumn{3}{|c|}{ Initially in the Fuel } & \multicolumn{3}{|c|}{ Released from the Fue 1} \\
\hline & \multicolumn{2}{|c|}{$\begin{array}{c}\text { Fission Gases } \\
\text { (Curies) }\end{array}$} & \multirow[t]{2}{*}{$\begin{array}{l}\text { Cesium } \\
\text { (Curies) }\end{array}$} & \multicolumn{2}{|c|}{$\begin{array}{c}\text { Fission Gases } \\
\text { (Curies) }\end{array}$} & \multirow[t]{2}{*}{$\begin{array}{l}\text { Cesium } \\
\text { (Curies) }\end{array}$} \\
\hline & $\mathrm{Kr}$ & $\mathrm{Xe}+\mathrm{I}$ & & $\mathrm{kr}$ & $X e+I$ & \\
\hline 1 & 792.3 & 53.2 & & 277.3 & 1.596 & \\
\hline 2 & 2376.2 & 159.5 & & 831.7 & 4.785 & \\
\hline 3 & 1659. & 111.3 & & 580.7 & 3.34 & \\
\hline 7 & 6200. & 476.1 & & 2170 & 12.48 & \\
\hline 8 & 8712.6 & 584.7 & & 3049. & 17.54 & \\
\hline 9 & 10296.6 & 691. & & 3604 . & 20.73 & \\
\hline 10 & 3774.2 & 253.3 & & 1321. & 7.6 & \\
\hline Totals & 33810.9 & 2269.1 & 11208.382 & 17833.7 & 68.07 & 112.08 \\
\hline TOTALS & \multicolumn{2}{|c|}{36080 . } & 11208.382 & \multicolumn{2}{|c|}{$11901.77^{\star}$} & $112.08 *$ \\
\hline
\end{tabular}

* These values are slightly less than those obtained from the model due to small conversion errors. 
calculated fission product inventory and activity for this spent fuel after 120 days cooling time were derived from results presented in Reference 11 for FFTF fuel assemblies that had been operating at $7.0 \mathrm{MW}$ each. The fission gases considered and the number of gram-atoms of each in the FFTF fuel are presented in Table 3-4. The calculated radioactivities of these fission gases are presented in Tables 3-5 and 3-6. The fraction of this inventory of fission gases that is expected to migrate to the fuel pin voids during operation and be available for release, if the clads burst, was calculated using the following equation (19)

$$
f=1-\frac{\left[\frac{1-\exp \left(-6.84 \times 10^{-5} B\right)}{6.84 \times 10^{-5} B}\right]}{[0.421 \exp (0.05 Q)]}
$$

where

$$
\begin{aligned}
& f=\text { the fractional release } \\
& Q=\text { the local linear heat rate, } k w / f t \\
& B=\text { the local burnup, MWD/MT. }
\end{aligned}
$$

It was determined that the local linear heat rate was about $8 \mathrm{kw} / \mathrm{ft}$. The local burnup was about 50,000 MWD/MT. Using these input values, a fractional release of 0.56 was calculated using Equation (3-18).

The remaining fission gases produced are bound up in the interstices of the fuel material and are referred to as "bound up" gases in this report.

The equations describing the various fission product release mechanisms and an explanation of how they were incorporated into the loss-ofcoolant models are presented in the following sections. The mechanisms to be discussed are:

1. Fuel pin clad failure caused by expansion of the free gases, resulting in their release,

2. Diffusion of the bound up fission gases from the fuel following clad failure, and 
Total Amounts of Significant Gaseous Fission Product Elements Calculated to be Present in Spent FTR (FFTF) Fue 1 - 100 Days Decay Time ${ }^{\dagger}$.

\section{(Reference 11)}

\begin{tabular}{|c|c|c|}
\hline Element & Gram - Atoms* & $\begin{array}{c}\text { Gram }- \text { Atoms } \\
\text { Per Piri** }\end{array}$ \\
\hline Tritium) & Negligible & - \\
\hline $\mathrm{Kr}$ & 10.30 & 0.00650 \\
\hline $\mathrm{I}$ & 7.64 & 0.000482 \\
\hline $\mathrm{Xe}$ & 108.50 & 0.006849 \\
\hline Br & Negligible & - \\
\hline & & \\
\hline TOTALS & 126.44 & 0.007981 \\
\hline
\end{tabular}

* No. of metric tons charged $=2.52$

$\star * 73$ drivers with 217 pins each $=15,841$ pins

+ Good for decay times of 100 days and 120 days

Conditions:

1. Power $=159 \frac{M W}{M T}(400 \mathrm{MW}$ in FTR)

2. Burnup $=50000 \frac{M W D}{M T}$

3. Flux $=7 \times 10^{15} \mathrm{n} / \mathrm{cm}^{2}-\mathrm{sec}$ 
Calculated Radioactivity (Total) of Gaseous

Fission Product Elements Present in Spent

FFTF Reference Core Fuel

(120 Days Decay Time)

(Reference 11)

\begin{tabular}{|c|c|c|c|c|}
\hline Element & $\begin{array}{c}\text { Curies, per Metric } \\
\text { Ton Charged }\end{array}$ & Curies & $\begin{array}{c}\text { Ave. Curies } \\
\text { per Pin }\end{array}$ & Percent \\
\hline $\mathrm{Kr}_{85}$ & $9,115$. & $22,969.800$ & 1.39278 & 97.69 \\
\hline $\mathrm{Xe}_{131 \mathrm{~m}}$ & 69.60 & 175.392 & 0.01063 & 0.75 \\
\hline $\mathrm{Xe}_{133}$ & 1.40 & 3.528 & 0.00021 & 0.02 \\
\hline $\mathrm{I}_{131}$ & 144. & 362.880 & 0.02200 & 1.54 \\
\hline $\mathrm{I}_{129}$ & 0.51 & 1.285 & 0.00008 & 0.01 \\
\hline TOTALS $_{130}$ & $9,330.51$ & $23,512.885$ & 1.42570 & 100.01 \\
\hline
\end{tabular}

* No. of metric tons charged in FTR $=2.52$.

$\star *$ No. of fuel pins in the core $=16,492$ (includes equivalent drivers in test elements).

Conditions:
1. Power $=159 \frac{\mathrm{MW}}{\mathrm{MT}}$
2. Burnup $=48,000 \frac{\text { MWD }}{\text { MT }}$
3. Flux $=7 \times 10^{15} \mathrm{n} / \mathrm{cm}^{2}-\mathrm{sec}$ 
Radioactivity in the Fission Gases in the

AliCO Spent Fuel Shipping Cask

(120 Days Decay Time)*

\begin{tabular}{|c|c|c|c|}
\hline $\begin{array}{c}\text { Node in } \\
\text { Loss-of-Coolant } \\
\text { Model }\end{array}$ & $\begin{array}{c}\text { Free } \\
\text { Gases } \\
\text { (Curies) }\end{array}$ & $\begin{array}{c}\text { Bound up } \\
\text { Gases } \\
\text { (Curies) }\end{array}$ & $\begin{array}{c}\text { Total } \\
\text { Gases } \\
\text { (Curies) }\end{array}$ \\
\hline 1 & 74 & 58 & 132 \\
\hline 2 & 221 & 174 & 395 \\
\hline 3 & 369 & 290 & 659 \\
\hline 4 & 520 & 408 & 928 \\
\hline 5 & 354 & 278 & 632 \\
\hline TOTALS & 1538 & 1208 & 2746 \\
\hline
\end{tabular}

* Based on nine average fuel elements in the cask, each of which had been operating at $5.2 \mathrm{MW}$. 
3. Release of bound u' fission gases following disintegration of the fuel due to oxidation. If failure of the pin clads exposes the fuel to air in the containment vessel, the $\mathrm{UO}_{2}$ will oxidize to $\mathrm{U}_{3} \mathrm{O}_{8}$, a loose granular material, from which the bound up gases are released.

\subsubsection{Fuel Pin Internal Pressures and Clad Stresses}

The pressure buildup of the fission gases in the pins as a function of time following loss of the primary coolant is presented in Figures 3-6 through 3-9 for the IF-300, and in Figure 3-10 for the AMC0 cask. The pressure in the pin voids is plotted for each fuel node of the cask simulation models shown in Figures 3-19, 3-20, and 3-21. The pressure which gives a hoop stress exceeding the creep rupture strength of the pin cladding at the fuel node temperature is also shown in Figures 3-6 through 3-9 as the burst pressure.

The void region in the fuel pin consists of the plenum space, the gap between the fuel and the clad, and the spaces between fuel pellets. The plenum space for a reference pressurized water reactor (PWR) fuel pin is illustrated in Figure 4, and the pertinent design dimensions are given in Table 2. $(1,8)$ The length of the plenum space in the FFTF driver fuel pin carried in the AMCO cask is presented in Table 4.

The circumferential or hoop stresses in the cladding of the pins in the fuel nodes are presented as functions of time after impact and fire in Figures 3-11 through 3-14 for the IF-300, and in Figure 3-15 for the AMCO cask. These figures not only show the hoop stresses as functions of time, but also present creep rupture strength curves for the pin clads in each node. The node temperatures are implicit in the results.

The strength of the fuel pin clad material is an important factor in determining the time when the clads will fail. The pin clads will fail when the hoop stresses exceed the strength of the clad material. At the present stage of model development, the strength of the clad material is assumed to follow a creep rupture strength vs. temperature relationship. This is only temporary until the model can be modified to calculate cladding failure based on the time-temperature dependent creep-rupture technique of 


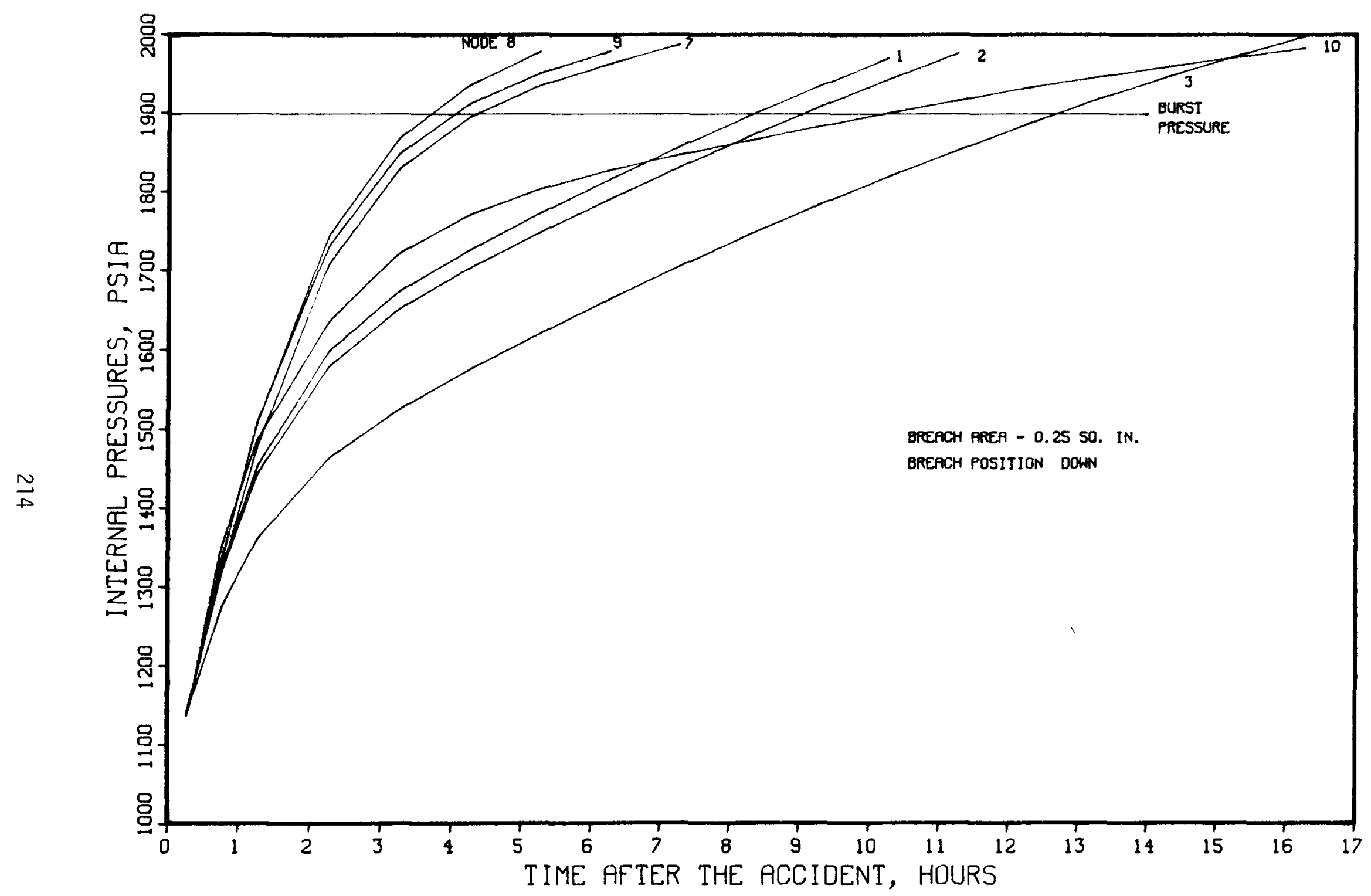

FIGURE 3-6. Pressures in the Fuel Pins in the IF-300 (Zircaloy-4, 10 Hour Creep Rupture) 


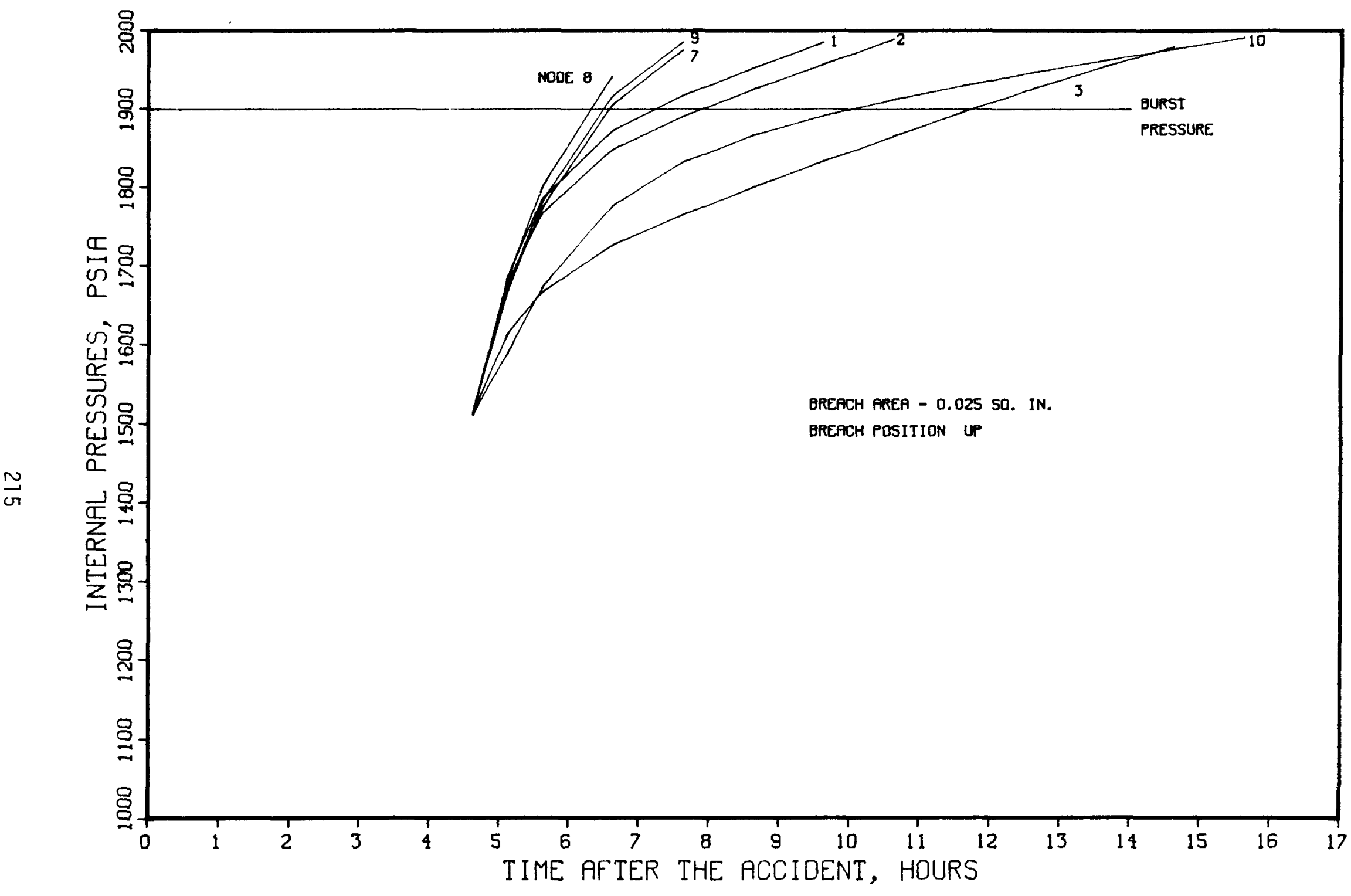

FIGURE 3-7. Pressures in the Fuel Pins in the IF-300 (Zircaloy-4, 10 Hour Creep Rupture) 


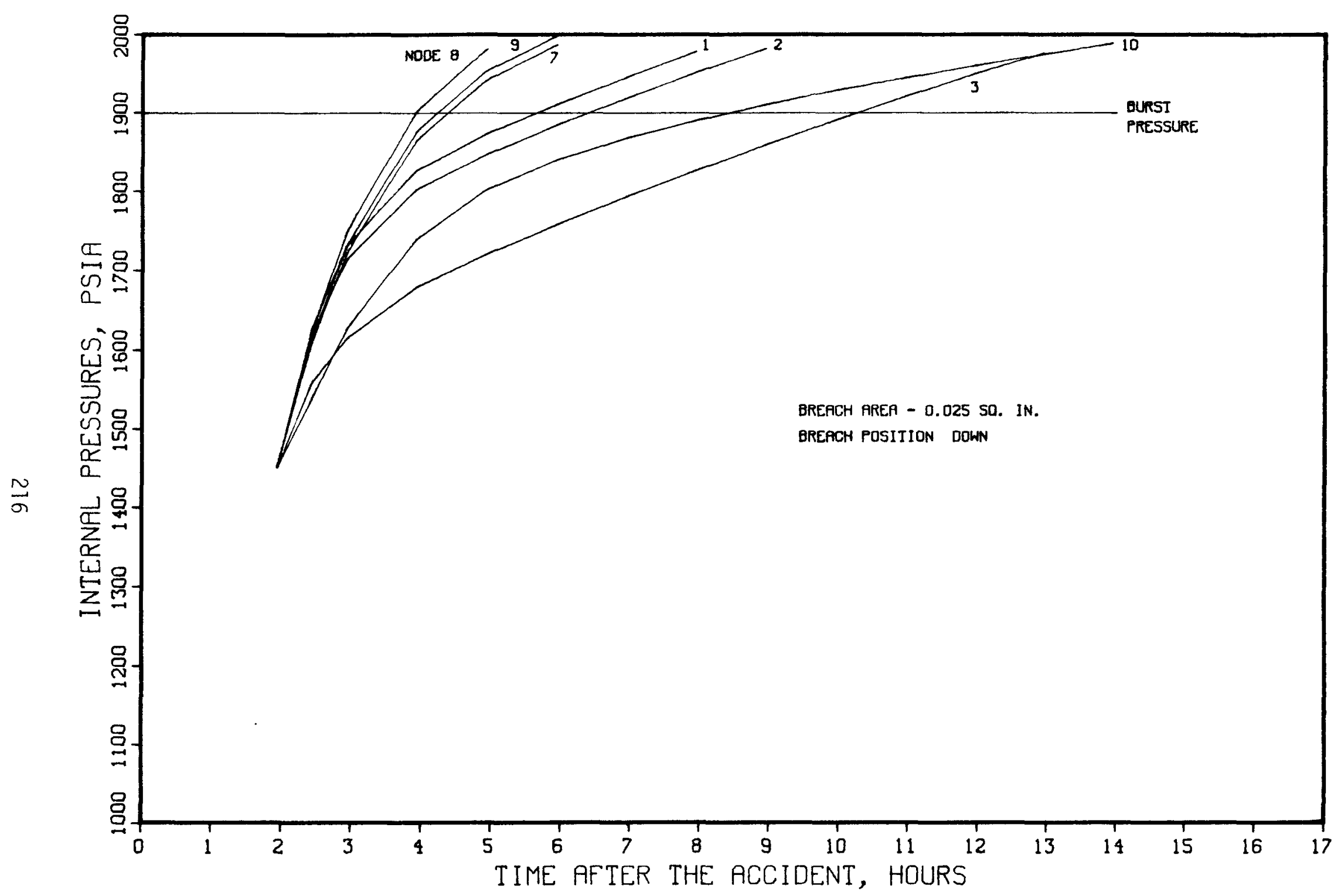

FIGURE 3-8. Pressures in the Fuel Pins in the IF-300 (Zircaloy-4, 10 Hour Creep Rupture) 


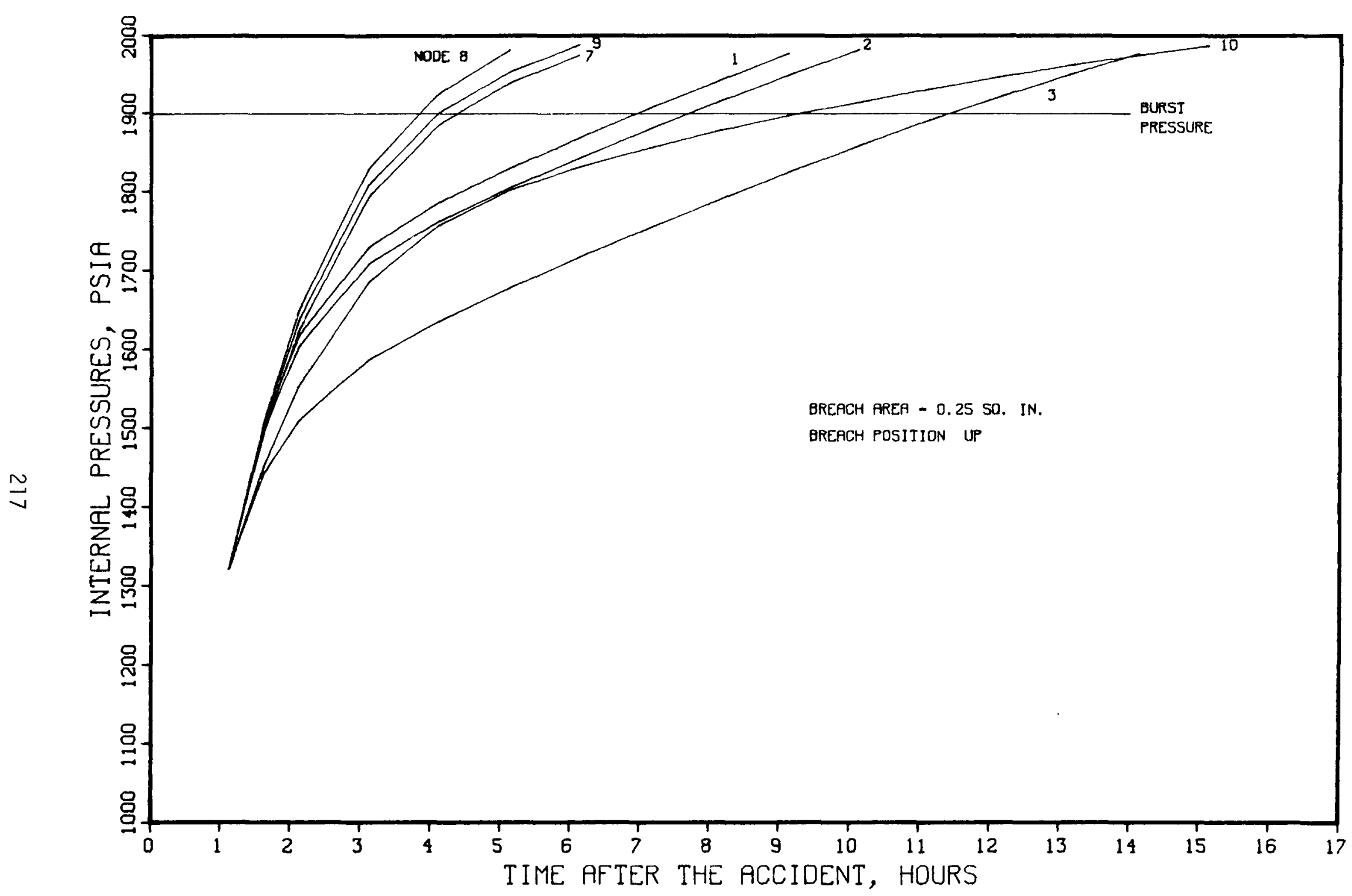

FIGURE 3-9. Pressures in the Fuel Pins in the IF-300 (Zircaloy-4, 10 Hour Creep Rupture) 


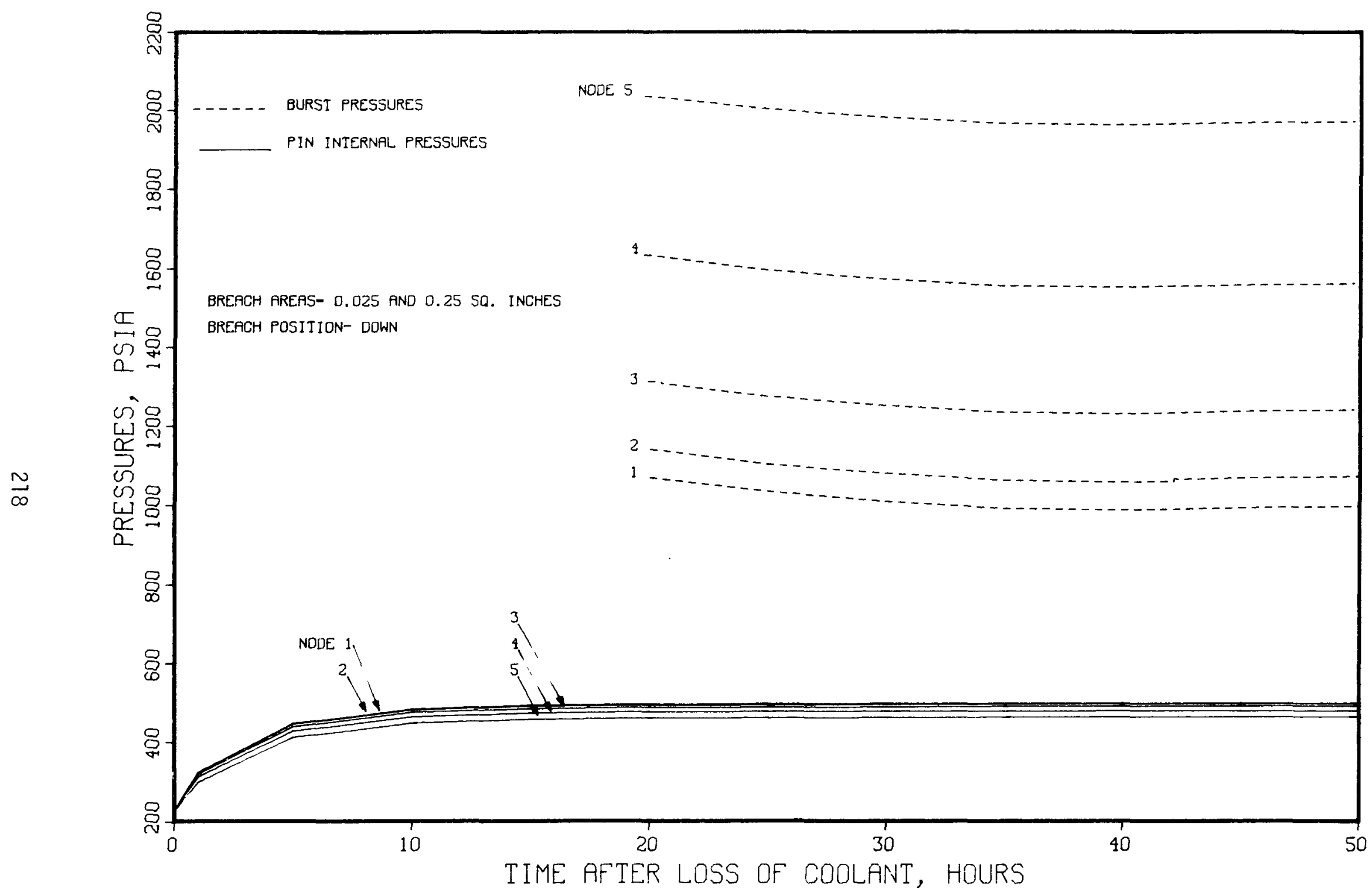

FIGURE 3-10. Pressures in the Fuel Pins in the AMCO Cask for Breach Areas of 0.025 and $0.25 \mathrm{Sq}$. Inches (for Cask in Breach Down Position) 


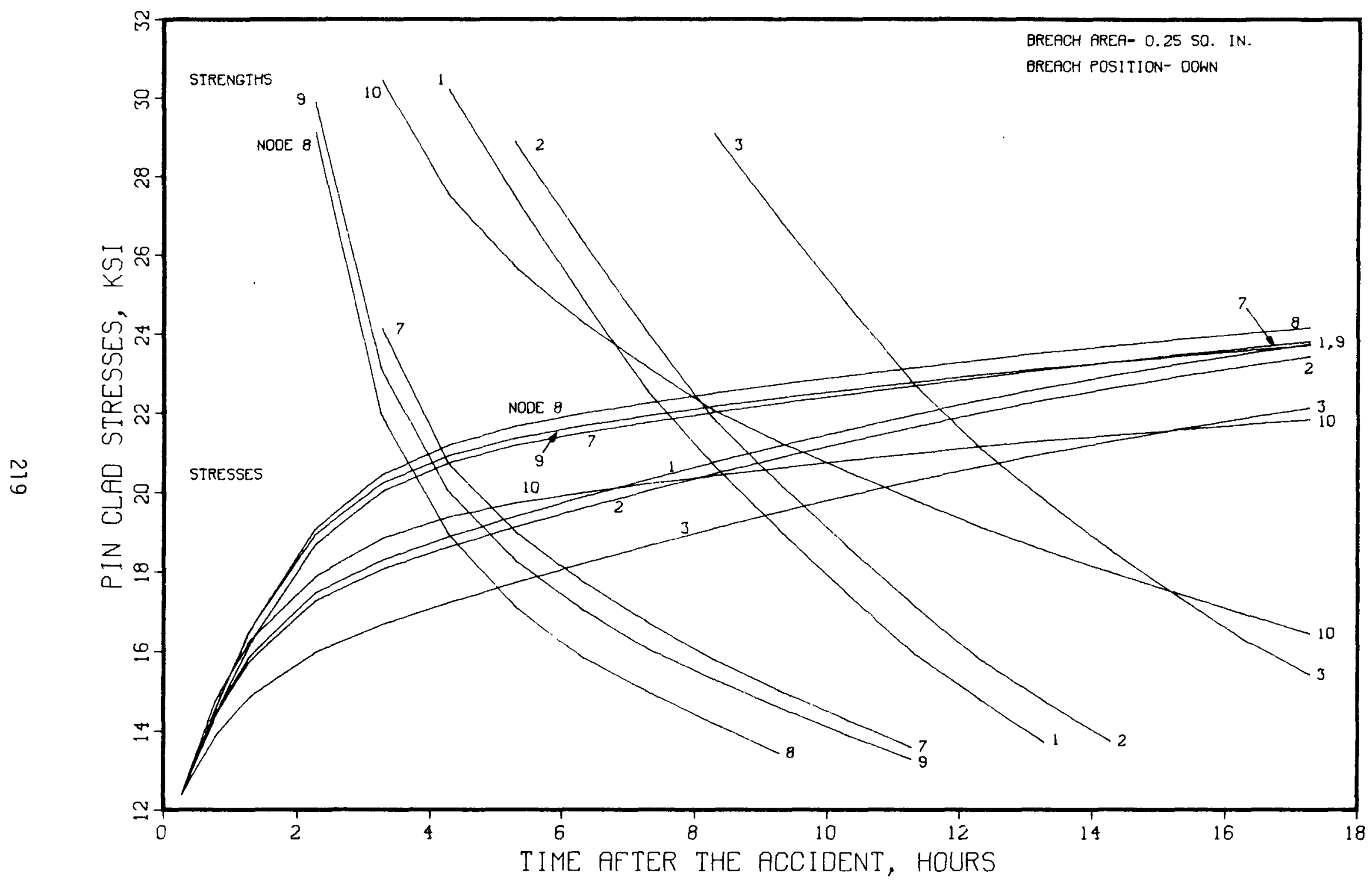

FIGLRE 3-11. Fue1 Pin Clad Stresses in the IF-300 (Zircaloy-4, 10 Hour Creep Rupture) 


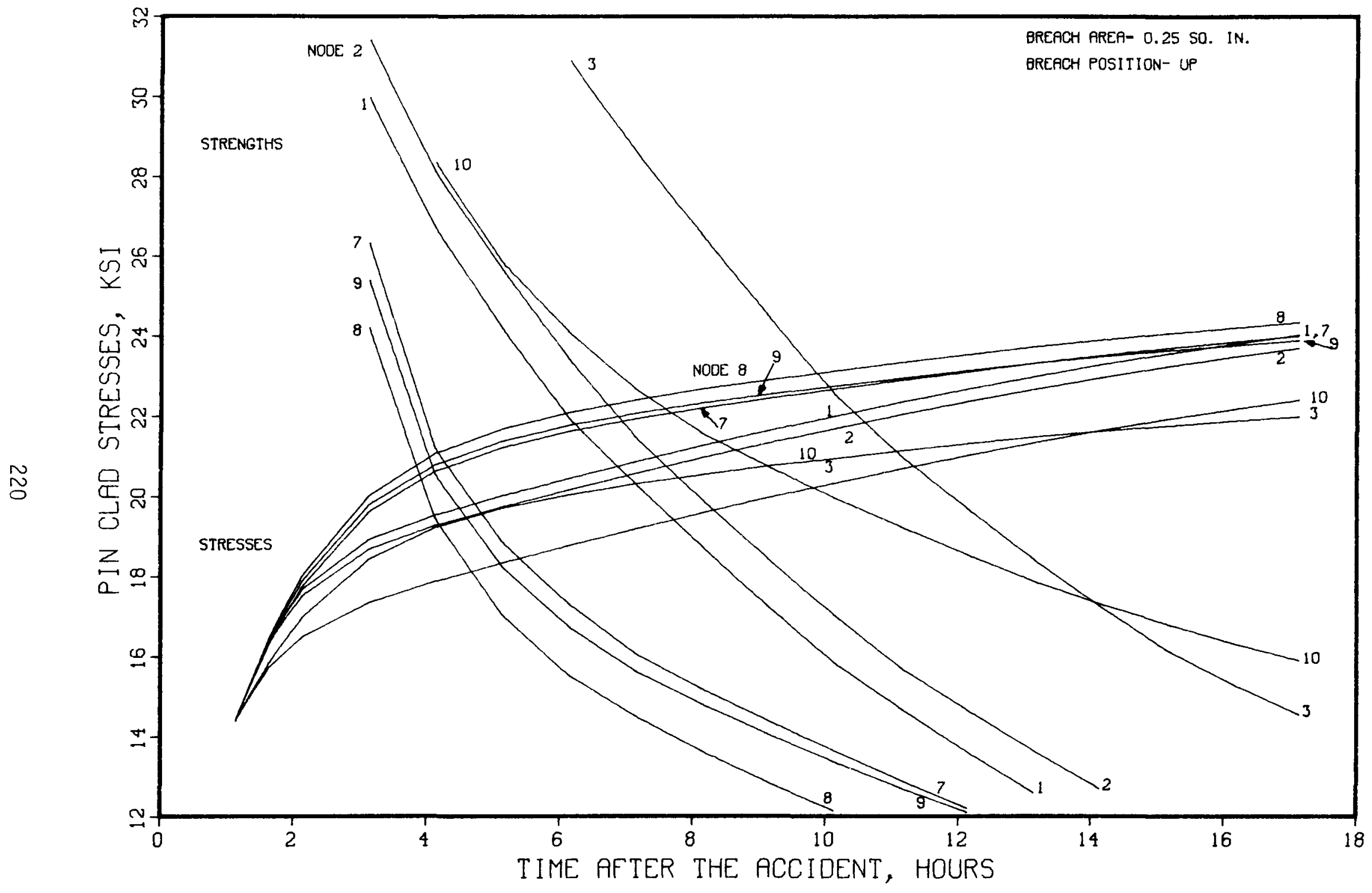

FIGURE 3-12. Fuel Pin Clad Stresses in the IF-300 (Zircaloy-4, 10 Hour Creep Rupture) 


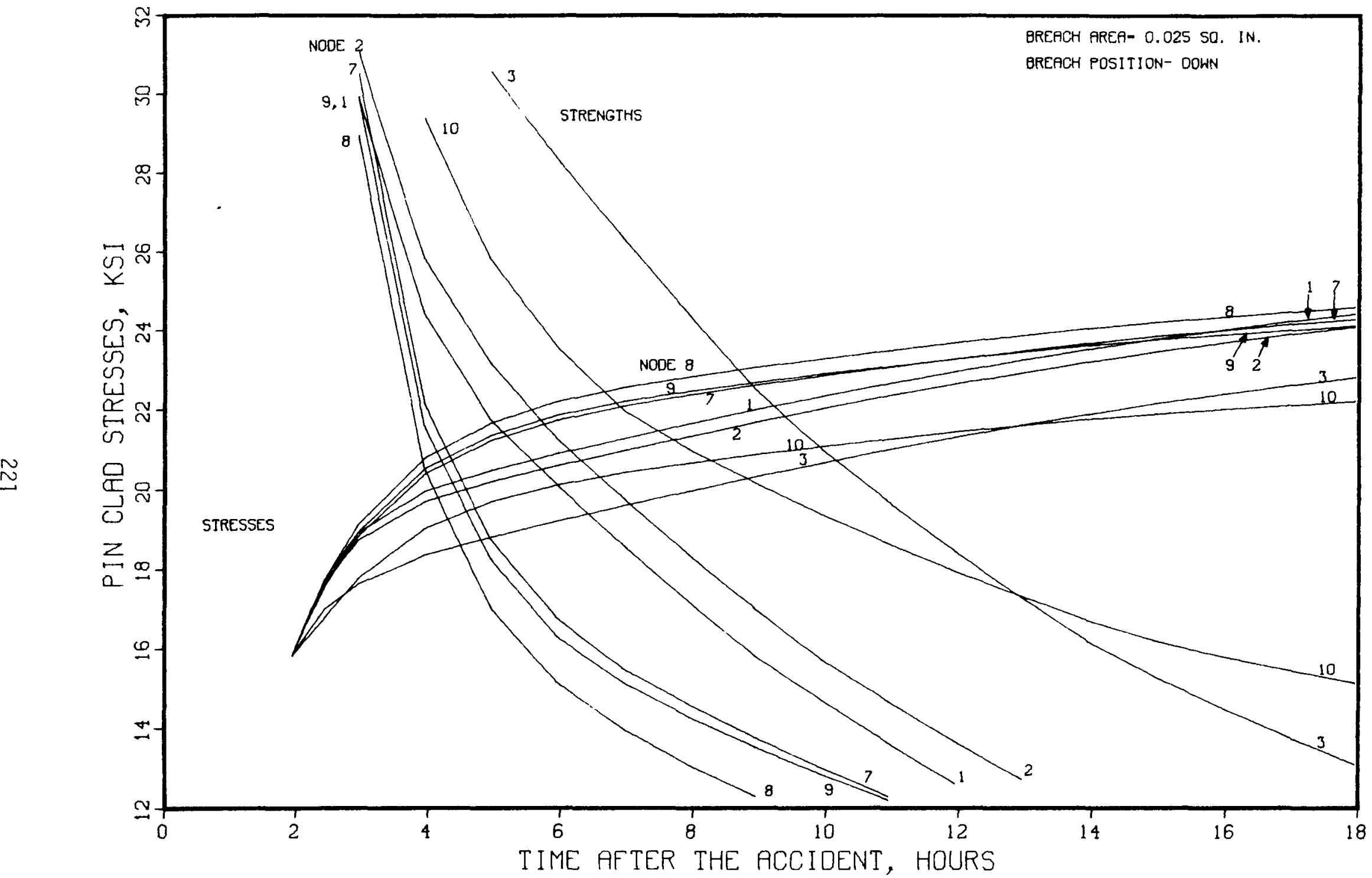

FIGURE 3-13. Fuel Pin Clad Stresses in the IF-300 (Zircaloy-4, 10 Hour Creep Rupture) 


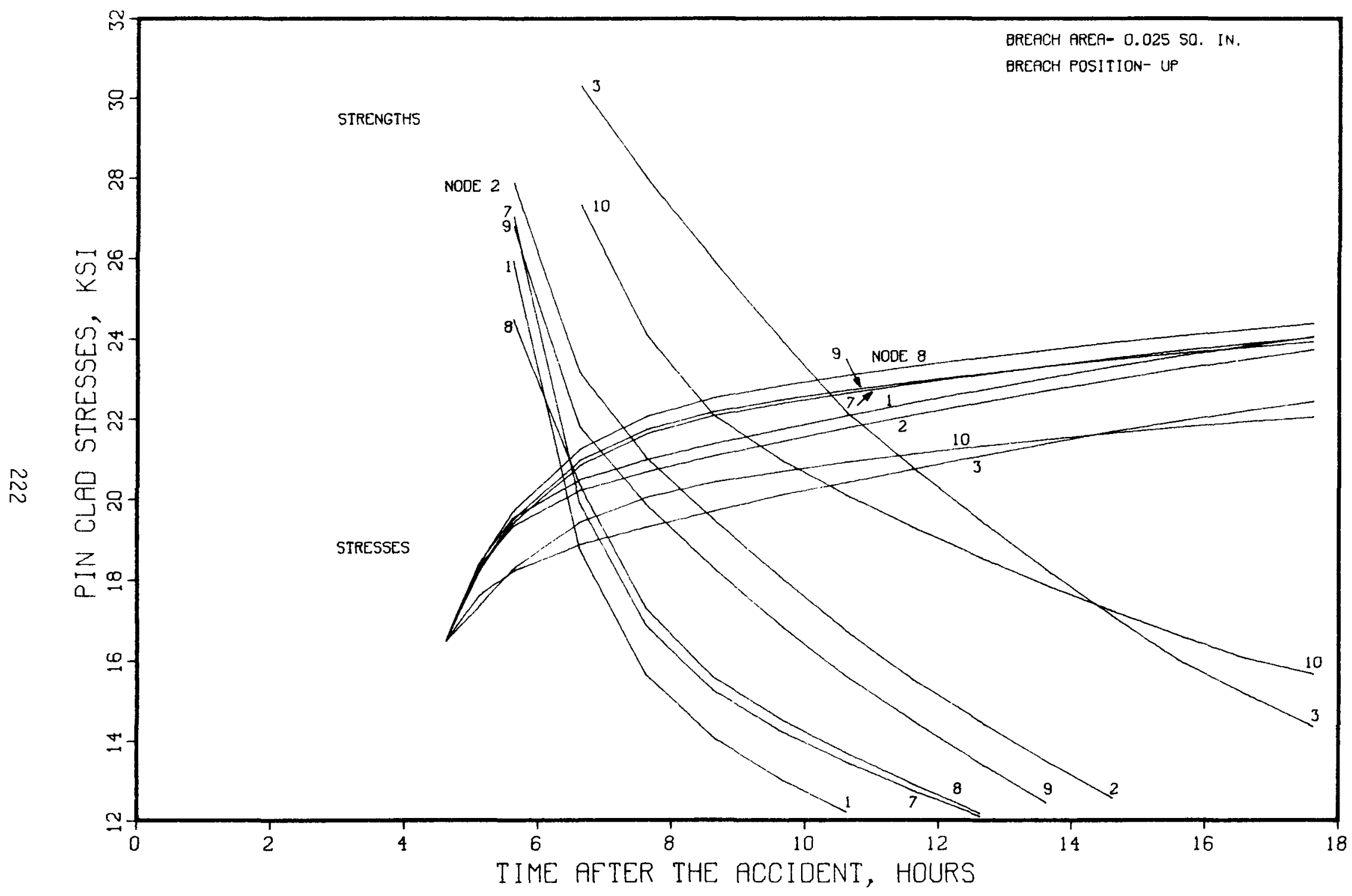

FIGURE 3-14. Fuel Pin Clad Stresses in the IF-300 (Zircaloy-4, 10 Hour Creep Rupture)

- - . 


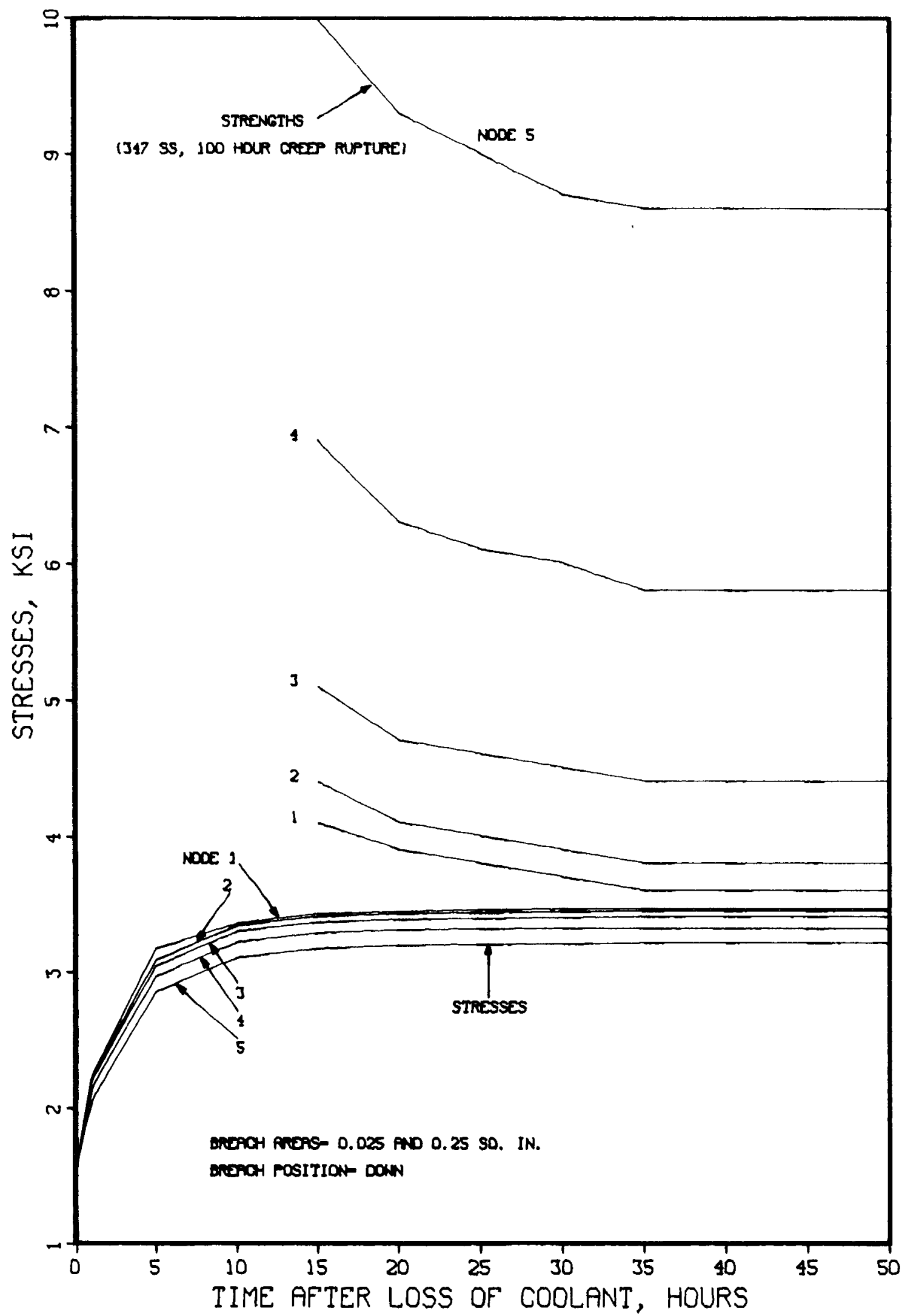

FIGURE 3-15. Fuel Pin Clad Stresses in the AMCO Cask for Breach Areas of 0.025 and $0.25 \mathrm{Sq}$. Inches (for Cask in Breach Down Position) 
Reference 20. The PWR fuel pin clads are Zircaloy-4. For this alloy, a 10 hour creep-rupture strength vs. temperature relationship from the Cask Designer's Guide (Reference 7, page 154) was used. The FFTF driver fuel pin clads are Type 316 stainless steel. A 100 hour creep-rupture vs. temperature curve from Reference 21 was used for these clads. These curves, or their equivalent, were programmed into the TAP loss-of-coolant models as controls. The calculated hoop stresses in the clads are compared to the clad strengths by a control function in the central processor, and when they exceed the strength, it represents failure of the clad. When this happens, a "switch" is activated that controls the release of the free fission gases in the pin void spaces, the onset of oxidation of the fuel leading to the release of bound up fission gases, and the diffusion of bound up gases through the fuel.

The internal pressures in the pins and the stresses in the clads are calculated as functions of temperature by the central processor as follows:

For thin-walled cylinders, the hoop stress, $S$, in the cylinder wall is related to the internal pressure, $P$, in the cylinder by the equation

$$
\frac{\Delta P}{S}=\frac{2\left(R_{0}-1\right)}{\left(R_{0}+1\right)} \quad \text { for } R_{0}<1.20
$$

where

$$
\begin{aligned}
R_{0}= & \text { the ratio of the outside diameter of the cylinder or } \\
& \text { clad to the inside diameter } \\
= & \frac{d_{0}}{d_{i}} \cdot \\
\Delta P= & \text { the pressure differential across the clad } \\
& \text { wall, } \frac{F}{L^{2}} \\
= & P-P_{\text {CAVITY }}
\end{aligned}
$$




$$
P_{\text {CAVITY }}=\text { the pressure in the cask cavity, } \frac{F}{L^{2}} \text {. }
$$

The outside diameters of the clads and their thicknesses, $t$, are specified in Table 2 and Table 4, therefore,

$$
d_{i}=d_{0}-2 t
$$

As an example, for the PWR fuel pin

and

$$
R_{0}=\frac{d_{0}}{d_{0}-2 t}=\frac{0.460}{0.460-0.04}=1.095<1.20
$$

or

$$
\frac{\Delta P}{S}=\frac{2\left(R_{0}-1\right)}{\left(R_{0}+1\right)}=0.0907
$$

$$
S=11.03 \Delta P \text {. }
$$

The stresses in the fuel pin clads in the AMCO cask were not calculated directly by the simulation model. Instead, experimental data on burst pressures as a function of temperature for Type 316 stainless steel clads (Reference 21, Table 16) were programmed into the model for monitoring clad failure. The clad stresses were calculated later from pressures obtained from the model.

For the IF-300, the internal pressure in a pin is calculated from the equation $(7)$

$$
P=\left(P^{\prime} f+P_{0}\right) \frac{T}{T_{0}}
$$

where:

$$
\begin{aligned}
P= & \text { the total gas pressure, } F / L^{2} \\
P^{\prime}= & \text { the pressure at } T_{0} \text {, resulting from } 100 \% \text { release of fission } \\
& \text { gases from the fuel pellets, } F / L^{2} \\
f= & \text { the fraction of gases released from the pellets to the pin } \\
& \text { plenum }
\end{aligned}
$$


$\begin{aligned} P_{0}= & \text { the initial fill pressure at } T_{0}, F / L^{2} \text { (taken to be } 55 \\ & \left.\text { psia at } 100^{\circ} F\right)(1)\end{aligned}$

$\frac{T}{T_{0}}=$ the ratio of the absolute temperature of the node repre-
senting the fuel region containing the pin to the base absolute temperature (temperatures in ${ }^{\circ}$ ).

The product $\mathrm{P}^{\prime} f$ represents the pressure of the gases actually released from the fuel pellets.

The pressure $\mathrm{P}^{\prime}$ is calculated from the gas law

$$
P^{\prime}=\frac{N R T}{V^{\prime}}
$$

expressed as

$$
P^{\prime}=\frac{1.45 E R T_{0}}{V^{\prime}}
$$

where $1.45=$ the total gas generation, Gm atoms/GWD

$\mathrm{E}=$ the exposure, GWD/MTU

$\mathrm{R}=$ the gas constant

$=40.84\left(p s i a-i^{3}\right) /\left(G m-m o l e e^{\circ} R\right)$

$V^{\prime}=$ the specific gas collection volume, $\mathrm{in}^{3} /$ MTU.

Fuel pin gas collection volumes for several pressurized water reactors are 1 isted in Table IX-6 of Reference 1. An average of these is $V^{\prime}=569$ $\mathrm{in}^{3} /$ MTU. The worst case PWR design basis fuel was assumed for this study. The fission product inventory for this fuel is summarized in Table 3-1, and in Table IX-9 in Reference 1. For this fuel,

$$
\begin{aligned}
E & =35 \mathrm{GWD} / \mathrm{MTU}, \\
P_{0} & =40 \mathrm{KW} / \mathrm{KgU},
\end{aligned}
$$

and the cooling time is 90 days following reactor shutdown. Using the above values of $E$ and $V^{\prime}$, and Equation (3-28), $P^{\prime}$ was calculated to be 2040 psia. Using a release fraction of 0.35 for all the fission gases, the pressure of the gases released to the pin voids is 


$$
\begin{aligned}
P^{\prime} f & =(2040)(0.35) \\
& =714 \text { psia. }
\end{aligned}
$$

This gas pressure, along with the initial fill pressure and temperature, was used in Equation (3-26) to obtain the final form of the pressure equation to be used in the model:

$$
\begin{aligned}
P & =\left(P^{\prime} f+P_{0}\right) \frac{T}{T_{0}} \\
& =(714+55) \frac{T}{560} \\
& =1.373 T \\
& =1.373\left(T_{f}+460\right)
\end{aligned}
$$

where $T_{f}=$ the temperature of the node representing the fuet region containing the pin, ${ }^{\circ} \mathrm{F}$.

The internal pressures in the fuel pins in the AMCO cask were determined using a different approach. It has been estimated that the endof-life pressure in these pins is about 750 psia at $1100^{\circ} \mathrm{F}$. (33) It was assumed that this pressure could be expressed as

or

$$
\begin{aligned}
P^{\prime} & =\frac{R}{V}\left(T_{f}+460\right), \\
750 & =\frac{R}{V}(1100+460) .
\end{aligned}
$$

The term $\frac{R}{V}$ was obtained by solving Equation (3-30) to give

$$
\frac{R}{V}=\frac{750}{1560}=0.48
$$

Since the product P'f represents the pressure of the gases actually released to the pin voids, Equation (3-30) may be rewritten as 


$$
\begin{aligned}
P & =P^{\prime} f \\
& =\frac{R f}{V}\left(T_{f}+460\right) \\
& =0.48 f\left(T_{f}+460\right),
\end{aligned}
$$

where $f$ is the fractional release defined by Equation (3-18). This fractional release was calculated to be 0.56 . Therefore, Equation (3-33) reduces to

$$
P=0.27\left(T_{f}+460\right)
$$

Equation (3-33) is part of the AMCO cask model and, during a simulation, the pressures obtained from this equation are compared to burst pressure vs. temperature data. When

$$
P \geqslant P_{\text {Burst }} \text {, }
$$

the pin clads fail, releasing the fission gases in the pin voids.

The stresses in the fuel pin clads in the AMCO cask were calculated later, using Equation (3-19) and the pressures obtained from Equation (3-33) during the simulation.

The failure of a pin clad in the simulation models not only signals the release of free gases from the pin void space, it also controls the release of bound up gases from the fuel by oxidation and diffusion. The activation of these release mechanisms is controlled by algorithms programmed into the central processor of the models. These algorithms for the IF-300 model are shown in Figures 3-16 and 3-27. The algorithms for the AMCO cask model are somewhat different due to the differences in the two approaches discussed above.

In Figure 3-16, the strength, $\mathrm{SU}_{\mathrm{m}}$, of the pin clads in fuel region $\mathrm{m}$ is determined as a function of the node temperature $T_{m}$. The internal pressure, $P_{m}$, is determined from Equation (3-29) in the form shown. Once $P_{m}$ is determined, the clad hoop stress, $S_{m}$, is then calculated. The clad stress 


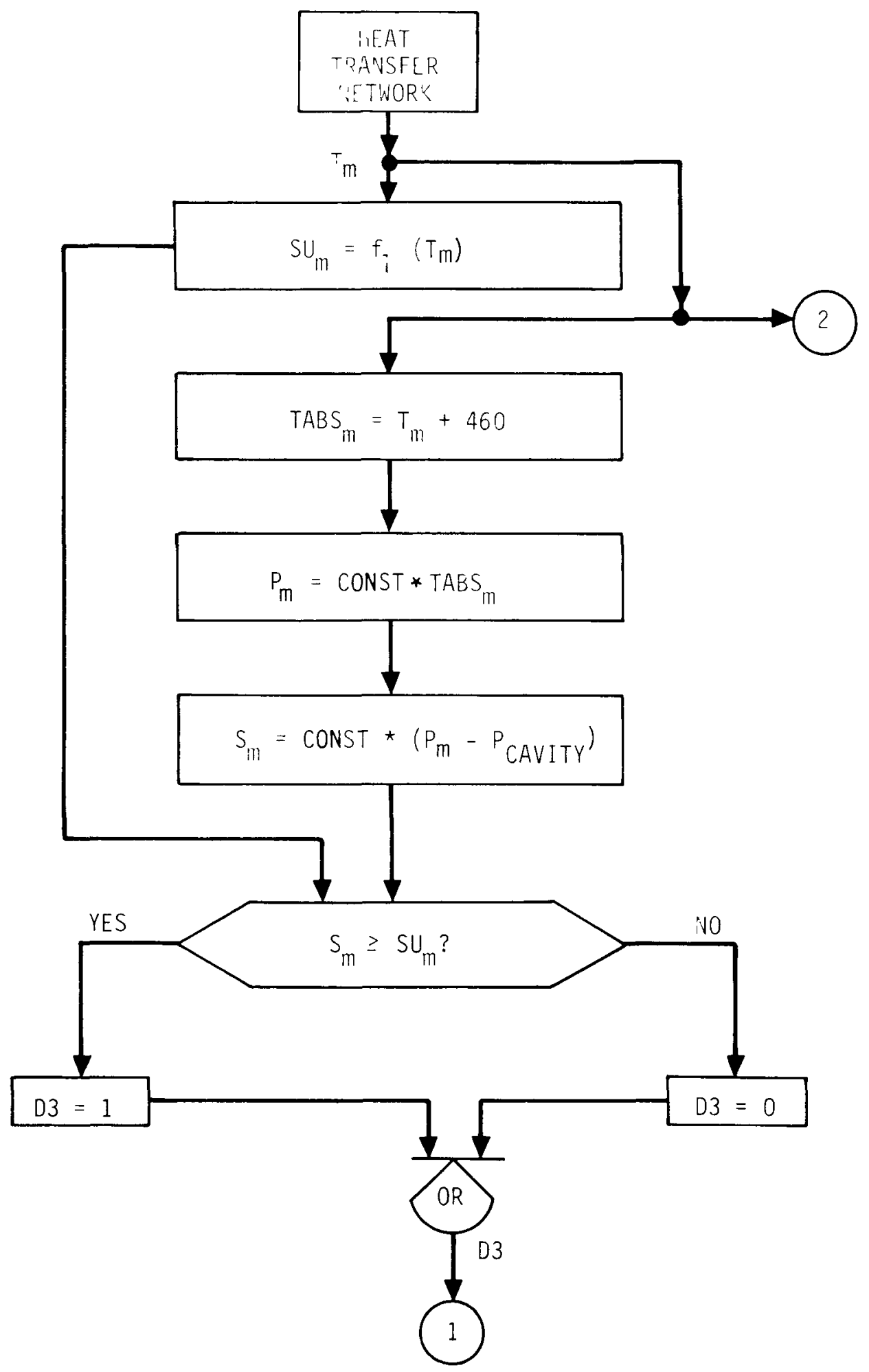

HEDL $7507-30.22$

FIGURE 3-16. Algorithm Controlling Simulation of Release Mechanisms (Page 1 of 2) 


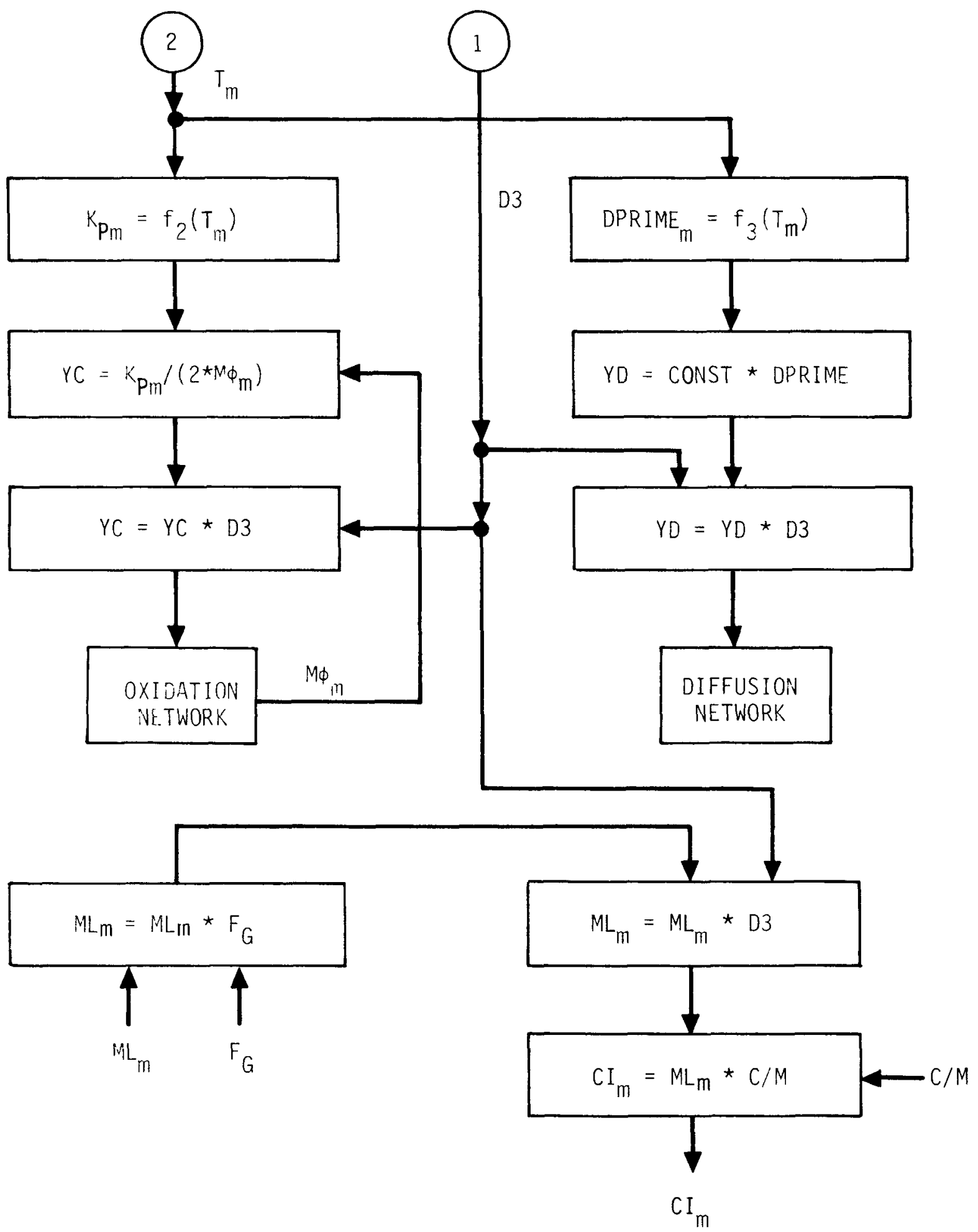

HEDL 7507-30.23

FIGURE 3-16. Algorithm Controlling Simulation of Release Mechanisms (Page 2 of 2) 
is compared to the clad strength and, if $S_{m}=S U_{m}$, the switching variable D3 is set equal to one. If $S_{m} \cdot S U_{m}, D 3$ is set equal to zero. Admittances attached to node $m$ in the oxidation and diffusion networks are activated or remain inactive, depending on the value of 03 .

Also, in the algorithm of Figure 3-16, the reaction rate constant, $\mathrm{K}_{\mathrm{pm}}$, and the diffusion coefficient $\mathrm{DPRIME}_{\mathrm{m}}$, are shown as functions of the fuel node temperature. The typical oxidation reaction admittance, ${ }_{C}$, is determined as a function of the reaction rate constant and the node oxygen concentration, $M_{m}$, from the oxidation network. The typical diffusion admittance, $Y_{D}$, is determined as a function of the diffusion coefficient, but is independent of the fission gas concentration.

The release of the free fission gases in the pin voids is also controlled by the switching variable D3. The total number of moles, $\mathrm{ML}_{\mathrm{m}}$, of fission gas in a fuel node, both free and bound up, is first multiplied by $F_{G}$ to convert it to the number of moles of free fission gases in the pin voids. This modified value of $\mathrm{ML}_{\mathrm{m}}$ is then multiplied by $\mathrm{D} 3$ and read out as a function of time. Finally, $\mathrm{ML}_{\mathrm{m}}$ is multiplied by a conversion factor, $\mathrm{C} / \mathrm{M}$, which is the number of curies present in a mole of gas, to get the total curies radioactivity, $C I_{m}$, released from node $m$.

\subsubsection{Diffusion of Fission Gases from the Fuel}

Results using the loss-of-coolant models have shown that the amount of fission gases released from the spent fuel by diffusion is negligible. The spent fuel temperatures never reach a level high enough to produce a diffusion coefficient large enough to allow other than negligible amounts of gas to be released. However, since this release mechanism is included as part of the model, the concepts and equations developed will be presented in the following sections.

\subsubsection{Volumetric Mass Dissipation}

Diffusion of fission gases in a "unit cel1" is illustrated in the following sketch, and defined by Equation (3-36). 


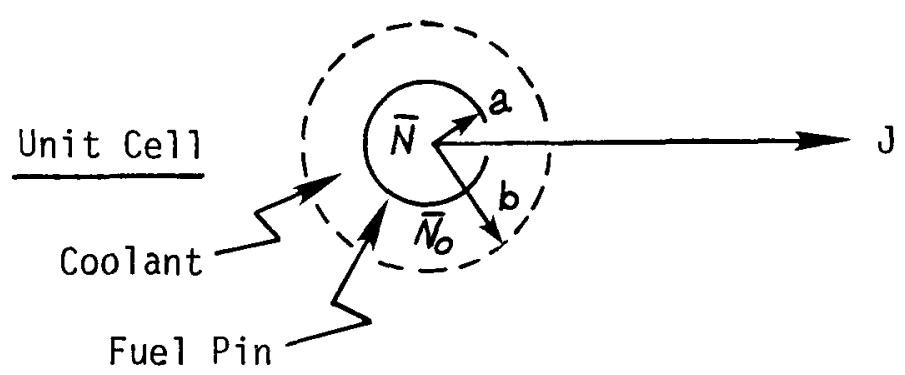

$$
-V \frac{d \bar{N}}{d t}=J \frac{D A}{L}\left(\bar{N}-\bar{N}_{0}\right)
$$

where

$$
\begin{aligned}
V= & \text { the volume of fue } 1, L^{3} \\
\bar{N}= & \text { the average fission gas concentration in the fuel, } M / L^{3} \\
\bar{N}_{0}= & \text { the concentration of fission gas in the voids, } M / L^{3} \\
t= & \text { time, } \theta \\
D= & \text { the coefficient for diffusion of fission gases through } \\
& \text { the fuel, } L^{2} \theta \\
A= & \text { the surface area of the fuel pin, } L^{2} \\
= & 2 \pi \text { adx } \\
L= & \text { the diffusion path length, } L \\
= & \text { a } \\
J= & \text { the mass of fission gas transferred, } M / \theta .
\end{aligned}
$$

The mass transfer from the pin to the voids is

$$
J=\frac{2 \pi a D}{a}\left(\bar{N}-\bar{N}_{0}\right) \Delta x .
$$


In volumetric terms, the mass transfer may be expressed as

$$
J=\pi b^{2} D_{v}\left(\bar{N}-\bar{N}_{0}\right) \Delta x
$$

where

$$
D_{v}=\text { the volumetric mass dissipation coefficient, } \frac{1}{\theta} \text {. }
$$

Substituting from Equation (3-37) into Equation (3-38), rearranging, and using Equation (1-11), the volumetric mass dissipation coefficient is defined as

$$
D_{v}=\frac{2 D}{a^{2}}(1-B)
$$

Equation (3-38), rewritten on a nodal basis for the diffusion network, is

$$
J=Y_{D}\left(\bar{N}-\bar{N}_{0}\right)
$$

where

$$
\begin{aligned}
Y_{D} & =\text { the mass dissipation admittance, } L^{3} / \theta \\
& =D_{V} S_{\text {node }} \Delta x .
\end{aligned}
$$

Substituting from Equation (3-39), Equation (3-41) becomes

$$
Y_{D}=\frac{2 D(7-B)}{a^{2}} S_{\text {node }} \Delta x
$$

\subsubsection{Diffusion Network}

It was assumed that the fission gases will not diffuse from pin to pin since the flow path through the voids (coolant space) is the path of least resistance. Assuming only diffusion to the voids, the network for one fue 1 node is shown in the following sketch. 




The capacitance of the fuel node in this basic network is the volume of the fuel. The sink or void gas concentration, $\bar{N}_{0}$, is assumed to be 0 .

\subsubsection{Coefficient for Diffusion of Fission Gases in the Fuel}

An empirical diffusicn coefficient was used to calculate the diffusion of fission gases through the fuel. According to Allen, (22) the empirical diffusion coefficient is related to the actual diffusion coefficient by the expression:

$$
D^{\prime}=\frac{D}{a^{2}}
$$

where

$$
\begin{aligned}
a= & \frac{3}{S} \\
s= & \text { the surface area per unit volume of the bulk fuel, } 1 / \mathrm{cm}, \\
a= & \text { the radius of hypothetical spheres which, it is assumed, } \\
& \text { constitute the } \mathrm{vO}_{2}, \mathrm{~cm} .
\end{aligned}
$$


For a basic sphere,

$$
S=\frac{4 \pi a^{2}}{\frac{4}{3} \pi a^{3}}=\frac{3}{a} .
$$

It was assumed that the diffusion of the fission gases would be similar to the diffusion of xenon alone, and that the coefficient for the diffusion of xenon through $\mathrm{UO}_{2}$ would be representative of the diffusion coefficient for the fission gases. ORNL-4228 (Reference 23) presents a plot of the $10 \mathrm{~g}$ of the diffusion coefficient for xenon as a function of the reciprocal of the absolute temperature. This plot was represented approximately by the equation

$$
\log D^{\prime}=-1.32\left(\frac{10^{4}}{T}\right)-1.0
$$

where

$$
\begin{aligned}
T & =\text { the absolute temperature, }{ }^{\circ} \mathrm{K}, \\
D^{\prime} & =\text { the empirical diffusion coefficient, } \frac{1}{\mathrm{sec}} .
\end{aligned}
$$

The plot in Reference 23 did not extend the temperature range below about $1000^{\circ} \mathrm{K}\left(1340^{\circ} \mathrm{F}\right)$. Therefore, extrapolations were made to lower temperatures, using Equation (3-46). The empirical diffusion coefficient for xenon used in this study, based on extrapolations using the above equation, is shown in Figure 3-17.

Calculated results have shown that the amount of fission gases released by diffusion from the fuel is negligible. The diffusion process is extremely slow, even at the highest temperatures reached during the simulation.

If oxidation of the solid $\mathrm{UO}_{2}$ to the granular or loose $\mathrm{U}_{3} \mathrm{O}_{8}$ occurs, the diffusion coefficient might improve drastically at the conversion point in a step-wise manner, rather than remaining a straight line function as indicated in Figure 3-17. The following sketch illustrates how the "improved" diffusion coefficient might appear on a $\log D^{\prime}$ versus $\frac{1}{T}$ plot. 


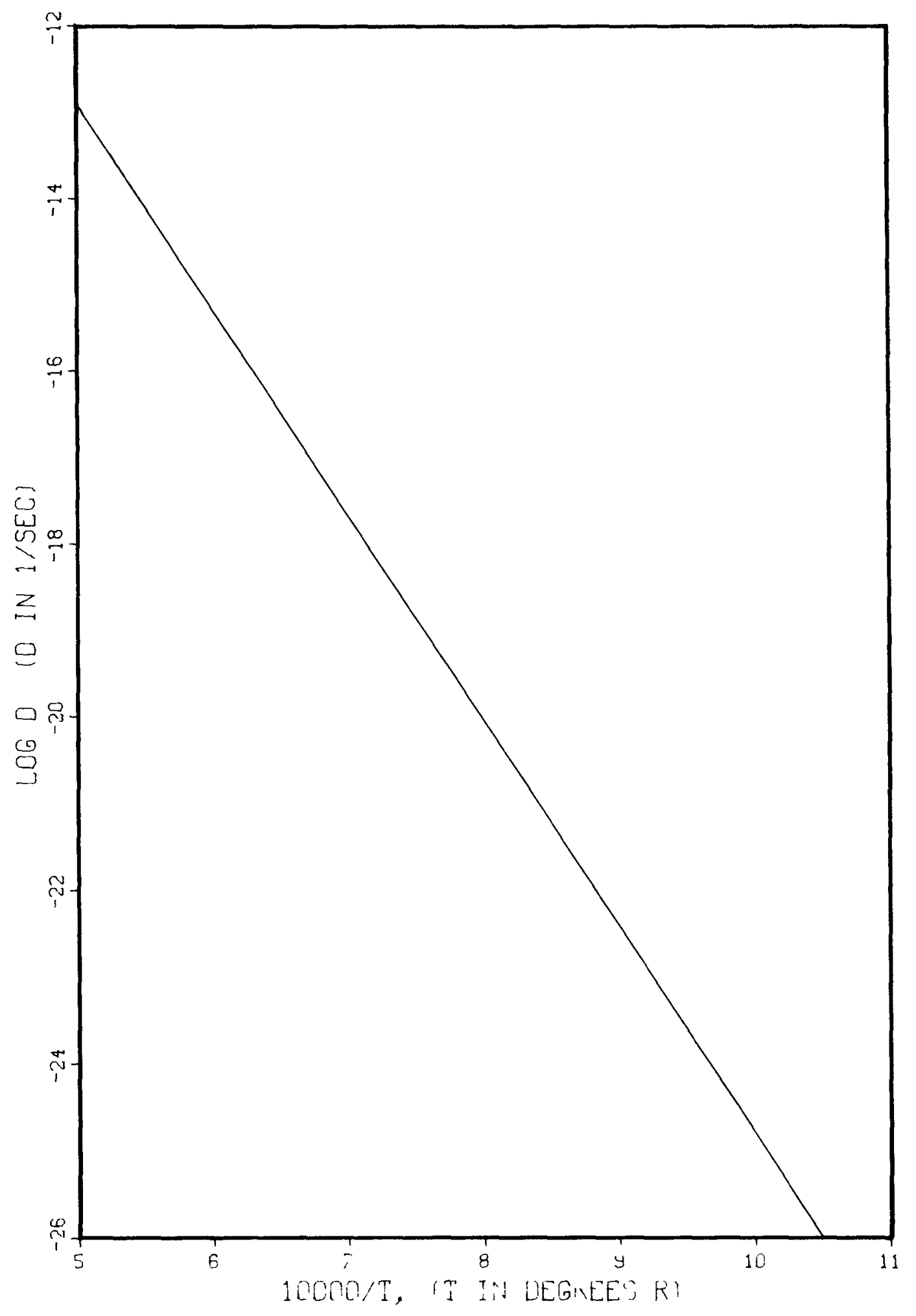

FIGURE 3-17. Empirical Diffusion Coefficient for Xenon (Reference 23) 


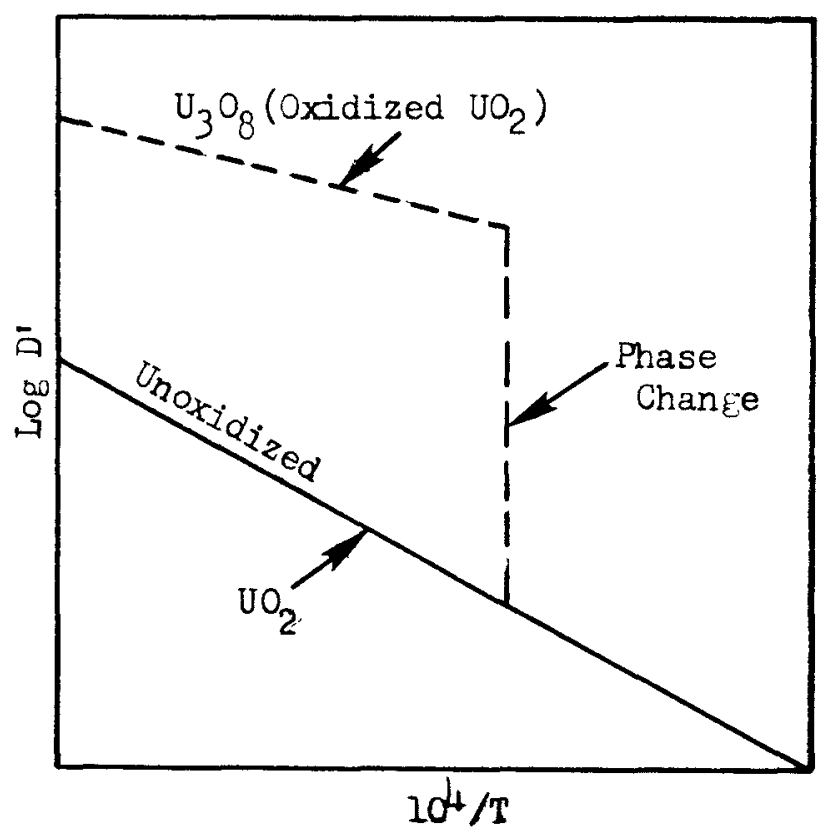

In this study it was assumed that the fission gases would be released instantaneously if the $\mathrm{UO}_{2}$ is converted to $\mathrm{U}_{3} \mathrm{O}_{8}$ which, in effect, implies that the diffusion coefficient goes to a very large value in a step manner.

The diffusion coefficient was not corrected for the effect of burnup while the fuel was in the reactor. The data of Daniel, Evans and Shilling $(24)$ indicate that the diffusion coefficient could be higher by as much as a factor of 30 . Even if this factor were applied in this study, diffusion would still be negligible.

\subsubsection{Oxidation of the Fuel}

Another mechanism included in the loss-of-coolant models for the release of "bound up" gases and solids from the fuel is oxidation of the $\mathrm{UO}_{2}$ to $\mathrm{U}_{3} \mathrm{O}_{8} . \quad \mathrm{U}_{3} \mathrm{O}_{8}$ is a fine granular material from which these bound up gases and solids can more easily be released. However, as the study progressed, results from use of the chain of simulation models seemed to indicate that this mechanism would be less likely to occur than originally thought. The results indicated that the cask would probably always be at a pressure 
higher than its surroundings. This would prevent any air from entering the cask.

There are at least two reasons why the pressure in the cask may be higher than the pressure of the surroundings. First, residual coolant vapor may be present in the cask for some time following the loss of primary coolant. The pressure of this residual vapor would increase as it is heated. Second, the fission gases released from the fuel pins are at the burst pressure of the pin clads. Although these pressures will drop to some lower value as the gases expand into the cask containment, they will increase again as the gases are heated by the fuel assemblies.

Oxidation of the fuel by the water vapor in the IF-300 has not yet been evaluated, but it is not expected to be significant.

Fuel oxidation as a release mechanism is part of the loss-of-coolant models, so the concepts and equations that describe this mechanism will be presented in the following sections.

\subsubsection{Parabolic Rate Law}

Fue1, exposed to the atmosphere after clad failure, was assumed to be oxidized according to the parabolic rate law.

$$
x=\sqrt{k t}
$$

where

$$
\begin{aligned}
& x=\text { the thickness of a second-phase oxide product, } L \\
& k=\text { the reaction constant } \frac{L^{2}}{\theta} \\
& t=\text { the time, } \theta .
\end{aligned}
$$

This equation was converted to a mass-based rate law for the simulation of fuel oxidation. This mass-based law, as developed later in this section, is

$$
M^{2}=K_{p} t
$$


where

$M$ = the mass of oxygen consumed, or the mass gain of the oxide product, $M / L^{2}$

$\begin{aligned} K_{p} & =\text { the mass-based rate constant, } M^{2} / L^{4} \theta \\ & =p^{2} k\end{aligned}$

$\rho=$ the second phase oxide product density, $\frac{M}{L^{3}}$.

The time derivative of Equation (3-48),

$$
2 M \frac{d M}{d t}=K_{p}
$$

was used as the basis for the oxidation network. In the simulation of oxidation using Equation (3-49), $K_{p}$ is a function of temperature (see Table 3-7 and Figure 3-18), and the fue 1 pellets are assumed to be spheres.

The heat of oxidation was not considered in the simulation; however, this could be included in the model later. This would be one of the interactions between the oxidation network and the heat transfer network.

Oxidation of the fuel might be impeded by lack of oxygen, since the fire would probably consume most of the oxygen in the immediate vicinity. In this study, it was assumed that the fuel would be exposed to a normal atmosphere in which the oxygen is not depleted by combustion of the petroleum, and therefore oxidation of the fuel would be reaction rate-controlled. An oxygen supply-limited reaction model may be used later rather than the rate-controlled model if it is possible to estimate the amount of oxygen (air) reaching the exposed fuel.

\subsubsection{Oxidation Network}

The oxidation of the fuel is a function of the temperature of a fuel node only, not of the "lumped" or "distributed" representation of the node. It is based upon the behavior of a representative pin in the node, not on the node as a set of pins. 
Oxidation of the fuel was simulated by converting Equation (3-49) to a mass conservation equation

$$
\frac{d M}{d t}=\gamma_{0}\left(M_{0}-M\right)
$$

where

$$
\begin{aligned}
& Y_{0}=\text { the oxidation admittance, } \frac{1}{\theta} \\
& M_{0}=\text { an oxidation potential, } \frac{M}{L^{2}} .
\end{aligned}
$$

If the oxidation admittance is defined as

$$
Y_{0}=\frac{K_{p}}{2 M M_{0}}
$$

and if

$$
M_{0}>>M
$$

then Equation (3-50) may be rewritten as

$$
\frac{d M}{d t}=\frac{K_{p}}{2 M M_{0}}\left(M_{0}-M\right) \simeq \frac{K_{p}}{2 M}
$$

which is Equation (3-49).

The electrical analog of Equation (3-53) is represented by the network in the following sketch:

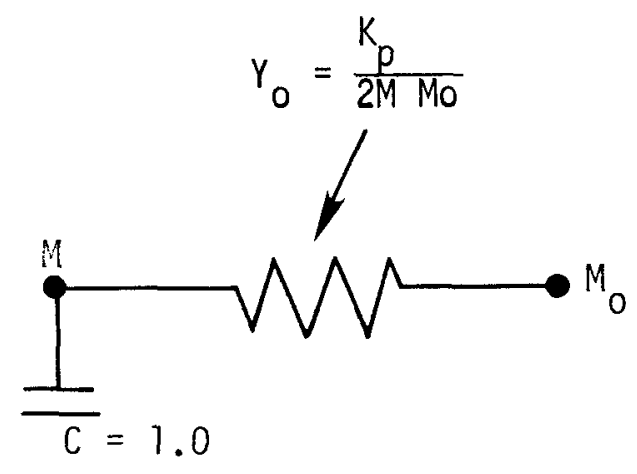




\subsubsection{Oxygen-Uranium Ratios}

The amount of oxygen in a fuel node is

$$
m=(M)(T S P I N)
$$

where

$m=$ the amount of oxygen in the node, $M$

TSPIN = the total surface area of the fuel in the node, $L^{2}$.

In determining the surface area of the fuel, each pellet in a pin was assumed to be a sphere. The volume of a pellet is

$$
V=2 \pi a \delta+2 \pi a^{2}
$$

where

$$
\begin{aligned}
& a=\text { the pellet radius, } \mathrm{L} \\
& \delta=\text { the pellet thickness, } \mathrm{L} \text {. }
\end{aligned}
$$

The radius of an equivalent sphere is

$$
\alpha=\left(\frac{V}{\frac{4 \pi}{3}}\right)^{1 / 3}
$$

and the surface area of this sphere is

$$
S=4 \pi \alpha^{2}
$$

The total surface area of the fuel in the node then is

$$
\operatorname{TSPIN}=(S)\left(N_{p}\right)(N P I N S)\left(S^{\prime}{ }_{\text {node }}\right)
$$

where

$$
\begin{aligned}
N_{p} & =\text { the number of pellets in a fuel pin, } \\
\text { NPINS } & =\text { the number of pins per unit area of fuel assembly, and } \\
S^{\prime} \text { node } & =\text { the cross-sectional area of fuel assembly in a fuel node. }
\end{aligned}
$$


The oxygen-uranium ratio in a fuel node is

$$
\text { Ratio }=\frac{\emptyset}{U}
$$

where

$\emptyset=$ the number of mass-atoms of oxygen in the fuel node,

$U=$ the number of mass-atoms of uranium in the fuel node.

The number of mass-atoms of oxygen is obtained from Equation (3-60)

$$
\emptyset=\frac{M}{A W \emptyset}
$$

where $A W \emptyset=$ the atomic weight of oxygen.

\subsubsection{Fuel 0xidation Reaction Rate}

It was assumed that the bound up fission gases in the fuel would be released by the oxidation of the $\mathrm{UO}_{2}$ to $\mathrm{U}_{3} \mathrm{O}_{8}$. Assumption of this release mechanism was based on statements made in ORNL-4436 (Reference 25) that

"fission product gases interstitially trapped in oxide fuels can be volatilized and collected in a relatively small volume when these fuels are heated in oxygen at temperatures greater than about $400^{\circ} \mathrm{C}\left(725^{\circ} \mathrm{F}\right) . "$

It was also stated that

". . . the oxidation of $\mathrm{UO}_{2}$ to $\mathrm{U}_{3} \mathrm{O}_{3}$ involves a phase change which tends to degrade the oxide into a fine granular form."

According to Blackburn, et al. ${ }^{(26)}$ oxidation of $\mathrm{UO}_{2}$ to $\mathrm{U}_{3} \mathrm{O}_{8}$ has been observed to occur in two steps. The initial pattern is a smooth parabolic curve from $\mathrm{UO}_{2}$ to $\mathrm{UO}_{2.33}$, where the reaction virtually ceases. The second oxidation stage above $\mathrm{UO}_{2} .33$ consists of an induction period, then a stage in which the reaction rate gradually increases, followed by a period in which the speed of reaction tapers off as the composition approaches $\mathrm{UO}_{2.67^{\circ}}$ In this study, the parabolic rate law was assumed to hold up to $100.67^{\circ}$ 
Blackburn further states that the initial oxidation stage is best explained as a diffusion-controlled process, the hypothesis proposed by other authors. He goes on to state, however, that oxygen diffusion is not through the $\mathrm{UO}_{2}$ structure but through the second phase, $\mathrm{U}_{3} \mathrm{O}_{7}$. This reaction is analogous to the diffusion-controlled oxidation of metals where the rate of oxidation is inversely proportional to the oxide thickness.

For spherical particles the parabolic rate equation $(26)$ is

$$
x=\operatorname{ra}\left[1(1-c)^{1 / 3}\right]=\sqrt{k t}
$$

where

$$
\begin{aligned}
x= & \text { the thickness of the second phase, } L, \\
r= & \text { the average radius of the spherical particle, } L, \\
a= & \text { the ratio of } U_{3} O_{7} \text { thickness to } \mathrm{UO}_{2} \text { thickness } \\
& \text { (approximately } 0.99 \text { ), } \\
c= & \text { the degree of conversion of } \mathrm{UO}_{2} \text { to } \mathrm{U}_{3} \mathrm{O}_{7}, \\
k= & \text { the reaction constant, } \frac{L^{2}}{\theta}, \\
t= & \text { the time, } \theta .
\end{aligned}
$$

For smal1 values of $c$, Equation (3-61) reduces to

$$
x=\frac{r c a}{3}=\sqrt{k t}
$$

which has already been presented as Equation (3-47).

The square of the slope in the parabolic rate equation gives the reaction constant, $k$, which varies with temperature. Data on the variation of $k$ with temperature, according to Blackburn, are given in Table 3-7. The heat of activation for the reaction was obtained from an Arrhenius plot. A least squares fit produced the equation

$$
\log _{e} k=\frac{21700}{R T}-9.47 \pm 0.15
$$

where $k$ is in $\mathrm{cm}^{2} / \mathrm{sec}$, and the heat of activation is $21.7 \mathrm{kcal} / \mathrm{mol}$. 
TABLE 3-7

\section{Rate of $\mathrm{UO}_{2}$ Oxidation from Parabolic Rate Equation and Experimental Observations}

(Reference 26)

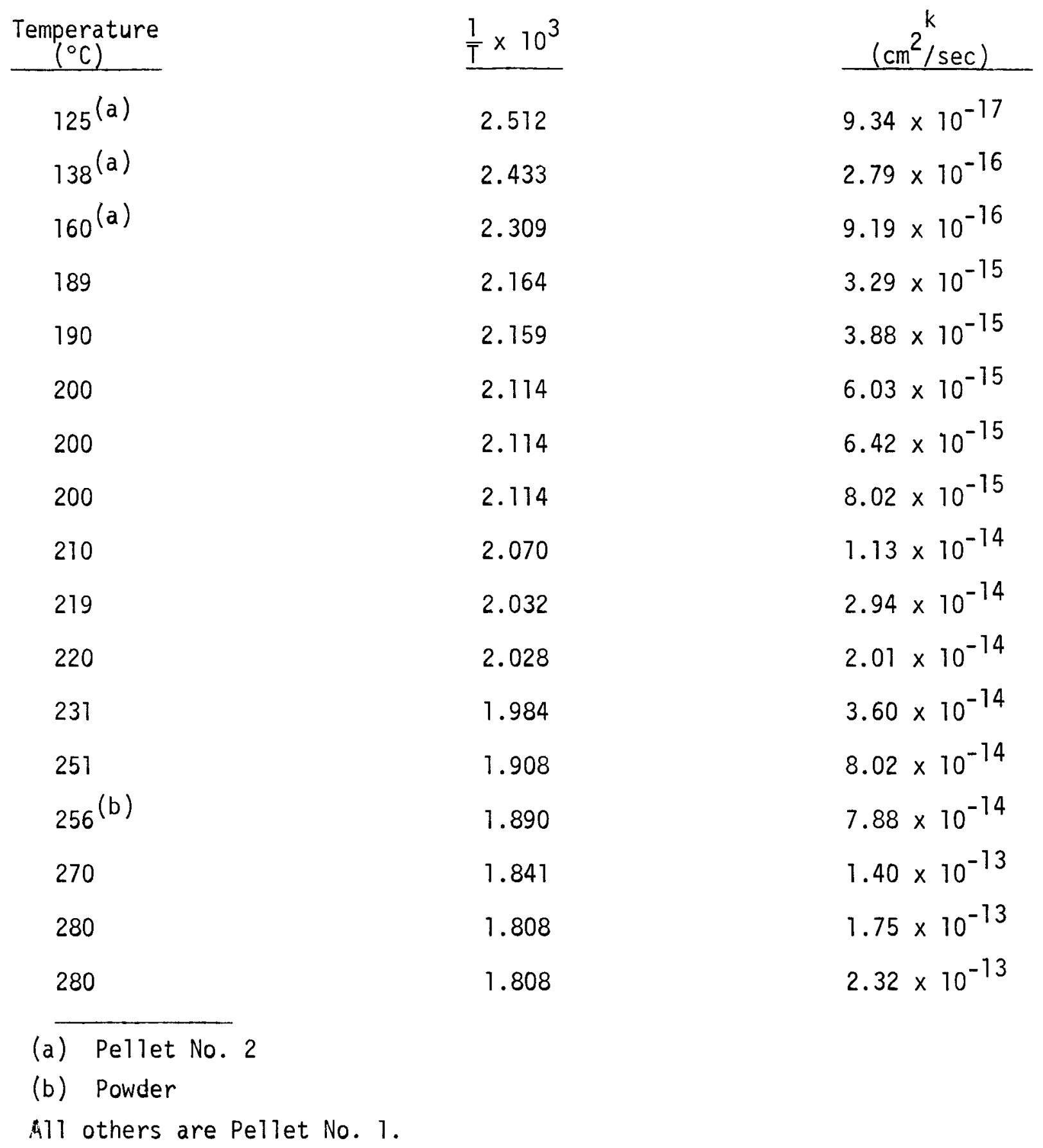


For the simulation of fuel oxidation, Equation (3-62) was converted to a mass-based rate law in the following manner:

The volume of the spherical particle would be

$$
V=\frac{4 \pi r^{3}}{3}
$$

and the surface area is

$$
A=4 \pi r^{2}
$$

The volume-area ratio, then, is

$$
\frac{V}{A}=\frac{\frac{4}{3} \pi r^{3}}{4 \pi r^{2}}=\frac{r}{3}
$$

which corresponds to the term in Equation (3-62) when $c \simeq a \simeq 1$.

In terms of the product shell thickness

$$
V \simeq 4 \pi r^{2} x
$$

therefore

$$
\frac{V}{A} \simeq \frac{4 \pi r^{2} X}{4 \pi r^{2}}=x
$$

The rate equation defines $X$ as

$$
x=\sqrt{k t}
$$

Multiplying both sides of the rate equation by $4 \pi r^{2}$ and by the density of the oxidation product gives

$$
\begin{aligned}
& 4 \pi r^{2} x_{\rho}=4 \pi r^{2} \rho \sqrt{k t} \\
& m=4 \pi r^{2} \rho \sqrt{k t .}
\end{aligned}
$$


Dividing both sides by $4 \pi r^{2}$ and rearranging, $M$ can be defined as

$$
M=\frac{m}{4 \pi r^{2}}=\sqrt{k \rho^{2} t}
$$

where

$$
\begin{aligned}
m= & \text { the mass of } \mathrm{U}_{3} \mathrm{O}_{7} \text { formed which is equivalent to the mass } \\
& \text { of oxygen added to the particle, gm, } \\
M= & \text { the mass per unit of particle surface area, } \mathrm{gm} / \mathrm{cm}^{2}, \\
\rho= & \text { the density of the oxidation product, } \frac{\mathrm{gm}}{\mathrm{cm}^{3}} .
\end{aligned}
$$

Let

$$
k_{p}=\rho^{2} k
$$

therefore

$$
M=\sqrt{K_{p} t},
$$

where

$$
K_{p}=\text { the mass-based rate constant, } \frac{\mathrm{gm}^{2}}{\mathrm{~cm}^{4}-\mathrm{sec} .}
$$

A plot of the mass-based reaction rate constant as a function of temperature is shown in Figure 3-18. The Arrhenius equation was used to extrapolate the experimental data to a temperature of $700^{\circ} \mathrm{C}\left(1292^{\circ} \mathrm{F}\right)$.

\subsection{Cask Simulation Networks}

The nodal arrangements for the loss-of-coolant models programmed on the Thermal Analyzer Program (TAP) are shown in Figures 3-19, 3-20, and 3-21. Figure 3-19 is the basic heat transfer network for the IF-300 simulation model, which shows the nodes but not how they are connected. This figure relates only the nodes and the dimensions. Figure 3-20 is the complete simulation network of the IF-300 loss-of-coolant model as it is programmed on TAP. This network is actually only a heat transfer network, however the oxidation and diffusion networks are shown since they were 


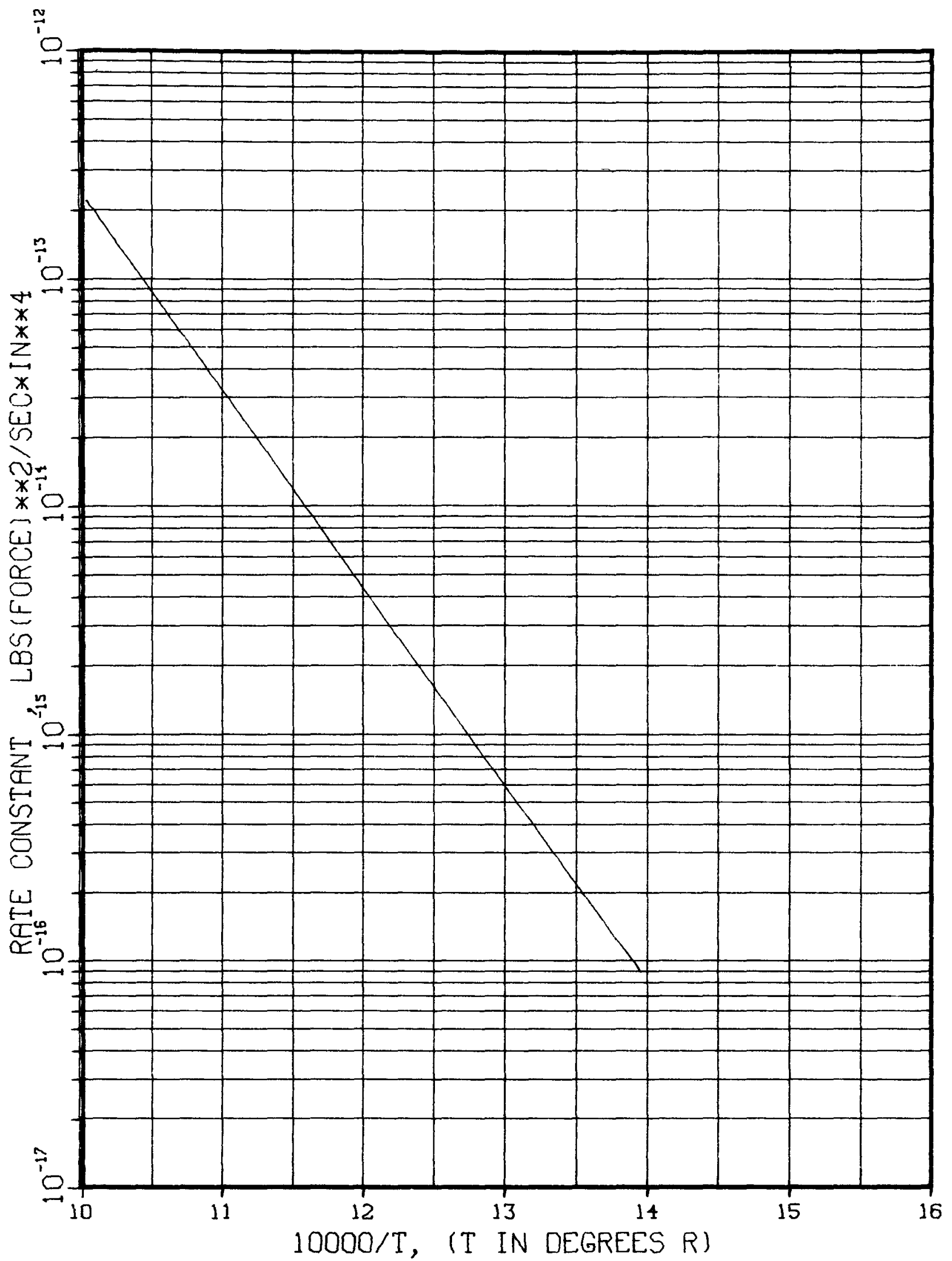

FIGURE 3-18. Reaction Rate Constant for Oxidation of Uranium Dioxide (Reference 26) 


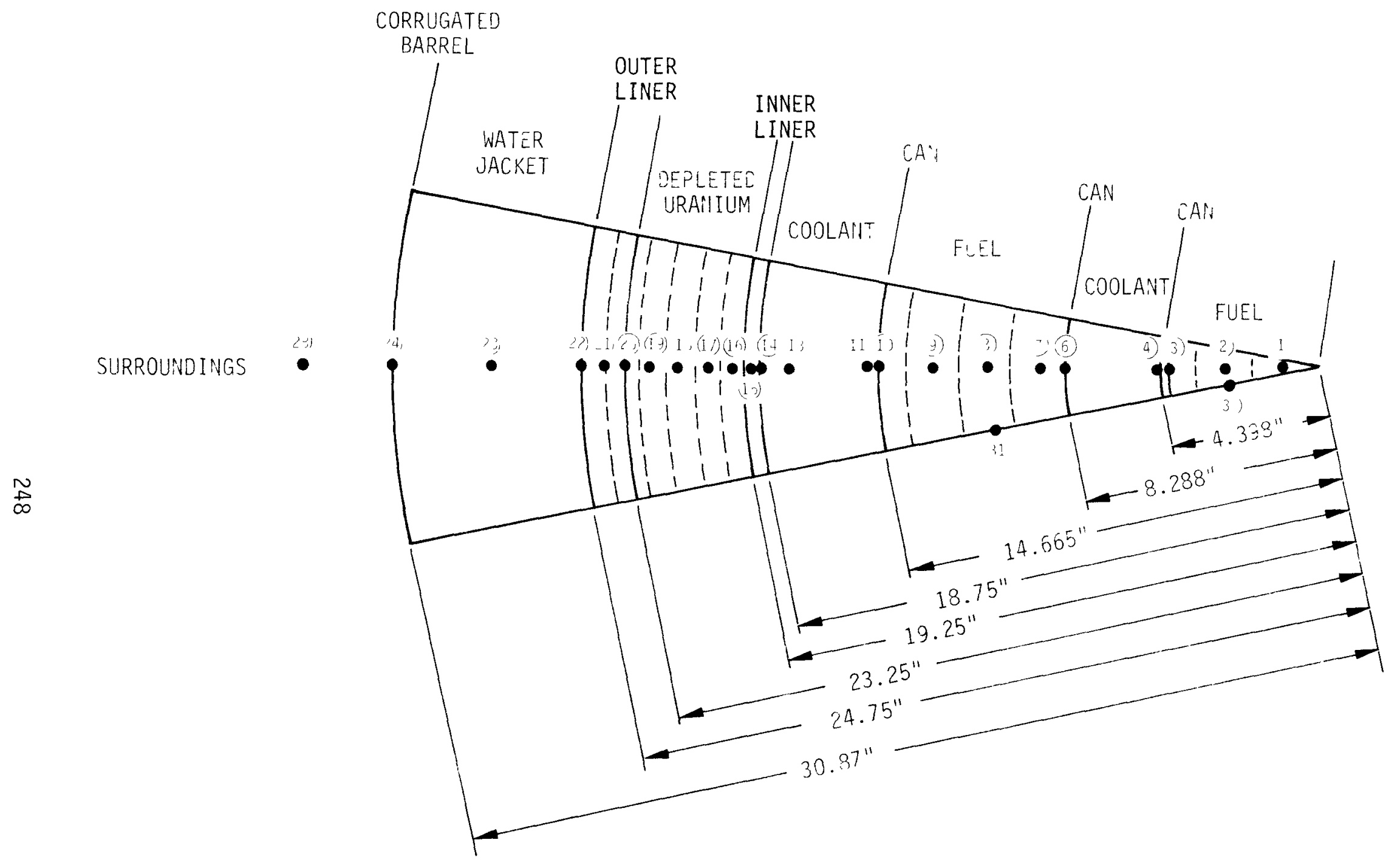

HEDL 7507-30.7

FIGURE 3-19. Nodal Arrangement for Steady-State and Loss-of-Coolant Models of the IF-300 

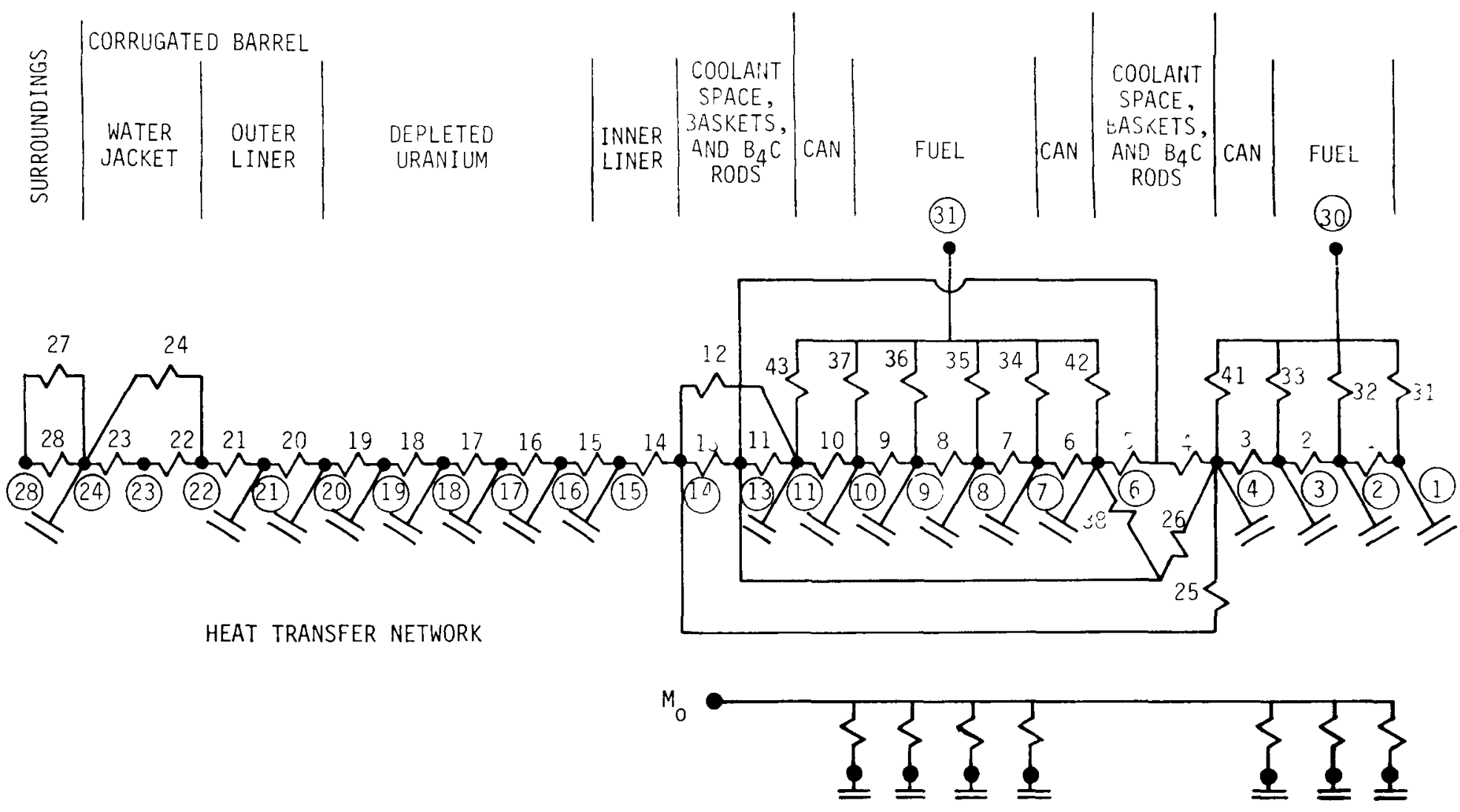

OXIDATION NETWORK

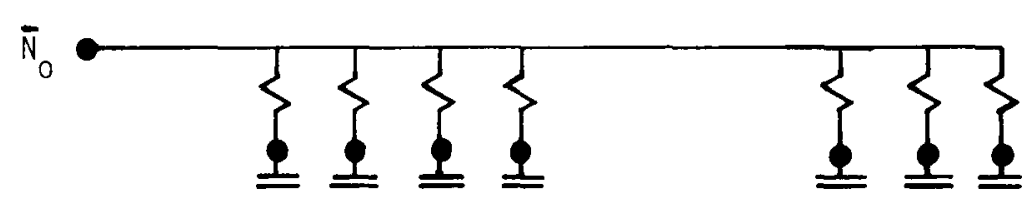

DIFFUSION NETWORK

FIGURE 3-20. Simulation Network of the Loss-of-Coolant Model of the IF-300. 


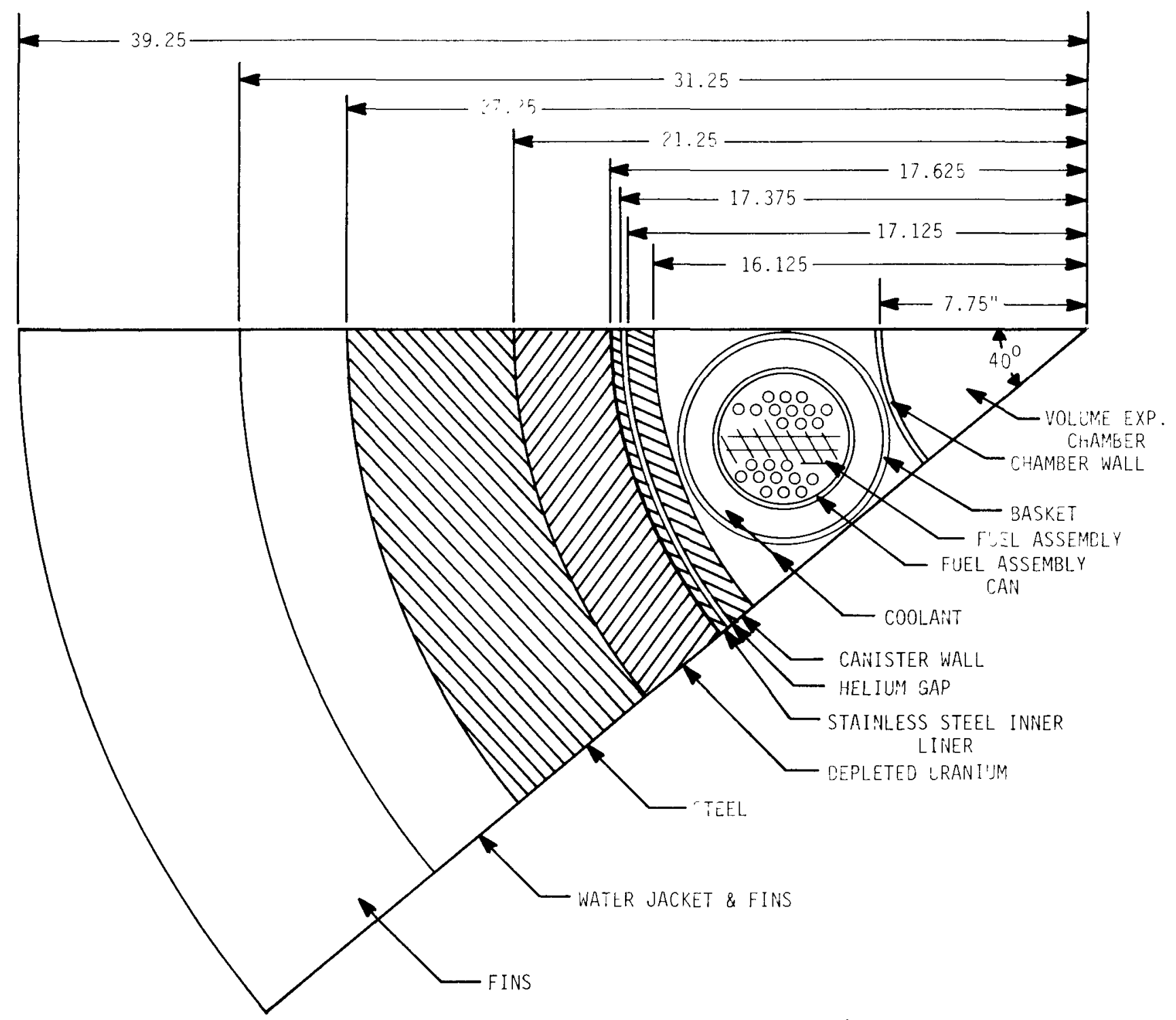

FIGURE 3-21. Idealized Representation of the AMCO Spent Fuel Shipping Cask and Simulation Network of the Loss-of-Coolant Mode1 (Page 1 of 2) 


\section{$\bullet$}

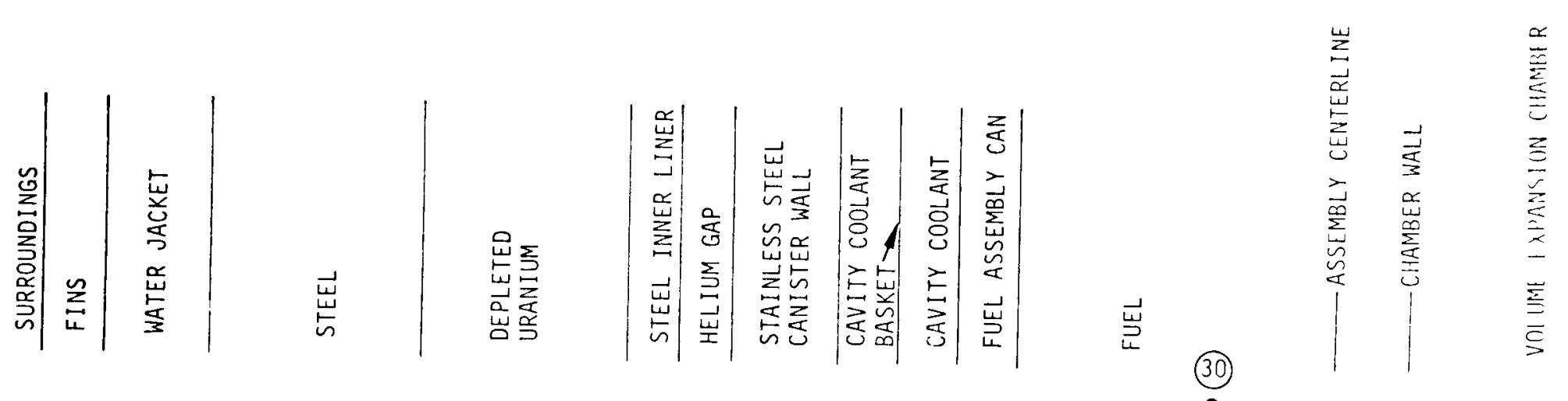

$\stackrel{\text { Y }}{\mathscr{Y}}$

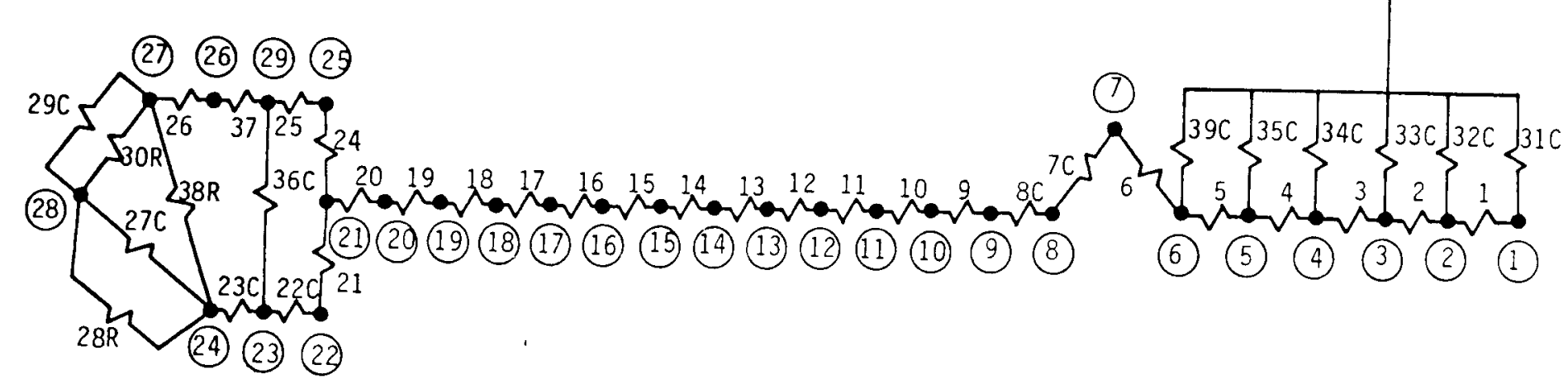

HEDL 7507-30.12

FIGURE 3-27. Idealized Representation of the AMCO Spent Fuel Shipping Cask and Simulation Network of the Loss-of-Coolant Model (Page 2 of 2 ) 
originally part of the model of the conceptual cask design simulated in the early stages of the study. The IF-300 model includes some new features which this early model did not have, but the oxidation and diffusion networks were not needed so they were not retained. However, these networks may be added later if desired. Network interactions, switching, and other functions of the central processor are not shown, but some of these have been discussed earlier and will be discussed further and illustrated in the next section. In Figure 3-20, the circled numbers identify only nodes. The admittances are also numbered since some are referred to in the following sections. Figure 3-21 is the simulation network of the loss-of-coolant model of the AMCO cask. It consists of only the heat transfer network. The oxidation and diffusion networks are omitted. In this figure, as in Figure 3-20, the node numbers are circled, and the admittance numbers are not circled. The central processor in TAP also controls the network interactions, switching and other functions for this network.

\subsection{Central Processor: Control of Thermal Radiation, Melting and Fuel Oxidation}

Algorithms controlling switching, melting, oxidation, and interactions of the three networks are functions of the central processor.

\subsubsection{Thermal Radiation}

In Figure 3-20, connectors 3, 4, 6, 10, 12, 24, 25, and 28 are thermal radiation admittances. Admittances 3 and 10 represent radiation heat transfer paths from the outer row of pins in the fuel assemblies to the inside of the assembly cans. Admittance 6 is a composite connector representing heat flow by conduction in the outer fringes of the fuel assembly, and radiation to the assembly can. Heat transfer between the inner fuel assembly and the outer fuel assemblies is represented by admittance 4 . Admittances 12 and 25 are the radiation paths from the outer fuel assemblies and the inner fuel assembly, respectively, to the inner surface of the cask cavity. Thermal radiation across the outer water jacket is represented by admittance 24 , and radiation from the outer surface of the jacket to the surroundings by admittance 28 . 
Thermal radiation is computed automatically by the TAP code central processor, based on the following development of an expression for the thermal radiation admittance.

The heat transferred from node $(m+1)$ to node $m$ is

$$
Q=\sigma A F\left(T_{m+1}^{4}-T_{m}^{4}\right)
$$

where

$T_{m}=$ the absolute temperature of the m-th node, $T$,

$\sigma=$ the Stefan-Boltzmann constant, $H / \theta T^{4} L^{2}$,

$F=$ the combination emissivity and shape factor,

$A=$ the surface area for radiation, $L^{2}$.

If Equation (3-74) is rewritten as

$$
Q=h_{r} A F\left(T_{m+1}-T_{m}\right)
$$

then the coefficient for heat transfer by radiation, $h_{r}$, is

$$
\begin{aligned}
& h_{r}=\sigma \frac{\left(T_{m+1}{ }^{4}-T_{m}{ }^{4}\right)}{\left(T_{m+1}-T_{m}\right)} \\
& \text { or } \\
& h_{r}=\sigma\left(T_{m+1}^{3}+T_{m} T_{m+1}^{2}+T_{m}^{2} T_{m+1}+T_{m}^{3}\right) . \\
& Y_{R}=h_{r} A F,
\end{aligned}
$$

and substituting from Equation (3-77), 


$$
Y_{R}=\sigma A F\left(T_{m+1}^{3}+T_{m}{ }^{T}+1+{ }^{2}+T_{m}^{2} T_{m+1}+T_{m}^{3}\right) .
$$

The central processor automatically computes values of $Y_{R}$ to be used between nodes $\mathrm{m}$ and $\mathrm{m}+1$ in the heat transfer network, based on temperatures from the previous iteration.

The combination emissivity and shape factor is expressed as

$$
F=F_{A} F_{\varepsilon}
$$

where

$F_{A}=$ the geometric view factor or shape factor,
$F_{\varepsilon}=$ the emissivity factor.

The emissivity factor used is given by the expression

$$
F_{\varepsilon}=\frac{1}{\frac{1}{\varepsilon_{m+1}}+\frac{1}{\varepsilon_{m}}-1}
$$

where

$E_{m}=$ the emissivity of the radiating $m$-th node.

Approximate shape factors were used for all radiation paths except those at the outer water jacket and finned surfaces. View factors for a finned cylindrical surface are shown in Figure 3-22. (27)

\subsubsection{Melting}

In the opening paragraphs of the Appendix it was pointed out that the IF-300 was not modeled until the final stages of the study. The LWR spent fuel shipping cask modeled and studied throughout most of the study was a conceptual design that was never actually built. One of the important differences between this cask and the IF-300 is the type of gamma shielding used. The conceptual design is lead-shielded. The IF-300 shield is depleted uranium. 


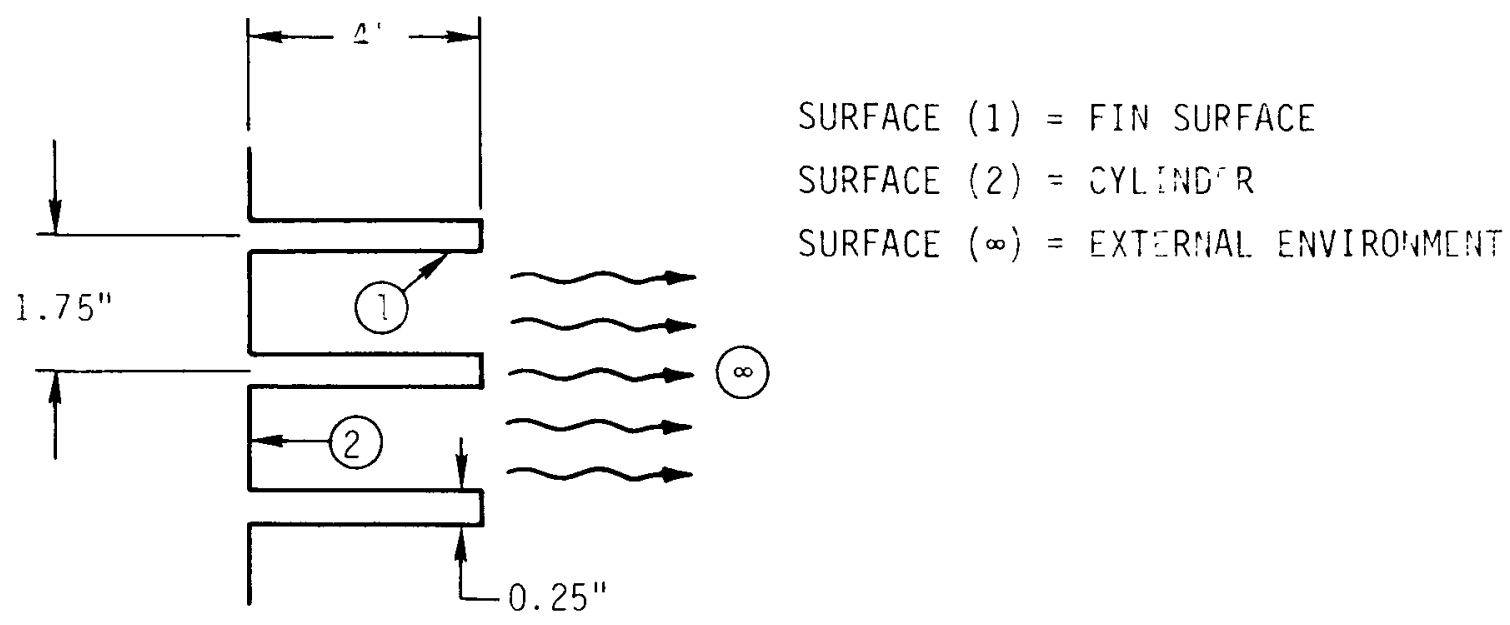

$$
\begin{array}{ll}
F_{G_{1}-\infty}=0.17 & F_{G_{2}-\infty}=0.18 \\
F_{G_{1}-1}=0.69 & F_{G_{2}-2}=0.00 \\
F_{G_{1}-2}=0.14 & F_{G_{2}-1=0.42 \times 2^{\star}} \\
{ }^{\prime} F_{G}=1.00 & { }^{F} F_{G}=1.00
\end{array}
$$

*NOTE THAAT THE CYLINDER SEES TWO FINS SIMULTANEOUSLY

HEDL 7507-30.17

FIGURE 3-22. Geometric View Factors for a Typical Fin-Cylinder Cavity (Reference 27) 
The simulation network of the loss-of-coolant model of the conceptual cask included circuitry and logical switches to simulate melting of the lead shield during a fire. Since the model of this cask has been preserved for possible future use to evaluate the behavior of casks designed with lead shields, a brief discussion of the techniques used to simulate melting of the lead shield will be presented.

Two sets of admittances are used to represent the lead shield, as shown in the following sketch. The admittance labeled $Y_{A}$ represents heat conduction in the lead between nodes 17 and 18. The admittance labeled $Y_{B}$ represents heat transfer by radiation from the outer steel she11, node 21 , and the lead node 17 , across the void space created when lead nodes 18,19 and 20 melt away.

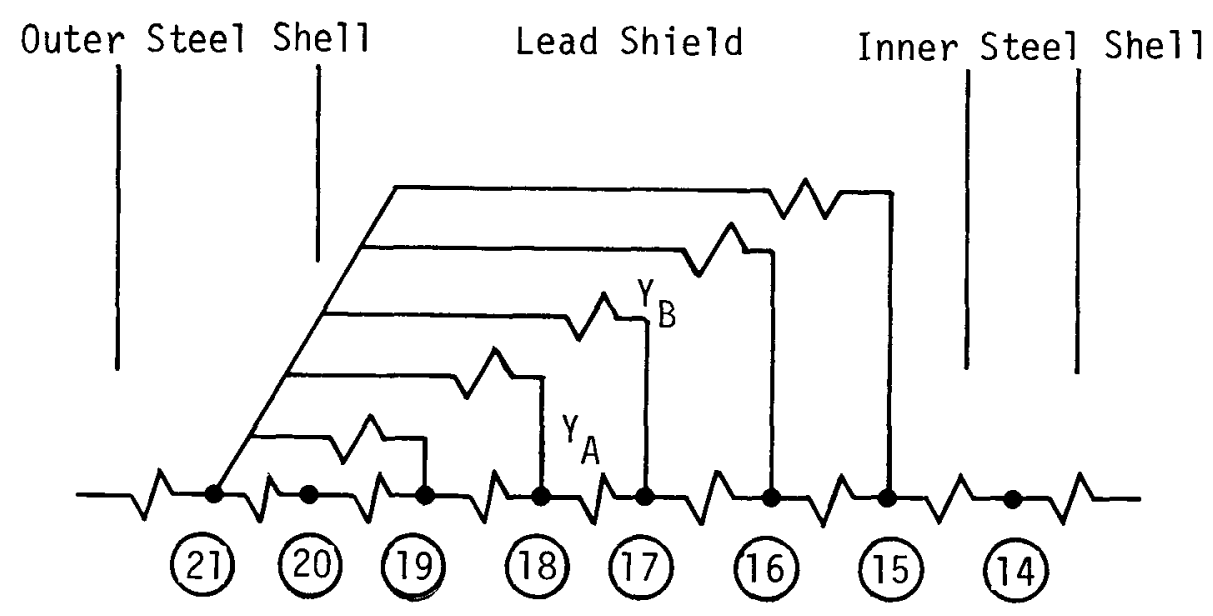

These thermal radiation and conduction admittances for the lead shield are activated by logical switches and are switched in and out of the circuit as the appropriate nodes reach the melting temperature of the lead, absorb the latent heat of melting, and melt or ablate away. Algorithms for controlling the switching of these admittances are shown in Figures 3-23 and 3-24. 


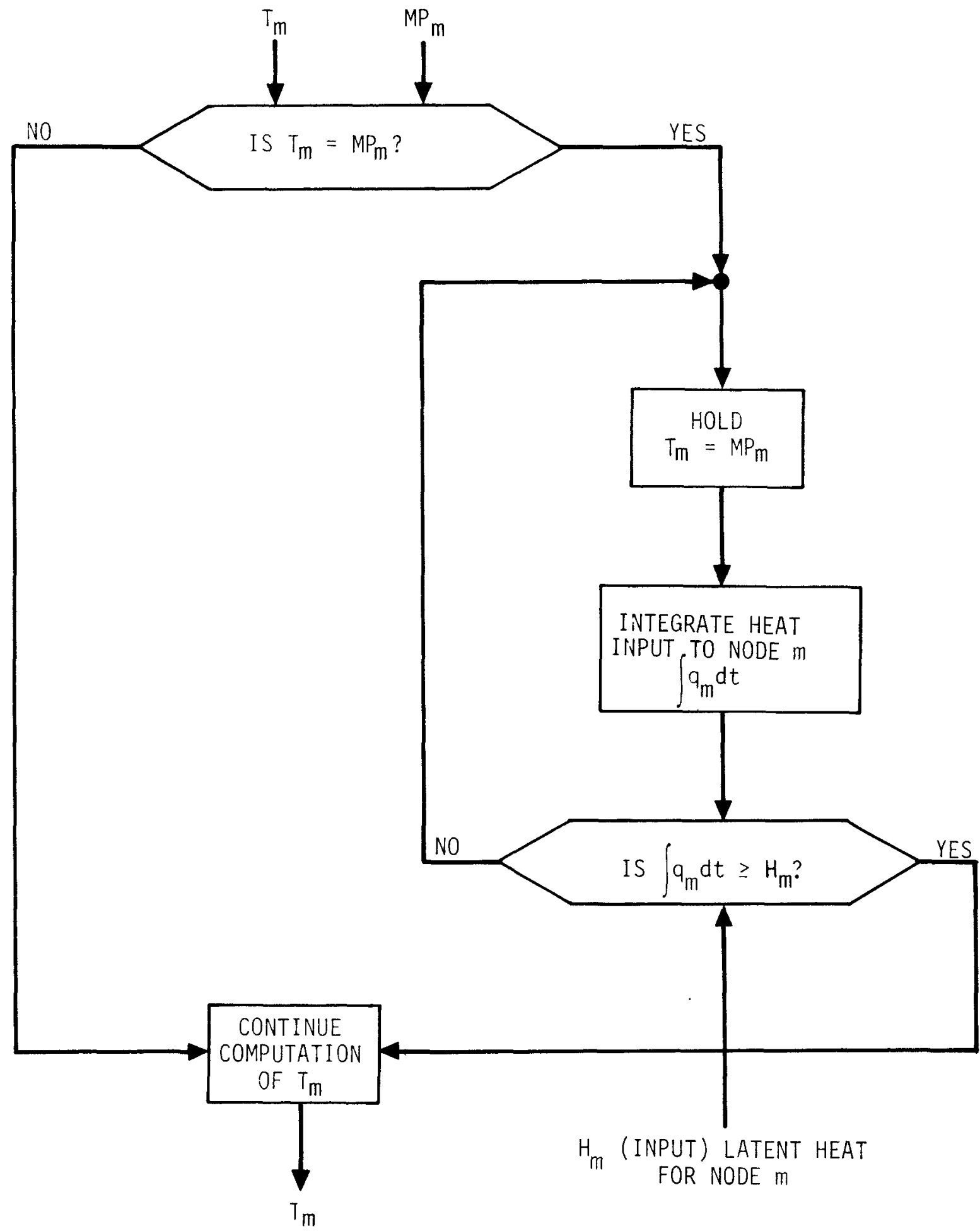

HEDL 7507-30.19

FIGURE 3-23. Algorithm for Controlling Latent Heat of Melting 


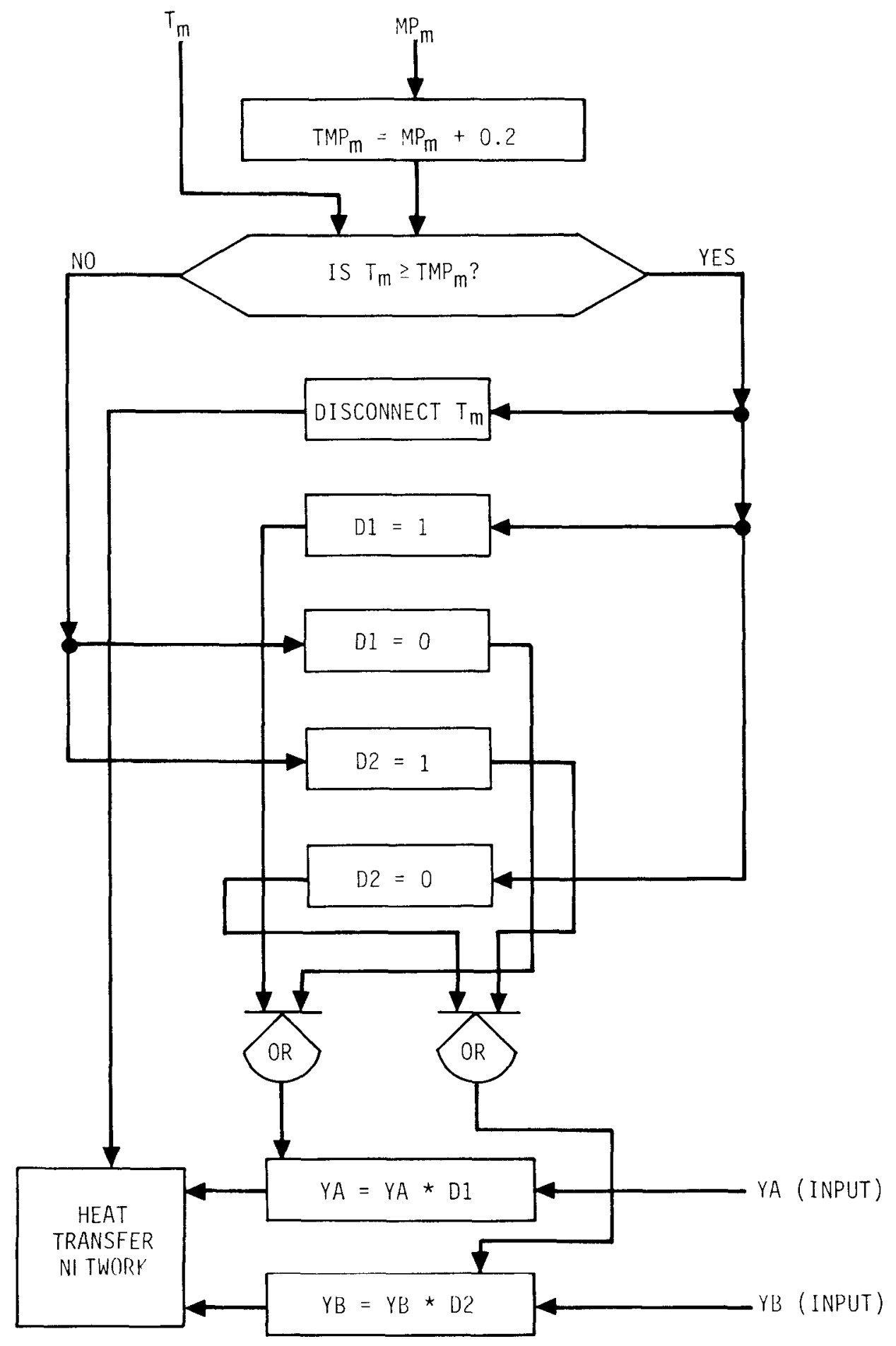

HEDL $7507-30.20$

FIGURE 3-24. Algorithm for Controlling the Switching of Admittances Simulating Melting 
In Figure 3-23, the node temperature is compared to the melting temperature of the node material. If the node temperature, $T_{m}$, is less than the melting temperature, $\mathrm{MP}_{\mathrm{m}}$, computation of the node temperature is continued as part of the network computations. If the node temperature is equal to the melting temperature, the node temperature is held equal to the melting temperature and the heat input to the node is integrated over time. The latent heat, $H_{m}$, for the node is precalculated and entered as input. This is a particular value depending upon the mass of material in node " $m$ ". The integrated heat to the node is compared to the latent heat for the node and, if it is equal to or greater than the latent heat, the computation of $T_{m}$ progresses as part of the regular network computations. If the integrated heat is less than the latent heat for the node, the algorithm returns the progress of the computations to the point where the node temperature is being held equal to the melting temperature, and the heat input is integrated again to complete the cycle.

Figure 3-24 shows how the node temperature is used to activate the switching circuits. First of a11, 0.2 of a degree, a very small arbitrarily selected temperature rise, is added to the melting point of the node. This is designated as TMP $_{m}$, a temperature slightly higher than the melting temperature. The node temperature $T_{m}$ is then compared to $\operatorname{TMP}_{m}$ and, if it is greater than or equal to TMP ${ }_{m}$, node " $m$ " is disconnected from the network. A7so, two switching variables, D1 and D2, are set either equal to zero or to one, depending upon whether the node temperature is equal to or greater than TMP ${ }_{m}$, or whether it is less than TMP ${ }_{m}$. When the node temperature is greater than the melting temperature, $D 1=1$, and $D 2=0$. If the node temperature is less than the melting temperature, $D 1=0, D 2=1$, and node " $m$ " is not disconnected from the network. The affected admittances are then multiplied by 01 and D2 and inserted into the heat transfer network. 


\subsubsection{Fuel Oxidation}

The algorithm in the central processor that controls the switching process simulating the release of the "bound up" fission gases by oxidation of the fuel is shown in Figure 3-25. This algorithm is an illustration of how interactions of the heat transfer, oxidation and diffusion networks are controlled by the central processor.

In Figure $3-25$, the mass gain per unit surface area of fue 1 in node $m$ due to oxidation, $M_{m}$, from the oxidation network is converted to the mass of oxygen, $m_{m}$, by multiplying by the total surface area of fuel in the node, TSPIN $_{m}$ [see Equation (3-54)]. The mass of oxygen is then divided by the atomic weight of oxygen, AW $\emptyset$, to obtain the number of mass atoms, $\emptyset_{m}$ [Equation (3-60)]. The oxygen-uranium ratio for the node, $\left(\frac{\emptyset}{U}\right)_{m}$, is then determined by dividing $\emptyset_{m}$ by the number of mass-atoms of uranium in the node, $U_{m}$ [Equation (3-59)]. This ratio is compared to the ratio, $\left(\frac{\emptyset P D}{U}\right)_{m}$, which bounds the $U_{3} 0_{8}$ region on a $\mathrm{UO}_{2}-\mathrm{U}_{3} \mathrm{O}_{8}$ phase diagram (see Figure $\left.3-26\right)$. $\left(\frac{Q P D}{\mathrm{U}}\right)_{\mathrm{m}}$ is a function of the node temperature, $T_{m}$, which is obtained from the heat transfer network. The decision block in the algorithm of Figure 3-25 compares the node ratio $\left(\frac{\emptyset}{U}\right)_{m}$ with the phase diagram ratio, $\left(\frac{\emptyset P D}{V}\right)_{m}$. A switching variable, $D 4$, is set either equal to zero or to one, depending upon whether or not $\left(\frac{\emptyset}{\mathrm{U}}\right)_{\mathrm{m}}$ is greater than or equal to $\left(\frac{\emptyset P D}{U}\right)_{m}$. When $\left(\frac{\emptyset}{U}\right)_{m} \geq\left(\frac{O P D}{U}\right)_{m}, D 4=1$, and when $\left(\frac{\emptyset}{U}\right)_{m}<\left(\frac{\emptyset P D}{U}\right)_{m}, D 4=0$. $^{m}$ The number of moles of bound up fission gases in the node, $\mathrm{N}_{\mathrm{m}}$, from the diffusion network, is multiplied by $D 4$ and becomes $\mathrm{GS}_{\mathrm{m}}$, the number of moles released from node $\mathrm{m} . \mathrm{GS}_{\mathrm{m}}$ is then multiplied by the factor $\mathrm{C} / \mathrm{M}$, which is the number of curies radioactivity per moTe, to give $C_{m}$, the number of curies radioactivity in the bound up gases released.

The PWR fuel is $\mathrm{UO}_{2}$, while the FFTF or LMFBR-type fuel is $\mathrm{UO}_{2}-\mathrm{PuO}_{2}$. It was assumed that the bound up fission gases would be released from the LMFBR-type fuel when the $\mathrm{UO}_{2}$ in the fuel oxidizes to $\mathrm{U}_{3} \mathrm{O}_{8}$, even though $\mathrm{PuO}_{2}$ is present. The $\mathrm{UO}_{2}-\mathrm{U}_{3} \mathrm{O}_{8}$ phase diagram used for the PWR fuel (Figure 3-26) is assumed to be valid for the LMFBR-type fuel. The oxygenuranium ratios that bound the $\mathrm{U}_{3} 0_{8}$ regions on this phase diagram are compared to the calculated ratios for both types of fuel to signal the conversion of $\mathrm{UO}_{2}$ to $\mathrm{U}_{3} \mathrm{O}_{8}$. 


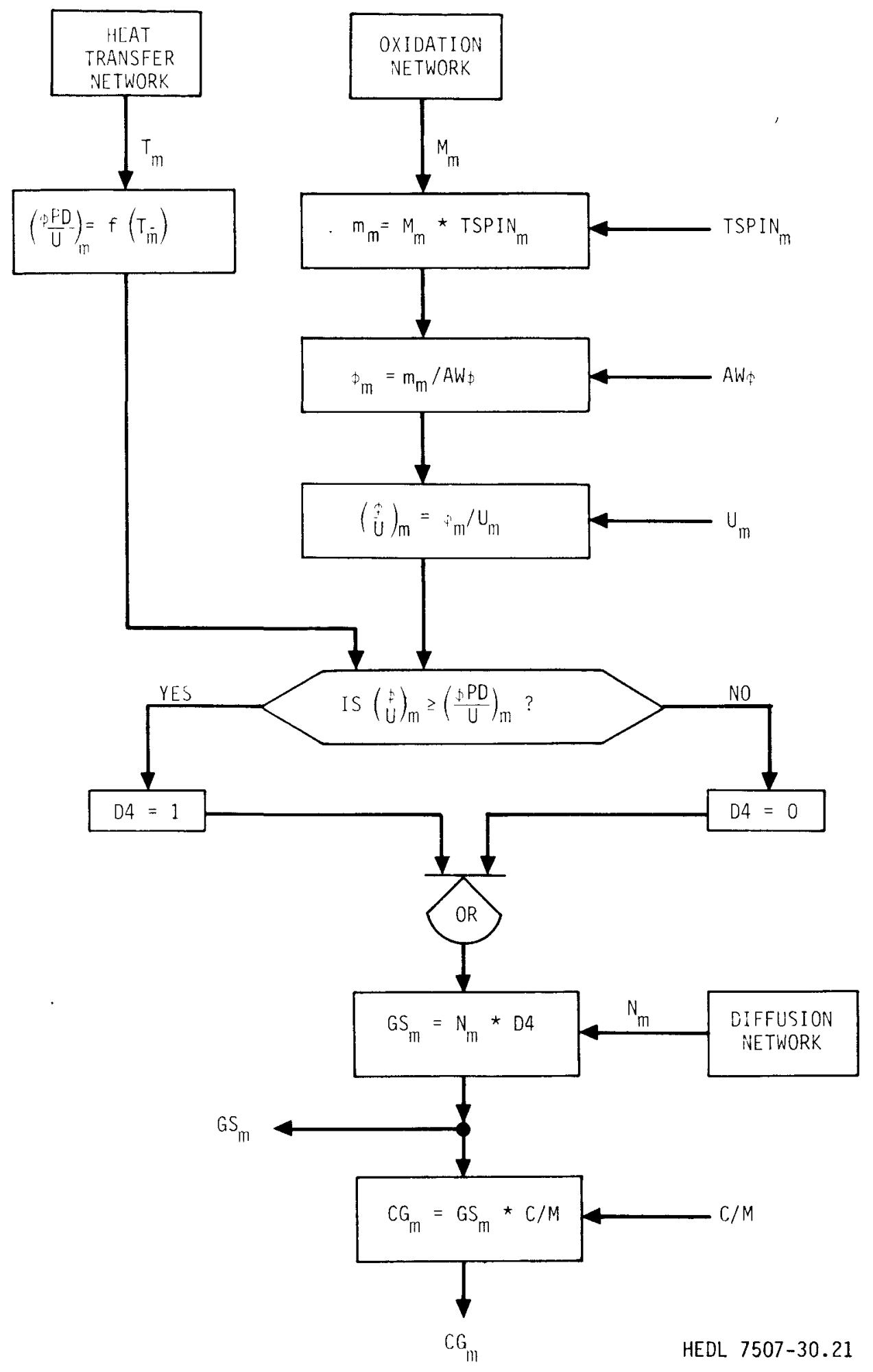

FIGURE 3-25. Algorithm Controlling the Simulation of the Release of "Bound Up" Fission Gases 


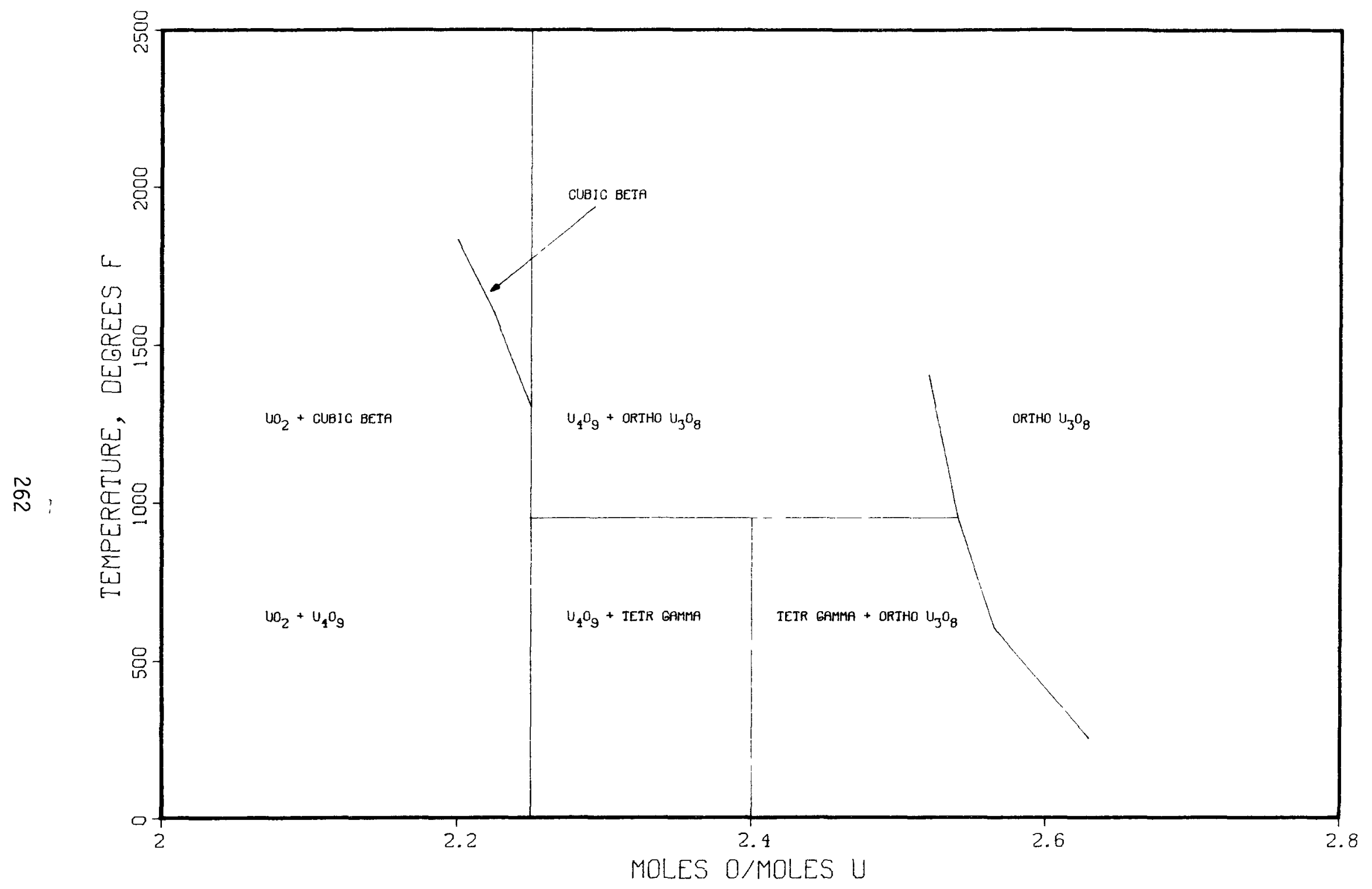

FIGURE 3-26. Phase Diagram for 0xides of Uranium (Reference 37) 
Figure 3-27 is a typical portion of the logic control and information flow of the processor in both loss-of-coolant models. Melting and switching algorithms for the lead in the conceptual cask, and controlling algorithms for monitoring the failure of the fuel pin clads and for the release of bound-up fission gases in both type casks are shown.

\subsection{Proposed Modifications to Loss-of-Coolant Models to Simulate the Flow of Fission Gases and Residual Coolant Vapor from the Casks}

Two breach sizes were evaluated, using the coolant loss rate models discussed in Section 2, to determine the rate at which the primary coolant is lost from the casks. After the primary coolant is lost, the fuel assembly temperatures will rise and the free fission gases in the pins will expand. Some of the fuel pins will reach temperatures high enough for the expanding fission gases to cause clad failure, releasing the fission gases to the cask containment. The events leading up to fission gas release and the mechanisms of release have already been discussed earlier in Section 3. Once the fission gases are released to the cask containment, they would mix with the residual coolant vapor, and the mixture could flow from the cask through the breach, just as the primary coolant did earlier in the sequence of events.

A system of equations was developed to define the rate of flow of fission gases and volatile solids from a cask. This system of equations was developed too late for modification of the present loss-of-coolant models and volatile solids release model. However, some of the equations will be derived and discussed here. Additional equations necessary for modification of the volatile solids release model will be presented and discussed in Section 4.

\subsubsection{Mass Balance on the Cask Containment}

A mass balance on the cask cavity, in terms of moles of fission gases, can be written as 


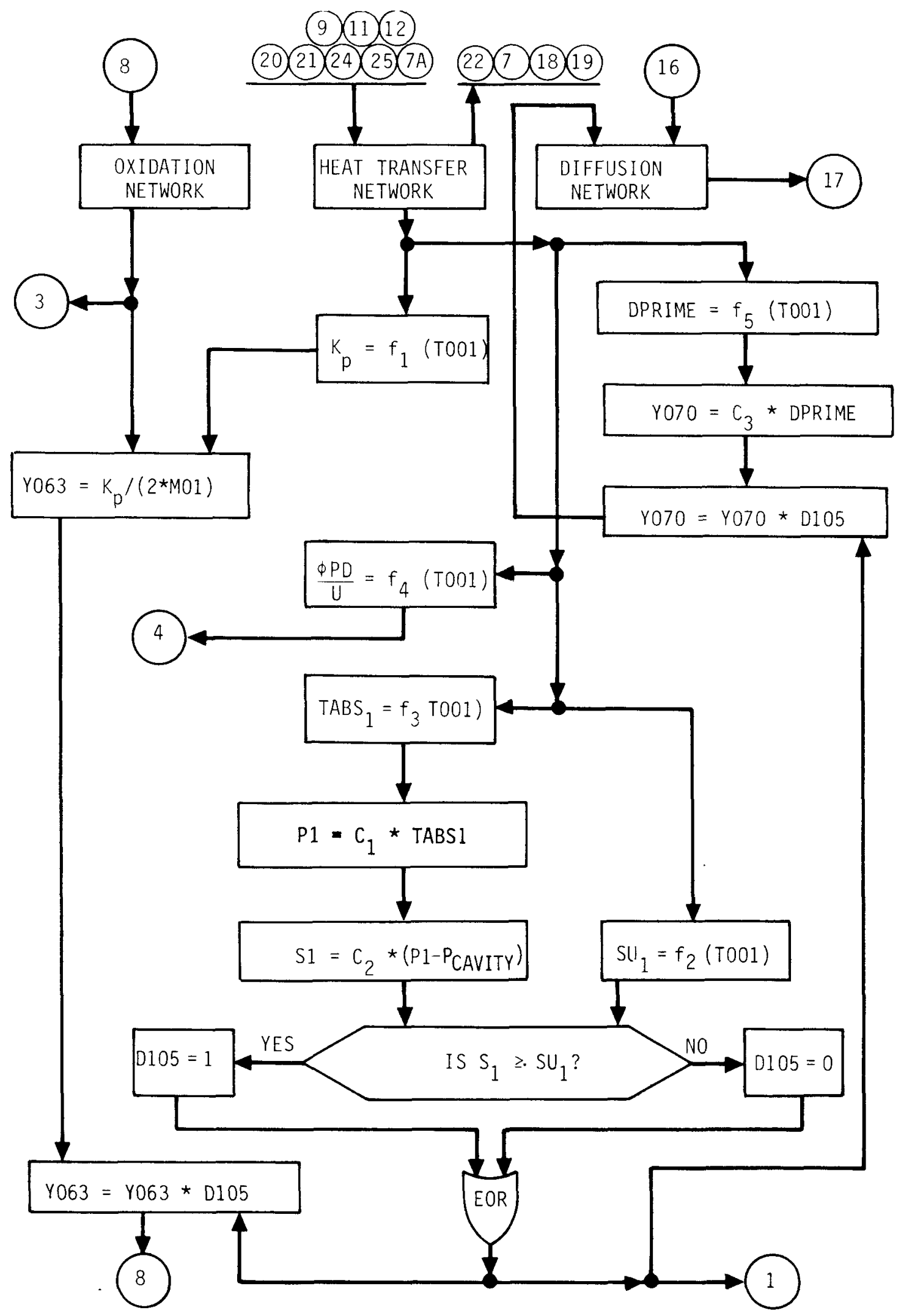

HEDL 7507-30.24

FIGURE 3-27. Typical Portion of the Logic and Information Control of the Processor (Page 1 of 7 ) 


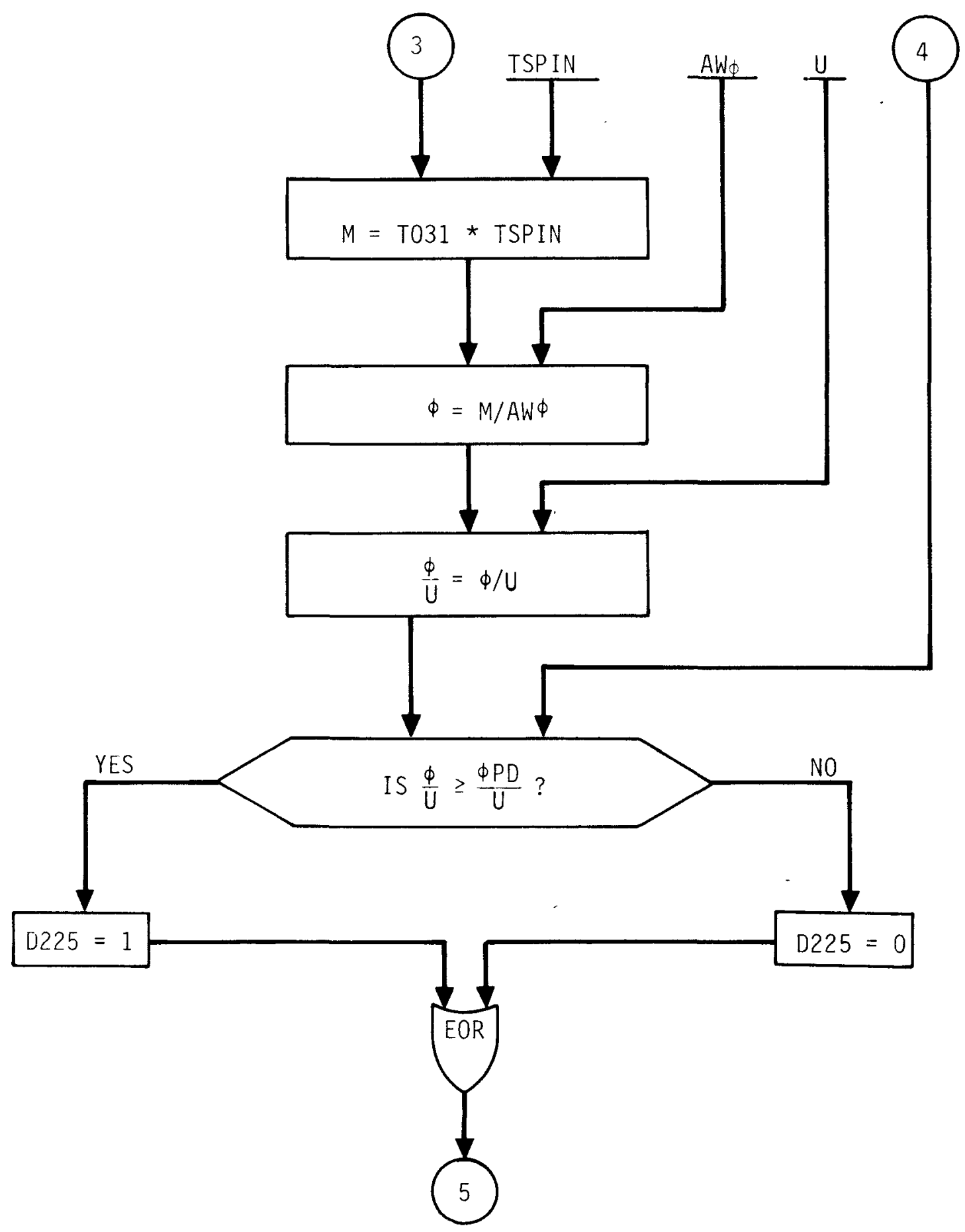

HEDL $7507-30.25$

FIGURE 3-27. Typical Portion of the Logic and Information Control of the Processor (Page 2 of 7 ) 


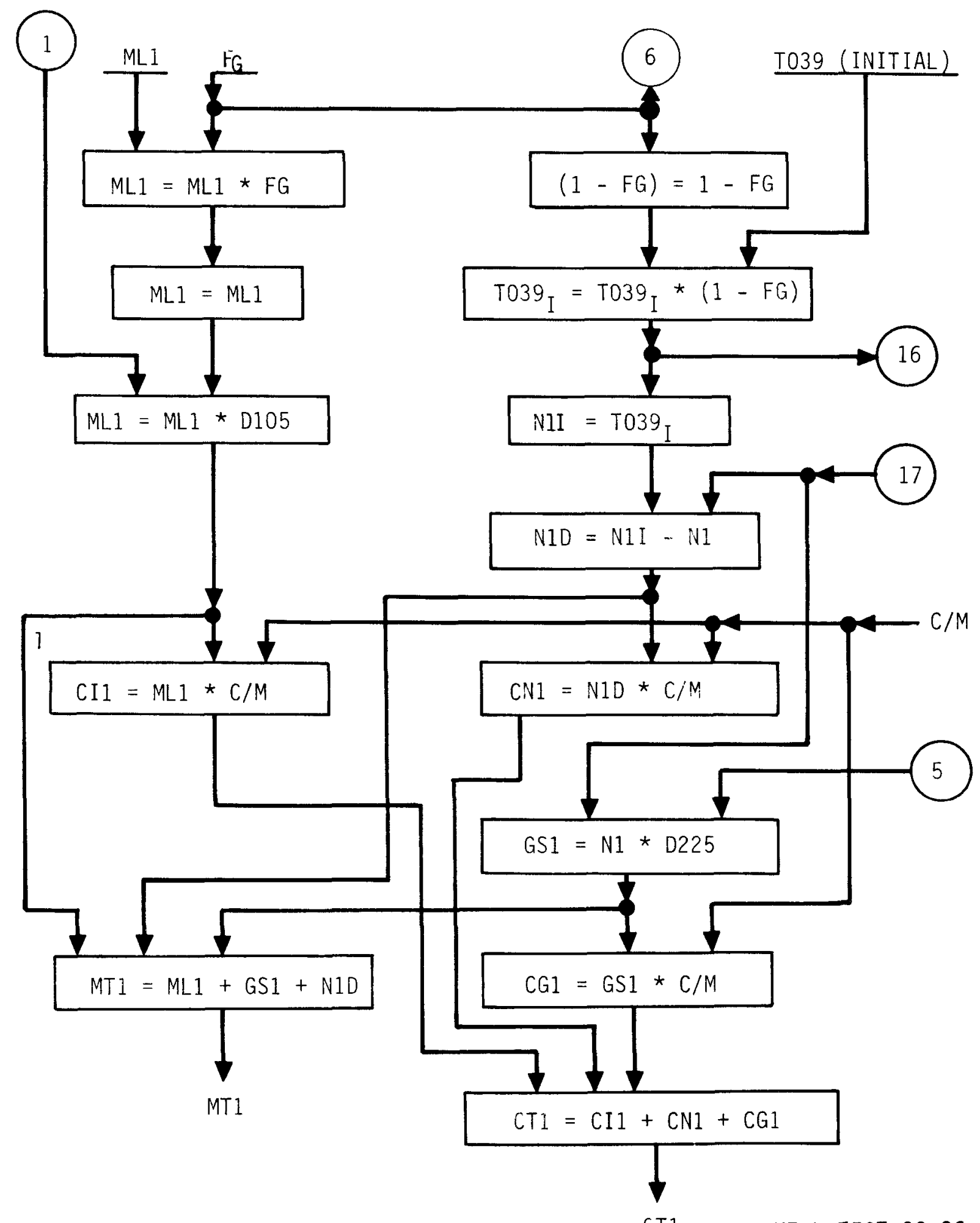

CT1 HEDL $7507-30.26$

FIGURE 3-27. Typical Portion of the Logic and Information Control of the Processor (Page 3 of 7 ) 


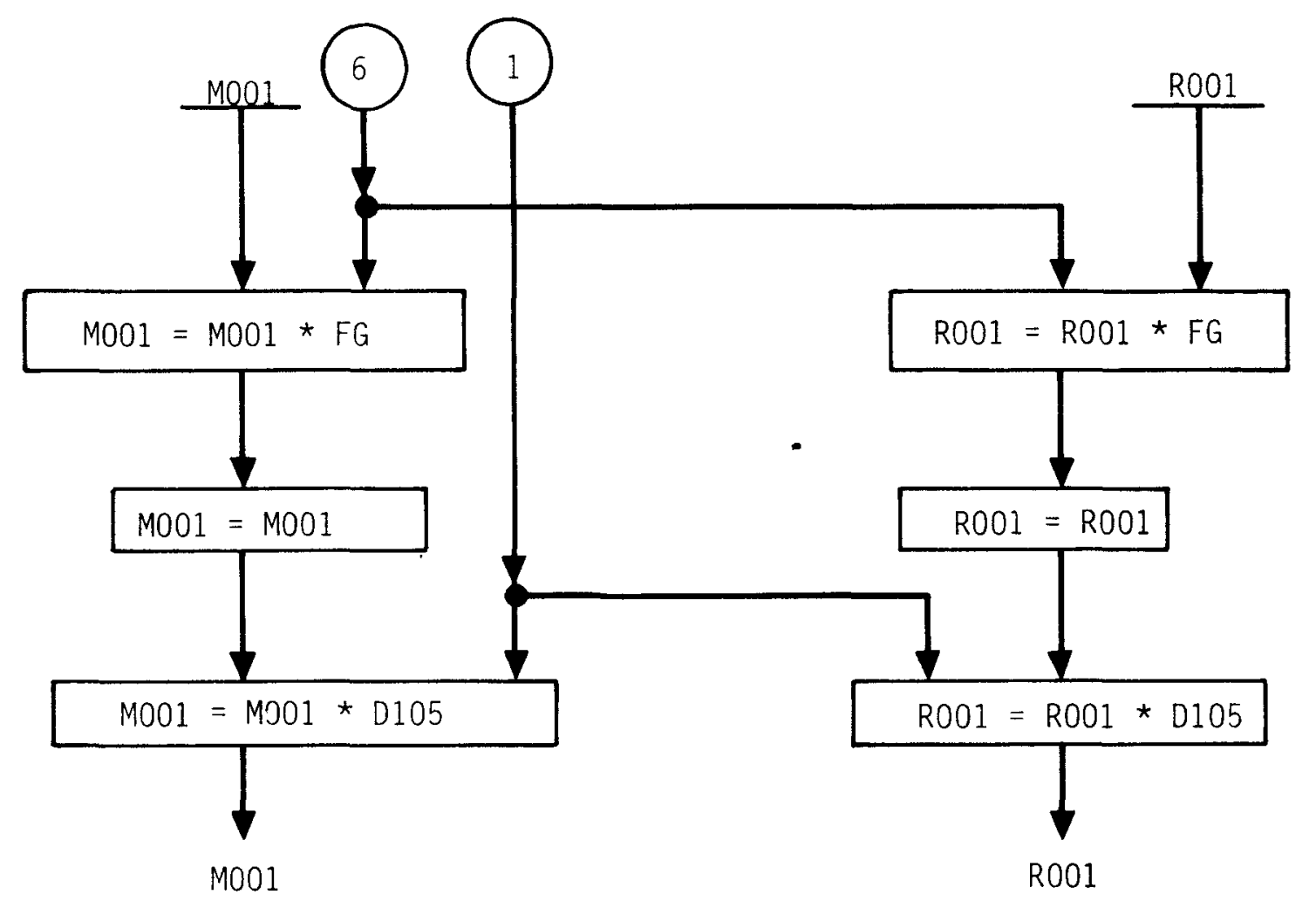

HEDL $7507-30.27$

FIGURE 3-27. Typical Portion of the Logic and Information Control of the Processor (Page 4 of 7 ) 


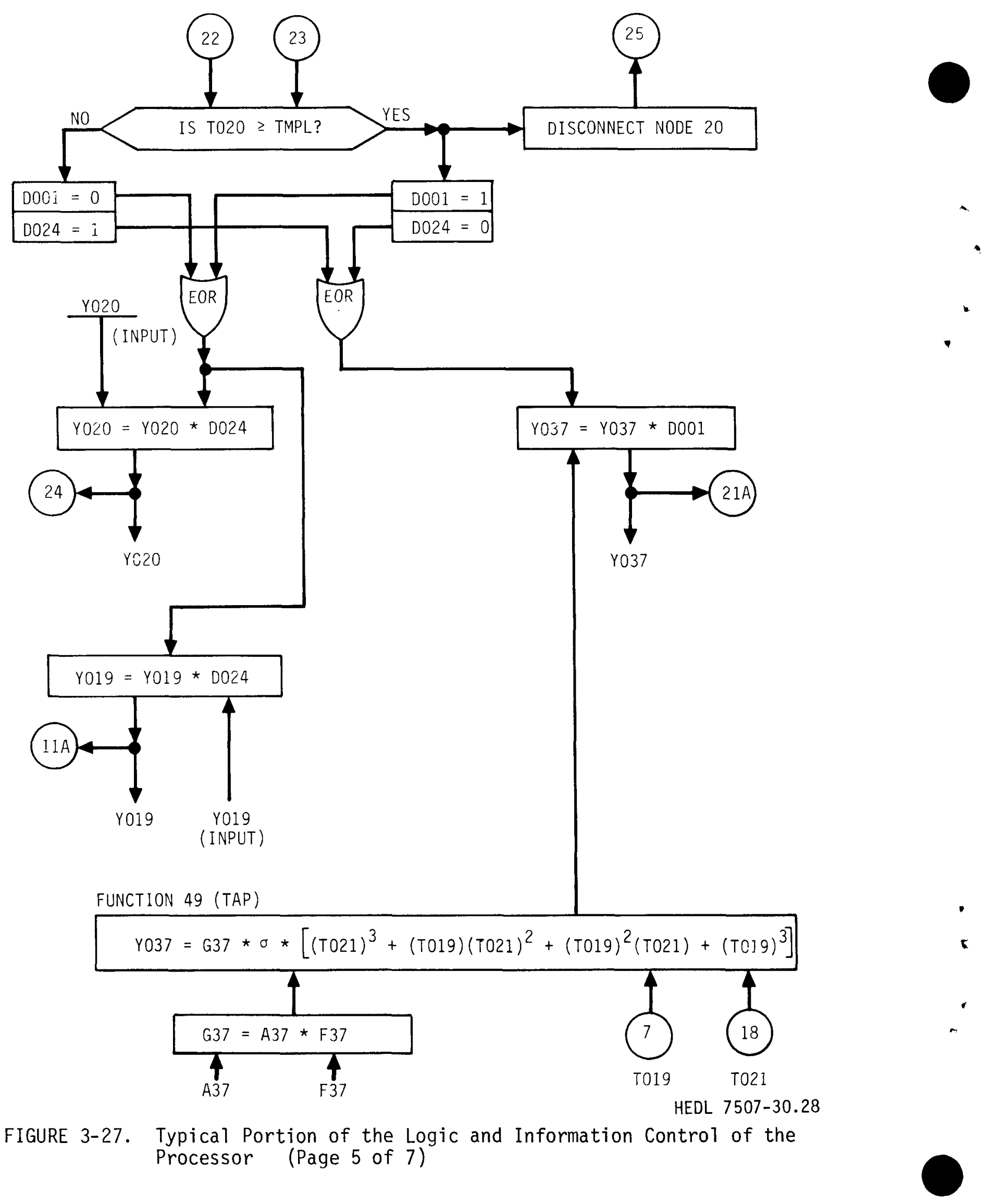




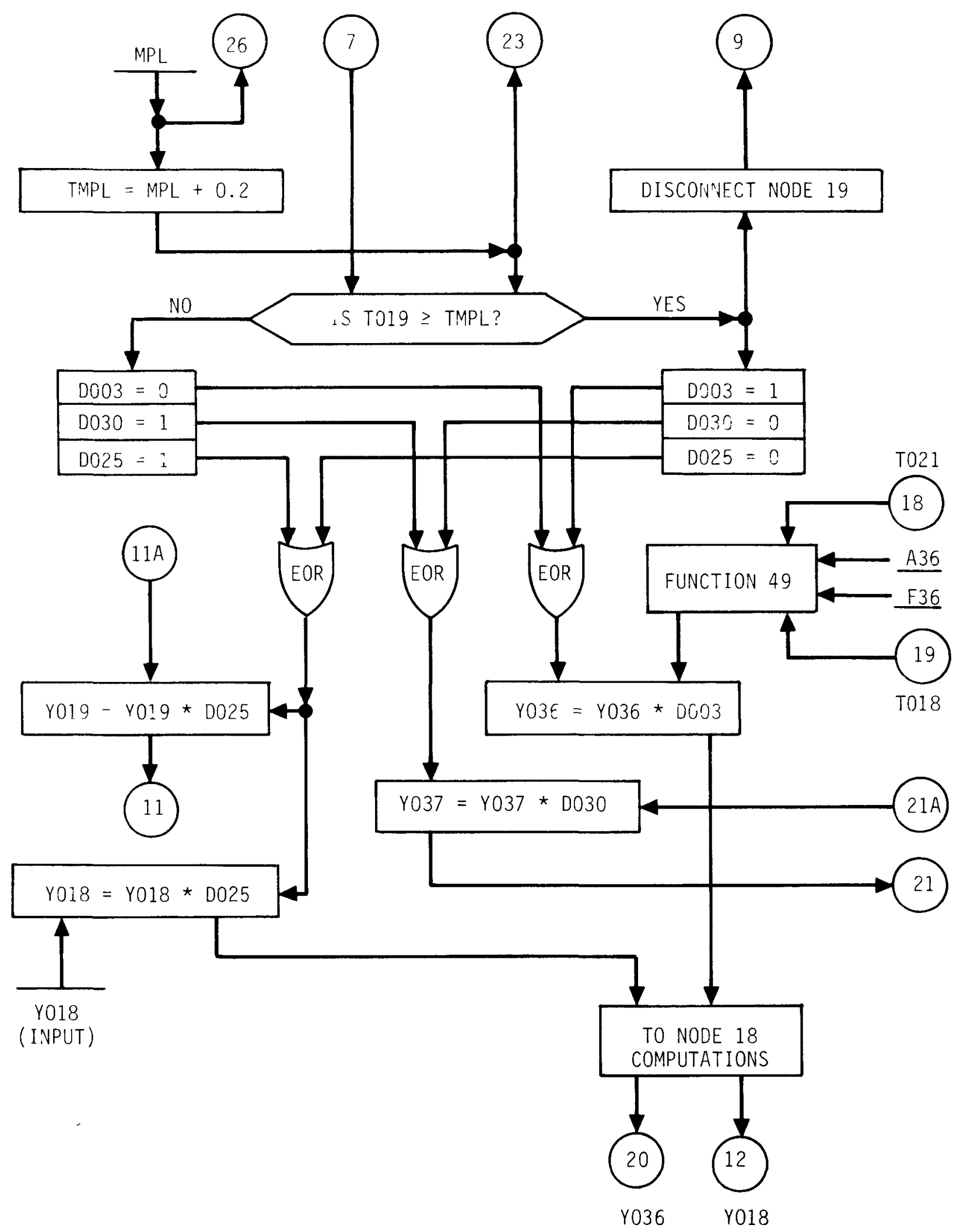

HEDL 7507-30.29

FIGURE 3-27. Typical Portion of the Logic and Information Control of the Processor (Page 6 of 7 ) 


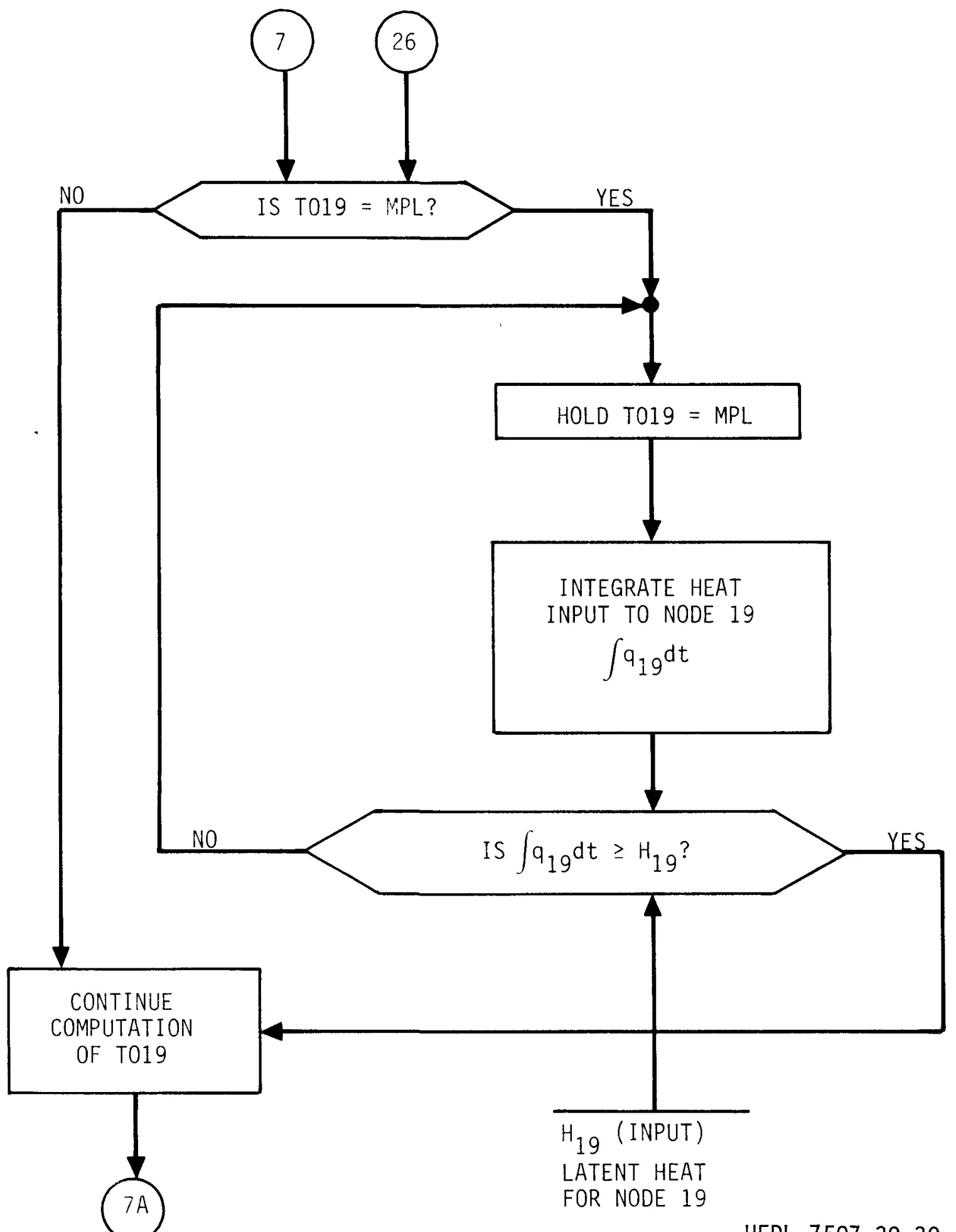

HEDL 7507-30.30

FIGURE 3-27. Typical Portion of the Logic and Information Control of the Processor (Page 7 of 7 ) 
$\left[\begin{array}{l}\text { Rate of Change of } \\ \text { Moles of Fission } \\ \text { Gases in the Cask } \\ \text { Cavity }\end{array}\right]=\left[\begin{array}{l}\text { Rate of release } \\ \text { of Fission Gases } \\ \text { to the Cavity } \\ \text { From the Fuel }\end{array}\right]-\left[\begin{array}{l}\text { Rate of loss of } \\ \text { Fission Gases } \\ \text { from the Cavity } \\ \text { by Leakage }\end{array}\right]$

or

$$
\frac{d m}{d t}=\sum_{k=1}^{k} \delta_{k}(t) m_{k}-\frac{m_{G A P}}{V_{C S K^{f}}}
$$

$$
(k=1, \ldots, k)
$$

where

$$
\begin{aligned}
m= & \text { the number of moles of fission gases in the cask, } \\
& \text { lb-moles, } \\
m_{k}= & \text { the number of moles of fission gases in the } k \text {-th } \\
& \text { fuel node, lb-moles, } \\
A_{G A P}= & \text { the cross-sectional area of the breach opened in the } \\
& \text { cask containment, } i^{2}, \\
v_{C S k}= & \text { the free volume inside the cask, in }{ }^{3}, \\
u= & \text { the velocity at which the gas mixture flows through } \\
& \text { the breach, in/sec, } \\
\delta_{k}(t)= & \text { the Dirac impulse function applicable to the } k \text {-th } \\
& \text { fuel node, } 1 / \text { sec, } \\
f_{m}= & \text { the mole fraction of fission gases in the mixture of } \\
& \text { residual coolant vapor and fission gases. }
\end{aligned}
$$

The first term on the right hand side of Equation (3-82) is a source term, and the second term is the leakage term.

The source term is based on known values of $m_{k}$ and the release times for the $k$ fuel nodes as obtained from results from the loss-of-coolant models. At the time the pin clads burst in fuel node $k$, the impulse function $\delta_{k}(t)=1$. Before and after this burst time, $\delta_{k}(t)=0$.

The leakage term is based on the volumetric rate of flow of fission gases from the cask, and the number of moles in a unit volume of fission gases. The flow velocity u was determined from an energy balance on the breach. 


\subsubsection{Energy Balance on the Breach: Determination of Flow Velocity}

The First Law of Thermodynamics states that the total energy change in a system is equal to the difference between the heat added to the system and the work done by the system. This is expressed as Equation (3-83)

$$
d E=J \delta Q-\delta W
$$

where

$$
\begin{aligned}
\mathrm{dE} & =\text { the change in the total energy in the system, F-L/M, } \\
\delta Q & =\text { the heat added to the system, } \mathrm{H} / \mathrm{M}, \\
\delta W & =\text { the work done by the system, } \mathrm{F}-\mathrm{L} / \mathrm{M}, \\
J & =\text { the mechanical equivalent of heat, } \mathrm{F}-\mathrm{L} / \mathrm{H} .
\end{aligned}
$$

In terms of the various forms of energy included in the total energy of the system, the energy balance for a unit mass of fluid flowing may be written as

$$
J d e+d\left(\frac{p}{\rho}\right)+d\left(\frac{u^{2}}{2 g_{C}}\right)+\frac{g d Z}{g_{C}}=J \delta Q-\delta w
$$

where

de = the change in the internal energy of the fluid, $H / M$, $d\left(\frac{P}{\rho}\right)=$ the change in the flow work of the fluid, F-L/M, $\rho=$ the fluid density, $M / L^{3}$. $d\left(\frac{u^{2}}{2 g_{c}}\right)=$ the change in the kinetic energy of the fluid, $F-L / M$, $\mathrm{dz}=$ the change in the height (potential energy) of the fluid, $L$ $\mathrm{g}=$ the local acceleration of gravity, $L / \theta^{2}$,

$g_{C}=$ the gravitational constant, $M L / F \theta^{2}$.

Considering the unit mass of fluid as if it were at rest, the internal energy term may be obtained from the First Law for a non-flow process,

$$
J \text { de }=J \delta Q_{T}-P d\left(\frac{1}{\rho}\right),
$$


where

$$
\begin{aligned}
\delta Q_{T} & =\text { the total thermal effects from all sources, } H / M \\
\operatorname{Pd}\left(\frac{1}{\rho}\right) & =\text { a term representing all compression effects, } F-L / M .
\end{aligned}
$$

Since $\delta n_{T}$ represents the total thermal effects from all sources, it may be written as

$$
\delta Q_{T}=\delta Q+\delta F
$$

where

$\delta F=$ the energy added to the fluid due to friction, $H / M$.

Substituting from (3-85) and (3-86) into (3-84), the total energy balance becomes

$$
J \delta Q+J \delta F-p d\left(\frac{1}{\rho}\right)+d\left(\frac{p}{p}\right)+d\left(\frac{u^{2}}{2 g_{C}}\right)+\frac{g d Z}{g_{C}}=J \delta Q-\delta w
$$

or $\quad J \delta Q+J \delta F-p d\left(\frac{1}{\rho}\right)+P d\left(\frac{1}{\rho}\right)+\frac{1}{\rho} d P+d\left(\frac{u^{2}}{2 g_{C}^{\prime}}\right)+\frac{g d Z}{g_{C}}=J \delta Q-\delta w . ~(3-88)$

Since the potential energy of the gas is negligible, and since no work is done by the system, Equation (3-88) may be reduced to

$$
-\frac{1}{\rho} d P=J \delta F+d\left(\frac{u^{2}}{2 g_{c}}\right)
$$

Assuming an average gas density, Equation (3-89) may be integrated across the breach to give

$$
-\frac{1}{\rho}\left(P_{A T M}-P_{C S K}\right)=J \Delta F+\frac{u^{2}-u_{C S K}^{2}}{2 g_{C}}
$$


where

$$
\begin{aligned}
& P_{C S K}=\text { the pressure inside the cask, } F / L^{2} \\
& P_{A T M}=\text { the pressure outside the cask, } F / L^{2} \\
& u_{C S K}=\text { the velocity of the gas inside the cask, } L / \theta \text {. }
\end{aligned}
$$

Since ${ }^{u_{C S K}} \simeq 0$

then Equation $(3-90)$ becomes

$$
\begin{aligned}
& P_{C S K}-P_{A T M}=\rho J \Delta F+\rho \frac{u^{2}}{2 g_{C}} \\
& P_{C S K}-P_{A T M}=\Delta P_{F}+\rho \frac{u^{2}}{2 g_{C}}
\end{aligned}
$$

where

$\Delta P_{F}=$ the pressure drop due to frictional effects, $F / L^{2}$.

The pressure drop, $\Delta P_{F}$, is the sum of the frictional losses of mechanical energy due to:

1. The contraction of the fluid at the entrance to the breach (entrance loss),

2. The flow of the fluid in the breach, and

3. The expansion of the fluid at the outlet of the breach (exit loss).

The entrance loss may be expressed as Equation (3-93) (28)

$$
\Delta P=0.4 \rho\left(1.25-\frac{A_{G A P}}{S_{C S K}}\right) \frac{u^{2}}{2 g_{C}}
$$


where

$S_{C S K}=$ the area of the inside surface of the cask, $L^{2}$.

The loss in the breach is defined by the Fanning equation (28)

$$
\Delta P=\frac{4 \rho f L_{G A P} u^{2}}{2 g_{C} D_{G A P}}
$$

where

$$
\begin{aligned}
L_{G A P} & =\text { the length of the flow passage represented by the breach, } L, \\
D_{G A P} & =\text { the equivalent diameter of the breach, } L \\
f & =\text { the Fanning friction factor. }
\end{aligned}
$$

For small Reynolds numbers $\left(R_{e}=\frac{D u p)}{\mu}\right.$, the Fanning friction factor may be expressed as

$$
f=\frac{16 \mu}{D_{G A P}{ }^{U \rho}}
$$

where

$$
\mu=\text { the absolute viscosity of the fluid, } \frac{M}{\theta L} \text {. }
$$

Substituting from Equation (3-95) into (3-94), the pressure loss in the breach may be expressed as

$$
\Lambda P=\frac{32 \mu L_{G A P} u}{D^{2}{ }_{G A P} g_{C}} .
$$

The exit loss is defined as (28) 


$$
\Delta P=\frac{\rho u^{2}}{2 g_{C}}\left(1-\frac{A_{G A P}}{S_{0}}\right)^{2}
$$

where

$S_{0}=$ the cross-sectional area of the outlet region, $L^{2}$.

Adding Equations (3-93), (3-96) and (3-97) and substituting the results into the energy balance [Equation (3-92)] gives

$$
\begin{aligned}
P_{C S K}-P_{A T M} & =0.4 \rho\left(1.25-\frac{A_{G A P}}{S_{C S K}}\right) \frac{u^{2}}{2 g_{C}}+\frac{32 \mu L_{G A P}}{D^{2}{ }_{G A P} g_{C}} \\
& +\frac{\rho u^{2}}{2 g_{C}}\left(1-\frac{A_{G A P}}{S_{0}}\right)^{2}+\frac{\rho u^{2}}{2 g_{C}} .
\end{aligned}
$$

Now

$$
S_{C S K ~}>A_{G A P}
$$

and

$$
S_{0}>A_{\text {GAP }} \text {, }
$$

therefore Equation (3-98) may be reduced to

$$
P_{C S K}-P_{A T M}=2.5 \frac{\rho u^{2}}{g_{C}}+\frac{32 \mu L_{G A P} u}{D_{G A P} g_{C}}
$$

It can be shown that the first term on the right hand side of Equation (3-99) is a small fraction of the second term and may be neglected. Therefore, the fluid velocity may be expressed as 


$$
u=\frac{D_{G A P}^{2} g_{C}\left(P_{C S K}-P_{A T M}\right)}{32 \mu L_{G A P}} \text {. }
$$

The pressure in the cask may be determined using the gas law

$$
P_{\text {CSK }}=\frac{m R T_{\text {CSK }}}{V_{\text {CSK }^{f} m}^{f}},
$$

where

$$
\begin{aligned}
R= & \text { the universal gas constant, } L-F / T-\text { Mole } \\
T_{\text {CSK }=} & \text { the absolute temperature of the mixture of residual } \\
& \text { coolant vapor and fission aases in the cask, } T .
\end{aligned}
$$

Substituting this into Equation (3-100) gives

$$
u=\frac{D_{G A P}^{2} g_{C}\left(\frac{{ }^{m R T} C S K}{V_{C S K^{f}}}-P_{A T M}\right)}{32 \mu L_{G A P}} .
$$

The mass barance [Equation (3-82)] may now be written as

$$
\begin{array}{r}
\frac{d m}{d t}=\sum_{k=1}^{K} \delta_{k}\left(t ; m_{k}-\frac{m A_{G A P} D_{G A P}^{2} g_{C}\left(\frac{m^{m T}{ }_{C S K}}{V_{C S K}{ }^{f}}-P_{A T M}\right.}{32 \mu L_{G A P} V_{C S K}{ }^{f} m}\right) \\
\frac{d m}{d t}=\sum_{k=1}^{K} \delta_{k}(t) m_{k}-\frac{A_{G A P} D_{G A P}^{2} g_{C}}{32 \mu L_{G A P} V_{C S K^{f} m}}\left(\frac{{ }^{R T}{ }_{C S K} m^{2}}{V_{C S K}{ }^{f}}-P_{A T M} m\right)
\end{array}
$$


or $\quad \frac{d m}{d t}=\sum_{k=1}^{K} \delta_{k}(t) m_{k}-A m^{2}+B m$

where

$$
A=\frac{A_{G A P} D_{G A P}^{2} g_{C} R T_{C S K}}{32 \mu V_{C S K}^{2} L_{G A P} f_{m}^{2}}
$$

and

$$
B=\frac{A_{G A P} D_{G A P}^{2} g_{C} P_{A T M}}{32 \mu V_{C S K} L_{G A P}{ }^{f}}
$$

The equivalent diameter of the breach is defined as

$$
D_{G A P}=\frac{4 A_{G A P}}{P_{W}}
$$

where

$$
P_{W}=\text { the wetted perimeter, } L \text {. }
$$

The wetted perimeter is obtained from

$$
P_{W}=2 \pi D
$$

where

$D=$ the mean diameter of the cask wall, L.

\subsubsection{Proposed Modifications to the Loss-of-Coolant Models}

To modify the present loss-of-coolant models to simulate the flow of fission gases from the cask through the breach to the surroundings, the following changes would be required. 
1. Another network, similar to the oxidation and diffusion networks, would have to be added to represent the fission gas mass balance on the cask containment [Equation (3-82)]. Also, the additional equations defining the flow velocity would have to be included in the central processor.

2. The pressure and temperature of the mixture of fission gases and residual coolant vapor in the cask containment would have to be determined. This would be done by treating the mixture as a coolant, using the same techniques discussed in Section 2.

\subsubsection{Fission Gas Leakage Network}

The fission gas mass balance on the cask containment is defined by Equation (3-82). This equation may be revised to express the loss or leakage term as a mass transfer term as shown in Equation (3-110),

$$
\frac{d m}{d t}=\sum_{k=1}^{K} \delta_{k}(t) m_{k}-Y_{L}\left(m-m_{0}\right)
$$

where

$\begin{aligned} m_{0}= & \text { the number of moles of fission gases in the surroundings, } \\ & 1 b \text {-moles }\end{aligned}$

and $Y_{L}=$ a fission gas leakage admittance, $1 / \theta$,

$=\frac{u A_{G A P}}{V_{C S K}}$.

The electrical analog of Equation $(3-110)$ is shown in the following sketch. 


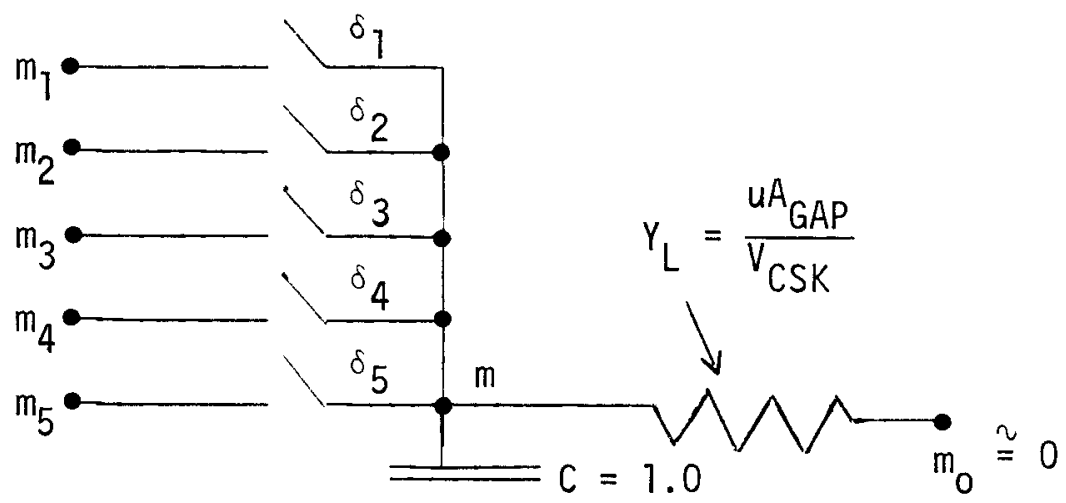

The capacitance of the node representing the number of moles of fission gases in the cask containment is equal to 1.0. The sink node is represented by $m_{0}$, which would be assumed to be approximately equal to 0 since the escaping fission gases will be dispersed and the concentration would be negligible. The switches in the network represent the Dirac impulse functions, $\delta_{k}$. These switches would be equivalent to the switch D3 in the algorithm of Figure 3-16, which is already programmed into the central processor.

\subsubsection{Gas Mixture in Cask Containment as a Coolant: Determination of Temperature and Pressure}

The velocity in the leakage term of Equations (3-82) and (3-111) is a function of the pressure of the mixture of fission gases and residual coolant vapor in the cask, as shown in Equation (3-100). Equation (3-101) states that the pressure is, in turn, a function of the temperature of the mixture. This suggests that the loss-of-coolant models must treat this mixture as a coolant. This would be no problem since the residual coolant vapor left in the cask after loss of the coolant is already treated as a coolant.

The volumetric heat dissipation admittances would be determined as outlined in Sections 1.2, 2.1.1.3.1, and 3.1.2, except that the mixture of fission gases and residual coolant vapor would be the coolant. 
The apparent thermal conductivity would be determined as outlined in Section 3.1.3 except that, instead of residual coolant vapor, a mixture of fission gases and vapor would be the heat transfer medium.

\subsubsection{Fission Gases in Cask Containment as a Deterrent to Fue 1 Pin Clad Failure}

Fission gases released to the cask containment from the first fue 1 pins to burst will tend to oppose the bursting of additional pins. As the released fission gases are heated, the pressure in the cask containment will rise. This would decrease the differential pressure across the remaining fuel pin clads, which would delay their failure.

The increased pressure in the cask would only delay clad failure and further release of fission gases, not prevent, it. As the fuel temperatures increase with time, the internal pressures in the pins will increase and the strength of the clads will decrease. During the same time interval, some of the fission gases already released to the cask containment will have leaked from the cask through the breach. This would tend to relieve the pressure in the cask. The net result would be a rise in the differential pressure across the fuel pin clads, some of which would eventually fail. Whenever any of the pins fail, the events outlined above would be repeated. The effect of the pressure in the cask on pin clad failure is evident upon examination of the hoop stress formula presented earlier as Equation (3-19),

$$
\frac{\Delta P}{S}=\frac{2\left(R_{0}-1\right)}{\left(R_{0}+1\right)} \text {, }
$$

where $\Delta \mathrm{P}$ is the differential pressure across the fuel pin clads. This equation shows that the stress on the clads is directly proportional to the differential pressure. 


\subsubsection{Choked Flow of Gas Mixture in the Breach: Determination of Sonic Velocity}

Fission gases and residual coolant vapor are compressible. Consequently, the flow of these gases through the breach must be checked to determine if the flow is choked. The flow would be choked if the gas velocity is equal to (or greater than) the velocity of sound in the gas, i.e., the Mach number would be equal to 1.0. Although it is felt that the flow would be substantially less than sonic, it should be checked because, if it is choked, the pressure in the cask would rise to higher levels. This would further prevent or delay failure of the pin clads.

Although the flow term in the mass balance equation [Equation (3-82)] was based on an energy balance which was not restricted to isentropic flow, the equations used to check for choked flow are based on an energy balance on the gas assuming it is flowing isentropically through the breach. This energy balance may be expressed as

$$
h_{0}=h+\frac{u^{2}}{2 g_{c}}
$$

where

$$
\begin{aligned}
& h=\text { the enthalpy of a unit mass of gas flowing in the breach, } F-L / M \text {, } \\
& h_{0}=\text { the enthalpy of a unit mass of gas in the cask, F-L/M. }
\end{aligned}
$$

Assuming the gas behaves as a perfect gas, Equation (3-112) may be rewritten as

$$
c_{p} T_{0}=c_{p} T+\frac{u^{2}}{2 g_{c}}
$$

where

$$
\begin{aligned}
& C_{p}=\text { the specific heat of the gas at constant pressure, } F-L / M T \\
& T_{0}=T_{C S K}=\text { the absolute temperature of the gas in the cask, } T, \\
& T=\text { the absolute temperature of the gas flowing in the breach, } T \text {. }
\end{aligned}
$$


Using the following definitions

$$
\begin{gathered}
\gamma=\frac{C_{P}}{C_{V}} \\
R=C_{p}-C_{V}
\end{gathered}
$$

where

$C_{V}=$ the specific heat of the gas at constant volume, F-L/MT and $R=$ the specific gas constant for the gas, F-L/MT, $C_{p}$ may be expressed as

$$
C_{p}=\frac{\gamma R}{\gamma-1} \text {. }
$$

Substituting Equation (3-116) into (3-113), and rearranging gives

$$
\frac{T_{0}}{T}=1+\frac{(\gamma-1)}{2} \frac{u^{2}}{g_{C} \gamma R T} .
$$

The definition of the velocity of sound in an ideal gas at temperature $T$ is

$$
\left.a=\sqrt{g_{c} \gamma R T .} \quad \text { (Reference } 29, p .643\right)
$$

Substituting Equation (3-118) into (3-117) yields

$$
\frac{T_{0}}{T}=1+\frac{(\gamma-1)}{2} \frac{u^{2}}{a^{2}}
$$

and, since the Mach number is defined as

$$
M=\frac{u}{a},
$$


Equation (3-119) becomes

$$
\begin{aligned}
& \frac{T_{0}}{T}=1+\frac{(\gamma-1)}{2} M^{2} \\
& T=T_{0}\left[1+\frac{(\gamma-1) M^{2}}{2}\right]^{-1} .
\end{aligned}
$$

If the flow is choked, the Mach number would be 1.0, so Equation (3-122) would reduce to

$$
T=T_{0} \quad\left[1+\frac{(y-1)}{2}\right]^{-1} \text {. }
$$

Substituting Equation (3-123) into (3-118) gives

$$
a=\sqrt{g_{C} \gamma R T_{0}\left[1+\frac{(\gamma-1)}{2}\right]^{-T}}
$$

which is compared to the value of $u$ computed during the transient. If $u<a$, the flow is not choked.

\subsubsection{Relationship of Gas Leakage to Volatile Solids Release Mode1s}

The proposed changes to the Loss-of-Coolant models, to simulate the flow of gas mixture from the casks, will allow modifications to be made to the Volatile Solids Release Models to determine the amount of volatile solids that may flow through the breach opened in the cask containment.

The modifications developed in Section 3.5 will allow determination of the velocity of the gas mixture flowing from the gap [see Equation (3-102)]. This velocity is the key variable in the development of a proposed term representing the removal of particles from an aerosol in the cask by leakage through the breach. This removal term will be added to the particle 
balance equation [Equation (4-44)] of Section 4.1.4. The derivation of this term and the procedure for adding it to the present Volatile Solids Release models are presented in Section 4.1.5. 
4. MODEL SIMULATING BEHAVIOR OF VOLATILE SOLIDS OR SOLID FISSION PRODUCTS RELEASED FROM DAMAGED SPENT FUEL IN A CASK

A model was devised to simulate the behavior of volatile solids or solid fission products (cesium compounds) released as an aerosol to the containment vessel or cavity in a spent fuel shipping cask following an accident, fire and loss of primary coolant. The purpose of the volatile solids release model (VSOL) development was to provide a tool to estimate the amount of volatile solids or solid fission products that would be suspended in the cask containment as an aerosol. The amount in suspension as an aerosol represents the amount that could potentially be released from the containment to the surroundings. Proposed modifications to the model to include a leakage term are presented in Section 4.1.5. This term will represent the flow of volatile solids from the breach opened in the cask at impact.

The volatile solids release model is a system of equations derived in this section. These equations were programmed for simulation using MIMIC, a continuous system simulation program. A calculation control flow diagram of the model is presented as Figure 4-1, and the MIMIC listing is presented as Figure 4-2.

\section{1 Coagulation Equation - A Particle Balance Equation for Aerosols}

The model VSOL was based on the basic coagulation equation for aerosols having a distribution of particle sizes, modified to include terms for particle removal or loss to the system and a source term ${ }^{(12)}$ :

$$
\frac{\partial n}{\partial t}(v, t)=A_{+}(v, t)-A_{-}(v, t)-R(v, t)+S(v, t)
$$

where

$$
\begin{aligned}
n(v, t)= & \text { the concentration of particles of volume } v, \\
& \text { particles } / \mathrm{cm}^{3} \text { of aerosol } \\
A_{+}(v, t)= & \text { the rate of formation of particles of volume } v \\
& \text { by agglomeration of smaller particles, par- } \\
& \text { ticles } / \mathrm{cm}^{3} \text { (aerosol) } \times \mathrm{sec} .
\end{aligned}
$$




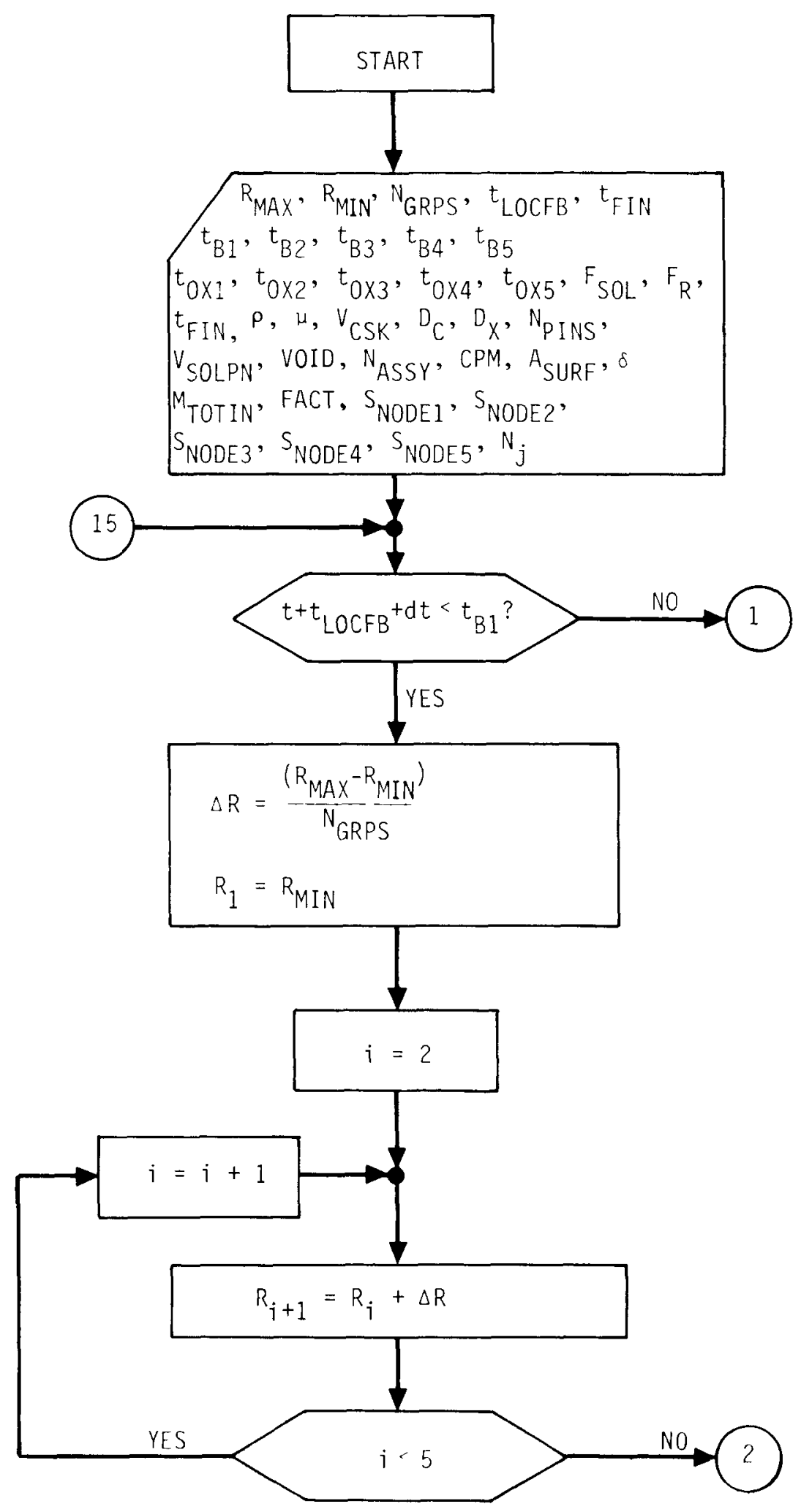

HEDL $7507-30.36$

FIGURE 4-1. Calculation Control Flow Diagram of the Volatile Solids Release Model of the IF-300 Spent Fuel Shipping Cask (Page 1 of 10) 


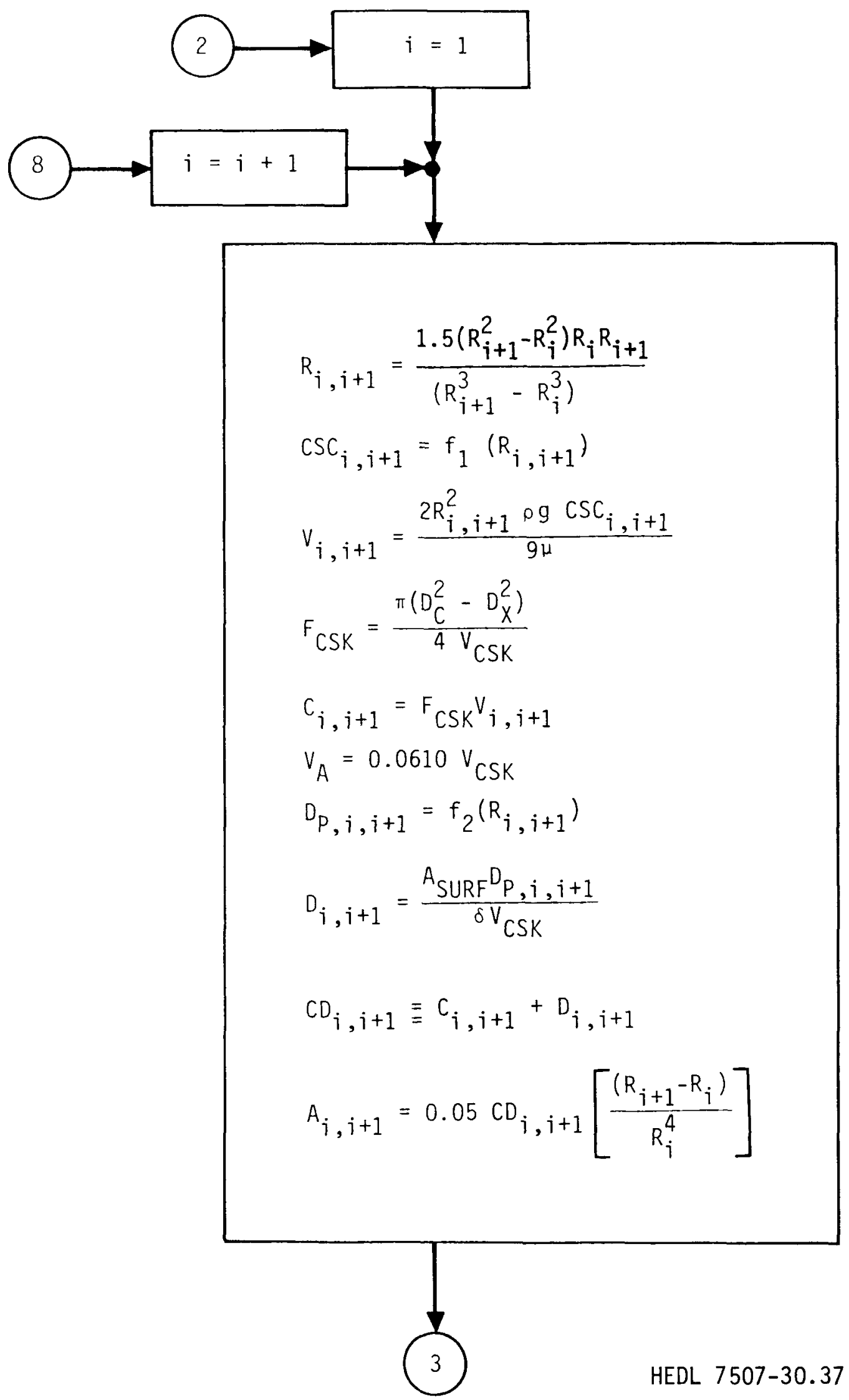

FIGURE 4-1. Calculation Control Flow Diagram of the Volatile Solids Release Model of the IF-300 Spent Fuel Shipping Cask (Page 2 of 10) 


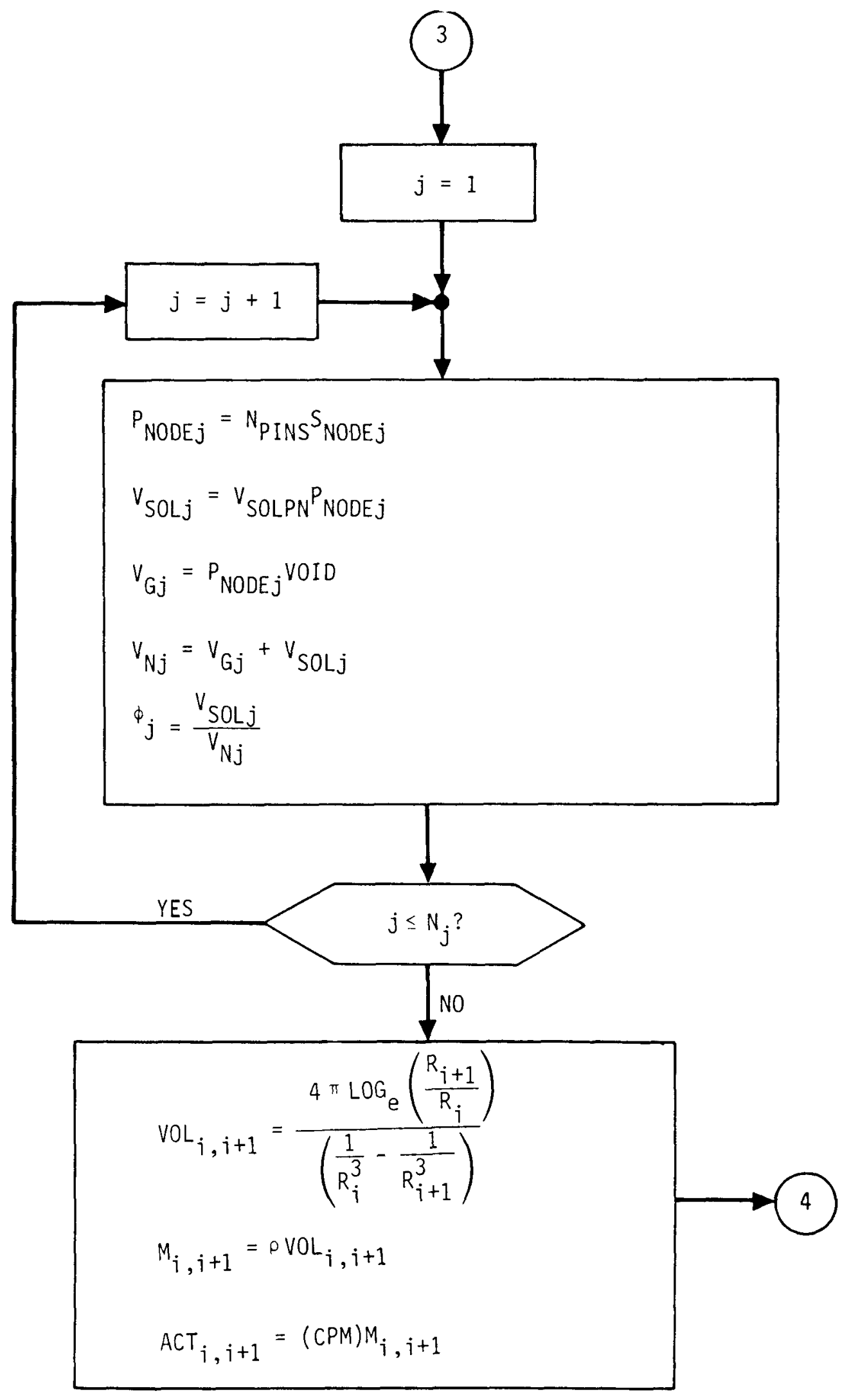

HEDL 7507-30.38

FIGURE 4-1. Calculation Control Flow Diagram of the Volatile Solids Release Model of the IF-300 Spent Fuel Shipping Cask (Page 3 of 10) 


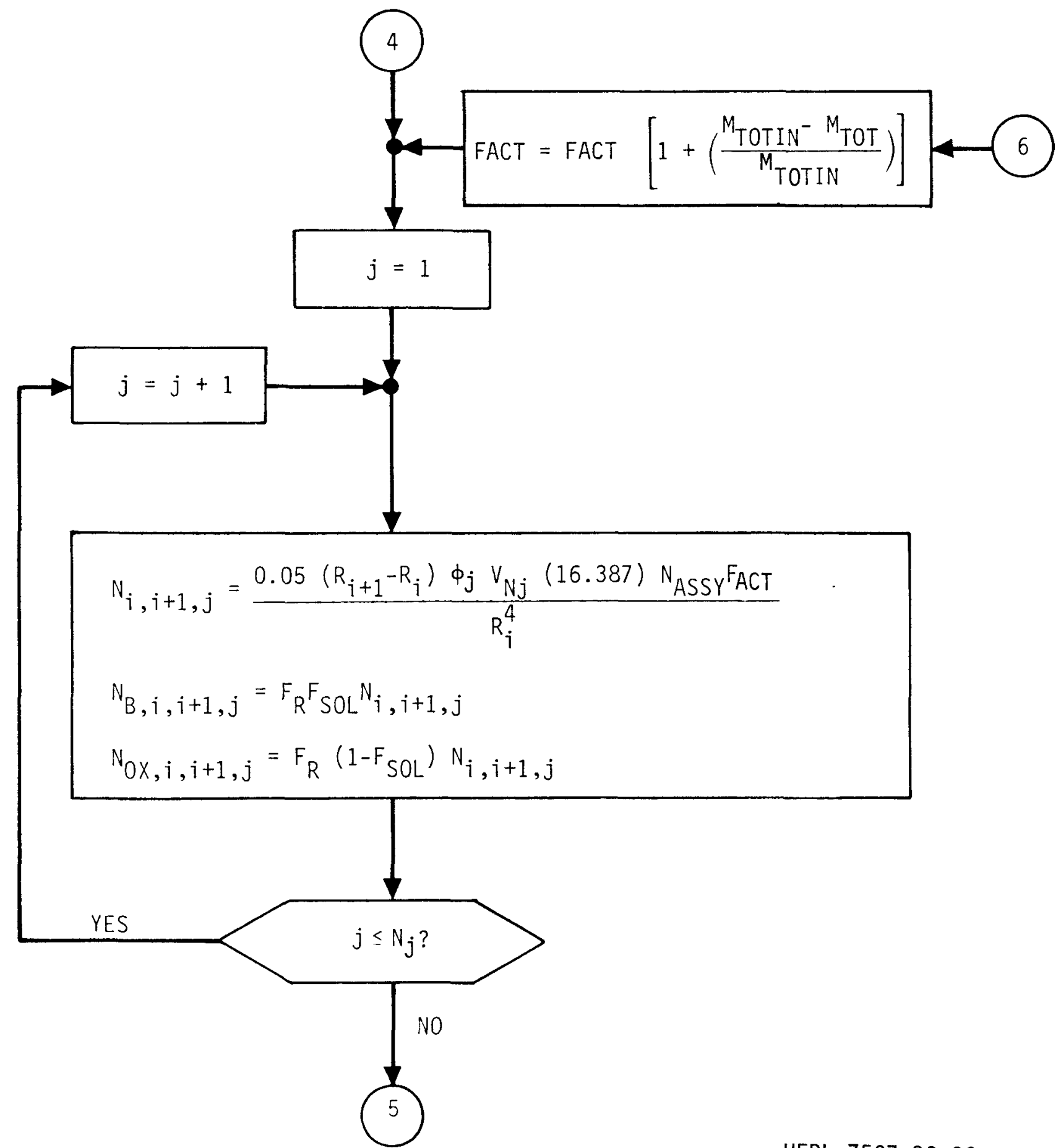

HEDL $7507-30.39$

FIGURE 4-1. Calculation Control Flow Diagram of the Volatile Solids Release Model of the IF-300 Spent Fuel Shipping Cask (Page 4 of 10) 


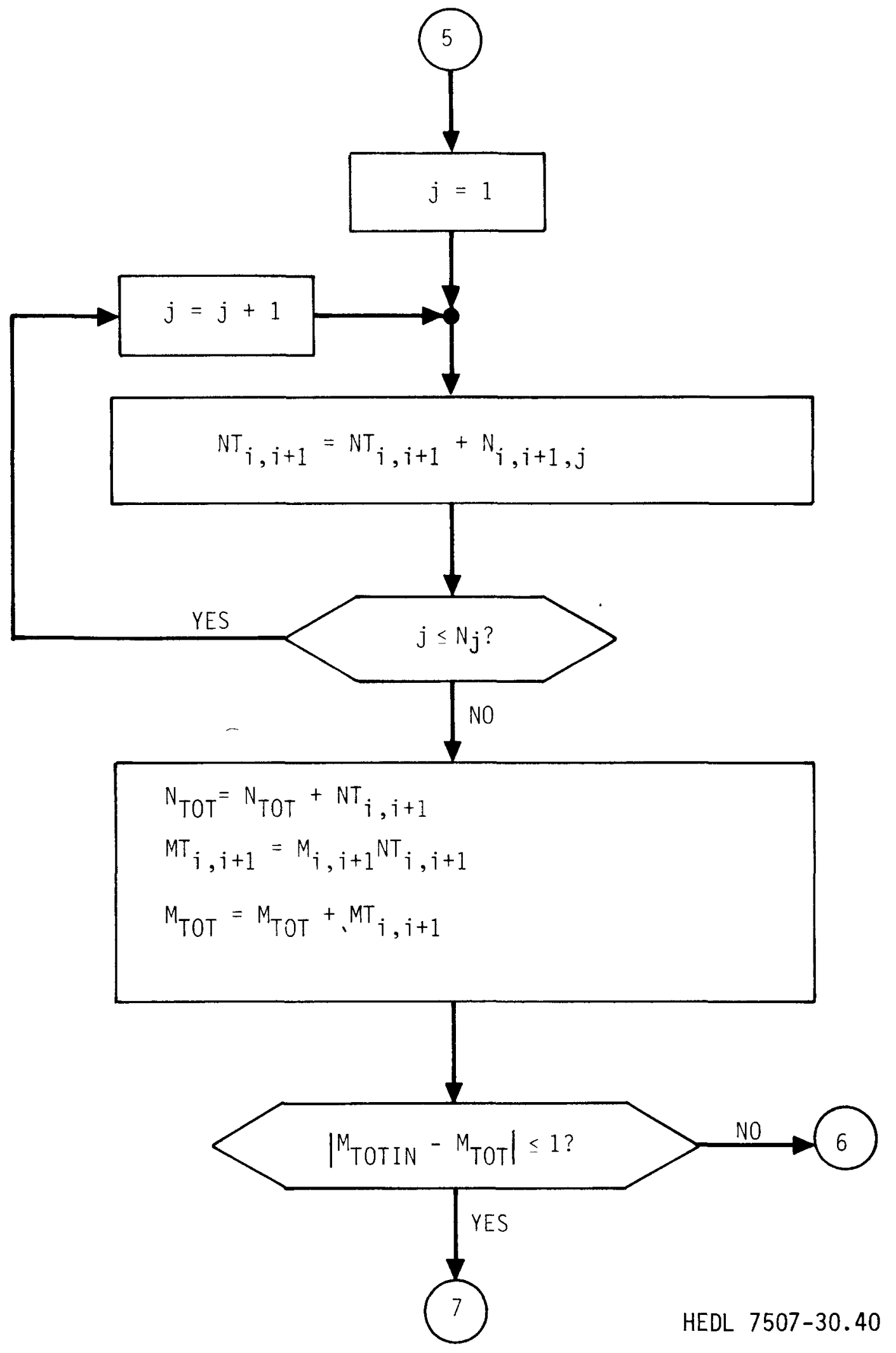

FIGURE 4-1. Calculation Control Flow Diagram of the Volatile Solids Release Model of the IF-300 Spent Fuel Shipping Cask (Page 5 of 10) 


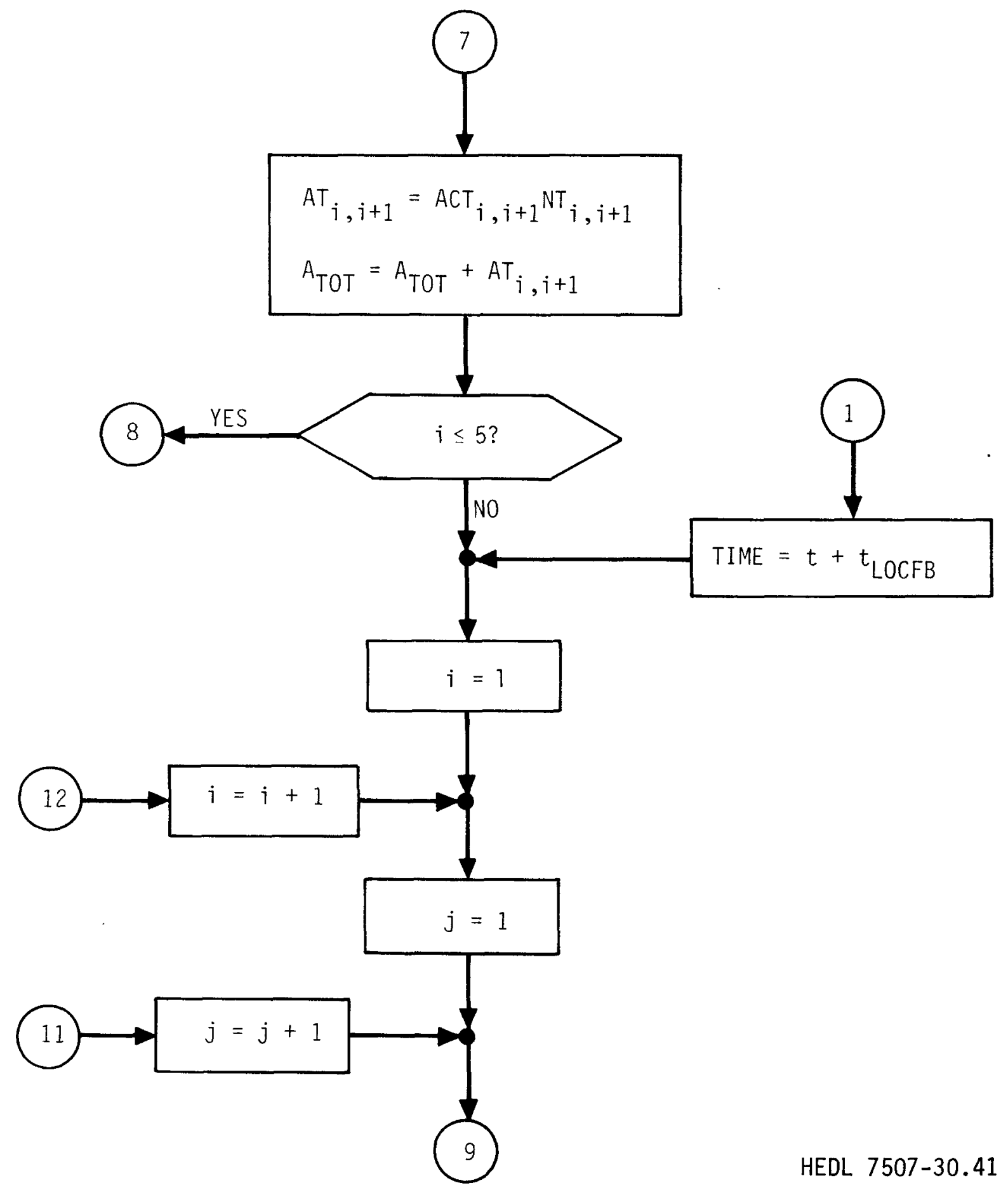

FIGURE 4-1. Calculation Control Flow Diagram of the Volatile Solids Release Model of the IF-300 Spent Fuel Shipping Cask (Page 6 of 10) 


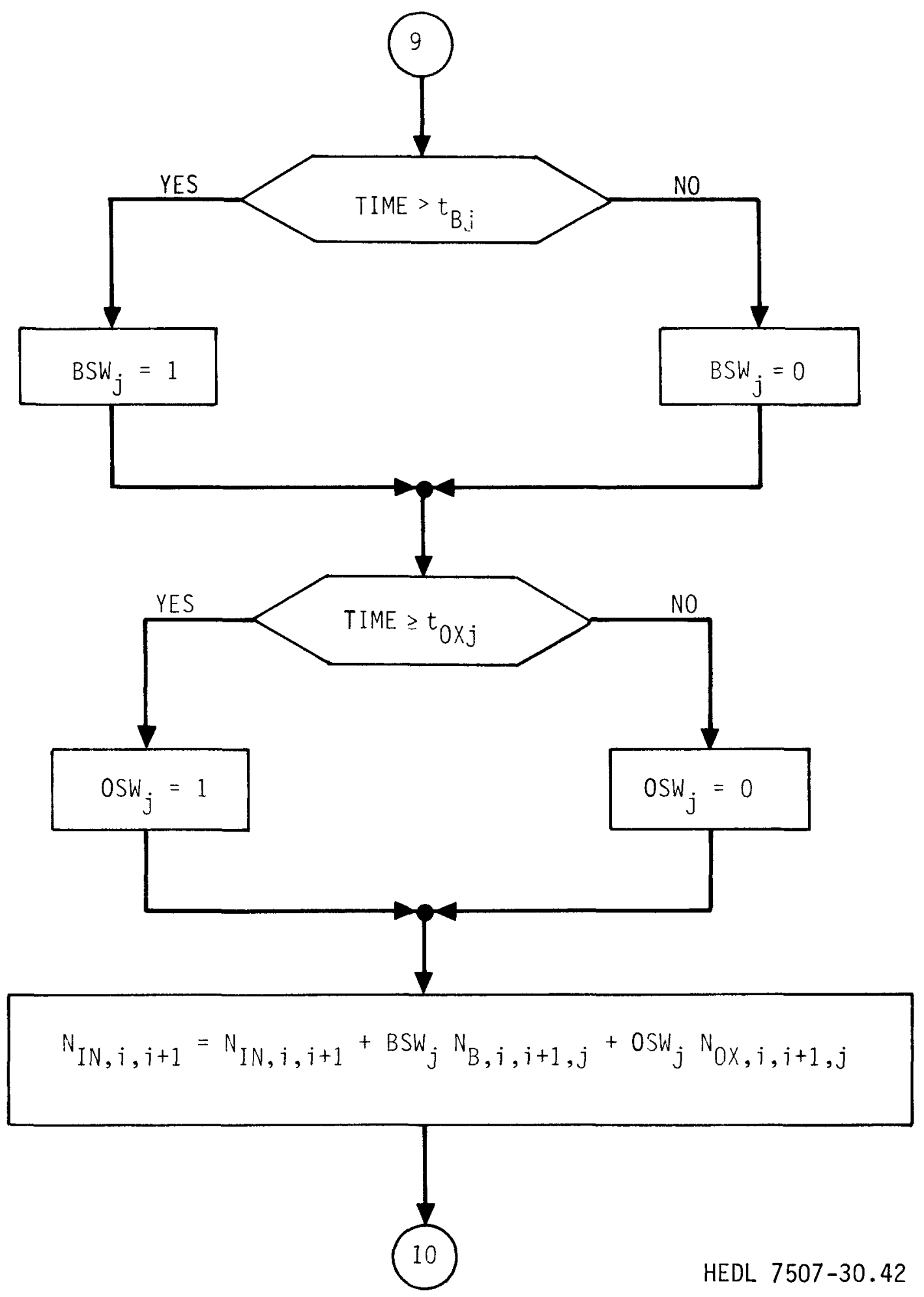

FIGURE 4-1. Calculation Control Flow Diagram of the Volatile Solids Release Model of the IF-300 Spent Fuel Shipping Cask (Page 7 of 10) 


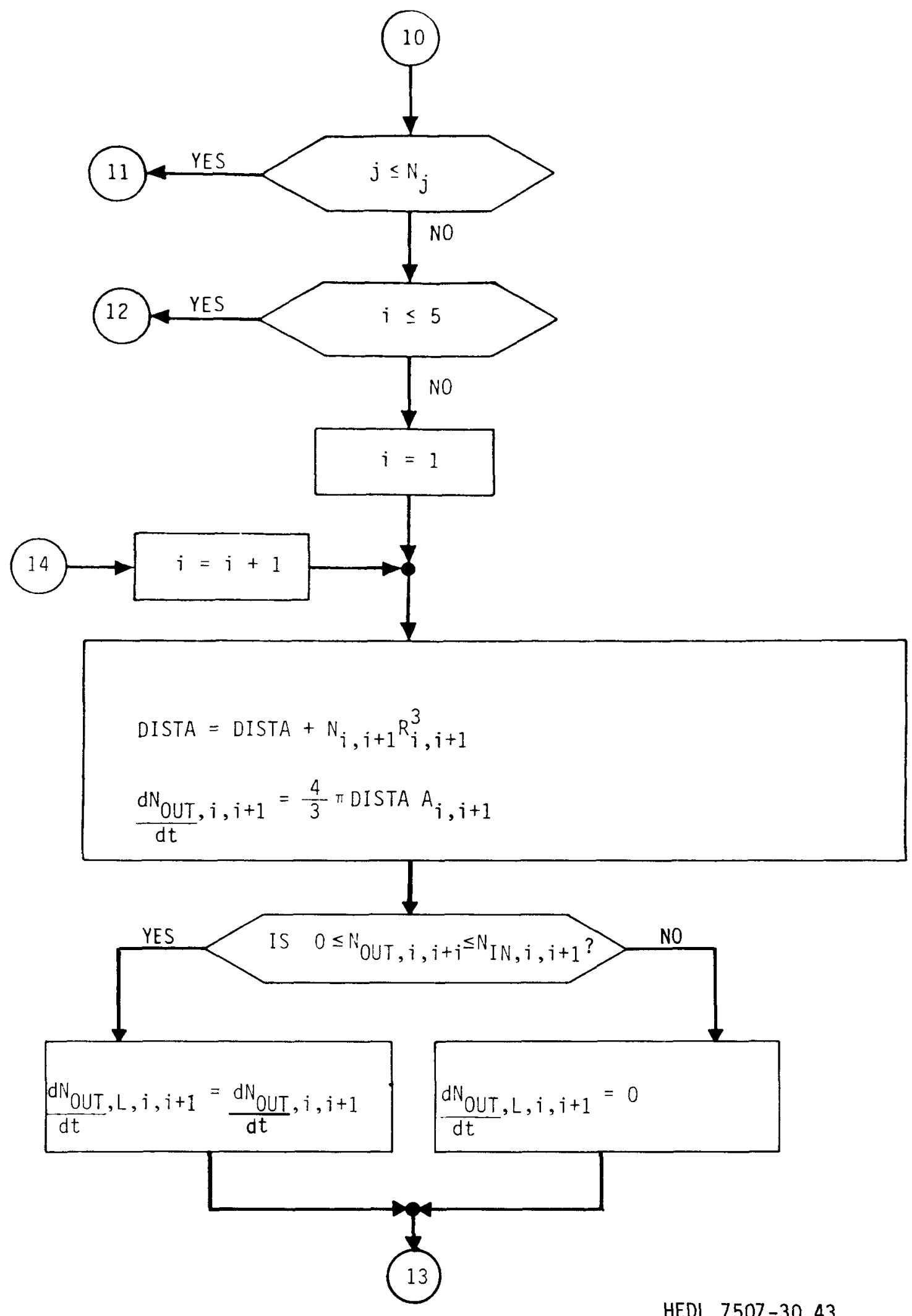

HEDL $7507-30.43$

FIGURE 4-1. Calculation Control Flow Diagram of the Volatile Solids Release Model of the IF-300 Spent Fuel Shipping Cask (Page 8 of 10) 


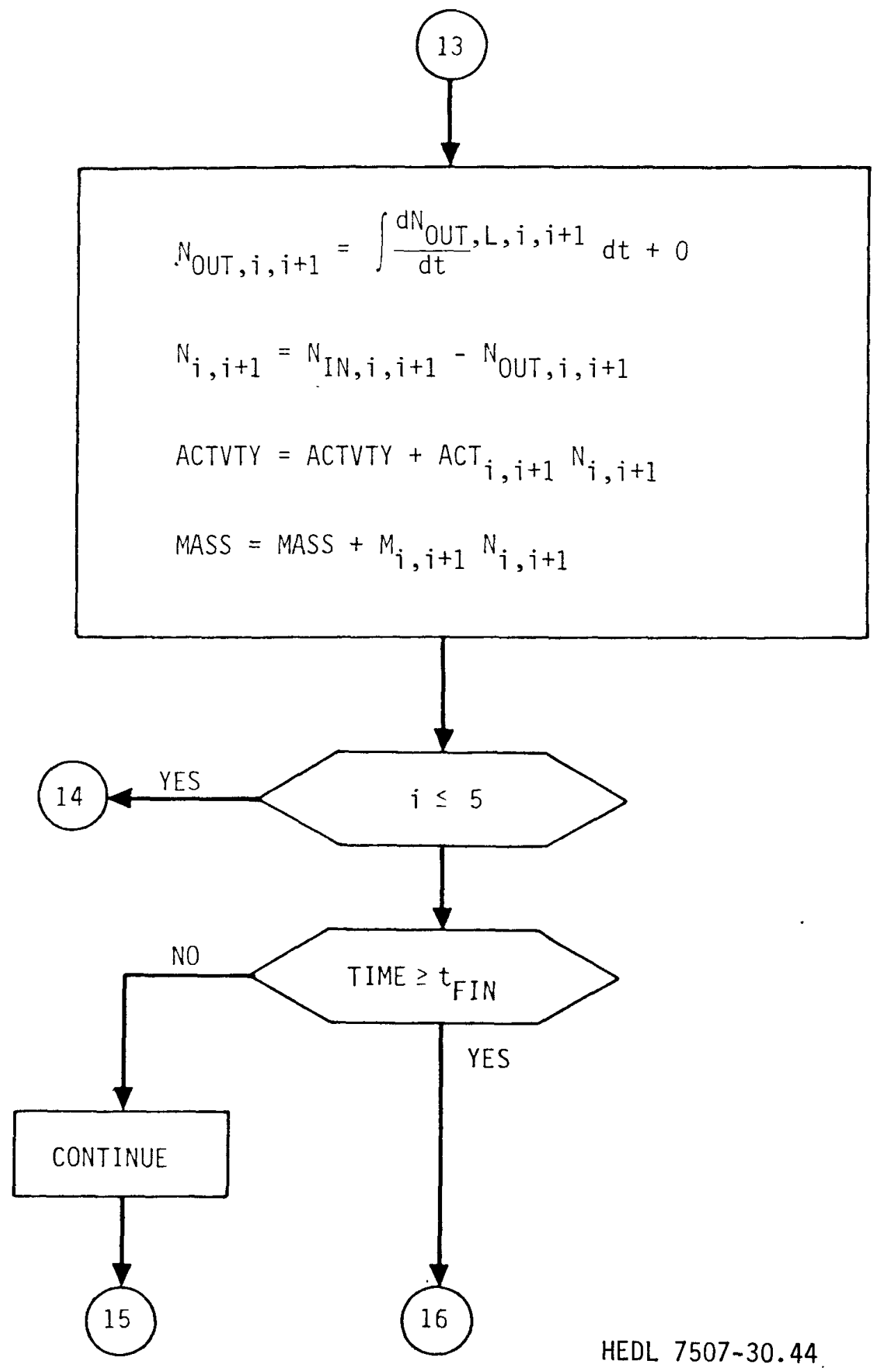

FIGURE 4-1. Calculation Control Flow Diagram of the Volatile Solids Release Model of the IF-300 Spent Fuel Shipping Cask (Page 9 of 10) 


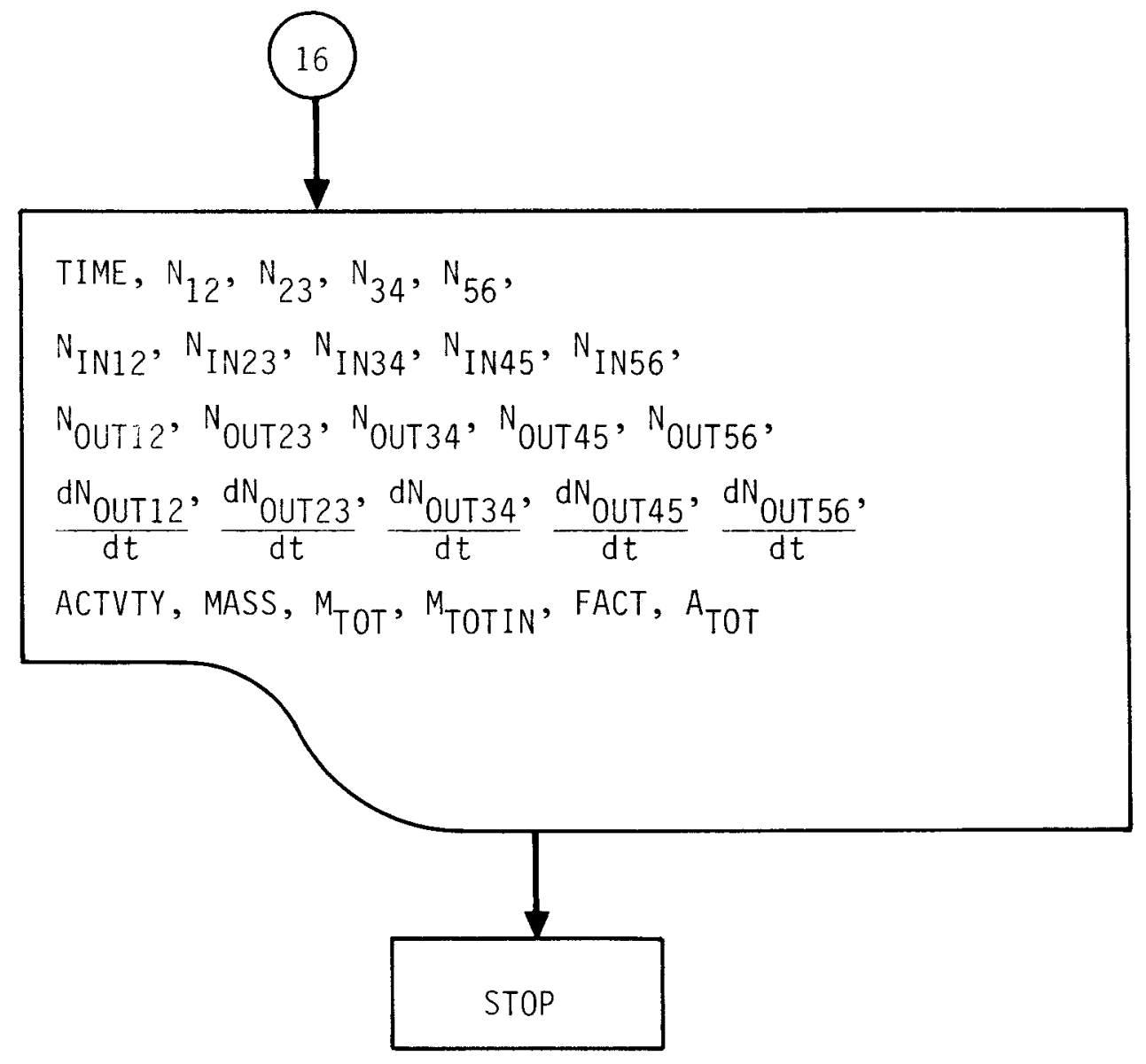

HEDL $7507-30.45$

FIGURE 4-1. Calculation Control Flow Diagram of the Volatile Solids Release Model of the IF-300 Spent Fuel Shipping Cask (Page 10 of 10) 


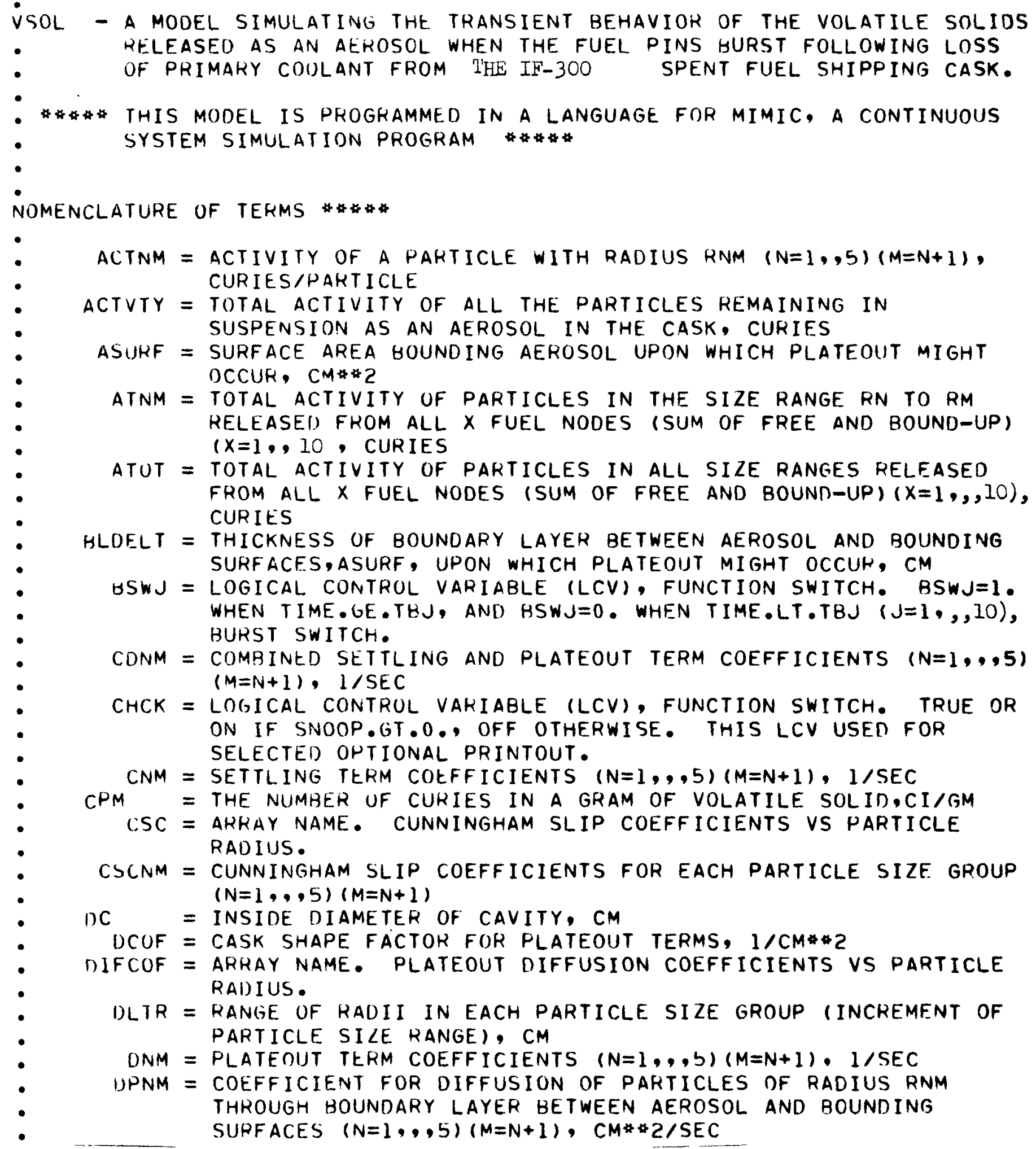$$
\text { : }
$$

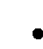

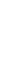

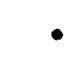

$$
\vdots
$$

$$
:
$$

:$$
\therefore
$$$$
:
$$

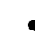$$
\therefore
$$$$
:
$$

FIGURE 4-2. MIMIC Listing of the Volatile Solids Release Model for the IF-300 (Page 1 of 16) 


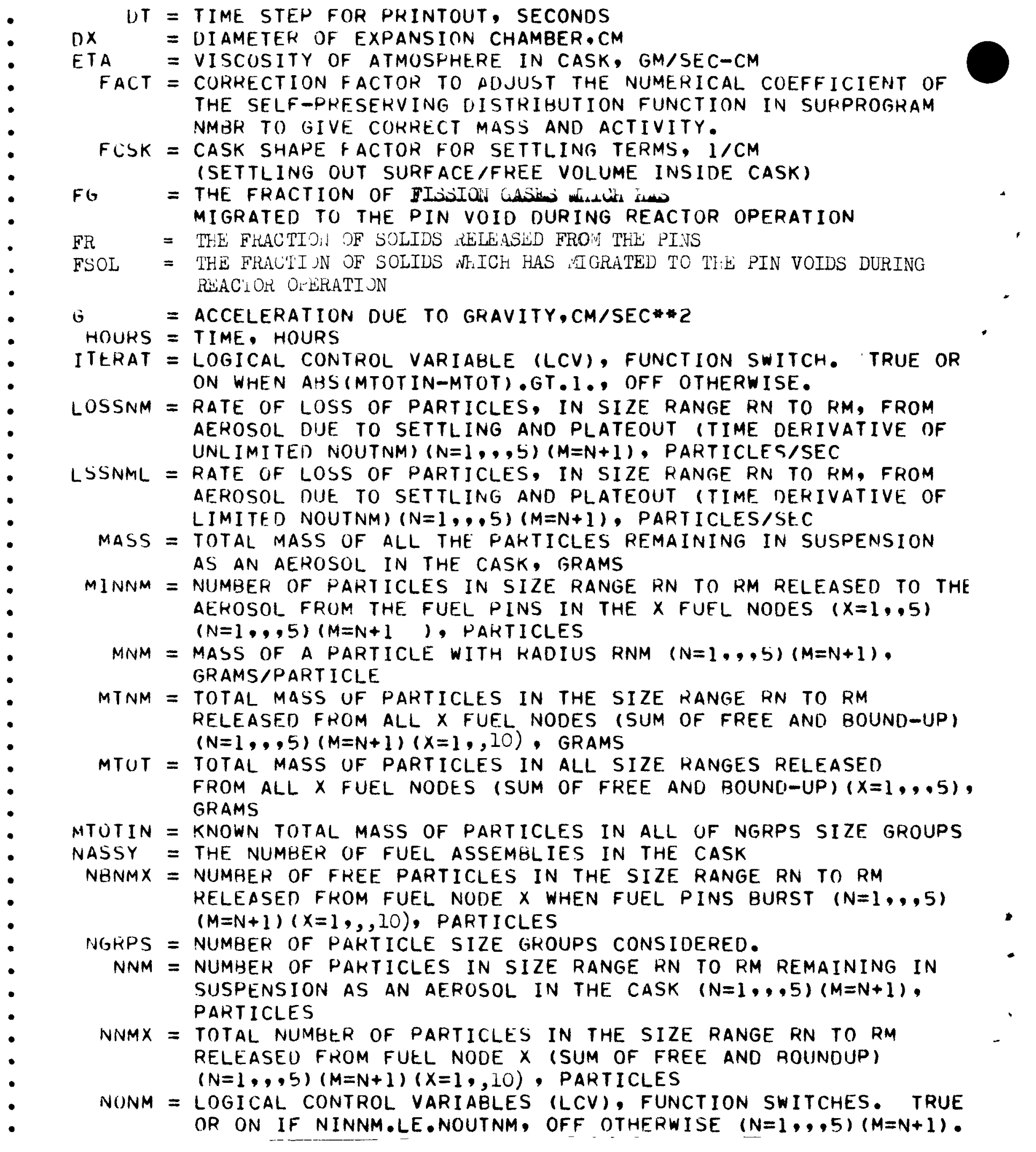

FIGURE 4-2. MIMIC Listing of the Volatile Solids Release Mode1

for the IF-300 (Page 2 of 16) 


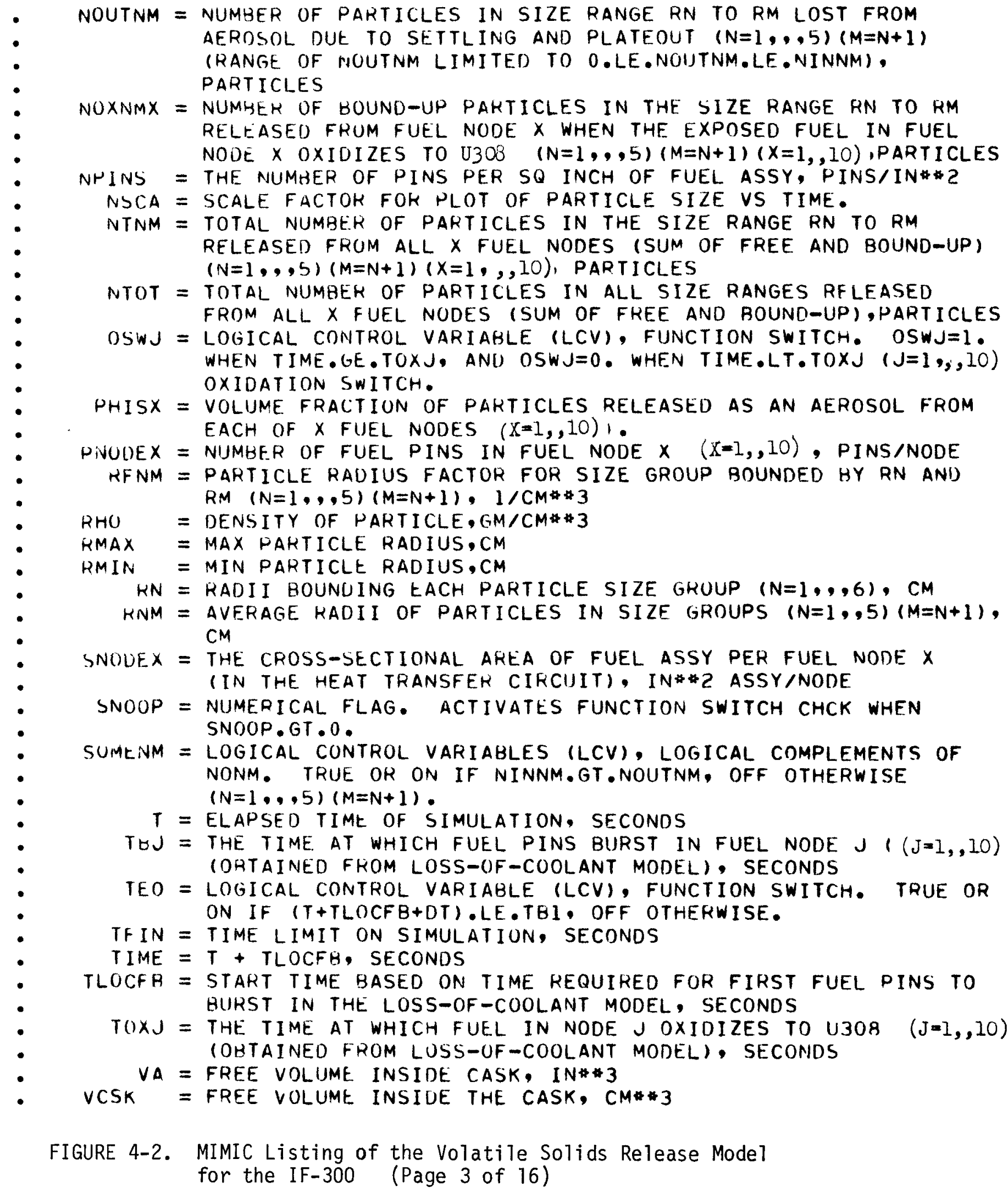




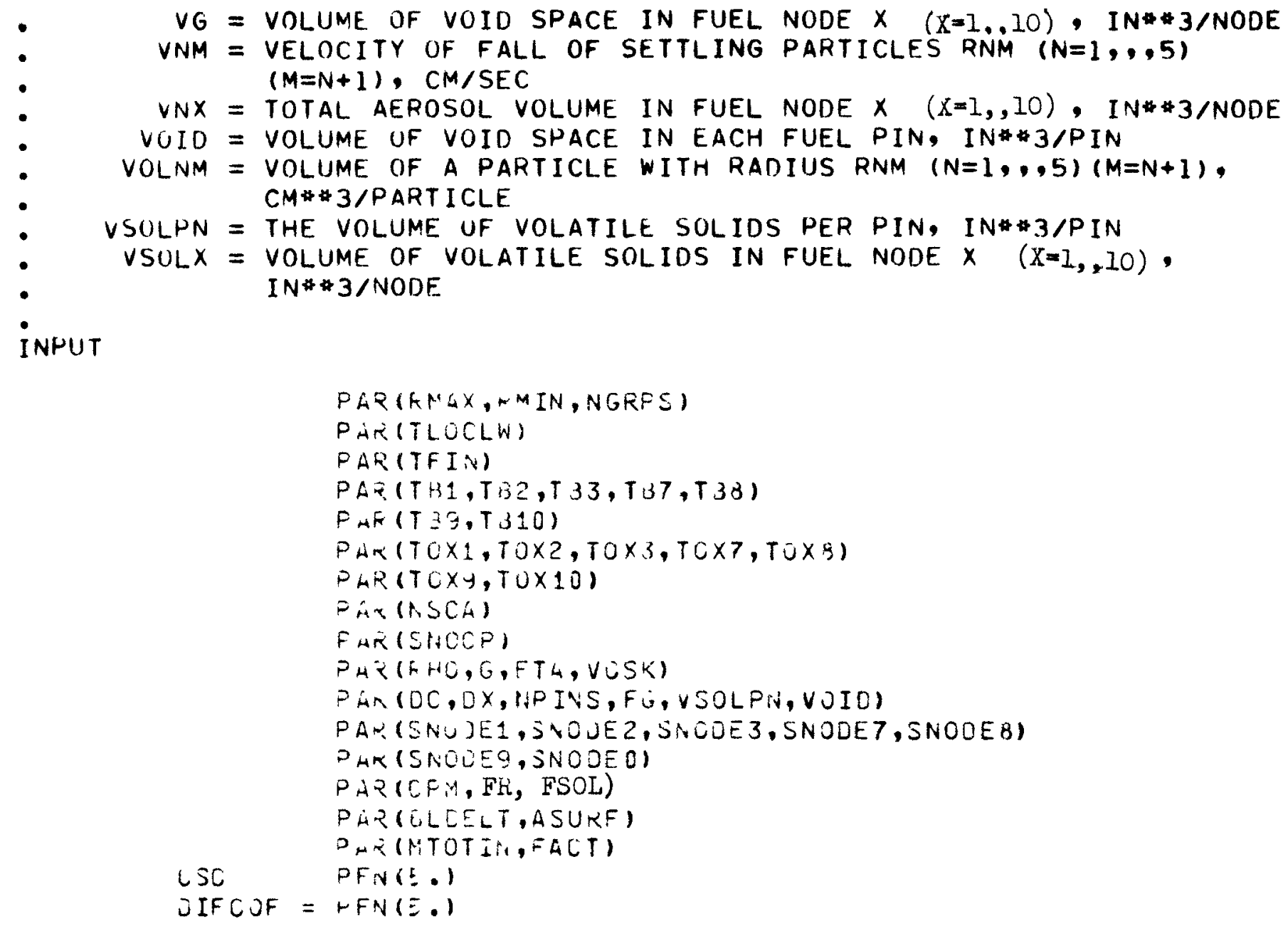

INPUT

FUNCTION SWITCH TEO. TRUE OR ON IF $(T+T L O C F B+D T) \cdot L E . T B I$, OFF OTHERWISE. -

TEO = FSW $(T+T L O C F B+D T-T B 1$, TRUE, TRUE, FALSE)

-

RANGE UF KADII IN EACH PARTICLE SIZE GROUP

-

TEO DLTR = (RMAX-RMIN) /NGHPS

$\bullet$

RADII HOUNDING FACH SIZE GROUP

-

$\begin{array}{lll}\text { TEO } & R 1 & =R M I N \\ \text { TEO } & H 2 & =R I+D L T R \\ \text { TEO } & R 3 & =R 2+D L T R \\ \text { TEO } & R 4 & =R 3+D L T R \\ \text { TEO } & R 5 & =R 4+D L T R \\ \text { TEO } & R 6 & =R 5+D L T R\end{array}$

FIGURE 4-2. MIMIC Listing of the Volatile Solids Release Model for the IF-300 (Page 4 of 16) 


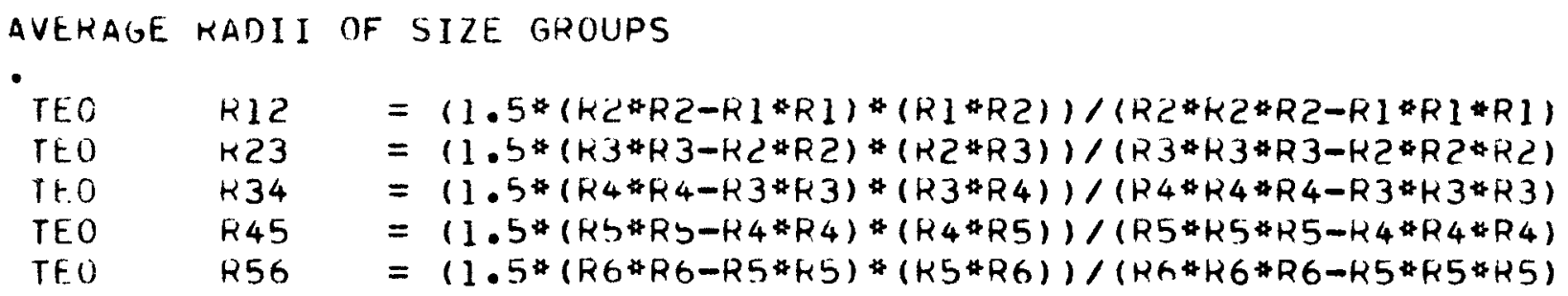

FIGURE 4-2. MIMIC Listing of the Volatile Solids Release Model for the IF-300 (Page 5 of 16) 


\begin{tabular}{|c|c|c|}
\hline \multicolumn{2}{|c|}{ SALCULATIUN OF } & E RADIUS FA \\
\hline EO & RF 1 & $=1 \mathrm{RZ}$ \\
\hline & KF & $=(k 3-k 2) /(R 2 * R 2 * R 2 * R 2)$ \\
\hline & KF 3 & $=(R 4-R 3) /(R 3 * R 3 * 1 * 3 * R 3)$ \\
\hline & RF 4 & $=(K 5-R 4) /\left(R_{4} * R_{4} * R 4 * R 4\right)$ \\
\hline T & RF56 & $=(R 6-R 5) /(R 5 * R 5 * R 5 * R 5)$ \\
\hline
\end{tabular}

\begin{tabular}{|c|c|c|}
\hline \multicolumn{2}{|c|}{ CALCULATIUN OF } & PLATEOUT UIFFUSION \\
\hline TEO & UP12 & $=F U N(D I F C O F, R 12)$ \\
\hline TEO & DP23 & $=F U N(D I F C O F, R 25)$ \\
\hline TEO & DP34 & $=F U N(D I F C O F, K 34)$ \\
\hline TE.O & UP4 5 & $=F U N(D I F C O F, R 45)$ \\
\hline TEO & DP56 & $=$ FUN (DIF COF, R56) \\
\hline
\end{tabular}

CALCULATIUN OF SHAPE FACTUR FOR PLATEOUT TERMS

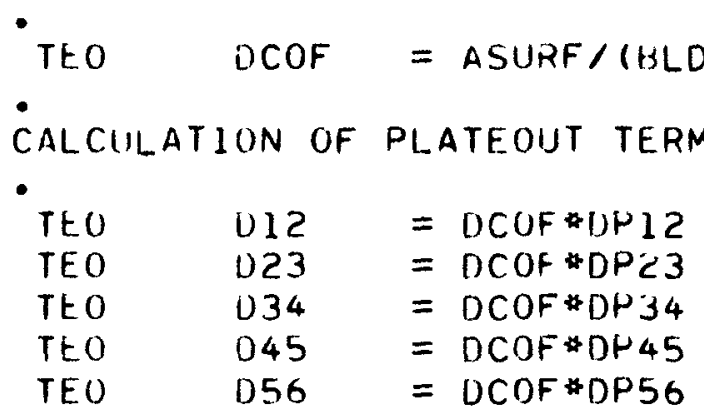

Combineo SETTLING and PLATEOUT COEFFICIENTS

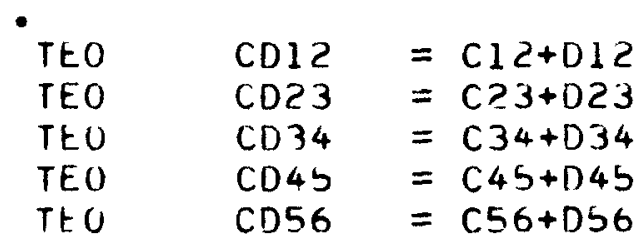

-

CALCULATIUN OF VOLUME FRACTION OF PARTICLES RELEASED AS AN AEROSOL FROM FACH FUEL NODE

-

\begin{tabular}{|c|c|c|}
\hline TFO & $P+1$ & $C u r^{2}(5 N O L E 1)$ \\
\hline TEO & & RSP (FNCCE1,VSOL1, VN1, PHISI) \\
\hline IEC & PHI & CSP(SNCLE?) \\
\hline TEC & & FJP(FFOLEZ, JSOLZ, UNZ, FHISZ) \\
\hline $\begin{array}{l}\text { TFO } \\
\text { TEO }\end{array}$ & $\mathrm{PHI}$ & $\begin{array}{l}\text { CJP(SNOCEZ) } \\
\text { KSP(FNOCEZ,VSOLZ, VN3,PHES3) }\end{array}$ \\
\hline T! U & N11I & $\operatorname{CSP}($ sivui! 7$)$ \\
\hline $\begin{array}{l}\text { TEC } \\
\text { TEO } \\
\text { TEO }\end{array}$ & $\mathrm{PHI}$ & 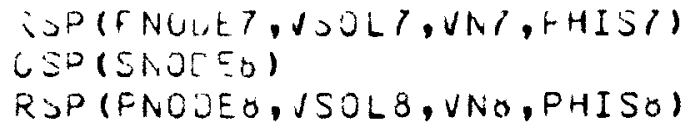 \\
\hline $\begin{array}{l}\text { TEO } \\
\text { TEC }\end{array}$ & PHI & $\begin{array}{l}\text { CSP (SNOOE9) } \\
\text { FSP(FNOUE, VSCL J,VNG, PHISG) }\end{array}$ \\
\hline TEC & $\mathrm{PHI}^{2}$ & CSP(SNOI'EO) \\
\hline TEO & & RSP (PNODET, VSOL) \\
\hline
\end{tabular}

FIGURE 4-2. MIMIC Listing of the Volatile Solids Release Model for the IF-300 (Page 6 of 16) 


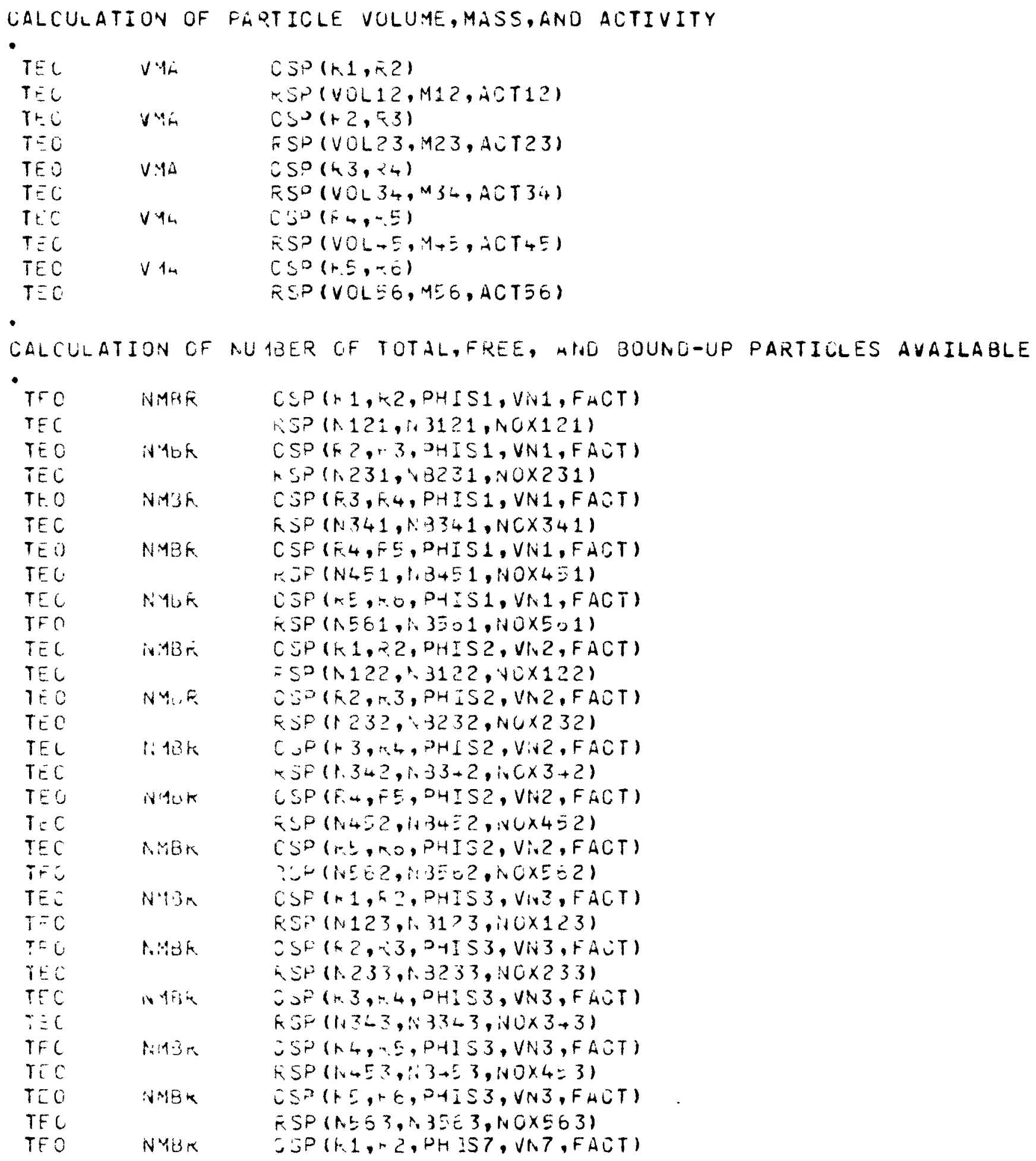

FIGURE 4-2. MIMIC Listing of the Volatile Solids Release Model for the IF-300 (Page 7 of 16) 


\begin{tabular}{|c|c|c|}
\hline & & \\
\hline TEC & & $\pi \operatorname{se}(1.127,1.3127,110 \times 127)$ \\
\hline TEO & NMBF & $\begin{array}{l}\operatorname{CSP}(K 2, F 3, P H I S 7, V N 7, F A C T) \\
K S P(1237,13237,(6 \times=37)\end{array}$ \\
\hline$T=U$ & N.49R. & USO (FI, N4, PHIST, VN7,FACT) \\
\hline TEC & & 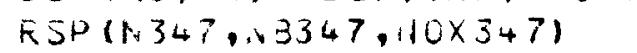 \\
\hline $\begin{array}{l}\text { TEU } \\
\text { TEC }\end{array}$ & $\sqrt{4} 4 \mathrm{~B} \pi$ & 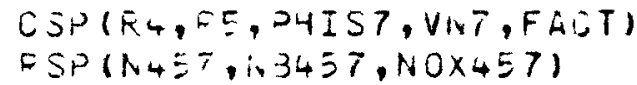 \\
\hline $\begin{array}{l}T=C \\
T F C\end{array}$ &.$J 4 R^{2} \mathrm{~K}$ & 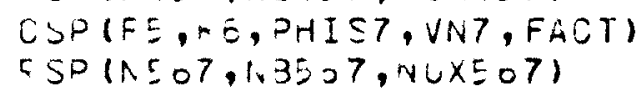 \\
\hline$T+C$ & $\therefore y_{t} 3 \mathrm{~F}$ & $\operatorname{CSP}\left(F 2, H 2,{ }_{H}\right.$ IS $\left.8, V N E, F A C T\right)$ \\
\hline IFC & & $\approx S 0(N 12, N 3123, N 0 \times 128)$ \\
\hline $\begin{array}{l}T=\imath \\
T E O\end{array}$ & WYik & $\begin{array}{l}\text { CSP }(K 2, k 3, \text { PHISA, VINE, FAUT) } \\
\text { RSP }(1236,1,3239, N C \times 238)\end{array}$ \\
\hline $\begin{array}{l}T E Q \\
T E Q\end{array}$ & $v+3 r$ & 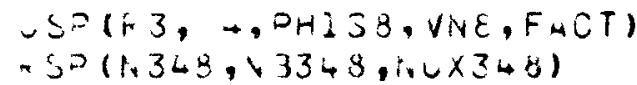 \\
\hline$T=C$ & VMuK & 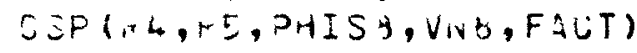 \\
\hline TEO & & $\nabla S P(1,45 \cdots, N B+58, N C x+50)$ \\
\hline $\begin{array}{l}\text { TEO } \\
\text { TEU }\end{array}$ & NoK & 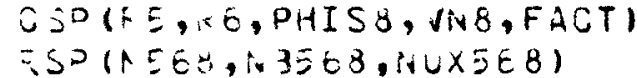 \\
\hline $\begin{array}{l}\text { TEC } \\
\text { TEC }\end{array}$ & NMEK & $\begin{array}{l}\text { CSP }(H 1, K 2, P H I S 9, \text { VING, FACT } \\
\text { XSP }(N 129, N 3129, N O \times 129)\end{array}$ \\
\hline $\begin{array}{l}\text { TEC } \\
\text { TEC }\end{array}$ & N. $48 R$ & $\begin{array}{l}\text { CSF (RE, K3, PHIS9, VN9,FACT) } \\
\text { XSP }(1239, \vee B 239, \text { :UN239) }\end{array}$ \\
\hline $\begin{array}{l}T E C \\
T \leftarrow C\end{array}$ & $N 47 \pi$ & $\begin{array}{l}\text { CSP (F 3, :4, PHISG, VN9,FAUT) } \\
\text { RSP }(1 \times 342, N 3349, N O \times 349)\end{array}$ \\
\hline $\begin{array}{l}\text { TEC } \\
\text { TEO }\end{array}$ & $\mathrm{NHiH}$ & $\begin{array}{l}\operatorname{CSP}\left(K 4, \equiv, D_{H}=S Y, V N G, F A C T\right) \\
-\operatorname{SF}(K 4 \equiv 9, \mathrm{~B} 3+29,(10 \times 4=9)\end{array}$ \\
\hline $\begin{array}{l}\text { TEC } \\
\text { TEO }\end{array}$ & Math & $\begin{array}{l}\text { CSP (KE, } 6, \text { PHIS } 9 \text {, VN9, FACT) } \\
\text { KSP(1NEE9,1.35 k9, NOXSOS) }\end{array}$ \\
\hline $\begin{array}{l}T E O \\
T E C\end{array}$ & NAB & $\begin{array}{l}\operatorname{CSP}(F 1, ; 2, \text { OHISO, VIV, FACT }) \\
\text { FSP(N12;, } 3120, \text { NOX120) }\end{array}$ \\
\hline $\begin{array}{l}T E C \\
T E C\end{array}$ & $i 1, F$ & 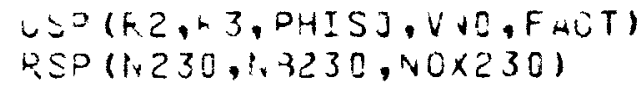 \\
\hline TEL & $N 126$ & 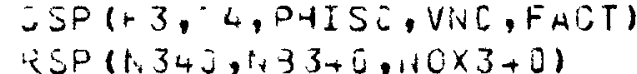 \\
\hline $\begin{array}{l}T E U \\
T F C\end{array}$ & in $46 x$ & $\begin{array}{l}\operatorname{CSP}(F 4, F E, P H I S C, V N O, F A C T) \\
\operatorname{RSP}(N 450, \text { IN } 3+50, \text { NOX4SO) }\end{array}$ \\
\hline $\begin{array}{l}T=0 \\
T=C\end{array}$ & $N 13 K$ & $\begin{array}{l}C \triangle P(F E, K G, P H I S O, V N C, F A C T) \\
\times S P(1.560, N 3500, N C \times E G O)\end{array}$ \\
\hline
\end{tabular}

FIGURE 4-2. MIMIC Listing of the Volatile Solids Release Model for the IF-300 (Page 8 of 16) 
$\dot{0}$ CALCULATIUI Uf TOTAL FAFTICLES, MASS, and AUTIVITY

\begin{tabular}{|c|c|c|c|}
\hline TEC. & NT12A & & $A 0 J(N 121, N 122$, iN $123, N 127, N 128)$ \\
\hline TEU & NT23A & & $A D J(N 231, N 232, N 233, \operatorname{ir} 237, N 234)$ \\
\hline$T E G$ & NT3 4 A & & $430(1.341,9342,1343,1 \times 3+7,14349)$ \\
\hline TE & $N T+E A$ & & $\operatorname{AOO}(1,-51,1,+52, N+53,1,457, N 450)$ \\
\hline TEL & $N T E \dot{O A}$ & & $A j j(N \equiv 51, \therefore 5 j 2, N \equiv 63,4507, N \equiv 68)$ \\
\hline$T \equiv こ$ & NT12 & & AUJ $(1124, N 129, N 120)$ \\
\hline$T E L$ & NT23 & & $A[1)(N . T 23 A, N 239, N 233)$ \\
\hline$T=\mathrm{C}$ & 11534 & & $403(1 . T 3-4,1349,13-0)$ \\
\hline TEO & $1+745$ & & $A C U\left(N T 4 \equiv A, V_{4} \equiv 9,11450\right)$ \\
\hline$T \div 0$ & $N T E O$ & & $A C J(1, T E O A, 1509$, iv 500$)$ \\
\hline TEE & ATCT & & AJ j(NT12,1.T23, NT 34,NT45, NTEE) \\
\hline TEL & 11112 & & $\because 12 * 1 . T 12$ \\
\hline TE & $4 T 23$ & $=$ & $\because 23 * i \div 23$ \\
\hline TFu & Mr3 & $=$ & $M j \rightarrow N T 3 \rightarrow$ \\
\hline TEO & $\because T 45$ & & $M 45 * T 45$ \\
\hline$T E C$ & $M \Pi \equiv 0$ & & $M 56 * 1 . T 50$ \\
\hline TEC & MTCT & & ADU (MTI2, PTL3, MT34, 4T45, MT56) \\
\hline
\end{tabular}

FU

FUNCTION SWITCH ITERAT. TRUE UR ON IF ABS(MTOTIN-MTOT),GT.1.. OFF OTHEHWISE.

TEL ITEKATI = FSW(LUS(MTOTIN-MTCT)-.jJ01,FALSE,FALSE,TRUE)

-

CALCULATION OF CURRECTION FACTOR FACT WHICH ADJUSTS THE DISTRIRUTION FUNCTION IN SUAPROGRAM NMBR TO GIVE THE CORRECT MASS AND ACTIVITY

.

ITERAT FACT = IMP(FACT,FACT*(1•+(MTOTIN-MTOT)/MTOTIN))

$\bullet$

TEO ATI2 ACTIZ*NTI2

TEO AT23 ACT23\#NT23

TEO AT34 ACT $34 \$ N T 34$

TEO AT45 ACT4S \#NT45

TEO ATSO ACT56*NT56

TEO ATOT ADU(ATI2,AT23,AT34,AT45, ATSE)

-

FIGURE 4-2. MIMIC Listing of the Volatile Solids Release Model

for the IF-300 (Page 9 of 16) 
-

SUPFROGRAMS

-

SUBFOJGRA TE CALEJLATE VELJETTY JF FALL

.

WHERE
- 1 = THE VELUCITY CF FALL, EM/SEC
- -XY = THE AVERLGE JF rLOII EX ANQ RY, CH


.

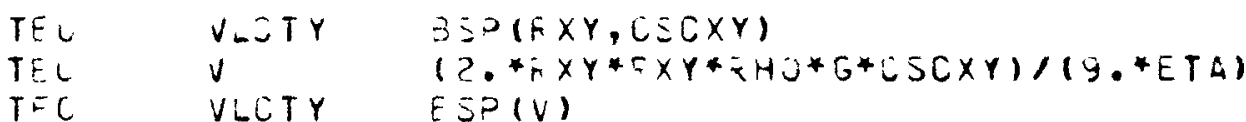

-

-

SUBFFUGFAM TU CALLJLATE VOLJHE FFACTIUN JF FAKTICLES IN AEROSCL

-

WHERE

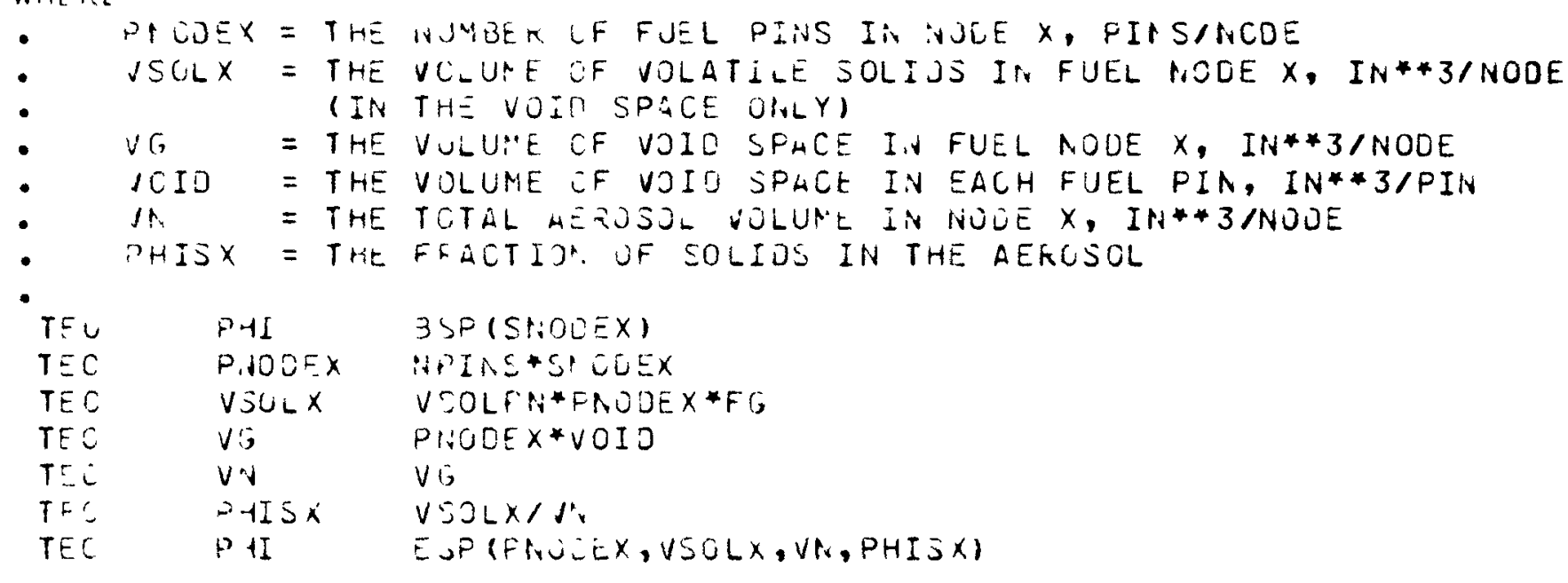

SURCROGNAM TO GLLUULATE NLMBER JF PARTICLES-DTOTAL, FFEE AND BOUND UP WHE E

- the CJNSTANT 1E.307 COLVERTS VR FROM IM**3 TU CM**3

- int = the total inuger of paktioles in the size range ka to fib

- frejent il fuel noDes of hassy fuel assemblies

- ig = The nuMbef if Free particles in nt which are released hHe THE PINS BURST

$\because C X$ = THE NUNBER CF 3JUHO-UF PAKTICLED IIN NT RELEASED WHEN FUEL IN MCOEX OXIOIZED

THE FALTUR 0.079 ADJUSTS THE DLSTKISUTIOIN FUNCTION TO GIVE THE

CCKREOT MASS ANO ACTIVITY. THE USE JF THIS FACTOR IJ EQUIVALENT

TO REPLACING THE COISTANT O. CE BY. 333.

TEC NMBK BSO(F, TB, DTIS, VN,FLTFI)

TEC KIHL KA * FA * RA * RA

TEO NT $\quad(.25 *(F B-K A) * F H I S * V . V * 15.337 * F C T R) \quad / R A 4$

FIGURE 4-2. MIMIC Listing of the Volatile Solids Release Model

for the IF-300 (Page 10 of 16) 


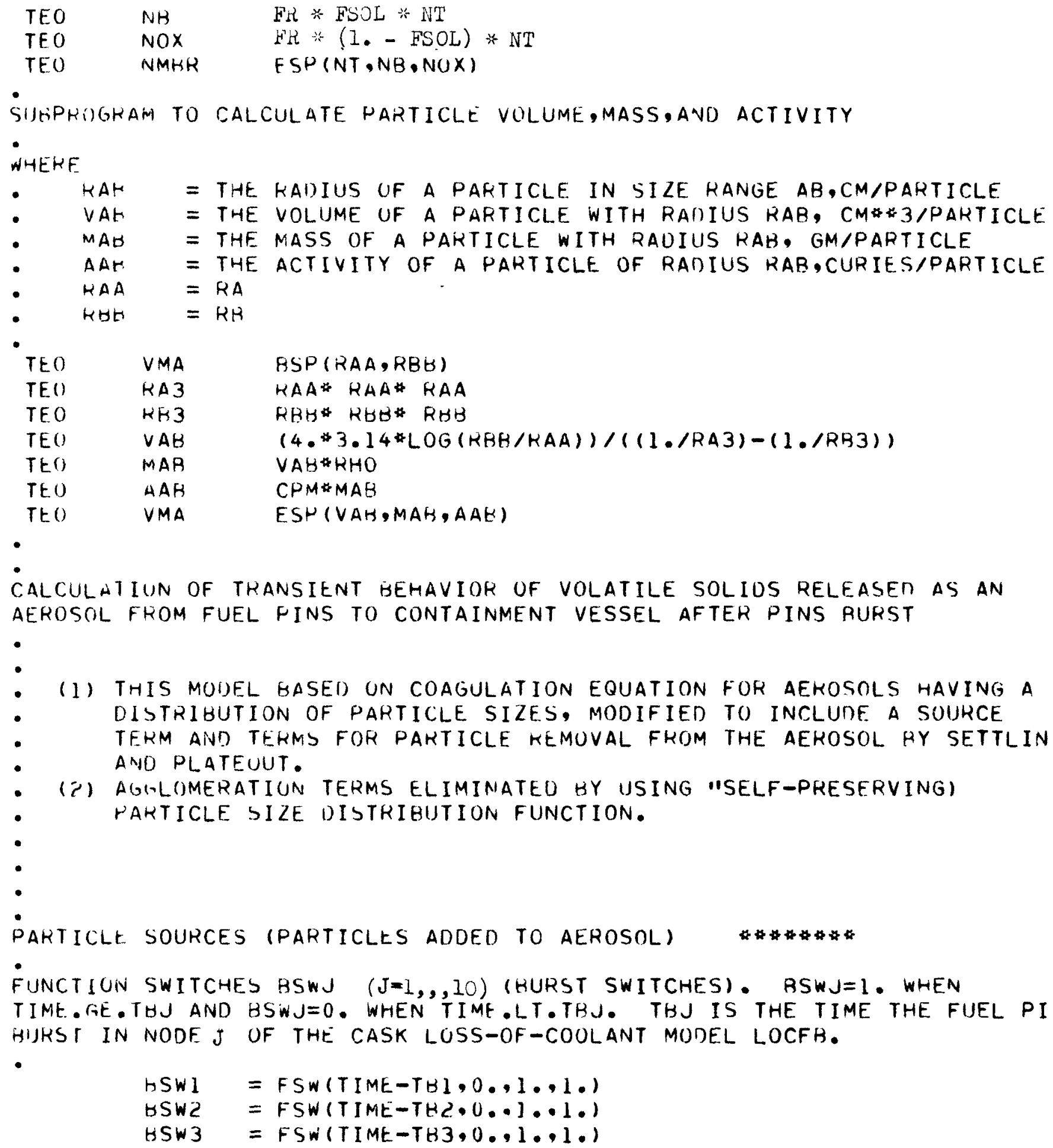

FIGURE 4-2. MIMIC Listing of the Volatile Solids Release Model for the IF-300 (Page 11 of 16) 


$$
\begin{aligned}
& \text { 3SW7 } 7=F S W(T I M E-T 37,0 ., 1 ., 1 .) \\
& \text { 3JHS = FSW (TINE-T } 38,0 \ldots 1 \ldots, 1,) \\
& \text { BSWy }=\text { FSW (TINE-T 3H, C.,1.,1.) } \\
& 3 \text { JW } 1 \text { J }=\text { ESW (TIME-T } 310,0,1,1,1
\end{aligned}
$$

FUNCTION SWITCHES OSWJ $(J=I,,, 10)$ (OXIDATION SWITCHES). OSWJ=I. WHEN TIME. GE.TOXJ AND OSWJ=0. WHEN TIME.LT.TUXJ. TOXJ IS THE TIME THE EXPOSEU FUFL OXIUIZES IN THE FUEL PINS WHICH HAVE BURST IN NONE $\&$ OF CASK LOSS-OF-COOLANT MUDEL LOCFB.

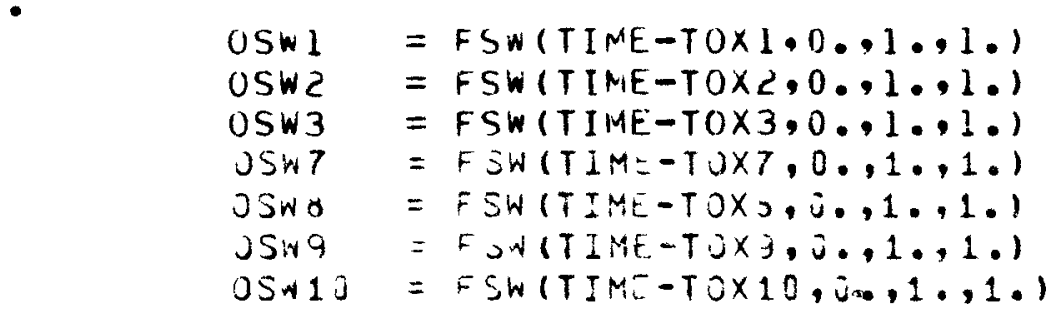

\begin{tabular}{|c|c|}
\hline A & $35 W 1 * 1.2121+35 W 2 * N B 122+35 W 3 *$ \\
\hline 128 & $12 A+E S W 8 * N 3128+B S W 9 * N 312 j+B S W 10 * N B 123$ \\
\hline 120 & $112 i+C 3.11 * v J \times 121+U S$ N $2 * N O \times 122+C S W 3+N O \times 123$ \\
\hline $2 \mathrm{~L}$ & $=N 12 L+C S W 7 * 10 \times 127+0 \sin 8 * N 0 \times 123+\operatorname{CSW}=N 0 \times 12 j$ \\
\hline$\times 12$ & $=\vee 12 L+C \Xi N 1 r * N 0 \times 120$ \\
\hline & $=3 \operatorname{sw1} 1 . B^{*} 31+B S W 2 * N 3232+3 S w^{2} * i \times B 233+B S w 7 * N B 23$ \\
\hline & $=4 ? 3 i+55 N E * V ? 33 y+35 W y * N 323 y+35 W 10 * N 8230$ \\
\hline 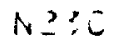 & $\therefore 23+C \operatorname{Csw} 1 * 13 \times 231+3 \leq N 2 * N O \times 232+U S W 3 * N O \times 233$ \\
\hline & 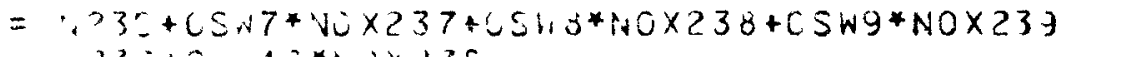 \\
\hline & $=23:+2041: * 3 \times 230$ \\
\hline $3 \rightarrow+$ & $3 \leq W 1 * \ln B 3+1+B \leq w 2 * N 33+2+35 * N 3 * N 3343+E S W 7 * N 334$ \\
\hline 340 & 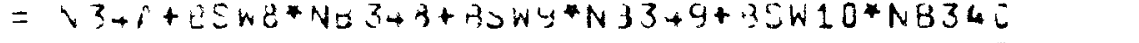 \\
\hline 4 & $=v 3+3+j 5 w: v 3 \times 3+1+U S W 2 * N: J \times 34 ?+L S W 3 * N O \times 343$ \\
\hline $36-3$ & $=.3+C+U 5 N 7 * N J \times 3+i+u 5 w 8 * 110 \times 345+C 5 w 9 * N u \times 3+3$ \\
\hline & $=v 3+u+0 \sin 20+v J \times 3+c$ \\
\hline & $1 S W 1 * 1+5-51+25 W 2 * 1+04=2+30 W 3 * 1 * 3453+B S W 7 * N$. \\
\hline & $=i 4+E H+B D N O * V 3+E 3+B S W+14 B+E y+B S W 10 * N B 45 D$ \\
\hline & 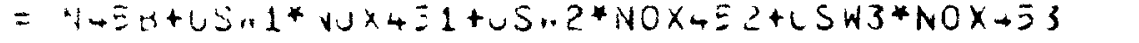 \\
\hline & $\sqrt{45 L}+C \leq N 7 * i \sqrt{3} \times 457+U S h 8 * N O \times 450+0 S W 9 * N O \times 459$ \\
\hline & 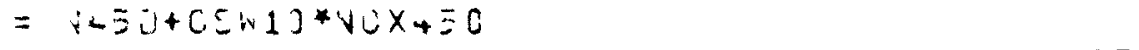 \\
\hline & $=35 W 1 * 1,3 \equiv 01+35 W 2 * N 3 E c 2+35 W 3 * N B 563+B S W 7 * N B$ \\
\hline & $=\therefore E 3 \mu+B \operatorname{Sh} 8 * 13: 66+35 n+108=05+65 h 10 * N B 560$ \\
\hline & $=N E \sigma E+C \sin 1 * v J \times \equiv 01+U S N 2 * N C \times \equiv E 2+C 5 W 3 * N u \times 563$ \\
\hline & 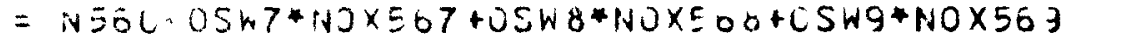 \\
\hline & $=N 56[+\sin 1] * N=000$ \\
\hline
\end{tabular}

CALCIILATIUN OF NUMHFR OF PARTICLES IN LACH SILE RANGE RELEASED (FROM FUEL PINS IN VANIUUS FUEL NOUES) TO THE AEROSOL.

-

FIGURE 4-2. MIMIC Listing of the Volatile Solids Release Model for the IF-300 (Page 12 of 16) 
-

REMOVAL UH LOSS UF PAKTICLES FROM AEROSOL

*

RATE OF LUSS OF PAKTICLES FHUM AEROSOL DUE TU SETTLING aND PLATEOUT.

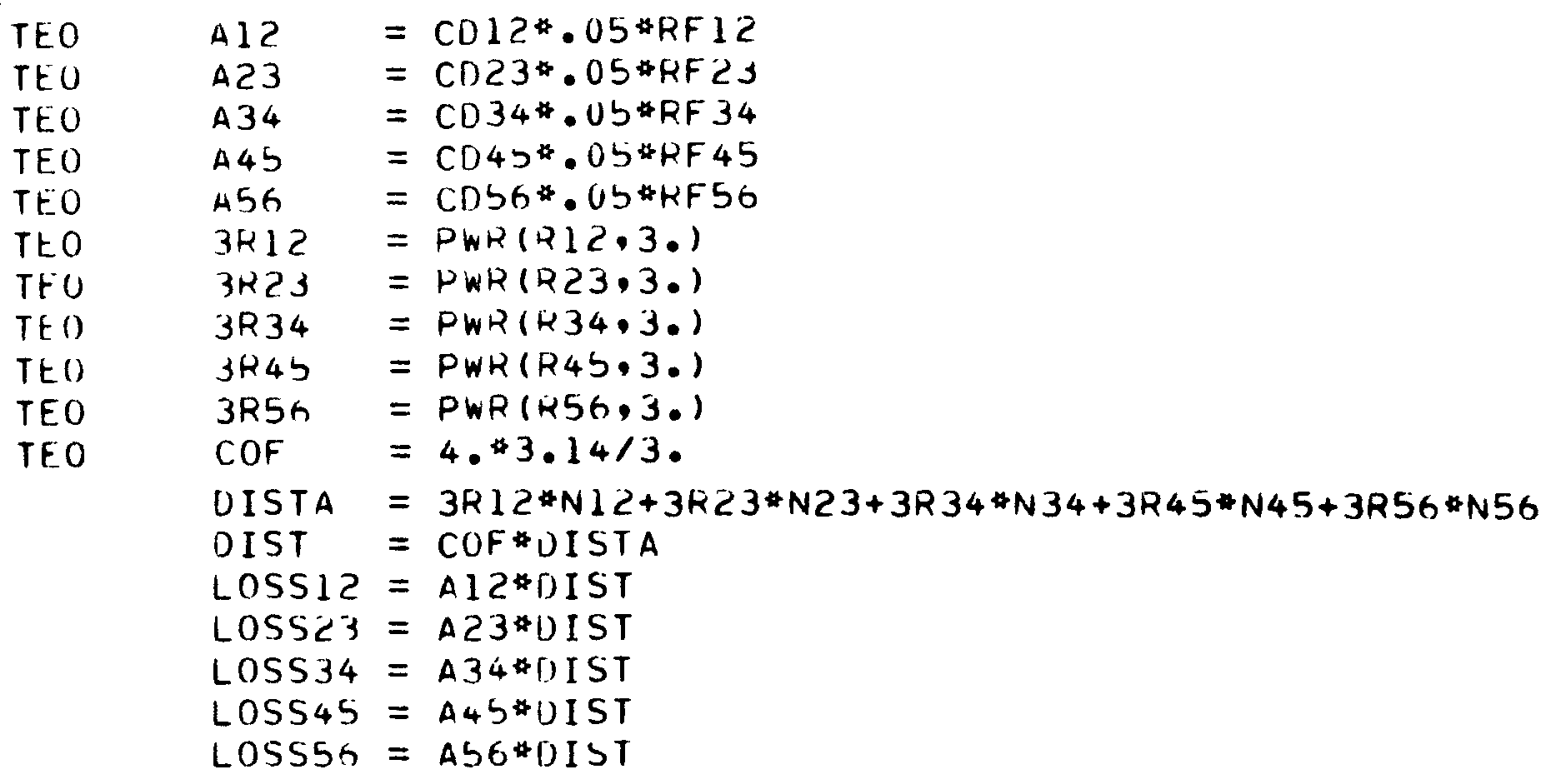

CALCULATION OF NUMGER OF PARTICLES IN EACH SIZE RANGE LOST FROM THE AEROSOL DUE TO SETTLING AND PLATEOUT.

-

$$
\begin{aligned}
& \text { LSSILL = LIN(LOSSIC,NUUTIZ,0.,NINI?) } \\
& \text { NOUTIZ = INT(LSSIZL,U.) } \\
& \text { LSS23L }=\text { LIN(LOSS23, NUUT23,0.,NIN23) } \\
& \text { NOUT23 = INT (LSS23L,0.) } \\
& \text { LSS34L = LIN(LOSS34, NOUT 34,0.,NIN34) } \\
& \text { NOUT34 = INT(LSS34L,0.) } \\
& L S S 45 L=L I N(L O S S 45, N O U T 45,0, \text { NIN45) } \\
& \text { NOUT4D = INT (LSS45L,0.) } \\
& \text { LSS56L }=\text { LIN(LOSS56,NOUT56,0.,NIN56) } \\
& \text { NOUTSG = INT (LSSSOL, 0.) }
\end{aligned}
$$

-

PARTICLES REMAINING IN SUSPENSION AS AN AEROSOL

$* * * * *$

FIGURE 4-2. MIMIC Listing of the Volatile Solids Release Model for the IF-300 (Page 13 of 16) 
FUNCTION SWITCHES NUNM $(N=1,,, 5)(M=N+1)$. TRUE OR ON IF NINNM.LE. NOUTNM, OFF OTHERWISE. THIS LCV ASSURES A NON-NEGATIVE VALUE FOR THE NUMBER OF PAKTICLES REMAINING IN SUSPENSION.

-

$$
\begin{array}{ll}
\text { N012 } & \text { FSW(NIN12-NOUT 12, TRUE, TRUE, FALSE) } \\
\text { N023 } & \text { FSW (NIN23-NOUT23, TRUE, TRUE, FALSE) } \\
\text { N034 } & \text { FSW (NIN34-NOUT 34, TRUE, TRUE, FALSE) } \\
\text { N045 } & \text { FSW(NIN45-NOUT 45, TRUE, TRUE, FALSE) } \\
\text { N056 } & \text { FSW(NIN56-NOUT56, TRUE, TRUE, FALSE) }
\end{array}
$$

LOGICAL CONTROL VARIABLES (LCV) SOMENM, THE LOGICAL COMPLEMENTS OF NONM $(N=1, . .5)(M=N+1)$.

$\cdot$

$$
\begin{aligned}
& \text { SOME } 12=\text { NOT }(N O 12) \\
& \text { SOME23 }=\text { NOT (NO23) } \\
& \text { SOME } 34=\text { NOT (NO34) } \\
& \text { SOME 45 }=\text { NOT (NO45) } \\
& \text { SOME56 }=\text { NOT (NOS6) }
\end{aligned}
$$

-

CALCULATION OF NUMBER OF PARTICLES REMAINING IN SUSPENSION AS AN AEROSOL

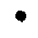

$\begin{array}{lll}\text { NO12 } & \text { N12 } & =0 . \\ \text { NO23 } & \text { N23 } & =0 . \\ \text { NO34 } & \text { N34 } & =0 . \\ \text { NO4S } & \text { N45 } & =0 . \\ \text { NO56 } & \text { N56 } & =0 . \\ \text { SOME } 12 & \text { N12 } & =\text { NIN12-NOUT 12 } \\ \text { SOME23 } & \text { N23 } & =\text { NIN23-NOUT23 } \\ \text { SOME } 54 & \text { N34 } & =\text { NIN34-NOUT34 } \\ \text { SOME 45 } & \text { N45 } & =\text { NIN4S-NOUT } 46 \\ \text { SOME56 } & \text { N56 } & =\text { NIN56-NOUTS6 }\end{array}$

CALCULATION OF TOTAL ACTIVITY OF PARTICLES IN AEROSOL

-

ACT VTY $=A C T 12 * N 112+A C T 23 * N 23+A C T 34 * N 34+A C T 45 * N 45+A C T 56 * N 56$ ACTOA $=$ ACT $12 *$ NCUT $12+A C T 23 *$ NOUT $23+A C T 34 *$ NOUT $34+A C T 45 *$ NOUT 45 ACTOUT = ACTUA+ACTEO*NOUTEO $\triangle J T B A L=A C T V T Y+A C T O U T$

CALCULATION of total mass of particles IN AEROSOl

-

MASS $=M 12 * N 12+M 23 * N 23+M 34 * N 34+M 45 * N 45+M 56 * N 56$

COMPUTE TIME IN SECONDS AND hUURS

FIGURE 4-2. MIMIC Listing of the Volatile Solids Release Model

for the IF-300 (Page 14 of 16) 


$$
\begin{aligned}
& \text { TIME }=T+T L O C L W \\
& \text { HUURS }=\text { TIMH } 360 \mathrm{C} .
\end{aligned}
$$

sं

STOP CUMPUTATIONS WHEN TIME = TFIN

FIN (TIME, TFIN)

$\cdot$

FUNCTIUN SWITCH CHCK. TRUE OR ON WHEN SNOOP.GT.O., OFF OTHERWISE. USED FOK PRINTING SELECTED OUTPUT FOR CHECK PURPOSES.

$\cdot$

CHCK = FSW (SNOOP, FALSE, FALSE, TRUE)

$\dot{T}$

TIME STEP FOR PRINTOUT

-

$$
\text { DT }=60 \text {. }
$$

DUTPUT

-

TEU

$T E C$

$T E D$

$T E O$

TES

TEC

$T E C$

$T E C$

TEO

$T \Xi U$

TEO

TEC

TEC

TEO

$T: 0$

TEL

$T=0$

Tr L

TiC

$T \leq C$

$T=U$

TEO

TEC

TEU

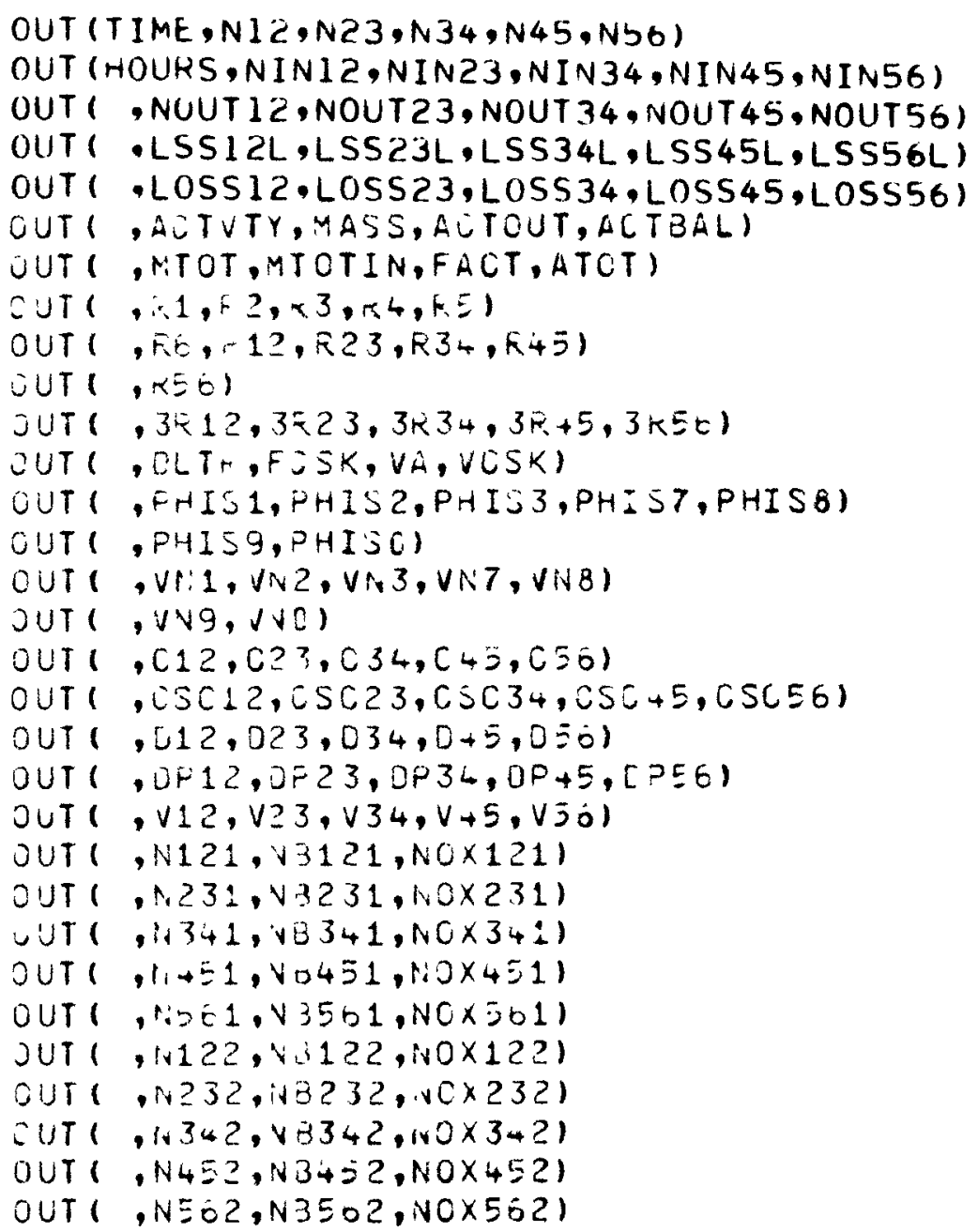

FIGURE 4-2. MIMIC Listing of the Volatile Solids Release Model for the IF-300 (Page 15 of 16) 


\begin{tabular}{|c|c|c|}
\hline $\begin{array}{l}\text { TEO } \\
\text { TEC }\end{array}$ & $\begin{array}{l}\text { outr } \\
\text { outi }\end{array}$ & $\begin{array}{l}\text { NN123,N8123,NOX1231 } \\
\text { N N233,N8233,NOX2331 }\end{array}$ \\
\hline TEO & oUT & $.1 \times 343,143343, N 0 \times 3+31$ \\
\hline TEU & our 1 & $, 10+53, v 4453,100 \times 4531$ \\
\hline TEL & CUT1 & , N $=03, V 8503,10 \times 5631$ \\
\hline$T E S$ & ivit & , N127,N N127, NCX127) \\
\hline TEC & OUT 1 & $, 1.237,19237,1.0 \times 2371$ \\
\hline$T E U$ & OUT1 & $, N 3+7, N+347, N C \times 3471$ \\
\hline$T E \sigma$ & OUT & , N4 \\
\hline$T E こ$ & CUTI & , $1407.48507,40 \times 507)$ \\
\hline TẼ & JUT1 & $, 14229, v 128, \times 0 \times 1231$ \\
\hline TFO & our1 & , iv233, N3238, N $0 \times 2331$ \\
\hline $\begin{array}{l}\text { TEC } \\
\text { TEC }\end{array}$ & $\begin{array}{l}\text { JUTí } \\
\text { OUTí }\end{array}$ & $\begin{array}{l}, 1 ; 343, v 8340, N C \times 3+31 \\
, N 4 \equiv 8, \sqrt{ }, \sqrt{3} 58, \mathrm{NO} \times(591\end{array}$ \\
\hline TEZ & OUT 1 & , $: N 563, \vee B 558$, NuXE631 \\
\hline TEO & OUTI & , N129,N312y,NOX12łI \\
\hline TEL & DUT & , N23y, Ne23y, NOX239) \\
\hline$T E C$ & SUTI & $, N 3+3, i v 33+9, i v 0 \times 3+9)$ \\
\hline$T E C$ & OUT & $, N+59, N 3453, N C X+59)$ \\
\hline TEC & JUT1 & $N=E 9, N 3569, N G \times 569)$ \\
\hline$T=C$ & OUTI & , N123, (N312J, NOX120) \\
\hline$T E C$ & CUT 1 & $, N 230,18230, N 0 \times 2301$ \\
\hline$T=0$ & JUT & $, 1342,133+0,(10 \times 3+0)$ \\
\hline TEC & SUTI & $, N 4 E Z, N 34 \equiv 3, N(\times 450)$ \\
\hline $\begin{array}{l}\text { TEO } \\
\text { TEC }\end{array}$ & $\begin{array}{l}\text { JUTi } \\
\text { OUTi }\end{array}$ & $\begin{array}{l}\text {,NEEI, N356C, NOX5001 } \\
\text {, VOL12, M12, ALT121 }\end{array}$ \\
\hline$T E C$ & OUTi & $, V \cup L 23, M 23, A C T 23)$ \\
\hline$T E C$ & OUI & , VEL $3 \rightarrow,, 3 \backsim$, ACT 341 \\
\hline$T \equiv \delta$ & UUTi & , VOLL-5,M-E, ACT + SI \\
\hline TEC & EJTI & , VOLSG, MEO, ACT $\equiv 6)$ \\
\hline $\mathrm{CHCK}$ & OUTI & , BSW1, 3SW2, BSW3, 3SW7, BSW81 \\
\hline $\mathrm{CHCK}$ & SUTi & , 3569, 35W10) \\
\hline $\mathrm{CHCK}$ & OUTI & $, 05 w 1,05 w 2,05 N 3,05 n 7,05 w 81$ \\
\hline \multirow[t]{12}{*}{ CHCK } & OUTi & , OSWJ,JSW1C) \\
\hline & OUT & \\
\hline & out & \\
\hline & \multicolumn{2}{|c|}{ 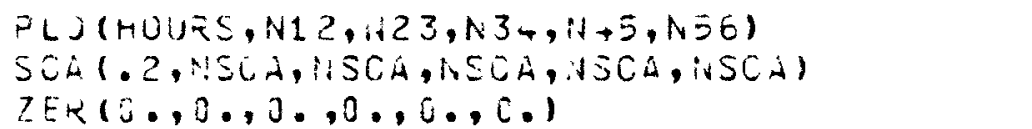 } \\
\hline & \multirow{2}{*}{\multicolumn{2}{|c|}{$\begin{array}{l}\text { TTO (VOL SOLI US PARTICLE CONCENTRATIONSI } \\
\text { TTY INUMBER JF PARTICLES IN EACH SIZE GRP) } \\
\text { TTX (TIME IN HOURS) }\end{array}$}} \\
\hline & & \\
\hline & \multirow{2}{*}{\multicolumn{2}{|c|}{$\begin{array}{l}\text { PLD }(\text { HCURS, ADTVTY }) \\
\text { SCA }(O \cdot 2,2 .) \\
\text { ZEP }(C ., .,)\end{array}$}} \\
\hline & & \\
\hline & \multirow{2}{*}{\multicolumn{2}{|c|}{$\begin{array}{l}\text { TTO (VOLATILE SOLISS ACTIVITY) } \\
\text { TTY(VCLATILE SOLIOS ACTIVITY, JURIES) }\end{array}$}} \\
\hline & & \\
\hline & \multicolumn{2}{|c|}{ TTX(TIME IN HOURS) } \\
\hline & \multicolumn{2}{|c|}{ END } \\
\hline
\end{tabular}

FIGURE 4-2. MIMIC Listing of the Volatile Solids Release Model for the IF-300 (Page 16 of 16) 


$$
\begin{aligned}
A_{-}(v, t)= & \text { the rate at which particles of volume } v \text { are } \\
& \text { lost by agglomeration to yield larger par- } \\
& \text { ticles, particles/ } \mathrm{cm}^{3} \text { (aerosol) } \times \text { sec. } \\
\mathrm{R}(v, t)= & \text { the rate at which particles of volume } v \text { are } \\
& \text { removed from the system by settling (fallout), } \\
& \text { leakage from the cask, and by deposition } \\
& \text { (plateout) on the walls of the containment } \\
& \text { vessel and any other "cold" surfaces in the } \\
& \text { cask, particles/cm } 3 \text { (aerosol) } \times \text { sec, and } \\
= & \text { the aerosol production rate, i.e., the rate } \\
& \text { at which particles of volume } v \text { are added to } \\
& \text { the system upon bursting of the fuel pins, } \\
& \text { particles } / \mathrm{cm}^{3} \text { (aerosol) } x \text { sec. }
\end{aligned}
$$

In this study, this equation was further modified by eliminating the agglomeration terms by using the "self-preserving" particle size distribution function.

The agglomeration term $A_{+}$represents a rate of formation (addition) of particles to the size group by coagulation of particles of smaller size, and the term $A_{\text {_ }}$ represents a rate of loss of particles from the size group due to coagulation to form particles of larger size (and transfer to a size group containing larger particles) (see Figure 4-5). If one assumes that these "transfers" of particles between particle size groups occur at rates that maintain a particular particle size distribution throughout the life of the aerosol, and that this distribution holds for any quantities of aerosol added to or taken away from the main aerosol, such as by pin bursting, settling, plateout, etc., then the "transfer terms" may be eliminated by using the assumed particular particle size distribution function to define the particle size distribution in these various source and removal terms. This is based on an approach suggested by Davis on pp. 36-46 of ORNL-4437 (Reference 13). In the present model, the "self-preserving" particle size distribution function was assumed. In this distribution function there is a term $\phi$ defined as the volume fraction of particles dispersed in 
the aerosol, i.e., the ratio of the volume of all particles suspended in the aerosol to the total volume of the aerosol. When the particles of a particular size range are being considered and the particle balance equation is being evaluated for this particular size range, the transfer terms are dropped and the number of particles in this range, in the remaining source and removal terms, is expressed in terms of the "self-preserving" particle size distribution. The numbers of particles in all the other size ranges in the aerosol are related to the number of particles in the size range being considered through the volume fraction $\phi$ in the source and removal terms. Before it can be shown how this is done, the particle size distribution function must be discussed, the settling and plateout terms must be derived, and the source term must be derived for the pulsed inputs representing the release of free and bound up mixtures of fission gases and volatile solids from the bursting fuel pins. The self-preserving particle size distribution function used was obtained from the work of Davis. (13) The settling and plateout terms were also first derived by Davis. These derivations are repeated here using a slightly different approach in each case.

\subsubsection{Particle Size Distribution Function}

Áccording to Davis, $(13)$ the concept of the "self-preserving" size distribution has both theoretical and experimental basis. He points out that the concept is a steady-state size distribution resulting from coagulation (a process that makes big particles from little ones) and settling (which preferentially removes big particles). He also states that "The self-preserving distribution may well describe aerosols in a containment; in fact, it is not unlikely that the self-preserving distribution is achieved with highly coagulated aerosols soon after nucleation."

The self-preserving distribution function is

$$
\frac{d n(v, t)}{d r}=0.05 \phi r^{-4}
$$


where

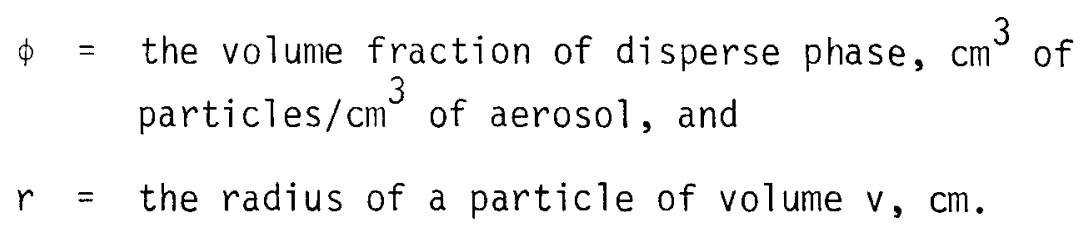

In order for Equation (4-2) to be dimensionally correct, the coefficient 0.05 must be in units of particles. Before it can be shown how the "seifpreserving" distribution function can be used to eliminate the agglomeration terms in the coagulation equation, Equation (4-1), the removal and source terms in this equation must be derived.

\subsubsection{Rate of Particle Removal from the Aerosol}

The removal term, $R(v, t)$, in Equation (4-1) includes removal of particles from the system by settling, leakage and plateout. At the present stage of model development, only settling and plateout have been included. However, since the present model was completed, a leakage term representing the loss of particles through the breach in the cask containment has been developed and will be included in the model during the next development phase. The general concept of the leakage term is presented in Section 4.1 .5 , along with a discussion of the modifications required to include it in the present model.

\subsubsection{Particle Removal by Settling}

The particle settling term is based on the concept that the aerosol in the cask is well-stirred, i.e., that the concentration of particles in each of the size groups considered is the same everywhere in the free volume in the cask, except in the boundary layer between the cask volume and the available floor space. There is no mixing in the boundary layer. The particle settling term is also based on the assumption that all the particles obey Stoke's law, and that the velocity at which the particles fall through the boundary layer to the floor may be determined from this law.

Consider a particle balance on a size group containing particles with an average radius of $r_{i j}$, with no source of particles and with the only loss of particles due to stirred settiing: 


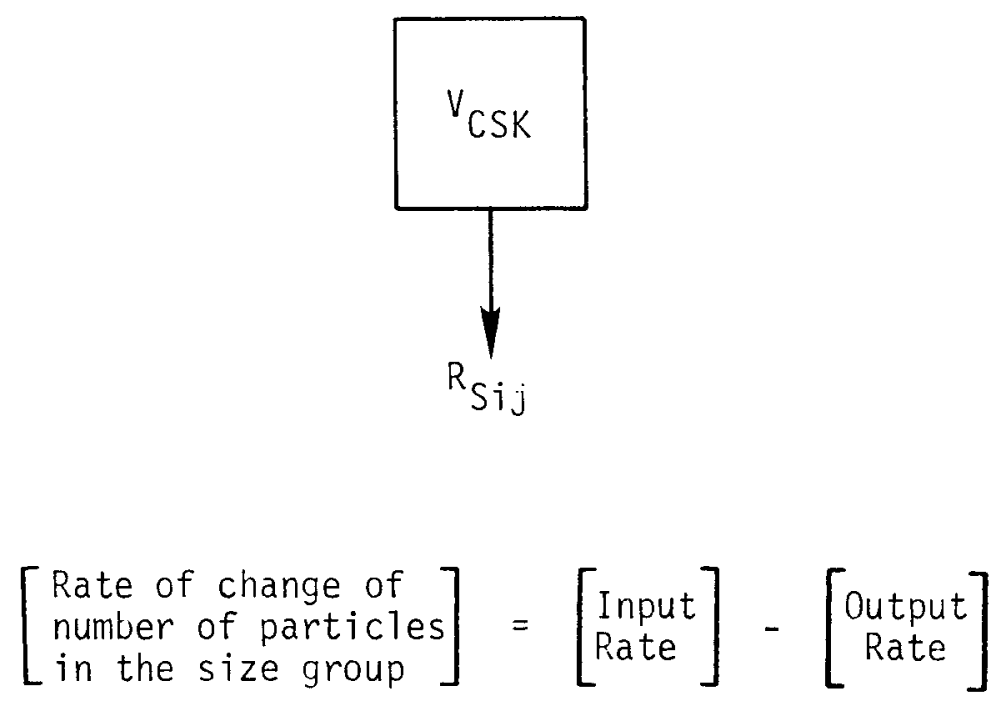

or

$$
\frac{d n_{i j}}{d t}=0-R_{S i j}
$$

where

$$
\begin{aligned}
V_{C S K}= & \text { the free volume inside the cask, and the volume of } \\
& \text { the aerosol containing all size groups, } \mathrm{cm}^{3}, \\
n_{i j}= & \text { the number of particles with an average radius of } \\
& r_{i j} \text { (ranging from } r_{i} \text { to } r_{j} \text { ) present in the cask, } \\
& \text { particles } / \mathrm{cm}^{3} \text { of aerosol, } \\
\mathrm{R}_{\mathrm{Sij}}= & \text { the rate at which particles with an average radius } \\
& \text { of } r_{i j} \text { are removed from the aerosol by settling, } \\
& \text { particles/cm } 3 \text { aerosol } \times \mathrm{sec} .
\end{aligned}
$$

The rate at which the particles of average radius $r_{i j}$ pass through the boundary layer on the floor and fall to the floor is

$$
R_{S i j}=\frac{n_{i j} V_{f i j} A_{f}}{V_{C S K}}
$$


where

$$
\begin{aligned}
V_{f i j}= & \text { the velocity of fall of a particle of radius } \\
& r_{i j} \text { through the aerosol in the cask (and through } \\
& \text { the boundary layer on the floor), } \mathrm{cm} / \mathrm{sec}, \\
A_{f}= & \text { the surface area of the floor, } \mathrm{cm}^{2} .
\end{aligned}
$$

Therefore, the particle balance equation [Equation (4-4)] may be written as

$$
\frac{d n_{i j}}{d t}=\frac{{ }_{i j} V_{f i j} A_{f}}{V_{\operatorname{CSK}}} .
$$

The settling velocity or velocity of fall, $v_{f_{j}}$, is determined from Stoke's law. Stoke's law is simply a force balance on a particle falling at a constant velocity through some medium. Assuming the particle to be spherical, the force balance is derived as follows. A spherical particle of mass $m_{i j}$ falling vertically through the medium is subjected to two forces, a viscous drag force and the force of gravity. A sketch of this sphere and the forces acting is shown below:
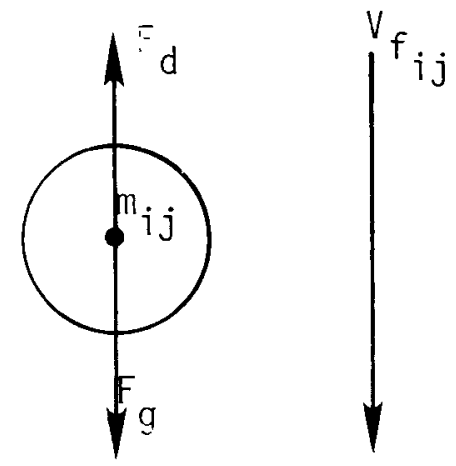

A force balance on this sphere may be written as

$$
\Sigma F=m_{i j} a_{i j}
$$


or

$$
F_{d}-F_{g}=m_{i j} \frac{d V_{f j}}{d t}
$$

where

$$
\begin{aligned}
F_{d} & =\text { the viscous drag force, } F \\
F_{g} & =\text { the force of gravity on the particle, } F \\
m_{i j} & =\text { the mass of the particle, } M \\
V_{f_{i j}} & =\text { the velocity of fall of the particle } \frac{L}{\theta} .
\end{aligned}
$$

The force on the particle due to gravity is

$$
F_{g}=m_{i j} g
$$

where

$$
g=\text { the acceleration of gravity, } L / \theta^{2} \text {. }
$$

The frictional force of viscous drag for a spherical body of radius $r_{i j}$, moving at a velocity $V_{f_{i j}}$ in a continuous medium, is

$$
F_{d}=6 \pi n r_{i j} V_{f j}
$$

where

$$
n=\text { the viscosity of the medium, } F / L^{2} \theta \text {. }
$$

Substituting from Equations (4-9) and (4-10) into the force balance Equation (4-8) we get

$$
6 \pi n r_{i j} V_{f i j}-m_{i j} g=m_{i j} \frac{d V_{f j}}{d t},
$$

but since the body is assumed to be moving through the medium at a constant velocity of $v_{f i j}$, the inertial term is zero, and Equation (4-11) becomes 


$$
6 \pi n r_{i j} V_{f j}=m_{i j}{ }^{g}
$$

Solving for the velocity of fall, Equation (4-12) becomes

$$
v_{f j}=\frac{m_{i j} g}{6 \pi n r_{i j}} \text {. }
$$

The mass of the spherical particle is

$$
m_{i j}=\frac{4}{3} \pi r_{i j}^{3} \rho
$$

where

$p=$ the density of the particle, $: 1 / L^{3}$.

Substituting the mass of Equation (4-14) into Equation (4-73), the velocity of fall becomes

$$
v_{i j}=\frac{2 r_{i j}^{2} \rho g}{9 n} .
$$

When the particle diameter is on the order of or smaller than the mean free path of molecules in the medium, the assumption of a continuous medium (continuum) is no longer valid. The drag on the particle is now mainly due to collisions with the molecules, and the particle falls freely, or slips, between collisions. Under these conditions, Equation (4-15) is no longer applicable. However, a correction factor applied to Stoke's law restores the validity of this equation. The correction factor is called the cunningham slip coefficient, $C$. Applying this factor to Equation (4-15), the velocity of fall is

$$
v_{f_{i j}}=\frac{2 r_{i j}^{2} \rho g c}{9 n} .
$$

The Cunningham slip coefficient as a function of particle diameter is presented as Figure $4-3$. (13) 


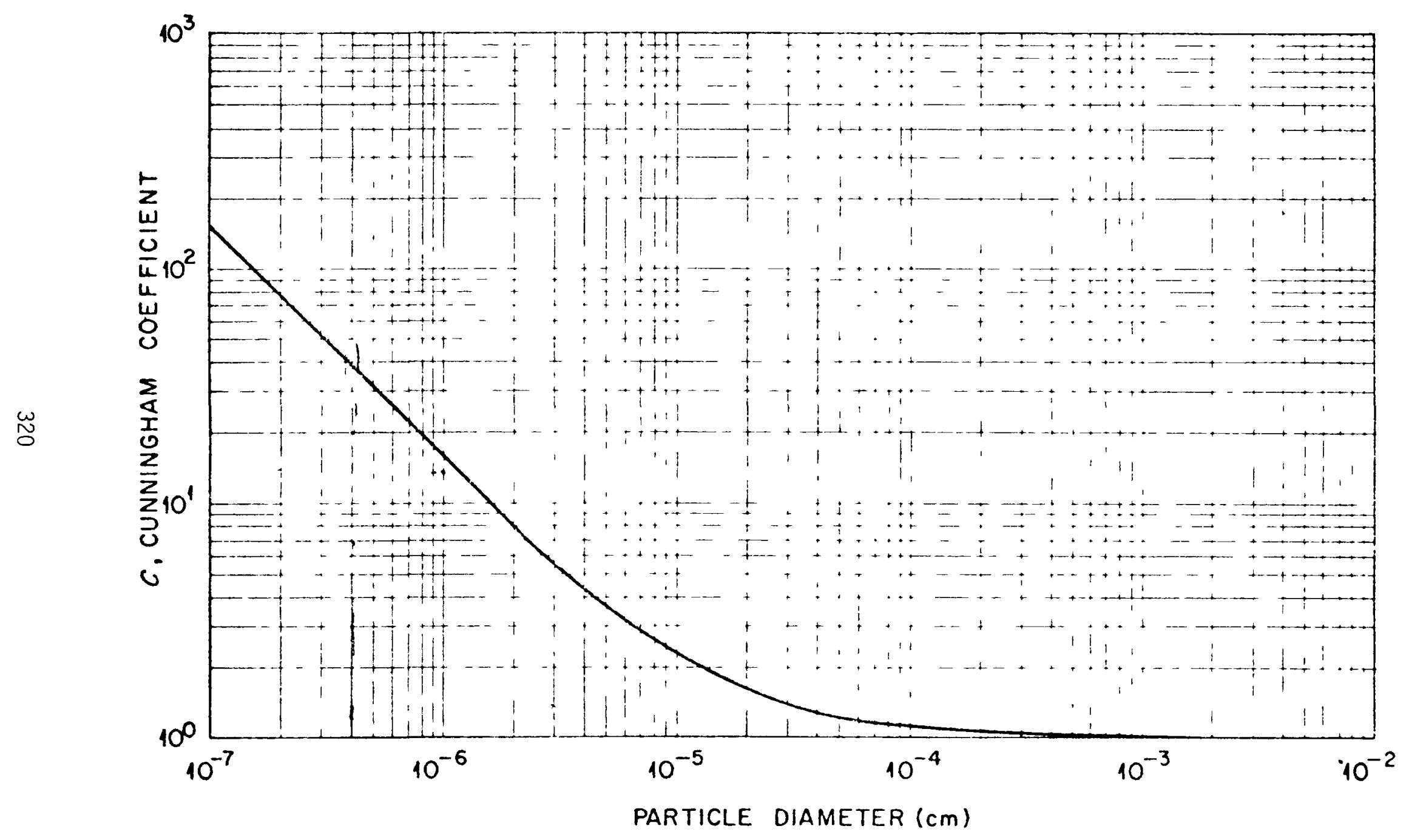

FIGURE 4-3. Cunningham Coefficient at Room Conditions (Reference 13) 
In the AlCO cask, the area upon which the particles settle, the floor area $A_{f}$, is assumed to be that area between the volume expansion chamber wall and the inside surface of the canister,

$$
A_{f}=\frac{\pi}{4}\left(D_{C}^{2}-D_{x}^{2}\right)
$$

where

$$
\begin{aligned}
& D_{C}=\text { the inside diameter of the canister, } \mathrm{cm} \\
& D_{X}=\text { the outside diameter of the volume expansion chamber, } \mathrm{cm} \text {. }
\end{aligned}
$$

For the IF-300, $D_{x}=0$, and $D_{C}$ would be the inside diameter of the cavity.

\subsubsection{Particle Removal by Plateout}

The term for particle removal from an aerosol due to plating out on colder surfaces bounding the aerosol is based on the concept that the particles diffuse through the boundary layer at the surfaces. It is assumed that the aerosol in the cask is well stirred so that the concentration is the same everywhere except in the boundary layer. According to Davis, (13) a poorly stirred aerosol is not only difficult to model but, physically, reduces plateout substantially.

Consider a particle balance on a size group containing particles with an average radius of $r_{i j}$, with no source of particles and with the only loss of particles due to plateout on a surface bounding a well stirred aerosol:

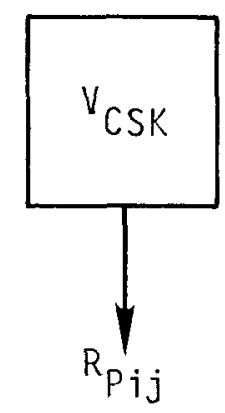

$$
\left[\begin{array}{l}
\text { Rate of change of } \\
\text { number of particles } \\
\text { in size group }
\end{array}\right]=\left[\begin{array}{l}
\text { Input } \\
\text { Rate }
\end{array}\right]-\left[\begin{array}{l}
\text { Output } \\
\text { Rate }
\end{array}\right]
$$


or

$$
\frac{d n_{i j}}{d t}=0-R_{P i j} .
$$

where

$R_{P_{i j}}=$ the rate at which particles with an average radius or $r_{i j}$ are removed from the aerosol by plating out on the bounding colder surfaces, particles $/ \mathrm{cm}^{3}$ aerosol $\times \mathrm{sec}$.

Since plateout is based on the concept that the particles diffuse through the boundary layer at the surfaces, Equation (4-19) is written as

$$
-\frac{d n_{i j}}{d t}=\frac{D_{P_{i j}} A_{\text {SURF }}}{\delta V_{C S K}}\left(n_{i j}-0\right)=R_{P_{i j}}
$$

where

$$
\begin{aligned}
A_{\text {SURF }}= & \text { the surface area of the bounding colder surfaces, } \\
& \mathrm{cm}^{2}, \\
V_{\text {CSK }}= & \text { the free volume in the cask (assumed to be the } \\
& \text { volume of the aerosol in the cask), } \mathrm{cm}^{3} \text { aerosol } \\
& \text { in cask, } \\
D_{P_{i j}=} & \text { the coefficient for diffusion of particles of } \\
& \text { radius } r_{i j} \text { through the boundary layer, } \mathrm{cm}^{2} / \mathrm{sec}, \\
\delta= & \text { the boundary layer thickness, cm, } \\
n_{i j}= & \text { the concentration or number of particles at the } \\
& \text { cask containment side of the boundary layer, } \\
& \text { particles/cm aerosol in cask. (The number of } \\
& \text { particles at the surface is zero because the } \\
& \text { particles become part of the surface and no } \\
& \text { longer exist as particles in the aerosol.) }
\end{aligned}
$$

The diffusion coefficient varies su'ustantially with particle size as shown in Figure 4-4. (13) 


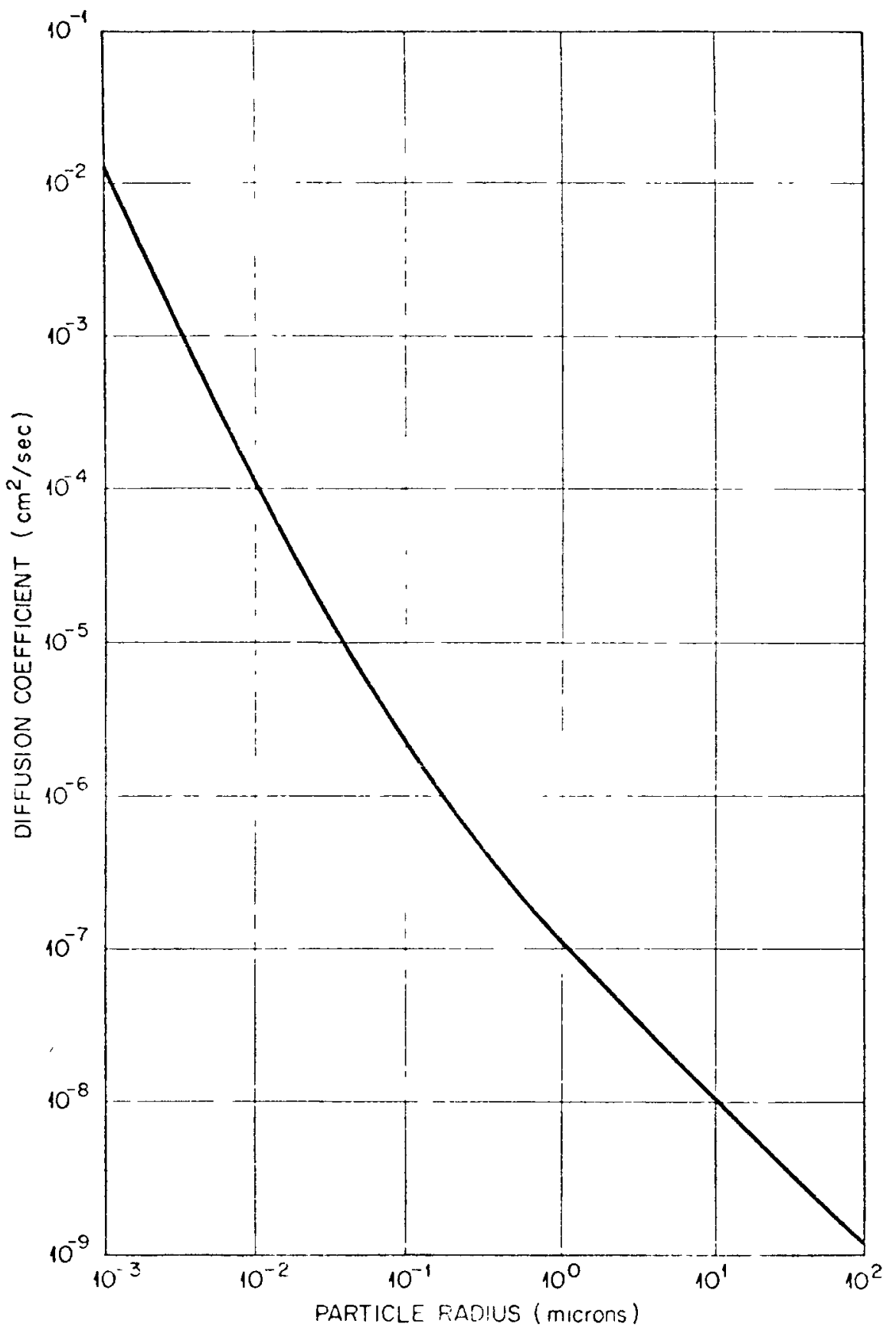

FIGURE 4-4. Diffusion Coefficient of Particles (Reference 13) 
Considerable uncertainty is introduced into Equation (4-20) due to the uncertainty of any estimation of the boundary layer thickness. Following the lead of Javis, (13) a value of $0.1 \mathrm{~cm}$ was assumed for $\delta$. Davis points out, however, that this value is probably in the low end of the range of possible values and would yield a high plateout rate estimate.

He cites a reference in which the estimation of $\delta$ is discussed, but points out that the estimation is uncertain. This is analogous to the dilemma faced by investigators studying heat transfer by convection from a fluid to a bounding surface. Some, if not most, of these investigators visualize the heat transfer to the surface as a conduction mechanism that could be represented by an equation similar to Equation (4-20):

$$
-\rho C V \frac{d T}{d t}=\frac{k A_{\text {SURF }}}{\delta}\left(T-T_{S}\right)
$$

where

$$
\begin{aligned}
\mathrm{CV}= & \text { the thermal capacity of the fluid, } H / T, \\
T= & \text { the temperature of the fluid, } T, \\
T_{S}= & \text { the temperature of the bounding surface, } T, \\
k= & \text { the thermal conductivity of the fluid in the } \\
& \text { boundary layer, H/बLT. }
\end{aligned}
$$

Because of the difficulty in estimating the value of $\delta$, and the uncertainty of any such estimation, a film or convective coefficient was defined as

$$
h=\frac{k}{\delta}
$$

which is determined experimentally. Before the removal of particles from an aerosol by plateout can be determined with any reasonable accuracy, perhaps a similar film coefficient will have to be determined experimentally.

The particle balance equation [Equation (4-20)] may be rewritten as

$$
\frac{d n_{i j}}{d t}=\frac{-D_{P i j} A_{\text {SURF }} n_{i j}}{\delta V_{\text {CSK }}} .
$$




\subsubsection{Rate of Aerosol Production}

The aerosol production rate term or particle source term of Equation (4-1) represents the releases of aerosol from the fuel pins when they burst, and again if the exposed fuel oxidizes to $\mathrm{U}_{3} \mathrm{O}_{8}$. When the fuel pins first burst, the aerosol released consists of "free" fission gases and volatile solids or solid fission products (cesium compounds). Later, if the exposed fuel in the burst pins oxidize to $\mathrm{U}_{3} \mathrm{O}_{8}$, the remaining "bound up" fission gases and volatile solids are released as an aerosol.

The released quantities of aerosol contain particles of solids in several sizes, ranging from those with a minimum radius of $r_{\text {min }}$ to a maximum radius of $r_{\max }$. The number of particles is assumed to be distributed among $N_{\text {GPS }}$ size groups, according to the "self-preserving" particle size distribution function of Equation (4-2).

Seven nodes are used to represent radial increments of the fuel assemblies in the loss-of-coolant model of the IF-300 (see Figures 3-19 and 3-20). As the temperature distributions in the fuel assemblies develop with time following the loss of coolant, each of these fuel nodes will be at different temperatures. Some will reach the temperature at which the fuel pins burst before others and, if oxidation is possible, some will reach the oxidation point before others. This means that the release of aerosol from the fuel pins in the seven fuel nodes may occur at different times. It is assumed that the releases are instantaneous, that is, there is no distinguishable rate of release, but rather that the release of particles are pulsed releases which may be represented by impulse functions.

Consider a particle balance on a size group containing particles with an average radius of $r_{i j}$ which receives particles from a source, but which does not lose any particles.

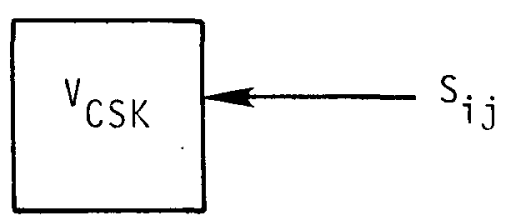


The particle balance is

$$
\frac{d n_{i j}}{d t}=S_{i j}
$$

where

$$
\begin{aligned}
S_{i j}= & \text { the rate at which particles with an average radius } \\
& \text { of } r_{i j} \text { are added to the size group, particles } / \mathrm{cm}^{3} \\
& \text { aerosol in cask } \times \text { sec. }
\end{aligned}
$$

In terms of an impulse function and the number of particles added to the aerosol in the cask, Equation (4-24) becomes

$$
\frac{d n_{i j}}{d t}=n_{S_{i j}} \delta(t) \frac{V_{N}}{V_{C S K}}
$$

where

$$
\begin{aligned}
& { }^{n_{S}}{ }_{i j}=\text { the number of particles contributed by the source, } \\
& \text { particles } / \mathrm{cm}^{3} \text { aerosol in the source. [ilote that } \\
& \text { the number of particles from the source is denoted } \\
& \text { by } n_{S_{i j}} \text { rather than } n_{i j} \text {. This is because } n_{S_{j j}} \text { is } \\
& \text { expressed as the number of particles in a } \mathrm{cm}^{3} \text { of } \\
& \text { aerosol in the source whereas } n_{i j} \text { is expressed as } \\
& \text { the number of particles in } \mathrm{a}^{3} \text { of aerosol in the } \\
& \text { cask.] } \\
& \delta(t)=\text { the Dirac impulse function, } 1 / \mathrm{sec} \\
& =0 \text { when } t<t_{B} \\
& =1 \text { when } t=t_{B} \\
& =0 \text { when } t>t_{B} \\
& t_{B}=\text { the time at which the particles are released from } \\
& \text { the source, sec, } \\
& V_{N}=\text { the volume of aerosol in the source which is re- } \\
& \text { leased to the cask, } \mathrm{cm}^{3} \text { aerosol in the source, }
\end{aligned}
$$


$V_{\text {CSK }}=$ the volume of the aerosol in the cask (assumed to be the free volume in the cask), $\mathrm{cm}^{3}$ aerosol in the cask or $\mathrm{cm}^{3}$ of cask volume.

The total number of particles contributed by the source is

$$
\int_{0}^{n_{i j}} d n_{i j}=n_{S_{i j}} \frac{v_{N}}{V_{C S K}} \int_{0}^{t} \delta(t) d t
$$

or

$$
n_{i j}=n_{S_{i j}} \frac{V_{N}}{V_{\text {CASK }}} H(t)
$$

where

$$
\begin{aligned}
H(t) & =\text { Heaviside's unit function } \\
& =0 \text { when } t<t_{B} \\
& =1 \text { when } t \geq t_{B},
\end{aligned}
$$

and $n_{i j}=0$ at $t=0$.

If there were $n_{i j o}$ particles in the size group before the contribution from the source, then the number of particles in the size group would be

$$
n_{i j}=n_{i j o}+n_{S} \frac{V_{i j}}{V_{C S K}} H(t)
$$

where

$$
n_{i j 0}=\text { the initial value of } n_{i j} \text {. }
$$

The unit function $H(t)$ is represented in the simulation model by the fuel pin clad burst switches BSWk and the fuel oxidation switches OSWk, where $k$ denotes the $k$-th fuel node.

\subsubsection{Modification of the Particle Balance Equation to Eliminate the AggTomeration Terms}

It was stated at the beginning of this section that the agglomeration or particle transfer terms in the general particle balance equation, Equation 
(4-1), could be eliminated if it is assumed that these rates are such that they maintain a particular particle size distribution throughout the life of the aerosol, provided that the same particle size distribution holds for any quantities of aerosol added to or removed from the main aerosol. A "self-preserving" particle size distribution function was chosen to represent the distribution of particles throughout the life of the aerosol. This distribution has been presented and discussed in Section 4.1.1. Terms have been derived in Section 4.1.2 that represent the rate of particle removal from the aerosol by settling and by plating out of particles on the colder surfaces bounding the aerosol. Also, a term representing the rate of aerosol production (a source term) has been derived in Section 4.1.3. It wil1 now be shown how these terms and the self-preserving particle size distribution function can be combined to eliminate the need for the agglomeration terms that represent the rate of transfer of particles from one size group to another (see Figure 4-5).

The aerosol is arbitrarily divided into several size groups, and a particle balance equation, without agglomeration terms, is written for each of these size groups. The numbers of particles in the source and removal terms are expressed in terms of the self-preserving particle size distribution function. The numbers of particles in all the other size groups are related to the number of particles in the size group considered through the volume fraction $\phi$ in the particle size distribution function.

Five particle size groups were considered, encompassing particles from a minimum radius $r_{\min }$ to a maximum radius $r_{\max }$. A size range increment for this spread of particle sizes was determined by dividing the range by the number of size groups

$$
\Delta r=\frac{r_{\max }-r_{\min }}{N_{G P S}}
$$

where

$$
\begin{aligned}
\Delta r= & \text { the particle radius increment for each size } \\
& \text { group, } L, \\
r_{\max }= & \text { the maximum particle radius considered, } L,
\end{aligned}
$$




$$
\begin{aligned}
r_{\text {min }}= & \text { the minimum particle radius considered, } L, \\
N_{\text {GPS }}= & \text { the desired number of particle size groups to be } \\
& \text { considered. }
\end{aligned}
$$

The radii bounding each of the five size groups considered are:

$$
\begin{gathered}
r_{1}=r_{\min } \\
r_{2}=r_{1}+\Delta r \\
r_{3}=r_{2}+\Delta r \\
r_{4}=r_{3}+\Delta r \\
r_{5}=r_{4}+\Delta r \\
r_{6}=r_{5}+\Delta r=r_{\max } .
\end{gathered}
$$

and

The weighted average radius of the particles in each of the five size groups is

$$
r_{i j}=\frac{\int_{r_{i}}^{r_{j}} r d n}{\int_{r_{i}}^{r_{j}} d n} \quad(i=1, \ldots, 5)(j=i+1)
$$

The "self-preserving" particle size distribution is

$$
\frac{d n}{d r}=0.05 \phi r^{-4}
$$

Substituting this into Equation (4-36) gives 


$$
\begin{aligned}
r_{i j}= & \frac{\int_{r_{i}}^{r_{j}} 0.05 \phi r^{-3} d r}{\int_{r_{j}}^{r_{j}} 0.05 \phi r^{-4} d r} \\
= & \frac{\int_{i}^{r_{j}} r^{-3} d r}{\int_{r_{i}}^{r_{j}} r^{-4} d r} .
\end{aligned}
$$

Integrating between the indicated limits

$$
r_{i j}=\frac{-\frac{1}{2}\left(\frac{1}{r_{j}^{2}}-\frac{1}{r_{i}^{2}}\right)}{-\frac{1}{3}\left(\frac{1}{r_{j}^{3}}-\frac{1}{r_{i}^{3}}\right)}
$$

or, since $r_{j}>r_{i}$

$$
r_{i j}=1.5 \frac{\left(\frac{1}{r_{i}^{2}}-\frac{1}{r_{j}^{2}}\right)}{\left(\frac{1}{r_{i}^{3}}-\frac{1}{r_{j}^{3}}\right)} .
$$

This equation can be rearranaed in the following manner: 


$$
\begin{aligned}
r_{i j}=1.5 & \frac{\left(\frac{r_{j}^{2}-r_{i}^{2}}{r_{j}^{2} r_{j}^{2}}\right)}{\left(\frac{r_{j}^{3}-r_{i}^{3}}{r_{i}^{3} r_{j}^{3}}\right)} \\
=.1 .5 & \left.\frac{\left(r_{j}^{2}-r_{i}^{2}\right)\left(r_{i} r_{j}\right.}{\left(r_{j}^{3}-r_{i}^{3}\right.}\right)
\end{aligned} .
$$

The particle balances on each of the five size groups considered are shown in Figure 4-5. Only one of the five particle balance equations will be used to illustrate how the transfer or agglomeration terms are eliminated. Consider the particle balance equation for particle size group 3, which contains particles with radii ranging from a minimum of $r_{3}$ to a maximum of $r_{4}$, with an average radius of $r_{34}$ :

$$
\begin{gathered}
\frac{\partial n_{34}}{\partial t}=S_{34}+\left(A_{-1,3}+A_{-2,3}\right)-\left(A_{-3,4}+A_{-3,5}\right)- \\
R_{S, 34}-P_{P, 34}
\end{gathered}
$$

where

$$
\begin{aligned}
\mathrm{n}_{34}= & \text { the number of particles with an average radius } \\
& \text { of } r_{34} \text { (ranging from } r_{3} \text { to } r_{4} \text { ) present in a } \\
& \text { unit volume of aerosol suspended in the cask, } \\
& \text { particles } / \mathrm{cm}^{3} \text { aerosol in cask, } \\
\mathrm{S}_{34}= & \text { the rate at which particles with an average } \\
& \text { radius of } r_{34} \text { are added to the size group } \\
& \text { upon bursting of the fuel pins (or oxidation } \\
& \text { of fuel), particles } / \mathrm{cm}^{3} \text { aerosol in cask } \times \text { sec. }
\end{aligned}
$$




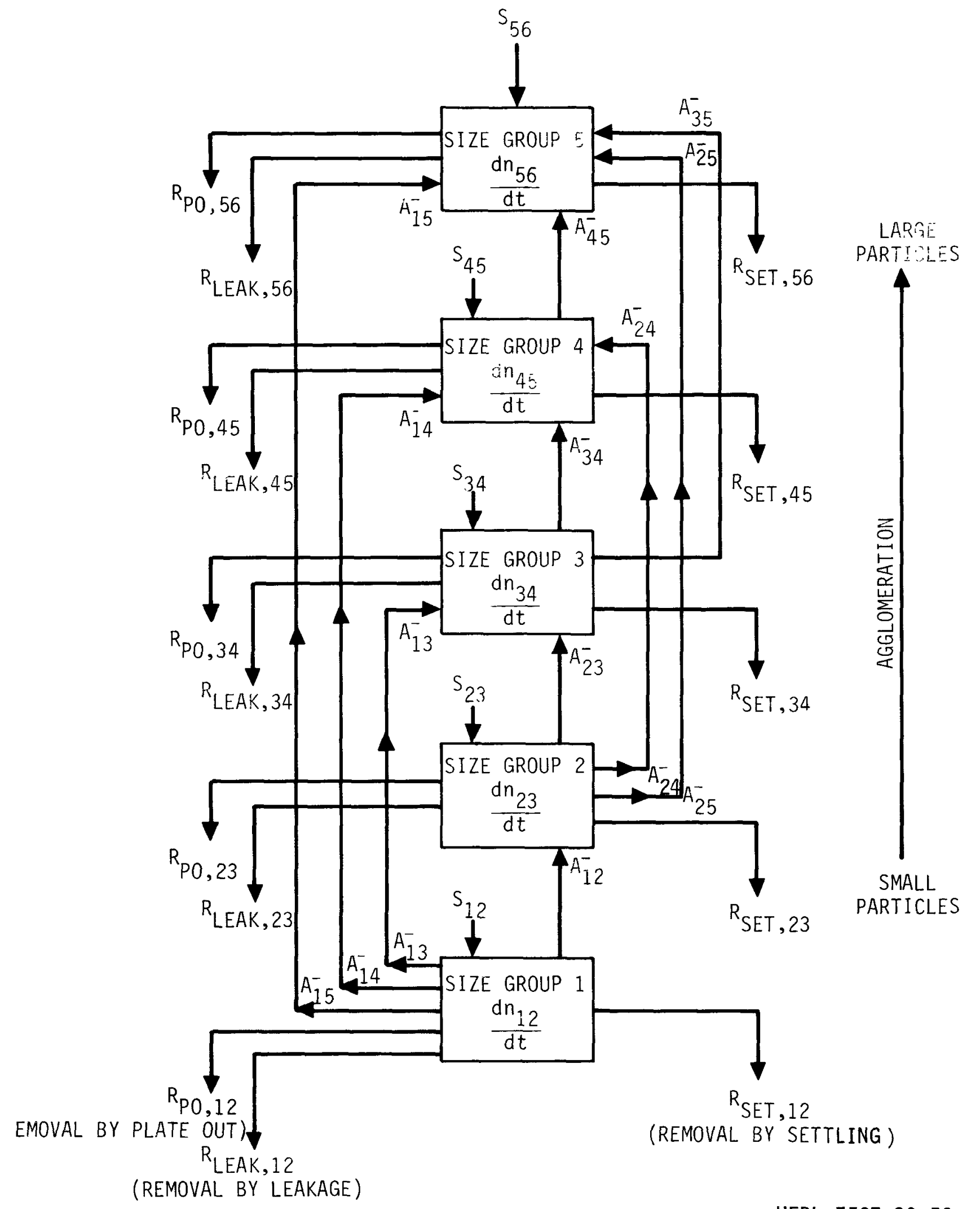

HEDL 7507-30.56

FIGURE 4-5. Particle Balances on Size Groups and Illustration of Particle Flow Between Groups. 


$$
\begin{aligned}
& R_{S, 34}=\text { the rate at which particles with an average } \\
& \text { radius of } r_{34} \text { are removed from the size } \\
& \text { group by settling, particles } / \mathrm{cm}^{3} \text { aerosol } \\
& \text { in cask } x \text { sec. } \\
& R_{P, 34}=\text { the rate at which particles with an average } \\
& \text { radius of } r_{34} \text { are removed from the size } \\
& \text { group by plateout, particles } / \mathrm{cm}^{3} \text { aerosol } \\
& \text { in cask } x \text { sec. } \\
& A_{-1,3} \text { and }=\text { the rates of formation of particles of average } \\
& A_{-2,3} \quad \text { radius } r_{34} \text { in size group } 3 \text { by agglomeration } \\
& \text { of smaller particles from size groups } 1 \text { and } \\
& 2 \text {, respectively, particles } / \mathrm{cm}^{3} \text { aerosol in } \\
& \text { cask } \times \text { sec. } \\
& A_{-3,4} \text { and = the rates at which particles of average radius } \\
& A_{-3,5} \quad r_{34} \text { in size group } 3 \text { are lost from size group } \\
& 3 \text { by agglomeration to yield the larger par- } \\
& \text { ticles of size groups } 4 \text { and } 5 \text {, respectively, } \\
& \text { particles } / \mathrm{cm}^{3} \text { aerosol in cask } x \mathrm{sec} \text {. }
\end{aligned}
$$

The transfer rates $A_{-1,3}, A_{-2,3}, A_{-3,4}$, and $A_{-3,5}$ may be eliminated from Equation (4-43) if it is assumed that they are such that the seifpreserving particle size distribution is maintained throughout the life of the aerosol. Using this assumption, the particle balance equation reduces to

$$
\frac{d n_{34}}{d t}=S_{34}-R_{S, 34}-R_{P, 34}
$$

where it is to be noted that the accumulation or storage rate is no longer a partial derivative with respect to time.

Since $n_{34}$ is the number of particles of average radius $r_{34}$ present in a unit volume of aerosol in the cask, then the total particles of this size in the cask would be 


$$
N_{34}=n_{34} V_{C S K}
$$

where

$V_{\text {CSK }}=$ the total free volume in the cask, $\mathrm{cm}^{3}$.

It is assumed that the total volume of the aerosol in the cask is the total free volume in the cask containment.

Substituting the source rate and removal rate terms defined by Equations (4-25), (4-6) and (4-23) into Equation (4-44) gives

$$
\frac{d n_{34}}{d t}=n_{S 34} \frac{V_{N}}{V_{C S K}} \delta(t)-\frac{n_{34} V_{f_{34}} A_{f}}{V_{C S K}}-\frac{D_{P 34} A_{S U R F} n_{34}}{\delta V_{C S K}} .
$$

The loss-of-coolant model of the IF- 300 consists of numerous nodes or regions connected by admittances that represent the cask as an analogous electrical network (see Figure 3-20). Seven of these nodes represent the spent fuel assemblies. Each of these seven nodes is a potential source of particles. Consequentiy, Equation (4-46) may be modified as follows:

$$
\begin{aligned}
\frac{d n_{34}}{d t} & =\sum_{k=1}^{7} n_{S, 34 k} \frac{V_{N k}}{V_{C S K}} \delta_{k}(t)-\frac{n_{34} V_{f} A_{f}}{V_{C S K}} \\
& \frac{-D_{\text {P34 }} A_{\text {SURF }} n_{34}}{\delta V_{C S K}}
\end{aligned}
$$

where

$$
k=\text { the number of fuel nodes. }
$$

The variables $n_{34}$ and $n_{S, 34 k}$ in this equation represent the number of particles in the size range $r_{3}$ to $r_{4}$ so, in a spatial sense, they may be considered to be increments. Therefore, an approximate value for these variables may be obtained from the self-preserving particle size distribution 
function, which expresses the variation of the number of particles in an aerosol with respect to particle radius

$$
\frac{d n}{d r}=0.05 \phi r^{-4}
$$

For the increment of particle size radius beginning with $r_{3}$ and ending with $r_{4}$, we can write the approximations:

$$
\frac{n_{34}}{\left(r_{4}-r_{3}\right)}=0.05 \phi r_{3}^{-4} \text {. }
$$

and

$$
\frac{n_{S, 34 k}}{\left(r_{4}-r_{3}\right)}=0.05 \phi_{k} r_{3}^{-4} \text {. }
$$

It should be recalled that the subscripts on the variables $n_{34}$ and $n_{S, 34 k}$ signify that this is the number of particles in the size range $r_{3}$ to $r_{4}$, but that a weighted average radius was used for the particles rather than trying to cope with a range of radii [see Equations (4-36) through (4-42)]. A weighted average radius was necessary to calculate the volume of the particles in a size group. This would not have been possible if only the number of particles in a size range were determined, because there would be no way of knowing the actual numbers and sizes of the particles in the size group.

The volume fraction of the disperse phase of the aerosol in the cask is

$$
\phi=\frac{V_{P}}{V_{C S K}}
$$

where

$$
\begin{aligned}
V_{p}= & \text { the volume of all the particles in all the size } \\
& \text { groups in the aerosol in the cask, } \mathrm{cm}^{3} \text { of par- } \\
& \text { ticles in the cask, }
\end{aligned}
$$


$V_{\text {CSK }}=$ the free volume inside the cask and also the volume of the aerosol in the cask containing particles in all the size groups, $\mathrm{cm}^{3}$ of aerosol in the cask.

The volume fraction of the disperse shase of the aerosol contained in the $k$-th fuel node is:

$$
\phi_{k}=\frac{V_{P k}}{V_{N k}}
$$

[See Section 4.2 Equation (4-95)]

where

$$
\begin{aligned}
V_{P k}= & \text { the volume of all the particles in all the size } \\
& \text { groups contained in the k-th fuel node, } \mathrm{cm}^{3} \text { of } \\
& \text { particles in the } k \text {-th fuel node, } \\
V_{i j k}= & \text { the volume of the aerosol in the } k \text {-th fuel node, } \\
& \mathrm{cm}^{3} \text { of aerosol in } k \text {-th fuel node. }
\end{aligned}
$$

Combining Equation (4-48) and Equation (4-50) and rearranging yields

$$
n_{34}=0.05 \frac{V_{p}}{V_{C S K}}\left(r_{4}-r_{3}\right) r_{3}^{-4}
$$

Similarly, Equations (4-49) and (4-51) may be combined to give

$$
n_{S, 34 k}=0.05 \frac{V_{P k}}{V_{N k}}\left(r_{4}-r_{3}\right) r_{3}^{-4} \text {. }
$$

The total number of particles with an average radius of $r_{34}$ has been expressed as Equation (4-45)

$$
N_{34}=n_{34} V_{\text {CSK }} \text {. }
$$

Applying the same relationship to the $k$-th fuel node gives the following equation for the total number of particles of this size in the aerosol released from the $k$-th fuel node 


$$
N_{S, 34 k}=n_{S, 34 k} V_{N k}
$$

Multiplying Equation (4-47) by $V_{C S K}$ and applying (4-45) and (4-54) gives

$$
\frac{d N_{34}}{d t}=\sum_{k=1}^{7} N_{S, 34 k} \delta_{k}(t)-\frac{V_{f 34} A_{f} N_{34}}{V_{C S K}}-\frac{D_{P 34} A_{S U R F} N_{34}}{\delta V_{C S K}}
$$

or

$$
\frac{d N_{34}}{d t}=\sum_{k=1}^{7} N_{S, 34 k} \delta_{k}(t)-\left(\frac{V_{f 34} A_{f}}{V_{C S K}}+\frac{D_{P 34} A_{S U R F}}{\delta V_{C S K}}\right) N_{34} .
$$

Also, applying Equations (4-45) and (4-54) to Equations (4-52) and (4-53), respectively, yields

$$
N_{34}=0.05 v_{p}\left(r_{4}-r_{3}\right) r_{3}^{-4}
$$

and

$$
N_{S, 34 k}=0.05 V_{P k}\left(r_{4}-r_{3}\right) r_{3}^{-4}
$$

Setting

$$
\begin{aligned}
& c_{34}=\frac{V_{f 34} A_{f}}{V_{C S K}}, \\
& D_{34}=\frac{D_{P 34} A_{\text {SURF }}}{\delta V_{C S K}},
\end{aligned}
$$

and

$$
\mathrm{CD}_{34}=\mathrm{C}_{34}+\mathrm{D}_{34},
$$


Equation (4-56) can be written as

$$
\frac{d N_{34}}{d t}=\sum_{k=1}^{7} N_{S, 34 k} \delta_{k}(t)-C_{34} N_{34} .
$$

Substituting from Equations (4-57) and (4-58) into Equation (4-62) gives:

$$
\frac{d N_{34}}{d t}=0.05\left(r_{4}-r_{3}\right) r_{3}^{-4} \sum_{k=1}^{7} v_{P k} \delta_{k}(t)-0.05 C D_{34} v_{P}\left(r_{4}-r_{3}\right) r_{3}^{-4} .
$$

Setting

$$
A_{34}=0.05 \mathrm{CD}_{34}\left(r_{4}-r_{3}\right) r_{3}^{-4}
$$

and

$$
B_{34}=0.05\left(r_{4}-r_{3}\right) r_{3}^{-4} \text {, }
$$

Equation (4-63) may be written as

$$
\frac{d N_{34}}{d t}=B_{34} \sum_{k=1}^{7} V_{P k} \delta_{k}(t)-A_{34} V_{P}
$$

The total volume of the particles in the aerosol in the cask is

$$
v_{p}=\frac{4}{3} \pi\left(r_{12}{ }^{3} N_{12}+r_{23}{ }^{3} N_{23}+r_{34}{ }^{3} N_{34}+r_{45}{ }^{3} N_{45}+r_{56}{ }^{3} N_{56}\right),
$$

and the total volume of the particles in the aerosol in the k-th fuel node is 


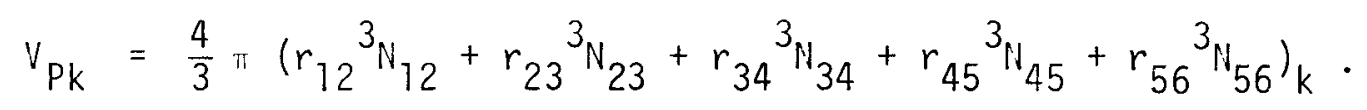

Finally, substituting these particle volumes in Equation (4-66) gives

$$
\begin{aligned}
\frac{d N_{34}}{d t}= & B_{34} \sum_{k=1}^{7} \frac{4}{3} \pi\left(r_{12}{ }^{3} N_{12}+r_{23}{ }^{3} N_{23}+r_{34}{ }^{3} N_{34}+r_{45}{ }^{3} N_{45}+r_{56}{ }^{3} N_{56}\right)_{k} \delta_{k}(t) \\
& -\frac{4}{3} \pi A_{34}\left(r_{12}{ }^{3} N_{12}+r_{23}{ }^{3} N_{23}+r_{34}{ }^{3} N_{34}+r_{45}{ }^{3} N_{45}+r_{56}{ }^{3} N_{56}\right) .
\end{aligned}
$$

In general, the modified particle balance equation for particles in the size range $r_{i}$ to $r_{j}$ may be written as

$$
\frac{d N_{i j}}{d t}=B_{i j} \sum_{k=1}^{K}\left[\sum_{i=1}^{N_{G P S}} \frac{4}{3} \pi\left(r_{i j}{ }^{3} N_{i j}\right)\right]_{k} \delta_{k}(t)-\frac{4}{3} \pi A_{i j} \sum_{i=1}^{N_{G P S}} r_{i j} 3_{N_{i j}}
$$

where

$$
\begin{aligned}
& i=1,2,3, \ldots, N_{\text {GPS }}, \\
& j=i+1 \\
& k=1,2, \ldots, k
\end{aligned}
$$

and, in the present study,

$$
N_{G P S}=5
$$

and

$$
K=7 .
$$

The derivation of Equations (4-69) and (4-70) shows that, if it is assumed that (1) the agglomeration terms (terms which represent the rate of 
transfer of particles from one size group to another) are such that a selfpreserving particle size distribution is maintained throughout the life of the aerosol, and that (2) the same self-preserving particle size distribution holds for any quantities of aerosol which may be added to or removed from the main aerosol, then the agglomeration terms may be removed from the general particle balance of Equation (4-1). The number of particles in any one size group retains its influence on the number of particles present in the other size groups through the particle size distribution function factored into the source and removal terms in the respective particle balance equations.

Integration of Equation (4-69) yields

$$
\begin{aligned}
\int_{0}^{N_{34}} d N_{34}= & \int_{0}^{t} B_{34} \sum_{k=1}^{7} \frac{4}{3}-\left(r_{12}{ }^{3} N_{12}+\ldots+r_{34}{ }^{3} N_{34}+\ldots+r_{56}{ }^{3} N_{56}\right) \delta_{k}(t) d t \\
& -\int_{0}^{t} \frac{4}{3} \pi A_{34}\left(r_{12}{ }^{3} N_{12}+\ldots+r_{34}{ }^{3} N_{34}+\ldots+r_{56}{ }^{3} N_{56}\right) d t
\end{aligned}
$$

or

$$
W_{34}=B_{34} \sum_{k=1}^{7} \frac{4}{3} \pi\left(r_{12}{ }^{3} N_{12}+\ldots+r_{56}{ }^{3} N_{56}\right)_{k} H_{k}(t)-\int_{0}^{t}(\text { LOSS })_{34} d t .
$$

The integration of Equation (4-70) yields

$$
\left.H_{i j}=B_{i j} \sum_{k=1}^{K}\left[\sum_{i=1}^{\prime K G P S} \frac{4}{3} \pi\left(r_{i j} 3_{i j}\right)\right]_{k} H_{k}(t)-\int_{0}^{t} \text { (LOSS }\right)_{i j} d t
$$


where

$$
\begin{aligned}
(\text { LOSS })_{i j}=\frac{4}{3} \pi A_{i j} \sum_{i=1}^{N_{G P S}}\left(r_{i j}{ }^{3} N_{i j}\right) \\
i=1,2,3, \ldots, N_{G P S} \\
j=i+1 \\
k=1,2, \ldots, k .
\end{aligned}
$$

Setting

$$
\text { NIN }_{i j}=B_{i j} \sum_{k=1}^{K}\left[\sum_{i=1}^{N} \frac{4}{3} \pi\left(r_{i j}{ }^{3} N_{i j}\right)\right]_{k} H_{k}(t),
$$

and

$$
\text { NOUT }_{i j}=\int_{0}^{t}(\text { LOSS })_{i j} d t \text {, }
$$

the integrated particle balance equation becomes

$$
N_{i j}=N I N_{i j}-\text { NOUT }_{i j} \text {. }
$$

The unit functions $H_{k}(t)$ are represented in the simulation model by the fuel pin clad burst switches BSWk and the fuel oxidation switches OSWK, where $k$ denotes the $k$-th fuel node (see Figures $4-1$ and 4-2).

The total mass of the particles in the aerosol remaining in suspension in the cask is:

$$
\text { IIASS }=\sum_{i=1}^{N_{G P S}} M_{i j} N_{i j} \text {, }
$$


and the total activity of the particles in suspension is

$$
\text { ACTVTY }=\sum_{i=1}^{N G P S} A C T_{i j} N_{i j} \text {, }
$$

where

$$
\begin{aligned}
M_{i j}= & \text { the mass of an average particle in the size range } \\
& r_{i} \text { to } r_{j} \text {, grams/particle } \\
\text { ACT }_{i j}= & \text { the activity of an average particle in the size } \\
& \text { range } r_{i} \text { to } r_{j}, \text { curies/particle. }
\end{aligned}
$$

Equations (4-73) through (4-79) are programmed as the transient portion of the simulation model VSøL (see the MIMIC simulation program listing of VSQL in Figure 4-2).

\subsubsection{Proposed Modification of the Model to Include Particle Removal by Leakage from the Cask}

It was stated earlier that a particle leakage term was not included in the present model but that, since this model was completed, a leakage term has been developed which will be included in the model during the next development phase. The development of this leakage term and the procedure for adding it to the present model are presented in this section.

The key variable in the proposed leakage term is the velocity of the mixture of residual coolant vapor and fission gases flowing from the breach opened in the cask containment at impact. This velocity will be obtained from proposed additions to the Loss-of-Coolant models described in Section 3 . The proposed modifications to the Loss-of-Coolant models are presented in Section 3.5.3. The velocity of the gas mixture leaking from the gap is defined by Equation (3-102).

\subsubsection{Particle Removal by Leakage}

The term for particle removal from the aerosol in the cask by leakage is very similar to the term for particle removal by settling. Like the settling term, the leakage term is based on the assumption that the aerosol in the cask is well-stirred, i.e., that the concentration of particles in 
each of the size groups considered is the same everywhere in the free volume in the cask. Also, it is assumed that this applies to the gas volume flowing through the breach。

Consider a particle balance on the size group containing particles with an average radius of $r_{i j}$, with no source of particles and with the only loss of particles due to leakage from the breach.

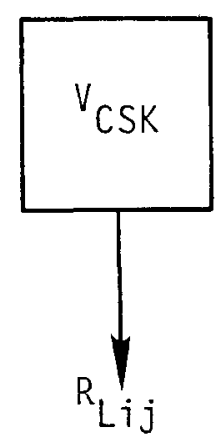

$$
\left[\begin{array}{l}
\text { Rate of Change of } \\
\text { Number of Particles } \\
\text { in the Size Group }
\end{array}\right]=[\text { Input Rate }]-[\text { Output Rate }]
$$

or

$$
\frac{d n_{j j}}{d t}=0-R_{L i j}
$$

where

$$
\begin{aligned}
R_{L i j}= & \text { the rate at which particles with an average radius } \\
& \text { of } r_{i j} \text { are removed from the aerosol due to leakage } \\
& \text { from the breach, particles } / \mathrm{cm}^{3} \text { aerosol } \times \mathrm{sec} .
\end{aligned}
$$

The rate at which the particles pass through the breach and escape from the cask is

$$
R_{L i j}=\frac{n_{i j} u A_{G A P}}{V_{C S K}}
$$


where

$u=$ the velocity of the mixture of fission gases and residual coolant vapor flowing through the breach, $\mathrm{cm} / \mathrm{sec}$,

$A_{G A P}=$ the cross-sectional or flow area of the breach, $\mathrm{cm}^{2}$.

It is assumed that the particles will be traveling at the same velocity as the gas mixture, i.e., there is no slip or drag.

The particle balance, Equation (4-81), may now be written as

$$
\frac{d n_{i j}}{d t}=\frac{n_{i j} u A_{G A P}}{V_{C S K}} .
$$

The velocity $u$ is defined by Equation (3-102) of Section 3.5 .3

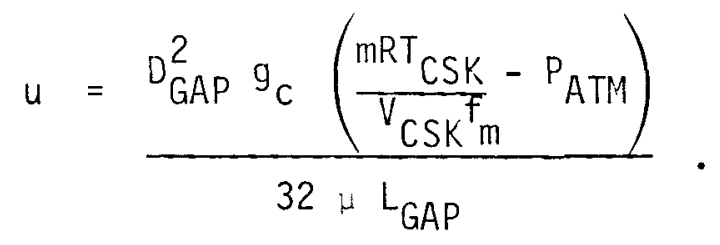

\subsubsection{Modification of the Particle Balance Equations and the Model} to Include the Leakage Term

There are five particle balance equations in the model, one for each of five particle size groups considered. In Section 4.1.4, only one of these was used to illustrate how the transfer or agglomeration terms are eliminated. The same approach will be used here to show how the particle balance equations will be modified to include the leakage term of Equation $(4-83)$.

Consider the reduced particle balance equation for particle size group 3 , which contains particles with radii ranging from a minimum of $r_{3}$ to a maximum of $r_{4}$, with an average radius of $r_{34}$ :

$$
\frac{d n_{34}}{d t}=S_{34}-R_{S, 34}-R_{p, 34} .
$$


This equation is a reduced form of Equation (4-43), which includes agglomeration terms. It was assumed that the agglomeration terms could be eliminated if they were such that the self-preserving particle size distribution [see Equation (4-2)] is maintained throughout the life of the aerosol.

Including the loss rate due to leakage, Equation (4-44) is changed to:

$$
\frac{d n_{34}}{d t}=S_{34}-R_{S, 34}-R_{P, 34}-R_{L, 34} .
$$

Substituting the source rate term defined by Equation (4-25), and the settling, plateout and leakage removal rate terms defined by Equations $(4-6),(4-23)$, and $(4-83)$, respectively, into Equation (4-84) gives

$$
\frac{d n_{34}}{d t}=n_{S, 34} \frac{V_{N}}{V_{C S K}} \delta(t)-\frac{n_{34} V_{f 34} A_{f}}{V_{C S K}}-\frac{D_{\text {P34 }} A_{\text {SURF }} n_{34}}{V_{C S K}}-\frac{n_{34} u A_{G A P}}{V_{C S K}} .
$$

Since each of the seven fuel nodes in the loss-of-coolant model of the IF-300 is a potential source of particles, the source term is written in a form to include all the fuel nodes, and Equation (4-85) becomes

$$
\frac{d n_{34}}{d t}=\sum_{k=1}^{7} n_{S, 34 k} \frac{V_{\text {Nk }}}{V_{\text {CSK }}} \delta_{k}(t)-\frac{n_{34} V_{f 34} A_{f}}{V_{C S K}}-\frac{D_{P 34} A_{S U R F} n_{34}}{V_{C S K}}-\frac{n_{34} u A_{G A P}}{V_{C S K}} .
$$

The total number of particles in the aerosol in the cask, with an average radius $r_{34}$, has been defined by Equation (4-45) in Section 4.1.4 as

$$
N_{34}=n_{34} V_{\text {CSK }}
$$

Similarly, the total number of particles of this size in the aerosol released from the $k$-th fuel node has been defined as 


$$
N_{S, 34 k}=n_{S, 34 k} V_{N k}
$$

iultiplying Equation (4-86) by $V_{C S K}$, applying (4-45) and (4-54), and rearranaing, gives

$$
\frac{d i_{34}}{d t}=\sum_{k=1}^{7} N_{S, 34 k} \delta_{k}(t)-\left(\frac{V_{f 34} A_{f}}{V_{C S K}}+\frac{D_{P 34} A_{S U R F}}{\delta V_{C S K}}+\frac{u A_{G A P}}{V_{C S K}}\right) N_{34} .
$$

From Section 4.7.4,

$$
\dot{c}_{34}=\frac{V_{f 34} A_{f}}{V_{C S K}}
$$

and

$$
D_{34}=\frac{D_{P 34} A_{\text {SURF }}}{\delta V_{\text {CSK }}} \text {. }
$$

Setting

$$
L_{34}=\frac{u A_{G A P}}{V_{C S K}}
$$

and

$$
\mathrm{CD}_{34}=\mathrm{C}_{34}+\mathrm{D}_{34}+\mathrm{L}_{34},
$$

Equation (4-87) may be written as

$$
\frac{d i_{34}}{d t}=\sum_{k=1}^{7} i_{S, 34 k} \delta_{k}(t)-\mathrm{CD}_{34} \mathrm{~N}_{34},
$$

which is the same as Equation (4-62) in Section 4.1.4. The development of this equation to the final form used [Equation (4-69)], and to the general equation for all size groups [Equation (4-70)], is carried out as outlined earlier in the remainder of Section 4.1.4. 
The modification of the general particle balance equation, and of the model, to include a term for particle removal by leakage turns out to be quite simple. The leakage term only changes the equation for $C_{i j}$. An additional slight change would have to be made to the model to input the velocity $u$ as a function of time, as obtained from the loss-of-coolant model.

\subsection{Supplementary Equations and Procedures}

\subsubsection{The Volume Fraction of the Disperse Phase of the Aerosol} Contained in the k-th Fuel Node

The number of fuel pins in the k-th fuel node (in this case, representing seven fuel assemblies) is

$$
P_{k}=N_{P I N S} S_{k}
$$

where

$$
\begin{aligned}
P_{k}= & \text { the number of fuel pins in node } k \text {, pins/node, } \\
N_{\text {PINS }}= & \text { the number of pins in a unit area of fuel assembly, } \\
& \text { pins } / \mathrm{cm}^{2}, \\
S_{k}= & \text { the cross-sectional area of fuel assembly in fuel } \\
& \text { node } \mathrm{k}, \mathrm{cm}^{2} \text { assembly/node. }
\end{aligned}
$$

The volume of volatile solids or solid fission products in the k-th fuel node is

$$
V_{P k}=V_{P I N} P_{k}
$$

where

$$
\begin{aligned}
V_{P k}= & \text { the volume of volatile solids in the } \mathrm{k} \text {-th fuel node, } \\
& \mathrm{cm}^{3} \text { particles/node, } \\
V_{P I N}= & \text { the volume of volatile solids in a pin, } \mathrm{cm}^{3} \text {-particles/ } \\
& \text { pin. }
\end{aligned}
$$


The volume of void space in the fuel pins in the $k$-th node is

$$
V_{G K}=P_{k} \text { VOID }
$$

where

$V_{G k}=$ the volume of void space in the pins in the $k-t h$ node, $\mathrm{cm}^{3}$ of void space/node,

VOID = the volume of void space in a fuel pin, $\mathrm{cm}^{3}$ of void space/pin.

The total volume of aerosol in all the fuel pins in the $k$-th node is

$$
V_{\text {Nk }}=V_{G k}+V_{P k}
$$

where

$V_{\text {ivk }}=$ the total volume of aerosol in the $k$-th fuel node, $\mathrm{cm}^{3}$ aerosol in the $\mathrm{k}$-th node.

Finally, the volume fraction of the disperse phase of the aerosol contained in the $k$-th fuel node is

$$
\phi_{k}=\frac{V_{P k}}{V_{N k}} .
$$

\subsubsection{Calculation of the Volume, liass and Activity of Average Particles in the Size Range $r_{i}$ to $r_{j}$}

\subsubsection{The Weighted Average Volume}

The determination of the mass and activity of a particle in the size range $r_{i}$ to $r_{j}$ was based on a weighted average volume, since this produced slightly higher values than those obtained using the weighted average radius of Equation (4-42). The weighted average volumes determined by the method in this section were about 22 percent higher in the size group containing the smallest particles and about 0.3 percent higher in the size group containing the largest particles. 
The weighted average volume, using the weighted average radius of Equation (4-42), was determined from Equation (4-96),

$$
v_{i j}=\frac{4}{3} \pi r_{i j}^{3}
$$

The weighted average volume used in the model was based on the assumption that the volume could be weighted according to the number of particles of each size present in the range considered, as shown in Equation (4-97),

$$
v_{i j}=\frac{\int_{r_{j}}^{r_{j}} v d n}{\int_{r_{i}}^{r_{j}} d n}
$$

where

$$
\begin{aligned}
V_{i j}= & \text { the average volume of the particles in the size range } \\
& r_{i} \text { to } r_{j}, \text { weighted according to the number of par- } \\
& \text { ticles of each size present in the range, } \mathrm{cm}^{3} / \text { particle, } \\
V= & \text { the volume of a particle, } \mathrm{cm}^{3} / \text { particle, } \\
n= & \text { the number of particles of volume } V \text {, particles. }
\end{aligned}
$$

The volume $V$ of a particle, assumed to be spherical, is

$$
V=\frac{4}{3} \pi r^{3}
$$

Using the self-preserving particle size distribution function, Equation (4-2), and Equation (4-98), Equation (4-97) may be rewritten as 


$$
v_{i j}=\frac{\int_{r_{i}}^{r_{j}}\left(\frac{4}{3} \pi r^{3}\right)\left(0.05 \phi r^{-4} d r\right)}{\int_{r_{i}}^{r_{j}}\left(0.05 \phi r^{-4} d r\right)}
$$

or

$$
v_{i j}=\frac{\frac{4}{3} \pi \int_{r_{i}}^{r} \frac{d r}{r}}{\int_{r_{i}}^{r} r^{-4} d r} .
$$

Finally, carrying out the integrations in Equation (4-100), the weighted average volume becomes

$$
v_{i j}=\frac{4 \pi \ln \frac{r_{j}}{r_{i}}}{\left(\frac{1}{r_{i}^{3}}-\frac{1}{r_{j}^{3}}\right)} \text {. }
$$

\subsubsection{Calculation of the ilass and Activity of an Average Particle}

Of all the potentially volatile solids in PWR fuel, there is more cesium present than all the others combined. This cesium is not present as the metal, but probably exists as various chemical compounds, including several oxides, the molybdenite, the iodide, the uranate and diuranate, and the zirconate. The temperature at which the pins burst, following loss of primary coolant from the IF-300, is about $921^{\circ} \mathrm{F}$ and the pressure is about 1896 psia. It was assumed that, when the pins burst, particles 
of these compounds would be released with the fission gases. Since the relative amounts of the compounds present were unknown, it was convenient to assume that they could be considered to be the oxide, $\mathrm{Cs}_{2} \mathrm{O}$.

Experimental data show that it is unlikely that more than one percent of the total cesium in all of the fuel pins will migrate to the pin void space during reactor operation and that, of this amount, less than one percent would be released under conditions postulated to occur in a severe transportation accident.

General Electric's analysis of the release of fission products from the spent fuel in the IF-300 ${ }^{(1)}$ was limited to the release of the fission gases $I$, $K r$, and $X e$; consequently, the fission product inventories presented in Reference (1) did not include cesium. An estimate of the amount of cesium present in the PWR spent fuel was derived from fission product inventories for spent Diablo Canyon reference fuel that had been cooled 90 days. (14) A small correction factor was applied to these data to account for differences in exposure. The fission product inventories for the Design Basis PWR 1 spent fuel of Reference (1), and the spent Diablo Canyon reference fuel of Reference (14) are compared in Table 3-1.

The mass and activity of the cesium are calculated as follows. From Table 3-1, the mass of the cesium in the Design Basis PIVR 1 spent fuel is about $2910 \frac{\text { grams }}{\text { MTU }}$, the mass of uranium in a fuel assembly is $457 \mathrm{kgU}$, and the number of PWR fuel assemblies carried by the IF-300 is 7 . Therefore, the mass of the cesium in the cask is

$$
\begin{aligned}
i(C s) & =\left(2910 \frac{\text { grams }}{M T U}\right)\left(\frac{\text { MTU }}{10^{3} \mathrm{kgU}}\right)\left(457 \frac{\mathrm{kgU}}{\text { Assemb Ty }}\right) \quad(7 \text { assemb } 1 \text { ies }) \\
& =9310 \text { grams. }
\end{aligned}
$$

Also, from Table 3-1, the activity of the cesium in the Design Basis fuel is about $353,000 \frac{\mathrm{Ci}}{\mathrm{MTU}}$. Therefore, the activity of the cesium in the cask is

$$
\begin{aligned}
A(C s) & =\left(353,000 \frac{C i}{M T U}\right)\left(\frac{M T U}{10^{3} \mathrm{kgU}}\right)\left(457 \frac{\mathrm{kgU}}{\text { Assembly }}\right)(7 \text { assemb lies }) \\
& =1.13 \times 10^{6} \mathrm{Ci} .
\end{aligned}
$$


It was assumed that the cesium is released from the fuel pins as the oxide $\mathrm{Cs}_{2} \mathrm{O}$. The atomic weight of $\mathrm{Cs}$ is $133 \frac{\text { grams }}{\text { gram-atom }}$, and the molecular weight of $\mathrm{Cs}_{2} \mathrm{O}$ is $282 \frac{\text { grams }}{\text { gram-mole }}$. Therefore, if all the cesium in the fuel in the cask is assumed to be in the form of $\mathrm{Cs}_{2} \mathrm{O}$, the mass of the oxide in the cask would be

$$
M\left(\mathrm{Cs}_{2} 0\right)=\frac{(9310 \text { grams })(282)}{(2)(133)}=9870 \text { grams } .
$$

The number of curies in a gram of $\mathrm{Cs}_{2} \mathrm{O}$ is

$$
C_{P M}=\frac{1.13 \times 10^{6} \mathrm{Cj}}{9870 \mathrm{grams} \mathrm{Cs}_{2} 0}=114.6 \frac{\text { curies }}{\text { gram }} \text {. }
$$

Less than one percent of the total cesium in the fuel will migrate to the pin voids during reactor operation, and only one percent of this amount will be released when the fuel pins burst. Therefore, the maximum amount of $\mathrm{Cs}_{2} \mathrm{O}$ that might be released from the spent fuel would be

$$
M_{\text {TOTIN }}=(0.0001) M\left(\mathrm{Cs}_{2} 0\right)=0.987 \text { grams }
$$

with a total activity of

$$
A_{\text {TOTIN }}=(0.0001) A(C s)=113 \text { curies } .
$$

The mass of an average particle of $\mathrm{Cs}_{2} \mathrm{O}$ in the size range $r_{i}$ to $r_{j}$ would be

$$
M_{i j}=\rho V_{i j}
$$

where

$$
M_{i j}=\text { the mass of the average particle, } \frac{\text { grams }}{\text { particle }} \text {, }
$$


$v_{i j}=$ the weighted average volume of the average particle as defined by Equation (4-101), $\mathrm{cm}^{3} /$ particle, $\rho=$ the density of $\mathrm{Cs}_{2} 0$, grams $/ \mathrm{cm}^{3}$.

The activity of an average particle in the size range $r_{j}$ to $r_{j}$ would be

$$
A C T_{i j}=C_{P M} M_{i j}
$$

\subsubsection{Correction Factor Required for the Calculation of the Mass and Activity of an Average Particle}

The number of particles in the size range $r_{i}$ to $r_{j}$ present as an aerosol in the k-th fuel node is obtained from the following form of the selfpreserving particle size distribution function

$$
\begin{aligned}
N_{i j k}= & 0.05 \phi_{k} V_{N k}{ }_{A S S Y} r_{i}^{-4}\left(r_{j}-r_{i}\right), \\
& (i=1, \ldots, 5)(j=i+1)(k=1, \ldots, K)
\end{aligned}
$$

where

$$
\begin{aligned}
& N_{i j k}=\text { the number of particles in the size range } r_{i} \text { to } r_{j} \\
& \text { present in the } k \text {-th fuel node, particles, }=n_{i j k} V_{i v k} \text {, } \\
& \phi_{k}=\text { the volume fraction of the disperse phase of the } \\
& \text { aerosol in the k-th fuel node [See Equation (4-95)], } \\
& \frac{\mathrm{cm}^{3} \text { of particles in } \mathrm{k}-\mathrm{th} \text { fuel node }}{\mathrm{cm}^{3} \text { of aerosol in } \mathrm{k} \text {-th fuel node }} \text {, } \\
& V_{\text {Ilk }}=\text { the volume of the aerosol in the } k \text {-th fuel node, } \\
& \mathrm{cm}^{3} \text { aerosol in the } \mathrm{k} \text {-th fuel node, } \\
& \mathrm{N}_{\text {ASSY }}=\text { the number of fuel assemblies in the cask. }
\end{aligned}
$$

The total mass of the particles available in all the size groups and fuel nodes would be 


$$
\begin{gathered}
i_{\text {TOT }}=\sum_{i=1}^{N} \sum_{k=1}^{N} N_{i j k} N_{i j}, \\
\left(i=1, \ldots, N_{G P S}\right)(j=i+1)(k=1, \ldots, K) .
\end{gathered}
$$

When the total mass of the $\mathrm{Cs}_{2} \mathrm{O}$ calculated from Equation (4-105) was compared with the known mass, MOTIN, they were not the same. After a study of all the factors involved, it was concluded that the difference was somehow due to the discretization or lumping of the particles into size increments and representing them by a weighted average radius and volume. It was decided that the simplest way to correct the discrepancy would be to apply a correction factor based on the difference between MTOTIN and $\mathrm{N}_{\text {TOT }}$.

The correction factor, FACT, was defined as shown in Equation (4-106):

$$
\text { FACT }=1+\frac{\text { MOTIN }_{\text {TOMTOT }}}{M_{\text {TOTIN }}} .
$$

$M_{\text {TOT }}$ is repeatedly calculated at time zero, using Equations (4-101), (4-102), (4-104) and (4-105), and compared to MTOTIN. As long as

$$
\left|M_{\text {TOTIN }}-M_{\text {TOT }}\right|<1
$$

the simulation time is held at zero and the correction factor of Equation $(4-106)$ is applied. As soon as

$$
\left|M_{\text {TOTIN }}-M_{\text {TOT }}\right| \geq 1
$$

the iteration is stopped, the last value of ${ }^{M} \mathrm{TOT}$ accepted, and the simulation time advanced.

Unfortunately, the correction factor FACT was applied to Equation (4-104), which alters the number of particles injected into the aerosol from 
the fuel regions. This implies that the self-preserving particle size distribution function somehow is in error. This is unfortunate since this distribution function is believed to be a valid representation of the particle size distribution in the aerosol produced. The correction factor should have been applied to the weighted average volume defined by Equation (4-101). The weighted average volume of particles in the size range $r_{j}$ to $r_{j}$ is based on the discretization or lumping of the particles into several size groups. This lumping of particles into size groups, where the particles are assigned an average radius and volume, is believed to be the source of the difference between the calculated and known total mass of the cesium. A simple readjustment will be made later in the simulation model to apply the correction factor to the weighted average volume rather than to the number of particles in a size group.

The total activity of the particles available in all the size groups and fuel nodes would be

$$
\begin{gathered}
A_{\text {TOT }}=\sum_{i=1}^{N_{\text {GPS }}} \sum_{k=1}^{K} N_{i j k} A_{i j} \\
\left(i=1, \ldots, N_{\text {GPS }}\right)(j=i+1)(k=1, \ldots, K) \\
A_{\text {TOT }}=C_{\text {PM }} M_{\text {TOT }}
\end{gathered}
$$

or

\subsubsection{Calculation of the Number of Average Particles Available: Total, Free and Bound up}

The total number of particles in the size range $r_{i}$ to $r_{j}$ available as an aerosol in the $k$-th fuel node is obtained from Equation (4-104) (see Section 4.2 .2 .3 )

$$
N_{i j k}=0.05 \phi_{k} V_{N_{k}} N_{A S S Y} r_{i}^{-4}\left(r_{j}-r_{i}\right) \text {. }
$$


The total number of free particles, in the size range $r_{i}$ to $r_{j}$ in the void spaces of the fuel pins in the $k$-th node, released when the pin clads burst is

$$
N_{B i j k}=F_{R} F_{S O L} N_{i j k}
$$

where

$$
\begin{aligned}
F_{S O L}= & \text { the fraction of the inventory of the total cesium } \\
& \text { in the fuel that migrates to the pin voids during } \\
& \text { reactor operation, } \\
F_{R}= & \text { the fraction of the cesium migrated to the pin } \\
& \text { voids that is released with the fission gases } \\
& \text { when the pin clads burst. }
\end{aligned}
$$

The total number of particles in the size range $r_{j}$ to $r_{j}$ in the $k$-th fuel node, bound up in the fuel and released only after the fuel is oxidized to the granular $\mathrm{U}_{3} \mathrm{O}_{8}$, is

$$
N_{\text {Oxijk }}=F_{R}\left(1-F_{S O L}\right) N_{i j k} \text {. }
$$




\section{REFERENCES}

1. Design and Analysis Report, IF-300 Shipping Cask, NED0-10084-1, General Electric Company, Nuclear Fuel Department, February 1973.

2. Conceptual System Description - LMFBR Spent Fuel Shipping Cask System, AMCO-05-M-01, Aerojet Manufacturing Company, FulTerton, California, February 1972.

3. Sansom, F.J., and H. E. Peterson, MIMIC Programming Manual, Technical Report SEG-TR-67-31, Systems Engineering Group, Aeronautical Systems Division, Air Force Systems Command, Wright-Patterson Air Force Base, Ohio, July 1967.

4. Dray, B.J., Thermo-Physics Technical Note No. 57: Thermal Analyzer Program (TAP) User's Manual, FORTRAiv-II Version, NAA-SR-MEMD-11812, North American Aviation Inc., Canoga Park, California, January 11 , 1966.

5. Code of Federal Regulations: Title 10, Office of Federal Register, National Archives and Records Service, General Services Administration, Washington, D.C., 1971.

6. Potential Radiological Implications of Nuclear Facilities in the Upper Mississippi River Basin in the Year 2000, WASH-1209, Division of Reactor Technology, U.S. Atomic Energy Commission, January 1973.

7. Shappert, L.B., Cask Designer's Guide, ORNL-NSIC-68, Oak Ridge National Laboratory, Oak Ridge, Tennessee, February 1970.

8. Current Status and Future Technical and Economic Potential of Light Water Reactors, WASH-7082, Tab7e 5-7, pp. 5-6, Division of Reactor Development and Technology, U.S. Atomic Energy Commission, Washington, D.C., March 1968.

9. Moody, F.J., Maximum Flow Rate of a Single-Component, Two-Phase Mixture, APED-4378, General ETectric Company, Atomic Power Equipment Department, San Jose, California, October 25, 1963.

10. Dowtherm Heat Transfer Fluids, Dow Chemical Co., 1971.

11. Bunch, W.L., and L.D. 0'De11, Fission Product Inventory and Decay Heat Associated with FTR Fuel, BNWL-967, Battelle Memorial Institute, Pacific Northwest Laboratory, Richland, Washington, February 1969.

12. Fish, B.R., G.W. Keilholtz, W.S. Snyder, and S.D. Swisher, Calculation of Doses Due to Accidentally Released Plutonium from an LMFBR, ORNL-NSIC-74, Oak Ridge National Laboratory, Oak Ridge, Tennessee, November 1972 . 
13. Davis, R. J., A ivuclear Safety Particle Primer, ORNL-4337, Oak Ridge National Laboratory, Oak Ridge, Tennessee, January 1969.

14. Siting of Fuel Reprocessing Plants and Waste Management Facilities, USAEC Report ORNL-4451, Oak Ridge National Laboratory, Oak Ridge, Tennessee, July 1970.

15. Fields, S.R., Transient Temperatures and Inelastic Thermal Stresses in Gas-Cooled Perforated Ceramic Cvclinders with Internal Heat Generation, thesis submitted to Oregon State University as partial fulfillment of requirements for the Professional Degree of Chemical Engineer, April $20,1962$.

16. Stoever, H.J., Applied Heat Transmission, McGraw-Hill Book Company, New York, 1947.

17. Jakob, M., Heat Transfer, Vol. 1, John Wiley and Sons, New York, 1958.

18. Salmon, R., A Computer Code for Calculating the Cost of Shipping Spent Reactor Fuels as a Function of Burnup, Specific Power, Cooling Time, Fuel Composition, and Other Variables, ORNL-3648, Oak Ridge National Laboratory, Oak Ridge, Tennessee, August 1964.

19. Dutt, D.S., et a1., "A Correlated Fission Gas Release Model for Fast Reactor Fuels," American Nuclear Society Transactions, Vo1. 15, No. 1, pp. 198-9, 1972 annual meeting, Las Vegas, Nevada, June 18-22, 1972.

20. Nichols, J. P., and D. R. Winkler, A Program for Calculating Optimum Dimensions of Alpha Radioisotope Capsules Exposed to Varying Stress and Temperature, ORIV-TM-1735, Oak Ridge National Laboratory, Oak Ridge, Tennessee, April 1967.

21. ASME Boiler and Pressure Vessel Code, Case 1331-5.

22. Allen, J., "The Release of Iodine from Uranium Dioxide Fuel," British Nuclear Energy Society Journal, 6(2), pp. 127-133, 1967.

23. Nuclear Safety Program Annual Progress Report for Period Ending December 31, 1967, 0RNL-4228, Oak Ridge National Laboratory, Oak Ridge, Tennessee, 1968.

24. Morrison, D. L., W. A. Carbiener and R. L. Ritzman, "Evaluation of the Applicability of Existing Data to the Analytical Description of a Nuclear-Reactor Accident," BMI-1856, Quarterly Progress Report for October through December 1968, January 1, 1969.

25. fqueous Processing of LMFBR Fuels - Technical Assessment and Experimental Program Definition, ORNL-4436, Chemical Technology Division, Oak Ridge National Laboratory, Oak Ridge, Tennessee, June 1970.

26. Blackburn, P.E., J. Weissbart, and E. A. Gulbransen, Oxidation of Uranium Dioxide, Vol . 62, p. 902, August 1958. 
27. Serkirz, A.W., and E. C. Lusk, "Shipping Container Design for Fire Accident Protection, Minimum Restriction to Decay Heat Removal," Proceedings of the Third International Symposium on Packaging and Transportation of Radioactive Materials, CONF-710801, V01. 2, U. S. Department of Commerce, Washington, D.C., August 1971.

28. Perry, J. H., Editor, Chemical Engineer's Handbook, 3rd Edition, McGraw-Hi11 Book Co., New York 1950.

29. Lay, J. E., Thermodynamics, A Macroscopic-Microscopic Treatment, Charles E. Merri11 Books, Inc., Columbus, Ohio, 1963.

30. Pritzker, A. A. B., Users Manual for GERT Simulation Program, ERC-10209, National Aeronautics and Space Administration, University of Arizona, undated.

31. Lang, S. M., F. P. Knudsen, C. L. Fillmore, and R. S. Roth, "High Temperature Reactions of Uranium Dioxide with Various Metal Oxides," National Bureau of Standards Circular 568, Government Printing Office, Washington, D.C., February 20, 1956.

32. Environmental Survey of Transportation of Radioactive Materials to and from Nuclear Power Plants, WASH 1238, Directorate of Regulatory Standards, U. S. Atomic Energy Commission, December 1972.

33. Sim, R., and A. Veca, FFTF Fuel Pin Final Design Support Document, FCF-213, Advanced Reactor Division, Westinghouse Electric Corporation, December 10, 1971.

34. Fields, S. R., Simulation of the Mechanical Behavior of a Spent Fuel Shipping Cask in a Rail Accident Environment, HEDL-TME 76-18, Hanford Engineering Development Laboratory, Richland, Washington, February 1977. 
$\underline{\text { UC-71 }}$ (157)

ERDA-PL (2)

Manager

Chief Paterit Attorney

FFTF-PO (5)

Director

$\underline{\mathrm{RDD}-\mathrm{HQ}}$ (2)

Director

HEDL (43)

R. A. Bennett

F. G. Blasewitz

W. L. Eunch

T. T. Claudson

R. E. Eaht

E. A. Evans

S. R. Fields (2)

J. F. Fletcher

E. N. Greene

J. P. Hale

J. J. Holmes

L. D. Jacobson

H. G. Johnson

R. E. Keyes

W. C. Kinsel

R. L. Knecht

SPECIAL DISTRIBUTION（22）

Mr. William A. Brobst, Chief

Transportation Branch

Division of Environmental Control Technology ERDA

M.S. F-309

Washington, D. C. 20545
W. W. Little

J. Muraoka

D. C. Norquist

R. P. Omberg

D. E. Peterson

R. E. Peterson

R. E. Schenter

P. F. Shaw

V. F. Sheely

J. C. Sonnichsen

A. Squire

H. H. Yoshikawa Central Files (10)

Document Control (2)

Technical Publications (2)
Dr. Jerry Counts

Transportation Branch

Division of Environmental Control Technology ERDA

M.S. F-309

Washington, D. C. 20545 


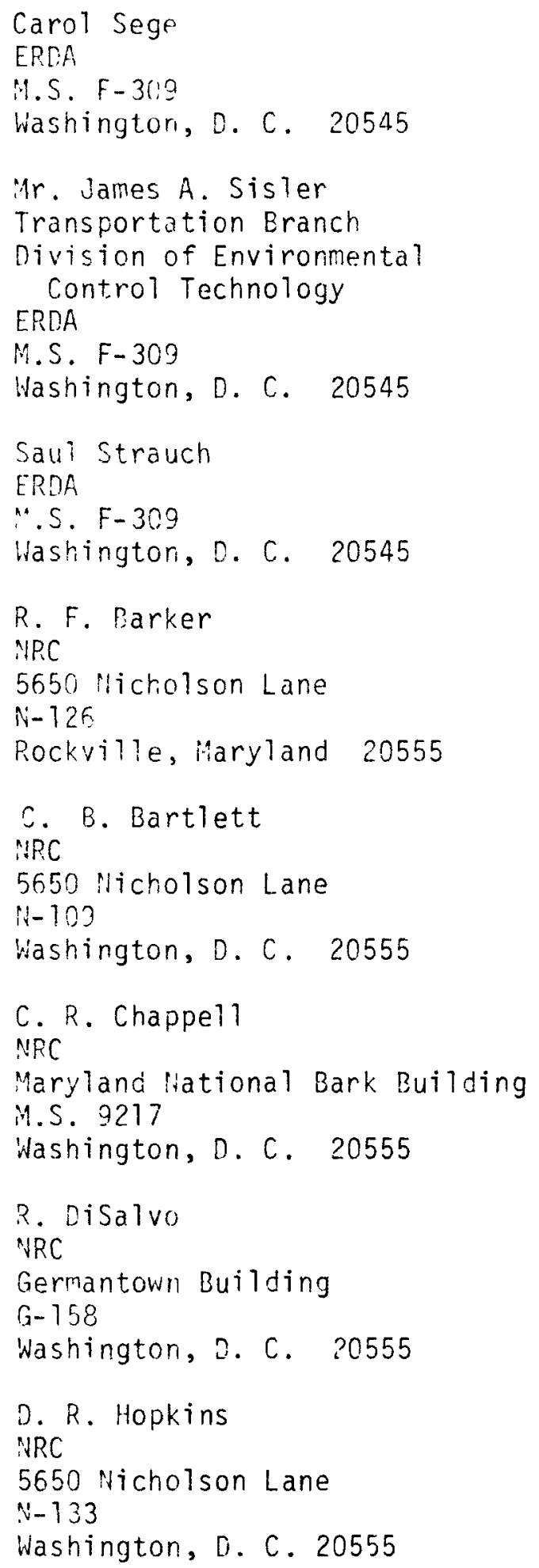

U. V. Johnston

NRC

Germantown Building

G- 158

Washington, D. C. 20555

William Lahs

MRC

5650 Nicholson Lane

$\mathrm{N}-107$

Washington, D.C. 20555

W. H. Lake

NRC

Maryland iational Bank Building i.s. 9217

Washington, D.C. 20555

C. B. MacDonald

NRC

Maryland National Eank Building M.S. 9217

Washington, D. C. 20555

P. H. Odegaarden

IIRC

Maryland National Pank Building M.S. 9217

Washington, D. C. 20555

L. B. Shappert

Oak Ridge National Laboratory

P. 0. Box $X$

Dak Ridge, Tennessee 37830

Mr. Thomas A. Butler

Los Alamos Scientific Laboratory

Group WX-B, MS 312

Los Alamos, New Mexico 87545

Mr. Robert M. Jefferson

Sandia Laboratories

P. 0. Box 5800

Albuquerque, New Mexico 87115

Mr. Tom Priddy

Sandia Laboratories

P. 0. Box 5800

A 1buquerque, New Mexico 87115 
Mr. Russell E. Rhoades

Battelle-Pacific Northwest Laboratory

P. 0. Box 999

Richland, Washington 99352

Mr. L. Donald Williams

Battelle-Pacific Northwest Laboratory

P. 0. Box 999

Richland, Washington 99352

Mr. John W. Langhear

E. I. du Pont de Nemours and Co.

Wilmington Trust Building

1007 Market Street

Wilmington, Delaware 19898 